\title{
Animali maravigliosi : Orientalismo e animali esotici a Firenze in epoca tardogotica e rinascimentale: conoscenza, immaginario, simbologia
}

\author{
Lurati, Patricia
}

Abstract: A Firenze, città di mercanti che intrattenevano intensi scambi commerciali con l'Oriente, il gusto per l'esotico alimentato da viaggi, pellegrinaggi, delegazioni diplomatiche, diari odeporici, novelle e mappae mundi era particolarmente vivo. Questa ricerca a carattere interdisciplinare indaga il tema vasto e complesso degli scambi culturali tra la città del giglio e l'Oriente nell'arco cronologico compreso tra la seconda metà del XIV secolo e il 1492 - anno della morte di Lorenzo il Magnifico ma anche della scoperta del continente americano - gettando nuova luce sul ruolo svolto dai mercanti dotati di una forma mentis analitica nell'evoluzione della conoscenza della fauna esotica, le implicazioni artistiche e culturali connesse agli «animali maravigliosi» e l'affermarsi della loro raffigurazione "naturalistica".

DOI: https://doi.org/10.35263/ casagrande-920-7

Posted at the Zurich Open Repository and Archive, University of Zurich ZORA URL: https://doi.org/10.5167/uzh-211590

Monograph

Published Version

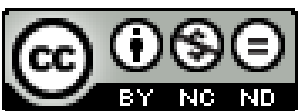

The following work is licensed under a Creative Commons: Attribution-NonCommercial-NoDerivatives 4.0 International (CC BY-NC-ND 4.0) License.

Originally published at:

Lurati, Patricia (2021). Animali maravigliosi : Orientalismo e animali esotici a Firenze in epoca tardogotica e rinascimentale: conoscenza, immaginario, simbologia. Bellizona: Edizioni Casagrande.

DOI: https://doi.org/10.35263/ casagrande-920-7 
Patricia Lurati

\section{Animali maravigliosi}

Orientalismo e animali esotici a Firenze in epoca tardogotica e rinascimentale: conoscenza, immaginario, simbologia

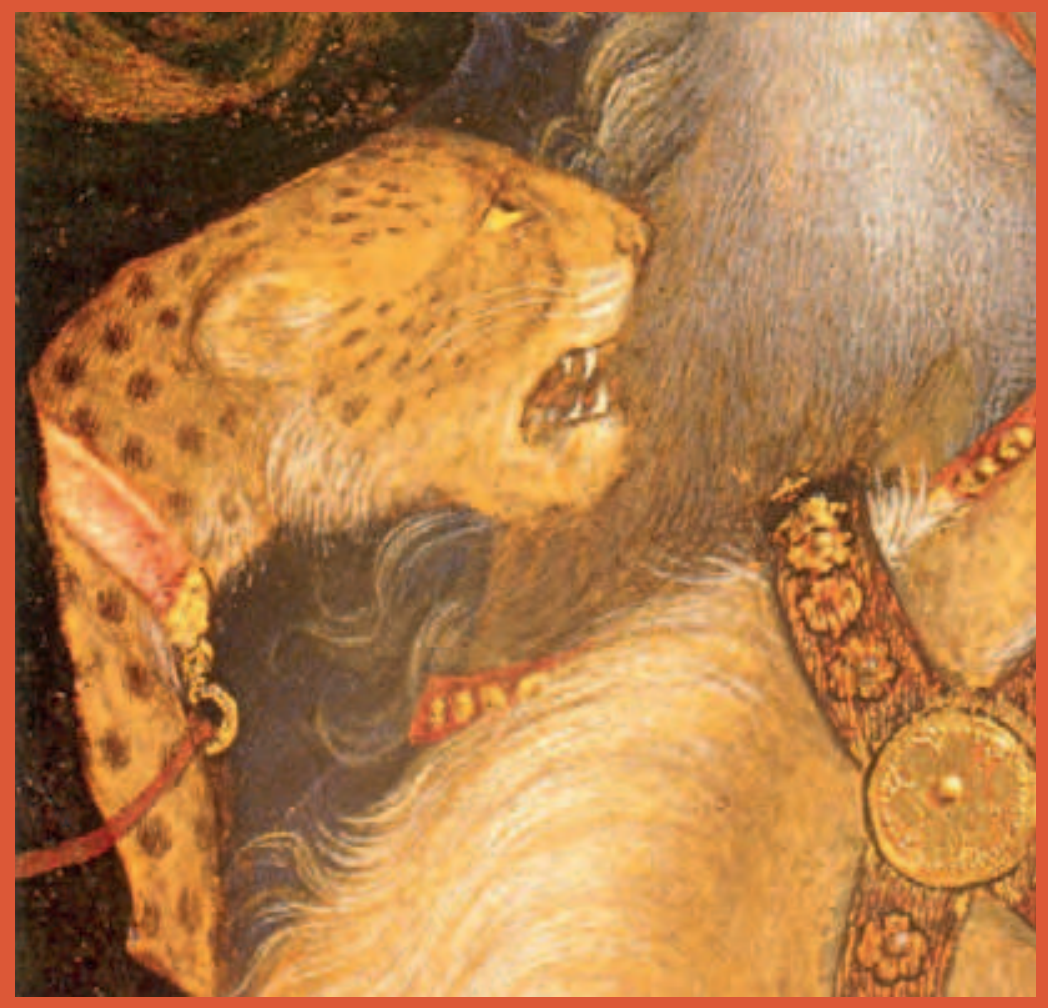

Edizioni Casagrande 
22.

\section{Patricia Lurati}

Animali maravigliosi

Orientalismo e animali esotici a Firenze in epoca tardogotica e rinascimentale: conoscenza, immaginario, simbologia 



\section{Patricia Lurati}

\section{Animali maravigliosi}

Orientalismo e animali esotici a Firenze in epoca tardogotica e rinascimentale: conoscenza, immaginario, simbologia

Edizioni Casagrande $\cdot$ Bellinzona 
This work was accepted as a PhD thesis by the Faculty of Arts and Social Sciences, University of Zurich in the Spring semester 2018 on the recommendation of the Doctoral Committee: Prof. Dr. Tristan Weddigen (main supervisor) and Prof. Dr. David Ganz.

Opera pubblicata con l'appoggio del Fondo nazionale svizzero per la ricerca scientifica (FNS) e della Repubblica e Cantone Ticino, Aiuto federale per la lingua e la cultura italiana.

\section{(3)}

This work is licensed under the Creative Commons Attribution-NonCommercial-NoDerivs 4.0 which means that the text may be used for non-commercial purposes, provided credit is given to the author.

For details go to http://creativecommons.org/licenses/by-nc-nd/4.o/

Immagine in copertina:

Gentile da Fabriano, Adorazione dei Magi (part.), I423

Firenze, Gallerie degli Uffizi

(C) 202I Edizioni Casagrande SA · Bellinzona

ISBN: 978-88-77I3-920-7

ISBN PDF: 978-88-77I3-926-9

E-Book (PDF): DOI: I0.35263/casagrande-920-7 


\section{Indice}

Introduzione

PARTE I

BORGHESIA MERCANTILE FIORENTINA:

POLITICA, AFFARI E CULTURA

Dall'oligarchia alla Signoria medicea

I. Contesto storico-politico

2. Ruolo economico e sociale dei mercanti-banchieri

3. Relazioni commerciali con l'Oriente

PARTE II

FASCINAZIONE ORIENTALE

Oriente in letteratura e nelle biblioteche dei mercanti

I. Mercanti avventurieri e "viaggiatori da camera"

I.I Marco Polo

I.2 Jean de Mandeville

I.3 Niccolò de' Conti

2. Pellegrini e missionari

2.I Pellegrinaggi "di carta» 45

2.2 Missionari "curiosi"

2.3 Pellegrini-scrittori

3. Oriente nei poemi didattici e nelle novelle 57

3.I. Temi orientali 57

3.2. Poemi enciclopedico-didattici 6I

3.3. Viaggi romanzeschi e cantari 64

3.4. Novelle 66

Oriente a Firenze

I. Concilio del I439 7I

I.I. Delegazioni bizantine $7 \mathrm{I}$

$\begin{array}{ll}\text { I.2. Delegazioni copte ed etiopi } & 74\end{array}$ 
2. Firenze e il mondo islamico 76

2.I. Caduta di Costantinopoli $\quad 76$

2.2. Ambasciata di Mohamed Ibn-Mahfuz 78

PARTE III

FAUNA ESOTICA: DALLA ZOOLOGIA FANTASTICA

ALL'OSSERVAZIONE DIRETTA

«Mens mercatoris»: misurare e annotare $\quad 85$

I. Una nuova forma mentis $\quad 85$

I.I. Scuole di abaco $\quad 85$

I.2. Dai libri di mercatura ai libri di ricordi 88

I.3. Descrivere il «maraviglioso» 92

$\begin{array}{lr}\text { L'occhio del mercante e gli animali esotici } & 99\end{array}$

I. Libri di viaggio dei fiorentini 99

$\begin{array}{lr}\text { I.I. Missionari } & 99\end{array}$

$\begin{array}{ll}\text { I.2. Mercanti IOS } & \text { IO }\end{array}$

2. Animali esotici a Firenze II4

2.I. Animali "familiari" II4

2.2. Animali «maravigliosi» $\quad$ I22

2.3. Animali simulati I29

$\begin{array}{ll}\text { Reminiscenze medievali e riscoperta dei testi antichi } & \text { I37 }\end{array}$

$\begin{array}{ll}\text { I. Enciclopedie medievali } & \text { I37 }\end{array}$

2. Naturalis historia di Plinio il Vecchio I43

PARTE IV

ANIMALI ESOTICI: DALLE PAROLE ALLE IMMAGINI

Raffigurazioni di animali esotici $\quad$ I5I

I. Animali "di carta" ISI

I.I. Mappae mundi e carte geografiche I5I

$\begin{array}{lr}\text { I.2. Scritti di viaggiatori illustrati } & \text { I70 }\end{array}$

$\begin{array}{ll}\text { I.3. Taccuini di disegni } & \text { I79 }\end{array}$

2. Animali dipinti 199

2.I. Gentile da Fabriano e gli animali esotici 199

2.2. Animali esotici nella pittura fiorentina post I 423 
PARTE V

ANIMALI ESOTICI E POTERE

Valenza simbolica degli animali esotici $\quad 239$

I. Segni di potere e ricchezza $\quad 239$

I.I. Animali esotici come doni diplomatici 239

I.2. Animali esotici come status symbol 246

Secolarizzazione di un'iconografia religiosa $\quad 257$

I. Magi, Oriente e animali esotici 257

I.I. Festa dei Magi 257

I.2. Valenza simbolica dei Magi nella Firenze oligarchica 262

I.3. Valenza simbolica dei Magi in epoca medicea 265

I.4. La Cavalcata dei Magi di Benozzo Gozzoli 270

$\begin{array}{lr}\text { Conclusioni } & 278\end{array}$

$\begin{array}{ll}\text { Bibliografia } & 279\end{array}$ 

a Piero, mio padre 
Sono grata ai miei genitori, Paola e Piero, che mi hanno portato in giro per il mondo alla scoperta delle culture orientali e degli animali esotici.

Un particolare ringraziamento va al mio direttore di tesi Professore Tristan Weddigen, che ha saputo guidare le mie ricerche e al tempo stesso lasciarmi piena libertà nella scelta dei temi, e al Professor David Ganz per i preziosi consigli.

Vorrei inoltre ringraziare Paolo Agnelli, Lucia Aquino, Nicoletta Baldini, Roberta Bartoli, Maria Teresa Costa, Bruce Eldestein, Albert Elen, Elena Gurrieri, Wolfang Loseries, Zoltán Kárpáti, Irene Malfatto, Marco Masseti, Annamaria Nistri, Antonio Quattrone, Antonio Rollo, Alessandro Scafi, Gail Solberg, Vittorio Vasarri, Paola Ventrone, The Parker Library, Corpus Christi College, Cambridge. Infine sono riconoscente agli istituti fiorentini che hanno ospitato il lavoro di ricerca, ai direttori e al loro impareggiabile personale: Kunsthistorisches Institut, Villa I Tatti The Harvard University Center for Italian Renaissance Studies, Biblioteca Nazionale Centrale e Istituto Nazionale di Studi sul Rinascimento. 


\section{Introduzione}

«quella fama che voi dovreste cercare mediante la virtù dell'animo, la seguite con la novità de' peregrini animali». ${ }^{\mathrm{I}}$

Rimprovero, quello espresso da Francesco Petrarca nei De' rimedi dell'una, et altra fortuna (I354-I366), che rivela la sfrenata passione per il possesso di fauna esotica. ${ }^{2}$ Se il monito petrarchesco era rivolto ai signori delle corti italiane ed europee, l'interesse per questi animali non era da meno in una città di mercanti come Firenze. Scopo di questa ricerca è gettare nuova luce sulla conoscenza, la presenza e i valori simbolici attribuiti agli animali esotici nella città del giglio tra la seconda metà del XIV secolo e il I 492, anno della morte di Lorenzo il Magnifico ma anche della scoperta del continente americano.

Lo studio degli animali esotici e della loro raffigurazione "naturalistica" nella Firenze tre e quattrocentesca non poteva prescindere da un'indagine interdisciplinare per comprendere appieno la portata dei rapporti che all'epoca intercorrevano tra la città e il mondo orientale, da intendere nell'accezione di Vicino e Medio Oriente. I fiorentini si erano recati oltremare essenzialmente per tre motivi: commercio, pellegrinaggio e diplomazia. Gli orientali erano giunti sulle sponde dell'Arno per stringere alleanze, negoziare accordi e partecipare al concilio per l'unione delle due Chiese tenutosi tra il I439 e il I443. Tutte occasioni che avevano dato luogo a vivacissimi scambi culturali. Ma il profondo interesse nutrito dai fiorentini per il mondo orientale non si limitava ai contatti diretti: oltre a essere avidi lettori di guide di pellegrinaggio, diari odeporici, testi enciclopedici e novelle dedicati a questo argomento, possedevano aggiornate mappae mundi e carte nautiche. Quello che emerge con evidenza è, quindi, il ritratto di una società in cui il gusto per l'Oriente in tutte le sue varianti e sfaccettature era particolarmente vivo. In una città dominata da una classe di ricchi mercanti alla ricerca di conoscenze geografiche utili a favorire le loro attività commerciali, e dotati di una forma mentis analitica e pragmatica, la "maravigliosa» fauna esotica non poteva che catturare la loro attenzione. ${ }^{3}$

Peculiarità di questa ricerca è aver indagato un arco cronologico compreso tra gli ultimi decenni del XIV secolo, quando i contatti tra Firenze e l'Oriente si

I. PETRARCA i584, p. IIIv, libro I, LX.

2. Per un approfondimento vedi ID. 2002, vol. I pp. 289-29I; vol. 2 308-309.

3. LURATI 20I8, pp. 8I-88. 
erano particolarmente intensificati, e il I492, anno emblematico segnato dalla morte di Lorenzo il Magnifico e dalla scoperta del Nuovo Mondo, che oltre a sconvolgere profondamente gli equilibri geo-politici ed economici aveva offuscato l'interesse nei confronti dell'Oriente.

Se la maggior parte degli studi finora condotti - in realtà scarsi e frammentari - si sono prevalentemente focalizzati sul XVI e XVII secolo, epoca che aveva visto l'allargarsi degli orizzonti geografici e l'affermarsi di un metodo scientifico moderno, già sullo scorcio del XIV secolo il mondo animale aveva iniziato a essere indagato con un'attenzione che si potrebbe definire "pseudo-scientifica". Si trattava di un approccio basato sull'osservazione empirica che con il trascorrere dei decenni aveva iniziato a dubitare delle informazioni fino ad allora accolte senza riserve perché tramandate dalle auctoritates. Non solo, la curiosità e la fascinazione per l'Oriente, stimolate dalle letture e dai continui contatti, avevano favorito l'arrivo in città di esemplari di fauna esotica e reso nota l'usanza delle corti orientali di esibire e offrire in dono questi animali quale segno di magnificenza e prestigio. Diretta conseguenza fu l'affermarsi nell'immaginario fiorentino di una specifica valenza simbolica attribuita a questi animali quando ritratti in pittura, e in particolare nell'iconografia dei Magi soggetto molto diffuso nella Firenze del tempo.

Con questo studio si è, pertanto, voluto cogliere l'invito espresso dallo storico Franco Cardini quando affermava che una «preistoria dell'orientalismo moderno» restava ancora da scrivere, focalizzando l'attenzione sulla conoscenza degli animali esotici e la loro raffigurazione "naturalistica" nella pittura fiorentina. ${ }^{4}$ Rivelatasi praticamente inesistente la letteratura in merito, l'indagine è stata condotta ricavando informazioni da scritti e documenti dell'epoca, così come pure da testi e articoli di studiosi che hanno anche solo in parte affrontato l'argomento. Si è trattato di un minuzioso lavoro di raccolta dati per riuscire a delineare una storia culturale riguardo all'interesse e alla presenza di fauna esotica nella Firenze tardo tre e quattrocentesca e, parallelamente, alla simbologia attribuita alle sue raffigurazioni.

La ricerca ha quindi preso le mosse da una ricostruzione del contesto culturale basata, da un lato, sull'analisi dei libri che la classe dominante custodiva nelle sue biblioteche quali indicatori dell'interesse per l'Oriente e, dall'altro, delle occasioni e dell'intensità dei contatti con questa civiltà e la sua cultura. Questa prima fase ha comportato una ricerca a tappeto dei manoscritti contenenti testi che affrontavano temi legati al mondo orientale e che potevano essere ricondotti con certezza, grazie alle note di possesso apposte sui frontespizi, a personaggi del ceto mercantile fiorentino. È così emersa con evidenza la portata dell'attrazione che l'oltremare, terra di sultani, sede del regno di una figura leggendaria come il Prete Gianni e del paradiso terrestre, esercitava nell'immaginario del

4. CARDINI 2009, p. 75. 
tempo. Firenze si è rivelata, proprio perché dominata da un'élite di facoltosi mercanti proiettati verso terre più o meno lontane dove acquistare materie prime e commerciare $\mathrm{i}$ loro prodotti, una città particolarmente aperta alla conoscenza di nuovi mondi. Per accrescere il bagaglio di informazioni i fiorentini erano soliti interrogare viaggiatori, pellegrini, missionari e marinai che in Oriente si erano recati, così come pure gli orientali che arrivavano in città, per lo più in veste di diplomatici, per poi inserirle nei loro scritti o servirsene per aggiornare mappe e carte geografiche.

Fondamentale in questo contesto è risultata la formazione degli aspiranti mercanti presso le scuole di abaco, dove in giovane età apprendevano l'attitudine a osservare con occhio attento e concreto la realtà circostante e a registrare fatti ed esperienze attraverso lo strumento della scrittura. Libri di ricordi, zibaldoni, cronache, guide di pellegrinaggio e diari odeporici si sono così rivelati un'indispensabile fonte di notizie sulla fauna esotica che avevano avuto modo di vedere e descrivere nel corso dei loro viaggi in Oriente oppure giunta in città in forma di doni diplomatici. Esperienze dirette, in forma di annotazioni o disegni, che a volte contribuivano a integrare le conoscenze mentre altre insinuavano dubbi o, addirittura, smentivano le notizie da secoli ritenute veritiere perché tramandate da testi autorevoli come la Naturalis historia pliniana, le enciclopedie, i bestiari medievali. Si è quindi reso necessario mettere a confronto le descrizioni di animali esotici fornite da fonti ritenute attendibili con quelle di mercanti e pellegrini fiorentini per verificare quanto queste ultime fossero di prima mano oppure debitrici delle auctoritates, accertando, nel contempo, quali testi antichi e medievali all'epoca fossero consultabili a Firenze per attingervi informazioni.

Dopo aver contestualizzato l'interesse e le notizie a disposizione dei fiorentini, si è delineato un quadro della presenza di esemplari di fauna esotica nella città del giglio, ricerca per lo più basata sulle rare informazioni reperite nei documenti e negli scritti del tempo. È stato così possibile appurare, smentendo quanto finora asserito dagli studiosi che a distanza di oltre un secolo continuano a riportare le informazioni raccolte dallo zoologo francese Gustave Loisel nella sua Histoire des ménageries de l'Antiquité à nos jours - testo fondamentale ma ormai superato -, che gli animali esotici in carne e ossa erano alquanto rari. ${ }^{5}$ Considerata la scarsità e le difficoltà degli artisti nel tratteggiare specie che potevano aver conosciuto unicamente attraverso testi scritti e racconti orali, è quindi emersa la necessità di comprendere il ruolo svolto da strumenti di lavoro quali taccuini di disegno e libri di modelli. Se l'interesse suscitato dagli animali esotici era in parte connesso alle scoperte geografiche, come attesta la loro raffigurazione su mappae mundi, portolani e carte nautiche per connotare paesi asiatici e africani, la

5. LOISEL I9I2. A questo proposito Angelica Groom, nel suo approfondito studio sugli animali esotici alla corte dei Medici nel XVI secolo, cita Loisel avvertendo, però, che le sue affermazioni spesso non sono supportate da documenti vedi GROOM 20I8, pp. 37-38. 
loro presenza nelle corti più raffinate della penisola aveva dato origine a numerose raccolte di disegni che circolavano nelle botteghe degli artisti in qualità di repertori ai quali attingere quando chiamati a dipingere iconografie ispirate all'Oriente. Nel capitolo dedicato alla raffigurazione degli animali esotici ampio spazio è stato quindi riservato ai disegni riconducibili ad ambito fiorentino per comprendere la loro influenza nella realizzazione di dipinti e affreschi. È altresì emerso il forte valore simbolico e politico attribuito dalla società del tempo a queste immagini, rendendo a sua volta necessario sia indagare la consuetudine orientale di offrire in dono animali rari quale segno di munificenza, sia delineare una storia dell'importanza del tema dei Magi nella città di Firenze. Se a partire dalla fine del XIV secolo i tre re orientali erano gli attori principali di uno sfarzoso corteo che il giorno dell'Epifania sfilava lungo le vie della città, appena qualche decennio più tardi assursero a protagonisti di una delle iconografie più amate e richieste dall'élite dei ricchi mercanti: l'Adorazione dei Magi che, evocando il mondo orientale, consentiva di ritrarre ricchezze e fauna esotica e, quindi, convogliare espliciti messaggi di magnificenza e potere.

Questa ricerca, che s'inserisce a pieno titolo nel filone dei global e cross-cultural studies, consente di aprire una finestra su un tema tanto vasto quanto complesso, in modo da poter disporre di una nuova chiave di lettura per interpretare il fenomeno della raffigurazione "naturalistica" degli animali esotici a Firenze tra il XIV e il XV secolo, così come pure le sue implicazioni artistiche e culturali in una società dove il gusto per l'orientalismo era particolarmente vivo e il progressivo passaggio dalla zoologia immaginaria del Medioevo allo studio scientifico degli animali dei secoli successivi iniziava a muovere i primi passi. ${ }^{6}$

6. Testo pioneristico nell'indagare l'influenza degli scambi culturali sulla cultura visiva del Rinascimento è il volume Reframing the Renaissance. Visual Culture in Europe and Latin America I450-I650 vedi FARAGO I985, pp. $\mathrm{I}-2 \mathrm{O}$. 
PARTE I

Borghesia mercantile fiorentina:

politica, affari e cultura 



\section{Dall'oligarchia alla Signoria medicea}

\section{Contesto storico-politico}

Nel XIV e XV secolo Firenze si prospettava come una città governata da un regime repubblicano, ma in realtà il potere politico era concentrato nelle mani di un ristretto gruppo di facoltose famiglie. Breve parentesi era stato il crescente malcontento da parte della classe dei lavoratori esclusi dalla vita politica che nell'estate del I378 sfociò nel tumulto dei Ciompi, un'insurrezione popolare capeggiata dai salariati dell'industria della lana e sostenuta dagli artigiani che, esasperati dalla forte pressione economica e sociale, rivendicavano con la forza il diritto di prendere attivamente parte alla vita politica. ${ }^{\mathrm{I}}$ Dopo alcune giornate di disordini e violenze il "popolo minuto» riuscì a ottenere cariche governative per i suoi rappresentanti, ma la presenza del proletariato fiorentino tra le fila governative ebbe vita breve. La precaria coesistenza tra esponenti del ceto mercantile e artigiani, minata da continui conflitti e attriti, si protrasse fino al I382, quando la danarosa classe dei mercanti attuò una serie di provvedimenti legislativi volti a limitare il peso delle corporazioni e a concentrare il potere nelle mani di una ristretta élite di casati dediti al commercio e alle attività bancarie. ${ }^{2}$ Furono così instaurate le basi per il "governo di reggimento" che, attraverso una classe politica selezionata tra i lignaggi fiorentini di maggior spicco, nei primi decenni del XV secolo vide opporsi il partito degli Albizzi e quello dei Medici in lotta per l'egemonia. ${ }^{3}$ Grazie all'introduzione di nuove regole nel sistema elettorale, la fazione capitanata da Rinaldo degli Albizzi riuscì a escludere dalle cariche pubbliche gli oppositori e in alcuni casi a bandirli dalla città, come quando nell'ottobre I433 l'avversario Cosimo de' Medici, ricco e affermato banchiere, fu condannato all'esilio. Appena un anno più tardi, l'elezione di una Signoria in gran parte composta da membri filomedicei aveva però sovvertito gli equilibri richiamando in patria Cosimo il Vecchio e decretando l'espulsione dalla città di Rinaldo degli Albizzi e dei suoi sostenitori che, per opporsi a questa decisione, tentarono d'impadronirsi del Palazzo dei Signori. ${ }^{4}$

I. BRUCKER I968, pp. 3I4-356; FRANCESCHI 2008, pp. 286-29I, 296-300. Il termine "Ciompi» indica i cardatori, lavoratori appartenenti all'Arte della lana. Sergio Tognetti si discosta dalla maggioranza degli studiosi non condividendo pienamente l'idea di un carattere elitario del governo fiorentino vedi TOGNETTI 2017 , pp. I44-I48.

2. BRUCKER I977, pp. 39-59; NAJEMY 2006, pp. I6I-I8I.

3. TADDEI 20Io, pp. 35-37. Per un approfondimento vedi KENT I978, pp. 289-348.

4. RUBINSTEIN I97I, pp. 2-6; NAJEMY 2006, pp. 27I-277; TADDEI 20IO, p. 37. 
Il ritorno di Cosimo nell'autunno I434 segnò l'inizio di un nuovo corso della storia politica fiorentina. Primo provvedimento fu quello di far esiliare i suoi avversari, tra i quali il ricchissimo e potente Palla Strozzi schieratosi con la fazione albizzesca, e privare dei diritti politici interi casati. ${ }^{5}$ Il capofamiglia mediceo modificò poi la procedura per eleggere la Signoria introducendo un sistema "a mano» che consentiva di manipolare discrezionalmente i sorteggi escludendo gli oppositori e favorendo l'accesso dei suoi fedeli alle cariche più alte. ${ }^{6}$ Ma l'abilità di Cosimo fu soprattutto quella di riuscire, pur mantenendo una parvenza di regime repubblicano, a esercitare saldamente il suo potere. Per raggiungere questo scopo si prodigò nel tessere una fitta rete di rapporti clientelari, in modo da poter influenzare occultamente la scena politica attraverso legami di ogni sorta: amici, soci in affari, parenti di sangue o acquisiti attraverso alleanze matrimoniali, membri di confraternite da lui patrocinate. ${ }^{7}$ Il fatto, poi, che il suo lignaggio non vantasse origini nobili e che un parente, Salvestro de' Medici, avesse sostenuto il tumulto dei Ciompi lo rese particolarmente benvoluto dalla popolazione. ${ }^{8}$

In realtà, fin dai tempi di Giovanni di Bicci il casato mediceo, impegnato in attività bancarie ad alto livello tanto da conquistare l'ambito ruolo di principali banchieri della Santa Sede, era andato via via accumulando enormi ricchezze: nel catasto del I427 il padre di Cosimo de' Medici risultava essere l'uomo più facoltoso di Firenze secondo solo a Palla Strozzi. ${ }^{9}$ Oltre a ciò, Cosimo intratteneva relazioni amichevoli e diplomatiche con papa Eugenio IV, i signori delle più importanti città italiane - motivo per cui durante il suo esilio veneziano fu accolto con tutti gli onori dal Doge - e straniere, riuscendo così a guadagnarsi i consensi e l'appoggio delle famiglie fiorentine più influenti, tanto da essere considerato, nonostante il perdurare delle istituzioni repubblicane, de facto signore della città del giglio. A incrementare la sua fama fu soprattutto l'abilità nelle trattative per ottenere il trasferimento del concilio per l'unione della Chiesa greca e latina dalla sede di Ferrara a Firenze, dove papa Eugenio IV, il patriarca di Costantinopoli Giuseppe II e l'imperatore bizantino Giovanni VIII Paleologo giunsero nell'inverno I 439. ${ }^{\text {IO }}$

Il sempre più crescente controllo esercitato dai Medici sulle sorti della città finì per alimentare nel corso degli anni congiure ordite ai loro danni: nel I 458 i ceti più abbienti avevano tentato di opporsi, senza successo, a una riforma del sistema fiscale che li avrebbe danneggiati, mentre nel i 466 una serie di pesanti bancarotte e la richiesta di Piero il Gottoso di recuperare alcuni prestiti a suo tempo elargiti agli

5. KENT I978, pp. 290, 343-344. Cosimo il Vecchio si assicurò che l'esilio di Palla Strozzi fosse continuamente rinnovato fino alla sua morte, avvenuta a Padova nel I 462.

6. RUBINSTEIN I97I, pp. I-I05.

7. KENT I978.

8. TADDEI 2010, pp. $37-38$.

9. HOLMES I968, pp. 378-379; NAJEMY 2006, pp. 262-269, 289-29I; HERLIHY - KLAPISCH-ZUBER I978, pp. 34-35. Il catasto del I 427 introdusse un nuovo sistema di esazione fiscale: la tassazione era valutata sulla reale entità del patrimonio che i contribuenti rendevano nota al governo tramite autodichiarazione.

IO. NAJEMY 2006, pp. 286-288. 
alleati dal padre - deceduto nel I464 - incrinarono i legami clientelari fino a dar vita a una coalizione che aveva messo in dubbio il suo diritto di succedere a Cosimo il Vecchio. Tutti questi tentativi di rivolta furono però sedati, il sistema che consentiva di influenzare le nomine di governo ulteriormente rafforzato e i cospiratori mandati in esilio. ${ }^{\text {II }}$ Grazie a questi interventi quando, alla morte di Piero de' Medici nel dicembre I469, il figlio Lorenzo prese le redini del potere il governo non manifestò la benché minima opposizione. Sotto la sua guida la politica, già strettamente oligarchica, si andò ancor più consolidando fino ad assumere un tono marcatamente principesco: Lorenzo - poi detto «il Magnifico» - prese le distanze dalle attività mercantili, convolò a nozze con Clarice Orsini appartenente all'antica nobiltà romana e si dedicò a promuovere l'arte e la cultura in veste di mecenate illuminato. ${ }^{\mathrm{I} 2}$ Questo ulteriore accentramento di potere nelle mani del signore mediceo diede origine alla congiura ordita dalla famiglia Pazzi, ostacolata in campo politico e concorrente negli affari bancari, che con l'appoggio di papa Sisto IV e del re di Napoli Ferdinando I d'Aragona architettò un piano per assassinare Lorenzo e Giuliano de' Medici. Nell'aprile I478 i due fratelli furono aggrediti mentre assistevano alla messa pasquale nella chiesa di Santa Maria del Fiore: Giuliano fu pugnalato a morte, Lorenzo riuscì a fuggire riportando una lieve ferita. Scampato all'attentato, la repressione intimata da Lorenzo de' Medici fu durissima: cospiratori e complici furono ricercati per settimane, catturati, giustiziati e i loro corpi fatti a pezzi, mentre i membri della famiglia Pazzi subirono la confisca di tutti i beni, l'imposizione a cambiare cognome e la proibizione alle giovani donne di contrarre matrimonio per anni in modo da scongiurare la possibilità di stringere alleanze. ${ }^{\mathrm{I} 3}$

Nel suo disegno di affermazione politica Cosimo il Vecchio non trascurò certo di promuovere l'immagine pubblica della famiglia attraverso il mecenatismo, strumento utile per esaltare l'onore di Dio, della città e, non da ultimo, del casato mediceo. A lui sono da ricondurre alcune delle più imponenti imprese architettoniche del tempo: la ricostruzione della chiesa e del convento di San Marco, l'erezione del magnifico palazzo di famiglia affacciato su via Larga, la riedificazione della chiesa di San Lorenzo, tutte costruzioni che stagliandosi nello spazio urbano posto sotto l'influenza medicea avevano il potere di connotarlo visivamente. ${ }^{\mathrm{I} 4}$ Sempre con questo intento fondò la prima biblioteca pubblica all'interno del convento di San Marco, progetto già ventilato dal suo antagonista Palla Strozzi ma che Cosimo ebbe il merito di realizzare, mentre il patronato sulla Compagnia dei Magi gli consentì di mettere in scena e prendere parte allo sfarzosissimo corteo di sapore orientaleggiante che il giorno dell'Epifania sfilava per le vie della città; spettacolo a

II. RUBINSTEIN I97I, pp. I07-2I0; FUBINI I996, pp. I5I-I53; NAJEMY 2006, pp. 293-296, $298-306$.

I2. Ivi, pp. 34I-348; TADDEI 20IO, pp. 43-44.

I3. FUBINI I996, pp. I53-I54; NAJEMY 2006, pp. 352-36i. Per un approfondimento storico del cruento episodio vedi DANIELS 2013.

I 4. KENT 2005, pp. 227-252, 283-307; NAJEMY 2006, pp. 328-330. Riguardo al mecenatismo mediceo vedi anche GOMBRICH I973, pp. 5I-83. 
tal punto significativo per i Medici da costituire il tema degli affreschi commissionati a Benozzo Gozzoli per le pareti della cappella nel palazzo di famiglia. ${ }^{\text {Is }}$ Anche i discendenti di Cosimo il Vecchio furono grandi mecenati, ma guidati da un gusto più marcatamente principesco: il figlio Piero nutriva una particolare predilezione per manoscritti miniati, bronzetti antichi e moderni, porcellane orientali, medaglie e monete, gioielli, gemme e cammei antichi, suppellettili in oro e argento e vasi in pietre dure e cristallo di rocca che custodiva gelosamente nel suo "studietto", così come pure il nipote Lorenzo che, oltre a condividere con il fratello Giuliano la passione per la glittica - sua era la famosa Tazza Farnese -, aveva riunito attorno a sé un nutrito gruppo di artisti, letterati e filosofi. ${ }^{\mathrm{I} 6}$

\section{Ruolo economico e sociale dei mercanti-banchieri}

La fortuna economica della Firenze tre e quattrocentesca fu strettamente legata all'industria tessile: fino alla metà del XIV secolo la manifattura laniera, dedita alla confezione di panni sia in pregiata lana inglese sia di mediocre qualità, era stata uno dei settori trainanti della produzione cittadina, mentre a partire dalla seconda metà del secolo si andò sempre più affermando l'industria serica. ${ }^{17} \mathrm{~A}$ innescare questo cambiamento fu la devastante epidemia di peste del I348 e le successive ondate epidemiche che colpirono la popolazione fiorentina ed europea provocando un crollo demografico e, quindi, la riduzione di manodopera disponibile a basso costo da impiegare nell'industria della lana. L'arco cronologico compreso tra il tumulto dei Ciompi nel I 378 e il catasto del I 427 aveva così segnato il lento ma inesorabile declino dell'industria laniera, e in particolare dei panni di mediocre qualità detti «del Garbo», confezionati con lane maghrebine, iberiche e italiane, destinati ai ceti più bassi ormai decimati e impoveriti. ${ }^{I 8}$ La produzione di panni

I5. Per un approfondimento sulla biblioteca di San Marco vedi The Public Library I972.

I6. ACIDINI LUCHINAT 20I I, pp. I03-II7. La Tazza Farnese - piatto cerimoniale in sardonica di epoca ellenistica - nell'inventario stilato alla morte di Lorenzo de' Medici nel I492 fu valutata l'esorbitante somma di Io.ooo fiorini, approssimativamente un quarto del costo stimato per la costruzione di Palazzo Medici in via Larga (il prezzo, non essendo sopravvissuti documenti, è stato calcolato sulla base di quanto speso negli stessi anni da Filippo Strozzi per l'edificazione del suo palazzo, ossia 30.000 fiorini) e della cifra sborsata per la ristrutturazione del complesso di San Marco, 36.000 fiorini a detta di Giorgio Vasari e 40.000 secondo Vespasiano da Bisticci vedi Libro d'inventario I992, p. 36 c. I8; GOLDTHWAITE 20I3, p. 76I; VASARI I966-I997, vol. 3, p. 235; BISTICCI I970-I976, vol. I, p. I78.

I7. HOSHINO I980, pp. 65-I52; FRANCESCHI I993, pp. 3-3I; ID. I995, pp. 4-7. Allo sviluppo della produzione serica fiorentina nella seconda metà del XIV secolo contribuì l'arrivo di imprenditori del settore e maestranze altamente specializzate provenienti da Lucca, città all'epoca dilaniata da lotte intestine e fin dal XIII secolo centro specializzato nella lavorazione della seta vedi EDLER DE ROOVER I999, pp. 3-I I.

I8. HOSHINO I980, pp. I53-229; TOGNETTI 2002, pp. I6-24; NAJEMY 2006, pp. 307-3II. I panni di lana detti "del Garbo», confezionati nei conventi dell'Oltrarno, di San Piero in Scheraggio e di San Pancrazio, utilizzavano lana importata dal bacino occidentale del Mediterraneo. Denominazione con un riferimento geografico ben preciso: nella Nuova cronaca (I333-I348) del mercante fiorentino Giovanni Villani una regione del Magreb detta "'l Garbo" si trova in Africa, mentre in una novella del Decameron l'impero del re del Garbo si estende dalla costa africana occidentale sul Mediterraneo a una regione della penisola iberica. Gli studiosi ottocenteschi hanno invece interpretato il termine "garbo" quale sinonimo di finissimo, confondendo i panni "del Garbo" di mediocre 
in lana pregiata, pur perdurando, fu invece ostacolata dallo sviluppo dell'industria laniera inglese e dall'introduzione, per contrastare la concorrenza, di una politica doganale protezionistica volta a rendere difficoltosa l'importazione della materia prima a Firenze. Nel contempo, il crollo demografico comportò una diminuzione della popolazione cittadina e, quale conseguenza, la ridistribuzione delle ricchezze nelle mani di una ristretta cerchia di sopravvissuti che, disponendo di maggior denaro, poteva ora aspirare a uno stile di vita più lussuoso. ${ }^{19}$ La produzione di manufatti serici ben si adattava alla nuova compagine sociale ed economica: da un lato la confezione di drappi, pur richiedendo artigiani specializzati, comportava un numero ridotto di operai e di fasi di lavorazione rispetto a quella dei panni di lana, dall'altro le stoffe seriche appagavano appieno il desiderio di sfarzo e ostentazione dell'emergente e facoltosa borghesia. ${ }^{20}$

Le potenzialità dell'industria serica fiorentina furono prontamente recepite dalla classe dei mercanti-banchieri, e tra questi anche la famiglia Medici, che non esitarono a investire $i$ loro capitali in un'attività volta a soddisfare la sempre più pressante richiesta da parte dei mercati europei e mediterranei di tessuti pregiati e costosi, fino ad allora esclusivamente prodotti nelle città di Lucca, Genova, Venezia e Bologna. ${ }^{2 \mathrm{I}}$ Oltre a ciò, le stoffe in seta avevano un ampio ed eterogeneo raggio di diffusione tra le élite laiche ed ecclesiastiche garantendo un sicuro guadagno poiché utilizzate per gli indumenti e gli accessori personali, l'arredamento di palazzi signorili, gli addobbi di spazi pubblici, i paramenti e le vesti religiose. Tra le varie tipologie furono i tessuti serici broccati in oro, per lo più velluti, a riscuotere enorme successo nel corso del XV secolo nonostante fossero $i$ più cari in assoluto: il prezzo della stoffa necessaria per confezionare una sopravveste - circa 25 braccia - si aggirava intorno ai 400 fiorini mentre il Tondo Cook dipinto da Beato Angelico ne valeva Ioo. $^{22}$ L'altissimo livello raggiunto dalla città del giglio nella produzione serica quattrocentesca trapela, certo non immune da campanilismo, dalle pagine dello Zibaldone (I457-I48I ca.) di Giovanni Rucellai, ricchissimo mercante-banchiere che annotava:

Il mestieri della seta non lavorò mai tanti drappi quanto in questo tenpo e mai si feciono $i$ più ricchi drappi d'oro e di seta di maggiore pregio che al presente. $\mathrm{E}$ in questa età si principiò fare nella nostra città l'oro filato che al dì d'oggi si fa migliore e più bello che in niun'altro luogo. ${ }^{23}$

qualità con quelli in pregiata lana inglese noti come panni «di San Martino» perché prodotti nell'omonimo convento e nell'area circostante vedi HOSHINO I980, pp. II7-I24, I44, 2IO-2II; TOGNETTI 2002, p. 65; BOULOUX 20I4, p. 8; VILLANI I99I, vol. 3, pp. 5I4-I58; BOCCACCIO I992, vol. I, pp. 224-257, II:7 e in particolare p. 227 nota 4.

I9. GOLDTHWAITE I985, pp. 659-675.

20. FRANCESCHI I995, pp. 7-IO; TOGNETTI 2002, pp. II-24.

2I. Ivi. 2002 , p. 26.

22. DUITS I999, p. 62; ID. 2008, pp. 90-91. L'elevato costo dei drappi broccati in oro era dovuto, oltre al prezzo della seta, alla complessa lavorazione dei fili in metallo prezioso: sottili lamine d'oro realizzate dai battiloro avvolte attorno a un'anima di seta o pelle.

23. RUCELLAI 20I3, p. I8I. 
Gli uomini d'affari fiorentini, oltre ad aver intuito il favore che questi prodotti avrebbero riscosso in una società in piena ascesa, erano consapevoli dell'opportunità che si offriva loro di sfruttare la fitta rete commerciale da tempo consolidata in Europa e nel Levante. Le terre d'oltremare erano fonte principale di approvvigionamento di materie prime molto costose, quali la seta grezza, le sostanze tintorie e l'allume, indispensabili per la produzione serica e, nello stesso tempo, rappresentavano un mercato in piena espansione per l'esportazione di panni di lana e drappi serici. ${ }^{24}$ Quando nel I42I, con l'acquisizione di Porto Pisano e Livorno, la città del giglio riuscì finalmente ad accaparrarsi uno sbocco sul mare si era prontamente dotata sulla scorta dell'esempio delle «mude» veneziane - di una flotta di galee di Stato in grado di garantirgli collegamenti regolari lungo le rotte verso le Fiandre e l'Inghilterra, il Maghreb, l'Andalusia e l'intero Mediterraneo occidentale, i porti catalani, provenzali e di tutto il Tirreno, Costantinopoli e Alessandria. Firenze era così riuscita a garantirsi le condizioni per poter competere con le altre città marinare, e in particolare Venezia e Genova anch'esse produttrici di manufatti tessili. ${ }^{25}$ Le galee fiorentine non viaggiavano mai vuote: all'andata trasportavano pregiati tessuti in seta e panni di lana, mentre al ritorno erano cariche di materie prime destinate all'industria tessile e altri prodotti orientali, quali spezie, zucchero, tappeti, tessuti in lino e cotone, da rivendere in Italia e in Europa. ${ }^{26}$

Negli ultimi decenni del XV secolo le difficoltà politiche ed economiche insorte a Firenze, dovute alla contrazione dei mercati orientali dopo la conquista turca di Costantinopoli nel I453, la sempre più incalzante concorrenza e la dilagante pirateria lungo le rotte marittime indusseo i mercanti fiorentini a rinunciare alla flotta di galee. ${ }^{27}$ Del resto, molte materie prime come l'allume e la seta grezza avevano cominciato a essere prodotte nella penisola e gran parte dei drappi serici a essere venduti sul mercato europeo, motivo per cui gli elevati costi per il mantenimento di trasporti marittimi statali non avevano più ragione di essere poiché per la spedizione delle merci era possibile usufruire dei servizi svolti da navi straniere. ${ }^{28}$ L'esperienza marittima maturata per decenni fu però determinante - come evidenzia Michael Mallet - nel contribuire allo sviluppo dell'industria tessile e nell'instillare nei fiorentini la passione per la geografia e la conoscenza delle terre d'oltremare:

24. EDLER DE ROOVER I999, pp. 26-29.

25. MALLET I967, pp. 2I-I07; TOGNETTI 20II, p. 78; FRANCESCHI 20I5, pp. I36-I40. Vedi anche CICCAGLIONI 2009, pp. 9I-I25. Per le merci fiorentine inviate, prima del I42 I, in Barberia, Siria, Egitto, Cipro, Romania, Candia e Morea avvalendosi dei trasporti marittimi veneziani vedi BABINGER I963, p. 306.

26. MALLET I967, pp. II3-I23; GOLDTHWAITE 20I3, pp. 246-247; EDLER DE ROOVER I999, pp. II7-II9.

27. Per la delibera emanata dal Comune nel I46 I con l'intento di contrastare il costante pericolo di assalti alle galee da parte dei pirati vedi Documenti sulle relazioni i 879, pp. 298-299 doc. XV.

28. MALLET I967, pp. I44-I52. Nel I46I furono scoperte miniere di allume a Tolfa, nei pressi di Roma, mentre la seta grezza in precedenza importata dal Mar Caspio fu in parte sostituita con quella proveniente dalle sericulture impiantate in Romagna, Abruzzo, Calabria e Marche vedi FRANCESCHI 20I4, pp. I67-I69; EDLER DE ROOVER I999, pp. 25-29. 
The whole galley enterprise had in fact rendered valuable service to Florence. It had played a major part in revitalizing the flagging wool industry and launching the new silk industry. It had won for Florence commercial and to a certain extent political prestige in all parts of Europe and the Levant. It had provided a fund of experience and maritime tradition to which the names of Amerigo Vespucci and Giovanni da Verazzano are abundant testimony. ${ }^{29}$

Peculiarità degli avveduti uomini d'affari fiorentini fu quella di non essersi limitati a investire nelle manifatture tessili e nei commerci, ma di aver utilizzato parte dei loro capitali per svolgere operazioni bancarie tra cui la concessione di prestiti. Nella città del giglio il «trinomio seta-mercatura-finanza», attività tra loro complementari, aveva così consentito l'accumulo di enormi ricchezze in breve tempo. ${ }^{30}$ Caso esemplare era quello del casato mediceo il cui impero economico, costituitosi grazie ai profitti ricavati dalle industrie laniere e seriche e dagli introiti delle attività svolte dal Banco Medici fondato dal capostipite Giovanni di Bicci sullo scorcio del XIV secolo, aveva dato origine all'istituto bancario più importante d'Europa con filiali dislocate nelle maggiori piazze finanziarie..$^{31}$

La grande disponibilità economica dei mercanti-banchieri fiorentini, ceto in ascesa a partire dalla seconda metà del XIV e pienamente affermato nel XV secolo, permetteva loro di esercitare una forte influenza in campo politico, sociale e artistico. ${ }^{32}$ Innanzitutto erano assurti a figure di riferimento per il governo cittadino nell'eventualità di dover appianare il debito pubblico, così come pure per pontefici e sovrani europei quando necessitavano ingenti prestiti, pervenendo così a instaurare una fitta rete di legami personali che non di rado implicavano risvolti politici. ${ }^{33}$ Non solo, la formazione e le esperienze dei mercanti contribuirono a plasmare la cultura del tempo. Istruitisi nelle scuole di abaco, dove apprendevano a scrivere e a fare di conto, gli uomini d'affari impegnati a livello internazionale avevano introdotto l'uso di libri contabili e carteggi mercantili per registrare e trasmettere informazioni utili per le loro attività, pratica che nella sfera privata aveva ben presto dato origine alla redazione di libri di ricordi nei quali annotare eventi familiari, consigli per i discendenti e notizie sul patrimonio personale. Sempre alla passione dei mercanti per la scrittura è da ricondurre la pratica di copiare di proprio pugno manoscritti da custodire nelle loro biblioteche, tra i quali a riscuotere grande favore erano i testi dedicati ai viaggi e ai pellegrinaggi in Oriente. Proprio a questo bagaglio culturale tipico dei mercanti fiorentini doveva riferirsi nel XV secolo il trattatista catalano Arnau de Capdevila quando asseriva: "comunament son la major part gran filosofs». 34

\footnotetext{
29. MALLET I967, p. I5I.

30. GOLDTHWAITE 20I3, pp. 283-3 I6.

3I. Per una storia del Banco Medici vedi DE ROOVER I970.

32. TOGNETTI 2015 , p. 698.

33. GOLDTHWAITE 20I3, pp. 3i6-344.

34. A questo proposito è interessante l'osservazione di Mario del Treppo riguardo all'opinione maturata dal
} 
L'ampio ventaglio delle attività mercantili consentì ai mercanti-banchieri fiorentini di entrare in contatto sia con signori e sovrani europei sia con il meraviglioso mondo dei sultani orientali, rapporti che a loro volta avevano contribuito, da un lato, a far loro conoscere stili di vita regali e sfarzosi e, dall'altro, ad alimentare la fascinazione per l'esotico. E poiché i casati più facoltosi avevano il desiderio, ma anche la necessità, di manifestare pubblicamente potere e prestigio sia per garantirsi un ruolo politico all'interno del governo sia per conquistare il favore della cittadinanza, quale modo migliore per raggiungere questo scopo se non la promozione di spettacoli e committenze artistiche volte a evocare ambientazioni cortesi e fastosi cerimoniali orientali? ${ }^{35}$ A Firenze, dove la scena politica era dominata dalla famiglia Medici, la legittimazione del potere personale passava quindi attraverso rimandi visivi con una forte connotazione esotica quali il corteo dei Magi da loro patrocinato e l'affresco benozzoliano con la Cavalcata dei Magi nella cappella del palazzo di via Larga. Se la scelta iconografica intendeva evocare il meraviglioso mondo d'oltremare, gli abiti in preziosi drappi serici broccati in oro indossati dai Magi, da Cosimo il Vecchio e dai suoi familiari svolgevano una duplice funzione: connotarli visivamente quali membri del ceto nobiliare e alludere alla fonte dei loro lauti guadagni. ${ }^{36}$ Ben si comprende allora la lettera che Piero de' Medici, incaricato dal padre a soprintendere ai lavori di affrescatura, aveva inviato a Benozzo Gozzoli sollecitando ragguagli sulla raffigurazione delle vesti e la risposta dell'artista che lo aveva prontamente rassicurato: «el brochato ellaltre cose saranno fatte allora chelle figure, e prima». ${ }^{37}$

\section{Relazioni commerciali con l'Oriente}

A partire dalla seconda metà del XIV e per tutto il XV secolo Firenze aveva mantenuto stretti rapporti con l'Oriente: la manifattura serica in continua espansione e la necessità di approvvigionamento di materie prime per l'industria tessile innescarono una serie di relazioni diplomatiche ed economiche. Se già nella seconda metà del XIV secolo i mercanti fiorentini esportavano nel Levante stoffe di loro produzione, i commerci con i paesi d'oltremare si intensificarono dopo che il governo fiorentino si era dotato di una flotta di galee. ${ }^{38}$ Nel 1422 il setaiolo Felice

trattatista catalano Arnau de Capdevila nei confronti dei mercanti fiorentini: «si rendeva conto che l'arte della mercatura aveva a Firenze un fondamento scientifico, e che quegli spregiudicati e odiati uomini d'affari uscivano da scuole, dove, fin dalla puerizia, venivano addottrinati nel metodo, onde, se non altro per ragioni di legittima difesa, egli proponeva che si introducesse anche nelle scuole di Barcellona tutti gli insegnamenti più idonei alla preparazione di un moderno mercante», DEL TREPPO I972, p. 306.

35. Per il nuovo orientamento delle committenze da parte dei mercanti-banchieri quattrocenteschi che ambivano a manifestare pubblicamente il loro potere economico vedi NAJEMY 2006, pp. 3I9-340.

36. Per le leggi suntuarie volte a regolamentare le tipologie di vesti e ornamenti consentiti alle varie classi sociali vedi MUZZARELLI I996.

37. PADOA RIZZO I993, p. 362 n. 3.

38. HOSHINO 200I, pp. IO4-IO5. 
Brancacci e Carlo Federighi furono inviati al Cairo in veste di ambasciatori con lo scopo di ottenere dal sultano mamelucco Barsbay (r. I422-I438) agevolazioni doganali, privilegi pari a quelli di cui già godevano le città marinare di Pisa e Venezia, l'autorizzazione a mantenere un console e un fondaco al Cairo e il riconoscimento del fiorino come moneta corrente. Dopo essere stati ricevuti dal sultano, al quale avevano offerto pregiati tessuti serici di manifattura fiorentina, le trattative si protrassero per sei mesi per poi concludersi con successo, tanto da essere ricordate dal mercante e banchiere Giovanni Rucellai nel suo Zibaldone:

Nel mccccxxij si diè principio nella nostra città al navicare con galee grosse da mercato et mandossi due ambasciadori al Soldano di Babilonia in su due galee sottili, con richi presenti, per fare patti e conventioni con lui et maxime perché il nostro fiorino d'oro avessi corso nelle terre sue, come il ducato vinitiano [...] Gli ambasciadori furono messer Carlo Federighi et Felice di Michele Brancacci. ${ }^{39}$

I rapporti commerciali con l'impero bizantino si erano invece rafforzati nel I439 in occasione del concilio per l'unione delle due Chiese quando l'imperatore Giovanni VIII Paleologo prima di lasciare Firenze:

levò la metà de' passaggi e ghabelle a tutti i fiorentini in Costantinopoli et per tutto il suo reame. Et simile donò a questo popolo una habitatione che avevano in Gostantinopoli e Pisani antichamente per loro Consolo che da ora innançi e merchatanti fiorentini vi possono tenere in Costantinopoli il Consolo loro. $4^{\circ}$

Nei decenni successivi i fiorentini si adoperarono per mantenere relazioni mercantili stabili con l'Oriente. Quando l'avanzata turca minacciava Costantinopoli si erano astenuti dal prendere posizione, nonostante i continui solleciti da parte dei pontefici, adottando una sottile strategia diplomatica che consentì loro di evitare di schierarsi apertamente. ${ }^{4 \mathrm{I}}$ Dopo la conquista musulmana della capitale bizantina nel I453 Firenze si era apprestata a prendere contatto per stipulare accordi commerciali con Mehmed II (r. I45I-I 48I), sfruttando a proprio vantaggio l'ostilità che il sultano ottomano nutriva nei confronti dei concorrenti veneziani. ${ }^{42}$ Latteggiamento tenuto dai fiorentini verso i turchi risulta estremamente ambiguo: nel I455 la Signoria ringraziò il sultano ottomano per i privilegi concessi ai mercanti fiorentini e riprese i trasporti marittimi, l'anno successivo lodò il proposito del re del Portogallo di combattere i musulmani e informò papa Callisto III dell'esultanza del popolo alla notizia della vittoria riportata sugli in-

39. TRIPODI 20IO, pp. 4I2-4I6; YOUSEFZADEH 20I8, pp. I-5; RUCELLAI 20I3, p. I37. Per la cronologia dei sultani mamelucchi vedi Medieval Islamic 2006, vol. I, p. 226.

40. GOLDTHWAITE 20I3, p. 245; PETRIBONI - RINALDI 200i, p. 290. Vedi anche Documenti sulle relazioni 1879 , pp. XXXVI-XXXIX, I74-I77 doc. CXXII.

4I. BABINGER i963, pp. 308-309.

42. Documenti sulle relazioni 1879 , p. I82 doc. CXXXII. Per la cronologia dei sultani ottomani vedi Medieval Islamic 2006 , vol. 2, p. 58I. 
fedeli a Belgrado, mentre nel I459 Cosimo il Vecchio eluse accuratamente le richieste di appoggio, più volte sollecitate da papa Pio II, per promuovere una crociata antiturca. Non solo, nel i 460 la Signoria si rivolse nuovamente a Mehmed II per raccomandare i mercanti fiorentini che si recavano a Costantinopoli, mentre l'anno successivo Benedetto Dei, rappresentante ufficioso inviato dai Medici in Oriente per caldeggiare i loro interessi, riferiva «nnoi v'avano più banchi e più chase e più fondahi e più merchantìe di drapi e di panni, che non ebbono mai nessuna nazione che mai fusse lì. ${ }^{43} \mathrm{Nel}$ frattempo accordi commerciali per assicurarsi privilegi sul Mar Nero furono stipulati anche con l'imperatore bizantino di Trebisonda Davide II Comneno (r. I458-I46I). ${ }^{44}$ Grazie a questa fitta rete di rapporti quando negli anni settanta del XV secolo le linee di navigazione delle galee fiorentine furono sospese i commerci con l'impero ottomano proseguirono senza interruzioni, soprattutto l'esportazione di panni di lana di media qualità detti «del Garbo» tanto da far dichiarare ai consoli dell'Arte della Lana che il Levante era «in buona parte lo stomaco de' nostri panni garbi».45

La politica estera condotta da Lorenzo de' Medici fu prettamente volta a garantire l'esportazione in Oriente delle merci prodotte dalle industrie tessili fiorentine, motivo per cui era indispensabile godere dell'appoggio degli ottomani in Turchia e dei mamelucchi in Egitto. Aveva perciò abilmente intrattenuto rapporti amichevoli, nonostante in lotta tra loro, sia con il sultano turco Mehmed II, al quale nel I48I era succeduto il figlio Bayezid II (r. I48 I-I5I2), sia con il sultano egiziano Qā' it Bey (r. I 468-I 496). ${ }^{46} \mathrm{Nel}$ I 483, per incentivare i rapporti commerciali e poter così fronteggiare la grave situazione economica ereditata dal padre, Bayezid II inviò nella città del giglio un ambasciatore con l'autorizzazione a importare in Turchia cinquemila pezze di panno ogni anno, pari a quasi un terzo della produzione fiorentina. A sua volta, nel I 488, la Signoria mandò a Costantinopoli l'ambasciatore Andrea de' Medici per ottenere la conferma dei privilegi a suo tempo accordati ai mercanti fiorentini dal padre Mehmed II. ${ }^{47} \mathrm{Nel}$ frattempo anche i legami con i mamelucchi si andarono consolidando: nel I484 l'ambasciatore del sultano egiziano Qà'it Bey giunse a Firenze recando un documento che garantiva l'immunità ai mercanti fiorentini impegnati in attività commerciali nei territori posti sotto il suo dominio. ${ }^{48}$ I rapporti proseguirono stabilmente fino al I487, quando l'ambasciatore Mohamed Ibn-Mahfuz si presentò nuovamente sulle rive dell'Arno per offrire ai fiorentini i privilegi di cui già godevano i mercanti

43. GOLDTHWAITE 20I3, p. 246; Documenti sulle relazioni I879, pp. I82-I84 doc. CXXXII-CXXXIV; DEI I984, pp. I59-I60 c. 78v, I6 г c. 79v; HOSHINO 200I, pp. II3-II4. A Costantinopoli la colonia dei mercanti fiorentini era concentrata a Pera, nella parte nord del Corno d'Oro, dove risiedeva anche il console.

44. Documenti sulle relazioni I879, pp. I86-I87 doc. CXXXVIII.

45. HOSHINO I980, p. 243; ID. 200I, pp. II4-II5.

46. Per la cronologia dei sultani mamelucchi e ottomani vedi Medieval Islamic 2006, vol. I p. 226; vol. 2, p. 58 I. 47. Documenti sulle relazioni I879, p. 235 doc. CXCIX, 238-239 doc. CCIV; BABINGER I963, pp. 357-358;

HOSHINO 200I, p. II3; GOLDTHWAITE 20I3, p. 247.

48. I diplomi arabi I863, doc. XXXI. 
veneziani in Egitto e in Siria. ${ }^{49}$ Per tutta risposta l'anno successivo Luigi Della Stufa partì per il Cairo, al seguito dell'ambasciatore egiziano, con l'incarico di negoziare e definire gli accordi e portando con sé preziosi doni diplomatici da offrire al sultano mamelucco: panni di lana, velluti e drappi broccati offerti dalla Signoria, una lettiera, una cassapanca, un forziere e uno specchio lavorati in avorio e altri tessuti in lana e seta da parte del Magnifico. ${ }^{\circ}$ Le trattative per la stesura definitiva dell'intesa commerciale si protrassero per ben otto mesi, fatto che indusse Luigi Della Stufa, ormai impaziente di rientrare in patria, a lamentarsi con Lorenzo de' Medici: «Io mi truovo ancora qui nel Chairo et non mi posso dispacciare et non v'è faccenda nessuna, salvo che havere licenza da questo gloriosissimo signore Soldano et farmi dar eli capitoli et buona licenza; et per ancora non posso venire alla fine». ${ }^{5 \mathrm{I}} \mathrm{Nel}$ novembre $\mathrm{I} 489$ riuscì finalmente a imbarcarsi recando con sé i tanto agognati accordi che avrebbero reso Firenze diretta concorrente della Serenissima nelle attività commerciali con l'Egitto.

Tra la fine del XIV e i primi decenni del XV secolo, grazie allo sviluppo dell'industria tessile e all'intensificarsi dei commerci con le terre d'oltremare, la classe mercantile fiorentina era in piena ascesa. La grande disponibilità economica concentrata nelle mani dei mercanti, da un lato, e una società di stampo repubblicano, dall'altro, avevano finito per conferire loro il potere - come si vedrà nei capitoli successivi - d'influenzare la cultura cittadina in tutte le sue sfaccettature: dall'istruzione scolastica agli interessi letterari, dallo stile di vita alle relazioni sociali, dal concetto di prestigio al valore simbolico attribuito all'arte.

49. BABINGER I963, pp. 349-353; MELI 2009, pp. 243-244; TRIPODI 201o, pp. 4I9-429; Documenti sulle relazioni $\mathrm{I} 879$, p. 237 doc. CCIII.

50. BABINGER I963, pp. 354-356; MELI 2009, pp. 250-258. Vedi anche MONTESANO 2007, pp. 282-29I; TRIPODI 20Io, pp. 42I-427. Nella sua relazione di viaggio ser Antonio del Lavacchio, membro della comitiva al seguito di Luigi Della Stufa, descrive i regali destinati al sultano: "Adì 24 [giugno] mandò el presente della Signoria, cioè panni 68 e 2 peze di brochato e altri velluti. [...] Adì primo d'agosto portamo al Soldano el presente del Magnifico Lorenzo, cioè una lettiera con una cassapancha, tutto lavorato di vivorio, che al Soldano parve detta lettiera una dignissima chosa, che la stimò più che se fussi stata d'oro; e mandògli uno forziere e uno spechio, lavorati tutti di vivorio; e mandògli una peza di panno per fare chamice: tutto e' ripieno era d'oro, era una chosa dignissima; e brochati e altri drappi» vedi CORTI I958, p. 255.

5I. MELI 2009 , p. 265 doc. 7. 

PARTE II

Fascinazione orientale 



\section{Oriente in letteratura e nelle biblioteche dei mercanti}

\section{Mercanti avventurieri e "viaggiatori da camera»}

\section{I.I. Marco Polo}

Nel i368, con l'avvento al potere della dinastia Ming, la Cina chiuse i suoi confini agli stranieri. ${ }^{\mathrm{I}}$ L'Oriente narrato da Marco Polo alla fine del XIII secolo nel Divisament dou monde fu così drasticamente ridimensionato. L'Oriente come luogo mentale continuò, invece, a occupare ampio spazio nell'immaginario dell'epoca. Non per nulla il testo poliano, tra i più letti e tradotti fino al punto da assurgere a vero e proprio best seller, si rintraccia con frequenza tra i volumi gelosamente custoditi negli scaffali delle biblioteche del ceto mercantile fiorentino tra il XIV e il XV secolo. ${ }^{2}$ Frutto della collaborazione tra il mercante veneziano Marco Polo e Rustichello da Pisa, suo compagno di cella nelle carceri genovesi, il Divisament dou monde (I298) - noto anche con il titolo Milione - fu composto in francese. ${ }^{3}$ La convivenza forzata tra colui che il geografo tedesco Alexander von Humboldt aveva definito «il più grande esploratore terrestre di tutti i tempi e di tutti i paesi» e un mediocre compilatore di storie cavalleresche aveva dato origine alla stesura di un manoscritto - andato perduto - nel quale si raccontava il lungo e avventuroso viaggio compiuto da Marco Polo. ${ }^{4}$ Partito da Venezia nel I27I, al seguito del padre Niccolò e dello zio Matteo, il giovanissimo Marco attraversò l'Asia cavalcando lungo le piste carovaniere fino a raggiungere la Cina, dove fu al servizio del sovrano mongolo Qubilai (r. I260 -I294) per diciassette anni, per

I. REINHARD I987, pp. 32-33; GADRAT 2005, pp. 32-34; CONCINA 20I8, p. II8.

2. Ancora prima della morte di Marco Polo nel $\mathrm{I} 324$, il testo fu tradotto in francese e latino e probabilmente anche in veneziano e toscano, mentre nel giro di due secoli fu oggetto di ben ventisei adattamenti o traduzioni e diffuso in tredici lingue diverse vedi GADRAT-OUERFELLI 2015 , p. 6.

3. Notizie sulla genesi dell'opera sono fornite nel prologo del testo poliano: «stando nella prigione di Genova, fece mettere inn-iscritto tutte queste cose a messere Rustico da.pPisa, lo quale era preso in quelle medesime carcere ne gli anni di Cristo I298", POLO 200I, p. 4, I:6. Il titolo Milione, sovente erroneamente interpretato quale allusione alle mirabolanti descrizioni delle terre d'Oriente, corrisponde alla forma aferetica di Emilione, soprannome della famiglia Polo, anche se Christiane Gadrat-Ouerfelli non esclude, come altri prima di lei, che il titolo possa implicare un'allusione alla ricchezza e all'esagerazione del testo vedi BENEDETTO I930, pp. I-2; GADRATOUERFELLI 20I5, p. I5I Per la sterminata letteratura poliana vedi WATANABE I986.

4. HUMBOLDT i847, vol. 2, p. 290; MONTESANO 20I4, p. 64. L'evento che portò alla detenzione di Marco Polo, certamente da ricondurre alla rivalità tra repubbliche marinare e alle loro attività commerciali, non è in realtà noto vedi JACOBY 2006, pp. 200-20I. Sulla primitiva stesura e la tradizione manoscritta dell'opera poliana vedi GADRAT-OUERFELLI 2015. 
poi fare ritorno in patria nel I295, dopo un'assenza di quasi cinque lustri, solcando le acque del Mar Cinese meridionale e dell'Oceano Indiano. ${ }^{5}$

Caratteristica che decretò il rapido e straordinario successo a livello internazionale del Milione era la coesistenza in un unico testo, come in un gioco di scatole cinesi, di molteplici generi letterari: resoconto geografico, trattato di etnografia, itinerarium, relazione diplomatica, manuale mercantile e romanzo. Libro di viaggio atipico, si discostava dai consueti modelli in forma di récit di memorie personali per assumere la veste di trattazione enciclopedico-scientifica con intento didattico, come del resto annunciato nel prologo dall'auctor-scriptor Rustichello quando affermava:

niuno huomo di niuna generazione non vide né cercò tante maravigliose cose nel mondo come fece messer Marco Polo. E però disse infra'sse medesimo che troppo sarebbe grande male s'egli non mettesse inn'iscritto tutte le maraviglie ch'egli à vedute, perché chi no'lle sa l'appari per questo libro. ${ }^{6}$

L'impatto suscitato dal Milione nella società contemporanea dovette essere dirompente considerato che si trattava della più antica relazione di viaggio composta in lingua volgare, quindi alla portata del ceto borghese, e che la miriade di nozioni contenute, solitamente reperibili in libri di mera utilità pratica, erano trasmesse al lettore attraverso una narrazione di natura romanzesca. Il tono da fiction medievale che Rustichello, compilatore di storie cavalleresche per professione, aveva saputo infondere al racconto e la scelta della redazione in franco-italiano, destinata a un'eterogenea audience laica e internazionale, avevano avuto il potere di catturare l'interesse di un vasto pubblico, trasformando quella che si prospettava come una dilettantesca relazione di viaggio in un accattivante libro di avventure esotiche. ${ }^{7}$ Attraverso la descrizione delle meraviglie dell'Asia il protagonista riferiva una mole impressionante di notizie la cui veridicità era certificata nel prologo, secondo uno schema ricorrente nella letteratura odeporica, per il fatto che «egli medesimo le vide». ${ }^{8}$

Che il lettore, nonostante l'iniziale stupore e divertimento, accordasse fiducia alle affermazioni di Marco Polo, solo in rari casi reputate fasulle o inverosimili, è stato di recente appurato dalla puntuale analisi delle note apposte lungo i margini delle pagine delle copie del Milione come pure dai rimandi inseriti in altri testi. ${ }^{9}$

5. La tesi di Frances Wood che Marco Polo non si fosse mai recato in Cina è stata smentita dalle ricerche di numerosi studiosi tra cui Igor de Rachewiltz, Stephen Haw e Hans Ulrich Vogel vedi WOOD I995; RACHEW ILTZ I997; HAW 2006; VOGEL 20I3. Vedi anche RUBIÉS 2000, pp. 46-47 nota 33.

6. BOLOGNA I987, p. I85; POLO 200I, pp. 3-4, I:4-5.

7. BERTOLUCCI PIZZORUSSO I994, pp. 6I-63. La scelta della redazione in franco-italiano mirava a raggiungere un vasto pubblico: nobili e borghesi leggevano cronache, trattati, enciclopedie e romanzi cavallereschi in francese, mentre mercanti e pellegrini se ne servivano per comunicare quando si trovavano nel Levante.

8. POLO 200I, p. 3, I:3. Formula adottata anche nei libri di viaggio immaginari per conferire credibilità alla narrazione vedi CARDONA I986, p. 705 .

9. GADRAT-OUERFELLI 20I5, pp. IO, I55-I57. Varie sono le opinioni degli studiosi riguardo alla ricezione del Milione da parte dei contemporanei: per alcuni fu recepito come un libro di favole (PASTORE STOCCHI 
Se nel I307 lo stesso Marco Polo si fece promotore della sua opera affidandone una copia a Thibaut de Chepoy, cavaliere al servizio del fratello del re di Francia, perché la recapitasse al suo signore Carlo di Valois impegnato a progettare una spedizione in Oriente per riconquistare Costantinopoli, la credibilità accordata al libro trova conferme sia nella Nuova Cronica (I307-I348) - poderosa compilazione dedicata alla storia fiorentina degli ultimi centocinquant'anni - del mercante e uomo politico Giovanni Villani, che per un approfondimento sui rapporti con i mongoli rimandava al «libro detto Milione, che fece messere Marco Polo di Vinegia, il quale conta molto di loro podere e signoria, imperciò che lungo tempo fu tra-lloro", sia nel Fons memorabilium universi (I374-I4I8) - monumentale enciclopedia geografica - dell'aretino Domenico Bandini, insegnante di grammatica gravitante nell'orbita dell'umanista Coluccio Salutati, che vi attinse a piene mani. ${ }^{\text {IO }}$

Anche cartografi e navigatori fecero tesoro delle notizie riferite nel Milione. Intorno al 1375 l'ebreo-maiorchino Abraham Cresques aveva potuto ampliare l'Atlante catalano (fig. 8), commissionatogli da Pietro IV d'Aragona quale dono per Carlo V di Francia che nel i380 lo custodiva nella sua biblioteca, includendo la rappresentazione dell'Asia centrale, della Cina e dell'Oceano Indiano grazie alle conoscenze tramandate da Marco Polo, personaggio forse evocato sulla mappa al seguito di una carovana di cammelli lungo la Via della Seta (fig. 8d). ${ }^{\text {II }}$ E ancora due secoli più tardi l'edizione a stampa del Milione in latino, pubblicata a Gouda tra il I 483 e il I484, figurava tra i libri posseduti dal celeberrimo Cristoforo Colombo corredata da annotazioni vergate di suo pugno. ${ }^{\text {I2 }}$

A essere particolarmente apprezzato nel Milione, oltre al contenuto, fu il tono romanzesco dell'esposizione che ben appagava la concezione tutta medievale di una letteratura didattica capace d'istruire in maniera piacevole. ${ }^{\mathrm{I3}}$ Libro complesso per la quantità e la varietà delle informazioni raccolte, il testo poliano offrì a

I986a, pp. 5I7-5I8; ECO 200I, p. 66; TUCCI 2005, pp. 38-39), per altri la fiducia accordatagli variava in relazione all'ambiente di diffusione (ALMAGIÀ I955, pp. 3I-34) o all'ampiezza degli interventi operati da copisti e traduttori (LARNER I999, pp. I09-II5), mentre un'altra corrente ritiene che lo scetticismo fosse alquanto limitato (OLSCHKI I957, pp. I24-I25; GADRAT-OUERFELLI 20I5, p. I64). Per Marina Münkler, invece, dubitare rispondeva a un topos funzionale a rafforzare l'eccezionalità del racconto, MÜNKLER 200I, pp. 8I-86.

Io. GADRAT-OUERFELLI 20I5, p. II7; GALLO I955, pp. I42-I43; POLO 200I-2009, vol. I, pp. 24-28; VILLANI I990, vol. I, p. 256. Giovanni Villani dal I300 al I308 fu socio della compagnia commerciale dei Peruzzi e a partire dal I324 di quella dei Bonaccorsi vedi DAVIDSOHN I929, p. 283. Per un'analisi puntuale dei debiti e dei riferimenti al testo poliano vedi GADRAT-OUERFELLI 20I5, pp. I96-20I, 247-253. Per la credibilità accordata da Domenico Bandini di Arezzo alle informazioni di Marco Polo vedi POLO i928, pp. CCXVI-CCXVII; LARNER I999, pp. I36-I37.

II. MASSING I99I, pp. 27-33; BECDELIÈVRE 20I8; BRILLI 20I3, pp. I46-I49 (che però indica come destinatario del dono Carlo VI); MOROSINI 20Io, p. I9. Riguardo al grande interesse di Carlo V per la geografia, nel I37I gli era stata regalata la prima copia nota del testo originale del Livre des merveilles du monde di Jean de Mandeville vedi DELUZ I987, p. 215.

I2. L'idea che il Milione avesse ispirato Cristoforo Colombo nel progetto di raggiungere l'Oriente attraversando l'Oceano Atlantico è stata di recente messa in dubbio a favore dell'ipotesi che se ne fosse invece servito, in un secondo tempo, per conferire credibilità alle sue scoperte vedi GADRAT-OUERFELLI 20I5, pp. 3I9-335.

I3. MAZZI I997, p. 25. Vedi anche OLSON I982. 
traduttori e trascrittori la possibilità di focalizzare l'attenzione su di un determinato argomento, pervenendo così a elaborare versioni, riassunte, ridotte, alleggerite o sfrondate, espressamente concepite per soddisfare le aspettative dell'audience di destinazione: dagli aristocratici che ne traevano diletto agli eruditi che affinavano le loro conoscenze, dagli ecclesiastici che vi trovavano ispirazione per i sermoni ai mercanti che ne ricavavano informazioni per i loro commerci. ${ }^{\mathrm{I}} 4$ Pratica che trova conferma nell'eterogeneo assortimento di titoli che di volta in volta copisti e proprietari assegnarono al manoscritto per evidenziarne un determinato aspetto contenutistico: Divisament dou monde - ossia «descrizione del mondo» - per la ricognizione geo-etnografica del continente asiatico, De mirabilibus mundi per il quadro politico e antropologico, Livre del Gran Khan o Historia Tartarorum per la celebrazione di Qubilai e del suo impero, Livre des merveilles per la descrizione dell'esotico, Libro di messere Marco Polo cittadino di Vinegia o Milione per le notizie di carattere geografico-commerciale e gli spunti novellistici. ${ }^{\text {IS }}$

Il successo riscosso dal Divisament dou monde fu tale da essere tradotto in numerosi idiomi: francese, latino, catalano, portoghese, tedesco, boemo, irlandese e vari dialetti italiani tra cui anche quello toscano. ${ }^{16}$ Sono ben undici i volgarizzamenti in lingua toscana giunti sino a noi databili tra la prima metà del XIV e la fine del XV secolo; numero significativo considerato che le versioni del testo poliano adattate e tradotte nel corso di due secoli ammontano a centoquarantuno e che nel XV secolo una biblioteca privata del ceto borghese fiorentino conteneva in media sette volumi. ${ }^{17}$ Oltre a ciò il fatto che sei copie furono scritte in «mercantesca» - grafia nata sullo scorcio del XIII secolo nell'ambiente dei mercanti fiorentini per redigere lettere e documenti commerciali e, in seguito, adottata per la trascrizione di testi letterari in volgare a uso privato - testimonia il grande interesse suscitato dall'opera nella classe mercantile. ${ }^{18}$ Due esemplari sono con certezza riconducibili a membri di importanti casati fiorentini: Pietro del Riccio che nel I 458 appuntò, sulla trascrizione fatta dal bisavolo Niccolò Ormanni

I4. A questo proposito Marie-Thèrese Gousset suggerisce che la presenza nella stessa biblioteca di più versioni, cinque nel caso di Carlo V e tre in quello del duca di Berry, fosse dovuta alla consapevolezza delle differenze di contenuto; Christine Gadrat-Ouerfelli ritiene, invece, che si tratti di doni oppure di testi lussuosi da custodire con cura mentre altri meno pregiati erano destinati alla lettura vedi POLO 2002, p. 7; GADRAT-OUERFELLI 20I5, pp. I36-I38. Interessanti riguardo ai manoscritti miniati sono le osservazioni di Joan-Pau Rubiés sulla necessità di operare una netta distinzione tra il testo, non esclusivamente volto a confermare leggende e auctoritates, e le illustrazioni, realizzate in un secondo tempo e concepite con lo scopo di suscitare meraviglia senza prestare particolare attenzione alla realtà dei fatti narrati, RUBIÉS 2000, pp. 35-40.

I5. Per un elenco dei titoli più frequenti vedi GADRAT-OUERFELLI 20I5, pp. I48-I5I.

I6. Riguardo alla traduzione in francese, il manoscritto consegnato da Marco Polo a Thibaut de Chepoy era in un francese mescidato d'italianismi, motivo per cui prima di presentarlo a Carlo di Valois fu adattato in «buon francese» vedi ivi, p. I I 7 .

I7. Ivi, pp. 8-9, 29-3I, 45-47; CIAPPELLI 200I, p. 426. Nel computo dei volgarizzamenti toscani è stata esclusa la versione cinquecentesca del codice Vaglienti perché non pertinente all'arco cronologico di questa ricerca vedi Iddio ci dia buon viaggio 2006 , p. 2 I.

I8. POLO 200I, p. XV. Per un approfondimento sulla grafia mercantesca vedi ORLANDELLI I959; PETRUCCI i989, pp. I56-I6I. 
deceduto nel I309, di averla ricevuta dalla madre e Amelio Bonaguisi, che in una nota precisava di aver terminato di copiare la sua versione il I2 novembre I392 per «passare tenpo e malinconia» mentre svolgeva l'incarico di podestà a Cerreto Guidi. ${ }^{19}$ Se Pietro del Riccio rientrava nella cerchia dei mercanti fiorentini, lo stesso si può dire di Benedetto di Banco degli Albizzi, che nel I39I trascrisse una copia del Milione. ${ }^{20}$ Piero Peruzzi, possessore di una copia eseguita alla fine del Trecento da uno scriba professionista, e Gachinoto d'Adonardo de' Bardi, anch'egli detentore di una copia realizzata nel I425 dal mercante fiorentino Doffo Spini, erano a loro volta membri di famiglie a capo delle più importanti compagnie commerciali. ${ }^{21}$ Sempre da ricondurre al milieu mercantile era il «libro di Marcho Polo di Vinegia, in charta di pechora» elencato tra i volumi inventariati nel I4I4 alla morte del banchiere Filippo di Piero Rinieri. ${ }^{22}$ Il casato dei Benci, invece, riuscì ad accaparrarsi lo zibaldone autografo del fiorentino Antonio Pucci, autore di poemi cavallereschi, che nella seconda metà del XIV secolo vi aveva ricopiato brani tratti dal Milione con aneddoti e usanze dei popoli, soprattutto i mongoli, tralasciando invece i capitoli, per lui di scarso interesse, relativi agli itinerari di viaggio. ${ }^{23}$

In un'epoca in cui, pur essendo assai richiesti, $i$ testi in lingua volgare erano esclusi dalle biblioteche pubbliche, dove si raccoglievano esclusivamente manoscritti in latino, la loro circolazione fu per lo più affidata alla pratica diffusa tra il ceto borghese di prestare i propri libri a conoscenti e amici in modo che potessero leggerli e trascriverli, come rivela l'iscrizione «di Piero di Iacopo Peruzzi et delli amici» apposta su una copia del Milione. ${ }^{24}$ Caso emblematico è quello della famiglia Benci che nel XV secolo disponeva di una fornitissima biblioteca privata costituita in gran parte da volumi che loro stessi avevano copiato. ${ }^{25}$ Sebbene favorevoli a concederli in prestito, il valore che i Benci attribuivano ai manoscritti di loro proprietà si deduce dalle note di possesso vergate su alcuni esemplari: «Priego acchi Io lo prestassi melo renda o a mie [e]rede e pigline utile e consolazione allanima ealchorpo eprieghi iddio per me chello chopiato esoprattutto lo

I9. RUBIÉS 2000, p. 57; POLO 200I, p. 328; I manoscritti della letteratura 2002, p. 93 n. I7; GADRATOUERFELLI 20I5, p. 362 nn. 27-28. Se la datazione ante I309, basata sull'iscrizione apposta centocinquant'anni più tardi dal bisnipote, ha suscitato qualche perplessità tra gli studiosi, le analisi della scrittura e della filigrana della carta hanno confermato che è da posticipare alla prima metà del XIV secolo vedi POLO I928, p. LXXXI; I manoscritti della letteratura 2002, pp. 67-68; POLO 200I, p. 333; PINZAUTI 20I5, pp. I92-I93 n. 60.

20. POLO 200I, pp. 33I-332; Firenze e la scoperta I992, p. 4I n. I4; GADRAT-OUERFELLI 20I5, p. 362 n. 24.

21. POLO I928, pp. CVII-CVIII; Firenze e la scoperta I992, pp. 4I-42 n. I5; GADRAT-OUERFELLI 20 I5, p. 362 n. 25 , p. 363 n. 30; SAPORI I926. Per un elenco delle copie del Milione in italiano vedi anche O'DOHERTY 20I3, pp. 3I2-33I. Per un approfondito studio sulle vicende della compagnia Peruzzi e per l'appartenenza di Doffo Spini al ceto mercantile vedi HUNT i994; BEC I967, p. 386.

22. ID. I984, p. I50.

23. PUCCI I957, pp. IX-XVIII, 45-80; POLO I928, pp. LXXXV-LXXXIX; GADRAT-OUERFELLI 2015 , pp. I6I-I62. Per lo Zibaldone di Antonio Pucci con estratti del Milione vedi POLO 200I, pp. 333-335.

24. PETRUCCI I983b, p. 546; ID. I983a, pp. 5I8-522; CIAPPELLI 200I, p. 436; NEBBIAI DALLA GUARDA 2006, p. 390; POLO I928, p. CVII.

25. TANTURLI I978, pp. I97-3I3. 
ghardi dalla lucierna omacchie accio nonsi guasti amen» oppure "Questo libro e di progienia di [...] di lorenzo di giouanni di taddeo benci preghiamo che sello prestasimo apersona neprenda piaciere edileto Eabine ghuardia apresso per sua chortesia cielorenda chedio Ilghuardi esimile noi». ${ }^{26}$ Sono sempre queste iscrizioni sui libri a rivelare la frequenza dei prestiti: nel I482 Francesco d'Antonio di Nanni sul suo manoscritto appuntò "Tu che l'hai nelle mani adoprilo et prega Iddio per quello chel'à prestato et rendilo presto", mentre qualche decennio prima un certo Giovannino ricordava «E cchi l'acchatta da mme, presto e· renda, / che chosì parmi voglia la ragione; / e cchi l'avesse questa istanza intenda, / che cqui chonsiste mia consolazione, / che no llo doni e no llo inpengni ho venda", fino ad arrivare alla copia di Francesco di Filippo Lapaccini, nipote dell'umanista Niccolò Niccoli, che sul foglio di guardia aveva addirittura riportato un Sonetto per util[ità] et honore de' libro:

$\mathrm{O}$ tu che legi, fa' che ben discierna questo libretto di [g]ientil volume, che quando legi e tiello preso a lume pregho che 'l ghuardi da olio di lucerna,

che far si suol quando da noi si verna. E quando letto avrai questo volume, rendi i- libretto perché gli è chostume di gentil huomo [e] di donna superna.

$[\ldots]$

Et è di Francesco di Filippo Lapaccini che volentier lo presta chortexe ment[e] a cui se ne dilecta. ${ }^{27}$

Attraverso questa condivisione i "copisti per passione» - così indicati da Vittore Branca - tra la fine del XIV e quella del XV secolo riuscirono a dare vita e arricchire le loro biblioteche private senza dover sborsare ingenti somme per l'acquisto di libri. ${ }^{28}$ Altre volte si rivolgevano, invece, a "cartolai» che, oltre a materiali per la scrittura e la confezione di codici, nella loro bottega disponevano di libri già pronti o di seconda mano oppure, su espressa richiesta, assumevano l'incarico di commissionare la trascrizione di testi a copisti di loro fiducia. ${ }^{29}$ Nel I 426 tra $i$

26. Ivi, pp. $285-286,265$.

27. I manoscritti datati della Biblioteca Riccardiana I997-2013, vol. 3, p. 43 n. 9I; vol. 4, p. I5 n. 22; vol. 2 , p. 53 n. IO2.

28. BRANCA I96I, pp. 7I-72. Alla metà del XIV secolo il costante incremento del pubblico di lettori e potenziali scriventi laici appartenenti al ceto mercantile, istruitisi nelle scuole di abaco, comportò l'affermarsi della pratica della "scrittura per la lettura», fino a farla diventare una valida opzione al doversi per forza rivolgere a scribi professionali vedi CURSI 2007, p. 47.

29. DANIELS 2009, p. 22. Marco Cursi nel suo studio ridimensiona la tesi di Vittore Branca che i mercanti fossero "copisti per passione" sostenendo, sulla base di ricerche paleografiche e codicologiche, che buona parte delle copie del Decameron sono da ricondurre a "copisti a prezzo", ossia professionisti, anche nei casi in cui la qua- 
beni inventariati nella modesta bottega del «cartolaio» Giovanni di Michele Bandini figurava, oltre a grammatiche per fanciulli, libri devozionali, testi per notai e opere di Giovanni Boccaccio, anche «I Marco Polo in assi». ${ }^{30}$

A testimoniare l'interesse prettamente utilitario del Milione da parte dei mercanti fiorentini è la realizzazione di copie esclusivamente su carta, a eccezione del lussuoso esemplare membranaceo appartenuto insieme a «ja charta da navicare» al ricco banchiere Filippo di Piero Rinieri, e l'assenza di illustrazioni, a differenza di quanto avveniva per i manoscritti destinati a un pubblico colto e raffinato che al piacere della lettura di storie esotiche vergate su costosa pergamena coniugava quello della vista allietata da sfavillanti miniature. ${ }^{3 \mathrm{I}}$ Il fatto che la metà dei volgarizzamenti toscani del testo poliano si trovi in volumi miscellanei detti «zibaldoni» - libri-contenitore tipici dell'ambiente mercantile dove a loro gusto e piacere i possessori trascrivevano testi integrali o estratti di opere di vario genere - fornisce un'ulteriore prova, oltre che lo strumento stesso, della

precisa volontà di acculturazione extrascolastica, autodidattica, che era insieme professionale e ideologica: volontà propria al mercante artigiano dell'Italia tre-quattrocentesca, che non per caso (come pur sembrerebbe) scriveva nel proprio zibaldone tariffe di porti e cambi di moneta accanto a ricette mediche, a trattatelli di devozione, a laude, a rime amorose, riassumendo così in un breve orizzonte cartaceo e di umile apparenza quelli che erano i capisaldi fondamentali della sua cultura e della sua stessa presenza nella società del tempo. ${ }^{32}$

I presupposti per catturare l'attenzione di questa tipologia di lettori non mancavano certo. Frutto di un'iniziativa privata e autonoma, a differenza di quanto avvenuto per le precedenti relazioni dovute a missionari inviati in Oriente dal loro ordine per diffondervi la religione cristiana o dal pontefice con l'incarico di stringere alleanze con i mongoli in funzione antimusulmana, l'opera di Marco Polo si prospettava come referenziale e unica nel suo genere. ${ }^{33}$ Immedesimarsi con il protagonista, infaticabile viaggiatore ed esploratore del mondo appartenente a una facoltosa famiglia di mercanti, doveva risultare alquanto semplice. Originato dalla collaborazione tra un veneziano e un pisano, entrambi cittadini di repubbliche marinare, il testo si delineava come un elogio della mercatura e, al tempo stesso, un'autocelebrazione del mercante che «possiede le chiavi per la conoscenza del mondo, per penetrarne e conquistarne le meraviglie». ${ }^{34}$ Oltre a ciò, la narrazione che si snoda in forma di itinerarium, secondo uno schema tipico dei prontuari commerciali, ben si confaceva alla mentalità dei mercanti fiorenti-

lità appare scarsa, opinione condivisa anche da Rhiannon Daniels vedi BRANCA I96I, pp. 69-83; CURSI 2007 , pp. 56-57, I40-I 42; DANIELS 2009, p. I74. Per un approfondimento vedi CURSI I998, pp. 463-55I.

30. DE LA MARE I973, p. 248.

3I. BEC I984, p. I50. Tra i prestigiosi manoscritti miniati si annovera quello offerto da Giovanni senza Paura al duca di Berry nel I4I3 vedi POLO 2002, pp. 7-94; BECDELIÈVRE 2019.

32. PETRUCCI i983a, p. 5I3.

33. BERTOLUCCI PIZZORUSSO i994, pp. 6I-62.

34. AIRALDI 2007 , p. 46. 
ni, come pure il carattere economico delle notizie riguardo ai prodotti disponibili sulle piazze orientali che andava a eccitare la loro bramosia di guadagno. ${ }^{35}$ L'orientamento spiccatamente commerciale del testo originale traspare, inoltre, dalla totale assenza di accenni al paradiso terrestre, discostandosi così dalle relazioni dei missionari, dal libro fittizio di Jean de Mandeville e dalle mappe geografiche, che secondo una radicata concezione cristocentrica medievale lo localizzavano in Oriente. Il fugace riferimento a Gerusalemme, all'epoca ritenuta il centro dell'universo perché vi era custodito il corpo di Cristo, è da ricondurre all'espressa richiesta di Qubilai al padre e allo zio di Marco in occasione del loro primo viaggio in Cina, ossia di recapitargli alcune gocce d'olio prelevate dalla lampada del Santo Sepolcro. ${ }^{36}$ L'universo di Marco Polo gravitava quindi esclusivamente attorno a due poli: Venezia e "Canbalu» - odierna Pechino - cardini del suo mondo mercantile. ${ }^{37}$ Interesse che del resto trapela dal numero di capitoli dedicati nel Milione al commercio e alle mercanzie: ben Io9 su un totale di $234 \cdot{ }^{38}$

A influenzare la visione di Marco Polo dovette certamente contribuire l'appartenenza a una famiglia da generazioni dedita all'attività commerciale e, con tutta probabilità, l'aver frequentato una scuola di abaco dove s'insegnavano i fondamenti del calcolo mercantile. ${ }^{39}$ La struttura stessa dell'opera, simile a quella delle pratiche di mercatura per la presenza di schede con informazioni utili al mercante, e la ricchezza dei dati forniti hanno indotto gli studiosi a ritenere che Rustichello non si fosse limitato a scrivere quanto dettatogli dal mercante veneziano, ma si fosse avvalso degli appunti che lo stesso Marco Polo doveva aver diligentemente annotato su di uno scartafaccio, una sorta di zibaldone, nel corso del suo annoso viaggio. ${ }^{\circ}$ Non è dato sapere se il mercante veneziano avesse ordinato i suoi ricordi seguendo lo schema tipico dei prontuari commerciali con lo scopo di comporne uno oppure se a influenzarlo fosse stata la sua attitudine mentale di mercante, che lo induceva a osservare e descrivere il mondo in quell'ottica, certo è che a Firenze le notizie di natura commerciale confluite nel Milione furono prontamente recepite dall'emergente classe mercantile. ${ }^{\text {II }}$ A questo riguardo è oltremodo interessante l'avvertenza che precede una serie di estratti del libro poliano trascritti, intorno al I430, dal mercante toscano Meo Ceffoni su alcuni

35. JACOBY 2006, p. 207; POLO 2008, pp. XIV-XV.

36. YEAGER 2008, p. I73; POLO 200I, p. I5, I0:2-3. Per la concezione cristocentrica del mondo e la raffigurazione del paradiso terrestre sulle mappe vedi LE GOFF I972, p. 177; SCAFI 2007.

37. POLO 200I, p. I26, 83:I.

38. BORLANDI I962, p. II2.

39. TUCCI 1976, pp. 642-643. Di opinione diversa è invece Leonardo Olschki che ritiene le notizie mercantili fornite nel testo poliano assolutamente prive di finalità a uso commerciale, OLSCHKI I957, pp. 95-98. Per le scuole di abaco vedi pagine $85-88$.

40. L'ipotesi, a suo tempo avanzata da Luigi Benedetto, oggi comunemente accettata ha trovato conferma nello studio di Franco Borlandi, POLO 1928, pp. XXVI-XXVII; BORLANDI 1962, pp. I07-I47. Ugo Tucci e Alvaro Barbieri, pur condividendo le conclusioni di Franco Borlandi, dissentono dall'idea che lo scartafaccio possa essere considerato la redazione 'prima' dell'opera poliana, TUCCI I976, pp. 643, 647; POLO 2008, pp. XVIXVII. Per le pratiche di mercatura vedi pagine 88-9I.

4I. TUCCI 1976, p. 643; CARILE I977. 
fogli intonsi in un manoscritto di sua proprietà con la Commedia dantesca: «E questto libro istà a Vinega in sul Rialto, apichato cholle chatene ch'onnun el può leger $\mathrm{d}[\ldots]$ dire d'alchuno»..$^{2}$ Sebbene non supportata da prove documentarie, l'indicazione che a Venezia un esemplare del libro di Marco Polo «che tratta di portti del mare e 'tterra» si trovasse incatenato a Rialto per poter essere liberamente consultato ha indotto gli studiosi ad avanzare ipotesi sulla sua localizzazione: la biblioteca della scuola annessa alla chiesa di San Giovanni Elemosinario, dove i volumi erano custoditi legati con catene, il quartiere di Rialto, centro nevralgico dei commerci internazionali, o la loggia dei mercanti dove, tra le immagini affrescate sulle pareti intorno al $\mathrm{I}_{322}$, figurava anche un mappamondo, altro strumento estremamente utile per gli addetti alle attività mercantili. 43

Il grande successo riscosso a Firenze dall'opera di Marco Polo era da ricondurre al fatto che, sullo scorcio del XIII secolo, proponeva una visione mercantile affermatasi in Toscana solo nei secoli successivi. ${ }^{44}$ Non deve allora stupire se, tra le molteplici chiavi di lettura applicate da copisti e traduttori, nel volgarizzamento toscano del Milione fu proprio il risvolto commerciale a prevalere grazie a mirati interventi volti a modificare il testo originale: da un lato l'attenuazione del tono epico-cavalleresco, tanto amato dalla nobiltà, e la soppressione di alcune parti storiche quali le cronache di battaglie, dall'altro aver posto in risalto le informazioni particolarmente utili e attendibili perché fondate sull'osservazione acuta e competente di chi era abituato a ragionare in termini economici. Del resto, proprio negli anni in cui il libro di Marco Polo andava ad arricchire gli scaffali delle biblioteche dei mercanti, Francesco di Balducci Pegolotti, valente fattore al soldo di una delle più grandi compagnie commerciali del tempo, quella fiorentina dei Bardi, era impegnato nella redazione di un manuale di mercatura con lo scopo di ragguagliare su «divisamenti di paesi, e di misure di mercatantie e d'altre cose bisognevoli di sapere a mercatanti di diverse parti del mondo».45

\section{I.2. Jean de Mandeville}

Alla fascinazione orientale del tempo sono pure da ricondurre $\mathrm{i}$ «viaggi di carta», filone letterario così designato dagli studiosi per essere scaturito dalla penna di autori mai avventuratisi oltre i confini della loro cospicua biblioteca. Si trattava di scritti immaginari in forma di guide o relazioni di viaggio redatti attingendo a

42. I manoscritti datati della Biblioteca Riccardiana I997-20I3, vol. 2, pp. 46-47 n. 83; SIMION - BURGIO 2015 , pp. 189-190.

43. Ibid.; GALLO I955, pp. I43-I44; CESSI - ALBERTI 1934, pp. 39, 258-259; GADRAT-OUERFELLI 20I5, pp. 224-225. Per Franco Borlandi il testo sarebbe da identificare con lo scartafaccio originale scritto da Marco Polo in volgare veneziano, BORLANDI I962, p. I32. Scettico riguardo all'affermazione di Meo Ceffoni è, invece, John Critchley che ritiene le informazioni fornite dal testo poliano ormai superate per essere ancora utili ai mercanti nella prima metà del XV secolo, CRITCHLEY I992, pp. 48-50.

44. CARILE I977, p. 35.

45. PEGOLOTTI, I936, p. 3. 
piene mani informazioni, poi sapientemente amalgamate tra loro, da testi antichi quali enciclopedie e trattati assurti ad auctoritates e memorie di viaggiatori e pellegrini pressoché contemporanei, risultando oltremodo verosimili. ${ }^{46}$ Tra i più illustri «viaggiatori da camera» un ruolo di primo piano spetta, senza ombra di dubbio, a Jean de Mandeville, autore la cui identità resta tuttora un enigma, che intorno alla metà del XIV secolo compose in lingua francese il Livre des merveilles $d u$ monde (I356-I357) - nella versione italiana intitolato Viaggi, ovvero trattato delle cose più meravigliose e più notabili che si trovano nel mondo. ${ }^{47}$ Tra gli accorgimenti adottati dall'autore per infondere credibilità all'opera di fantasia quello più evidente si rintraccia nel prologo quando asseriva:

io John Mandeville, cavaliere (sia pure indegno), nato in Inghilterra, nella città di St Albans, avendo preso il mare nell'anno del Signore I322, il giorno di San Michele, ed essendo a lungo rimasto al di là di esso, dopo aver percorso e visitato molti paesi, molte province e regni e isole [...] dove abitano popolazioni assai diverse, con diverse usanze e culti, e uomini di forma diversa, vi parlerò qui di seguito più ampiamente di tutte quelle terre e quelle isole. Via via vi metterò a parte delle cose che vi si trovano, secondo quanto mi verrà meglio alla mente, rivolgendomi in particolare a coloro che vogliono e si propongono di visitare la città santa di Gerusalemme e i luoghi santi che vi sono intorno. Vi indicherò quindi il tragitto che bisogna seguire da quelle parti, da me più volte visitate cavalcando, grazie a Dio, in buona compagnia di parecchi gentiluomini. $4^{8}$

Prospettato come guida per i pellegrini che intendevano recarsi in Terrasanta, corredata di notizie su Maometto, il Corano e la religione musulmana, in realtà il testo forniva a Jean de Mandeville il pretesto per redigere una relazione di viaggio ben più ampia e articolata d'impronta marcatamente geografica. Dopo aver fornito ben tre itinerari alternativi per raggiungere Gerusalemme e indicazioni sui luoghi santi da visitare nei dintorni, il «viaggiatore da camera» si dilungava nella descrizione di terre e popolazioni esotiche incontrate nel corso del lungo e immaginario viaggio che lo aveva condotto nel Vicino Oriente e da lì in Asia fino a raggiungere la Cina, senza per altro tralasciare il fantomatico regno del Prete Gianni e il mitico paradiso terrestre, anche se a malincuore aveva dovuto ammettere: «Del paradiso non so parlare nel modo dovuto, perché non ci sono stato; è troppo lontano, mi dispiace. E poi non ne sarei stato degno. Ad ogni modo quello che ho saputo da certi saggi di quei luoghi, ve lo dirò volentieri».49

46. MANDEVILLE 2000, pp. I2-I3; TZANAKI 2003, pp. 5-6. Per un elenco delle fonti a cui attinse Jean de Mandeville vedi The Book of Jean 20II, pp. 219-22I.

47. MANDEVILLE 2000, pp. 9-IO.

48. ID. I982, pp. 5-6.

49. ID. 2000 , p. I5; ID. I982, p. 205 . All'epoca il termine Terrasanta indicava un territorio che oggi comprenderebbe Palestina, Libano, Siria e Israele. Sulla leggendaria quanto inesistente figura del Prete Gianni vedi pagine $59-60$. 
Composto in volgare e dedicato a un argomento profano, a partire dalla seconda metà del XIV e per tutto il XV secolo il Livre des merveilles du monde riscosse un successo senza precedenti diventando uno dei capisaldi della cultura europea sorpassato soltanto dalla Bibbia. Nello spazio di due secoli l'opera scritta in francese da Jean de Mandeville fu tradotta in dieci lingue - latino, inglese, irlandese, gaelico, tedesco, italiano, spagnolo, ceco, olandese e danese - come dimostrano i trecento manoscritti e le centottanta edizioni a stampa sopravvissute..$^{50}$ La molteplicità degli argomenti trattati riuscì a catturare l'interesse di tutti gli strati sociali tanto da figurare nelle biblioteche dell'aristocrazia europea, attratta dalla descrizione del mondo e del potere di sultani e regnanti orientali, quanto in quelle di facoltosi mercanti, avidi di informazioni geografiche e commerciali, fino a comparire tra le letture di un modesto mugnaio cinquecentesco come il friulano Domenico Scandella, affascinato dal racconto delle meraviglie esotiche ma ancor più dalla tolleranza religiosa dei popoli d'Oriente..$^{5 \mathrm{I}}$

Ritenuto a tutti gli effetti veritiero nonostante la narrazione di fenomeni e personaggi fantastici e irreali, che per l'appunto trovavano piena giustificazione nelle fonti antiche, il Livre des merveilles du monde ottenne grande consenso fino al punto da offuscare il testo poliano che, per aver confutato sulla base di esperienze personali alcune credenze radicate, aveva finito per suscitare qualche perplessità, come nel caso di un copista toscano che nel I392 aveva annotato nel suo manoscritto con il Milione: «E bene potrebbe essere vero quello di che ragiona, ma io non lo credo; tuttavia per lo mondo si truovano assai isvariate cose d'uno paese a un altro. Ma questo mi pare, come ch'io lo rasenprasse a mio diletto, cose da no credere né di darvi fede, io dico quanto a me». ${ }^{2}$ L'accorto Jean de Mandeville, consapevole di poter incorrere in smentite da parte di chi aveva veramente visitato i luoghi da lui descritti, si era invece premurato di avvertire nel prologo «le cose che da tempo sono lontane dalla mente dell'uomo, o dal suo sguardo, vengono presto dimenticate, perché la mente umana, nella sua fragilità, non riesce a ritenerle e a rammentarle».53

All'epoca la distinzione tra un testo veritiero come il Milione di Marco Polo e le opere fittizie dei "viaggiatori da camera» era alquanto labile, motivo per cui nei volumi con velleità di antologie di viaggio furono indistintamente trascritti passi desunti da entrambe le tipologie: un manoscritto datato I 478 conteneva il Livre des merveilles $d u$ monde, la relazione di viaggio del missionario Odorico da Pordenone e la fasulla Lettera del Prete Gianni, mentre ancora agli inizi del XVI secolo un volume miscellaneo raccoglieva estratti del Milione, il testo di Jean de Mandeville, alcune lettere di Amerigo Vespucci, la relazione di Girolamo Servigi, mercante fiorentino di stanza a Lisbona, sul primo viaggio di Vasco de Gama e

50. DELUZ 2007, p. II; The Book of Jean 20II, pp. XII-XIII.

5I. GINZBURG 2009, pp. 35, 49-58.

52. POLO 200I, p. 333 .

53. MANDEVILLE i982, p. 6. Alle versioni inglesi fu aggiunto l'episodio con l'autore che si recava a Roma per presentare il testo al papa e ottenere la garanzia di veridicità vedi LETTS I953, vol. I, p. 222. 
la più antica traduzione in volgare del Corano. ${ }^{54}$ Del resto anche tra i libri preferiti da un esploratore del calibro di Cristoforo Colombo figuravano, non tanto per diletto quanto per documentazione, sia il Milione di Marco Polo sia il Livre des merveilles $d u$ monde di Jean de Mandeville che con le loro descrizioni di mondi lontani traboccanti di ricchezze dovevano averlo alquanto stimolato nella ricerca di una via più diretta per raggiungerli. 55

Pregio del Livre des merveilles du monde fu indubbiamente quello di riuscire a elaborare con grande maestria una perfetta sintesi tra le credenze tramandate dai testi antichi, ormai assurte nella cultura del tempo a indiscusse verità, e le notizie di prima mano fornite da mercanti e missionari avventuratisi in Oriente nel XIII e nel XIV secolo, in particolare il Liber de quibusdam ultramarinis partibus (I336) del domenicano Guglielmo di Boldensele e la Relatio (I330) del francescano Odorico da Pordenone, dando vita a un nuovo sapere geografico. ${ }^{56}$ L'autore perveniva in questo modo a plasmare una nuova immagine della terra che ben appagava le aspettative dei suoi contemporanei, dal momento che le relazioni di viaggio furono ritenute attendibili solo quando confermavano le auctoritates. Collocando leggende e monstra dentro una cornice geografica concreta, Jean de Mandeville riuscì a conferire autenticità a fatti fino a quel momento solo immaginati poiché relegati a luoghi che la mentalità medievale considerava esistenti ma irraggiungibili. ${ }^{57}$

Così come il Milione si era prestato, proprio per la molteplicità dei temi trattati, a modifiche, riduzioni ed estrapolazioni da parte di copisti e traduttori, lo stesso avvenne per il testo mandevilliano. La versione latina destinata a un'audience religiosa fu oggetto di una consistente revisione in modo da poter soddisfare appieno i dettami della Chiesa: l'estensione delle terre visitate drasticamente ridotta focalizzando l'attenzione sulla Terrasanta, la teoria della circumnavigazione del globo

54. ROSSEBASTIANO I992, pp. I8-20 n. Io; Iddio ci dia buon viaggio 2006, pp. 3I-34. Riguardo alla commistione di testi reali e immaginari, il volume offerto da Giovanni senza Paura al duca di Berry nel I4I3 riuniva conferendogli lo stesso valore documentario - le seguenti opere: il Livre des merveilles di Marco Polo, l'Itinerarium de mirabilibus orientalium Tartarorum di Odorico da Pordenone, il Liber de quibusdam ultramarinis partibus et praecipue de Terra sancta di Guglielmo di Boldensele, lo scambio epistolare intercorso tra papa Benedetto XII, il Khan ToghonTemür e i cristiani di Pechino, il De l'estat et du gouvernement du grant Kaan de Cathay, empereur des Tartares di autore anonimo, i Voyages di Jean de Mandeville, il Fleur des estoires de la terre d'Orient di Hayton di Corico e il Liber peregrinationis di Riccoldo da Monte di Croce vedi BECDELIÈVRE 20I9. Per un approfondimento sui rapporti tra papa Benedetto XII e i cristiani in Estremo Oriente vedi CONCINA 20I8, pp. II3-I I8.

55. CARDONA i986, p. 69I

56. DELUZ I987, p. 206. Come osserva Martina di Febo: «Poiché le esplorazioni di missionari e mercanti avevano in parte scardinato alcune immagini convenzionali codificate dalla geografia mistica delle enciclopedie altomedievali, Mandeville avverte l'esigenza di riportare ordine, cercando di ricondurre le osservazioni empiriche all'interno di un sistema epistemologico consolidato. In questo tentativo di conciliazione e riorganizzazione, assume un ruolo fondamentale la categoria della meraviglia, perché è proprio attraverso il movimento dello stupore che è possibile domesticare l'ignoto. Ma la meraviglia certificata permette di ribadire altresì con la perentorietà del fatto l'esistenza di fenomeni che altrimenti l'esplorazione de visu avrebbe gradualmente scardinato", DI FEBO 2016 , p. I75.

57. Di tutt'altra opinione è, invece, Jacques Le Goff che, nonostante i numerosi viaggi compiuti dagli occidentali nei due secoli precedenti, ritiene l'Oceano Indiano uno spazio rimasto onirico fino alla seconda metà del XV secolo a causa dell'attitudine degli uomini medievali che a suo dire non sanno guardare, ma son sempre pronti ad ascoltare e a credere tutto ciò che si dice loro. E così, nel corso dei loro viaggi, si danno loro a bere racconti meravigliosi, ed essi credono di aver visto ciò che hanno appreso, sul posto certamente, ma per sentito vedi LE GOFF I970, p. 247. 
terrestre omessa a favore dell'esaltazione della figura di Dio creatore del mondo e delle sue meraviglie, Gerusalemme scalzata dal centro del mondo per mancanza di prove attendibili e il fittizio esploratore Jean de Mandeville in men che meno trasformato in un agguerrito viaggiatore pronto a deridere e denigrare le religioni degli altri popoli. ${ }^{58}$ Di tutt'altro tenore, invece, la versione italiana redatta prima del I 432 di cui sopravvivono quattordici manoscritti integrali, alcune trascrizioni di estratti in volumi miscellanei e, a partire dal I 480 , numerose edizioni a stampa. 59 È infatti assai probabile - come emerso dalla ricerca condotta da Christiane Deluz sulle note apposte lungo i margini di cinquantasette manoscritti francesiche la traduzione italiana del Livre des merveilles du monde avesse catturato l'attenzione del pubblico per la dovizia di informazioni sulla geografia fisica e sulle caratteristiche antropologiche dei popoli d'Oriente. ${ }^{60}$ Il libro di Jean de Mandeville non fu pertanto recepito come una guida di pellegrinaggio, anche se maggiormente incentrato sull'aspetto religioso-devozionale rispetto a quello poliano, e tanto meno come un testo di storia, ma piuttosto quale summa in forma di «romanzo geografico» delle conoscenze del tempo più completa ed esaustiva rispetto all'opera, ironia della sorte, dell'instancabile viaggiatore Marco Polo. ${ }^{61}$

Che all'epoca il ceto mercantile fiorentino nutrisse un particolare interesse per la geografia trapela con evidenza dalle biblioteche private dove, insieme a testi dedicati all'argomento tra cui il Livre des merveilles du monde trascritto da Bartolomeo Benci nel I492, si custodivano carte geografiche e mappamondi: nel I4I7 nello scrittoio di Cosimo de' Medici era conservato «i mappamundi, bello», nel I 459 Francesco Castellani prestò il suo mappamondo all'astronomo e geografo Paolo dal Pozzo Toscanelli, direttore di una compagnia mercantile dedita al commercio delle spezie, e tra i beni inventariati alla morte di Lorenzo de' Medici nel I492 figuravano ben quattro carte con l'immagine del mappamondo, «una carta dipintavi tre reami d'India» e altre due con la Terrasanta. ${ }^{62}$ Tra le molteplici chiavi di lettura possibili sembrerebbe - come suggerisce Francis Tobienne - che l'opera di Jean de Mandeville fu recepita dal ceto mercantile quale fonte di utili informazioni sulle mercanzie disponibili e le modalità dei commerci nelle terre d'Oriente, come avvenuto mezzo secolo prima per il Milione. ${ }^{63}$ Affermando che:

58. TZNAKI 2007, pp. 79-82. Potrebbe sembrare contraddittorio che la versione latina, in gran parte destinata all'ambiente clericale, confutasse l'idea di Gerusalemme centro del mondo ma, ormai appurato che la città non si trovava lungo l'equatore, sostenere tale idea avrebbe finito per inficiare la credibilità dell'intero testo mandevilliano.

59. MANDEVILLE 2000 , p. 3 I.

60. DELUZ I987, pp. 208-2 I0.

6I. HIGGINS I997, pp. I2-I3; DELUZ i987, pp. 208-2 io. Per la definizione di «romanzo geografico» vedi MAZZI I997, p. 25 .

62. ROSSEBASTIANO I992, pp. 20-2 I n. i i; I manoscritti datati della Biblioteca Riccardiana I997-2013, vol. 3, p. 48 n. I05; Inventari medicei I996, p. 23; GADRAT-OUERFELLI 20I5, p. 322; BRACCIOLINI 2004, p. I8; Libro d'inventario I992, p. 53. Nel I 474 Paolo dal Pozzo Toscanelli inviò al re del Portogallo Alfonso V una lettera con una carta da lui disegnata spronandolo, dato che la terra era sferica, a mandare i suoi marinai nelle Indie attraverso l'ovest vedi ZUMTHOR I995, p. 2 I8.

63. TOBIENNE 2016 , pp. I-3. 
la terra e il mare sono di forma e configurazione rotonda, perché la parte di firmamento che appare da un lato non si vede dall'altro. E sia per esperienza che per sottile investigazione della mente si può capire che, se si trovassero imbarchi su navi disposte ad esplorare il mondo, si potrebbe navigare intorno a tutta quanta la terra, sia di sopra che di sotto. Questo posso testimoniarlo, perché l'ho visto

Jean de Mandeville non solo offriva un'immagine rinnovata e, soprattutto, amplificata del mondo «rendant plus pressante l'invitation à le parcourir», ma - si potrebbe aggiungere - incoraggiava ad ampliare gli orizzonti dei propri affari. ${ }^{64}$

\section{I.3. Niccolò de' Conti}

A distanza di un secolo sarà ancora una relazione di viaggio, anche se in forma di racconto, a confermare il perdurare dell'importanza che all'epoca si attribuiva all'esperienza empirica per ampliare la conoscenza del mondo. L'incontro tra il mercante chioggiotto Niccolò de' Conti, che per venticinque anni aveva viaggiato e commerciato in Oriente, e il dotto umanista fiorentino Poggio Bracciolini portò alla stesura del IV libro del De varietate fortunae (I447-I448). ${ }^{65} \mathrm{Fu}$ durante gli anni del concilio di Firenze che il segretario papale ebbe l'opportunità di raccogliere notizie di prima mano intervistando Niccolò de' Conti, giunto in città per chiedere a Eugenio IV l'assoluzione per la sua conversione all'Islam - a suo dire forzata, ma quasi certamente per convenienza - durante la lunga permanenza nelle terre d'oltremare. ${ }^{66}$ In cambio della riammissione alla fede cristiana il papa pretese un dettagliato resoconto dell'avventurosa esperienza vissuta dall'intraprendente mercante che, partito da Damasco per raggiungere la Persia, l'India, l'Indocina e il Borneo, dopo aver perso moglie e due figli al Cairo a causa della peste era riuscito a tornare sano e salvo in patria. ${ }^{67}$

Il racconto, integrato con notizie apprese da membri di delegazioni orientali che partecipavano al concilio fiorentino, fu prontamente incluso da Poggio Bracciolini nella sua opera - una raccolta di exempla su come l'esistenza umana fosse in balìa del caso - per illustrare «la gran forza della fortuna, la quale uno huomo dagli extremi fini del mondo per tanti mari et terre venticinque anni in diverse parti portato ridusse in Italia sano et salvo». ${ }^{68}$ Caratteristica del IV libro del De varietate fortunae - detto anche Liber de rebus Indiae - era quella, da un lato, I6.

64. MANDEVILLE I982, pp. I23-I24; ID. 2000, p. 24. Per la sfericità della terra vedi DELUZ 2007, pp. I4-

65. BRACCIOLINI I993, pp. 9-24.

66. GROSSATO I994b, p. 49; CHAUDHURI 2009, pp. 264-265.

67. Richiesta, quella del pontefice, probabilmente stimolata dalle notizie che il viaggiatore castigliano Pero Tafur, incontrato a Ferrara durante la fase iniziale del concilio, gli aveva riferito precisando che quelle relative al Prete Gianni le aveva apprese da un certo Niccolò de' Conti incontrato in Egitto vedi ROGERS I962, p. I28; TREXLER I997, p. I28; TAFUR 20I4, p. I74.

68. BRACCIOLINI 2004, pp. 22-23, 46-5I; Viaggi in Persia I929, p. II8. 
di offrire notizie inedite rispetto a quelle apprese da fonti antiche e medievali o da relazioni di viaggiatori che avevano preceduto Niccolò de' Conti - poiché come rimarca Alessandro Grossato "curiosamente il Bracciolini dimostra di ignorare i viaggi di Marco Polo, di Giovanni da Montecorvino e di Odorico da Pordenone»-e, dall'altro, il tono disincantato dovuto alla mancanza di accenni al paradiso terrestre e alla quasi totale assenza del «meraviglioso». ${ }^{69}$ Alla mentalità pragmatica del mercante chiogiotto è inoltre da ricondurre il carattere documentario della mole d'informazioni etnografiche, geografiche e commerciali relative all'India e al sudest asiatico ordinate, come già avvenuto per il Milione, seguendo un itinerario con l'indicazione delle distanze da percorrere quantificate in giorni. ${ }^{70}$

E probabile che ancora prima del I448, anno in cui fu divulgato il De varietate fortune in quattro libri, il resoconto di Niccolò de' Conti fosse già in circolazione dal momento che è stata rintracciata una copia che reca la data $1444 .{ }^{7 \mathrm{I}}$ Che il grande interesse per l'Oriente fosse ancora particolarmente vivo nella seconda metà del XV secolo lo dimostrano i ventuno manoscritti in forma integrale del De varietate fortunae così come pure le ventitré trascrizioni complete o in forma frammentaria del IV libro, numero non indifferente per un testo in latino, e a distanza di pochi anni i volgarizzamenti in lingua toscana..$^{72}$ Di queste, quattro trascrizioni integrali del De varietate fortunae sono con certezza riconducibili a membri della cerchia familiare di Poggio Bracciolini e un'altra al fiorentino Girolamo de' Panzani. ${ }^{73} \mathrm{Ma}$ a decretare il successo di quest'opera fu soprattutto il desiderio di conoscere cose nuove direttamente apprese dalla testimonianza di un viaggiatore contemporaneo e affidabile. ${ }^{74}$

\section{Pellegrini e missionari}

\section{I. Pellegrinaggi «di carta»}

L'intensificarsi, tra il XIV e il XV secolo, della pratica devozionale del pellegrinaggio portò alla fioritura di una letteratura declinata in molteplici generi tra loro legati dall'esperienza comune del viaggio gerosolomitano. ${ }^{75}$ Tra le testimo-

69. GROSSATO I994b, p. 49. Vedi anche I viaggi I883, pp. 34-35; Viaggi in Persia I929, p. I20 nota I; BRACCIOLINI 2004, pp. 35-36; MERISALO I993, pp. 433-439.

70. CHAUDHURI 2009, pp. 276-277.

7I. MERISALO I993, pp. I4-I5; CATTANEO 2005, p. I79; BRACCIOLINI 2004, p. 64. Per il manoscritto autografo vedi BARTOLETTI 2004, pp. IO8-IO9 n. II.

72. CATTANEO 2005, p. I79 in particolare note 49 e 5I; CHAUDHURI 2009, p. 265 ; BRACCIOLINI 2004, p. 70.

73. Ivi, pp. 60-62 nn. I, 5, 6, Io; O'DOHERTY 20I3, pp. 326-327 n. 6.

74. Firenze e la scoperta I992, pp. I70-I73 n. 82.

75. PASTORE STOCCHI I986b, pp. 520-523. In questo studio sono stati presi in esame i testi sopravvissuti in un numero di copie che ne attesti una certa diffusione tra il ceto mercantile fiorentino, tralasciando quindi, 
nianze più famose spicca, per la sua particolarità, l'Itinerarium ad sepulcrum Domini nostri Ihesu Cristi (1358) scaturito dalla penna di Francesco Petrarca quando, durante il suo soggiorno presso la corte viscontea, l'amico lombardo Giovanni di Guido Mandelli l'aveva invitato a unirsi a lui e alla comitiva di amici in partenza per il pellegrinaggio. ${ }^{76}$ Per tutta risposta il poeta, instancabile viaggiatore in gioventù, gli inviò una lettera in latino in cui declinava l'offerta, adducendo quale giustificazione la paura del mare e i disagi che ne derivavano, corredata di una guida erudita con notizie storiche, geografiche e archeologiche sui luoghi che il pellegrino avrebbe incontrato durante il viaggio da Genova fino in Terrasanta e in Egitto. ${ }^{77} \mathrm{E}$ poiché le esperienze di viaggio di Petrarca erano limitate al tratto tra Genova e Napoli, l'itinerario concepito per l'amico - forse mai partito - fu elaborato con la stessa modalità compositiva adottata, proprio negli stessi anni, da Jean de Mandeville per il suo Livre des merveilles du monde, ossia attingere informazioni da fonti antiche - l'Eneide di Virgilio, la Naturalis historia di Plinio il Vecchio di cui possedeva una copia, il De Chorografia di Pomponio Mela e i Vangeli - per conferire autorevolezza al testo e integrarle con nozioni desunte da coeve memorie di pellegrini, da mappamondi e da carte geografiche, alcune di sua proprietà, per infondergli credibilità. ${ }^{7} \mathrm{Si}$ discostava, invece, da Jean de Mandeville per la candida ammissione «ti aspetti di sentire da me, che certamente non ancora ho visto tutto, né mai forse lo vedrò, quello che tu con i tuoi occhi tra breve vedrai», abbandonando la consueta forma retrospettiva dell'io narrante per calarsi nelle vesti del cicerone prospettivo, mentre la scelta di comporre il testo in latino, come del resto la lettera di accompagnamento, trovava piena giustificazione in un uomo di cultura come Giovanni di Guido Mandelli quale destinatario. ${ }^{79}$ Ciò che contraddistingue l'opera petrarchesca è il predominante interesse umanistico per la geografia e i luoghi della cultura classica a scapito di informazioni di utilità pratica per i pellegrini e l'assenza di qualsiasi accenno alla cultura musulmana, fino al punto da far terminare il suo Itinerarium non a Gerusalemme, con la consueta visita al Santo Sepolcro, bensì ad Alessandria d'Egitto dove si trovava la tomba del leggendario eroe macedone Alessandro Magno. ${ }^{80}$

sebbene cronologicamente pertinenti, le relazioni di pellegrinaggio di Mariano da Siena (I43I), Gaspare di Bartolomeo (I43I), Pierantonio Buondelmonti (I468), Alessandro Rinuccini (I474), Michele da Figline (I490), come pure i ricordi di viaggio che Giovanni Marignolli (I357-I359 ca.) aveva integrato nel Chronicon Bohemorum commissionatogli dall'imperatore Carlo IV di Lussemburgo. Per la letteratura di viaggio e la sua evoluzione vedi RICHARD I996; PORCASI 2010.

76. PETRARCA I990, pp. I5-I6. L'autografo di Petrarca - ora conservato alla Biblioteca Statale di Cremona - entrò a far parte della biblioteca del convento fiorentino di San Marco dopo la morte dell'autore avvenuta nel I374. Per la figura di Giovanni di Guido Mandelli vedi Petrarch's Guide 2002, pp. 57-6I.

77. SABBATINO 2006, pp. 268-270.

78. PORCASI 20Io, pp. I97-I98; PETRARCA I990, p. 32 in particolare nota 75; ROMBAI 2004a, p. 40; BOULOUX 2002, pp. 92-93, I34-I4I. Per l'importanza attribuita da Francesco Petrarca alle questioni geografiche e l'abitudine a confrontare i testi antichi con le carte geografiche del suo tempo vedi Firenze e la scoperta I992, pp. 50-53 n. 22; BOULOUX 2002, pp. I85-202.

79. PETRARCA I990, p. 4I; GUÉRIN DALLE MESE I989, pp. I5-I6.

80. PETRARCA I990 pp. 29, 83 . 
Sebbene nato come opera per la consultazione privata, l'Itinerarium riscosse fin da subito grande successo: copiato a un anno di distanza da Giovanni Boccaccio, ospite a Milano dell'amico poeta, nel XV secolo già si contavano, oltre a qualche volgarizzamento, una ventina di trascrizioni, tra cui quella a opera del mercante Antonio di Bartolomeo Corbinelli, proprietario di una tra le più fornite biblioteche fiorentine che nel I 446 comprendeva una trentina di volumi, quella eseguita da Niccolò Ugolini nel I473 durante il soggiorno nell'isola di Chio e, sempre negli stessi anni, un esemplare di copista anonimo probabilmente destinato a Lorenzo de' Medici. ${ }^{8}$

All'ambito dei viaggi puramente immaginari è invece da ascrivere l'ingegnoso opuscolo approntato da autore anonimo intorno alla metà del XIV secolo intitolato Questi sono $i$ viaggi che debbono fare li pellegrini che vanno Oltramare per salvare l'anima loro e che può fare ciascuna persona stando nella casa sua, pensando in ciascuno luogo che di sotto è scritto, e in ogni santo luogo dica uno Paternostro e Avemaria, che proponeva il modo in assoluto più economico per compiere il pellegrinaggio, vale a dire quello con la mente. ${ }^{82}$ Elaborando una descrizione estremamente sintetica delle località situate lungo il canonico circuito seguito dai pellegrini, corredata dall'indicazione delle distanze, l'autore offriva al fedele un itinerario mentale utile a visualizzare i loca sancta ai quali indirizzare le proprie preghiere senza varcare la soglia di casa. ${ }^{83}$ Idea che, pur nella sua semplicità, corrispondeva all'elevato concetto petrarchesco secondo cui l'unico vero viaggio era quello dello spirito. ${ }^{84}$ Del resto, se già alla fine del XIV secolo il frate vallombrosano Giovanni delle Celle aveva aspramente criticato la voga del pellegrinaggio d'oltremare, ancora nel I425 san Bernardino da Siena durante le sue prediche raccomandava ai devoti il pellegrinaggio mistico e interiore, abbracciando la corrente religiosa che non vedeva di buon occhio il viaggio in Terrasanta. ${ }^{85} \mathrm{Fu}$ forse per caldeggiare questa posizione, contraria a quella propugnata dalla futura santa Caterina da Siena fervente sostenitrice della crociata e del pellegrinaggio gerosolomitano, che l'eminente orafo fiorentino Marco di Bartolomeo Rustici si accinse a comporre la Dimostrazione dell'andata o viaggio al Santo Sepolcro e al monte Sinai (I447-I453 ca.), resoconto del viaggio che tra il I44I e il I442 avrebbe compiuto in compagnia del lanaiolo Antonio di Bartolomeo dei Ridolfi e del mi-

8I. Firenze e la scoperta I992, pp. 6I-65 nn. 29-30; BEC I984, p. I22; Codici latini I99i, pp. 3I0-3 II; Petrarch's Guide 2002 , pp. 5I-56. Per altre trascrizioni dell'Itinerarium contenute in manoscritti appartenuti a fiorentini e toscani vedi Codici latini I99I, pp. I24-I27, 205-210, 352-357, 359-364. Per i volgarizzamenti quattrocenteschi in napoletano e in toscano vedi PETRARCA I979; ID. I993.

82. Pellegrini scrittori I990, p. I5; Viaggio in Terrasanta I990, pp. 313-3 I8.

83. Per la relazione di pellegrinaggio quale utile strumento per elaborare una rappresentazione mentale da parte di chi era impossibilitato a recarsi ai luoghi santi vedi GENTILE 2008, pp. 77-IO4.

84. PETRARCA I990, p. 29; RICHARD 2003, pp. 24-27. L'idea della vanità del viaggio vero e proprio contrapposta all'utilità ed efficacia del viaggio dell'anima deriva da un concetto agostiniano.

85. CARDINI I99Ic, pp. 8-9; ID. 2002b, pp. 78-80; BEDINI 2007, pp. 259-262; SIENA I935, pp. 524-528. Il soprannome «delle Celle» era dovuto alla sua volontà di vivere autosegregato in una cella esterna al monastero di Vallombrosa. 
sterioso maestro Leale, ma che recenti studi ritengono immaginario. ${ }^{86}$ Il testo, emendato fino alla morte, si presentava suddiviso in tre parti rispettivamente dedicate ai monumenti di Firenze, al viaggio verso la Terrasanta e al pellegrinaggio vero e proprio, arricchito da disegni utilitari di suo pugno e da numerose digressioni su argomenti disparati che lo rendevano più simile a uno zibaldone che a un diario odeporico. ${ }^{87} \mathrm{La}$ natura «libresca» della narrazione - basata su notizie tratte dall'Itinerarium petrarchesco, dal Libro d'Oltramare del missionario Niccolò da Poggibonsi e dai diari tardo trecenteschi dei pellegrini fiorentini, oltre che da portolani e dalla Cosmographia di Tolomeo - diede vita, nonostante qualche utile indicazione di viaggio, a una sorta di Itinerarium mentis in Deum, ossia una guida che consentiva di compiere un pellegrinaggio mentale. ${ }^{88} \mathrm{Ma}$ il percorso devozionale virtuale non si limitava alla Terrasanta: approntando un elenco delle chiese fiorentine, corredato lungo i margini da disegni, e delle reliquie che vi erano custodite, Marco di Bartolomeo Rustici offriva al lettore un pellegrinaggio da compiere quotidianamente nella propria città se non addirittura, attraverso la contemplazione delle immagini, comodamente a casa. ${ }^{89}$ Ed è in quest'ottica che si deve interpretare l'esclamazione del pellegrino-scrittore al suo rientro dal viaggio d'oltremare, reale o immaginario che fosse: "e' mi parve esser tornato in paradisso", fugando così ogni dubbio sul fatto che la vera patria celeste non si trovava nella lontana Gerusalemme bensì a Firenze..$^{\circ 0}$ Poche sono le copie note del testo: una pressoché coeva all'autografo e un'altra intitolata Viaggio del sancto sepolcro eseguita nel I473 dal fiorentino Lorenzo di Giovanni Vitelli, che apponendo l'iscrizione "Chi acchata questo libro lo renda sanza macchia e sanza stracci» ribadiva la consuetudine di far circolare le conoscenze prestando i libri ad amici e conoscenti. ${ }^{\text {I }}$

\subsection{Missionari "curiosi"}

Un altro genere di letteratura odeporica affermatosi a partire dalla seconda metà del XIII secolo, sovente copiato dai mercanti fiorentini insieme a testi di viaggio come il Milione di Marco Polo o il Livre des merveilles du monde di Jean de Mandeville, fu quello delle relazioni dei missionari inviati in Oriente dal loro ordine per diffondervi la religione cristiana o dal pontefice per stringere alleanze con i Mongoli

86. Se Lucia Gai ritiene il viaggio narrato da Marco di Bartolomeo Rustici reale, gli studi recenti di Kathleen Olive, Nerida Newbigin e Cristina Acidini lo considerano invece fittizio, mentre Franco Cardini, pur manifestando dubbi sulla veridicità di quanto affermato dall'autore, non prende posizione in merito vedi GAI I982, pp. 2062I0; OLIVE 20I5, pp. 43-44; NEWBIGIN 20I5, p. 47; ACIDINI 20I9, pp. 25-26; CARDINI 20I5, pp. I8-23. Per i compagni di pellegrinaggio vedi OLIVE 20I5, p. 42 nota 25.

87. WEDDLE 2008, p. I8I; OLIVE 2009, pp. 593-596, 60I-603.

88. NEWBIGIN 20I5, p. 45-47; WEDDLE 2008, p. i86. Per la guida di Petrarca, il testo di Niccolò da Poggibonsi, i diari dei pellegrini tardo trecenteschi e la Cosmographia di Tolomeo vedi pagine 45-47, 50-52, 54-56, I6I.

89. WEDDLE 2008, p. I82; ACIDINI 20I9, pp. 26-3I.

90. RUSTICI 2015 , p. 290.

9I. I manoscritti datati della Biblioteca Nazionale 20I I, pp. 80-8I n. 4I; OLIVE 20I5, p. 44. 
in funzione antimusulmana..$^{92}$ Concepiti quali utili strumenti per $\mathrm{i}$ confratelli che si avventuravano nelle terre orientali con il compito di divulgare la parola di Dio, nei loro scritti i missionari annotavano osservazioni, descrizioni e considerazioni in modo da offrire, da un lato, un contributo per l'accrescimento delle conoscenze e, dall'altro, un'utile vademecum per la sopravvivenza quotidiana. Proprio la curiosità e la voglia di apprendere notizie su realtà diverse, oltre al gusto per il meraviglioso, fecero sì che questi testi circolassero anche al di fuori della cerchia religiosa, conquistando il pubblico laico fino a farli assurgere a veri e propri best seller dell'epoca. ${ }^{93} \mathrm{Al}$ milieu strettamente fiorentino era da ricondurre il Liber peregrinationis (I289/9I-I300) di Riccoldo da Monte di Croce, frate domenicano del convento di Santa Maria Novella, partito in qualità di missionario nel I288 per raggiungere, dopo la consueta tappa obbligata in Terrasanta, l'Asia Minore, la Persia e la Mesopotamia. ${ }^{94}$ La relazione, scritta a Firenze dopo un'assenza di una decina d'anni e concepita quale strumento didattico destinato ai confratelli missionari, segnò una svolta nella letteratura di pellegrinaggio: le succinte descrizioni di luoghi e memorabilia lasciavano ampio spazio all'approfondimento di costumi e credenze dei popoli, arrivando in alcuni casi a riferire dati fino ad allora sconosciuti in Occidente. 95

All'ordine francescano era invece da ricondurre la Relatio (I330) - nota anche come Itinerarium - del frate friulano Odorico da Pordenone. ${ }^{96}$ Rientrato nel 1330 dal suo viaggio di evangelizzazione in Oriente protrattosi per ben dodici anni, il missionario fu spronato da superiori e confratelli a redigere un resoconto delle sue esperienze, che aveva dettato - pare di malavoglia - a frate Guglielmo da Solagna nel convento di Sant'Antonio a Padova. ${ }^{97}$ Oltre agli immancabili mirabilia della fede cristiana, la Relatio, che si presentava in forma breve e in tono dimesso perché - come sottolinea Jeannine Guérin Dalle Mese - «il narratore non intende affascinare il lettore, ma solo comunicargli la verità», riferiva con attenzione etnografica le tradizioni dei popoli incontrati da Odorico lungo il percorso che lo aveva condotto attraverso l'Armenia, la Persia, l'India, l'Indocina e l'Indonesia fino a raggiungere la corte mongola di Cambalec - odierna Pechino - dove nel 1307 il francescano Giovanni da Montecorvino fu eletto primo arcivescovo..$^{8}$

Generalmente redatti in lingua latina, questi testi "tecnici” pensati per un'audience religiosa furono ben presto riadattati e tradotti in numerosi idiomi, tra cui

92. Per i missionari francescani inviati dal pontefice in Cina nei decenni precedenti vedi PASTORE STOCCHI I986a, pp. 5I8-520; CARDINI 200I, pp. 42-46; BRILLI 20I3, pp. 28-47.

93. BALESTRACCI 2008, pp. 43-44. Per i resoconti del pellegrinaggio in Terrasanta quali fonti utili per ampliare la conoscenza del mondo vedi HEERS I993.

94. MONTE DI CROCE 2005, p. XIX.

95. Ivi, pp. XXV-XXVI; SABBATINI 20I4, pp. I28-I29.

96. ANDREOSE 20I2, p. 9 nota 3. Di recente è stata pubblicata la prima edizione critica completa della Relatio de mirabilibus orientalium Tatarorum a cura di Annalisa Marchisio vedi PORDENONE 20 I6.

97. ID. 2000, p. 39. Per quanto riguarda l'incertezza sulla lingua primitiva dell'opera vedi ID. 20 I6, p. 43 .

98. ID. I990, p. I7; ANDREOSE 20I2, pp. I2-I3; BRILLI 20I3, pp. I53-I54. 
anche l'italiano, a partire dalla seconda metà del XIV e per tutto il XV secolo. Se del Liber peregrinationis di Riccoldo da Monte di Croce, intellettuale poco incline a soffermarsi sui dati mercantili, sono sopravvissuti solo sedici manoscritti, due dei quali in forma di volgarizzamenti toscani, tutt'altra sorte era stata invece riservata alla Relatio odoriciana: sono ben centotré i manoscritti giunti sino a noi, di cui diciotto in italiano e tra questi nove - noti con il titolo di Memoriale toscano - riconducibili alla cerchia dei mercanti fiorentini. ${ }^{99} \mathrm{Fu}$ certamente la quantità di informazioni geografiche e commerciali, pari se non addirittura superiori a quelle presenti nel Milione di Marco Polo, coniugata alla narrazione di inediti fatti esotici e vivaci episodi personali tipici del diario di viaggio a rendere la Relatio particolarmente apprezzata dal ceto mercantile. ${ }^{100}$ Le similitudini tra il testo del mercante veneziano e quello del missionario friulano indussero i lettori a ritenerli in qualche modo complementari, fino al punto da trascriverli nello stesso libro o d'integrarli vicendevolmente. ${ }^{\text {IOI }}$ L'orientamento prettamente utilitario della versione toscana della Relatio traspare, poi, dal supporto cartaceo più economico rispetto alla pergamena, dal testo in forma di compendio e, soprattutto, dall'omissione del brano di fondamentale importanza con la descrizione del martirio subito nel I32I da alcuni missionari francescani nella città indiana di Tana così come pure il ricordo dell'incarico conferito nel I324 a Odorico di trasportare le loro spoglie in Cina per dargli degna sepoltura nell'arcidiocesi cristiana di Cambalec. ${ }^{\mathrm{I02}}$ La prima trascrizione in lingua toscana nota del testo risale al I 377 ma ancora un secolo più tardi, intorno al I480, fu copiato da un fiorentino che apponendo l'annotazione "Questo libro [...] si è d'Andrea di Lorenzo di Cieffo di Masino Ceffi del popolo di San Simone in Firenze. Chillo avessi, gli piaccia per sua beningnità renderlo senza esserli richiesto» confermava il perdurare dell'abitudine a prestare i libri. ${ }^{\text {I03 }}$

Sempre a un frate francescano si deve il Libro d'Oltramare (I346-I350), relazione di viaggio scritta da Niccolò da Poggibonsi che la critica considera essere «il primo dei grandi viaggiatori toscani trecenteschi». ${ }^{\mathrm{IO}}$ Il testo, la cui paternità non

99. MONTE DI CROCE 2005, p. XXV; O’DOHERTY 20I3, pp. 306, 3I6-3I7; CARDINI I992a, p. 370; PORDENONE I990, pp. 68-69; ID. 20I6, pp. IO-I5; MONACO I978-I979, pp. I84-I94 nn. I-2, 6, IO, pp. 200209 nn. I-3, 5-6; ANDREOSE 20I2, pp. 22 (dei centodieci manoscritti centotré hanno una datazione anteriore al XVI secolo), 9I. Riguardo alla maggior diffusione del testo nel corso del XV secolo e l'ambito di destinazione laico vedi O’DOHERTY 2009, pp. 202-204.

IOo. PORDENONE I990, pp. 56-57 in particolare nota 43; ANDREOSE 2012, pp. 26-27.

IOI. PORDENONE 2000 , pp. I8-I9. Un manoscritto trecentesco di proprietà del convento fiorentino di Santa Maria Novella contiene sia la trascrizione della Relatio di Odorico da Pordenone sia quella del Milione di Marco Polo, quest'ultima nella versione latina tradotta dal frate bolognese Francesco Pipino vedi Firenze e la scoperta I992, pp. 42-44 n. I6.

IO2. PORDENONE I990, p. 74.

I03. Ivi, pp. 69, 83 .

I04. POGGIBONSI I990, pp. 3I-I58; Pellegrini scrittori I990, p. 9; GIOLA 2019, p. I. Tra gli studiosi Jeannine Guérin Dalle Mese è l'unica a insinuare il dubbio che si possa trattare di un viaggio fittizio, ma la recente scoperta di numerosi disegni, alcuni con chiese e animali mai raffigurati in precedenza, posti a corredo del testo ritenuto autografo sembra smentire questa ipotesi vedi GUÉRIN DALLE MESE I99I, p. 73; BLAIR MOORE 2009 , pp. 402-4I5; EAD. 2017, pp. I38-I4O. 
lascia dubbi grazie all'ingegnoso escamotage delle iniziali dei primi ottantasei capitoli che creano un acrostico con il suo nome, quello del padre e il luogo d'origine, narrava il viaggio intrapreso nel I346 per recarsi a Gerusalemme e conclusosi quattro anni più tardi dopo aver visitato Damasco, Beirut, Damietta,

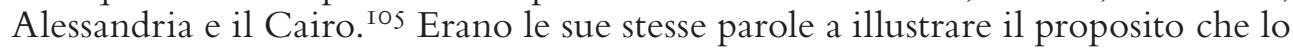
aveva guidato nel corso della sua lunga peregrinazione:

l'animo mio puosi di volere tutte cose visitare e in altro modo non volere mai ritornare in mio paese. E quello che cogli occhi vedea e colle mani toccava, e anche altrui domandando, e com'io era della casa ben certificato, e io lo scriveva in su un paio di tavolelle [tavolette] che allato portava. Poi, essendo in Gerusalem, io pigliai una misura di braccio, con uno passo, andando, e tutto per ordine, come qui udirete, sì misurava gli spazii e le lunghezze e le larghezze e recavale tutte a misura, e poi subito lo scriveva. E la ragione perché di questo m'affaticava si è questa: prima, che molti, che hanno grande voluntà di visitare le sante luogora [luoghi], a molti nuoce la povertà e altri lasciano per troppa fatica, e chi per non potere avere licenzia, che si debba avere, dal papa. ${ }^{106}$

Oltre alle informazioni pratiche di viaggio, il frate forniva precise indicazioni sui luoghi santi e le reliquie, descrizioni dettagliate delle chiese fino a riportarne materiali e misure, le preghiere da recitare, la tipologia delle indulgenze e dove lucrarle; pervenendo così ad approntare una guida pratica, la prima scritta in volgare per essere comprensibile a tutti, rivolta al pellegrino intenzionato a seguire le sue orme mettendosi in viaggio, ma anche strumento per i devoti che, impossibilitati ad affrontare il pellegrinaggio vero e proprio, avevano così l'opportunità di compierlo virtualmente. ${ }^{107} \mathrm{Il}$ Libro d'Oltramare non si limitava però al ruolo di guida devozionale dato che l'appartenenza a un ordine religioso non aveva certo precluso al frate francescano una visione a tutto campo delle terre d'Oriente. Curioso e dotato di uno spiccato spirito d'osservazione, Niccolò da Poggibonsi non tralasciò nessun aspetto: leggende dei santi, usi liturgici di ebrei e musulmani, confessioni cristiane diverse da quella cattolica, monumenti antichi e moderni, paesaggi, animali esotici, piante, usi e costumi delle popolazioni. $\mathrm{E}$, fatto ancora più singolare, nella redazione datata intorno alla metà del XIV secolo, probabilmente da considerare autografa, le dettagliate descrizioni erano accompagnate - come di recente scoperto da Kathryn Blair Moore - da un centinaio di schizzi eseguiti a penna perfettamente integrati nel testo, mentre nelle copie databili alla seconda metà del XV secolo i disegni acquarellati, quando

I05. L'acrostico, composto dalle iniziali dei primi ottantasei capitoli, forma la seguente frase: «Frate Nicoolao; Frate Nicola di Corbico da Poeibonici del contado di Fiorenca de la prouincia di Toscoana», POGGIBONSI ig9o, p. 33 nota 2 .

I06. Ivi, pp. $42-43$.

I07. ID. I945, pp. XI-XII, XXII-XXVIII; GUÉRIN DALLE MESE I99I, p. 3I. Tra la fine del XV e l'inizio del XVI secolo, a causa delle crescenti difficoltà a raggiungere la Terrasanta, l'ordine francescano fece realizzare riproduzioni dei luoghi santi, i Sacri Monti, in modo da consentire ai devoti di vivere l'esperienza del pellegrinaggio virtuale vedi CARDINI 2002a, pp. 400-40I; GENTILE 20I9, pp. I6I-I78. 
presenti, risultano essere l'opera di miniatori. ${ }^{\text {I08 }} \mathrm{Si}$ trattava, quindi, non solo della prima guida di pellegrinaggio per la Terrasanta scritta in italiano probabilmente con lo scopo di consentire al lettore meno abbiente di compiere un viaggio devozionale virtuale che gli avrebbe consentito di riscattare i propri peccati, ma anche della prima corredata da una serie di immagini. ${ }^{\text {IO9 }}$ Che il Libro d'Oltramare avesse suscitato grande interesse lo dimostrano le tredici trascrizioni eseguite nel corso del XV secolo di cui almeno sei riconducibili ad ambito fiorentino, come quella posseduta da Simone del Pavone sulla quale il figlio Paolo si era premurato di annotare: «fatto chopiare a dì 20 di maggio I453 da l'originale proprio de lo inponitore» e, dopo che i fogli sciolti erano stati rilegati in un volume: «a dì 27 di luglio I 453 lo riavemo dal chartolaio legatto». ${ }^{\text {I IO }}$

\subsection{Pellegrini-scrittori}

Agli stessi anni risale un pellegrinaggio di tutt'altra natura: quello compiuto dal fiorentino Dolcibene dei Tori, uomo di corte, musico, poeta e giullare scherzosamente incoronato «re dei buffoni» nel I355 da Carlo IV di Lussemburgo, recatosi a Gerusalemme per sciogliere il voto fatto in caso di vittoria nel duello che lo aveva visto sfidare un giullare della corte carrarese di Padova. ${ }^{\text {I I }}$ Partito per la Terrasanta nel I349, al seguito del signore di Rimini Galeotto Malatesta e del nipote Malatesta Unghero, al suo ritorno scrisse un breve componimento in versi, non privo di accenni sarcastici e irriverenti, intitolato Avemaria (I349), nel quale descriveva a ritroso, cioè partendo da Damasco fino a giungere al Santo Sepolcro, l'itinerario con i luoghi santi visitati nella speranza di riscattare la sua anima di peccatore. ${ }^{\text {II } 2}$ È assai probabile che il testo di Dolcibene, personaggio pubblico protagonista di ben nove storie nel Trecentonovelle (I385-I392) del contemporaneo Franco Sacchetti, di cui due dedicate al pellegrinaggio, e celebrato da Giovanni Gherardi nel Paradiso degli

IO8. BLAIR MOORE 2009, pp. 402-403; EAD. 20IO, p. 58; EAD. 2013, pp. 369-370; EAD. 20I7, pp. I32I33; EAD. 20I9, p. X.

I09. EAD. 2009, pp. 405-4IO.

IIo. Alle undici trascrizioni quattrocentesche che figurano nell'elenco stilato nel I945, da considerare una versione aggiornata di quello tardo ottocentesco compilato da Alberto della Lega che ne menzionava nove, sono da aggiungere le due portate alla luce dal recente studio di Marco Giola vedi POGGIBONSI I945, pp. XXXIIIXXXV; ID. I968, vol. I, pp. IX-XIII nn. I-7, 9-Io (per schede aggiornate vedi I manoscritti datati della Biblioteca Nazionale 20II, p. I22 nn. IO5-IO6); BLAIR MOORE, 20I0, p. 58; GIOLA 20I9, pp. 6-IO. Vedi anche GOLUBOVICH I906-I927, vol. 5, pp. 22-24. Il testo di Niccolò da Poggibonsi riscosse grande fortuna a partire dal XVI secolo con le edizioni a stampa: in un primo tempo pubblicato con il titolo Viazo da Venesia al Sancto Iherusalem di autore anonimo e nel XVII secolo erroneamente attribuito al frate veneziano Noè Bianco, anch'esso autore di un diario di pellegrinaggio in Terrasanta ma compiuto nel i 527 e dato alle stampe nel I566 vedi DONATI I938, p. 265 nota 37; Viazo da Venesia I972; BLAIR MOORE 20I3, pp. 357-4II; BARBIERI 2OI9, pp. 7I-I56; GIOLA 20I9, pp. I3-I6.

III. Le informazioni biografiche su Dolcibene dei Tori sono desunte dalla coeva letteratura vedi SACCHETTI I996, p. 488, CLIII; GHERARDI 1975, pp. I40-I45, III.

II2. Pellegrini scrittori I990, p. 23; TORI I990, pp. I59-I66. 
Alberti (I 425 ca.), avesse avuto una certa risonanza a Firenze, dove le sue laudi furono copiate in numerosi manoscritti miscellanei. ${ }^{\mathrm{II}} 3$

Se già sullo scorcio del XIII secolo i frati missionari Riccoldo da Monte di Croce e Odorico da Pordenone si discostarono dal consolidato modello schematico delle guide pratiche destinate ai pellegrini, arricchendo le loro relazioni con informazioni etno-geografiche e annotazioni personali in modo da condividere con il lettore sia l'esperienza spirituale sia quella odeporica, e qualche decennio più tardi il francescano Niccolò da Poggibonsi aveva redatto quello che può essere considerato il primo testo di "memorie di pellegrinaggio», una svolta ancora più marcata si ebbe con gli scritti di tre mercanti fiorentini partiti per la Terrasanta nel I384. L'itinerario scelto differiva da quello consueto che approdava a Giaffa per compiere le «cerche» in Terrasanta, vale a dire le visite alle reliquie custodite nelle chiese e nei monasteri, e poi rimbarcarsi nello stesso porto o in quello di Beirut per fare ritorno in patria. La comitiva fiorentina aveva preferito seguire il tragitto in uso in epoca precristiana e tornato in voga a partire dal secondo quarto del Trecento, quando il controllo esercitato dai sultani mamelucchi aveva reso l'area più sicura, che attraversava l'Egitto e il Sinai permettendo al fedele di visitare il monastero di Santa Caterina e la montagna di Mosè prima di giungere a Gerusalemme. ${ }^{\text {II } 4}$ Si trattava quindi di un viaggio inusuale per il percorso, la durata e, di conseguenza, il ragguardevole costo. ${ }^{\text {II }}$

I diari, pur non tralasciando gli aspetti religiosi che avevano spinto i tre fiorentini a compiere il pellegrinaggio, rivelano tutto il loro carattere autobiografico nell'ampio spazio dedicato alla narrazione del viaggio vero e proprio, dei luoghi visitati, delle cose viste e delle impressioni suscitate, senza per altro trascurare informazioni di natura politica e commerciale che, nel caso del ceto mercantile, rientravano a pieno titolo nell'ambito degli interessi personali. ${ }^{\text {II }}$ In altre parole, il rito del pellegrinaggio aveva subito un'evoluzione in senso laico trasformandosi in «viaggio» vero e proprio. In alcuni casi, poi, non si concludeva - come osserva Pietro Porcasi - "con il semplice ritorno in patria, ma con la parola Amen posta alla fine di un racconto", circostanza comunque da considerare insolita e per lo più limitata alle classi abbienti e istruite, dato che nella maggior parte dei casi i pellegrini non si accingevano a mettere su carta i loro ricordi ma restavano in silenzio. ${ }^{\mathrm{II} 7}$ Proprio per questo motivo le scarse testimonianze scritte da laici assumeva-

II3. SACCHETTI 1996, pp. 3I-33, X (dedicata al pellegrinaggio); 75-76, XXIV; 77-78 (dedicata al pellegrinaggio), XXV; I03-I05, XXXIII; 354-357, CXVII; 449-453, CXLV; 488-49I, CLIII; 503-507, CLVI; 629-633, CLXXXVII.

II4. CARDINI I99Ic, p. 29. Per la determinazione di Lionardo Frescobaldi a seguire questo inusuale itinerario vedi FRESCOBALDI 199I, p. I27:I4-24.

IIs. Ciascun pellegrino spese trecento fiorini, comprensivi della quota per il famiglio al seguito, equivalenti alla cifra che un operaio fiorentino guadagnava in due anni di lavoro e un impiegato in poco meno di uno, mentre il tour più economico si aggirava sui cinquanta fiorini vedi PINTO I982, pp. 267-270, 274-278; BEDINI I999, pp. 27-28; SIGOLI I999, p. II8.

II6. PORCASI 20I0, p. 204.

II7. Ivi, p. 208. 
no una rilevanza fuori dal comune: da un lato perché la redazione in volgare e priva di finalità letterarie allargava considerevolmente l'audience di ricezione, dall'altro perché l'ampio ventaglio degli argomenti trattati e le informazioni ricavate dall'osservazione diretta li rendevano particolarmente apprezzati dal pragmatico ceto borghese. Se i pellegrini-scrittori illustravano e confermavano la storia di Cristo, i pellegrini-mercanti descrivevano il mondo attraverso i loro occhi, ridimensionando il valore incontrastato fino ad allora attribuito alle auctoritates.

Furono ben tre i membri della comitiva di mercanti partita da Firenze nell'agosto I384 per il pellegrinaggio durato quasi un anno che, dopo essersi recati a Damasco, in Libano e a Beirut, una volta rientrati in patria si dedicarono alla stesura di un diario di viaggio narrando da tre angolazioni diverse un'esperienza comune. Fatto, questo, che ha portato gli studiosi a ipotizzare l'esistenza di appunti condivisi o, per lo meno, uno scambio d'idee per accertare i loro ricordi nel corso della stesura. ${ }^{\text {II8 }}$ I mercanti-scrittori erano esponenti di spicco dell'oligarchia fiorentina da poco tornata al potere dopo il tumulto dei Ciompi: Lionardo Frescobaldi, Giorgio Gucci e Simone Sigoli. Che lo scopo primario del viaggio fosse compiere il pellegrinaggio in Terrasanta è evidente dallo spazio che $i$ tre laici fiorentini avevano dedicato alle chiese e alle "cerche» dei loca sancta, ma i diari lasciavano pure trasparire interessi particolari in relazione alle loro personalità. Lionardo Frescobaldi, uomo politico nato in una nobile e antica famiglia dedita al commercio e all'attività bancaria, era il più anziano - pare fosse partito all'età di sessant'anni - e il più colto. ${ }^{\mathrm{II} 9} \mathrm{Nel}$ suo diario intitolato Viaggio in Terrasanta, arricchito con informazioni desunte da altre fonti tra cui il Libro d'Oltramare di Niccolò da Poggibonsi e gli scritti dei suoi compagni di pellegrinaggio, aveva descritto luoghi, popoli e meraviglie esotiche senza tralasciare considerazioni politiche e militari, forse in relazione al millantato incarico da parte del re di Napoli Carlo III di sondare la fattibilità di una crociata, così come pure indicazioni sulle attività mercantili e manifatturiere. ${ }^{\mathrm{I} 20}$

Giorgio Gucci, rampollo di una rinomata famiglia attiva nel commercio della lana, era un importante personaggio pubblico impegnato in politica e in missioni diplomatiche che, come l'amico Lionardo Frescobaldi, gravitava nell'orbita del convento agostiniano di Santo Spirito, luogo di confronto tra dotti della città e culla del primo Umanesimo. Nel Viaggio ai Luoghi Santi, più esteso e puntuale in merito al percorso devozionale rispetto al testo frescobaldiano, Giorgio Gucci riportava notizie sul mondo musulmano e sulle altre confessioni cristiane presenti in Terrasanta, rivelando un atteggiamento distaccato del tutto inusuale

II8. CARDINI 2002a, p. 235 .

II9. ID. I99IC, p. I3.

I20. Ivi, pp. I7-I 8, 24; FRESCOBALDI I99I, pp. I24-I86. In realtà le stesure del testo furono tre: una molto sintetica subito dopo il rientro a Firenze, mentre le altre due risultano successive a quelle dei suoi compagni di viaggio Giorgio Gucci e Simone Sigoli vedi BARTOLINI I99I, pp. 99-I Io. Un'altra versione del resoconto di Lionardo Frescobaldi è stata pubblicata nel I990 a cura di Antonio Lanza vedi FRESCOBALDI I990. 
rispetto alle prese di posizione denigranti dell'epoca. ${ }^{\text {I2I }}$ Inoltre, l'indole di acuto osservatore lo aveva portato sia ad annotare usanze, curiosità e stranezze del Vicino Oriente sia a rivolgere particolare attenzione alle questioni economicomercantili tanto da poter considerare il suo resoconto un piccolo trattato di

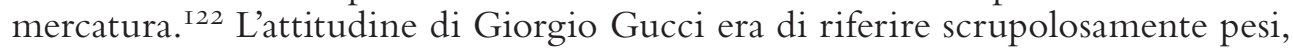
misure, prezzi, costi, merci e origine dei prodotti, come quando a proposito del monte Sinai scriveva:

dall'India molte volte l'anno con molte navi e grandi cariche di spezie vengono per questo Mare Rosso presso Santa Caterina e ivi scaricano; e poi i detti camelli d'indi le portano al $\mathrm{Ca}[\mathrm{i}] \mathrm{ro}$, e poi dal $\mathrm{Ca}[\mathrm{i}] \mathrm{ro}$ per acqua vanno in Ales[s]andria, dove si fanno i gran fatti di mercatantìa; e così dal detto Mare Rosso sono portate in Domasco, dove anche gran fatti di mercatantìa si fa. ${ }^{\mathrm{I} 23}$

Altro aspetto da non sottovalutare, sempre nell'ottica mercantile, era la quantità e la qualità delle informazioni geografiche fornite: non solo ragguagliava su città, paesi, fiumi, laghi e distanze, ma descriveva i paesaggi in modo da renderli reali a chi non aveva mai avuto occasione di vederli. Non da ultimo, la sua mente concreta e pragmatica aveva insinuato il dubbio - unico tra i viaggiatori a lui contemporanei e successivi - che le piramidi non fossero, come tramandava la tradizione popolare, "granai del Faraone» bensì monumenti dato che "a vederli elli paiono più tosto cose fatte a una perpetuale memoria che a granai». ${ }^{\mathrm{I} 4} \mathrm{Fu}$ forse l'atteggiamento tollerante e aperto nei confronti di un mondo multiculturale e multireligioso, associato al grande interesse per i commerci, ad aver spinto il frate vallombrosano Giovanni delle Celle, eminente figura della spiritualità toscana con il quale Giorgio Gucci intratteneva uno scambio epistolare, a esprimere in una lettera inviatagli nel I389 la sua contrarietà al pellegrinaggio terreno, ritenendolo privo di valori spirituali e prettamente volto alla ricerca del piacere e della bellezza temporale. ${ }^{\text {I25 }}$

Il terzo diario di viaggio era quello di Simone Sigoli che - sulla base delle scarse notizie reperibili - risulta provenire da un'importante famiglia fiorentina e non aver mai rivestito cariche pubbliche. ${ }^{\text {I26 }}$ Il suo Viaggio al monte Sinai si discostava dagli altri due testi per la prosa essenziale e l'approccio curioso e allo stesso tempo privo di pregiudizi, quasi una sorta di reportage, verso il mondo musulmano e le sue tradizioni. ${ }^{127}$ Se Lionardo Frescobaldi aveva intenzionalmente esaltato la sua figura di pellegrino vantandosi del presunto incarico di raccogliere informa-

I2I. GUCCI I990, pp. 257-3I2.

I22. BEDINI 20IO, pp. 37-46.

I23. Ivi, pp. 46-47; GUCCI 1990, p. 273:4.

I24. MONTESANO 20II, pp. I43-I 45; GUCCI I990, p. 269:9. Ancora nel I439 Pero Tafur, provetto viaggiatore, nel suo resoconto riporta di aver visto, descrivendoli accuratamente, i «granai di Giuseppe», TAFUR 20I4, p. 78.

I25. BEDINI 20I0, p. 39.

I26. ID. I999, pp. 3I-38.

I27. SIGOLI I999, pp. 67-I I8. Un'altra versione del testo è stata pubblicata nel I990 a cura di Antonio Lanza vedi SIGOLI I990. 
zioni per una futura crociata, l'interesse sigoliano per gli aspetti religioso-devozionali era di natura prettamente popolare: oltre alle accuratissime descrizioni dei luoghi santi e a un elenco dettagliato delle indulgenze che vi si potevano lucrare, ampio spazio era dedicato alla narrazione di fatti miracolosi e all'identificazione degli spazi dove, secondo quanto tramandato dall'Antico e dal Nuovo Testamento, si erano verificati. ${ }^{\mathrm{I} 28} \mathrm{La}$ sua indole mercantesca lo rendeva, poi, particolarmente incline a registrare qualità, quantità e prezzo dei prodotti presenti nei mercati delle città visitate, non riuscendo a trattenere lo stupore per la bellezza delle mercanzie e per le dimensioni e l'abbondanza di frutta e verdura.

Poiché il pellegrinaggio era un impegno economicamente oneroso e fisicamente logorante, nonché rischioso per gli imprevisti di un naufragio o di un attacco da parte dei pirati, una volta scampati questi pericoli ed essere tornati in patria sani e salvi era consuetudine del ceto abbiente affidare i propri ricordi alle pagine di un diario in modo da mantenere vivo il ricordo dell'esperienza vissuta e, nel contempo, aumentare il proprio prestigio agli occhi dei concittadini. ${ }^{\mathrm{I} 29} \mathrm{~A}$ decretare la precoce e ampia fortuna dei diari dei tre mercanti fiorentini, che costituivano un'eccezione nel panorama dei testi di pellegrinaggio, doveva aver contribuito la narrazione in lingua italiana di un avvincente viaggio arricchito da spunti autobiografici in grado di trasmettere una visione laica e mercantesca dell'Oriente: non era loro intenzione stupire bensì riferire quello che avevano visto con i propri occhi, annotando informazioni utili e affidabili, a volte addirittura in contrasto con quanto tramandato dalle fonti antiche. Il numero di manoscritti, databili tra la fine del XIV e quella del XV secolo, riconducibili ad ambito fiorentino con trascrizioni dei diari di viaggio dei tre mercanti-pellegrini testimonia la notevole e immediata fortuna: dodici per il Viaggio in Terrasanta di Lionardo Frescobaldi, in un libro associato al testo di Niccolò da Poggibonsi e in altri due alla Sfera di Gregorio Dati; quattro per il Viaggio ai Luoghi Santi di Giorgio Gucci, in un codice miscellaneo seguito dall'Avemaria di Dolcibene dei Tori; otto per il Viaggio al monte Sinai di Simone Sigoli, nel volume appartenuto a Giachinoto d'Adonardo de' Bardi abbinato a un volgarizzamento del Milione di Marco Polo e in un altro alla Leggenda dei tre monaci che andarono al paradiso deliziano e alla Sfera di Gregorio Dati. ${ }^{\text {I30 }}$ Infine, quattro manoscritti datati tra il XIV e il XV secolo includevano un testo che risulta essere il prodotto della commistione tra lo scritto di Giorgio Gucci e quello di Lionardo Frecobaldi, nel quale si accennava pure ad Andrea Rinuccini, rampollo di una potente famiglia fiorentina, partito insieme alla comitiva nel I384 e deceduto a Damasco durante il viaggio di ritorno. ${ }^{\mathrm{I}}{ }^{\mathrm{I}}$

I28. BEDINI 2007, pp. 262-266; ID. I999, pp. I8-2I.

I29. RICHARD 2003, pp. 26-28; BEDINI 20I0, p. 39.

I30. BARTOLINI I99I, pp. 99-IOo in particolare note 4 e 5, II7-II9 in particolare note I, 3, 4; DELFIOL I982, pp. I45-I46, I49-I76; BEDINI I999, p. I I in particolare nota I.

I3I. FRESCOBALDI I99I, pp. I82:32-34, I83:I-5; DELFIOL I982, pp. I42-I 43, I47, I49; BERTELLI I999, p. 296 in particolare nota 2. 


\section{Oriente nei poemi didattici e nelle novelle}

\section{I. Temi orientali}

L'interesse del ceto mercantile dell'epoca per le relazioni di viaggio era strettamente connesso alla volontà di ampliare la conoscenza del mondo, dominare lo spazio e, non da ultimo, estendere il raggio d'azione delle proprie attività commerciali. La voglia di acquisire notizie concrete sulla geografia in un periodo in cui i contatti con l'Oriente erano particolarmente intensi, attraverso i commerci e i viaggi di missionari e pellegrini, non deve certo stupire considerato che fin dai tempi di Alessandro Magno (356-323 a.C.), quando le relazioni si erano interrotte, l'Estremo Oriente e gran parte dell'Africa erano rimaste terre praticamente sconosciute. ${ }^{\mathrm{I} 32}$ Oltre a ciò, fin dal XIII secolo testi antichi come il Romanzo di Alessandro, incentrato sull'ambiziosa esplorazione del mondo da parte del re macedone con il proposito di conquistarlo, e copie della sua Lettera ad Aristotele, nella quale illustrava al precettore la campagna condotta in India, non solo contribuirono ampiamente ad alimentare l'esotismo nell'immaginario occidentale, ma furono ritenuti fonti attendibili per la conoscenza dell'Oriente, tanto da riportarne alcuni brani nelle didascalie delle mappae mundi o da raffigurarvi la figura di Alessandro Magno. ${ }^{\mathrm{I} 3}$ D'altro canto il conquistatore macedone, che «aveva oltrepassato ogni confine noto alle scoperte geografiche e trovato reami nuovi d'ogni tipo per rivendicarli a sé», confessando di essere in balìa di difetti e debolezze umane o di aver dovuto ridimensionare le proprie aspirazioni, come quando non gli fu consentito varcare la soglia del paradiso terrestre, aveva il potere di suscitare un forte moto d'immedesimazione tra i lettori appartenenti al ceto mercantile che, con le loro ambizioni e insicurezze, si avventuravano alla scoperta di terre lontane e ignote. ${ }^{\mathrm{I}}{ }^{34}$ In questo contesto culturale ben si comprende, allora, la curiosità e la meraviglia che resoconti di viaggio pressoché contemporanei, connessi sia a esplorazioni mercantili come il Milione (I298) di Marco Polo sia a missioni evangelizzatrici come la Relatio (I330) di frate Odorico da Pordenone, dovevano esercitare su una società che, proprio a causa della mancanza d'informazioni, da secoli aveva visto il proliferare di leggende e credenze, non da ultima quella che localizzava il paradiso terrestre in Oriente ai confini con l'India. ${ }^{\mathrm{I} 5}$

I32. ZAGANELLI I997, pp. 8-9.

I33. LE GOFF I970, pp. 249-25I; MOROSINI 20II, pp. 335-364; ZAGANELLI I997, pp. 87-I29; HOOGVLIET 2007, pp. 224-228. Per la controversa datazione del Romanzo di Alessandro, da alcuni studiosi assegnata al III sec. a.C. e da altri al III sec. d.C., e l'influenza esercitata nel plasmare l'idea dell'India, dell'Egitto e di Gerusalemme nell'immaginario medievale vedi STONEMAN 20I8, p. VIII; DRONKE i997, pp. XXVIII-XLI. Per un approfondimento sulla lettera apocrifa che Alessandro avrebbe inviato ad Aristotele vedi ZAGANELLI I995, pp. I39-I53.

I34. DRONKE I997, pp. XXI-XXII.

I35. ZUMTHOR I995, pp. 222-223. Per il mito del paradiso terrestre vedi anche GRAF I892, vol. I. 
Per l'uomo medievale, che considerava la Bibbia fonte principale del sapere, l'idea promossa da Agostino d'Ippona di un giardino dell'Eden quale luogo reale della geografia, dove Adamo ed Eva furono creati, e che Isidoro da Siviglia, rifacendosi alla Genesi, aveva localizzato in Oriente continuò a godere di credibilità anche tra mercanti e religiosi che in quella parte di mondo si erano recati personalmente. ${ }^{136}$ Motivo per cui i viaggiatori, e non esclusivamente i missionari, nei loro resoconti si erano premurati di attribuire delle coordinate al paradiso terrestre: assai prudenti Odorico da Pordenone, che vi collocava l'origine del fiume Eufrate, e Marco Polo, che riferiva di un giardino simile all'Eden in una valle dell'Iran abitata dal Veglio della Montagna, più assertivo Cristoforo Colombo, certo di essere giunto in India ma in realtà alla foce dell'Orinoco, quando affermava di essersi trovato nelle immediate vicinanze, mentre Niccolò da Poggibonsi, Lionardo Frescobaldi e Simone Sigoli si erano limitati a informare che il Nilo sgorgava dal paradiso terrestre. ${ }^{\mathrm{I} 37}$

A testimoniare quanto fosse radicata questa credenza è la cartografia quattrocentesca: nonostante avesse avuto inizio il graduale passaggio dalle mappae mundi medievali, simili a enciclopedie figurate, alle carte geografiche rinascimentali di matrice topografica, il paradiso terrestre continuò a essere raffigurato nella regione dell'Oriente più estremo. ${ }^{\mathrm{I} 38} \mathrm{Nel}$ I 436 il veneziano Andrea Bianco, uomo di mare e autore di portolani, pur attenendosi alla realtà della cartografia nautica non tralasciò d'includere nel suo mappamondo il giardino dell'Eden con le figure di Adamo ed Eva in prossimità dell'India «sup[er]liores» e del Catai - antico nome della Cina settentrionale. ${ }^{\mathrm{I} 39}$ Neanche un decennio più tardi, dopo essersi documentato sul testo poliano, la Cosmographia di Tolomeo da poco riscoperta e le recenti mappe nautiche, il cartografo Giovanni Leardo realizzò un'aggiornata mappa del mondo dove, vicino all'India "de sora», si ergeva una città fortificata che una didascalia indicava come "paradixo teresto». ${ }^{40} \mathrm{E}$ se intorno alla metà del

I36. CARDINI I993, pp. 77-79; SCAFI 2007, pp. 32-38; ZUMTHOR I995, pp. 225-226. Vedi anche ZAGANELLI I985, pp. I5-22. Genesi (2:8): «Il signore Dio piantò un giardino in Eden, a oriente, e vi collocò l'uomo che aveva plasmato".

I37. PORDENONE I990, p. 94, 2:I; POLO 200I, pp. 56-57, 40:I-8; SCAFI 2007, p. 207; POGGIBONSI I990, pp. iा I, CLXII:8; iा7, CLXXIX:I; I20-I21, CLXXXVIII:3; FRESCOBALDI i990, p. I77:46; ID. I991, p. I35:I2-I3; SIGOLI I999, p. 76. A differenza dei suoi compagni di viaggio nel testo di Giorgio Gucci non compare alcun accenno al paradiso terrestre.

I38. EDSON 2005, p. I7; SCAFI 2007, pp. 78-79, IOI-I07, I62-I73. Riguardo alla funzione dei mappamondi Andrea Cantile afferma: «L'esigenza che muove queste rappresentazioni non è certo legata alla mobilità: esse non devono far spostare eserciti né guidare carovane né orientare imbarcazioni. Il loro fine è piuttosto quello di accompagnare e sostenere i percorsi di conoscenza, di meditazione e di preghiera. Ciò che al cartografo viene chiesto è di epitomare in forma grafica una sorta di sapere enciclopedico, con brevi ed essenziali elementi di storia e di geografia, nel pieno rispetto dei precetti religiosi, ma con una certa libertà di illustrazione che può comunque sconfinare in quello che oggi appare come fantastico", CANTILE 20Io, p. 45.

I39. SCAFI 2007, p. I7I; EDSON 2007, p. 9. Nel tardo Medioevo il vasto e misterioso territorio genericamente indicato come «India» fu suddiviso in India inferior (prima o minor, a oriente della Persia), India superior (secunda o maior, il subcontinente e l'Asia sud-orientale) e India tertia (o ultima, che solitamente comprendeva l'Etiopia e l'Africa orientale) vedi SCAFI 2007, p. I8I.

I40. NURMINEN 20I5, pp. II8-II9. 
XV secolo Fra' Mauro, incerto su dove collocare il giardino dell'Eden abitato da Dio e dai progenitori, preferì raffigurarlo in un angolo all'esterno della mappa circolare con l'ecumene, negli stessi anni il Mappamondo Estense (I45O-I460 ca.) lo situava nel corno d'Africa vicino all'oceano Indiano, mentre sullo scorcio del secolo nella mappa allegata alla carta nautica attribuita a Cristoforo Colombo appariva in forma di isola di fronte al Catai. ${ }^{\mathrm{I}}{ }^{\mathrm{I}}$

Il fascino che l'Oriente esercitava nell'immaginario europeo non si esauriva però con i mirabilia e il giardino dell'Eden. Nel XIV e nel XV secolo la figura del Prete Gianni, mitico sovrano cristiano dotato di immense ricchezze e a capo di un regno situato in una parte non ben precisata dell'Oriente confinante con il paradiso terrestre, godeva di grande popolarità, non da ultimo nell'ottica di una possibile alleanza per riconquistare Gerusalemme e sconfiggere l'Islam. ${ }^{\mathrm{I} 2}$ Tale credenza, diffusasi a partire dalla seconda metà del XII secolo, aveva avuto origine da una lettera - in realtà un falso - che il fantomatico Prete Gianni avrebbe inviato all'imperatore bizantino Manuele I Comneno (r. II43-II80) e ben presto diffusa in tutta Europa nella quale, oltre a prospettarsi come il massimo rappresentante terreno di Dio, decantava l'opulenza e la vastità del suo impero. ${ }^{\mathrm{I} 33} \mathrm{La}$ missiva fu accettata senza riserve perché il personaggio era noto in Europa fin dal II45: nella Chronica sive historia de duabus civitatibus (I I46) il vescovo Ottone di Frisinga ricordava l'incontro tra papa Eugenio III e il vescovo franco-siriano Ugo di Jabala, giunto a Viterbo per chiedere aiuto contro i musulmani, e di aver appreso in quell'occasione la notizia di un certo sovrano e sacerdote Gianni che professava la religione cristiana e regnava nel più remoto angolo orientale dell'Asia. ${ }^{\text {I4 }}$ Sebbene la lettera inviata dalla Santa Sede al Prete Gianni nel II77 fosse rimasta senza risposta, per secoli pontefici e sovrani europei perseverarono nel tentativo di stabilire contatti epistolari: Enrico IV d'Inghilterra agli inizi del XV secolo, il duca di Berry nel I430, papa Eugenio IV nel I 438 e Alfonso V d'Aragona nel I450. ${ }^{\text {I45 }}$ A confermare l'importanza attribuita dalla società del tempo

I4I. DI PALMA I985, pp. IOI-I04; SCAFI 2007, pp. I90-I92, 202-206. Se per realizzare il mappamondo Fra' Mauro si avvalse della collaborazione di Andrea Bianco - come attesta la nota nel Libro di entrata e uscita di San Michele di Murano, sede del laboratorio cartografico, del io marzo I459: "per suo premio del lavorier lui fece a dicto Mappamundi" (somma poi devoluta in messe di suffragio essendo nel frattempo deceduto) - l'indecisione riguardo a dove collocare il paradiso terrestre, in Estremo Oriente nel planisfero realizzato da Andrea Bianco nel I 436, doveva essere sorta a seguito della lettura del De varietate fortunae e, probabilmente, del colloquio con il mercante e grande conoscitore dell'Oriente Niccolò de' Conti stabilitosi a Venezia intorno al I449-I450 vedi CATTANEO 2005 , p. 200. Per un approfondimento sul mappamondo di Fra' Mauro vedi FALCHETTA 20I6, pp. 23-26, 68-7I, 99-IOI.

I42. Per un approfondimento sulla leggenda del Prete Gianni vedi OLSCHKI I957, pp. 376-39I; WITTKOWER I987, p. Io8; BALESTRACCI 2008, pp. 30-37; GADRAT 2005, pp. I80-I83; Prester John 2015. Vedi anche SALVADORE 20I7, pp. 27-30.

I 43. Adattamenti e traduzioni della lettera furono inviati anche all'imperatore tedesco Federico - non è dato sapere se Barbarossa o suo nipote -, a papa Alessandro III (p. II59-II8I) e al re di Francia Luigi VII (r. II37-II80). Per un approfondimento sulla versione originale in latino della lettera e la redazione con testo a fronte in italiano vedi GIARDINI 20I6, pp. I in particolare nota I, 9-I3; La lettera I992. Tutte le fonti relative alla figura del Prete Gianni sono state pubblicate da ZARNCKE I876-I879.

I44. TARDIOLA I990, pp. 69-76; CARDINI i99Ia, pp. 209-2I2; GIARDINI 20i6, pp. 5-9.

I45. La lettera I992, p. 32; LEFEVRE I967-I968, p. 22. 
alla missiva del leggendario prete sono le oltre cento trascrizioni e traduzioni sopravvissute del testo latino. ${ }^{\mathrm{I}}{ }^{6} \mathrm{La}$ fascinazione esercitata dalla Lettera del Prete Gianni trapela, poi, in maniera evidente dai volgarizzamenti toscani, che si discostavano dall'originale per l'inserzione di dettagli fantastici su animali e popoli così da appagare appieno il gusto per l'esotico dei lettori tre e quattrocenteschi. ${ }^{\mathrm{I} 7}$

Un personaggio di tale portata non lasciò certo indifferenti i viaggiatori europei avventuratisi nelle terre d'oltremare che, invano, cercarono di rintracciarlo: se già Marco Polo aveva creduto di poterlo identificare con un defunto sovrano della Mongolia interna e Odorico da Pordenone con un principe mongolo, ridimensionandone drasticamente l'estensione del regno, Simone Sigoli lo aveva invece riconosciuto in un "signore della prima Yndia che confina col soldano", mentre alla metà del XV secolo Alfonso V d'Aragona riteneva fosse da individuare nel negus d'Etiopia. ${ }^{\mathrm{I} 8}{ }^{8}$ La localizzazione del mitico sovrano nella coeva cartografia risulta invece più coerente: nel I320 la mappa del genovese Pietro Vesconte lo collocava ancora in Asia non lontano dalla Cina e dalla sede del Gran Khan, mentre a partire dal I339 nel mappamondo realizzato da Angelino Dulcert, pure genovese, cominciò a essere situato in Africa, tradizione poi perpetuata da Andrea Bianco (I436), Giovanni Leardo (I442), Fra' Mauro (I45O ca.) e un cartografo anonimo nel Mappamondo Estense (I45O-I $460 \mathrm{ca}$.). ${ }^{\mathrm{I}} 49$

In una società di natura prettamente mercantile come quella fiorentina proiettata verso l'esplorazione di nuove realtà geografiche, sebbene non ancora totalmente affrancata dall'influenza delle auctoritates, non deve stupire se nel XIV secolo temi da tempo penetrati nell'immaginario collettivo quali il paradiso terrestre, lussureggiante giardino colmo di ricchezze, e il leggendario Prete Gianni, sovrano illuminato che regnava su di un immenso impero traboccante di mirabilia, confluirono nella nascente letteratura scritta in volgare e destinata a un pubblico borghese. ${ }^{I 50}$ Del resto - come afferma Stefano Pittaluga:

I46. EDSON 2007, p. 97; GIARDINI 20I6, p. 3 .

I47. BENDINELLI I978, pp. 59-6I.

I48. POLO 200I, pp. I04, 72:6; I05-I06, 73:I-I9; PORDENONE I990, pp. I36-I37, 49:I; I49-I50; SIGOLI I999, p. 88. Di recente Evelyn Edson ha accolto l'ipotesi che il Prete Gianni fosse un personaggio realmente esistito: si tratterebbe del principe cinese Yeh-Liu Ta-Che che, allontanato dai suoi domini, trovò rifugio in Asia centrale e alleatosi con gli Uiguri cristiani nel I I 4 inflisse una cocente sconfitta ai turchi musulmani Selgiuchidi, EDSON 2007, p. 97. Vedi anche GIARDINI 20I6, p. 7.

I 49. HOOGVLIET 2007, pp. 23I-232; KAPLAN I985, pp. 54-55; SCAFI 2007, pp. I63, I7I-I72, I92; MASSING I99I, p. 28. Dopo aver percorso l'Asia senza trovare traccia del Prete Gianni, agli inizi del XIV secolo i viaggiatori spostarono le loro ricerche in Etiopia, terra fin dai tempi della Naturalis historia pliniana inclusa, insieme all'Egitto, nel continente asiatico vedi PISTARINO I96I, pp. II3-I23; LE GOFF I970, p. 255. Christine Gadrat, sulla scorta di Alfonso di Nola, considera il missionario francescano Jordan Catala de Sévérac il primo ad aver localizzato, intorno al I330, il regno del Prete Gianni in Etiopia, discostandosi così dalla maggior parte dei geografi che lo collocavano in Asia. In realtà, dopo aver a lungo interrogato gli ambasciatori del sedicente sovrano etiope in attesa d'imbarcarsi a Genova, il prete e cartografo Giovanni da Carignano nella carta-portolano realizzata tra il I320 e il I325 aveva incluso le informazioni apprese, ossia la presenza in Africa dell'Abissinia - antico nome per l'Etiopia - e di "christiani nigri»; carta che a sua volta influenzò l'Atlante catalano (I375 ca.) e le mappe successive vedi GADRAT 2005, p. I82; DI NOLA I966, p. 5I; LEFEVRE 1967-I968, pp. 7-8. Per Giovanni da Carignano vedi pagine I54-I57.

I50. ZAGANELLI I985, pp. 25-27. 
Con le missioni in Oriente dei padri francescani e domenicani nel XIII e nel XIV secolo, intese a trovare una soluzione al pericolo mongolo, e con i primi viaggi mercantili incominciava a emergere la volontà di attenersi alla realtà autoptica della geografia e dell'etnologia, ma la millenaria tradizione dell'immaginario, le aspettative dei mirabilia di cui l'Europa aveva caricato l'Oriente mantenevano comunque la loro forza condizionante. ${ }^{\text {ISI }}$

È nell'ottica di questa nuova compagine sociale che si deve comprendere la presenza nelle biblioteche del ceto mercantile fiorentino, insieme a carte nautiche, portolani e mappamondi, di testi contemporanei che avevano come tema l'esplorazione dei paesi d'oltremare o, nel caso specifico della narrativa, scenari e personaggi orientali. Le pagine dei manoscritti in forma di zibaldoni - tipologia da Giovanni Rucellai argutamente definita «una insalata di più erbe» - riunivano trascrizioni di resoconti di viaggio realmente compiuti utili ad ampliare la conoscenza del mondo, testi enciclopedici, poemi didattici, a volte in forma allegorica, romanzi odeporici e novelle con soggetti o ambientazioni orientali. ${ }^{152}$ Coesistenza di generi letterari che rispecchia appieno la cultura fiorentina tra la seconda metà del XIV e la fine del XV secolo, quando il sapere geografico non aveva ancora assunto un andamento lineare perché imbrigliato nel tentativo di mediazione tra i dati tramandati delle auctoritates, ossia la geografia fantastica del Medioevo, e quelli forniti dalla riscoperta di testi antichi così come pure dall'osservazione empirica dei viaggiatori del tempo. ${ }^{\mathrm{IS} 3}$

\subsection{Poemi enciclopedico-didattici}

I testi di argomento geografico connesso all'Oriente che ricorrevano con maggior frequenza nei libri di proprietà dei mercanti fiorentini si possono a grandi linee distinguere in due filoni, a volte tra loro intrecciati: la letteratura didattica e quella di fantasia. Alla prima categoria è certamente da ricondurre il Tresor del notaio fiorentino Brunetto Latini, testo in lingua francese in origine intitolato Li livres dou trésor (I263-I266 ca.) composto durante l'esilio in Francia, presente in forma integrale o di estratti tradotti in toscano in almeno una quindicina di volumi databili tra la fine del XIII e la metà del XV secolo. ${ }^{\text {I54 }}$ Due esemplari, come indi-

I5I. PITTALUGA 200i, pp. 54-55.

I52. RUCELLAI 20I3, p. 5 .

I53. MAZZI I997, pp. I6I-I63. Condivido pienamente l'opinione di Albrecht Classen che ritiene errata la tesi di Jacques Le Goff di un Occidente dove la conoscenza medievale dell'Oceano Indiano si fondava esclusivamente su mediocri fonti ellenistico-latine e su scritti leggendari, dal momento che è stato possibile appurare la grande attenzione all'epoca prestata sia ai testi arabi sia alle narrazioni scritte e orali di viaggiatori contemporanei vedi CLASSEN 2013, p. 22-23; LE GOFF I970 vedi pagina 42 nota 57.

I54. Nel I260 il Comune di Firenze inviò Brunetto Latini alla corte di Alfonso X di Castiglia e di León con la richiesta di aiuto contro i ghibellini, durante il viaggio di ritorno, appresa la notizia della vittoria ghibellina di Montaperti, decise di raggiungere la Francia dove visse in esilio fino al I266. All'elenco stilato da Marco Giola con cinquantuno volgarizzamenti italiani del Tresor, nove dei quali riconducibili a Firenze con datazione tra la fine del XIII e il primo quarto del XV secolo, sono da aggiungere i tre rintracciati nel catalogo approntato qualche anno più tardi da Brigitte Roux e - a mio avviso - altri tre estratti datati tra il primo quarto e la metà del XV secolo conservati alla Biblioteca Riccardiana di Firenze vedi GIOLA 2006, pp. 8,9, I2-I5, I 8, 20, 22; ROUX 2009, pp. 346, 
cano le note di possesso, alla metà del XIV secolo appartenevano a influenti famiglie di mercanti fiorentini: quella dei Benci, dedita al commercio della lana, e quella dei Gaddi, impegnata in attività bancarie e mercantili, che disponevano di grandi biblioteche. ${ }^{\mathrm{I} 5}$ Sebbene ancora d'impronta marcatamente medievale, ossia summa di conoscenze ricavate da autorevoli fonti classiche, la compilazione enciclopedica di Brunetto Latini che trattava ogni branca del sapere - teologia, storia, fisica, geografia, agricoltura, etica, economia, retorica e politica - risultava rivoluzionaria nella scelta della composizione in lingua volgare, caratteristica che ne decretò il grande successo. ${ }^{156}$ Rendendo accessibili a un pubblico allargato nozioni fino ad allora esclusivamente riservate all'élite che padroneggiava il latino, il Tresor contribuì a fissare leggende e schemi geografici che continuarono a circolare fino al XV secolo, tra cui anche il topos che collocava il paradiso terrestre in India dove avevano origine i quattro fiumi fondamentali. ${ }^{\text {I57 }}$ Nell'opera, allo stesso tempo narrativa e didascalica, ampia parte della sezione di storia naturale era dedicata alla descrizione, oscillante tra credenze e realtà, degli aspetti geografici, antropologici e zoologici del favoloso Oriente.

Sempre da ricondurre al genere didattico, anche se in forma odeporica, è il Dittamondo (I346-I367), poema didascalico in volgare e di sapore ancora enciclopedico, scritto da Fazio degli Uberti durante l'esilio trascorso in nord Italia nel quale raccontava in forma autobiografica e immaginaria il viaggio compiuto alla scoperta dell'Europa, dell'Africa e dell'Asia in compagnia del geografo romano Solino vissuto nel III secolo d.C. Il testo, privo della sezione dedicata all'Asia per la sopraggiunta morte dell'autore, sebbene concepito come un trattato di geografia alla portata di tutti in realtà si configurava come una raccolta di notizie su popoli e rituali. ${ }^{158}$ Ancora in gran parte basato su conoscenze assimilate dalle auctoritates e dalle mappae mundi, l'autore non tralasciò d'inserire alcune informazioni aggiornate come quelle che dichiarava di aver appreso dalla consultazione di carte e portolani oppure ricavate dalla lettura di fonti «moderne», tra cui gli scritti del frate fiorentino Riccoldo da Monte di Croce. ${ }^{\mathrm{I} 9}$ Se Isidoro da Siviglia, Plinio il Vecchio ed Erodoto erano semplicemente citati, tutt'altro ruolo fu invece riservato al missionario domenicano addirittura inserito nella narrazione quale suo compagno di viaggio per un breve

36I, 374; I manoscritti datati della Biblioteca Riccardiana I997-20I3, vol. I, pp. 47-48 n. 79; vol. 2, pp. 32-33 n. 59; vol. 4, p. 25 n. 42. Per un elenco dei manoscritti in versione toscana vedi anche LATINI 2007, pp. L-LII.

I55. ROUX 2009, pp. I3O-I3I; I manoscritti della letteratura 20 I, pp. I02-IO3 n. 4, p. I07 n. 78 . Per un approfondimento sulle biblioteche dei Benci e dei Gaddi vedi TANTURLI I978, pp. I97-3I3; BEC I984, pp. I27-I32. I56. MONTEMAGNO CISERI 2009, pp. 6-9. A oggi sopravvivono più di centotrenta manoscritti in francese e in italiano vedi ROUX 2009, p. 60. La scelta della stesura de Li livres dou trésor in francese fu adottata, qualche decennio più tardi, anche da Marco Polo per il Milione.

I57. MONTEMAGNO CISERI 2009, p. 26.

I58. MOROSINI 2006, pp. 200-20I.

I59. BOULOUX 2002, pp. 9I-92, 94-95, 2I3-2I4; MOROSINI 2006, pp. 202-204. Tra le fonti sarà pure da comprendere il Flos historiarum terrae Orientis ( $\mathrm{I} 307$ ) dello storico armeno Hayton di Corico, al quale si ispirò per la descrizione dell'Egitto vedi LEVI DELLA VIDA I959, pp. 449-454. Per il testo di Riccoldo da Monte di Croce vedi pagina 49. 
tratto. Incontrato a Tripolitania - regione dell'Africa settentrionale affacciata sul Mediterraneo - e congedato a Tripoli, dove Riccoldo si imbarcò per fare ritorno a Firenze, l'autore gli aveva dapprima confessato «l'anima mia, che per lunghe spazia / bramosa è stata del vostro volume, / piacciavi che per voi or ne sia sazia» per poi subissarlo di domande su Maometto e il Corano, rivelando così di conoscere il testo Contra legem Sarracenorum scritto dal frate mezzo secolo prima. ${ }^{160}$ Delle cinquantacinque copie del testo ubertiano databili tra la seconda metà del XIV e la fine del XV secolo almeno sette sono con certezza riconducibili a Firenze e tra queste ben due custodite nella stessa biblioteca: quella della facoltosa famiglia Benci, mercanti che durante il tempo libero si dilettavano nella trascrizione di testi, come il Dittamondo terminato "questo diprimo difebbraio I448", che generosamente prestavano ad amici e conoscenti per leggerli o a loro volta copiarli. ${ }^{\text {I6I }}$

Di tutt'altra portata fu la fortuna riscossa dal poema didascalico in volgare la Sfera, compilato nei primi anni del XV secolo dal fiorentino Gregorio - detto Goro - Dati sulla scorta delle sue esperienze personali di mercante, viaggiatore e, non da ultimo, provetto navigatore. Concepito quale manuale pedagogico destinato a istruire $\mathrm{i}$ fanciulli che frequentavano le scuole d'abaco per poi intraprendere l'attività mercantile, ma molto apprezzato anche dal ceto borghese sia come lettura d'intrattenimento sia come utile strumento per il commercio, il testo fu fin da subito molto popolare, tanto da costituire un vero e proprio best seller di cui sopravvivono oltre centocinquanta trascrizioni. ${ }^{\mathrm{I}}{ }^{62}$ Sono almeno dieci le copie datate entro la fine del XV secolo appartenute a mercanti fiorentini, di cui due possedute dalla stessa famiglia Benci. ${ }^{163}$ A decretarne il successo furono la lingua volgare e la composizione in versi, volta a favorire l'apprendimento mnemonico, di un'ampia gamma d'informazioni che spaziavano dall'astronomia alla cosmografia fino alla geografia e che, sebbene in gran parte ancora desunte dal duecentesco Tractatus

I60. UBERTI i952, vol. I, pp. 317, libro IV, XXII:63; 365, libro V, X:7-9. Se con una trentina di manoscritti sopravvissuti il Contra legem Sarracenorum si prospetta come l'opera più nota di Riccoldo da Monte di Croce, non è tuttavia da escludere che Fazio degli Uberti avesse attinto informazioni su luoghi e popolazioni anche dal Liber peregrinationes vedi MONTE DI CROCE 2005 , pp. LI-LII nota 25.

I6I. UBERTI I952, vol. 2, pp. 77 n. 4, 80 n. 6, 85-86 n. I3; I manoscritti datati del fondo Acquisti 2004, pp. 63-64 n. 68; TANTURLI I978, pp. 250, 302. Nel I 436 tra i libri di Nicolò III d'Este figurava una copia del Dittamondo corredata da un commento approntato da Guglielmo Capello, umanista minore e precettore dei figli, nel quale chiariva e aggiornava i riferimenti geografici, storici e mitologici alla luce delle nuove conoscenze; una copia di questa versione commentata databile al I447 apparteneva a Filippo Maria Visconti vedi MATARRESE I992, pp. 58, 60-6I.

I62. BERTOLINI I984, pp. 35-36; Firenze e la scoperta i992, pp. 74-76 n. 35; ROMBAI 2004 b, pp. $95-97$ n. 5; CLEMENS 2008, p. 256 nota 32. Di recente Patrick Gautier Dalché, ritenendo poco plausibile che l'opera fosse stata concepita con finalità didattiche per i fanciulli, ha precisato: «Il faut donc distinguer entre les intentions de l'auteur et la réception de son œuvre, qui est nécessairement de nature variée. Il est clair que la Sfera a pour but de donner une image de l'univers, qui peut certes être utile au marchand, mais qui dépasse largement la simple intention didactique. Il s'agit en fait d'une mise en scène symbolique de l'univers culturel du marchand, fondée en partie sur la carte marine et sur les autres outils de la navigation, mais aussi sur le comput, l'astronomie et la météorologie, domaines que l'on retrouve fréquemment dans les taccuini émanant de ce milieu», GAUTIER DALCHÉ 20I9, pp. I78-I79. Ipotesi che - a mio avviso - non esclude la possibilità che il testo, in origine destinato al milieu mercantile, fosse poi stato adottato nelle scuole di abaco quale manuale didattico.

I63. BERTOLINI I985, pp. 889-940; BEC i984, p. I94; TANTURLI I978, pp. 277, 3 II. 
de sphaera mundi di Giovanni Sacrobosco in uso nelle università, l'autore aveva provveduto a integrare con informazioni di prima mano apprese, oltre che dalla propria esperienza, da mercanti, viaggiatori e navigatori. ${ }^{\mathrm{I} 64} \mathrm{~A}$ consolidare l'impianto eminentemente pratico dello scritto contribuivano, poi, la sezione dedicata alle tecniche di navigazione e agli strumenti necessari - bussola, clessidra, portolano e carta nautica - come pure il ricco apparato illustrativo ispirato a mappe e portolani posto lungo i margini per facilitare la comprensione del testo. ${ }^{\mathrm{I} 5}$

\subsection{Viaggi romanzeschi e cantari}

All'ambito della letteratura odeporica di fantasia che all'epoca godeva di una certa credibilità è da ascrivere il Viaggio dei tre monaci al paradiso terrestre, testo precarolingio che nel corso del XIV secolo diede origine a tre versioni e a numerosi volgarizzamenti, nel quale si narrava il lungo e avventuroso viaggio intrapreso dai religiosi che, dopo aver scorto tra le onde del fiume un ramo d'oro proveniente dall'Eden, si erano allontanati dal monastero per raggiungere il paradiso terrestre, dove furono accolti da un angelo. ${ }^{166}$ Espediente adottato dall'anonimo autore per conferire autenticità alla storia fu quello di riferire un miracolo accaduto ai monaci stessi in presenza di testimoni: rientrati al monastero dopo aver trascorso settecento anni, a loro parsi quindici giorni, nel paradiso terrestre, avevano celebrato una messa conclusasi con la loro morte e, al cospetto dei confratelli attoniti, l'ascesa al cielo delle loro anime trasportate da angeli. ${ }^{167} \mathrm{La}$ versione toscana del testo approntata nel XV secolo, pur mantenendo il proposito di edificazione morale, si differenziava dall'originale per l'ampio spazio riservato all'esotico in modo da rispondere appieno alle aspettative dell'audience mercantile. Ispirata ad antiche leggende e integrata con dati geografici attendibili, la narrazione del lungo peregrinare dei monaci si snodava alternando rocambolesche avventure a descrizioni di mirabilia fino a includere una visita al regno del leggendario Prete Gianni. ${ }^{\mathrm{I} 68}$ Indice del favore riscosso a Firenze dal Viaggio dei tre monaci al paradiso terrestre sono le numerose trascrizioni: almeno cinque in manoscritti miscellanei con resoconti di viaggi reali, come quelli di Odorico da Pordenone o Simone Sigoli, oppure a scritti didattici, come la Sfera di Gregorio Dati. ${ }^{169}$

I64. Un manoscritto datato I475 di proprietà del fiorentino Giovanni di Raggio comprende sia la trascrizione del Tractatus de sphaera mundi di Giovanni Sacrobosco in volgare sia quella della Sfera di Gregorio Dati vedi I manoscritti datati della Biblioteca Nazionale 20 I , p. I2 I n. I04.

I65. CLEMENS 2008, pp. 237-249, 250-25 I. Nonostante il perdurare della controversia se il testo sia da attribuire a Gregorio Dati, mercante e console dell'Arte della Seta, o al fratello Leonardo, monaco dell'ordine domenicano, gli studi recenti propendono per il primo vedi GAUTIER DALCHÉ 20I9, p. I76.

I66. RAVASCHIETTO I997, pp. XII-XIII. Non è stata presa in considerazione la terza versione della storia dove i monaci, ormai prossimi al paradiso terrestre, avevano appreso da san Macario che era proibito accedervi vedi ivi, pp. X-XI.

I67. Ibid.

I68. Ivi, pp. 3-24.

I69. Ivi, pp. I-2; MONACO I978-I979, pp. 202-204; I manoscritti datati del fondo Palatino 2003, pp. $25-26$ n. I28. 
Anello di congiunzione tra i poemi didattici e la letteratura d'intrattenimento è, invece, il Guerrin Meschino, scritto in prosa di Andrea da Barberino databile ai primi decenni del XV secolo. Divenuto in breve tempo popolare, il testo di matrice cavalleresca narrava le mirabolanti avventure del giovane Guerrino che, rapito ancora in fasce dai pirati, peregrinò in Europa, Africa e Asia alla ricerca dei suoi legittimi genitori. L'esplorazione del mondo, modellata sulla leggendaria impresa di Alessandro Magno, lo aveva portato nel continente africano, dove visitò il favoloso palazzo del Prete Gianni e combatté al suo soldo, e in Asia, dove vide di sfuggita il paradiso terrestre attraverso la porta dischiusa dei profeti Enoc ed Elia con la proibizione però di varcarne la soglia. ${ }^{170} \mathrm{Ma}$ il viaggio intrapreso dal protagonista alla ricerca delle proprie origini, ignaro di appartenere a un nobile lignaggio, non era fine a sé stesso, bensì il pretesto per trasmettere al lettore una mole di notizie su popoli, usanze e animali dei paesi visitati e aggiornate nozioni geografiche desunte dalla Cosmographia di Tolomeo, tradotta dal greco in latino appena qualche anno prima a Firenze. ${ }^{\text {I7I }}$ L'avvincente trama e i riferimenti ai mirabilia gli accordarono un posto nelle biblioteche quattrocentesche di mercanti e banchieri fiorentini: le copie di proprietà del ceto mercantile ammontavano a dieci, compresa quella trascritta dai Benci nel $1445 \cdot{ }^{172}$ La saga del cavaliere errante riuscì inoltre a catturare l'attenzione del pubblico meno colto quando a recitarla sulla piazza di San Martino, luogo riservato alle esibizioni di giullari e cantastorie, era lo stesso Andrea da Barberino. ${ }^{173}$

Già nell'ultimo quarto del XIV secolo il famoso poeta e canterino Antonio Pucci era solito esibirsi davanti alla chiesa di San Martino, dove borghesi e plebei si radunavano per ascoltare i suoi cantari, ossia poemi popolari in versi, tra cui quello intitolato Reina d'Oriente che all'epoca riscuoteva grande successo. ${ }^{174} \mathrm{E}$ al "piacevole fiorentino, dicitore di molte cose in rima» - così definito dal contemporaneo Franco Sacchetti - è stato di recente attribuito l'importante ruolo di mediatore culturale che, grazie ai suoi poemi epico-cavallereschi, era riuscito a rendere la letteratura «alta» alla portata di tutti. ${ }^{175}$ Proprio in quest'ottica sarà, allora, da interpretare la selezione di brani tratti dal Milione di Marco Polo, dal Libro d'Oltramare di Niccolò da Poggibonsi, da alcuni favolosi racconti di Alessandro

I70. ALLAIRE 2006, p. 20; CARDINI I983, pp. 2I8, 220; BARBERINO 2005, pp. 430-438, VI:27-30. Mauro Cursietti propone di datarlo all'inizio del secondo decennio del Quattrocento, CURSIETTI 2005 , pp. XIII-XIV.

I7I. ALLAIRE 2006, p. I4; LESTER 2009, pp. I53-I58. Riguardo alle fonti usate pare che Andrea da Barberino attingesse alla sua biblioteca vedi ALLAIRE 2002, p. 27 nota 9; EAD. 2006, p. I3. Per un approfondimento sulla Cosmographia di Tolomeo vedi pagina I6I.

I72. CURSIETTI I999, pp. I2, I9-22, 46; TANTURLI I978, p. 285. Vedi anche ALLAIRE I994, pp. 233-24I. I73. VILLORESI 2006, pp. I7-I8. Gloria Allaire ritiene che la struttura del testo priva di ripetizioni, tipiche della prosa destinata alla recitazione orale, come pure il fatto che l'autore si rivolga direttamente al lettore indichino il Guerrin Meschino quale opera destinata alla lettura, ALLAIRE 2002, pp. 34-35.

I74. Per il testo, un approfondimento sulla storia e una proposta d'identificazione storica della Reina d'Oriente vedi PUCCI i968; MOTTA 2006, pp. 219-24I.

I75. SACCHETTI I996, p. 586, CLXXV; MOTTA 2006, pp. 239-240. 
Magno e da una sintesi del Viaggio dei tre monaci al paradiso terrestre copiati da Antonio Pucci nel suo zibaldone e che dovevano averlo ispirato nel tratteggiare l'atmosfera esotica che aleggia nella Reina d'Oriente. ${ }^{176}$

\subsection{Novelle}

Altro filone letterario "di fantasia" particolarmente amato dai mercanti fiorentini tre e quattrocenteschi fu quello delle novelle, genere narrativo destinato all'intrattenimento che sovente rappresentava in chiave ironica vizi e virtù della società contemporanea. In questo ambito la vera rivoluzione fu quella operata da Giovanni Boccaccio, figlio di un agente di una delle più potenti compagnie mercantili fiorentine, con il Decameron (I348-I360) che - come scrive Vittore Branca - con «la scelta della nuova classe dirigente - quella dei mercatanti -, quale vera protagonista» era riuscito "a segnare il salto dall'epopea alla rappresentazione contemporaneizzata della vita e dei suoi vari motivi». ${ }^{77}$ In men che non si dica eroi, nobili e cavalieri di mondi antichi e leggendari furono spodestati dal ruolo di protagonisti per essere sostituiti da Boccaccio con uomini del suo tempo, in gran parte appartenenti al ceto borghese, impegnati a confrontarsi con problemi politici e sociali attinenti alla realtà, facilitando così l'immedesimazione da parte dei lettori. ${ }^{178}$ Del resto Boccaccio, che in giovane età aveva svolto pratica mercantesca e bancaria nella succursale napoletana della compagnia dei Bardi, ben conosceva gli interessi, le curiosità e i gusti dell'emergente classe borghese. ${ }^{179}$ Motivo per cui nelle cento novelle raccontate a turno dalla «lieta brigata» di giovani rifugiatisi, dopo l'incontro nella chiesa di Santa Maria Novella, in una villa del contado per sfuggire all'epidemia di peste del I348, non tralasciò d'inserire ambientazioni esotiche e personaggi orientali in grado di appagare il fascino che l'altrove esercitava sull'immaginario del tempo. ${ }^{\text {I }}{ }^{80}$

L'Oriente di Boccaccio però, pur non ignorando accenni alle leggendarie figure del Prete Gianni e del Veglio della Montagna, si prospettava ormai privo di connotati fantastici e meravigliosi: ampio spazio era invece riservato al mondo e alle terre che i mercanti avevano avuto modo di conoscere attraverso i loro viaggi e le attività commerciali. ${ }^{18 \mathrm{I}}$ Proprio per rendere credibili le sue novelle agli occhi dei lettori,

I76. Ivi, p. 223; MOROSINI 20II, p. 344; PUCCI I957, pp. 34-35.

I77. BRANCA I992, vol. I, p. XI. Di opinione diversa è Amedeo Quondam che ritiene Giovanni Boccaccio dotato di scarsa affinità elettiva con il mondo dei mercanti, QUONDAM 20I3, pp. 29-3I. Per le varie proposte di datazione del Decameron vedi CURSI 2007, p. I9.

I78. BRANCA I992, vol. I, pp. VII, X.

I79. NICOLINI I925, p. I8; SAPORI I926, p. 259; BRANCA I992, vol. I, pp. XLII-XLIII; ID. I98 I, pp. I $38-\mathrm{I} 39$.

I80. Sono venti le novelle con personaggi o riferimenti geografici all'Oriente: I:3, I:9, II:4, II:6, II:7, II:9, III:7, III:8, III:Io, IV:3, IV:4, V:I, V:2, V:7, VII:9, VIII:9; VIII:Io, IX:9, X:3, X: 9. Per un approfondimento sul Decameron vedi BRANCA I992, vol. I, pp. LII-LXIII; FIORILLA 20I3, pp. I29-I36.

I8I. MOROSINI 20I0, pp. 2I-23; BRANCA I992, vol. I, pp. VII-IX. Nella novella III:8 si rintraccia un riferimento al Veglio della Montagna, secondo Vittore Branca ripreso dal Milione di Marco Polo e nella novella 
molti dei quali in Oriente ci erano stati per davvero, lo scrittore si era discostato dalle consuete narrazioni odeporiche di tipo fantastico per infondervi un'ambientazione il più possibile attinente alla realtà, grazie all'inserzione di notizie geografiche e informazioni mercantili aggiornate ed elevando a protagonista assoluto l'uomo contemporaneo, con il suo linguaggio, i suoi timori e le sue aspettative. ${ }^{\mathrm{I} 2}{ }^{2}$ In altre parole - come ben sintetizza Luca Marcozzi - «lo spazio geografico della letteratura medievale è uno spazio immaginario; lo spazio dei viaggi nel Decameron diventa invece uno spazio conoscibile e misurabile, che corrisponde a un allargamento ricco e audace delle prospettive umane». ${ }^{183}$ Per pervenire a questo risultato Boccaccio attinse sia al suo bagaglio culturale, plasmatosi nei quindici anni trascorsi a Napoli dove frequentò la biblioteca di Roberto d'Angiò, una delle più ricche e fornite del tempo, e incontrò un appassionato di geografia antica come Paolino Veneto, sia all'esperienza diretta fornita da portolani, pratiche di mercatura, guide di pellegrinaggio - tra cui il Libro d'Oltramare di Niccolò da Poggibonsi - e, non da ultimo, da resoconti orali di mercanti e viaggiatori, come quello dell'amico Niccolò Acciaiuoli che per oltre due anni soggiornò nel Peloponneso. Il novelliere era così riuscito nell'intento di dispensare al lettore notizie attendibili su rotte commerciali, distanze e tempi di navigazione per l'Africa e l'Asia Minore. ${ }^{184}$ Lo spiccato interesse geografico che Giovanni Boccaccio nutriva nei confronti dell'Oriente emerge con evidenza da uno dei suoi zibaldoni - noto come Zibaldone Magliabechiano - con trascrizioni di passi della Naturalis historia di Plinio il Vecchio, brani dedicati all'Africa, all'Egitto, alla Siria e a Gerusalemme tratti dalla Chronologia magna (I32 I-I323) di Paolino Veneto, informazioni sui regni asiatici ricavate dal compendio Flos historiarum terrae Orientis (I307) dello storico armeno Hayton di Corico e notizie apprese da una lettera inviata dal capitano della flotta spagnola incaricata di esplorare le Canarie alla succursale sivigliana della compagnia dei Bardi nel I34I. ${ }^{\text {I85 }}$ Proprio questo suo interesse prettamente focalizzato sul mondo reale doveva averlo spinto, mentre copiava alcuni passi di Paolino Veneto, a tralasciare la parte consacrata al paradiso terrestre. ${ }^{186}$

Il Decameron - negli inventari del tempo sovente denominato Centonovelle esercitò fin da subito un notevole impatto sulla borghesia mercantile fiorentina in fortissima ascesa, particolarmente sensibile al tema del viaggio quale filo con-

VIII:9 un'allusione al Prete Gianni - indicato con il nome di Presto Giovanni - vedi BOCCACCIO I992, vol. I, p. 420, III:8 nota I; vol. 2, p. 989, VIII:9.

I82. BRANCA I98I, pp. 347-357.

I83. MARCOZZI 20IO, p. I77.

I84. MOROSINI 20Io, pp. I3, 25-28, 32; BUDINI GATTAI 20Io, pp. IO3-Io8; MARCOZZI 20IO, p. I74 in particolare nota 32. Per l'importanza attribuita da Giovanni Boccaccio alla geografia vedi QUAGLIO I967; BOULOUX 2002, pp. I25-I34. Per un approfondimento sul tema del viaggio in Boccaccio vedi MARCOZZI 2010, pp. I59-I77.

I85. Firenze e la scoperta I992, pp. 65-69 n. 3I; BOULOUX 2002, pp. I27-I33; GREPPI 2010, pp. 90-9I; CARRARA 2020, 2.2. Per Giovanni Boccaccio e l'abitudine di trascrivere nei suoi zibaldoni brani di testi dai quali attingere informazioni durante la redazione degli scritti vedi ARDUINI 20I5, pp. 29-33. Lo Zibaldone Magliabechiano si trova oggi alla Biblioteca Nazionale Centrale di Firenze (Banco Rari 50).

I86. BOULOUX 2002 , p. I32. 
duttore e alla scelta di membri del suo ceto sociale in veste di protagonisti. Non solo, l'epopea dei mercanti mossi da una smisurata "ragion di mercatura» gravitava attorno al Mediterraneo, luogo centrale della geografia boccacciana, evocando lo spazio dove s'intrecciavano rapporti tra nazioni e culture e frenetico crocevia di scambi di merci d'ogni tipo. ${ }^{187}$ L'immediato entusiasmo suscitato dalla raccolta di novelle boccacciane trapela dalla lettera che il I3 luglio I360 Francesco Buondelmonti inviò a Giovanni Acciaiuoli pregandolo di prendere in custodia la sua amata copia del Decameron, probabilmente commissionata l'anno precedente in occasione del suo soggiorno fiorentino:

Domine reverende echo che Monte Belandi scrive a la mogle che vi dia il libro delle novelle di meser Giovanni Bocacci, il quale libro è mio, sì che vi priego quantum possum che ve lo facciate donare. E se l'arcivescovo di Napoli non è partito vi priego il mandiate per lui, cioè per li suoi camerieri, e che non lo desse né a meser né a nullo se non a me. E se lo arcivescovo è partito fatelomi dare a Cenni Bardella; lo me mandi a L'Aquila o a Sermona o voi me lo mandate per chi pare a voi, che venga in mia mano. E guardate non venga a mano a messer Neri per che non l'avrei. Io il fo dare a voi perché mi fido più che di nullo altro e ollo troppo caro; e guardate di non prestarlo a nullo perché molti ne sareno malcortesi [...] (nel verso) E guardatevi de libro mio di prestarlo a ser Nicolò però ch'egli ne sarà ladro. ${ }^{188}$

Alcune trascrizioni dell'opera, tra cui quella posseduta da Francesco Buondelmonti, furono eseguite quando Giovanni Boccaccio era ancora in vita, ma sarà soprattutto negli anni immediatamente successivi alla sua morte, ossia a partire dall'ultimo quarto del XIV secolo, che si verificò un consistente incremento delle copie in circolazione, la maggior parte delle quali realizzate su supporto cartaceo e prive di decorazione, dato che l'audience mercantesca concepiva il libro più come "strumento" che come status symbol. ${ }^{189}$ Escludendo frammenti e codici miscellanei, i manoscritti decameroniani finora rintracciati databili tra il XIV e il XV secolo ammontano a una sessantina. ${ }^{190} \mathrm{E}$ se le iscrizioni presenti su alcuni esemplari non lasciano dubbi sull'appartenenza al ceto mercantile di coloro che si erano accinti a copiare di proprio pugno il testo boccacciano, come nel caso dei "copisti per passione» Francesco d'Amaretto Mannelli, Giovanni d'Agnolo Capponi, Lodovico di Salvestro Ceffini, Piero di Daniello Fei, sono soprattutto gli inventari dell'epoca a rivelare quanto il Decameron fosse particolarmente apprezzato tra le fila dei mercanti fiorentini. ${ }^{\text {III }}$ Tra i possessori di manoscritti soliti affidare le

I87. QUONDAM 20I3, p. 36; BRANCA I98I, p. I56.

I88. ID. I958-I99I, vol. 2, pp. I63-I64; CURSI 2007, p. 20. Vedi anche BEC I967, p. 4IO.

I89. CURSI 2007, pp. I27-I30.

I90. Ivi, pp. I43, I6I-238.

I9I. Ivi, pp. I34-I36, I40. Per le schede descrittive dei singoli manoscritti vedi BRANCA I958-I99I, vol. 2, pp. 76-78, 78-79, I07-IO8, I08-IIO; CURSI 2007, pp. I80-I82 n. I5, I84-I85 n. I8, 216-2I7 n. 43, 2I7-2I9 n. 44. Sulla base di una ricerca condotta su sessanta copie del Decameron, Marco Cursi, pur condividendo l'idea di una circolazione per la maggior parte circoscritta agli ambienti mercanteschi, si dichiara propenso ad allargare la fruizione dell'opera a un pubblico più eterogeneo. Includendo nella sua ricognizione l'elenco stilato da Vittore Branca 
trascrizioni a scribi professionali si annoverano - tanto per citarne alcuni - i nomi di Bernardo Bardi, Matteo Tanaglia, Niccolò Peruzzi, Antonio Corbinelli, Giovanni Benci, Tommaso Raffacani, Ludovico da Verrazzano e Doffo Spini che nel I 434 annotò di aver prestato la sua copia a un commerciante di Volterra. ${ }^{\text {I92 }}$ Anche tra i libri privati della famiglia Medici figuravano copie della raccolta decameroniana: nel I4I7 Cosimo il Vecchio custodiva nel suo scrittoio «Le Cento Novelle e'l Corbaccio di messer Giovanni Boccaccio in bambagia», mentre nel I 456 tra i libri in volgare del figlio Piero vi erano «uno Decameron del Bocchaccio coperto di velluto paghonazo fornito d'ariento» e tra quelli frammentari o di piccole dimensioni un «Decameron del Bocacio di velluto pagonazzo con affibbiatoi d'ariento». ${ }^{193}$ Del resto non deve certo stupire che la borghesia mercantile fiorentina si fosse oltremodo appassionata alla lettura di un testo nel quale per la prima volta si descriveva:

Quel mondo di mercanti e di banchieri, tenaci e audaci, che avevano creato la circolazione europea della ricchezza, palleggiandosi i milioni di bei fiorini d'oro da Londra a Damasco, da Barcellona al Mar Nero, da Parigi ad Alessandria d'Egitto, da Bruges a Costantinopoli, trova[ndo] la sua prima apoteosi letteraria proprio nel Decameron: in questa scintillante epopea mercatantesca, in questa chanson de geste dei paladini di mercatura. ${ }^{194}$

nel I99I, che comprende una cinquantina di codici oggi non reperibili, e considerando i dati emersi dagli studi di Christian Bec, ritengo invece plausibile affermare che nel XIV e nel XV secolo l'ambito di ricezione del Decameron fosse prettamente mercantesco vedi ivi, p. I36; BRANCA I958-I99I, vol. 2, pp. I80-I8I.

I92. BEC I975-I976, pp. 247-260; ID. I984, pp. I09-III; ID. I967, p. 397.

I93. AMES-LEWIS I982, pp. I26 n. 78, I3 I n. I44; Inventari medicei I996, pp. 22, I I3, II7; BRANCA I958I99I, vol. 2, p. I9.

I94. ID. I992, vol. I, p. LXII. 



\section{Oriente a Firenze}

\section{Concilio del I439}

\section{I.I. Delegazioni bizantine}

Alimentata da resoconti di viaggio, poemi enciclopedico-didattici e novelle tre e quattrocentesche, la fascinazione fiorentina per il mondo orientale raggiunse il culmine nel I439, quando a Firenze giunsero delegazioni provenienti dalle terre d'oltremare per partecipare al concilio per l'unione della Chiesa greca e latina. Indetto da papa Eugenio IV per promuovere una crociata contro i musulmani in difesa della religione cristiana, il concilio mirava nel contempo a contrastare, da un lato, la sempre più minacciosa espansione turca che assediava Costantinopoli e, dall'altro, i tributi che il sultano mamelucco del Cairo aveva imposto sia sui traffici che si svolgevano nel Mediterraneo sia sui commerci destinati all'Europa che transitavano lungo la costa africana del Mar Rosso e la valle del Nilo. ${ }^{195}$ Minacce che non erano certo una novità. Già nei decenni precedenti Giovanni VIII Paleologo, prospettando la disponibilità a intraprendere trattative per l'unione delle due Chiese, aveva a più riprese sollecitato un intervento militare da parte dell'Occidente per scongiurare la caduta in mani turche di Costantinopoli. Nel I423 si era recato a Venezia, Milano e persino in Ungheria, ma rientrato in patria senza aver ottenuto risposte concrete fu costretto a stipulare un trattato di pace con il sultano ottomano Murad II (r. I42I-I444 e I446-I45I). Aveva poi ripreso i contatti nel I430 esortando papa Martino V a indire un concilio a Costantinopoli, mentre l'anno successivo si era mostrato più accondiscendente con papa Eugenio IV, da poco assurto al soglio pontificio, dichiarando di accettare quale sede una città italiana e garantendo la sua partecipazione. ${ }^{196}$

Iniziato a Ferrara nel gennaio I 438 e trasferito agli inizi dell'anno successivo a Firenze per il dilagare di un'epidemia di peste, oltre che per le pressanti insistenze di Cosimo de' Medici supportato dal ceto dirigente fiorentino, l'assemblea conciliare svolse un ruolo di particolare rilievo per le sue implicazioni religiose, politiche e culturali. ${ }^{\mathrm{I} 7}$ Dopo lunghe trattative e discussioni teologiche, la lettura del

I95. GILL I967; Firenze e il concilio, I994; VITI 2013, pp. I97-203; TEDESCHI I993, pp. 337-338.

I96. CARILE 2008, pp. 20-2I.

I97. Il concilio iniziò a Basilea nel I43 I ma la forte opposizione di una fazione di prelati che reputava l'autorità conciliare superiore a quella papale indusse Eugenio IV a farlo trasferire nel i 437 a Ferrara. Per quanto riguarda, invece, lo spostamento da Ferrara a Firenze le recenti ricerche di Luca Boschetto sembrano indicare che l'idea di Cosimo de' Medici quale deus ex machina sia da ridimensionare a favore di una compartecipazione del dominan- 
decreto di unione tra la Chiesa cattolica e quella ortodossa ebbe luogo, in presenza di un folto pubblico, il 6 luglio I 439 nella chiesa di Santa Maria del Fiore, ma le speranze di ricucire l'antico scisma si rivelarono ben presto vane, soprattutto per la riluttanza delle chiese orientali ad accettare la superiorità papale. ${ }^{198}$

Il contatto diretto con il mondo bizantino esercitò, invece, effetti ben più duraturi sulla nascente cultura rinascimentale: l'arrivo d'intellettuali che recavano codici di autori greci portò alla riscoperta della cultura e della lingua elleniche, le fogge abbigliamentarie esotiche influenzarono la moda, mentre in ambito artistico la raffigurazione di personaggi orientali generò una vera e propria iconografia volta a evocare ricchezza e potere. ${ }^{199}$

Il Is febbraio I 439 l'imperatore bizantino Giovanni VIII Paleologo fece il suo solenne ingresso a Firenze accompagnato da un seguito di oltre settecento persone tra cui cardinali, prelati, monaci, dignitari, diplomatici e intellettuali che per il loro aspetto esotico, le vesti sontuose e i copricapi stravaganti suscitarono un forte impatto nell'immaginario fiorentino. ${ }^{200}$ Il vinattiere Bartolomeo del Corazza, incline a registrare nel suo diario fatti ed eventi accaduti sulle rive dell'Arno, aveva così descritto il basileus il giorno del suo arrivo: con «adosso una porpora bianca (sic), suvi un mantello di drappo rosso, con cappelletto bianco apuntato dinanzi; di sopra il detto cappelletto aveva un rubino grosso più che un buono uovo di colombe, con altre pietre». ${ }^{2 \mathrm{OI}}$ Il cartolaio e colto umanista Vespasiano da Bisticci, che lo aveva osservato nella chiesa di Santa Maria del Fiore il giorno della proclamazione dell'unione delle due Chiese, nel suo libro dedicato alle vite dei personaggi illustri riferiva:

lo 'mperadore cor una vesta alla greca di brocato domaschino molto rica, cor uno capeletto alla greca, che v'era in su la punta una bellissima gioia; era uno bellissimo uomo colla barba al modo greco. Et d'intorno alla sedia sua erano molti gentili uomini aveva in sua compagnia, vestiti pure alla greca molto ricamente, sendo gli abiti loro pieni di gravità, così quegli de' prelati, come de' secolari. ${ }^{202}$

Del resto già a Ferrara le fattezze dei greci, le loro barbe, le fogge di abiti e copricapi, come pure i cavalli con le narici spaccate secondo l'uso orientale, avevano colpito la fantasia di Pisanello che, designato ritrattista ufficiale dallo stesso basileus, si apprestò a eseguire numerosi schizzi dal vero per poi riutilizzarli in pittura e nella medaglistica. ${ }^{203} \mathrm{Fu}$ soprattutto l'immagine di Giovanni VIII Paleologo di

te ceto mercantile vedi GATTESCHI 2008, pp. 35I-353; DE ROOVER I970, pp. 279-321; BOSCHETTO 20I3, pp. I54-I55, I76, 245 .

198. ANGHIARI 2002, p. 58; PETRIBONI - RINALDI 200I, p. 289; GILL I967, pp. 350-353, 4I7-4I8; SETTON I976-I984, vol. 2, pp. 66-67.

I99. Per l'influenza esercitata dalla presenza greca a Firenze vedi CENTANNI 2017, pp. 32-40; LAZZI I994, pp. 389-407; EAD. 2009, pp. I22-I23.

200. ANGHIARI 2002, p. 56 (che però quantifica il seguito in 400 uomini); PETRIBONI - RINALDI 200I, p. 286; CHASTEL I985, p. 76; SOULIER I924, pp. I67-I74.

20I. CORAZZA I 894, p. 297.

202. BISTICCI I970-I976, vol. I, p. I9.

203. RONCHEY 2006, pp. I56-I57, I75. Per i disegni di Pisanello con immagini “a soggetto bizantino" vedi 
profilo con i lunghi riccioli, la barba a due punte e il bizzarro copricapo appuntito «alla grecanica» - lo skiadon - immortalata da Pisanello su una medaglia in bronzo a dare origine a un'iconografia che nel corso del XV e nella prima metà del XVI secolo riscosse enorme successo. ${ }^{204}$ L'effige, ritratta su quella che è considerata la prima medaglia del Rinascimento italiano, diventò fonte d'ispirazione per pittori, miniatori e scultori grazie alla circolazione di numerosi multipli. ${ }^{205}$ Nel I445 Filarete, architetto e scultore fiorentino, vi fece ricorso per raffigurare l'imperatore bizantino nei quattro bassorilievi con episodi salienti del concilio che decoravano la porta bronzea della basilica di San Pietro a Roma. ${ }^{206}$ Piero della Francesca, sempre conformandosi alla medaglia pisanelliana, attribuì le fattezze di Giovanni VIII Paleologo al volto di Ponzio Pilato nel dipinto con la Flagellazione (I458); stessa sorte toccò qualche anno più tardi ai tratti fisiognomici di Costantino, probabilmente con l'intento di celebrare la dinastia bizantina che aveva contribuito all'unione delle due Chiese, nel ciclo di affreschi con le Storie della Vera Croce (I452-I459) nella chiesa di San Francesco ad Arezzo. ${ }^{207}$ Nella maggior parte dei casi, però, il profilo esotico della medaglia fu recepito dagli artisti in un'ottica più ampia e riproposto alternativamente quale generica immagine di uomo orientale, greco o levantino, personificazione del potere e altre volte addirittura, ironia della sorte, volto di Mehmed II, acerrimo nemico del basileus, finendo così per vanificare il valore di testimonianza dal vero del ritratto pisanelliano. ${ }^{208}$

A Firenze caso emblematico fu quello dell'affresco con la Cavalcata dei Magi (I459) commissionato dai Medici a Benozzo Gozzoli per la cappella nel palazzo di via Larga. Scegliendo questa iconografia Cosimo il Vecchio intendeva espressamente celebrare il concilio per l'unione delle due Chiese tenutosi un ventennio prima in città, al quale aveva attivamente contribuito politicamente e finanziariamente, e nello stesso tempo evocare la dieta di Mantova indetta da papa Pio II nel I459, anno di esecuzione dell'affresco, per promuovere una crociata antiturca. ${ }^{209}$ I tre Magi, due dei quali identificati con gli illustri ospiti bizantini giunti a Firenze nell'inverno I439, si stagliavano sulle pareti del sacello rispettando l'ordine di arrivo: il i2 febbraio l'anziano patriarca Giuseppe II e tre giorni più tardi l'imperatore Giovanni VIII

Pisanello I996, pp. I95-209 nn. II2, II3, II6, iा8; BAMBACH 2004, pp. 527-534 nn. 3I8, 3I9. Gli orientali reputavano che le narici allargate consentissero ai cavalli di respirare più aria e quindi correre più velocemente.

204. CHASTEL I999, p. 22 I; RONCHEY 2006, pp. 79-8I, I75-I76, I85-I89. Per la medaglia in particolare vedi WEISS i966b; Pisanello I996, pp. 209-20Io n. II9; BESCHI 2004, pp. II7-I20.

205. WEISS i966b, pp. 9-IO.

206. CHASTEL I999, pp. I93-I94, 217-218, 233-238.

207. CLARK I95I, pp. I9-20; CHASTEL I999, p. 224; RONCHEY 2006, pp. I92-I95; GINZBURG I994, pp. 39, 4I; RONCHEY 2006, pp. 84-85.

208. WEISS I966b, pp. 20-24, 27-28; RABY 1982, p. I8; CHASTEL I999, pp. 224-225; RONCHEY 2006, pp. I80-I83, I85-I 89; EAD. 2009, p. I36 nota 5.

209. PADOA RIZZO I972, pp. 56-57; EAD. 2009, pp. III-II2; RONCHEY 2009, pp. I 47 -I 48 nota 38. L'allusione pittorica alla dieta di Mantova sarà da intendere quale celebrazione del casato mediceo, che ospitò con tutti gli onori Papa Pio II e Galeazzo Maria Sforza diretti alla volta di Mantova, piuttosto che una vera e propria condivisione del progetto di crociata contro i turchi promosso da papa Pio II, al quale Cosimo il Vecchio aveva in tutti i modi evitato di aderire vedi LURATI 20I2, pp. 37-40, 46. 
Paleologo. ${ }^{210}$ Per tratteggiare il volto del canuto prelato in sella a una mula, raffigurato nei panni del mago Melchiorre, pare che Benozzo si fosse ispirato a un disegno di Jacopo Bellini, forse eseguito durante lo sbarco del bizantino a Venezia, oppure all'immagine dipinta sulla tomba nella chiesa di Santa Maria Novella dove, morto durante l'assise conciliare, fu inumato; per l'imperatore bizantino, impersonato dal mago Baldassarre, aveva invece tratto spunto dalla medaglia pisanelliana. ${ }^{2 \mathrm{II}}$

Se gli abiti dei Magi, pur nella loro ricchezza, non lasciavano trasparire particolari accenni a fogge orientali, tranne la corona piumata di Baldassarre, erano i copricapi e le barbe dei personaggi raffigurati nel seguito così come pure le scene di caccia, passatempo regale molto amato dal basileus, a infondere agli affreschi quel tono di magnificenza principesca ed esotica che l'arrivo dei bizantini doveva aver impresso nell'immaginario fiorentino. Le immagini dipinte nella cappella privata della famiglia medicea, all'occorrenza adibita a sala di rappresentanza dove ricevere gli ospiti illustri, evocavano, nonostante fossero ormai trascorsi vent'anni, ricordi ben vivi nella memoria collettiva perché - come osserva André Chastel - «Il faut imaginer que cette parade d'un an et demie à Ferrare puis à Florence devant des yeux qui savent regarder suscite un phénomène d'une grande portée artistique». ${ }^{2 \mathrm{I} 2}$

\section{I.2. Delegazioni copte ed etiopi}

La promulgazione nel luglio I 439 della bolla Laetentur Coeli - «che i cieli si rallegrino» - con la quale si sanciva la ricomposizione dello scisma fra la Chiesa greca e latina non aveva segnato la conclusione dei lavori conciliari che si protrassero ancora per qualche anno. Nel mese di novembre papa Eugenio IV sottoscrisse l'unione con gli Armeni, mentre a dicembre affidò al frate francescano Alberto da Sarteano l'incarico di recarsi in Oriente per sollecitare la partecipazione al concilio di Giovanni XI patriarca copto di Alessandria, del leggendario Prete Gianni sovrano degli etiopi e dell'immaginario "Tommaso imperatore degli Indiani». ${ }^{213}$ L'inviato papale rientrò a Firenze un anno più tardi, nell'agosto I44I, accompagnato da una delegazione copta e, a causa delle difficoltà nel raggiungere l'Etiopia, da un gruppo di religiosi etiopi provenienti da un monastero di Gerusalemme. ${ }^{214}$ Arrivo che doveva aver generato grande fermento se Alesso Pelli, segretario di Cosimo de' Medici, in una lettera indirizzata al figlio del signore mediceo affermava: «amba-

2IO. PETRIBONI - RINALDI 200I, p. 286; ANGHIARI 2002, p. 56.

2II. GILL I967, pp. 3I8-32I; CHASTEL I999, pp. 225-226; RONCHEY 2006, pp. I04-Io6; EAD. 2009 , p. I 4 I nota I9. Riguardo al valore simbolico attribuito al mulo di colore bianco quale segno di prestigio pontificio vedi PARAVICINI BAGLIANI 20I6, p. 69.

2I2. CHASTEL I999, p. 2 I6.

2I3. GILL I967, pp. 383-389; SANTONI I974, pp. I86-I99; WEBER 20Io, pp. 44I-442; SALVADORE 20I7, pp. 58-59. Per un approfondimento sulla delegazione etiope composta da monaci scismatici vedi anche KELLY 2016.

2I4. BIONDO I963, pp. 93I-932; GILL I967, pp. 383-390; LEFEVRE I967-I968, pp. 5-26; TEDESCHI I993, pp. 338-340; CARDINI 20I5, pp. I8-I9. 
scieria del presto Ianni e di molti signori d'India et di non so chi dal Cairo che si conclude molta gente $[. .$.$] e ànno penato 2$ anni a venire di tanto lungo paese vengono $[. .$.$] grande exaltazione della nostra sede per tutta questa settimana». { }^{215}$

Le aspettative per l'arrivo in città di emissari orientali dovevano quindi essere grandi, soprattutto riguardo all'Etiopia, terra all'epoca ancora non ben localizzata dove si credeva regnasse il mitico Prete Gianni, sovrano orientale dotato di immense ricchezze e a capo di un vasto impero confinante con il paradiso terrestre. Preceduti da cotanta fama, alimentata da leggende, resoconti di viaggiatori e dalla famosa quanto fasulla Lettera del Prete Gianni, l'arrivo degli etiopi che «nel vero a vederli parevano uomini molto deboli» suscitò non poco sconcerto nei fiorentini, ben presto superato dall'allettante possibilità di poterli interrogare per apprendere notizie di prima mano riguardo a un'area dell'Africa ancora inesplorata. ${ }^{216}$ Utili per accrescere e aggiornare le conoscenze geografiche del tempo, le informazioni che gli etiopi fornirono alla commissione cardinalizia non furono ritenute degne di credibilità perché delineavano nuovi orizzonti geografici in contraddizione con quanto tramandato dalla Cosmographia di Tolomeo. ${ }^{27}$ Tutt'altro atteggiamento fu, invece, quello di Flavio Biondo e Poggio Bracciolini, segretari della curia pontificia e colti umanisti, che si dimostrarono inclini a prestare fede a quanto riferito poiché già altre volte si erano riscontrate inesattezze o errori nel testo tolomeiano. ${ }^{218}$ Poggio Bracciolini aveva inoltre ottenuto informazioni sui luoghi visitati e le distanze percorse da un emissario proveniente da un non ben precisato regno «dell'India superiore verso nord», a venti giorni di viaggio dal Catai, dove viveva una comunità cristiana di fede nestoriana, tralasciando però, considerate le difficoltà linguistiche, di porre domande in merito a costumi, riti e animali esotici. ${ }^{219}$ Dal canto suo, Flavio Biondo riferiva di aver appreso che il sovrano etiope in realtà si chiamava «Zareiacob»-Zara Yaqob (r. I434-I468) - e che i suoi delegati reputavano ridicolo l'appellativo di Prete Gianni in uso in Europa. ${ }^{220}$ Notizie che confluirono nelle Decadi di Flavio Biondo, il cui interesse era prevalentemente focalizzato sugli aspetti religiosi e dinastici, e nel IV libro del De varietate fortunae di Poggio Bracciolini, dove le testimonianze sull'Oriente riportate da Niccolò de' Conti, anch'esso giunto a Firenze in occasione del concilio, furono integrate con quelle fornite dagli etiopi e dall'emissario indiano, pervenendo così a delineare quella che all'epoca si prospettava come la descrizione più completa dell'India e dell'Etiopia .2.

Se la delegazione inviata dal patriarca copto di Alessandria Giovanni XI ripartì da Firenze nell'estate I 442 recando una copia della bolla Cantate Domino, che atte-

2I5. KENT 2005, p. 404 nota 40.

216. CERULLI I933, p. 349; OLSCHKI I937, p. 206; SALVADORE 20I7, p. 59.

2I7. Firenze e la scoperta I992, pp. I69-I70 n. 8I.

218. BIONDO i963, pp. 935-936. L'Occidente acquisì approfondite conoscenze sull'Etiopia solo a partire dal Cinquecento, quando una delegazione portoghese vi soggiornò dal I520 al I526 vedi TEDESCHI I993, pp. 333-334. 219. I viaggi I883, p. 36; Viaggi in Persia I929, pp. I03-I04; BRACCIOLINI 2004, p. I65.

220. BIONDO I963, p. 934; CONTE 20II, p. 49.

22. TEDESCHI i993, pp. 334-335; KELLY 20i6, pp. 3-4. Per il IV libro del De varietate fortunae vedi pagine 44-45. 
stava l'avvenuta unione tra la Chiesa latina e quella copta, nessun accordo concreto fu invece raggiunto con gli emissari etiopi, rimessisi in viaggio con una lettera di papa Eugenio IV indirizzata al negus Zara Yaqob invitandolo ad aderire all'unione delle due Chiese. ${ }^{222}$ Malgrado l'incontro si fosse concluso senza risoluzioni in ambito religioso, di tutt'altra portata fu il risultato raggiunto nello sviluppo delle conoscenze geografiche: l'«Aethiopia incognita» di Tolomeo, fino ad allora ritenuta disabitata, cominciò a popolarsi grazie ai resoconti dei religiosi etiopi. Si aprivano così «nuovi e 'sconvolgenti' orizzonti geografici agli Occidentali». ${ }^{223}$

\section{Firenze e il mondo islamico}

\section{I. Caduta di Costantinopoli}

Il 29 maggio I 453, dopo un assedio durato due mesi e l'uccisione dell'ultimo imperatore bizantino Costantino XI, l'esercito del giovane sultano ottomano Mehmed II espugnò Costantinopoli segnando la fine dell'impero romano d'Oriente. La notizia della presa della capitale bizantina, ultima roccaforte del potere cristiano in Oriente, giunse a Venezia un mese più tardi, il 29 giugno, per poi diffondersi in tutta Europa. Tragico evento che, preceduto da numerosi tentativi di conquista da parte dei turchi, sconvolse il mondo occidentale e, soprattutto, mise in allarme il papato da tempo preoccupato per l'inarrestabile espansione in Occidente dell'Islam ai danni della religione cristiana. ${ }^{24}$ I primi tentativi di bandire una crociata, caldeggiati da papa Niccolò V nel I453 e dal suo successore Callisto III nel I455, andarono miseramente in fumo per l'incapacità delle potenze occidentali di allearsi. Nel I459 papa Pio II, al secolo l'umanista Enea Silvio Piccolomini, convocò tutti i principi cristiani alla dieta di Mantova per promuovere un progetto di spedizione militare con spirito di crociata contro gli ottomani. Progetto anche in questo caso rivelatosi fallimentare sia per l'iniziale tergiversare e le mancate promesse dei partecipanti, sia perché nel I464 il pontefice, messosi a capo delle truppe crociate, era deceduto nel porto di Ancona in attesa d'imbarcarsi per Costantinopoli. ${ }^{225}$

In realtà in Italia più che la volontà di difendere la religione cristiana furono gli interessi politici ed economici di potenze marinare quali Genova, Venezia e Firenze - che nel I 406 aveva conquistato Pisa e nel I42 I acquisito i porti di Livorno e Porto Pisano - a prevalere: lo scalo di Costantinopoli aveva un ruolo di primo piano nell'ambito delle attività commerciali che si svolgevano nel Mediterraneo

22. WEBER 2010, pp. 446-447; KELLY 2016, p. 9.

223. Firenze e la scoperta I992, p. I70.

224. CARILE 2008, pp. I7-25.

225. BABINGER I957, pp. 35I-355; CORSI 2008, pp. 66-67; ANGHIARI 2002, p. I43. Per la delegazione di ambasciatori orientali capeggiati dal ciarlatano fra' Ludovico da Bologna recatasi da papa Pio II e presso i sovrani europei millantando di volersi unire nella lotta contro Mehmed II vedi BABINGER I957, pp. 279-285. 
orientale. ${ }^{226}$ Proprio per non compromettere i rapporti mercantili con l'Oriente, quando nella primavera I459 papa Pio II, in viaggio verso Mantova, fece tappa per qualche giorno a Firenze Cosimo de' Medici, adducendo un malessere, evitò d'incontrarlo per sottrarsi alle insistenti richieste di aderire alla crociata antiturca. ${ }^{227}$ Sempre in quest'ottica, negli anni in cui il pontefice convocava la dieta di Mantova, il potente casato mediceo affidò al mercante fiorentino Benedetto Dei la missione di recarsi in Oriente per stringere con il "Gran Turco» un'alleanza politica e mercantile anti-veneziana così da assicurarsi uno sbocco commerciale per i panni di lana fiorentini. ${ }^{228}$ Del resto il mercante e avventuriero, rientrato in patria dopo aver viaggiato per sei anni in Africa e in Medio Oriente, nella sua Cronica (I474 ca.) non lasciava dubbi sul modus operandi dei fiorentini affermando:

Li Fiorentini usano tanta industria e tanta saghacità e tanta artte ched e' choronpono e ànno chorrotto ogni chonsiglio segreto. [...] E notate bene ciaschuno che fFirenze dall'anno I 460 all'anno I 472 à senpre tenuto e ttiene pratiche e 'ntiligienze col gran turcho e co' Maumett Bascià, chapitano de' chapitani. ${ }^{229}$

Non solo, Firenze, città di mercanti le cui ricchezze erano in larga parte generate dai traffici con l'Oriente, era da tempo attivamente impegnata a mantenere cordiali e duraturi rapporti sia con il sultano ottomano di Costantinopoli sia con quello mamelucco del Cairo. Rapporti che non dovevano certo essere facili da gestire, considerato che nella seconda metà del XV secolo si erano riaccese le rivalità tra gli ottomani, che ambivano a controllare l'Egitto e i suoi porti di Damietta e Alessandria per garantirsi il dominio su tutti i traffici di spezie e merci preziose che si svolgevano tra l'Africa, il Mar Rosso, l'Oceano Indiano e l'Occidente, e i mamelucchi strenuamente impegnati nella difesa del loro impero. ${ }^{230}$

A rafforzare il legame tra Lorenzo il Magnifico e Mehmed II contribuì una vicenda personale che tanto stava a cuore al signore mediceo: nella primavera I 479 il sultano ottomano fece arrestare Bernardo di Bandino Baroncelli, cospiratore della congiura dei Pazzi ed esecutore materiale dell'assassinio di Giuliano de' Medici, che dopo la fuga da Firenze trovò rifugio presso alcuni parenti a Costantinopoli. ${ }^{23 \mathrm{I}}$ Consegnato dal sultano ottomano all'ambasciatore fiorentino Antonio di Bernardetto de' Medici per riportarlo in patria, il 29 dicembre I 479 l'omicida fu impiccato per ordine della Signoria a una finestra del Palazzo del Capitano di Giustizia - attuale Bargello -, come documenta un disegno di Leonardo da Vinci che lo aveva ritratto - secondo quanto narrato dal contemporaneo Lionardo

226. CARDINI I992a, p. 37I.

227. PASTOR I96I, p. 44; RICCIARDI I992, pp. I30-I3I.

228. MALLET I967, pp. I22-I23.

229. ORVIETO I969, p. 2 I i ; DEI I984, pp. II4-II5 c. 49 r.

230. MONTESANO 2007, pp. 284-285.

23I. Documenti sulle relazioni I879, pp. 225-228 doc. CLXXXIX; BABINGER i963, pp. 3I6-3I7. Per una contemporanea descrizione dell'attentato ai danni dei fratelli Giuliano e Lorenzo de' Medici ordito dalla famiglia Pazzi il 26 aprile I 478 nella chiesa di Santa Maria del Fiore vedi LANDUCCI I969, pp. I7-20; POLIZIANO 20 I 2. 
Morelli - «cor una vesta alla Turchesca indosso azzurra, come ne venne preso di Turchia». ${ }^{232}$ Per manifestare la sua riconoscenza a Mehmed II, che aveva concesso l'estradizione dell'assassino, Lorenzo de' Medici commissionò allo scultore Bertoldo di Giovanni una medaglia in bronzo commemorativa con il busto del sultano di profilo sul recto e un'immagine con il suo trionfo sul verso. Opera probabilmente consegnata all'emissario del sultano ottomano quando nel marzo I 480 giunse a Firenze con l'incarico di reclutare artisti e artigiani da portare a Costantinopoli. ${ }^{233}$ Il dono della medaglia da parte del potente casato mediceo finì così per legittimare il «Gran Turco", a dispetto di quanti lo consideravano il peggior nemico della cristianità, incontrastato imperatore d'Oriente. ${ }^{234}$

\subsection{Ambasciata di Mohamed Ibn-Mahfuz}

Tra le numerose ambasciate orientali giunte a Firenze fu quella capitanata dal diplomatico egiziano Mohamed Ibn-Mahfuz, che l'i I novembre I 487 fece il suo solenne ingresso in città, a suscitare maggior stupore imprimendo un ricordo indelebile nell'immaginario collettivo. ${ }^{235}$ A colpire la fantasia non fu l'arrivo di personaggi orientali, all'epoca ormai abituali sulle rive dell'Arno, quanto la visione degli animali esotici che il sultano mamelucco Qà'it Bey aveva inviato in dono a Lorenzo de' Medici: «uno lione dimestico, una giraffa, uno cavallo corridore, uno becco e una capra con orecchi grandi cascanti, uno castrone e una pecora con code grosse». ${ }^{236}$ Come diligentemente annotato nel suo Diario dallo speziale fiorentino Luca Landucci:

E a dì I 8 di novenbre I487, el sopradetto anbasciadore del Soldano presentò alla nostra Signoria la sopradetta giraffa, e lione e l'altre bestie; e stette a sedere in mezzo alla Signoria, in sulla ringhiera de' Signori, parlando e ringraziando per bocca d'uno interpetro. Fu, per questa mattina, in piazza un grande popolo, a vedere tale cosa. Era parata la ringhiera colle spalliere e tappeti, e a sedere tutti e principali cittadini. Stette qui quello inbasciadore molti mesi. ${ }^{237}$

232. BABINGER I957, pp. 572-574; LANDUCCI I969, p. 33; ANGHIARI 2002, p. 2 I3 (riporta la data 28 dicembre); MORELLI I785, pp. I95-I96. Il disegno di Leonardo - oggi al Musée Bonnat-Helleu di Bayonne - è corredato da una postilla con l'accurata descrizione dell'abbigliamento esotico dell'impiccato: «Berrettino di tane / farsetto di raso nero / cioppa nera foderata / giupba turchina foderata / di ghole di gholpe / elchollare della giupba / soppannato di velluto appicci / lato nero errosso / Bernardo di Bandino / Baroncigli / calze nere» vedi VIATTE 2004, pp. I5-I7. A Sandro Botticelli fu invece affidato l'incarico di affrescare sulla facciata del Bargello le immagini dei traditori impiccati vedi BUDD 2006, pp. I04-I05.

233. BABINGER 1957, pp. 576-577; ID. I963, pp. 316-322; SPINALE 2005, pp. 76-77; RABY I987, pp. I82I83. Testimonianza di questo evento si trova pure in una lettera inviata dalla Signoria al console fiorentino di stanza a Pera vedi Documenti sulle relazioni I879, p. 237 doc. CCIII.

234. CENTANNI 20I7, p. 303 .

235. LANDUCCI I969, p. 52. Un'anonima cronaca fiorentina pubblicata da Babinger data invece l'arrivo dell'ambasciatore egiziano al 9 novembre I487 vedi BABINGER I963, p. 35I nota I37.

236. Ricordi storici, I840, p. CXLIII.

237. LANDUCCI I969, pp. 52-53. Sempre secondo Luca Landucci: «el detto anbasciadore presentò Lorenzo de' Medici di certe cose odorifere, in begli vasegli alla moresca; e fiaschi pieni di balsamo, e un bello e grande padiglione vergato alla moresca, che si distese, e vidilo", ibid. 
Scopo principale del viaggio dell'ambasciatore egiziano era quello di negoziare il trasferimento del principe Djem, fratello minore del sultano ottomano Bayezid II che versava una somma annuale alla Francia per tenerlo in ostaggio, in Egitto o in alternativa presso la corte papale di Roma, dove sarebbe stato utile al sultano mamelucco Qā’it Bay per intimorire il rivale turco. ${ }^{238} \mathrm{E}$ poiché tutte le potenze europee si contendevano il principe Djem, che per le sue aspirazioni al trono era un potenziale alleato dei cristiani in funzione antiturca, Lorenzo de' Medici si era subito attivato per esaudire la richiesta di Qā’it Bey in modo da salvaguardare gli interessi commerciali dei fiorentini in Egitto. ${ }^{239}$ Non solo si mise in contatto con Anne de Beaujeu, reggente di Francia fino alla maggiore età del fratello Carlo VIII, ma è probabile che per accattivarsi i suoi favori le avesse prospettato, in cambio di aiuto, la possibilità di cederle la giraffa da poco ricevuta in dono. ${ }^{240}$ Promessa che doveva aver alquanto allettato la reggente se, dopo aver concesso nel marzo I 489 l'affidamento del principe turco a papa Innocenzo III, il Is aprile scrisse al Magnifico sollecitandolo - forse incuriosita dalla lettura del Milione di Marco Polo - a tener fede all'impegno d'inviarle l'animale esotico: "Car c'est la beste du monde que j'ay plus grand désir de veoir». ${ }^{24 \mathrm{I}}$ Richiesta però destinata a rimanere inesaudita perché appena qualche mese prima, nel gennaio I489, l'animale, ricoverato nelle stalle in via della Scala per proteggerlo dal freddo, «alzando el capo percosse in uno cardinale d'uno uscio, e di quello si morì». ${ }^{242}$ Lo sconcerto per la morte della giraffa fu tale che per espresso ordine delle autorità cittadine fu deciso di «ischortichorola per serbare la pelle». ${ }^{243}$

Se a Firenze lo stupore suscitato dall'arrivo della giraffa, animale mai visto prima in carne e ossa, fu così grande che tutti desideravano ammirarla, ragione per cui fu condotta per le vie della città e persino nei conventi per mostrarla alle suore di clau-

238. VATIN I997, pp. 38-47; HOUSLEY 20I3, pp. 69-7I; MEDICI I977-20II, vol. II, pp. 4I2-4I5 n. IIO3, 487-489 n. II2I; MELI 2009, pp. 245-246. Già durante il sultanato di Mehmed II un presunto fratello, noto in Europa con il soprannome di «turchetto", giunto a Roma nel I456 vi fu trattenuto per decenni con lo scopo di poter rivendicare pretese al trono; e sempre con questo proposito nel I 464 prese parte alla spedizione capeggiata da Pio II in partenza per riconquistare Costantinopoli vedi HOUSLEY 20I3, p. 70. Per un approfondimento sulla figura del principe ottomano Djem vedi VATIN I997.

239. BABINGER I963, pp. 352-354; MEDICI I977-20II, vol. I2, pp. 303-305; vol. I5, pp. 228-230.

240. ID. vol. II, pp. 305-306 nota I. Vedi anche CLOULAS I984.

24I. THUASNE I892, p. I75 nota I; LOISEL I9I2, p. 26I; BABINGER I963, pp. 352-354; GADRATOUERFELLI 2015 , p. I 40. Vedi anche CLOULAS I984; BELOZERSKAYA 2006, pp. 87-I29; MONTEMAGNO CISERI 20I2-20I3, pp. 35I-372. Trascorsero oltre tre secoli prima dell'arrivo di una giraffa, dono del viceré d'Egitto Mehmet Ali a Carlo X, in Francia nel i 827 vedi PASTOUREAU 2002, pp. I93-200.

242. MASI I906, p. I8. Sebbene libri di ricordi e cronache riportano date discrepanti per la morte della giraffa, quella fornita dal Priorista - sorta di cronaca cittadina redatta da Angelo e Francesco Gaddi - che la fa risalire al 4 gennaio I 489 (I 488 ab incarnatione) sembra degna di fede vedi BROWN I960, p. 63. Tribaldo de' Rossi la data invece al 2 di gennaio I489 (I488 ab Incarnatione), ROSSI I786, p. 247.

243. Ivi, pp. 247-248. Già il sovrano spagnolo Alfonso X, che nel I26I aveva ricevuto in dono dal sultano d'Egitto numerosi animali esotici tra cui una zebra, un dromedario, una giraffa e un elefante, dopo il loro decesso li fece scorticare per appendere le loro pelli sulle pareti esterne della cattedrale di Siviglia, mentre uno scheletro di coccodrillo fu sospeso al soffitto del Patio de los Naranjos. E ancora nel I46I Renato d'Angiò pagò Guillaume Sebille perché conciasse le pelli di un leopardo e di un leone del suo serraglio vedi O'CALLAGHAN I998, pp. $95-96$; Extraits des comptes I 873 , p. 38 n. I20. 
sura, la sua celebrità non si affievolì certo con il trascorrere degli anni. ${ }^{244}$ Non solo si parlava della giraffa ma se ne scriveva pure: nei comuni libri di ricordi dello speziale Luca Landucci e del letterato Alamanno Rinuccini, che ne registrarono l'arrivo in città, o del calderaio Bartolomeo Masi, che ne fornì una descrizione minuziosa, così come pure in un passo latino del poeta Angelo Poliziano, sconcertato per il fatto che $i$ testi antichi non menzionassero le sue corna, e in un epigramma dell'umanista fanese Antonio Costanzi, nel quale era la giraffa stessa a lamentarsi con Lorenzo de' Medici del fatto che gli antichi avessero tralasciato di segnalare le sue piccole corna. ${ }^{245}$

A serbare memoria della "giraffa molto grande e molto bella e piacevole» non erano solo gli scritti dei contemporanei e un'immagine che illustrava le Historiae senenses (I5O6-I525) del prelato Sigismondo Tizio (fig. I), ma opere di artisti noti quali Piero di Cosimo, Domenico Ghirlandaio, Raffaello Botticini, il «forzierinaio» Bartolomeo di Giovanni, e forse molti altri - di cui sfortunatamente non sono rimaste tracce - se Luca Landucci nel suo Diario annotava «com'ella fussi fatta se ne può vedere i' molti luoghi in Firenze dipinte». ${ }^{246}$

Se già nella prima metà del Trecento le letture più apprezzate dal ceto mercantile fiorentino rivelano una particolare attrazione per gli scritti dedicati all'esotico e all'Oriente, a partire dalla seconda metà del secolo, con l'affermarsi delle attività mercantili nelle terre d'oltremare e il diffondersi della pratica del pellegrinaggio gerosolomitano, questa fascinazione finirà per tramutarsi in un vero e proprio interesse mosso sia da ambizioni commerciali sia dalla voglia di conoscere il mondo attraverso i resoconti di mercanti, pellegrini e viaggiatori che quell'Oriente "meraviglioso» lo avevano esplorato per davvero. Alimentata da scritti odeporici, novelle, testi didattici e mappe geografiche custodite nelle biblioteche dei mercanti così come pure dai cantari recitati nelle piazze cittadine, la curiosità nei confronti di mondi lontani era stata ulteriormente stimolata nel corso del XV secolo dall'arrivo in città di delegazioni diplomatiche orientali.

244. ROSSI I786, pp. 246-247. Vedi anche BUQUET 20I3b, p. i i7.

245. LANDUCCI I969, p. 52; MASI I906, p. I8; Ricordi storici I840, p. CXLIII; POLIZIANO I994, p. 228; COSTANZI I5O2, c. Ir-2r; LAUFER I928, pp. 79-80; PASTORE STOCCHI 2OI4, p. I24. Il dettaglio delle corna della giraffa, tralasciato dagli antichi e pure da Alberto Magno, non era però sfuggito ai pellegrini fiorentini Lionardo Frescobaldi, Giorgio Gucci e Simone Sigoli quando alla fine del XIV secolo avevano avuto modo di osservarne alcune al Cairo vedi MAGNO I999, vol. 2, pp. I449-I450; per le descrizioni dei pellegrini vedi pagine I06-I07. Nel gennaio I 488 il poeta Antonio Costanzi inviò al principe di Faenza Galeotto Manfredi una lettera con una lunga descrizione di una giraffa vista personalmente corredata da un piccolo disegno - con tutta probabilità l'esemplare offerto a Lorenzo de' Medici nel novembre I487-vedi JOLY - LAVOCAT I840, pp. 27-28 nota 3 (con la trascrizione del testo della lettera); MONTEMAGNO CISERI 20I2-20I3, pp. 364-367.

246. LANDUCCI I969, p. 52; DONATI I938, pp. 247-249; HIND I938-I948, vol. 5.2, p. 307 A.I. Add. 97; vol. 7, tav. 9II; ZUCKER I994, pp. 2I3-2I5. L'immagine delle Historiae senenses è stata inclusa perché il testo, redatto nei primi decenni del XVI secolo, fu elaborato sulla base di un diario compilato tra il i476 e il i505 vedi DONI GARFAGNINI 2002, pp. 66-68. Per le raffigurazioni pittoriche fiorentine con l'immagine della giraffa vedi pagine $222-232$. 


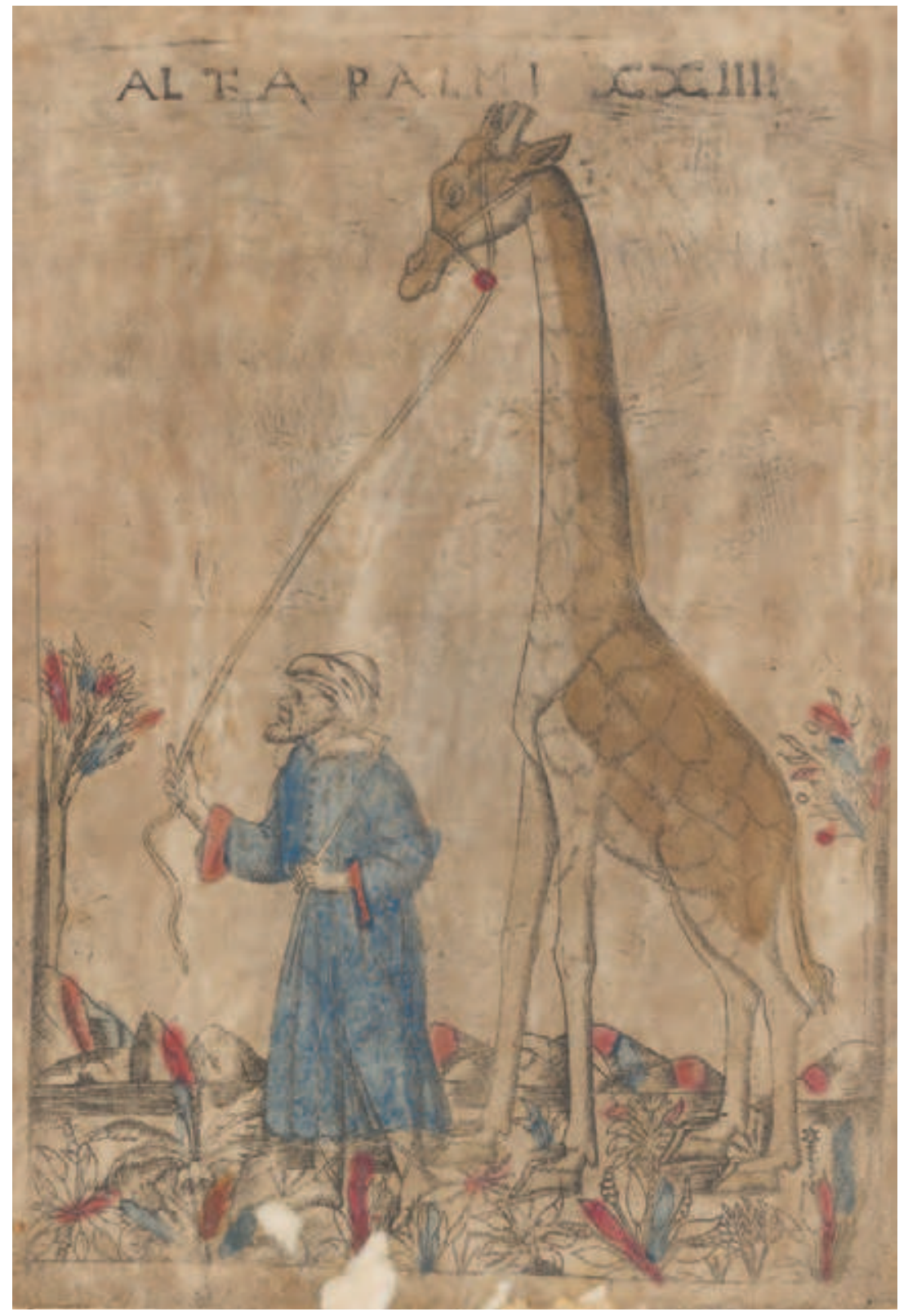

Fig. I: Sigismondo Tizio,

Giraffa, Historiae senenses, I506-I525 ca.

Roma, Biblioteca Apostolica Vaticana (ms. Chig.G.II.36, c. I48v)

(C) 202I Biblioteca Apostolica Vaticana 



\section{PARTE III \\ Fauna esotica: \\ dalla zoologia fantastica all'osservazione diretta}





\section{«Mens mercatoris»: misurare e annotare}

\section{Una nuova forma mentis}

\section{I.I. Scuole di abaco}

Con l'ascesa della classe dei mercanti fiorentini si andò affermando una nuova visione del mondo. A determinare questo cambiamento fu il proliferare, alla metà del XIV secolo per poi raggiungere l'apogeo in quello successivo, delle scuole d'abaco sorte con il mirato scopo di insegnare ai giovani che aspiravano a intraprendere la carriera mercantile a essere "accorti e scaltri negli affari». ${ }^{\mathrm{I}}$

Nate in Italia, e soprattutto in Toscana sullo scorcio del XIII secolo a seguito dello sviluppo dei traffici internazionali, quando al mercante italiano si richiedeva un livello d'istruzione che gli consentisse di leggere, scrivere e fare di conto, le scuole d'abaco equivalevano a veri e propri istituti professionali. ${ }^{2}$ L'iter scolastico prevedeva l'accesso alla scuola intorno ai dieci-undici anni, dopo aver imparato a leggere e a scrivere in latino e in volgare nella scuola elementare, e durava circa un biennio durante il quale si studiava la matematica in un'ottica prettamente mercantile per poi svolgere l'apprendistato in un fondaco e, infine, perfezionarsi al seguito di esperti mercanti in viaggio d'affari. ${ }^{3}$ Le lezioni erano impartite in volgare e prevedevano un ciclo di moduli - detti «mute» - che spaziavano dalla conoscenza del sistema numerico indo-arabico alla rappresentazione dei numeri con le mani, dalle quattro operazioni aritmetiche alle frazioni e, non da ultimo, alla «regola del tre» indispensabile per risolvere i problemi mercantili relativi ai sistemi di monete, a pesi e misure e per calcolare prezzi, sconti, utili delle società e interessi dato che i mercanti sovente erano anche banchieri. ${ }^{4}$ Era, insomma, un sapere improntato a un approccio concreto, con esempi pratici e problemi da risolvere seguendo regole precise.

I. BLACK 2007, pp. 24I-243, 325-326, 362-385; BERTI 2009, pp. 48-49; BARSANTI I905, p. 55. Nella Cronica Giovanni Villani afferma che nel I338, su una popolazione di 90.000 abitanti, i fanciulli fiorentini che frequentavano le scuole d'abaco erano tra i I.00o e i I.200 vedi VILLANI I844-I845, vol. 3, p. 324, libro XI, XCIV.

2. Il termine abaco, derivato dal greco abákion cioè tavola, fu in origine adottato per indicare la tavola di conto, sorta di primitivo pallottoliere, mentre con la diffusione del Liber abaci nel XIII secolo assunse il significato di matematica applicata alle operazioni mercantili e finanziarie vedi MELIS I972, p. I26.

3. SAPORI I945, pp. 74-76; BEC I967, pp. 383-390; BLACK 2007, pp. 327-329; GOLDTHWAITE 20I3, pp. II4-II5. Per un approfondimento sulle scuole d'abaco a Firenze vedi ULIVI 2002, pp. I48-I55.

4. EAD. I998, pp. 56-60; FRANCI - TOTI RIGATELLI 2002, pp. 46-48. Per un approfondimento della "regola del tre" vedi CIOCCI 2003, pp. 69-7I. 
I trattati d'abaco, a loro volta redatti in volgare, illustravano concetti elementari nei quali ampio spazio era dedicato alle questioni commerciali. Si trattava di libri costosi, motivo per cui non erano impiegati come manuali per gli allievi, bensì come promemoria per i maestri d'abaco o sussidiari per i mercanti che già svolgevano la professione. 5 Tra i manoscritti sopravvissuti, che ammontano a circa trecento e sono per lo più di produzione fiorentina quattrocentesca, spicca l'Aritmetica compilata dal famoso abachista Filippo Calandri negli ultimi decenni del XV secolo, testo ornato da preziose miniature commissionato da Lorenzo de' Medici per il figlio Giuliano, rampollo di un casato il cui successo era strettamente connesso alle attività mercantili e bancarie, che per accedere al potere doveva dimostrare di saper gestire il patrimonio familiare. ${ }^{6}$

Autorevole fonte per l'elaborazione dei trattati d'abaco fu l'opera di colui che è stato definito il primo grande matematico dell'Occidente cristiano: Leonardo Pisano detto Fibonaci.7 Figlio di un funzionario doganale impiegato nella colonia pisana di Bugìa in Algeria, Leonardo raggiunse il padre in giovane età per frequentare la scuola di aritmetica e, dopo aver approfondito la cultura scientifica araba e maturato esperienze commerciali viaggiando nel bacino del Mediterraneo, una volta rientrato in patria compose il Liber abaci (I2O2), primo testo occidentale di matematica mercantile. ${ }^{8}$ Aspetto assolutamente rivoluzionario fu l'introduzione in Europa del sistema di numerazione indo-arabico importato dall'Oriente, vale a dire le nove cifre indiane e quella araba dello zero, che sostituendo i numeri romani facilitava le operazioni di calcolo e rendeva possibile effettuare le quattro operazioni matematiche, in precedenza limitate alle sole addizioni e sottrazioni, senza dover far ricorso all'abaco, strumento costituito da una tavoletta sulla quale si spostavano i gettoni e che pertanto non consentiva di verificare l'esattezza del risultato. ${ }^{9}$ Inoltre, nel capitolo dedicato all'aritmetica commerciale erano indicati i nomi delle unità di peso, capacità e lunghezza e quelli delle monete in uso nelle varie città italiane, europee e africane. ${ }^{\text {IO }}$ Questa «antologia scritta da un mercante (matematico) per altri mercanti che hanno sì bisogno di conoscenze tecniche, senza però mai perdere di vista l'utile e il concreto» riscosse un tale successo, sebbene scritta in latino, da richiedere una seconda stesura ampliata e riveduta nel $\mathrm{I} 228 .{ }^{\mathrm{II}}$

5. FRANCI I998, pp. 63-66.

6. ULIVI 2009, pp. 45-46; LAZZI 2008, pp. II-I 4, 58-62.

7. NASTASI $2006, \mathrm{p}$. X.

8. Copie di questo libro si trovavano nelle biblioteche di due tra i più importanti mercanti fiorentini: Antonio Corbinelli e Palla Strozzi vedi BEC I967, p. 408.

9. FRANCI I998, pp. 6I-63; FRANCI - TOTI RIGATELLI 2002, pp. 45-46. Per un approfondimento sui temi trattati nel Liber abaci e sul sistema di calcolo con la tavola d'abaco vedi GIUSTI 2002, pp. 6I-II2; SAPORI I982, vol. I, pp. 72-74.

IO. NASTASI 2006, p. XXXI. Il Liber abaci già conteneva parte della materia delle pratiche di mercatura vedi BERTI 2009, p. 47.

II. NASTASI 2006, pp. XI, XVII. 
L'intensificarsi delle attività commerciali ad ampio raggio tra il XIII e il XIV secolo e il diffondersi della matematica d'abaco provocarono profondi e radicali mutamenti nella società fiorentina del tempo. Se i trattati d'abaco, conferendo validità scientifica alla materia, contribuirono a legittimare le attività commerciali e finanziarie tanto vituperate dalla Chiesa, che condannava l'usura, e dalle autorità accademiche, che disprezzavano la manualità del mestiere, le concezioni matematiche apprese nelle scuole d'abaco finirono per condizionare la forma mentis della nuova classe mercantile. ${ }^{22}$ Tanto per cominciare il mercante, in netto contrasto con il precetto religioso che lo riteneva esclusiva proprietà di Dio, aveva accolto e fatto proprio il concetto laico del tempo. Si era così passati dal tempo della Chiesa, scandito dai ritmi della natura, al tempo del mercante, piegato alle necessità del profitto dal momento che:

quando una rete commerciale si organizza, il tempo diventa oggetto di misura. La durata di un viaggio per mare o per terra da un luogo a un altro, il problema dei prezzi che, nel corso di una stessa operazione commerciale, tanto più se il circuito si complica, salgono o scendono, facendo aumentare o diminuire i guadagni, la durata del lavoro artigianale e operaio, per questo mercante che è quasi sempre anche un datore di lavoro, [...] s'impone sempre più alla sua attenzione, diviene oggetto di regolamentazione sempre più precisa. ${ }^{13}$

Concezione avvalorata da un personaggio del calibro di Leon Battista Alberti, architetto, matematico e membro di un casato impegnato nei traffici internazionali, nei Libri della famiglia (I433-I440) dove il protagonista dedito alla mercatura affermava che la natura dell'uomo non si limita all'anima e al corpo ma comprende pure il tempo: "cosa molto pretiosissima» perché la capacità di sfruttarlo determina il valore e le azioni di ciascun individuo. ${ }^{\text {I4 }}$ In aggiunta, gli insegnamenti delle scuole d'abaco fornirono all'uomo d'affari gli strumenti indispensabili, vale a dire numeri, proporzioni e conoscenza delle forme geometriche, per analizzare e descrivere tutto ciò che lo circondava. Il mondo non era più concepito unicamente come creazione divina da contemplare, ma si era tramutato in un cosmo che poteva essere esplorato, esaminato e tradotto in numeri. Le attività mercantili, oltre ad aver spinto l'uomo d'affari a impossessarsi del tempo, ad allargare gli orizzonti e a conquistare lo spazio, contribuirono a stimolare il desiderio e la volontà di conoscere e comprendere la natura delle cose, che nell'ottica mercantile del profitto equivaleva a poterle dominare e sfruttare. ${ }^{\text {Is }}$

$\mathrm{Fu}$ in questo clima culturale che il mercante fiorentino, dotato delle competenze del buon computista, iniziò a sviluppare una spiccata propensione a quan-

I2. LAZZI 2008, p. 57; BEC I983, p. 272.

I3. LE GOFF I977, pp. I2-I3. Vedi anche SAPORI I972, pp. 53-54; TENENTI 2004, pp. 54-56.

I4. ALBERTI I946, p. 255; BEC, I98I, p. 20; TENENTI 2004, pp. 56-57. Copie del testo di Leon Battista Alberti figurano tra i manoscritti posseduti dai maggiori mercanti del tempo: Bernardo di Benedetto degli Alberti, Antonio Soldani, Giovanni di Matteo Strozzi vedi BEC i967, pp. 399-40o.

I5. LE GOFF I977, p. 22; BEC I983, p. 27I; TENENTI 2004, p. 49. 
tificare in dati numerici tutto ciò che si presentava davanti ai suoi occhi, come quando nel suo diario di viaggio Giorgio Gucci riferiva che la città di Damasco era difesa da «uno muro in su fossi di fuori grossissimo e alto circa di braccia XXX; poi uno altro muro di lunge da quello circa di XV in XVI braccia, più alto che 'l primo circa di braccia X [...] di L braccia in L braccia, ha le torri tonde ed alte sopra tutte le mura». ${ }^{\mathrm{I}}$ Non solo, la mente inquisitiva del mercator-viaggiatore non tralasciava di annotare informazioni inedite e descrizioni accurate riguardo a luoghi, razze, tradizioni, flora e fauna fino al punto da rivelare, in alcuni casi, uno spiccato interesse pseudo-etnografico e pseudo-scientifico. ${ }^{17}$ D’altronde - come osserva Michael Baxandall:

alcuni degli strumenti mentali con cui un uomo organizza la sua esperienza visiva possono variare, e buona parte di questi strumenti sono relativi al dato culturale, nel senso che sono determinati dall'ambiente sociale che ha influito sulla sua esperienza. In essi rientrano le categorie per mezzo delle quali egli classifica i suoi stimoli visivi, le conoscenze cui attingerà per integrare il risultato della sua percezione immediata. ${ }^{18}$

Non sarà allora un caso se in concomitanza con il diffondersi delle scuole d'abaco e l'affermarsi di una mentalità mercantile dominata dai numeri e dal calcolo si andò sviluppando l'uso della prospettiva matematica in pittura. Assimilando gli strumenti culturali del tempo, l'artista si serviva di numeri, matematica e geometria pratica per comprendere la realtà e riprodurla. Se nei primi decenni del XV secolo Leon Battista Alberti nel De pictura illustrava i fondamenti matematici dell'arte pittorica basata sull'osservazione della natura, che doveva essere indagata e scrutata in quanto "capo e principio di questa arte», nella seconda metà del secolo il Trattato d'abaco di Piero della Francesca - testo dedicato al calcolo commerciale in parte ancora influenzato dalla cultura medievale - dimostrava come le capacità matematiche usate dai pittori per analizzare e riprodurre le proporzioni e i volumi avessero strette analogie con quelle che il mercante impiegava ogni giorno per misurare la quantità delle sue mercanzie. Artisti e uomini d'affari, quest'ultimi sovente nel ruolo di committenti, finirono così per essere accomunati dalla stessa forma mentis. ${ }^{\text {I9 }}$

\section{I.2. Dai libri di mercatura ai libri di ricordi}

All'epoca le raccomandazioni rivolte ai futuri mercanti a «non perdonare [risparmiare] mai la penna» e che "stava così bene [...] sempre avere le mani tincte d'in-

I6. GUCCI I990, p. 300, XXII:3. Anche Simone Sigoli, membro della stessa comitiva di mercanti-pellegrini, riportava con lievi differenze le misure delle mura poste a difesa di Damasco vedi SIGOLI I999, p. 93.

I7. PASTORE STOCCHI i967, pp. I96-202.

I8. BAXANDALL I978, p. 5I.

I9. BASSI 20I4, pp. 322-323; BAXANDALL I978, pp. 86-87, 95. 
chiostro» non rimasero certo inascoltate. ${ }^{20}$ Furono le scuole d'abaco a dar vita a quello strato culturale intermedio, tra dotti e analfabeti, artefice di gran parte della letteratura del tempo in lingua volgare e scritta in "mercantesca», grafia in uso per i libri di conto. ${ }^{2 \mathrm{I}}$ Se la laicizzazione dell'istruzione diede origine a una nuova cultura dei mercatores, l'espandersi e l'intensificarsi dei commerci internazionali portarono alla nascita di compagnie commerciali che operavano attraverso fittissimi scambi di corrispondenza, grazie a efficienti servizi postali coordinati dalle corporazioni dei mercanti stessi, e a una gestione degli affari basata su libri contabili aggiornati quotidianamente, facendo della mercatura «l'unica professione non dotta che imponeva a chi la esercitava la pratica assidua della scrittura». ${ }^{22}$ Ben si comprende allora l'adolescente Lorenzo di Matteo Strozzi, impiegato come apprendista presso il fondaco dello zio a Valenza, quando nel I 446 scriveva alla madre: «sto tutto dì nello scrittoio, e copio il dì dodici lettere: iscrivo tanto presto, che ve ne maraviglieresti». ${ }^{23}$

Frutto di questa copiosa produzione scrittoria fu la pratica di mercatura, strumento indispensabile per chi in patria o all'estero si trovava a svolgere un'attività commerciale e finanziaria. Attingendo a resoconti di agenti di ritorno dai viaggi e alla corrispondenza con funzionari dislocati fuori sede, le maggiori case mercantili approntarono manuali di agile consultazione per i loro dipendenti, a volte addirittura corredati da un calendario perpetuo e da tavole e prontuari per eseguire rapidamente le operazioni di calcolo, con informazioni via via aggiornate relative ai costi di trasporto, notizie utili per gli spostamenti, modalità e regole per la negoziazione nei vari paesi, varietà delle merci e loro prezzo, indicazioni per riconoscere i prodotti di qualità da quelli scadenti, sistemi di misura e monetari, tassi di cambio, disposizioni legislative, tariffe e pratiche doganali. ${ }^{24}$

Espressamente elaborati per rispondere alle specifiche esigenze di ogni singola compagnia commerciale impegnata a operare ad ampio raggio geografico e merceologico, ossia strumenti per uso interno, ben presto questi compendi si rivelarono utili per i mercanti in generale. ${ }^{25}$ Si trattava, insomma, di una tipologia libraria creata dai mercanti e destinata ai mercanti importata, al pari della matematica d'abaco, dall'Oriente dove fin dall'XI secolo circolavano veri e propri manuali per

20. MORELLI I986, p. I78; ALBERTI I946, p. 32I. La tesi di Werner Sombart che ritiene il mercante incolto e illetterato è stata smentita sulla base di documenti prodotti dai mercanti stessi vedi SOMBART I925, pp. 99-I09; SAPORI I972, pp. 52-53; ID. I982, pp. 53-93. Per un approfondimento sulla cultura dei mercanti vedi BEC I967, pp. 393-4I5; ID. I98I, pp. 2I-23; ID. I983, pp. 274-282.

21. GAMBA 2008, p. 93; BLACK 2007, p. 456.

22. GIUSTI 2002, pp. II3-II4; SAPORI I982, vol. I, p. 70; MELIS i972, pp. I4-25; BERTI 2009 , pp. 35-37.

23. STROZZI I 877 , p. 30 .

24. MELIS I972, pp. I22-I24; TUCCI I977, pp. 215-23I; DINI I980, p. 53; SAPORI i982, vol. I, pp. I7-I9, 78-8I; TENENTI 2004, p. 53; BERTI 2009, pp. 3I, 35-40; GIAGNACOVO 20I4, pp. 8-I2. Vedi anche LUGLI 20I7, pp. I73-I79.

25. L'idea che si trattasse di libri segreti è stata smentita dagli studi di Armando Sapori e Federigo Melis, SAPORI I945, p. 66; ID. I982, pp. 83-84, MELIS I972, pp. I5-I6. Per un excursus sui più importanti libri di mercatura vedi GIAGNACOVO 20I4, pp. I3-23. 
commercianti che non dovevano essere passati inosservati ai viaggiatori europei. Tra questi il Libro delle bellezze del commercio e la conoscenza delle mercanzie dell'arabo al-Dimišhqī, con una lunga lista di merci e la descrizione del mondo degli affari siriano, e la Cronaca di parecchi paesi stranieri dell'ispettore doganale cinese Chau Ju-kua, elenco di merci e curiosità che si potevano incontrare lungo le vie commerciali che collegavano Cina-Mediterraneo-Europa, vale a dire il tragitto percorso in senso inverso da Marco Polo due secoli più tardi. ${ }^{26}$

In Italia le pratiche di mercatura fecero la loro comparsa, come del resto le scuole d'abaco, sullo scorcio del XIII secolo a seguito del grande sviluppo dei commerci internazionali. Primo manoscritto mercantile noto di area toscana è la Memoria de tucte le mercantie (I278), probabilmente stilata da un mercante, ancora simile a uno zibaldone per la presenza, oltre a dati specifici sulle merci all'interno dello spazio geografico dei commerci pisani, di una breve cronaca cittadina e di un prontuario astrologico utile per la navigazione. ${ }^{27}$ Qualche decennio più tardi fu la volta del Nottario di più cose (I3 I5), manuale fiorentino con un elenco di porti e prodotti importati ed esportati lungo la direttrice Europa-Levante-Cina. ${ }^{28}$

Vero e proprio spartiacque nel panorama dei manuali mercantili fu invece la Pratica della mercatura (I335-I343 ca.) di Francesco di Balducci Pegolotti che, prospettando in maniera sistematica il sapere del mondo mercantile esteso a un ampio spazio geografico, suscitò grande interesse nel folto pubblico di mercanti che costituivano l'asse portante della ricchezza fiorentina. ${ }^{29}$ Le informazioni confluite nel testo, oltre ad attingere a carteggi, documenti ufficiali e vecchi compendi, furono ritenute degne di fede in quanto ricavate dall'esperienza ventennale maturata dall'autore durante i suoi soggiorni nelle Fiandre, a Londra e a Cipro in qualità di fattore di una delle maggiori compagnie fiorentine, quella dei Bardi. ${ }^{30}$ Furono queste caratteristiche a rendere l'opera pegolottiana innovativa rispetto ai precedenti manuali, tanto da costituire un modello ancora in uso nel I472, quando fu copiata e arricchita da miniature in un manoscritto che recava l'annotazione: «questo assempro [copia] è levato dal libro d'Agnolo di Lotto dell'Antella, e 'l quale libro era levato dall'assempro del libro del detto Francesco Balducci». ${ }^{\mathrm{I}}$ All'azienda del mercante pratese Francesco di Marco Datini sono da ricondurre

26. SAYOUS I93 I, p. 579; BORLANDI I936, p. XVI nota 5; LOPEZ I98 I, p. 462; SAPORI I972, pp. 5I-52; ID. I982, pp. 82-83; BERTI 2009, p. 3 I.

27. LOPEZ I98I, pp. 464-469; LOPEZ - AIRALDI I983, pp. 99-I33; BERTI 2009, pp. 4I-42.

28. DINI I998, pp. 648-655; BERTI 2009, p. 44.

29. LAZZI 2004, pp. I06-I07 n. Io. Il titolo Pratica di mercatura, entrato nell'uso comune per indicare questo genere di manuali, si deve a Giovan-Francesco Pagnini del Ventura che nel i766 pubblicò con questa intestazione il Libro di divisamenti di paesi e di misure di mercatantie scritto da Francesco di Balducci Pegolotti. Nel I936 fu data alle stampe una nuova edizione a cura di Allan Evans, nella quale furono emendati gli errori della versione settecentesca e proposta una datazione compresa tra il I3 Io e il I340; datazione poi ricondotta al I330 da Roberto Lopez e posticipata tra il I335 e il I343 da Giuseppe Tucci vedi PEGOLOTTI i766; PEGOLOTTI i936, p. XV; LOPEZ I98I, p. 463; TUCCI 2005 , p. 45.

30. PEGOLOTTI I936, pp. XVII-XXII; BERTI 2009, p. 34; GIAGNACOVO 20I4, pp. I3-I5.

3I. PEGOLOTTI I936, pp. 3, 383. 
la Pratica della mercatura datiniana (I385-I390 ca.), sussidio per i dipendenti che svolgevano la loro attività nelle sedi europee e levantine, e la Ricordanza di robe (I394I395) di Ambrogio di Lorenzo Rocchi, agente datiniano dislocato a Maiorca e successivamente a Valenza, manuali ancora in parte debitori del testo pegolottiano. ${ }^{32}$ Sempre alla fine del XIV secolo si datano il Libro d'avisi di fatti di mercatantia scaturito dalla penna di Simone di Giovanni degli Acciaioli, membro di un'importante famiglia mercantile, e il testo oggi noto come Manuale di Saminiato di Guciozzo de' Ricci (I396) redatto da un mercante fiorentino impegnato a gestire l'azienda di famiglia a Genova. ${ }^{33}$ Prontuario commerciale, quest'ultimo, che con il passaggio dell'attività bancaria genovese, ormai in declino sullo scorcio del XIV secolo, nelle mani dei banchieri fiorentini doveva essere diventato una valida fonte di informazioni se nel I4I6 Antonio di Francesco da Pescia, fattore della compagnia di Giovanni di Bicci de' Medici, lo trascrisse integrandovi i «modi e forme che si deono tenere in merchantie e chambi in ongni luogho dove fosse». ${ }^{34}$ Giovanni di Antonio da Uzzano, rifacendosi ad alcuni capitoli del trattato genovese, approntò il Libro di gabelle e pesi e misure di più e diversi luoghi (I442), nel quale forniva informazioni sui commerci dei pisani con i paesi mediterranei corredate da un portolano e da notizie su Fiandre e Inghilterra. ${ }^{35}$ Neanche un decennio più tardi fu la volta de El libro di mercatantie et usanze de' paesi (I45O ca.), manuale particolarmente apprezzato per l'ampiezza dell'orizzonte geografico e dell'arco cronologico trattati, di cui sopravvivono tre copie: una eseguita da Giorgio di Lorenzo Chiarini a Ragusa nel I457 per il mercante fiorentino Ricciardo di Vieri del Bene, una di copista anonimo realizzata non prima del i46o e un'altra con la nota di possesso "Questo libro è di Francesco del Pugliese» e la data I483. ${ }^{36}$

Ma la passione dei mercanti per la scrittura tra il XIV e il XV secolo non si esauriva certo nell'ambito professionale. Non solo si erano personalmente impegnati nella trascrizione di gran parte dei volumi che arricchivano le loro biblioteche, ma furono estremamente prolifici nel comporre di proprio pugno cronache, diari, zibaldoni, libri di famiglia e di ricordi. ${ }^{37}$ L'impulso dei mercanti a scrivere fu fondamentalmente dettato da due propositi: il senso del profitto, ossia tenere traccia del patrimonio familiare, e la volontà di lasciare un ricordo del proprio operato ai discendenti. ${ }^{3}$ A testimoniare lo stretto legame tra affari e famiglia sono le prime ricordanze risalenti alla fine del XIII secolo, quando lungo i margini dei libri di conto e di bilancio comparvero brevi note riguardo a eventi domestici o cittadini. ${ }^{39}$ Del resto il legame tra libri commerciali e cronaca era già stato

\footnotetext{
32. DINI I980, pp. 35-65; CIANO I964, pp. 7-30; BERTI 2009, p. 44; GIAGNACOVO 20I4, pp. I7-I8. 33. FANTACCI I970; GIAGNACOVO 20I 4, p. 20.

34. BORLANDI I963, pp. 7, IO-II, 36-37; BERTI 2009, p. 44; GIAGNACOVO 20I4, pp. I8-I9.

35. UZZANO I766; BORLANDI I963, pp. 9-Io; BERTI 2009, p. 45; GIAGNACOVO 20I4, pp. 2 I-22.

36. BORLANDI i936, pp. XX-XXV, XXXIV-LI; ID. I963, p. 8; GIAGNACOVO 20I4, pp. $22-23$.

37. BEC I983, pp. 282-296; SAPORI I982, vol. I, pp. 56-60.

38. PEZZAROSSA i980, pp. 42-43.

39. Mercanti scrittori I986, pp. XIV-XVII.
} 
ipotizzato per il Milione di Marco Polo: sembra che per comporre il testo lo scriba Rustichello da Pisa avesse attinto informazioni da una pratica di mercatura stilata dal veneziano nel corso dei suoi viaggi in Oriente.

I brevi e sporadici appunti che arricchivano i libri di conto con il tempo si andarono via via ampliando fino a dar vita a veri e propri libri che rispecchiavano appieno la mentalità del mercante: trattavano di fatti pratici, esperienze vissute, memorie di fatti accaduti, spese domestiche e consigli utili per gli eredi. ${ }^{40}$ Proprio tra le innumerevoli informazioni contenute nelle cronache e nei libri di ricordi si rintracciano annotazioni e, più raramente, descrizioni degli animali esotici giunti a Firenze quali doni diplomatici. Mossi dall'impulso prettamente mercantile di osservare e quantificare, gli uomini d'affari applicarono ai bizzarri animali visti per la prima volta gli stessi parametri che erano soliti adottare per comprendere la realtà. Se Luca Landucci si limitò ad annotare che la giraffa giunta a Firenze nel I 487 era «molto grande e molto bella e piacevole» e Filippo Rinuccini, ancor più stringatamente, che «lo imbasciadore del Soldano [...] venne e menò innanzi a se la giraffa e uno lione domestico, le quali cose donò alla Signoria per parte del Soldano", di tutt'altro tenore furono le descrizioni di altri mercanti fiorentini. ${ }^{4 \mathrm{I}}$ Tribaldo de' Rossi appuntò «la Girafa era 7. bracia alta, el piè chomelbue piacevole animale e ogniuno piaceva", mentre Bartolomeo Masi, impressionato dall'arrivo di bestie mai viste prima, si dilungò nel riferire che tra i doni diplomatici:

v'era uno animale che si chiamava giraffa, che aveva la testa sua come una vitella, sanza corna, e aveva el pelo rossigno, e aveva le ganbe dinanzi alte circa di tre braccia, e quelle di drieto circa a dua, e aveva la coda sua come una vitella, el collo lungo circa di quattro braccia; e mangiava d'ogni cosa, ed era agievole [mansueta] quanto uno agniello. ${ }^{42}$

Superato lo stupore iniziale, la curiosità di conoscere la natura delle cose stimolò i mercanti a descrivere quella strana fauna esotica che potevano osservare per la prima volta in carne e ossa. Impresa certo non facile, sia perché la loro visione era ancora in parte influenzata dalle reminiscenze tramandate da enciclopedie e bestiari medievali, sia perché in alcuni casi erano i termini veri e propri per designare queste bestie a venire meno. ${ }^{43}$

\section{I.3. Descrivere il «maraviglioso»}

Ancora prima dell'arrivo a Firenze della giraffa e degli strani ovini orientali, i fiorentini avventuratisi nelle terre d'oltremare avevano incontrato non poche

40. Un primo catalogo dei testi tre e quattrocenteschi redatti dai mercanti fiorentini e pubblicati a stampa è stato stilato da Fulvio Pezzarossa, PEZZAROSSA i98o, pp. 93-I 49.

4I. LANDUCCI I969, p. 52; Ricordi storici I840, CXLIII.

42. ROSSI I786, p. 247; MASI I906, p. I8.

43. Fino agli ultimi decenni del XV secolo la Naturalis historia di Plinio il Vecchio, testo di riferimento per la conoscenza degli animali, risulta essere rara a Firenze vedi pagine I43-I 47 . 
difficoltà quando nei loro diari e resoconti di viaggio si accinsero a riferire le fattezze di animali sconosciuti visti nei mercati, nel deserto, lungo le rive del Nilo e, soprattutto, nel serraglio del sultano del Cairo. ${ }^{44}$ Queste nuove realtà zoologiche, da un lato, e la concezione mercantile di un mondo non più teocentrico ma che si poteva conoscere attraverso lo strumento laico della ragione, dall'altro, avevano dato vita a un impulso pseudo-scientifico che, pur tenendo conto della consolidata tradizione di bestiari ed enciclopedie medievali, si basava sull'osservazione diretta. Di fronte a un pantheon di animali orientali per la maggior parte mai visti prima, se non immaginati attraverso racconti orali o notizie lette nei bestiari, i viaggiatori fiorentini per sottolineare tutto il loro stupore fecero ricorso a termini come "maraviglia», "contraffatta [strana]", "travisata [inusuale]» e «mirabile» per evidenziarne il carattere bizzarro e insolito. ${ }^{45}$ Quando, poi, a mancare erano i nomi veri e propri per designare questa fauna, si videro costretti a tradurre il termine arabo in italiano, mentre altre volte addirittura a tralasciarlo, come aveva ammesso a malincuore Niccolò da Poggibonsi nel suo Libro d'Oltramare scrivendo: "Molte cose io vidi, cioè animali infiniti, de' quali io non seppi il nome adomandare, ch'io non avea allora lo 'nterpito [interprete]». ${ }^{6}$

Caso particolare fu certamente quello della giraffa: descritta nella Naturalis historia con testa simile a quella del cammello e manto chiazzato come quello del leopardo, da cui il nome "camelopardalis», nel XIV e nel XV secolo l'animale non fu riconosciuto come tale a causa delle indicazioni lacunose di Plinio il Vecchio che aveva tralasciato, dettaglio non da poco, di specificarne l'altezza e la lunghezza del collo, motivo per cui fu accolta la traduzione italiana del nome arabo zarâfa, come attesta Giorgio Gucci alla fine del XIV secolo nel suo Viaggio ai luoghi santi: «e come il nome suo è nuovo, giraffa, così è molto più nuova cosa a vedella». 47

I problemi non si limitavano però alla mancanza di zoonimi per designare la fauna esotica. Descrivere animali strani mai visti prima richiedeva uno sforzo notevole da parte dei viaggiatori. Alla fine del XIII secolo l'atteggiamento di Marco Polo, il cui interesse per gli animali era dettato da ragioni puramente

44. BUQUET 20I3a, p. 26.

45. POGGIBONSI i99o, pp. iा3, CLXX:2; i 8, CLXXXI:I; i i9, CLXXXIII: i; SIGOLI i999, p. 8; GUCCI I990, p. 268, IX:3; Diario di Felice Brancacci I88I, p. I78. L'aggettivo esotico associato agli animali fu usato per la prima volta da Rabelais nel I552 vedi BUQUET 20I3b, pp. 98-99.

46. POGGIBONSI I990, p. II8, CLXXXII:2. Riguardo all'adozione di zoonimi arabi in Europa vedi BUQUET 200I3c, pp. 382-383.

47. ID 2012, p. 75; ID. 20I3c, pp. 393-395; GUCCI I99o, p. 269, IX:7. Plinio il Vecchio riporta: «Gli Etiopi chiamano nabu una bestia che nel collo assomiglia a un cavallo, nei piedi e nelle zampe ai bovini e nella testa ai cammelli; sul suo fulvo pelame risaltano macchie di color rossastro ed è per questo motivo che viene chiamata $\mathrm{ca}$ melopardalis [cammello-leopardo]. Fu vista a Roma per la prima volta, durante la dittatura di Cesare, in occasione degli spettacoli circensi. Da allora la si può vedere spesso: è un animale che fa spicco più per la mole che per la sua indole, che le ha procurato anche il nome di pecora selvatica», PLINIO 20II, p. 69, libro VIII, XXVII. Ancora a distanza di secoli Isidoro da Siviglia, rifacendosi al testo pliniano, nelle Etymologiae non accenna né alla lunghezza delle zampe né a quella del collo vedi pagina ioo nota 68. Per quanto riguarda l'origine araba del nome giraffa, negli anni sessanta del XV secolo Alvise Ca' da Mosto indica l'animale con il termine italianizzato "ziraffe» vedi Le navigazioni atlantiche I966, p. 66. 
commerciali, come nel caso dell'elefante per le zanne in avorio, risulta ancora tipicamente medievale per aver preferito classificare come unicorno, attingendo al suo bagaglio culturale, la bestia sconosciuta con un corno sul muso - in realtà un rinoceronte - sebbene conscio delle differenze. ${ }^{48} \mathrm{Il}$ mercante veneziano - come nota Umberto Eco - reputò più appropriato, e forse più credibile, correggere «la descrizione vigente degli unicorni che, se ci sono, sono dunque come egli li ha visti e non come la leggenda racconta». ${ }^{49}$ Cominciava quindi ad affiorare la mentalità razionale del mercante che, pur accettando ancora incondizionatamente l'esistenza di un quadrupede leggendario, ne emendava l'immagine asserendo che gli unicorni "no son guari [per nulla] minori d'elefanti: e' son di pelo bufali, i piedi come di lefanti; nel mezzo de la fronte ànno un corno grosso e nero [...] lo capo ànno come di cinghiaro».50 Non solo, annotando "ell'è molto laida bestia (a vedere), né non è, come si dice di qua, ch'ella si lasci prendere a la pulcella, ma è 'l contrario" aveva negato in un colpo solo quanto tramandato da auctoritates e bestiari, ossia la straordinaria bellezza dell'animale e la credenza che per catturarlo fosse necessaria una giovane vergine. ${ }^{5 \mathrm{I}}$

Un atteggiamento più razionale comincerà a emergere nel corso del secolo successivo e si andrà sempre più consolidando con il trascorrere del tempo. Se già alcuni missionari avventuratisi oltremare si erano impegnati a fornire qualche informazione, sarà da ricondurre alla figura del mercante, contraddistinta da una

48. POLO 200I, pp. 50, 36:4; 287, I86:5; 290, I87:5. Non è da escludere che una certa confusione tra il rinoceronte e l'unicorno sia da far risalire al VII secolo quando Isidoro da Siviglia nelle Etymologiae scrive: «Il rinoceronte è stato così chiamato dai Greci: tale nome si interpreta in latino come avente un corno sul naso. Il rinoceronte è anche chiamato monocero, il che significa unicorno, in quanto avente al centro della fronte un unico corno della lunghezza di quattro piedi, così acuto e robusto che manda all'aria o perfora qualunque cosa sulla quale si avventi", SIVIGLIA 2004 , vol. 2, p. 29, libro XII, II:I2. Il primo rinoceronte asiatico visibile in Europa dai tempi dell'antichità fu quello che Manuele I del Portogallo, appena qualche mese dopo averlo ricevuto in dono dal sultano del Gujarat Muzafar II, inviò a papa Leone X - alias Giovanni de’ Medici - nel I5 I5. Annegato durante il trasporto per mare, quando la nave affondò al largo della costa ligure, la carcassa dell'animale fu recuperata, imbalsamata e recapitata a Roma l'anno successivo. Coeve testimonianze visive dell'esemplare si rintracciano negli affreschi che Giovanni da Udine eseguì su disegno di Raffaello nelle Logge Vaticane (I5I5-I5I7), nella scena con Giuseppe presenta il padre e i fratelli al Faraone (I5I7) dipinta da Francesco Granacci per Palazzo Borgherini a Firenze - ora agli Uffizi -, nei rilievi in stucco (I5I5-I520), alternativamente attribuiti a Giovanni da Udine e Pierino del Vaga, che decorano il soffitto di Palazzo Baldassini a Roma vedi LOISEL I9I2, p. 219; LACH I965-I9,93, vol. 2.I, pp. I6II62; BEDINI I997, pp. III-I36, I74-I75; JORDAN GSCHWEND 2004, p. 42; PERÉZ DE TULEDA JORDAN GSCHWEND 2007, p. 42I; METZGER 20I5, pp. I29-I3I n. 2.I; GROOM 20I8, p. I5; MASSETI 20I8, pp. 64-65.

49. ECO 2005 , p. 43. A testimoniare, a distanza di quasi due secoli, il perdurare del valore attribuito alla tradizione libresca è il resoconto dei pellegrinaggi compiuti nel I480 e nel I483-I484 dal missionario domenicano Félix Fabri che, fortemente vincolato alla simbologia cristiana, nell'Evagatorium Fratris Felicis in Terrae sanctae Arabiae et Egypti peregrinationem accolse senza riserve le indicazioni fornitegli dall'interprete riguardo all'insolito animale incontrato nel deserto chiamato «rhinocerotem» e da lui identificato con il leggendario unicorno vedi MEYERS 2008 , pp. I-3.

50. POLO 200I, p. 245, I62:I4-I5

5i.Ibid., I62:I6-I7. Descritto nel Physiologus, modello e origine di molti bestiari medievali, come un "piccolo animale, simile al capretto, ma ferocissimo. [...] ha un solo corno in mezzo alla testa» e impossibile da catturare se non attirandolo con una vergine, la leggenda continuò a essere tramandata per secoli attraverso le Etymologiae di Isidoro da Siviglia e il Tresor di Brunetto Latini vedi Il Fisiolgo 20I I, p. 6I:22; SIVIGLIA 2004, vol. 2, pp. 29-3I, libro XII, II:I3; LATINI 2007, p. 325, libro I, I98:2. 
spiccata attitudine a registrare e misurare, l'approccio decisamente più concreto e razionale nei confronti della fauna meravigliosa e sconosciuta minuziosamente descritta dopo essere stata osservata con occhio indagatore..$^{52}$ Le difficoltà incontrate non furono certo da poco tenuto conto di quanto dovesse essere complicato tratteggiare a parole la loro singolare morfologia. Per ovviare a questo inconveniente $\mathrm{i}$ viaggiatori fiorentini si avvalsero, a loro insaputa, di un accorgimento già adottato da Plinio il Vecchio: anziché creare un'immagine ex novo preferirono assemblare tra loro, in una sorta di mosaico, parti di animali ben noti in Europa in modo da riuscire a plasmare nella mente del lettore un animale ignoto ma facilmente comprensibile. ${ }^{53}$ Fecero quindi ricorso a schemi di classificazione basati sull'esperienza e sul senso pratico, ossia l'habitus mentale e il modus operandi appresi nelle scuole d'abaco, dato che «la percezione si origina e si organizza tramite rappresentazioni tassonometriche che prescrivono non solo "come" vedere il mondo, ma anche "cosa" percepire e "su cosa" fermare l'attenzione». 54 All'epoca le scienze naturali non avevano ancora sviluppato terminologie e metodi appropriati, le nuove conoscenze erano, dunque, il frutto di osservazioni riferite da individui che per lo più appartenevano allo stesso milieu culturale e, quindi, dotati di sistemi cognitivi e di classificazione comuni. ${ }^{55}$ Mosso dal suo spiccato senso pratico, il mercante, pur considerando l'animale esotico un'unità indivisibile, si era apprestato a frazionarlo in più parti con lo scopo di fornire una descrizione il più accurata possibile, spettava poi all'immaginazione del lettore il difficile compito di sintetizzare i singoli elementi in un'unica rappresentazione mentale e conferirgli le dimensioni indicate. Per raggiungere questo scopo i viaggiatori-scrittori non esitarono a fare raffronti con oggetti di uso quotidiano o ani-

52. Tra le generiche descrizioni di animali fornite da religiosi recatisi in Oriente, il testo Mirabilia descripta (I329-I330) del frate domenicano Jordan Catala de Sévérac spicca per l'attenzione riservata alla fauna esotica. Pur non dubitando dell'esistenza degli unicorni, che descrive "grandes comme des chevaux, avec une corne sur le front, mais une seule et très grosse et pointue, mais courte, toute solide, et aussi moelle», non li confonde con il rinoceronte puntualizzando "Il y a encore un autre animal, appelé rhinocéros, grand comme un cheval, ayant une corne longue et tordue sur le front: mais ce n'est pas la licorne", GADRAT 2005, pp. 89, 277:36; 287-288:109.

53. ECO 2005, p. 45; BEDINI I999, p. 24; ECKSTEIN 20I4, pp. 3, 6, I2. È alquanto improbabile che i viaggiatori avessero dedotto questo metodo descrittivo da Plinio il Vecchio, dato che fino all'ultimo quarto del XV secolo la Naturalis historia risulta essere un testo assai raro a Firenze. Sebbene non sia possibile escludere che il metodo "pliniano" fosse filtrato attraverso i testi di Solino e Isidoro da Siviglia, autori però rari tra le letture dei mercanti, questa maniera d'indagare e descrivere il mondo è - a mio avviso - assolutamente peculiare della struttura mentale del mercante. Che all'epoca il metodo descrittivo del paragone si applicasse a tutti gli ambiti lo dimostrano gli stessi pellegrini-scrittori: Giorgio Gucci rapporta il più grande mercato del Cairo al Rialto di Venezia o al Mercato Nuovo di Firenze e la piazza davanti al castello del soldano d'Egitto al prato fiorentino d'Ognissanti, lo stesso fa Simone Sigoli comparando la città di Gerusalemme a Pistoia e quella di Damasco a Firenze, GUCCI I990, pp. 269-270; SIGOLI I999, pp. 92-93.

54. Nel caso dei mercanti non sarà tanto da prendere in considerazione il mental habit di Erwin Panofsky, ossia «'insieme di schemi inconsapevoli, di principi interiorizzati che danno una loro unità ai modi di pensare di un tempo, qualunque sia l'oggetto pensato", bensì l'habitus di Pierre Bourdieu basato sull'esperienza e sul senso pratico fino a diventare tipico di una classe, dato che le esperienze sociali degli individui e le condizioni sociali in cui sono cresciuti influenzano i loro schemi di classificazione e di giudizio, PANOFSKY 20I4, p. I2O; BOURDIEU 20I0, pp. 93-95, I65-I70. Vedi anche KRAIS - GEBAUER 2009, pp. 24, 40, 49.

55. PANOKSKY 20I4, p. 22. 
mali noti in Europa: la bocca dell'elefante "quasi come storione», la proboscide crespa "com'uno lombrico» a foggia di «una tromba» o di un «corno da ssonare» e con l'estremità simile a "due bocche di lamprede», le zanne "grossissime come sono le corna di buoi», le orecchie come «ale di draco» o «ale di pipistrello» increspate «a modo come li aliotti» $\mathrm{o}$ "pendenti in giù come di segugi» e "grandi come tavolacci d'arme», le zampe a forma di «aliosso», le corna della giraffa simili a «cornicella piccole come di castrone» e "vestite di pelle come quelle del cavriuolo».56 L'espediente di accostare l'ignoto e il «maraviglioso» a realtà ben familiari all'audience di ricezione si prospettava come il modo più semplice e appropriato per infondergli credibilità e concretezza. ${ }^{57}$

I mercanti fiorentini non si limitarono però, come Marco Polo, a far corrispondere a tutti costi ciò che videro con quanto riferito dalle fonti antiche, ma si preoccuparono di fornire una descrizione minuziosa di ciò che si presentava davanti ai loro occhi. Se nella Naturalis historia la giraffa aveva collo di cavallo, piedi e zampe bovini, testa di cammello e pelame fulvo con macchie rossastre, una volta rientrati dal viaggio in Oriente si erano spinti oltre offrendo maggiori dettagli: «è animale corpolente come comunale cammello», «il pelo suo a modo di gran cervo", «il capo di cavallo et così i crini» e, soprattutto, "ha le corna sue vestite quasi a modo di cavriuolo giovane»..$^{8} \mathrm{~A}$ spiccare, oltre al maggior uso di paragoni con bestie diffuse in Europa, è indubbiamente l'attenzione posta nel quantificare e riferire le misure degli animali d'oltremare: a proposito dell'elefante Giorgio Gucci annotava «alto, secondo ch'io l'avisai, circa di braccia IIII e altrettanto largo» mentre Lionardo Frescobaldi nel descrivere la giraffa precisava «le gambe drieto lunghe circa a due braccia [...] le gambe dinanzi lunghe circa quattro braccia, il collo altrettanto", evidente retaggio culturale dell'istruzione appresa nelle scuole d'abaco. ${ }^{59}$ Dettaglio, questo, che sembra ulteriormente avvalorare l'inizio del passaggio da una concezione medievale della fauna esotica improntata al meraviglioso a un approccio marcatamente razionale con intenti pseudo-scientifici. Tanto è vero che nel XV secolo il mercante chioggiotto Niccolò de' Conti,

56. FRESCOBALDI I99I, p. I44:4-29; Diario di Felice Brancacci I88I, p. I78; GUCCI I990, p. 268, IX:4; SIGOLI I999, p. 8i; POGGIBONSI i990, p. i 8, CLXXXI:I. Le lamprede sono animali acquatici simili all'anguilla caratterizzati da una bocca circolare imbutiforme; gli «aliotti» erano dei cerchietti di panno attaccati alla zimarra, sopravveste maschile del tempo, intorno alla parte superiore del braccio presso la spalla, così chiamati perché simili a delle piccole ali (per una raffigurazione pressoché coeva vedi il disegno a corredo del Memoriale toscano, Roma, Biblioteca Apostolica Vaticana, ms. Urbinate lat. IoI3, c. I3v); le «tavolacce d'armi» erano grandi scudi lignei usati dai fanti per ripararsi; l'aliosso, detto anche astragalo, era un minuscolo osso ovino del tallone usato fin dall'antichità per il gioco e nel XV secolo ancora menzionato nei Ricordi di Lionardo Morelli vedi Compendio I739, vol. I, p. 89 ad vocem «aliosso»; PORDENONE I990, fig. 3; Vocabolario degli Accademici I863-I923, vol. I, p. 354; MORELLI i986, p. I93.

57. ECKSTEIN 20I4, pp. I-2.

58. FRESCOBALDI I99I, p. I44:23-24; GUCCI I990, p. 269, IX:6; SIGOLI I999, p. 8I.

59. GUCCI I990, p. 268, IX:3; FRESCOBALDI I99I, p. I 44:25-28. A questo proposito Gloria Allaire rimarca che le descrizioni di animali esotici fornite da Andrea da Barberino nel Guerrin Meschino riflettono la tipica ossessione fiorentina tardo medievale dei mercanti per le misure, mentre nelle auctoritates erano solo occasionalmente indicate, ALLAIRE 2002, pp. 33-34. 
impegnato a riferire i suoi ricordi di viaggio all'umanista Poggio Bracciolini perché li mettesse su carta, non fu minimamente sfiorato dall'idea che la bestia vista in Birmania con «capo di porco, la coda di bue et un sol corno a similitudine d'uno animale chiamato unicorno: ma el corno è più breve, perché solamente si distende un cubito. [...] di grandezza et di colore simile agli elefanti» - un rinoceronte indiano - fosse da identificare con l'animale mitologico. ${ }^{60}$ Alla metà del XV secolo solo l'orafo fiorentino Marco di Bartolomeo Rustici, autore di un diario di pellegrinaggio immaginario, si ostinava a sostenere di aver visto:

un liocorno, il quale era grande quanto u-mezano [di medie dimension] cavallo, quasi di pelo di lione, e 'l suo corno era in su la testa, lungo braccia quatro o piùe, quasi ritorto, tutto bianco. La sua fazione [fattezze] era a modo d'un cervio, il suo collo avea i crini come uno cavallo co' piedi fesso come la cervia. ${ }^{61}$

60. Viaggi in Persia I929, p. I44. Vedi anche Iviaggi I883, pp. I34-I35; GROSSATO I994b, p. 52; BRACCIOLINI 2004, p. I09.

6I. RUSTICI 20I5, p. 22I. La descrizione, affine alle immagini che circolavano all'epoca, sembra avvalorare l'idea che si tratti di un resoconto fittizio, così come pure le similitudini con la descrizione fornita da Andrea da Barberino nel Guerrin Meschino: «E viddono uno animale di grandezza d'uno comune ronzino "el quale avea la testa caprina, la barba come becco [caprone], le gambe e' piè come cerbio [cervo], e crini e lla coda come cavallo, e uno corno nella testa diritto e lungo circa quattro braccia: e non ci fece offensione". Disse el mediano: "Quello si chiama liocorno". Pareva di colore ora nero ora Sanguigno e lustrava el suo pelo, e quello lustro rosseggiava", BARBERINO 2005 , p. I22, libro II, XXI:I4-I6. In ambito religioso l'idea che l'unicorno fosse un animale realmente esistente continuò invece a perdurare vedi pagina 94 nota 49. 



\section{L'occhio del mercante e gli animali esotici}

\section{Libri di viaggio dei fiorentini}

\section{I.I. Missionari}

A partire dalla fine del XIII secolo alcuni missionari fiorentini furono inviati in Oriente dal loro ordine con l'espresso compito, dopo la tappa obbligata del pellegrinaggio in Terrasanta, di diffondervi la religione cristiana e, nel contempo, raccogliere informazioni utili per i confratelli che in futuro si sarebbero recati in quelle terre. ${ }^{62} \mathrm{Al}$ loro rientro in patria avevano poi riunito in una sorta di manuale notizie sul modo di vivere, tradizioni e culti delle popolazioni incontrate durante i viaggi. ${ }^{63}$ La scarsa attenzione dedicata agli animali esotici, a volte soltanto menzionati e ancor più raramente descritti, è probabilmente da ricondurre alla loro concezione teocentrica del mondo: erano, insieme ai mostri e agli animali fantastici, parte della creazione di Dio e della sua onnipotenza e quindi non andavano esaminati, ma semplicemente accettati in quanto tali. Assolutamente incuranti dei dati mercantili, l'interesse dei missionari si focalizzava sulle varie confessioni professate in Oriente, mentre le uniche descrizioni che lasciavano trapelare una palpabile partecipazione emotiva erano quelle relative ai luoghi dove, secondo quanto narrato dalla Bibbia, si potevano trovare tracce materiali della vita di Cristo o del passaggio degli apostoli. ${ }^{64}$

A cavallo tra il XIII e il XIV secolo il domenicano Riccoldo da Monte di Croce, rientrato a Firenze dopo essere stato in Terrasanta e aver poi viaggiato da Acri fino a Baghdad, nel suo Liber peregrinationis si limitò a descrivere due animali esotici: «'asino selvatico dell'India, che da alcuni è reputato essere l'onagro, il quale per la distinzione e varietà dei colori e la proporzione della screziatura supera in bellezza tutte le bestie e animali del mondo» visto a Tabriz - città dell'attuale Iran nord-occidentale - e «un serpente mostruoso che aveva quattro piedi come un cane, di dietro però traeva una coda serpentina e orribile» - un coccodrillo - osservato a Baghdad. ${ }^{65}$ A questo proposito è interessante notare come qualche decennio più tardi il friulano Odorico da Pordenone, missionario francescano che in

62. MONTE DI CROCE 2005 , p. XIX.

63. Ivi, pp. XXV-XXXVIII.

64. Ivi, p. XXIV.

65. Ivi, pp. 73-74, I33. L'onagro persiano (Equus hemionus onager) è una sottospecie dell'asino selvatico asiatico con mantello di colore beige rossiccio, ampie parti bianche nella parte inferiore del corpo, una striscia marrone chiaro lungo la colonna vertebrale affiancata da due strisce bianche che si prolungano negli arti posteriori e lungo le spalle. 
Oriente trascorse ben dodici anni, pur dispensando nella sua Relatio una gran quantità di informazioni commerciali e di utilità pratica, che resero la versione toscana molto popolare tra i mercanti fiorentini, trascurò invece quelle relative alla fauna esotica: si trattava per lo più di brevi accenni a «leoni neri [pantere] e vipistrelli [pipistrelli] grandi com'anitre», "calcatrici, overo coccodrilli, e leoni in gran copia, e diverse bestie che non sono infra noi», «testugini [tartarughe] mirabili», «leofanti», «serpenti» e «scimmie, gati mamoni». ${ }^{66}$

Un cambiamento nel modo di approcciarsi a queste realtà sconosciute e una maggiore curiosità per la fauna esotica da parte dei missionari si avverte intorno alla metà del XIV secolo grazie al Libro d'Oltramare del frate francescano Niccolò da Poggibonsi che, come asseriva nella prefazione, era mosso, da un lato, dalla curiosità di conoscere e comprendere quanto si presentava davanti ai suoi occhi e, dall'altro, dalla volontà di riportarlo fin nei minimi dettagli per chi non aveva la possibilità di compiere un viaggio in Oriente. Questa propensione all'osservazione non si esauriva quindi, come negli altri religiosi che lo avevano preceduto, nell'offrire informazioni sui luoghi santi, il modo di vivere e le credenze delle popolazioni indigene, ma comprendeva pure gli animali esotici. A lui si deve, infatti, la prima testimonianza oculare in lingua volgare disponibile in Europa della giraffa. ${ }^{67} \mathrm{Nel}$ suo manoscritto Niccolò da Poggibonsi raccontava di aver visto al Cairo una bestia:

fatta quasi come la capra, e il corpo suo è colorato di sotto come una rete; le gambe dietro hae cortissime, quelle dinanzi sì l'hae lunghissime e lo collo tanto lungo che, quando ella si rizza, pare che tocchi il tetto dove ell'era, ch'era molto alto. ${ }^{68}$

66. PORDENONE I990, pp. 70; IOо, I5:2; I02, I7:3; I08, 23:2; II2, 25:I; II3, 26:2; II5, 28:I; II 8, 3I:4; I23, 37:3. I pipistrelli giganti visti da Odorico da Pordenone a Thane - città sulla costa occidentale dell'India, oggi parte di Mumbai - sono probabilmente da identificare con gli scoiattoli volanti giganti che Niccolò de' Conti vide a Quilon - nel sud dell'India - e descrisse come "gatti salvatichi, i quali hanno una pelle dalle parti dinanzi insino alle parti di rieto distesa insino a piedi, et questa pelle si raguna insieme quando si riposano, et distesi i piedi et scosse l'ale volano da uno arbore all'altro", Viaggi in Persia I929, p. I53. Vedi anche I viaggi I883, p. 224; GROSSATO I994a, p. 30; BRACCIOLINI 2004, p. I23 (identificati da Michèle Guéret-Laferté con gli scoiattoli volanti giganti). Lo scoiattolo volante gigante (Biswamoyopterus) è una specie tipica dell'India del nord con corpo lungo $40 \mathrm{~cm}$.

67. GUÉRIN DALLE MESE I99i, p. I8. La descrizione della giraffa resa da Marco Polo si basava invece su quanto riferitogli vedi pagina Io6.

68. POGGIBONSI I990, p. iı8, CLXXXII: . Fazio degli Uberti nel Dittamondo (I346-I376) include una descrizione della giraffa: "giungemmo nel paese di Bisanzi, / che da levante a Tripoli s'afferra. / Io vidi, ricercando quelle stanzi, / un animal che mi fu maraviglia / veder le gambe e 'l suo collo dinanzi: / tanto l'ha lunghe, che aggiunge e piglia / da lontano una cosa diece braccia; / poi dietro bassa e 'l contrario somiglia. / Men che cammello ha la testa e la faccia; / tra quelle genti giraffa si chiama; / d'erbe si pasce, ché bestia non caccia. / "Solin, diss'io, di vedere avea brama / questo animale e parmi scontrafatto / assai via più che non porta la fama". / Ed ello a me: "Non ti paia gran fatto, / che, prima ch'eschi d'Africa, vedremo / di più maravigliosi in ciascun atto", UBERTI I952, vol. I, p. 360, libro V, VIII: 47-60. Poiché l'animale non ha nulla a che fare con le informazioni fornite da Plinio il Vecchio o da Isidoro da Siviglia, è probabile che l'autore si fosse rifatto al coevo testo di Niccolò da Poggibonsi oppure a racconti orali dei viaggiatori. Per la descrizione di Plinio il Vecchio vedi pagina 93 nota 47, mentre Isidoro da Siviglia nelle Etymologiae riporta: «Il cameolpardo, ossia la giraffa, è stato così chiamato perché, cosparso come il pardo di macchie bianche, ha collo simile a quello di un cavallo, piedi bovini e la testa simile a quella di un cammello: lo genera l'Etiopia", SIVIGLIA 2004, vol. 2, pp. 3I-33, libro XII, II: I9. 
E se questo animale non si era mai visto in Toscana, lo stesso si può dire dell'elefante - che arriverà solo nel I655 - sebbene la sua morfologia fosse già nota grazie alle numerose immagini in circolazione. ${ }^{69}$ Il frate francescano, certamente impressionato dalla visione ravvicinata del pachiderma, non aveva resistito dal riferire quanto osservato in prima persona:

egli è nero, tutto pelato [liscio] sanza peli, ed è sì grande che pare una maraviglia a vedere; egli non ha giuntura altro che nelle spalle; il capo si ha grandissimo e gli occhi piccolini e rossi, che fa paura ad altri, guardandolo; li denti [zanne] grandi di fuora della bocca parecchie braccia; il naso [proboscide] di sopra lungo infino a terra, cioè parecchie braccia: e con quello ricoglie di terra quello che mangia; gli orecchi fatti a modo d'ale di draco [drago]; la coda piccola; i piedi tutti ritondi. E quanto maggiore carico gli poni adosso, tanto va più forte: e' porta un castello di legname adosso con XXX uomini dentro forniti d'armadura e di pietre e altre cose da combattere. Io viddi uno di loro denti, che l'avea comperato un mercante viniziano, che gli costò fiorini XXXVI d'oro, il quale io misurai, ch'era lungo XIIII spanne alla mia mano ed era grosso quanto altri ha l'anca, ed era sì grave [pesante] ch'io no.llo poteva levare di terra niente..$^{70}$

\section{Sempre al Cairo rimase sbigottito nel vedere una capra di dimensioni inusitate con un babbuino sulla groppa:}

Or chi crederebbe che la capra portasse sella, e anche il freno [morso] e le poselle [posole], a modo di cavallo? Ma io mi credo che questa capra fosse delle salvatiche; e così era contraffatta [bizzarra] e travisata [inusuale] ch'ella avea la lana lunga infino a terra e tutta vergata

69. Prima dell'arrivo a Firenze nel i655 dell'elefantessa Hasken, l'unica presenza nota in Toscana di un pachiderma risale all'8o i quando l'esemplare chiamato Abul Abbas, inviato dal califfo di Bagdad Hārūn al-Rashīd a Carlo Magno, sbarcò a Pisa. Dopo aver raggiunto via terra Pavia, per incontrare l'imperatore di ritorno da Roma dov'era stato incoronato, l'elefante proseguì il viaggio dalla Liguria fino a Marsiglia a bordo di una nave per poi rimettersi in cammino alla volta di Aquisgrana. Non è da escludere che il pachiderma fosse uno dei sette esemplari, come ricorda un testo persiano dell'XI secolo, inviati dal governatore del Khurasan - regione dell'Asia centrale - a Hārūn al-Rashīd vedi HEIKAMP - ROSCAM ABBING, 20I3, pp. 40-7I; LOISEL I9I2, p. I62 (data l'arrivo dell'elefante al 797); LACH I965-I993, vol. 2.I, pp. I29-I30 (riporta che dopo lo sbarco a Pisa raggiunse Aquisgrana via terra); BEDINI I997, p. 30 (data l'arrivo dell'elefante al 797); PASTOUREAU 2002, pp. 90-92; ID. 20I I, p. 84; Ta'rikh-i Bayhaqi 20 I I, p. 48. Sarà inoltre da ricordare, per quanto riguarda l'Italia, che nel I5I 4 il re del Portogallo Manuele I inviò a Roma un elefante bianco di nome Annone per assicurarsi i favori di papa Leone X riguardo alle colonie portoghesi in Africa e Asia vedi LOISEL I9I2, pp. 202-203; LACH I965-I993, vol. 2.I, pp. I36-I38; BARCLAY LLOYD I97I, p. 47; BEDINI I997, pp. 28, I63-205; PÉREZ DE TUDELA - JORDAN GSCHWEND 2007, pp. 422-423; PARAVICINI BAGLIANI 20I6, p. 87; GROOM 2018, p. I5. E ancora nel I552, in occasione del suo rientro a Vienna dopo gli anni trascorsi in Spagna in qualità di reggente, Massimiliano II d'Asburgo recava con sé un elefante indiano chiamato Süleyman, esemplare che qualche anno prima il re di Ceylon aveva offerto a Giovanni III del Portogallo e da quest'ultimo regalato al principe Carlos di Spagna nel i549. Nel corso del viaggio che lo condusse dalla penisola iberica a Vienna l'elefante suscitò grande ammirazione sia al suo sbarco a Genova sia quando transitò da Milano, Cremona, Mantova e Trento prima d'incamminarsi lungo le Alpi vedi LACH I965-I993, vol. 2.I, pp. I44-I46; JORDAN GSCHWEND 20I0, pp. I5-24; GROOM 20I8, p. 23. Vedi anche PÉREZ DE TUDELA - JORDAN GSCHWEND 2007, pp. 428-432, 437; JORDAN GSCHWEND 20I5, p. I65, 3.7.

70. POGGIBONSI I990, p. iा8, CLXXXI:I-3. Nella Naturalis historia Plinio il Vecchio, pur dilungandosi sull'elefante, non fornisce una descrizione vera e propria, come del resto Solino, Isidoro da Siviglia e Brunetto Latini vedi PLINIO 20 I , pp. 23-47, libro VIII, I-XII; SOLINO I557, pp. I25-I 29, XXXVII; SIVIGLIA 2004 , vol. 2, p. 3I, libro XII, II:I4-I6; LATINI 2007, pp. 3I3-3I5, libro I, I87:I-8. 
[striata], e le corna sotto le mascelle, l'orecchie lunghe infino a terra; e di sopra le sedeva un babuino a cavalcione e sonava le nacchere a due mani. ${ }^{71}$

\section{Si era poi diretto a Giaffa - all'epoca principale porto della Palestina - dove sog- giornò per qualche tempo alla corte del conte Ugo Ibelin possessore di:}

uno uccello che si chiamava struzzolo [struzzo]; ed è così fatto ch'egli era più alto che uno cavallo, e così di grossezza; e per la grossezza non può volare niente; e intesi che portava uno uomo a cavalcione. E questo è l'uccello che fa l'uova così grande le quali noi appicchiamo [appendiamo] in alto per le chiese; e ha le penne sue più morbide che cosa ch'io vedessi mai. ${ }^{72}$

\section{Rimesso in viaggio, giunse a Damietta - città sul delta del Nilo - dove riferiva di aver visto:}

molte generazioni d'animali travisati [inusuali], sì come capre ch'aveano gli orecchi infino in terra lunghi; e avisai [calcolai] che lungo fosse ciascuno orecchio ben due braccia. Anco vidi castroni che aveano la coda larga parecchie spanne, ed era tonda a modo d'uno tagliere [piatto] ed è si grave che no'lla possono portare se none [non] poco a lunga [accresce in lunghezza]. ${ }^{73}$

7I. POGGIBONSI i990, pp. I I8-i i9, CLXXXIII: . Si tratta della capra siriana (Capra hircus) con corpo massiccio e di grosse dimensioni, pelo lungo e folto, corna inclinate all'indietro quando presenti e orecchie larghe e lunghe pendenti con le estremità rivolte all'esterno, razza originaria del versane mediorientale del bacino del Mediterraneo.

72. Ibid. Descrizione che si discosta da quella pliniana: «gli struzzi africani ed etiopici superano l'altezza di un uomo a cavallo e lo vincono in velocità ed è appunto per questo che gli sono state date le ali, cioè per aiutarlo mentre corre. Ma ad eccezione di quelle, essi in tutto il resto non sono degli uccelli, infatti non si sollevano da terra. Le loro unghie assomigliano a quelle dei cervi e se ne servono per combattere; sono divise e adatte ad afferrare le pietre che lanciano con le zampe, mentre fuggono, contro i loro inseguitori. Hanno la straordinaria capacità di poter digerire tutto quello che ingoiano a casaccio, ma non meno straordinaria è la stupidità che li caratterizza: credono, infatti, di rendere invisibile, nascondendo la testa in un cespuglio, anche tutto il resto del corpo che pure è così tanto alto. Le loro uova costituiscono un prezioso aiuto per l'uomo il quale può usarle, data la loro grandezza, come recipienti, mentre le penne gli servono per adornare i cimieri e gli elmi guerreschi», PLINIO 20I I, p. 303, libro X, I. Decisamente più parco d'informazioni è Isidoro da Siviglia: «Struzzo è nome greco. Questo animale, sebbene simile a un uccello, in quanto dotato di penne, non è in grado di sollevarsi da terra. Lo struzzo non si cura di covare le uova che, una volta deposte, prendono vita unicamente grazie al calore della polvere del suolo", SIVIGLIA 2004, vol. 2, p. 85, libro XII, VII:20. Nel Tresor Brunetto Latini si dilunga sulle caratteristiche morali del volatile, mentre riguardo alla fisionomia si limita a informare: «Lo struzzo è una grande bestia che ha ali e piume come un uccello e piedi di cammello; e non vola, anzi è grave e pesante per la sua complessione [...] due unghie nelle ali con le quali si colpisce e si batte quando decide di andare, come se fossero due sproni», LATINI 2007, pp. 285-287, libro I, I72:I-3. L'erronea informazione riguardo allo sperone posto sotto l'ala si ritrova un secolo più tardi nel Dittamondo di Fazio degli Uberti: «Lo struzzo è pigro e però la natura / gli ha fatto sotto l'ala uno sperone / col qual si punge a cercar sua pastura», UBERTI I952, vol. I, p. 362, libro V, IX:22-24. Per quanto riguarda, invece, l'annotazione di Niccolò da Poggibonsi che lo struzzo poteva essere cavalcato, a distanza di secoli trova conferma nell'Histoire naturelle di Georges Louis Buffon, BUFFON I770-I785, vol. 2, pp. $280-282$.

73. POGGIBONSI i99o, p. I46, CCL: i. Si tratta della pecora berbera (Ovis steatopyga), detta anche "a coda grassa" per il caratteristico deposito di grasso attorno alla radice della coda, tipica del nord Africa. Prima di Niccolò da Poggibonsi, le pecore con la "coda grassa" furono menzionate nelle Storie (V secolo a.C.) di Erodoto in relazione alla terra d'Arabia: "Hanno anche due specie di pecore degne di essere ammirate e che altrove non esistono da nessuna parte. Una delle due specie possiede code lunghe, non inferiori a tre cubiti: se si permettesse loro di trascinarle, poiché le code sfregano contro il suolo, le pecore se le impiagherebbero. Ogni pastore invece sa lavorare il legno tanto da fabbricare piccoli carri che attaccano alle code delle pecore, legando la coda di ciascun animale a ciascun carretto. L'altra specie di pecore ha coda larga, di una larghezza anche fino a un cubito" e nel Milione di Marco Polo che nella città di Camandi - attuale Kerman in Iran - vide "montoni come asini, che·lli pesa la coda bene .XXX. libbre», ERODOTO 20I3, p. I45, libro III, II3:I-2; POLO 200I, p. 48, 35:7. È interessante ritrovare un riferimento a questi ovini, probabilmente desunto dalle narrazioni dei pellegrini, nella Storia dei Re Magi (I370 
Nel caso di altri animali si era semplicemente limitato a evidenziarne alcune caratteristiche, come le "testugini grandissime», ormai morte, trasportate da un mercante europeo vicino al mare di Damietta:

e per la scrurità [impressione] ch'io ebbi, vedendole così grandissime, io no'lle potei misurare, ma lo compagno mio ne misurò una, la quale fu più lunga di lui uno palmo grosso; e io l'avisai [calcolai], secondo nostra misura, tre braccia e mezzo. E l'osso, cioè lo coperchio [carapace] ch'ella porta in sulla schiena, si è molto caro, imperò che li Saracini ne fanno scudi, ed è sì forte che nullo ferro ci può nuocere niente; e io viddi darci su fortemente con una scura [scure] a due mani, e niente la tagliava, anzi n'avea peggio la scura che l'osso. ${ }^{74}$

L'attenzione riservata ai cammelli verteva tutta sulla loro resistenza senza alcun accenno alla struttura fisica:

sono di grande astinenzia ch'elli starà se' [i] dì [giorni] sanza bere e tutto dì caminerà uno dì e due sanza mangiare e mai non poserà [riposerà] né dì né notte, se farà di bisogno. [...] Lo camello si è fortissimo, ché uno camello porta vettovaglia per quatro persone, cioè per due mesi e mezzo, come pane, carne, letto e masserizie e stoviglie da cuocere e altre cose, come fa bisogno per vivere alla persona, e una persona anche adosso sopra la soma; e tutte queste cose si conviene portare per due mesi e mezzo. E anco con esso porta due grandissimi otri d'acqua, sì come fa bisogno in così fatto camino. Feci ragione [appurai] collo interpito [interprete] che uno buono camello porta per $\mathrm{X}$ somieri. ${ }^{75}$

Sembrerebbe quindi di poter affermare che Niccolò da Poggibonsi, missionario dotato di una straordinaria curiosità verso tutti gli aspetti del mondo orientale e di una spiccata propensione, inconsueta per un religioso, a voler cogliere la natura intrinseca delle cose, possa essere considerato il primo viaggiatore toscano ad aver trasmesso notizie su animali esotici che da secoli non si erano più visti in Europa se non addirittura sconosciuti. Se la giraffa e l'elefante costituivano una novità, dato che le notizie sugli esemplari posseduti nella prima metà del XIII secolo dall'imperatore Federico II di Svevia risultano estremamente scarse, altrettanto fuori dal comune dovevano essere le tartarughe giganti, probabilmente importate dall'arcipelago indiano, viste a Damietta se avevano impressionato anche altri viaggiatori europei: nei primi decenni del XIV secolo Odorico da Pordenone, alquanto parco di informazioni sugli animali, e quasi due secoli più tardi Ludovico de Varthema ricordavano di averle viste a Sumatra. ${ }^{76}$

ca.) di Giovanni da Hildesheim quando narrava che i tre re giunsero a Gerusalemme recando, oltre a cammelli e dromedari, arieti di Nabaioth ossia «arieti di grossa taglia, i quali portano ammassato sulla coda tutto il grasso che le altre specie di arieti hanno di solito distribuito nelle parti posteriori. Sulle altre parti del corpo hanno, invece, grasso in scarsa quantità. E la loro coda è larga quanto i fianchi, ed è lunga oltre la metà delle zampe anteriori», aggiungendo, poi, «sono rimasti in quelle regioni, per ogni dove, fino ai dì nostri», HILDESHEIM I966, p. I I8.

74. POGGIBONSI I990, p. I45, CCXLVI:I-2.

75. Ivi, p. I25, CXCVIII:I-3.

76. MASPERO - GRANATA I999, p. I65; BUQUET 20I2, p. 78; PORDENONE I990, p. I08, 23:2. Un accenno all'esemplare di pachiderma posseduto dall'imperatore Federico II si rintraccia nel De' rimedi de l'una, et 
Ancora più sorprendente risulta nel Libro d'Oltramare l'atteggiamento di Niccolò da Poggibonsi, uomo di Chiesa che scrutava il mondo con gli occhi di un mercante pronto a descrivere e a misurare ogni aspetto del mondo orientale. Quando si tratta, poi, della fauna esotica la mente del missionario francescano dimostra un sostanziale interesse per l'apparenza fisica a scapito delle prevedibili interpretazioni simbolico-religiose, atteggiamento che denota una netta cesura con quando tramandato dalla consolidata tradizione dei bestiari nei quali - come sottolinea Brigitte Roux:

Le discours sur l'animal, où s'entrecroisent descriptions, images bibliques, interprétations patristiques et allégories morales, accuse un aspect stratifié dû aux constantes répétitions des lieux communs sur lesquels il se bâtit. Le recours à l'autorité des textes anciens occulte l'observation directe de la nature, entraînant des invraisemblances, voir des contradictions au sujet d'un même animal.77

Oltre a ciò, le descrizioni di animali rese da Niccolò da Poggibonsi nulla avevano a che fare con il popolare Tresor di Brunetto Latini, se non per la leggenda ampiamente diffusa da bestiari ed enciclopedie che le gambe dell'elefante fossero prive di giunture. ${ }^{78}$ A confermare la determinazione del missionario nel trasmettere al lettore un'immagine concreta degli animali esotici che più avevano colpito il suo immaginario - sempre che il manoscritto più antico conservatosi sia da ritenere, come plausibilmente ipotizzato da Kathryn Blair Moore, autografo sono gli schizzi di suo pugno poste a illustrazione del testo; nel caso in cui le

l'altra fortuna (I354-I366) quando Francesco Petrarca scrive «Et secondo ci raccontano i vecchi Federigo Imperatore de' Romani non hebbe se non uno [elefante]", PETRARCA I584, p. I I Ir, libro I, LX. Di ritorno da un viaggio in Oriente durato sette anni, Ludovico de Varthema nell'Itinerario (I5II) riferiva che le abitazioni di Sumatra: «sono coperte de scorze [carapaci] di Tartaruca di mare perché qui se ne ritrova gran quantità. Et nel tempo mio vidi pesarne una la qual pesava $\cdot \mathrm{C} \cdot \&$ tre libbre», Itinerario di Ludovico $20 \mathrm{I} 2$, p. $26 \mathrm{v}$. Per un approfondimento su Ludovico de Varthema vedi BRILLI 20I3, pp. I67-I74. Si tratta probabilmente della tartaruga gigante di Aldabra (Aldabrachelys gigantea), originaria dell'omonimo atollo nell'oceano indiano, che raggiunge i I $20 \mathrm{~cm}$ di lunghezza e i $200 / 250 \mathrm{~kg}$ di peso.

77. ROUX 2009, pp. 226-227.

78. Notizia che si rintraccia nel Physiologus «La natura dell'elefante è questa: se cade, non è capace di rialzarsi, perché non ha giunture nelle ginocchia», nelle Collectanea rerum memorabilium di Solino quando, a proposito di un animale simile a un alce, scrive "ha le ginocchia, come lo Elefante: e perciò non si puo piegare ", nelle omelie di Basilio «le gambe non sono da giuntura alcuna separate» e nel Tresor di Brunetto Latini che, a distanza di oltre un millennio, continua ad avvalorare questa credenza «E dicono coloro che l'anno visto che l'elefante, quando cade, non si può sollevare nonostante tutta la sua forza, perché non ha alcuna giuntura nei ginocchi», e ancora agli inizi del XV secolo Andrea da Barberino nel suo romanzo cavalleresco Guerrin Meschino «E quando [...] cade l'alifante, e non si può rizzare perché non ha giunture nelle gambe», Il Fisiologo 20 I I, p. 79:43; SOLINO I557, p. I Io, XXXII; BASILIO, I844, p. I68; LATINI 2007, p. 3I5, libro I, I87:8; BARBERINO 2005, p. 248, libro III, XXXVIII:I6. Discordanti risultano, invece, Aristotele nell'Historia animalium «al contrario di quanto alcuni sostenevano, [l'elefante] può sedersi e flettere gli arti», Plinio il Vecchio nella Naturalis historia "essi [gli elefanti] fanno atto di adorazione davanti al re, piegando le ginocchia e offrendogli delle corone» e Alberto Magno nel De animalibus «it sits and bends its front feet almost as do quadrupeds, but it bends its rear feet almost as does a human", mentre secoli più tardi Isidoro da Siviglia nelle Etymologie non accenna affatto alle gambe e alle giunture dell'elefante, ARISTOTELE I996, p. I67, libro II, 498a; PLINIO 20II, p. 25, libro VIII, I; MAGNO I999, vol. I, p. 292, libro II, II:I5; SIVIGLIA 2004, vol. 2, p. 3I, libro XII, II:I4-I6. 
immagini fossero, invece, l'aggiunta di uno zelante copista testimoniano il grande interesse suscitato dalla fauna esotica nella società fiorentina del tempo. ${ }^{79}$

Tutt'altra natura rivelano i resoconti di viaggio quattrocenteschi di missionari e pellegrini toscani interamente incentrati sui luoghi santi, le reliquie e le indulgenze fino ad assumere la forma di vere e proprie guide, a volte addirittura corredate con le preghiere da recitare in ogni chiesa, come i diari di pellegrinaggio in Terrasanta del sacerdote senese Mariano da Siena (I43I), del prete Michele da Figline (I498-I490) o del predicatore Alessandro di Filippo Rinuccini (I474), testi che sembrano aver avuto una diffusione estremamente limitata ${ }^{80}$ Sarà inoltre da tener presente che, per contenere le spese di viaggio, sovente i pellegrini approdavano direttamente nel porto di Giaffa evitando di passare dal Cairo, precludendosi così la possibilità di ammirare gli animali esotici posseduti dal sultano o quelli che avrebbero potuto incontrare navigando lungo il Nilo o attraversando il deserto. La figura del frate francescano Niccolò da Poggibonsi, che nella prima metà del XIV secolo viaggiò in Oriente per ben quattro anni con gli occhi sgranati e la penna pronta a registrare scrupolosamente tutto ciò che aveva modo di osservare, si prospetta quindi come un unicum nel panorama della letteratura di pellegrinaggio italiana tre e quattrocentesca, in particolare per quanto riguarda l'attenzione dedicata alla fauna esotica.

\section{I.2. Mercanti}

Il modo in cui i mercanti, dotati di una forma mentis plasmata nelle scuole d'abaco, osservavano il mondo trapela dalle pagine dei loro diari di viaggio e, forse ancor più, dalle descrizioni degli animali orientali. Produzione letteraria che aveva, da un lato, il mirato scopo di conferire prestigio all'autore attraverso la narrazione dell'impresa compiuta e, dall'altro, la volontà di registrare informazioni percepite da un occhio esercitato all'osservazione merceologica, al ragionamento economico, alla misurazione, strumenti che il viaggiatore-mercante era solito applicare alle realtà sconosciute e, quindi, anche alla fauna esotica. Se scopo delle scuole d'abaco era formare «buono ischrittore e buono abachisto e buono ragionieri» e tra le raccomandazioni dispensate da Giovanni Morelli al figlio vi era quella di guardare "coll'occhio i paesi, le terre dove hai pensiero di trafficare", gli scritti odeporici dei mercanti rispecchiano appieno la mentalità dell'epoca. ${ }^{8 \mathrm{I}}$ Dettami che trovano riscontro nella descrizione della fauna esotica già alla fine del XIV secolo, quando tre membri di una comitiva di mercanti fiorentini recatisi in pellegrinaggio al Santo Sepolcro si erano dedicati, al loro rientro, alla redazione di un diario di viaggio. A Lionardo Frescobaldi, Giorgio Gucci e Simone Sigoli si

79. Vedi pagine I7I-I74.

80. CARDINI I985, pp. 43-5i; SIENA I99I; MONTESANO 20I0; RINUCCINI I993.

8I. DEI I984, p. I25 c. 56 r; MORELLI i986, p. I77. 
devono, infatti, i primi resoconti in lingua volgare scritti da laici. ${ }^{82}$ A farla da padroni nei loro scritti erano, ovviamente, gli animali per eccellenza ritenuti esotici, ossia la giraffa e l'elefante mai visti a Firenze. Narrare di averli osservati nelle terre d'oltremare e fornirne una descrizione dettagliata doveva contribuire non poco alla reputazione di chi scriveva, considerato che questi testi circolavano tra amici e conoscenti che a loro volta li trascrivevano per serbarne una copia nelle loro biblioteche. Notizie che all'epoca costituivano una grande novità dato che nel Milione, testo assai diffuso tra i mercatores, Marco Polo aveva solo brevemente accennato alla presenza di animali esotici senza minimamente preoccuparsi di descriverli, tranne nel caso dell'unicorno che reputava molto diverso da quanto tramandato dai bestiari - e in effetti lo era trattandosi di un rinoceronte - e delle bizzarre giraffe, limitandosi però a riferire quanto appreso da altri non avendole viste di persona:

Elle ànno corta coda, e sono alquante basse dirieto, chélle gambe di drieto sono piccole, e-lle gambe dina`n`zi e ‘’l collo si è molto alto e grande: alt'è da·tterra bene .iij. passi. E la testa è piccola, e non fanno niuno male; ell'è di colore rosso e bianco a cerchi, ed è molta bella a vedere. ${ }^{83}$

Praticamente assente dai bestiari, le notizie di Marco Polo sulla giraffa sembrano essere le prime a disposizione degli europei, dato che non sono stati finora rintracciati documenti con le descrizioni degli esemplari inviati dal sultano mamelucco Baybars I (r. I260-I277) ad Alfonso X re di Castiglia e di León (r. I252-I284) nel I26I e a Manfredi re di Sicilia (r. I258-I266) l'anno seguente. ${ }^{84}$ Inoltre, avendo Plinio il Vecchio omesso di specificare nella Naturalis historia il lungo collo dell'animale chiamato "camelopardalis», quando nel XIII e nel XIV secolo fu visto in Europa e in Oriente non si pensò di associarlo alla giraffa. ${ }^{85}$ Ben si comprende allora l'attenzione riservata dai mercanti fiorentini all'animale quando, diretti al Santo Sepolcro, si presentò loro l'opportunità di ammirarne alcuni esemplari al Cairo. Lionardo Frescobaldi, appartenente all'oligarchia fiorentina e il più colto del gruppo, sostenendo di averne viste addirittura tre in un cortile scriveva:

la giraffa si è animale corpolente come comunale [di medie dimensioni] cammello e è mansueta come pecora e è di pelo di cerbio [cervo], li pie' [piedi] suoi fessi come di bue, le gambe drieto lunghe circa a due braccia, la coda come di capra, la schiena corta, le gambe dinanzi lunghe circa quattro braccia, il collo altrettanto, la testa come vitella di latte e corna vestite di pelle come quelle del cavriuolo [capriolo]. ${ }^{86}$

82. GUÉRIN DALLE MESE I99I, p. 22.

83. BUQUET 20I3c, p. 394; POLO 200I, p. 290, I87:8-IO.

84. BUQUET 2012, p. 78; ID. 2013c, pp. 381, 388, 392.

85. ID. 2008, pp. 49-5I; ID. 20I2, pp. 75-82. Per la descrizione lacunosa di Plinio il Vecchio vedi pagina 93 nota 47. Fu il bolognese Filippo Beroaldo, editore e commentatore di testi classici, a identificare nel I4 88 il «camelopardalis", ossia la giraffa, con lo strano "diversum confusa genus panthera camelo» descritto da Orazio vedi PASTORE STOCCHI 2OI4, p. I24.

86. FRESCOBALDI I99i, p. I44:23-29. 
Il compagno di viaggio Giorgio Gucci, membro di un'importante famiglia dedita alla mercatura, si era oltremodo dilungato nella sua descrizione:

ella è di schiatta e di natura di cammello; e così ha il viso fatto e il pelo suo a modo di gran cervo, ed ha le corna sue vestite quasi a modo di cavriuolo [capriolo] giovane, ed ha i piedi come il cammello o bue. Poi è alta in su le gambe dinanzi bene IIII braccia e in su quelle di dietro forse tre braccia, e istà così a pendio alta dinanzi e bassa di dietro; e ha il busto e casso [torace] suo a guisa di un muletto magro e molto schienuto. Poi dalle gambe in suso alto il guidalesco [garrese] ha bene due braccia; poi caccia fuori uno collo ch'è lungo bene braccia IIII; e coll'alteza delle gambe dinanzi e coll'alteza del casso e del detto collo così lungo col muso in ogni alto luogo agiugne [giunge]. ${ }^{87}$

Decisamente più sintetico e approssimativo Simone Sigoli, il più devoto della comitiva ma anche il più curioso, che a proposito del bizzarro animale riferiva:

quasi come lo struzzolo [struzzo] salvo non à penne, anzi à lana biancha et fine et à coda et piedi di cavallo salvo che lle ghanbe [gambe] di dietro sono alte intorno di braccia I-I/I et quelle dinanzi braccia III o più come ghanbe d'ucciello. Il collo sottile et lungo braccia III-I/I o più, il capo di cavallo et così i crini et à nella testa due cornicella piccole come di castrone

non riuscendo a trattenersi dall'aggiungere «veramente pare cosa troppo contraffatta». ${ }^{88}$

Tutte queste descrizioni rivelano l'importanza che i mercanti attribuivano alle misure, sforzandosi di quantificarle, e ai paragoni con animali comuni in Europa, tranne l'insolito caso di Simone Sigoli che preferì stabilire un parallelo con lo struzzo, in modo da fornire al lettore gli strumenti utili per elaborare un'immagine mentale il più possibile concreta e attinente alla realtà. L'altezza, il lungo collo e le piccole corna rivestite in pelle, tratti peculiari della giraffa, non passarono certo inosservati ai loro occhi vigili a differenza di quanto avvenuto nella Naturalis historia di Plinio il Vecchio, che non aveva però avuto modo di osservare personalmente il quadrupede. ${ }^{89}$

Altro animale che suscitò grande meraviglia nei viaggiatori fiorentini fu l'elefante. Trovandosi al cospetto dell'immenso pachiderma, a differenza della giraffa ben noto attraverso le numerose immagini in circolazione, i mercatores non avevano resistito al desiderio di potersi vantare di averlo visto di persona. Se Marco Polo si limitò a riferire che l'elefante era di grandi dimensioni, aggiungendo qualche dato sull'avorio e sul suo modo di accoppiarsi, i fiorentini riservarono invece ampio spazio alla sua descrizione. Lionardo Frescobaldi informava con dovizia di particolari che:

87. GUCCI I990, p. 269, IX:6-7.

88. SIGOLI I999, p. 8I.

89. In realtà Simone Sigoli, pur menzionando le corna piccole come quelle del castrone, tralascia il dettaglio del rivestimento in pelle. 
Nel Cairo è leofanti de' quali è la forma quasi come si dipingono, e erane uno nel cortile d'uno ammiraglio del soldano, il quale era legato per tre piedi con tre catene di ferro a tre grossi pali e sappiate che le sue gambe non hanno giunture nel ginocchio, anzi sono d'un pezzo e sono grosse come uno comunale [di medie dimensioni] uomo è nella cintola, el pie' [piede] suo è tondo come uno aliosso e ha intorno sei dita, la coda sua è caprina e l'orecchie sono come ale di pipistrello e grandi come tavolacci d'arme e pendenti in giù come di segugi. Ha due denti [zanne] di sotto ritti in su grossissimi e lunghi circa tre braccia l'uno, il suo naso [proboscide] è grossissimo allato alla bocca e lungo insino in terra e sanza avervi dentro osso, e dalla parte di sotto è come due bocche di lamprede e con queste prende il suo cibo avolgendolo a modo d'uno ruotolo all'angiù e mettendoselo nella bocca la quale ha dalla parte di sotto quasi come storione. Colle nare [narici] del naso gli vedemo votare uno bacino d'acqua sanza restare [fermarsi] e gittarla alta più di quindici braccia e mughiava [barriva] sì forte che pareva uno tuono e non n'è maraviglia percioché la sua forma era per più di tre gran buoi da carro. Il suo governale [guardiano] gli puose adosso una grandissima sella che dalla parte di sopra era ritratta [fatta] a modo d'uno pergamo nel quale sarebbono stati parecchi uomini armati; la sua lettiera era uno monte di letame al quale egli appoggiava $i$ fianchi perché essendosi posto a giacere, per non avere giunture nelle gambe non si sarebbe potuto levare..$^{90}$

Giorgio Gucci, pur non discostandosi molto dal resoconto del suo compagno di viaggio, quantificava con maggior attenzione dimensioni e lunghezze:

questo liofante era assai giovane; era alto, secondo ch'io l'avisai [calcolai], circa di braccia IIII e altrettanto largo; ha il pelo suo a guisa di porco salvatico, e la coda lunga e ritratta [fatta] al modo del bue; è giusto in gambe quanto uno ‘... i fianchi e ha isterminati occhi e orecchi.

I due denti [zanne] d'avorio che hanno avea segati per mezo, perché e' non facesse male; aveali fuori della bocca circa uno braccio, ché, se non fossono stati segati farebbono braccia II: e questo non è gran fatto, perch'io gran quantità n'ho veduti a Vinegia e altrove di braccia III e IIII l'uno. Esceli uno muso ch'è per li labri della bocca di sopra, ch'è grandissimo e piglia il naso [proboscide], ed è fatto come una tromba, grosso di sopra come l'uomo ha la coscia e viene digradando ed assottigliando di sotto; il quale è lungo bene III braccia ed agiugne [giunge] insino in terra, e con esso piglia quello che gli dà da mangiare e metteselo in bocca; e del detto naso fa ciò che vuole di menarlo [muoverlo] qua e là come l'uomo farebbe della mano. Istà legato con catene per li due piedi dinanzi; poi v’è quelli che lo guida che li fa fare ciò che vuole quasi come una bestia mansueta; e mostra essere bestia di grande intendimento a quello che colui che lo guida gli fa fare. Quando il mena [conduce] fuori, gli pone adosso a modo che uno grande basto a due grandi cocche [parti terminali] di legno, e cinghialo con più cinghie; e di sopra è a modo che uno piano di pergamo, dove stanno più uomeni e con maze [mazze] il guidano e vanno faccendo sopra esso nuovi giuochi. ${ }^{91}$

90. FRESCOBALDI I99i, pp. I43:34-35, I44:I-22. Per la credenza tramandata dal Physiologus delle zampe dell'elefante prive di giunture vedi pagina Io4 nota 78 .

9I. GUCCI I990, pp. 268-269, IX:3-5. Discostandosi da Lionardo Frescobaldi non accenna alla presenza o meno di giunture nelle zampe. 
Simone Sigoli, senza ombra di dubbio il più accurato e prolisso, fu talmente ammaliato dal pachiderma da descriverlo fin nei minimi dettagli:

la pelle come bufala nera ed è alto più che uno de' nostri buoi da carro ed è molto più grosso. La coda come di bufala, le ganbre [gambe] come I coscia d'uom comunale [di medie dimensioni] et sono quasi d'un pari [allo stesso modo] grosse. I piedi larghi et alti, il collo corto et grosso, li orecchi increspati a modo come li aliotti si soleno portare. Li occhi grossi come di bue. Della bocca li escono due sanne [zanne] grossissime come sono le corna d'un bue, salvo che quelle sono lunghe braccia due e mezzo l'una. Ed erano ancora più lunghe se non che '1 soldano [sultano] le fecie segare et anche le fecie ritorciere come corna di buoi, et questo fecie fare perché non faciessono male a persona perché alcuna volta il manda per mostra per la terra. Et le sue sanne sono grosse come la polpa [gamba] d'un uom comunale. Del niffolo [parte del muso intorno alle narici] escie un budello [proboscide] ad modo d'un corno da ssonare, et quando il leofante vuole il dilungha [distende] bene braccia otto e più. E pigla [piglia] l'acqua che vuole bere con esso, et io vidi tirallo a un tratto d'una bigoncia [recipiente] più d'un barile d'acqua in tanto avessi beuto un bicchieri di vino. Et così pigla ogni cibo et mette in bocca. Et quando va per cammino non è si grosso albero con questo budello non rompesse, tant'è la forza d'esso budello. Et se niuno li si appressa li dà di questo budello per modo il gitta inn alti braccia XX o più et poi ti ricieverebbe in sulle sanne et morresti. Ciascuno di questo leofante àe uno famiglio [guardiano] che llo governa et a llui non farebbe male però che à gran paura di lui per le battiture li dà. Et quando vuole si ponga a sedere o a ciacere [giacere] li gratta il corpo e llo leofante suona colla bocca a modo d'un trombettino quando squilla et con maggiore voce.

Et mai non si pone a giacere in terra, anzi et è da llato una montagnetta di letame che gli adgiugne [arriva] a mezzo il corpo et ivi si pone a giacere per lato però se ssi ponesse in terra a giacere non se ne potrebbe levare, però ch'elli à le ganbe et le coscie quasi d'un pezzo. Et quando si vuole levare da giacere si dà una grande scossa et così si rizza. Et quando fanno guerra fanno fare castella [torri] di legniame et mettonvi dentro i balestrieri e' liofante porta tutto. Et quelli il ghoverna vi sale suso [sopra] et guidalo; et quando fallasse [sbagliasse] li dà in sulla testa d'una mazza c'àe [che ha] un uncino in testa per modo che llo leofante tutto trema di paura. Et a questo modo il governa. ${ }^{92}$

Quasi mezzo secolo più tardi fu l'ambasciatore fiorentino Felice Brancacci a fornire la più estesa e puntuale descrizione quattrocentesca dell'elefante. Ritenuto esperto in materia mercantile perché titolare di un'impresa che commerciava seta, nel I 422 fu inviato in Egitto dalla Signoria per ottenere dal sultano mamelucco privilegi commerciali e l'accettazione del corso del fiorino con valore pari a quello del ducato veneziano. Nel suo diario di viaggio, dove ampio spazio era dedicato alle trattative con l'aggiunta di qualche passo relativo ai luoghi santi visitati, il setaiolo raccontava:

92. SIGOLI I999, pp. 8I-82. Pur conformandosi a quanto riportato dal compagno di viaggio Lionardo Frescobaldi riguardo all'assenza di giunture nelle zampe dell'elefante, Simone Sigoli sembra cadere in contraddizione quando accenna al fatto che il pachiderma può sedersi o sdraiarsi. 
ci fu menato a casa il leofante, il quale animale è tanto mirabile e di strana fazione [fattezze], che non mi dice il cuore di saperne parlare. Ma l'alteza sua ci parve braccia 6 , e inanzi più che meno, e lungo 7; ma tanto ventruto [panciuto], ch'era cosa maravigliosa; e molto più alto dinanzi che di drieto, e la sua pella proprio di bufola [bufalo], e la coda minore che di bufola, gl'orecchi come alia [ali] di vipistrello [pipistrello], grande quanto una rotelletta [scudo di forma circolare] mezana [di medie dimensioni], e continovo [continuamente] gli batteva in su le spalle, però che non ha punto [affatto] di collo. Le gambe sue dinanzi proprio paiono due colonne lunghe braccia $2 \frac{1}{2}$ e grosse una bracciata, e tonde; e à il nodo della giunta del piè e alterella [in alto]; e non à ginocchio ma piega la gamba su alto alla spalla; e le gambe di dietro son molto basse quasi un braccio. La sua testa è grossissima e alta più che le spalle assai, e gl'occhi piccolissimi, quasi come di porcho. Il naso [proboscide] suo è lungo circa di braccia cinque, tanto che toccha terra, ed è grosso a lato alla testa una bracciata, e va digradando fuor della testa, tanto che la punta s'aghavignerebbe [cingerebbe] con mano: ed ha un po' di choccha [incavo] e pare una bocca, e drento vi si vede due buchi tondi: e tutto questo naso è vaiolato [nerastro/colorato a macchie] com'uno surzone [serpente], e questo suo naso è crespo com'uno lombrico, e aronciglialo [torcere a forma di uncino] molto. E nelle mascelle di sopra à duo denti [zanne] che si volgono in su, grossi più che la gamba d'huomo, e tondi com'una chaviglia, e non sono quasi apuntati [appuntiti], E' labri suoi di sotto non si veggono per lo naso che li ricuopre; e per lo detto naso piglia ciò che vuol bere e mangiare, e con esso sel [se li] mette in bocca; e alcuna volta, preso che gl'à l'acqua drento al naso per que' due buchi, se la gitta [getta] in su le spalle e sotto il corpo nelle chogle [testicoli].

All'accurato resoconto delle fattezze dell'animale esotico che, pur nella sua semplicità, sembra rasentare la precisione di un trattato scientifico, seguiva un esteso passo incentrato sulle capacità d'interagire con il domatore:

E quegli ch'el governa, gli disse non so che parole, per le quali e' pigliava l'acqua e gittavala col naso, e bagnavaci tutti chi v'era intorno, che uno con un paiuolo non ne gitterebbe tanto quant'egli. E in nostra presenza gli fece fare le 'nfrascritte [seguenti] cose. Principalmente gli fece alzare un piè dinanzi, che non v'à catena, perochè gli altri sono incatenati insieme con grosse catene; e in su quel piè montò il suo governatore [guardiano]; e come vi fu su, l'alzò a poco a poco indietro, tanto che gl'agiugneva al dosso [dorso] con mano; e gitatovi su un tapeto, vi montò su a cavalcione, e fecelo mughiare [barrire] che parea che rispondesse a quel che diceva. Di poi, uno ch'era à piè [in basso], gli diè un bastone lungo un braccio e grosso quanto il braccio: e 'leofante lo prese con la punta del naso, e tenevalo stretto; e quegli ch'era a piè, avea un altro bastone ma più lungo, e gridava; e quegli alzava il naso a cielo con quel bastone e calavalo giuso [giù], e dava nel baston di colui le maggior picchiate [colpi] del mondo, e così vi diè [diede] dodici colpi ora all'insù e ora all'ingiù. E fatto questo, trovò quattro sacchetti pieni, di una spanna per ogni verso, e mostravagli al leofante; e quegli abassava il naso a terra e dava in questi sacchetti con esso, che gli mandava alti 25 braccia, e percotevagli [colpiva] per quelle case d'attorno: e alcuna volta colui lo 'ngannava, ch'essendo per colpire, tirava la mano a sé, ed e' menava [colpiva] a voto [vuoto]; e così fece molte volte. Poi lo fece mettere a giacere in terra, che un catellino [cagnolino] non si sarebbe posto sì destramente [con destrezza]; e poiché fu col corpo in terra, ma prima gli levò le catene da pié, e poi lo fe' levar su tanto tosto e bene, che parve maraviglia. Vedemolo pisciare, che parea una calla 
[corso d'acqua] di mulino; vedemo il suo pigholare [membro?] che giungneva a terra, conveniente all'alto busto, e sozo [lurido], e putiva [emanava fetore] d'attorno.

\section{Concludeva, poi, con alcune considerazioni personali frammiste a notizie che gli erano state riferite:}

E insomma e' par più un pezo di carne che si dimeni e vada, che animale di quattro piedi, dal naso in fuori, che ne fa ciò che vuole; e molto adagio va: e i piè ànno cinque unghie, come il porco n'à due, e tondo il piè. E secondo che ci fu detto da molti, questo leofante era molto giovanetto, e quasi era stimato [ritenuto] da tutti meno che mezo uno de' grandi; istimano [calcolano] che cignerlo in sul corpo bisognasse dieci braccia di corda o circa. ${ }^{93}$

Altro animale esotico a volte descritto e altre neppure menzionato, forse perché più difficile da vedere in natura oppure perché in Europa si poteva trovare imbalsamato sospeso al soffitto delle chiese, era il coccodrillo. ${ }^{94}$ Lionardo Frescobaldi narrava di averlo scorto mentre veleggiava alla volta di Damietta:

Trovamo sulla riva del Nilo uno serpente di lunghezza d'otto braccia, grosso come uno mezzano [di corporatura media] uomo ha la coscia, il suo colore verdegiante e la sua schiena unghiosa [bitorzoluta] come schienali [schiene] di storioni secchi. ${ }^{95}$

Sempre al mercante fiorentino si deve la descrizione degli ovini orientali, incontrati nei dintorni del Cairo poco prima di inoltrarsi nel deserto, molto simili a quelli che un trentennio prima Niccolò da Poggibonsi vide a Damietta:

le pecore e montoni sono grandissimi e la maggior parte con quattro corna e le loro code sono tonde come taglieri [piatti] e sono grassissime quasi sevo [sego], e quelle struggono come noi struggiamo il grasso del porco e così l'adoperano nelle loro cucine. Le capre e i becchi hanno gli orecchi lunghi e pendenti all'angiù [ingiù] come segugi e quando pascono gli orecchi toccano terra..$^{6}$

93. Diario di Felice Brancacci I88I, pp. I78-I79. Dante Catellacci propone per la parola «surzone» il significato di germoglio, derivato dal francese surgeon, ma poiché Felice Brancacci lo usa per descrivere la proboscide mi sembra più appropriato intenderla nell'accezione di "scurzone», ossia serpente nerastro e velenoso vedi Diario di Felice Brancacci I88I, p. I78 nota I; Grande dizionario I96I-2002, vol. I8, pp. 265-266 ad vocem "scorzone». Nella recente traduzione inglese del testo Mahnaz Yousefzadeh mantiene il termine germoglio e rende il termine "pigholare» con «its member», YOUSEFZADEH 20I8, pp. 75-76. Per il modo di descrivere di Felice Brancacci vedi ECKSTEIN 20I4, pp. 2-3.

94. La descrizione del rettile nella fittizia Dimostrazione dell'andata o viaggio al Santo Sepolcro e al monte Sinai, la più dettagliata finora rintracciata, induce a supporre che Marco di Bartolomeo Rustici avesse avuto modo di osservare un coccodrillo impagliato in quel di Firenze prima di apprestarsi a scrivere: «Navicando per lo Nilo, vedemo molti cuccodrilli grandi e maravigliosi, uscivano dal fiume. Sono di fazione quasi come un ramarro. Son grandi 3 o 4 braccia. Vanno sù per la riviera del Nilo, e trovando un uomo a piede o a ccavallo lo pigliano e o tiranlo in terra. Ed apre la sua boca in modo che piglia tutto il viso e 'l capo della criatura. E la sua testa di sotto la mascella è d'un pezo con lo 'mbusto [busto]; solo apre la mascella o vuo' dire la parte di sopra della testa. Ed ha nella bocca dua filari di denti molto pungenti e torti. E così lo 'mbusto è tutto nocciuluto [ossuto] a modo d'un testugine sù per lo dosso [dorso] in ogni lato; dalla parte di sopra è di colore perso e nero [nerastro], dalla parte di sotto è di colore giallo biancheggiante», RUSTICI 20I5, p. 2 I9.

95. FRESCOBALDI i99i, p. I38:I8-2 I. Fatto curioso, Lionardo Frescobaldi è l'unico della comitiva a menzionare e descrivere un coccodrillo.

96. Ivi, p. I49:24-29. Per informazioni sulle specie ovine vedi pagina Io2 note 7I e 73 
Paragonando le notizie sulla fauna esotica dovute alla penna dei mercanti fiorentini, che in Oriente si erano recati in veste di pellegrini o ambasciatori, con quelle fornite dal mercante chiogiotto Niccolò de' Conti all'umanista Poggio Bracciolini - che prontamente incluse nel suo IV libro del De varietate fortunae - ciò che colpisce è il diverso approccio nei confronti del mondo animale. Una volta rientrati a Firenze i mercatores, per dimostrare di aver superato i pericoli e conquistarsi la stima dei concittadini, si apprestarono a immortalare la loro impresa in un diario di viaggio dove non mancavano puntuali descrizioni di animali per eccellenza ritenuti esotici o ancora sconosciuti. Tutt'altro punto di vista fu, invece, quello di Niccolò de' Conti che in Oriente viaggiò per venticinque anni svolgendovi attività commerciali. Spronato dalla promessa di papa Eugenio IV di concedergli il perdono per aver abiurato alla fede cristiana, riferì la sua esperienza orientale a Poggio Bracciolini accennando alla fauna esotica esclusivamente in relazione al suo valore economico o all'uso di alcune parti del corpo, come nel caso del corno del rinoceronte, dei peli della coda dello yak, del piumaggio dell'uccello del paradiso, della pelle del varano o delle grandi corna dei buoi selvatici.97 È quindi assai probabile che nel corso della trasposizione su carta l'umanista avesse deciso di arricchire il testo, come nel caso dell'ampio passo dedicato all'elefante e alla sua cattura, con informazioni attinte dalla Naturalis historia pliniana, opera all'epoca ancora rara a Firenze ma disponibile nella biblioteca del suo caro e intimo amico Niccolò Niccoli e in quella di Cosimo il Vecchio..$^{8}$ Oltre a ciò, Poggio Bracciolini aveva provveduto a integrare i succinti accenni di Niccolò de' Conti riguardo a coccodrilli del Bengala, elefanti, rinoceronti e yak della Birmania, uccelli del paradiso di Giava, pappagalli delle isole Molucche, varani e pipistrelli giganti dell'estremo sud della penisola indiana e buoi selvatici di Cambay - città sulla costa occidentale dell'India - con notizie di prima mano ottenute, grazie all'aiuto di un interprete, da una delegazione di etiopi giunti a Firenze per partecipare al concilio. ${ }^{99} \mathrm{Al}$ colto umanista riferirono dell'esistenza di numerosissimi elefanti con zanne lunghe sei cubiti esibiti durante le parate o usati in guerra, leoni addestrati, cani grandi come asini e un animale simile alla lepre chiamato zibetto che secerne un odore soave ${ }^{\mathrm{IOO}}$. Ancora più sorprendenti le minuziose

97. I viaggi I883, pp. I34-I35, 200, 224, 235; Viaggi in Persia I929, pp. I44, I49, I52 ("serpente» identificato con il gaviale), I58; GROSSATO I994a, pp. 26, 30 ("serpente» identificato con il coccodrillo), 32-33; BRACCIOLINI 2004, pp. I09, II7, I2I, I3I.

98. Viaggi in Persia I929, pp. II8-I I9 nota I; I4 I nota I; BRACCIOLINI 2004, p. Io5; The Public Library I972, pp. 59-6o. Per le copie possedute da Cosimo il Vecchio e Niccolò Niccoli vedi pagine I 43-I 44.

99. BRACCIOLINI 2004, pp. 97, 99, I03, I09, II7, II9, I2 I, I23, I3 I, I67, I75-I77. Vedi anche I viaggi I883, pp. 36, II6, I33-I35, I43, 200, 2I0-2I I, 224, 235; Viaggi in Persia I929, pp. I36, I40, I44, I49, I50, I52, I53, I58; GROSSATO I $994 \mathrm{a}$, pp. 23, 26, 30-33, 4I-42.

Ioo. BRACCIOLINI 2004, p. I75. Vedi anche Viaggi in Persia I929, pp. I93-I94; GROSSATO I994a, pp. 43-44. È interessante apprendere che nei primi decenni del XV secolo Zara Yaqob, alias il Prete Gianni, inviò uno zibetto in dono al sultano mamelucco Barsbay, nel I476 Galeazzo Maria Sforza ricevette due esemplari dal sultano egiziano Qā’ it Bey, mentre nel I 480 papa Paolo II teneva in una gabbia una "gatta muschiata", termine all'epoca in uso per indicare lo zibetto vedi SALVADORE 20I7, p. 44; GHINZONI I875, pp. I57, I65 n. 2; MÄRTL 2004, p. I94; PARAVICINI BAGLIANI 20I6, p. 9I, I80 nota I. Per un approfondimento sullo zibetto vedi MASSETI 20I5, p. I52. 
descrizioni di buoi gibbosi come cammelli - zebù - e con corna lunghe tre cubiti usate per trasportare liquidi perché la loro capienza equivale a quella di un'anfora di vino; di una bestia selvaggia simile all'elefante ma con piedi di cammello, priva di proboscide e con due corna appuntite, uno sulla fronte e l'altro sul naso, della lunghezza di un cubito - rinoceronte africano; dell'animale lungo nove cubiti, alto sei e con il corpo non più di un cubito ricoperto di pelo simile a quello del leopardo e con i piedi fessi come il bue - quasi certamente la giraffa; dell'uccello con testa piccola, becco e collo simili a quelli della gallina, alto sei cubiti da terra con gambe sottili e piedi d'oca che vola poco ma è capace di correre più veloce dei cavalli - struzzo; dei serpenti che superano cinquanta cubiti di lunghezza, privi di piedi, con coda di scorpione e capaci di divorare un vitello intero - boa constrictor. ${ }^{\text {IOI }}$ Più vaghe, ma non per questo meno attendibili, le notizie riguardo a un animale selvaggio commestibile grande come un asino con il manto striato di rosso e di verde e con corna lunghe tre cubiti attorcigliate alle estremità - presumibilmente il bongo; uno di colore rosso simile alla lepre con piccole corna che salta più di un cavallo - forse l'oretrago; uno somigliante a una capra con corna lunghe più di due cubiti protese verso il dorso vendute a caro prezzo perché se bruciate guariscono dalla febbre - verosimilmente la capra nubiana; un altro affine a una capra ma privo di corna e con pelo rosso e collo lungo due cubiti - probabilmente il gerenuk. ${ }^{\text {I02 }}$ Tutte informazioni che Poggio Bracciolini, dopo aver appurato la coerenza delle versioni fornite dagli etiopi, decise di «trasmetterle agli altri a motivo di una utilità comune». ${ }^{\mathrm{IO}}$

Ior. BRACCIOLINI 2004, pp. I75, I77, I79. Vedi anche Viaggi in Persia I929, pp. I93-I95; GROSSATO I994a, pp. 43-44. Nel testo I Viaggi I883 non figura il passo con le informazioni fornite dagli etiopi.

I02. BRACCIOLINI 2004, p. I77. Vedi anche Viaggi in Persia I929, pp. I94-I95; GROSSATO I994a, p. 44. Grazie alla trascrizione del testo latino (Venezia, Biblioteca Nazionale Marciana, ms. Marc. 2560) a opera di Alessandro Grossato, che ha sostituito il passo solitamente tradotto "mantello striato di rosso e di verde» con «listato di rosso, con le corna di color verde», l'animale può essere identificato con un'antilope africana. Se Michèle Guéret-Laferté propone di riconoscervi il bongo, con mantello rossiccio striato di bianco e lunghe corna a spirale che si prolungano verso il dorso, Mario Longhena suggerisce invece il kudu, antilope pure con striature bianche ma pelo di colore grigio o marrone grigiastro, GROSSATO I994a, p. 94; BRACCIOLINI 2004 , p. I76 nota I95; Viaggi in Persia I929, p. 94 nota 3. Per l'animale simile alla lepre con piccole corna che salta più di un cavallo Michèle Guéret-Laferté indica la lepre saltatrice - però priva di corna -, Alessandro Grossato una generica antilope e Mario Longhena il dik dik, mammifero di piccole dimensioni che tra le sue caratteristiche non annovera però quella di saltatore. A mio avviso non è da escludere l'oreotrago detto anche "saltarupi", antilope africana alta circa $50 \mathrm{~cm}$ con manto di colore marroncino e bianco i cui esemplari maschi sono dotati di piccole corna, BRACCIOLINI 2004, p. I77 nota I96; GROSSATO I994a, p. 48 nota I52; Viaggi in Persia I929, p. I95 nota I. La bestia simile a una capra con lunghe corna, che Michèle Guéret-Laferté ritiene un'antilope mentre Mario Longhena e Alessandro Grossato un ibex, potrebbe forse essere una capra nubiana con le tipiche corna inarcate all'indietro, BR ACCIOLINI 2004, p. I77 nota I97; Viaggi in Persia I929, p. I95 nota 2; GROSSATO I994a, p. 48 nota I52. Infine, l'animale con pelo rosso e collo lungo due cubiti, che Michèle Guéret-Laferté considera una gazzella o un'antilope mentre Mario Longhena e Alessandro Grossato un'approssimativa descrizione della giraffa, potrebbe in realtà essere un gerenuk, antilope dell'Africa orientale con manto rossiccio, grandi orecchie, lunghe zampe e lungo collo nota anche come "antilope giraffa", BRACCIOLINI 2004, p. I77 nota I97; Viaggi in Persia I929, p. I95 nota 3; GROSSATO I994a, p. 48 nota I53.

I03. GROSSATO I994a, p. 44. Vedi anche Viaggi in Persia I929, pp. I95-I96; BRACCIOLINI 2004 , p. I79. Vedi anche SALVADORE 20I7, pp. 62-64. 
Con la caduta di Costantinopoli nel I 453 e l'espansione turca sempre più minacciosa in direzione dell'Europa, i viaggi in Oriente dei fiorentini andarono scemando, e di conseguenza anche i resoconti odeporici con le descrizioni degli animali esotici, che avevano però iniziato a essere presenti con sempre maggior frequenza nei serragli delle corti italiane.

\section{Animali esotici a Firenze}

\section{I. Animali "familiari"}

Tra la fauna esotica all'epoca familiare alla popolazione fiorentina un posto di primo piano spetta certamente al leone. ${ }^{\mathrm{IO}} 4$ Presenti in città almeno fin dalla metà del XIII secolo, i felini erano mantenuti a spese del Comune e custoditi dapprima presso il Palazzo del Podestà - futuro Bargello -, poi in piazza San Giovanni, dove fu costruita una loggia con gabbie, nel I3I9 trasferiti di fronte alla chiesa di San Piero in Scheraggio e nel I350 dietro a Palazzo dei Priori - attuale Palazzo Vecchio - dove oggi si trova via dei Leoni. ${ }^{105}$ Alla fine del XIV secolo nelle Istorie fiorentine il mercante Gregorio Dati riferiva che dietro a Palazzo dei Priori si trovava "una gran casa con uno grande cortile, dove stanno sempre assai lioni, che figliano ogni anno, dove oggi ve n'è ventiquattro, e al governo di detti lioni sono deputati tre uomini i quali sono dal Comune salariati». ${ }^{\text {I06 }}$ Vera e propria istituzione comunale, il serraglio delle fiere si era costituito grazie a doni diplomatici - come il leone "giovane e bello" inviato da papa Bonifacio VIII nel I303, le «due leonesse, in due gabbie fatte per loro» offerte dal marchese di Ferrara nel I387, il «bellissimo lione» da parte del duca di Milano Filippo Maria Visconti nel I4I9 e i tre esemplari mandati da Francesco Sforza nel I453 - da acquisti effettuati dal Comune e da nascite in cattività. ${ }^{107}$ Altre volte, invece, era il Comune a omaggiare signori, regnanti e pontefici con dei felini per stringere o suggellare alleanze politiche: nel I378 il dono del marchese d'Este fu ricambiato con l'invio di due leoni di sesso maschile, nel I 406 al re polacco fu offerta una coppia di

I04. BURCKHARDT I980, pp. 266-267. Sull'argomento vedi anche BELLUZZI 2009a, pp. 99- ior. A Michel Pastoureau si deve l'uso di «indigeno» per indicare il leone, animale esotico in epoca Medievale ormai familiare in Occidente, PASTOUREAU I999, p. 23.

I05. VILLANI I844-I845, vol. I, p. 289, libro VI, LXX; VOLPI i902, pp. I8-i9 nota 2; DAVIDSOHN I896I908, vol. 4, pp. 5I4-5I7; Le Consulte I896-I898, vol. I, pp. 376, 423, 433; vol. 2, pp. I9, 427, 592; DAVIDSOHN I956-I968, vol. 3, p. 584; vol. 4, pp. 348, 489; vol. 5, pp. 206-207; vol. 7, p. 5I3. Sull'argomento vedi anche LOISEL I9I2, pp. I5I-I53; SIMARI I985, pp. 23-25; RICCIARDI I992, pp. II6-I22; KÖNIG-LEIN I997, pp. 84-97 (con qualche imprecisione nelle date).

I06. DATI I902, p. II6. Per l'importanza attribuita agli uomini specializzati nella cura degli animali esotici vedi COCKRAM 2017 , pp. 277-296.

I07. VILLANI I844-I845, vol. 2, p. 78, libro VIII, LXII; Diario di anonimo I876, pp. 392, 47I; PETRIBONI - RINALDI 200 , p. I27; Il primo elefante I888, p. I05; VILLANI i844-I845, vol. 3, pp. I66, libro X, CLXXXIII; 294, libro XI, LXVII; VILLANI I846, vol. I, pp. 28I, libro III, XC; 45 I, libro V, LXVIII; vol. 2, pp. 2I I, libro IX, XXV; 352, libro X, LVII; Diario di anonimo I876, p. 453. 
felini in modo che si potessero riprodurre e nel I 455 a Renato d'Angiò furono regalati due leoni e una leonessa per rimpiazzare quelli appena deceduti nel serraglio del castello di Angers. ${ }^{\text {I08 }}$

Nel corso del tempo il leone diventò sempre più oggetto di venerazione superstiziosa da parte della popolazione: una nascita in cattività era interpretata quale buon auspicio per le sorti della città, mentre la sua morte equivaleva a un segno nefasto, sino al punto da associare il decesso di Lorenzo il Magnifico al fatto che quel giorno «eransi azzuffati insieme alcuni lioni ed uno bellissimo era stato morto dagli altri». ${ }^{09}$ Il felino finì così per assurgere a simbolo della potenza e della libertas della repubblica fiorentina - il cosiddetto Marzocco - godendo di grande popolarità: per ammirare i leoni i fiorentini pagavano un biglietto d'ingresso al serraglio, a volte causando incidenti come quando nel i487 un fanciullo entrato nella gabbia in compagnia di un guardiano fu azzannato a morte, mentre nel I474 il re di Norvegia in visita ufficiale espresse il desiderio di poterli vedere. ${ }^{\text {IIO }}$ Non solo, alla metà del XIV secolo la città pullulava di immagini leonine che decoravano edifici sia con funzione civile, come le quattro fiere in pietra con dorature che si stagliavano agli angoli del Palazzo dei Signori e qualche decennio più tardi una cinquantina di leoni scolpiti a tutto tondo sui pilastri della Loggia dei Signori, sia residenze private, come la villa di campagna di Giovanni Rucellai dove cespugli di bosso potati in forma di marzocchi reggevano la bandiera del Comune. ${ }^{\text {III }}$ Proprio in veste di simboli della potenza fiorentina, nel XV secolo le belve furono sovente impiegate durante gli spettacoli allestiti per celebrare l'arrivo in città di ospiti illustri: le cosiddette "cacce» che vedevano i leoni affrontare altri animali. Se nel giugno 1387 si svolse «una chaccia nel chortile del Capitano del Popolo - odierno Bargello -, cioè che ebono uno toro indomito e feciogli lanciare adosso i lioni» e nel I 439 - come appunta il notaio Giusto d'Anghiari nei Giornali - «si fece in Fiorenza ammazzare tori e porci da' lioni», tutt'altra risonanza aveva avuto l'evento, rammentato in molti scritti e celebrato da coevi poemetti in versi, organizzato per l'arrivo in città di Galeazzo Maria Sforza e papa Pio II nella primavera del I459, quando piazza dei Signori fu chiusa con alti steccati e trasformata in una grande arena dove «furono lupi, porci salvatichi, tori bravi, e cavagli, e cavalle brave, che fu una cosa bella: e tra loro

I08. Ivi, pp. 47I nota 3, 538; BOEHRER 2007, p. 20; Extraits des comptes I873, p. 34 n. IO5; LOISEL I9I2, p. 249. A quanto pare nel I 457 morì uno dei leoni regalati dai fiorentini vedi Extraits des comptes I873, p. 36 nn. IO5I06.

I09. GUICCIARDINI 20I0, p. I92; BARCLAY LLOYD I97I, pp. 40-4I.

IIo. ZDEKAUER I978, pp. I57-I58; LANDUCCI I969, p. 52; TREXLER I980, p. 326. Nonostante le molteplici ipotesi, l'origine della simbologia del Marzocco resta ancora oscura, quella che lo associa alla figura di Ercole, fondatore dell'urbe abbigliato con una pelle di leone, sembra alquanto plausibile vedi DEL MIGLIORE I976, p. 244. Per la simbologia del leone nell'arte medievale occidentale e la sua diffusione vedi PASTOUREAU 2000 , pp. II-30; ID. 2002, pp. I06-I08.

I I . VILLANI I846, vol. I, p. 262, libro III, LXXII; ZACCARIOTTO 20I3, p. I04; RANDOLPH 200 , pp. I3-I5; RUCELLAI 2OI3, p. I43. 
missono e' lioni». ${ }^{\mathrm{II} 2}$ Appena qualche anno più tardi, nel I462, fu allestito un altro combattimento con leoni che assalivano un cervo e un cinghiale. ${ }^{\text {II3 }}$

Con il trascorrere del tempo i felini, sia quelli in carne e ossa rinchiusi nel serraglio sia quelli in pietra scolpiti sulle facciate dei palazzi, diventarono parte integrante della vita cittadina finendo per perdere la loro originaria connotazione esotica. Quando nel I384 Lionardo Frescobaldi e i suoi compagni di pellegrinaggio visitarono il serraglio del Cairo erano ormai così familiari da non meritare alcuna attenzione nei loro diari di viaggio, mentre nell'inverno I4O7 dopo che cominciò "a nevicare, e nevicò quattro dì a lato» le loro fattezze erano così note che «Fecionsi per Firenze grande quantità di lioni e begli: quasi in sun ogni canto ne era uno; e alle loggie, grand e begli». ${ }^{\text {II }} 4$

Altro animale esotico appartenente alla famiglia dei felidi presente in città dalla fine del XIII secolo è il «leopardus»: termine all'epoca indistintamente usato per indicare le specie oggi note come leopardo (Panthera pardus) e ghepardo (Acinonyx jubatus). ${ }^{I I S}$ Dai documenti risulta, infatti, che nella primavera del I29I il Comune di Firenze acquistò da un certo Bindo di Lucca un leopardo proveniente «de longinquis partibus» e stanziò fondi sia per la costruzione di una loggia con gabbia dove custodirlo sia per il mantenimento, vale a dire cibo e compenso per il guardiano. ${ }^{\mathrm{II} 6}$ Nonostante la scarsità di notizie su questo animale, vari indizi attestano la presenza in città nel XIV e nel XV secolo di alcuni esemplari : Giovanni Boccaccio riferiva a Benvenuto da Imola di un corteo svoltosi a Firenze dove i fanciulli, dopo aver visto sfilare un leopardo, iniziarono a correre per le strade gridando «Ecco la lonza!» - altro termine all'epoca in uso per designare il felino - mentre a un libro di ricordi si deve la notizia che nel novembre I475 Lorenzo de' Medici prese parte a una caccia alle lepri, quasi certamente con l'ausilio di ghepardi, nelle campagne dell'Impruneta. ${ }^{\text {II7 }}$ Ben si comprende, allora, perché i

II2. Alle bocche I986, p. 74; ANGHIARI 2002, p. 58; PETRIBONI - RINALDI 200I, pp. 468-469; Ricordi di Firenze I907, pp. 25-26; RICCIARDI I992, pp. I47-I5I; MORELLI I785, p. I78; GROOM 20I8, pp. I34-I36.

II3. LOISEL I9I2, p. I99.

II4. CORAZZA I894, p. 246; BUQUET 20I3a, p. 3I; ID. 20I3b, p. Iо5.

I I5. MESSEDAGLIA I94I, pp. 5, 36-40; BUQUET 20II, pp. 22-27; ID. 2020, p. I 8. Il termine leopardo sarà d'ora in poi usato come all'epoca per designare indistintamente leopardi e ghepardi, tranne nei casi in cui risulterà palese l'appartenenza a una delle due specie vedi BUQUET 20I I, pp. 35, 43. Per un approfondimento su ghepardi e leopardi vedi ALLSEN 2006, pp. 73-76.

i 16. Le Consulte i896-I898, vol. 2, pp. I9-23, 26, 69, 9I, Io6; DAVIDSOHN i896-I908, vol. 4, p. 5I5; ID. I956-I968, vol. 3, p. 584 .

II7. MESSEDAGLIA I94I, p. 52; BUQUET 20I I, pp. 24-25; ANGHIARI 2002, p. I88. Mario Alinei ritiene che la lonza sia da identificare con il leopardo delle nevi, ossia la lince, ma il fatto che Marco Polo avesse accennato alla presenza della lonza a Zanzibar sembrerebbe avvalorare l'idea, già proposta da altri studiosi, di un felino africano come il ghepardo vedi ALINEI 20I5, pp. I47-I49; POLO 200I, p. 290, I87:5; MESSEDAGLIA I94I, pp. 5-6 nota I. Inoltre, in un disegno toscano della metà del XV - ora All'Albertina di Vienna (inv. 27v) - un felino maculato corredato dalla dicitura "lonza» è raffigurato nell'atto di azzannare un daino. Sebbene Giusto d'Anghiari non avesse specificato la presenza di ghepardi nella caccia del I 475 è assai probabile che vi avessero preso parte: già alla fine del XIV secolo il duca di Milano si dilettava nella caccia alle lepri con i ghepardi, mentre nel I4I3 il marchese Nicolò III d'Este, diretto al Santo Sepolcro, ricevette dal re di Cipro un ghepardo addestrato che mise subito alla prova nelle campagne catturando ben otto lepri. Infine, sia i versi petrarcheschi nei Trionfi (I35I-I374) «Non corse mai sì lievemente al varco / Di fuggitiva cerva un leopard / Libero in selva o di catene scarco" (Trionfo 
leopardi, animali feroci impiegati nei combattimenti, e i ghepardi, felini addomesticabili utilizzati per la caccia o come animali da compagnia, ormai da tempo presenti nelle maggiori corti italiane non avessero catturato l'attenzione dei mercanti tre e quattrocenteschi in viaggio in Oriente che, pur menzionando di averli visti all'interno dei palazzi o in azione durante le partite di caccia, non si preoccuparono minimamente di descriverli, forse anche perché all'epoca già circolavano numerosi disegni e dipinti con la loro raffigurazione. ${ }^{\mathrm{II} 8}$ Del resto in Toscana il felino doveva essere assai noto già agli inizi del XIII secolo se Leonardo Fibonacci, maggior matematico italiano del Medioevo, nel suo Liber abaci (I202), destinato all'istruzione di chi intendeva intraprendere la carriera mercantile, aveva inserito un problema incentrato sul calcolo del tempo che un leone, un leopardo e un orso impiegavano per divorare una pecora. ${ }^{\text {II9 }}$ Per quanto riguarda, poi, la moda di tenere ghepardi come animali da compagnia, una prima notizia in area toscana si rintraccia nella Cronaca (I283-I287) di frate Salimbene che tra il I243 e il I247 annotava di averne scorti alcuni nel cortile di un palazzo pisano accovacciati ai piedi di giovani intenti a suonare della musica. ${ }^{120}$

Tra gli animali esotici considerati domestici, in virtù del fatto che dimoravano nelle stanze di palazzo, sono certamente da annoverare quelli di piccola taglia come alcune tipologie di scimmia e i pappagalli. Importate in Italia fin dal X secolo, le scimmie diventarono ben presto l'animale da compagnia prediletto da nobili e alti prelati, che le agghindavano con ricche vesti foderate in pelliccia cucite dai loro sarti di fiducia, e in un secondo tempo da facoltosi mercanti. ${ }^{\text {I2I }}$ Gli esemplari di piccole dimensioni vivevano a stretto contatto con i proprietari che, per contenerne l'esuberanza e limitarne i movimenti, li munivano di collari oppure di

della pudicizia, 37-39), sia quelli nell'Orlando furioso (I5I6) «Non vuol parere il can d'esser più tardo, / ma segue Rabican con quella fretta / con che le lepri suol seguire il pardo" (VIII:7) sembrano confermare l'uso di questa pratica vedi CAMPO 201 I, pp. 242-243; MESSEDAGLIA I94I, pp. 2, 34-35. Per la presenza dei ghepardi in Italia vedi LOISEL I9I2, pp. I46-I48; MESSEDAGLIA I94I, pp. 3I-53; MASSETI 2009, p. 39; ID. 2015 , p. 4I; ID. 20I 8, p. 46 (data erroneamente il soggiorno di Niccolò d'Este a Cipro al I3 I4 invece che al I4I3 attribuendogli il ruolo di primo estimatore in Italia nord-orientale della caccia con il ghepardo), BUQUET 2020, p. 28.

I 8 . ID. 20 I3 b, pp. Iо5-I09. Nel I368 durante il banchetto nuziale in onore di Violante, figlia di Galeazzo II Visconti, e Lionello di Anversa, duca di Clarence e figlio del re d'Inghilterra, due ghepardi con preziosi guinzagli in velluto rosso e borchie dorate furono offerti agli sposi. Sempre negli stessi anni Bernabò Visconti scelse il felino quale emblema personale. Nel I375 Gian Galeazzo Visconti donò a Filippo l'Ardito un leopardo, nel I394 ricevette dal sultano mamelucco Barqūq dei ghepardi e sempre a lui si deve la caccia con l'uso di felini organizzata a Pavia nel 1397 in onore degli ambasciatori inviati dal duca di Borgogna. A sua volta il figlio Filippo Maria Visconti, che nel I 426 stipendiava dei "pardieri», richiese dei leopardi al sultano ottomano Murad II, mentre nel I 463 il successore Francesco Sforza disponeva di un «curator leopardorum» inviato a Venezia nel i 469 con l'incarico di acquistare un felino vedi ALIPRANDI i9ı,, p. I39; Motto di Bernabò Visconti 20I5; BUQUET 20II, pp. 33-34; ID. 2020, pp. 28-30; MESSEDAGLIA I94I, p. 35; DECEMBRIO I925, p. 32 I nota 2; MALAGUZZI VALERI I9I3, p. 742; Il primo elefante I 888 , p. IO5.

II9. Giochi matematici 2006 , pp. 23-24.

I20. SALIMBENE I987, pp. 62-63:24I; BUQUET 20I I, p. 26.

I2I. ID. 20I3b, pp.I09-IIO; FRIEDMAN 20I6, p. 83-89; DELORT 2000, p. I95. Dal poemetto Bisbidis (ante I329), composto da Manoello Giudeo in lode a Cangrande della Scala, si desume che il signore veronese possedesse dei "gatti mammoni», mentre al domenicano Galvano Fiamma si deve la notizia che nel I342 Azzo Visconti disponeva di scimmie e babbuini vedi MESSEDAGLIA I94I, p. 59 nota 2; FIAMMA I938, p. I7. 
catene fissate in vita o al piede e assicurate a un ceppo di legno, mentre le specie più aggressive o di dimensioni maggiori alloggiavano nei serragli. ${ }^{\mathrm{I} 2}$ Sembra che all'epoca le scimmie più diffuse in Europa fossero la bertucce (Macaca sylvana), il «gatto mamone»(Cercopithecus) e il babbuino (Papio), animali esotici assai costosi provenienti dall'Africa e importati attraverso le relazioni commerciali con l'Oriente. ${ }^{\mathrm{I} 23}$ Sebbene i documenti sull'importazione dei primati risultino scarsi, l'assidua presenza in disegni e dipinti che li ritraggono dal vero non lascia dubbi sul fatto che fossero assai comuni a Firenze. ${ }^{\text {I24 }}$ Del resto, già Franco Sacchetti in una novella tardo trecentesca narrava di una dispettosa bertuccia che nottetempo ridipingeva gli affreschi eseguiti da Buffalmacco durante il giorno, mentre nel coevo diario di viaggio il mercante Lionardo Frescobaldi aveva frettolosamente annotato che in Egitto si trovavano "gran quantità di pappagalli e babbuini e gatti di Faraone; bertucce e gatti mammoni» e ancor prima Niccolò da Poggibonsi riferiva di aver visto al Cairo «babuini e gatti mammoni». ${ }^{\text {I25 }}$

A distanza di oltre un secolo papa Pio II aveva offerto al giovanissimo Galeazzo Maria Sforza, che nella primavera del I459 lo accolse a Firenze dedicandogli un'orazione, «uno bono et bello cavallo, ij turchi, ij gati mamoni, uno pappagallo et altre cose», mentre la presenza di scimmie nel giardino vaticano si apprende dalla sua autobiografia quando racconta dell'amata cagnolina aggredita da «un grosso cercopiteco, che si trovava per caso libero». ${ }^{226}$ Negli stessi anni Benedetto Dei, in missione in Oriente, riferiva che in Algeria «si ve[n]dono le scimmie e le bertucce, et arreconsi a mazzi legate per i piè di dreto come i polli». ${ }^{\mathrm{I} 27}$ Ancora un decennio più tardi i registri doganali del porto di Roma tra le merci esotiche scaricate da una caravella nel i 475 elencavano uno schiavo africano e tre scimmie della razza "gattomammone», di cui due esenti da dazio perché destinate al cardinale Francesco Gonzaga che, proprietario di una «carta da navigare» e di ben due copie del testo poliano, doveva nutrire un particolare interesse per le

I22. JANSON I952, p. 82; BUQUET 20I3b, p. I Io ; ID. 20I3 d. Testimonianza dell'uso di limitare il movimento delle scimmie assicurandole con una catena a un ceppo si trovano sia in una novella di Franco Sacchetti sia nell'arazzo con l'allegoria del Tatto parte della serie di arazzi intitolata La Dama e l'unicorno (I50o ca.) - ora al Musée National du Moyen Age di Parigi. Per la novella di Francesco Sacchetti vedi nota I25.

I23. JANSON I952, p. I6; LACH I965-I993, vol. 2.I, pp. I75-I77. Il «gatto mamone» è un tipo di scimmia il cui nome sembra derivare dall'arabo maymūn che significa scimmia vedi JANSON I952, p. 268; CADORNA 200 I, p. 629; Compendio I739, vol. 3, p. 93 ad vocem «mammone». Già Brunetto Latini nel Tresor riferisce «E dicono gli Etiopi che nella loro terra ci sono scimmie di diverse varietà», LATINI 2007, p. 323, libro I, I95:2.

I24. Vedi capitoli III e IV.

I25. SACCHETTI I996, pp. 533-538, novella CLXI; FRESCOBALDI i99i, p. i43:6-7; POGGIBONSI I990, p. II 8, CLXXXII:2. I "gatti di Faraone», che Antonio Lanza ritiene "gatti egiziani», sono probabilmente da identificare con l'icneumone detto anche mangusta egiziana vedi FRESCOBALDI I990, p. I83 nota I. Ancora prima di Franco Sacchetti, nei De' rimedi dell'una, et l'altra fortuna (I354-I366) Francesco Petrarca biasima il possesso di questo "animale nell'aspetto brutto, \& cattivo nelle opere», pratica che all'epoca doveva essere assai diffusa, PETRARCA I584, p. IIIv, libro I, LXI.

I26. Appunti e notizie I887, p. 63I; CRISTINA I999, pp. 68-69 nota i87; PICCOLOMINI 2008, vol. 2, pp. 2259-226I, libro XI.24; MÄRTL 2004, p. I95; PARAVICINI BAGLIANI 20I6, pp. 90, 226.

I27. PISANI I923, p. I2; ORVIETO I969, p. 2 II 
terre d'oltremare. ${ }^{28}$ E proprio al Milione di Marco Polo, testo particolarmente amato e letto all'epoca, si deve la notizia che in Etiopia «si ànno gatti mamoni e iscimmie asai». ${ }^{\text {I29 }}$

Sempre dal documento doganale tardo quattrocentesco si ricava la notizia dell'arrivo nella città eterna di ben novantotto pappagalli, dato che conferma il perdurare della forte richiesta del più esotico tra i volatili, molto apprezzato negli ambienti ecclesiastici e aristocratici a partire dalla fine del XIII secolo. ${ }^{\mathrm{I} 30}$ L'origine esotica del pennuto è del resto ben attestata da Boccaccio nella spassosa novella di frate Cipolla che, millantando di aver riportato dal suo immaginario pellegrinaggio in Terrasanta una preziosa reliquia, si era procurato una piuma di pappagallo per spacciarla agli ingenui contadini certaldesi come «una delle penne dell'agnol Gabriello, la quale nella camera della Vergine Maria rimase quando egli la venne a annunziare in Nazarette». ${ }^{\mathrm{I} I} \mathrm{I}$ Non sarà allora un caso se proprio negli stessi anni nel Libro d'Oltramare frate Niccolò da Poggibonsi scriveva di aver visto lungo il Nilo «uccelli che si chiamano di Paradiso, e sono sì belli e hanno tante penne e sì travisate [particolari] che pare una maraviglia a vedere; e quando altri gli è appresso, no'llo puote la persona sguardare, tanto splendore danno le loro penne!».132

Uccello raro e di grande impatto per la sgargiante cromia del piumaggio, fino alla scoperta del Nuovo Mondo fu per lo più disponibile nella variante di colore verde con vistoso collare rosa sulla nuca (Psittacula krameri), tipologia menzionata da Brunetto Latini, Giovanni Boccaccio e Luigi Pulci; più difficili da reperire invece la specie di colore rosso con becco giallo (Lorius domicella o Lorius garrulus), ammirata da Niccolò de' Conti nelle isole Molucche e posseduta nel I467 da papa Paolo II, e quella grigia africana (Psittacus erithacus). ${ }^{\mathrm{I} 3}$ A contraddistinguere il pappagallo da tutti gli altri animali fu la straordinaria abilità, se adeguatamente addestrato, di saper parlare come l'uomo, caratteristica che lo connotò fin da subito come meraviglia orientale e in men che meno lo elevò ad animale da compagnia per eccel-

I28. MÄRTL 2004, p. I95; PARAVICINI BAGLIANI 20I6, p. 226; ESCH 2000, vol. 2, pp. IO2-IO3; CHAMBERS I992, pp. I72 n. 766, I74 nn. 788-789.

I29. POLO 200I, p. 295, I89:I7.

I30. GEBHART I887, p. I79; WALKER-MEIKLE 20I2, p. I5; LOISEL I9I2, p. 202; BOEHRER 20 IO, p. 79. Noti in Europa fin dall'antichità, nel III secolo i pappagalli furono cibo prelibato per la tavola dell'imperatore romano Eliogabalo e per i suoi leoni, mentre nei secoli successivi il declino delle attività commerciali con l'Oriente li rese sempre più rari vedi LACH I965-I993, vol. 2.I, pp. I78-I79; BOEHRER 2004, p. 20.

I3I. BOCCACCIO I992, vol. 2, pp. 766-777, VI:Io. Interessante è la credenza che il pappagallo sapesse pronunciare spontaneamente la parola "Ave», saluto che l'angelo Gabriele rivolse alla Vergine durante l'Annunciazione e per questo associato alla purezza vedi LEVI D'ANCONA 200I, p. I70 n. 4.

I32. POGGIBONSI i99o, pp. II3-Ii4, CLXX:2. Antonio Lanza identifica gli uccelli del paradiso con il martin pescatore, Donald Lach ritiene invece che il pappagallo fosse anche chiamato uccello del paradiso perché importato dall'Egitto dove scorre il Nilo, fiume la cui sorgente si credeva avesse origine nel paradiso terrestre, LACH I965-I993, vol. 2.I, p. I8I.

I33. LATINI 2007, p. 283, libro I, I68:I-2; BOEHRER 2004, p. 33; BOCCACCIO 20I I-20I7, vol. I, p. 555, libro IV, 49; MARCELLI 20I Ib, pp. 96, 98; I viaggi I883, pp. 210-2I I; Viaggi in Persia I929, p. I50; GROSSATO I994a, p. 30; BRACCIOLINI 2004, p. II9; PARAVICINI BAGLIANI 20I6, p. I53. Per la varietà con piumaggio rosso vedi anche LACH I965-I993, vol. 2.I, pp. I80-I8I; MASSETI 20I6, pp. 260-262. 
lenza. ${ }^{\mathrm{I} 34}$ Oltre a ciò, nel Livre des merveilles du monde Jean de Mandeville narrava che il regno del mitico Prete Gianni, posto al confine con il paradiso terrestre, fosse pieno di pappagalli contribuendo non poco alla fortuna del volatile. ${ }^{\mathrm{I}} 35 \mathrm{Nel}$ I 403 Luigi I di Valois duca d'Orléans ne possedeva uno, nel I439 il re di Francia Carlo VII commissionò una gabbia ottagonale per il suo, mentre nel I 457 Renato d'Angiò stipendiava Pierre Desbans perché si prendesse cura del suo volatile al quale era probabilmente destinata la "cage de fil de fer pour ung papegault» più tardi relegata nella guardaroba del castello di Angers. ${ }^{136}$ Per quanto riguarda la presenza di pappagalli in Italia, nel I420 Amedeo VIII di Savoia ne aveva ricevuto uno in dono, mentre nel I422 Parisina Malatesta - seconda moglie di Niccolò III d'Este - fece acquistare del mangime a Venezia per il suo esemplare e l'anno seguente commissionò un drappo rosso per coprirne la gabbia. ${ }^{\mathrm{I} 37}$

Bene di lusso in grado di conferire particolare prestigio al possessore, il loquace volatile diventò, in relazione alla leggenda dell'esemplare che confortava papa Leone IX (p. I049-IO54) chiamandolo per nome, una presenza costante presso la corte pontificia: nel I3I7, poco dopo l'elezione di papa Giovanni XXII, la Camera Apostolica acquistò da un chirurgo genovese un costoso esemplare, Urbano V (p. I362-I370) e Gregorio XI (p. I370-I378), ultimi pontefici avignonesi, rientrarono a Roma in compagnia del loro pappagallo e nel I4I7 il futuro papa Martino V partì alla volta di Costanza, dove fu eletto al soglio pontificio, con due domestici al seguito incaricati di prendersi cura del suo volatile. ${ }^{\mathrm{I} 38}$ Al 1462 risale un pagamento di papa Pio II per il custode del suo pappagallo, mentre alla fine del secolo il cardinale Ascanio Maria Sforza, figlio del duca di Milano, sborsò ben cento fiorini aurei per accaparrarsi un pappagallo che sapeva recitare per intero il Credo. ${ }^{139}$ Dai documenti si apprende che i papi, oltre ad affidarne la cura a domestici di fiducia e a farli nutrire con prelibatezze, non si separavano mai dai loro volatili, neppure durante i viaggi. ${ }^{\text {I }}{ }^{\circ}$ Quando nel I 459 papa Pio II si era recato alla dieta di Mantova non aveva voluto privarsi della compagnia del suo amato pappagallo verde, al quale aveva insegnato a recitare brani di sermoni in

I34. LACH I965-I993, vol. 2.I, p. I79; WALKER-MEIKLE 20I2, p. I5; BOEHRER 2004, p. 2; ID. 20 Io, p. 77; PARAVICINI BAGLIANI 20I6, p. I53. Francesco Petrarca denigra il possesso di tale uccello perché «il pappagallo salutatore grandissimo, e massimamente de principi, è stato fatto dalla natura come uno adulatore; onde viene fuora quel distico, in nome del pappagallo; "Io gli altrui nomi apparerò da voi: / Sol da per me, sò salutare Augusto"", PETRARCA I584, p. II5v, libro I, LXIIII.

I35. MANDEVILLE 2000, p. 437; BOEHRER 2004, p. 32.

I36. ID. 20 Iо, p. 79 ; Extraits des comptes I873, pp. 36 n. I IO, 249 n. 642.

I37. GANDINI I89i, p. I57; DIENER i967, p. 69.

I38. Ivi, pp. 62, 94-97; BOEHRER 2004, pp. 27-28; PARAVICINI BAGLIANI 20I6, pp. I44-I47, I50-I5I; ID. 2017 , pp. 70, 77; BEDINI I997, pp. 82-83.

I39. Ibid.; BOEHRER 20Io, p. 78; GIUSTINIANI I667-I675, vol. 3, pp. 674-675, CXXXVIII; Indagini I 875 -I 879 , vol. 2 , p. 52 .

I4O. WALKER-MEIKLE 20I2, pp. 42-43; PARAVICINI BAGLIANI 20I6, pp. I50-I5I. Per i significati simbolici attribuiti al pappagallo vedi BOEHRER 2004, pp. 26-3I; WEDDIGEN 2006, pp. 20I-205; PARAVICINI BAGLIANI 20I6, pp. I 45-I56; ID. 2017 , pp. 69-84. 
toscano, e nel corso del viaggio ne regalò uno a Gian Galeazzo Sforza. ${ }^{\text {I4I }}$ E a questo proposito è interessante la spiritosa novella di satira anti-senese composta intorno al I47I da Luigi Pulci, nella quale si narra che uno stolto senese avendo scambiato un picchio per un pappagallo lo fece recapitare a papa Pio II. ${ }^{42}$

Consuetudine, quella delle classi elevate di possedere o regalare pappagalli, che aveva radici lontane nel tempo se già nel I290 la principessa di Salerno ne inviò alcuni a Eleonora di Castiglia, mentre la maggiore disponibilità di ciarlieri pennuti tra il XIV e il XV secolo, dovuta all'intensificarsi dei traffici con l'Oriente, finì per conquistare anche il ceto borghese. ${ }^{\mathrm{I} 33}$ Proprio perché di piccole dimensioni e disponibili in gran quantità, come avevano potuto constatare Niccolò da Poggibonsi e Lionardo Frescobaldi in Egitto, e per di più a basso prezzo, pappagalli e scimmie furono sovente acquistati in Oriente da navigatori e mercanti per poi rivenderli al loro rientro in Europa, come nel caso del veneziano Alvise da Ca' da Mosto che nei primi anni sessanta del XV secolo riferiva di aver comperato in Senegal oltre centocinquanta uccelli esotici, tra cui anche pappagalli, e di aver trovato in Gambia «infiniti papagali» e "gatti maimoni e babuin de diverse sorte, e de picholi e de grandi, che in queste parte se ne trova grandissima quantitade» a un costo irrisorio. ${ }^{\text {I4 }}$

Pur avendo finora rintracciato un'unica testimonianza documentaria riguardo a un «pappagallo giovanino e bello» donato da Armorò Donati a Lorenzo di Giovanni de Medici nel I429, è quasi certo che fossero presenti nella città del giglio: il fatto che nella seconda metà del XV secolo il volatile fu adottato da Lorenzo de' Medici quale emblema lascia supporre che ne possedesse almeno uno, mentre già nel febbraio I42I i giovani appartenenti alla brigata organizzatrice di una festa presso il Mercato Nuovo indossavano divise «di damasco verde, con pappagallo di perle in su la manica ritta» così come pure i loro servitori «vestiti di taccolino con pappagallo verde in sulla manica», e ancor prima la trecentesca sala dei pappagalli presso Palazzo Davanzati fu affrescata con un tessuto a motivo geometrico en trompe-l'oil punteggiato di volatili verdi. ${ }^{\mathrm{I}} 45$

Per quanto riguarda, invece, il pavone (Pavo cristatus) si tratta certamente di un volatile esotico, ma da così tanto tempo presente in Europa da aver perso la sua connotazione meravigliosa: pur non mancando mai nelle corti e nei serragli poteva capitare persino di vederlo servito, con tutte le sue piume o rivestito in foglia d'oro, in occasione di banchetti lussuosi; era quindi ancora considerato un anima-

I4I. ID. 20I6, p. I53; Appunti e notizie I887, p. 63I; CRISTINA I999, pp. 68-69 nota I87.

I42. MARCELLI 20IIb, pp. 87-98.

I 43. WALKER-MEIKLE 2OI2, p. 25.

I44. LACH I965-I993, vol. 2.I, p. I23; POGGIBONSI I990, p. II8, CLXXXII:2; FRESCOBALDI I99I, p. I43:6-7; Le navigazioni atlantiche I966, pp. 66, I00, I08; BOEHRER 2010, p. 77.

I45. Inventari medicei I996, p. I73; Motto del pappagallo 20I5; PERI 2000, p. 28; CORAZZA I894, pp. $277,290$. Se fin dal XIII secolo furono disponibili preziose stoffe intessute con motivi di pappagalli, i volatili raffigurati sulle pareti di Palazzo Davanzati sembrano più debitori a un disegno che alle schematiche immagini tessili. Per raffronti con i tessuti vedi Tessuto e ricchezza 2017 , pp. I82-I83 cat. 33, I98-I99 cat. 40. 
le pregiato, ma non così raro ed esotico da essere risparmiato. ${ }^{\mathrm{I}}{ }^{6} \mathrm{~A}$ una lettera di Michele Verino si deve la notizia che Lorenzo de' Medici nella sua amata residenza di Poggio a Caiano aveva «ripieni i boschi di Fagiani e di Pavoni che s'è procurati dalla Sicilia». ${ }^{\mathrm{I} 7}$ Che tra le numerose specie avicole allevate alle Cascine di Poggio a Caiano, fattoria annessa alla villa, vi fossero dei pavoni si apprende anche da una lettera che il figlio Piero aveva inviato nel maggio I 490 al Magnifico per aggiornarlo sull'andamento delle attività agricole: «E pagoni la golpe ne ha ma[n]giati un paio», aggiungendo poi «le galline d'India se ne rivede» — galline faraone (Numida meleagris) -, uccelli che all'epoca dovevano essere considerati alquanto esotici se appena qualche decennio prima Benedetto Dei ne aveva acquistati alcuni ad Alessandria con l'idea, una volta tornato in patria, di regalarli a Piero di Cosimo de' Medici. ${ }^{\text {I }}{ }^{8}$

\subsection{Animali «maravigliosi»}

Se nel XIV e nel XV secolo alcuni animali esotici, ormai da tempo presenti sulle sponde dell'Arno, erano divenuti così familiari da essere considerati "indigeni", tutt'altro effetto suscitò la visione di specie mai viste prima, se non da qualche fortunato viaggiatore avventuratosi in Oriente, giunte in città in forma di regali diplomatici o di curiosità per gli studioli dei ricchi mercanti. ${ }^{\mathrm{I}} 49$ Che a Firenze l'interesse per gli animali esotici, alimentato dal grande fascino esercitato dalle terre d'oltremare, fosse particolarmente spiccato trapela da numerosi indizi frammentari, non sono però ancora stati rintracciati documenti che attestino l'esistenza di un vero e proprio serraglio di proprietà della famiglia medicea, infatti quando fu necessario trovare un alloggio per la giraffa ricevuta dal Magnifico nel i 487 si optò per le stalle in via della Scala, dove fu allestito un sistema di riscaldamento per proteggerla dalle insidie del rigido inverno fiorentino. ${ }^{\text {I5O }}$

I46. In occasione di banchetti particolarmente sontuosi i pavoni, dopo la cottura, erano ricoperti con le loro piume o rivestiti con foglie d'oro in modo da suscitare stupore negli invitati e palesare magnificenza. Se tra il I354 e il I366 Francesco Petrarca rammenta «si dice che Ortern`sio oratore fu il primo che in Roma uccidesse i pavoni per mangiarli", un secolo più tardi nel suo Libro de arte coquinaria il celebre cuoco Maestro Martino illustrava la ricetta per "pavoni vestiti con tutte le sue penne», PETRARCA I584, p. II2r-v, libro I, LXII; MAESTRO MARTINO 200I, p. IO.

I 47. In realtà, la lettera inviata da Michele nel maggio I487 all'amico Simone Cannigiani riporta: «et id Medicis industria, Phasides Aves, \& Phoenicopteri, quasille usque ex Sicilia devext", ma nella traduzione ottocentesca William Roscoe, ritenendo poco plausibile la presenza di fenicotteri, li sostituì con pavoni; versione poi accolta da Philip Foster e ancora di recente da Marco Masseti vedi TARGIONI TOZZETTI I768-I779, vol. 5, pp. 59-6I; ROSCOE I8I6, vol. 3, p. I50; FOSTER I969, p. 50; MASSETI 2002, pp. 2I2-2I3; ID. 20I5, pp. II4, II6-II8.

I48. FOSTER I974, pp. 72-73; PISANI I923, p. I9. All'epoca le faraone che vivevano allo stato brado in Abissinia - area geografica sovente confusa con l'India - erano dette "galline d'India", mentre dopo la scoperta delle Americhe questo termine fu adottato per indicare il tacchino vedi MASSETI 20I5, pp. II9-I20.

I 49. BUQUET 20I3a, pp. 26-27.

I50. Alcuni studiosi affermano che nel XV secolo i Medici disponevano di un serraglio, da qualcuno localizzato presso le Cascine di Poggio a Caiano, senza però citare documenti specifici. Inoltre, molti studiosi continuano a fare riferimento al testo di Gustave Loisel che, pur costituendo una pietra miliare per la storia dei serragli europei, risulta ormai datato, mentre altri includono i leoni di rappresentanza del Comune tra gli animali dei Medici. 
Si può quindi immaginare lo stupore quando nell'autunno I487 l'ambasciatore egiziano Ibn-Mahfuz, giunto in città per chiedere appoggio politico e finalizzare un accordo commerciale, fece il suo solenne ingresso seguito da «animali vivi, de' più begli e de' più maravigliosi che mai si vedessino in questa parte», ufficialmente inviati dal sultano mamelucco Qā'it Bey quale omaggio per la Signoria ma in realtà destinati a Lorenzo de' Medici. ${ }^{\mathrm{ISI}} \mathrm{A}$ testimoniare l'eccezionalità dell'evento è la lettera fatta recapitare dalla Signoria al console fiorentino di stanza a Costantinopoli per informarlo dei fatti: "giraphe qui altra non si ricorda che sieno state vedute». ${ }^{{ }^{52} 2}$ Davanti agli occhi sgranati dei fiorentini sfilarono - come annota Alamanno Rinuccini - «uno lione dimestico, una giraffa, uno cavallo corridore, uno becco e una capra con orecchi grandi cascanti, uno castrone e una pecora con code grosse», e se alcuni animali esotici come il leone e il cavallo arabo erano da tempo noti del tutto sconosciuti o quasi risultarono invece la giraffa e gli ovini orientali. ${ }^{153}$ Mai visti prima in carne e ossa, le uniche informazioni disponibili su questi bizzarri animali erano quelle fornite da qualche resoconto odeporico in rarissimi casi accompagnate da disegni esplicativi, come il trecentesco Libro d'Oltramare di Niccolò da Poggibonsi o la quattrocentesca lettera di Ciriaco d'Ancona. Se il frate francescano è infatti da ritenere il primo viaggiatore toscano ad aver fornito accurate descrizioni dal vero della giraffa e degli ovini orientali corredate da schizzi probabilmente di suo pugno (figg. I6-I8), al mercante e umanista Ciriaco d'Ancona si deve una lettera, spedita a più destinatari tra il I 442 e il I443 tra cui anche il fiorentino Andrea Stagi, dove le indicazioni sulla giraffa vista qualche anno prima al Cairo erano completate da un disegno di cui sopravvivono delle copie (figg. 20-2I). ${ }^{54}$ Informazioni che dovevano aver particolarmente eccitato la fantasia dei fiorentini se nel I459, tre decenni prima del suo arrivo in carne e ossa, per celebrare la visita ufficiale di papa Pio II e Gian Galeazzo Sforza fu deciso di allestire una "caccia» in piazza dei Signori dove, oltre ai consueti animali, compariva una giraffa in legno, probabilmente realizzata rifacendosi al disegno ciriacano. ${ }^{155}$

Patrizia Meli, più cautamente, ipotizza l'esistenza di un serraglio mediceo, mentre Christiane Joost-Gaugier ritiene che fino al XVII secolo l'interesse dei Medici per gli animali fosse di natura prettamente pittorica. Le prime notizie certe sull'esistenza di un serraglio mediceo con animali esotici risalgono al I580 vedi LOISEL I9I2, pp. I97-200; RUGGIERI TRICOLI 2004, p. I66; GALLETTI I996, pp. I96, I99; BEDINI I997, p. 28; RINGMAR 2006 , pp. 380-38I; BOEHRER 2007, p. 20; MELI 2009, p. 244; JOOST-GAUGIER I987, p. 94; MASSETI 20I5, pp. I63I64; BELLUZZI 2009a, pp. I05-IO6; GROOM 20I8, pp. 72-75, 87.

I5I. MASI I906, p. I8. Nella Cronaca Lionardo Morelli riporta: "A dì II di Novembre I 487 venne uno Imbasciadore del Soldano di Babillonia alla Signoria di Firenze: recò doni a detta Signoria, e in spezieltà a Lorenzo di Piero di Cosimo de i Medici, un lione, una giraffa, e altri animali, e altre cose», MORELLI I785, p. I97. I52. Documenti sulle relazioni 1879 , p. 237 doc. CCIII. Per la tradizione orientale di offrire giraffe quali doni diplomatici di particolare pregio vedi BUQUET 20I3c, pp. 388-389.

I53. Ricordi storici I840, p. CXLIII.

I54. BLAIR MOORE 20I3, pp. 365-370; MITCHELL I962, pp. 285-286 e tav. XXII; WEISS I977, pp. 289, 293; Firenze e la scoperta, I992, pp. I77-I80 n. 85; FANTONI 20I4, pp. 86-87; MASSETI 20I5, p. I60.

I55. Vedi pagina I30. 
Se alla giraffa giunta a Firenze nel I 487 fu riservato il ruolo di star assoluta, tanto da essere l'animale che tutti i regnanti europei invidiavano a Lorenzo de' Medici, gli ovini orientali non passarono certo inosservati come rivelano le annotazioni di Tribaldo de' Rossi nelle Ricordanze "variate dette Pechore e Chapre ale nostre chome in molti luoghi dipinte si veghono eron grandissime», quelle di Luca Landucci nel suo Diario "capre e castroni, molto strani» e di Alamanno Rinuccini nei Ricordi storici «uno becco e una capra con orecchi grandi cascanti, uno castrone e una pecora con code grosse». ${ }^{156}$ Già centocinquant'anni prima, durante le sue peregrinazioni in Oriente, Niccolò da Poggibonsi fu colpito dalle capre con «l'orecchie lunghe infino a terra» e dalla loro mole massiccia, tanto da fargli affermare «Or chi crederebbe che la capra portasse sella, e anche il freno [morso] e le poselle [posole], a modo di cavallo?», e dalle pecore con coda «larga parecchie spanne [...] tonda a modo d'uno tagliere [piatto] [...] sì grave che no.lla possono portare se none poco a lunga». ${ }^{157}$ Ovini che, nonostante il trascorrere del tempo, dovevano ancora essere una rarità se nel I487 Lorenzo de' Medici, destinatario del dono, decise di mandarli «al Pogio ala chascina sua» dove erano custoditi altri animali esotici. ${ }^{158}$

È invece curioso che il cammello (Camelus bactrianus) e il dromedario (Camelus dromedarius), bestie esotiche per eccellenza, all'epoca sovente confuse tra loro, non compaiano mai nei documenti o nei libri di ricordi fiorentini tre e quattrocenteschi, nonostante si possa ipotizzare la loro presenza nel corteo dell'imperatore bizantino Giovanni VIII Paleologo, giunto in città nel I 439 per partecipare al concilio, come pure al seguito della delegazione etiope arrivata nel I44I. ${ }^{\text {I59 }}$ È altresì vero che i camelidi erano da tempo penetrati nell'immaginario collettivo sia perché ricordati nella Bibbia e affrescati sulle pareti delle chiese, sia attraverso le narrazioni di mercanti e pellegrini che in Oriente ne avevano visti a bizzeffe. La notizia, poi, che alcuni studiosi si ostinano a riportare riguardo alla presenza di un cammello tra gli animali offerti dal sultano d'Egitto nel I 487 si è rivelata infondata: l'equivoco deriva dall'errata lettura di un documento dove, oltre agli animali, tra i regali offerti al Magnifico si elencano dei «ciambellotti», pregiati panni di pelo di cammello, che nel I773 Giovanni Targioni Tozzetti confuse con l'anima-

I56. ROSSI I786, p. 247; LANDUCCI I969, p. 52; Ricordi storici I840, p. CXLIII.

I57. POGGIBONSI I990, pp. II8-II9, CLXXXIII:I; I 46, CCL:I.

I58. ROSSI I786, p. 247.

I59. La confusione è dovuta al fatto che alcuni viaggiatori chiamano cammelli arabi i dromedari, probabilmente rifacendosi al Tresor di Brunetto Latini che, pur distinguendo le due specie, li scambia tra loro «I cammelli sono di due varietà: gli uni sono arabi e hanno due gobbe sulla schiena, gli altri sono battriani, e non hanno che una gobba", LATINI 2007, p. 299, libro I, I80:I. Errore quasi certamente da ricondurre a Isidoro da Siviglia che nelle Etymologiae afferma «i cammelli arabici [dromedari] hanno sul dorso una doppia gobba, mentre quelli delle altre regioni [cammelli] ne hanno una sola», SIVIGLIA 2004, vol. 2, pp. I7-I8, libro XII, I: 35-36. Plinio il Vecchio, invece, nella Naturalis historia distingue correttamente il cammello dal dromedario «esistono due specie, il cammello della Battriana e quello dell'Arabia. Li differenzia il fatto che i primi hanno due gobbe sul dorso e invece i secondi ne hanno soltanto una», PLINIO 20I I, p. 69, libro VIII, XXVI. Vedi CASTELLI 1986, p. 32. Già Maria Fossi Todorow ipotizza che il disegno di cammello eseguito da Pisanello sia da ricondurre alla visione dell'animale giunto a Ferrara in occasione del concilio al seguito dell'imperatore bizantino nel I438, FOSSI TODOROW I966, p. 78 n. 53. 
le. ${ }^{\mathrm{I} 60}$ In realtà, l'unico esemplare visto in carne e ossa dai fiorentini fu quello regalato a papa Martino V nell'aprile I4I9 quando, partito da Costanza e diretto a Roma, soggiornava a Firenze. ${ }^{\text {16I }}$ Per festeggiare la sua elezione al soglio pontificio, la sorella Paola e i figli giunsero da Piombino recando - come ricorda nel Priorista il contemporaneo Pagolo di Matteo Petriboni - «uno cammello et uno asino biancho et due struççoli e donorongli al papa Martino». ${ }^{\mathrm{I} 2} \mathrm{Fu}$ forse la visione di questo animale a fornire ad Andrea da Barberino, in quegli anni impegnato nella stesura del Guerrin Meschino, le informazioni necessarie per tratteggiare quella che risulta essere la più accurata descrizione del tempo: «El cammello ène grande quant'uno bue, ed ha i piè buini [bovini] e spugnosi; ed è rosso, di pelo bovino, ed ha il collo lungo circa a due braccia, e ha la testa piccola e ll'occhio varo [di colore tendente al nero], bocca asinile, orecchi piccoli, corti crini, poca coda, e 'n sul mezzo della schiena ha un piccolo scrigno [gobba]». ${ }^{163}$ Sembrerebbe, poi, che Francesco Sforza, avvertito da un guardiano del carattere intemperante del cammello ricevuto in dono dal re di Tunisi, nel 1452 avesse deciso di liberarsene inviandolo come dono diplomatico a Firenze. ${ }^{\text {I64 }}$

A indicare che nel XIV e nel XV secolo nella penisola i camelidi erano ancora assai rari è la notizia che nel $\mathrm{I} 367$, prima di lasciare Costantinopoli dove si era recato in difesa del cugino Giovanni V Paleologo, il conte Amedeo VI di Savoia organizzò il trasporto in patria di un cammello, come pure il fatto che per festeggiare il capodanno I 439 Ludovico I di Savoia inviò due esemplari a Filippo Maria Visconti, che pare possedesse anche dei dromedari, mentre nel I464 il duca di Modena ne donò due a Filippo Sforza. ${ }^{\mathrm{I} 5}$ In Francia, già nel 1325 i conti della Camera Apostolica riportano la presenza di un guardiano con la mansione di accudire un cammello alla corte avignonese di papa Giovanni XII, mentre dal I 450 al I472 Renato d'Angiò si sobbarcò l'onere per il mantenimento di alcuni cammelli presso il castello di Angers. ${ }^{66}$ Nel I 444 il cardinale Giuliano Cesarini, fi-

I60. MOSCO I985, p. II; AGRIESTI I990, p. 22; MASSETI 20I5, p. I32 (riferisce erroneamente a Luca Landucci la notizia di un dromedario giunto a Firenze il 2 dicembre I 487). Giovanni Targioni Tozzetti riporta di aver trovato l'informazione in un antico diario anonimo fiorentino del XVI secolo (Firenze, Biblioteca Nazionale Centrale, ms. Magliabechiano CL. XXV cod. I7, ora II.I.3I3, c. 84r,), in realtà un passo praticamente simile si rintraccia nei Ricordi storici di Alamanno Rinuccini vedi TARGIONI TOZZETTI I768-I779, vol. 5, p. 62; Ricordi storici I840, p. CXLIII. Già Marco Polo usa il termine "giambellotti» per indicare panni in lana di cammello, mentre nella trecentesca Pratica della mercatura Francesco di Balduccio Pegolotti impiega "ciambellotti», POLO 200 , pp. I04, 72:4-5; I05, 73:7; I78, II5:7; PEGOLOTTI I936, p. 4I6.

I6r. Nel suo Zibaldone Giovanni Rucellai riferisce «Nel mccccxviiij, tornando papa Martino da Gostanza, si fermò in Firenze con tutta la corte et stetteci mesi xviij», RUCELLAI 20I3, p. I37.

I62. PETRIBONI - RINALDI 200I, p. I20. L'allevamento di dromedari fu introdotto in Toscana da Ferdinando II de' Medici nel I622 presso la tenuta di San Rossore vedi MASSETI 2002, p. I68.

I63. BARBERINO 2005, p. I36, libro II, XXV:32. In realtà, sebbene indicato come cammello, la descrizione di Andrea da Barberino corrisponde a quella di un dromedario. Vedi anche ALLAIRE 2002, pp. 32-33; EAD. 2006 , p. 20. I64. MALAGUZZI VALERI I9I3, p. 739.

I65. COX I967, p. 234; CUTTLER I991, p. I63; MALAGUZZI VALERI I9I3, p. 742; MESSEDAGLIA I94I, pp. 37-39; DECEMBRIO I925, pp. 320 nota I, 32I nota 2; Il primo elefante I888, p. IO6.

I66. DELORT 2000, pp. I86-I87; Extraits des comptes I873, pp. 29 n. 92, 30 n. 94, 43 n. I46; LOISEL I9I2, p. 252 (menziona però dei dromedari). 
gura centrale del concilio per l'unione delle due Chiese in quegli anni impegnato a combattere i turchi al fianco di Ladislao III re di Polonia e di Ungheria, regalò un cammello al pontefice Eugenio IV:

Tra l'altre cose ci guadagnò detto cardinale un animale maggior d'un bufalo. Haveva la testa come un camelo, et il collo lungo un bon passo, e li piedi come un bove senza unghia, e la coda bovina e corta, e sul dorso haveva due monticelli a modo di due fanciulle, e sopra erano certi crini pelosi, e pareva una cosa mostruosa; chiamavasi dromedario, e mandollo per nobiltà a presentare al papa. ${ }^{167}$

A ulteriore conferma della presenza nella città eterna dell'animale è la testimonianza di Paolo dello Mastro che nel suo Memoriale appuntò: «e questo animale stette in Roma più mesi et io Pavolo ce cavalcai Rienzolo mio figlio che era molto piccolino». ${ }^{168}$

Anche gli struzzi furono rari a Firenze. Unico accenno è quello ai due esemplari ricevuti da papa Martino V, insieme al cammello, nel I4I9 quando i suoi familiari si premurarono di dotarlo di animali esotici con cui fare il suo solenne ingresso a Roma, altrimenti documenti e libri di ricordi non ne fanno menzione. Si trattava, però, di volatili noti attraverso i bestiari e gli scritti tre e quattrocenteschi di viaggiatori e pellegrini recatisi oltremare: Niccolò da Poggibonsi ne osservò uno alla corte del conte di Giaffa fornendo una descrizione corredata di schizzo, Lionardo Frescobaldi ricordava di averne visti molti sul monte Sinai, mentre Simone Sigoli per spiegare le fattezze della giraffa vista al Cairo riferiva: «è fatta quasi come lo struzzolo», dando quindi per scontato che al lettore il volatile fosse noto. ${ }^{169}$

Sembra, invece, che già intorno al I329 a Verona Cangrande della Scala possedesse degli struzzi e nel I342 Azzo Visconti ne custodisse alcuni nel castello di Milano, mentre nel I337 un certo Varino da Firenze recapitò ad Avignone due esemplari provenienti dalla Sicilia dono di Roberto d'Angiò a Benedetto XII. ${ }^{170}$ Per quanto riguarda la seconda metà del XV secolo, nel parco del castello di Pavia

I67. DELLA TUCCIA I852, p. I74; PARAVICINI BAGLIANI 20i6, p. 89. Anche in questo caso l'animale, un cammello per la presenza delle due gobbe, è confuso con il dromedario; errore riportato da Claudia Märtl e Agostino Paravicini Bagliani vedi MÄRTL 2004, p. I94; PARAVICINI BAGLIANI 20i6, p. 89.

I68. DELLO MASTRO i9i2, p. 92, XXXXII:38-39. Paolo dello Mastro, che a suo dire aveva pure tratteggiato un disegno, descrive così il camelide: «uno animale chiamato dormetario, et era secunno vederete fegurato in questa faccia, et era femmina et era prena, et infantatose in Roma, fece una dormentaria femmina, et allevosse; et era de grannezza più che niuno cavallo, e quanno se faceva annare forte de passo avevano fatiga li cavalli a giognierlo correnno. Contavase che per uno bisognio avria camenato in un die ciento miglia, e quanno era stracco strengeva li ditti cummi, e quanno si volea caricare, se colcava in terra, e quanno avea tanta soma che li bastasse e quello se rizava e tirava via», ivi, XXXXII:32-38.

I69. POGGIBONSI i99o, p. im, CLXXXIV:i; FRESCOBALDI i99i, p. isi:2i; SIGOLI i999, pp. 80-8I. Già un ventennio prima Fazio degli Uberti nel Dittamondo afferma che nel Levante gli struzzi si trovano abbondanti come le oche in Italia vedi UBERTI I952, vol. I, p. 362, libro V, IX: I7-I8.

I70. MESSEDAGLIA I94I, p. 59 nota 2; FIAMMA I938, p. I7; BARCLAY LLOYD I97I, p. 47; BEDINI I997, p. 82 (erroneamente indica recapitati in Vaticano); PARAVICINI BAGLIANI 20I6, p. 225; COCKRAM 2017 , p. 282. 
al tempo di Gian Galeazzo Sforza, oltre alla "Colombara» e alla "Conigliera», si trovava anche una «Struzzaria», intorno al I 470 uno struzzo fu regalato a Ludovico III Gonzaga, mentre a partire dal I47I Renato d'Angiò provvide al nutrimento di una coppia di struzzi, pare ricevuti dal re di Tunisi, alloggiati nel serraglio del castello di Angers, dove sopravvissero solo qualche anno: il maschio morì nel I 473 e la femmina nel I 477. ${ }^{\text {I7I }}$ Infine, Giovanni Lanfredini, uomo di fiducia di Lorenzo de' Medici e direttore della filiale del banco mediceo di Venezia, per celebrare la nascita del primogenito maschio di Ercole I d'Este nel I 476 gli fece recapitare uno struzzo e una gazzella, dono particolarmente gradito dal signore di Ferrara che lo reputò "una cossa molto digna et signorile». ${ }^{172}$

A suscitare meraviglia e stupore, oltre alle specie sconosciute, furono gli animali rari e bizzarri posseduti dall'élite dei ricchi mercanti che solo una ristretta cerchia di amici e familiari avevano il privilegio di ammirare. Tra queste sarà certamente da annoverare il camaleonte, sembrerebbe acquistato a Cartagine, che Benedetto Dei, dopo aver trascorso sei anni in Oriente, recava con sé al suo rientro in patria nel I467 specificando: "vive d'aria et arreca'lo vivo e dona'lo a Recco amico d'Uguccione Capponi». ${ }^{73}$ Rettile singolare accuratamente descritto da Brunetto Latini nel Tresor, testo all'epoca presente tra le letture dei mercanti in versione italiana, che incuriosì i fiorentini e continuò a farlo se - come ricorda Vasari - agli inizi del XVI secolo papa Leone X (p. I5I3-I52I) ne possedeva un esemplare ritratto in un disegno e affrescato in Vaticano da Giovanni da Udine. ${ }^{174}$

I7I. MALAGUZZI VALERI I9I3, p. 64I; La scienza a corte I979, p. 95; Extraits des comptes I873, pp. 42 n. I43, 43 n. I48, 44-45 nn. I54-I55; BARCLAY LLOYD I97I, p. 49; DELORT 2000, p.I9o. Gli struzzi furono presenti a Ferrara a partire dal $\mathrm{I} 452$, quando nella residenza di Belfiore giungevano grandi quantità di ghiande provenienti da Modena per nutrirli, al I 462 risale poi la notizia di Alessandro Gonzaga attaccato da uno struzzo nel parco e al I 479 quella dell'uovo di struzzo deposto a Belfiore che la duchessa estense fece recapitare al marito Ercole I vedi CAZZOLA I991, p. 206; CHAMBERS I984, p. 407; TUOHY I996, pp. 346-347.

I72. SCARTON 2007, p. 77. Agli inizi del XVI secolo le gazzelle continuavano a suscitare sensazione: nel I520 il duca Alfonso I d'Este, appreso che il doge Cornaro ne possedeva una, sollecitò il suo ambasciatore a Venezia a contattare Tiziano per farla ritrarre, opera mai realizzata a causa del decesso dell'animale, e ancora nel I532 Francesco Gonzaga, saputo dell'arrivo in laguna di una gazzella proveniente da Alessandria, incaricò il pittore di dipingerla vedi CAMPORI I874, pp. 589-590; SHAPLEY I945, pp. 27-28; BARCLAY LLOYD i97I, pp. 55-56; BODART I998, p. IO2.

I73. PISANI I923, p. I7; ORVIETO I969, p. 2 I I. Animale ancora raro agli inizi del XVI secolo se Andrea del Sarto lo raffigurò, insieme ad altra fauna esotica, nell'affresco con il Tributo a Cesare (I5I9-I52I) realizzato nella villa di Poggio a Caiano (vedi fig. 93).

I74. LATINI 2007, p. 307, libro I, I85:I-2; ID. I9I7, pp. I66-I67, libro V, LII; LOISEL I9I2, pp. 202-203; DACOS - FURLAN I987, pp. 23-24, 248; BEDINI I997, p. 84; PARAVICINI BAGLIANI 20I6, pp. 88, 226227. Se l'umanista e giureconsulto Fabrizio Delfini de Nobilibus nella sua copia del De situ orbis terraum di Solino, accanto alla voce "chameleon", annota: «Memini audisse me a viro Florentino Leonem X pont. max. habuisse in delitiis chameleontem», nella Vita di Raffaello Giorgio Vasari scrive: "Giovanni da Udine suo discepolo, il quale per contrafare animali è unico, fece in ciò tutti quegli animali che papa Leone aveva: il camaleonte, i zibetti, le scimmie, i pappagalli, i lioni, i liofanti et altri animali più stranieri» vedi CAMPANA I950, pp. 225-226; BEDINI I997, p. 84; PARAVICINI BAGLIANI 20I6, pp. 226-227; VASARI I966-I997, vol. 4, p. I97. Il camaleonte fu affrescato nella sala dei Chiaroscuri del Palazzo Apostolico, pitture murali che a distanza di pochi anni furono danneggiate a causa di alcuni lavori commissionati da papa Paolo IV. Si è però conservato un disegno di Giovanni da Udine raffigurante un camaleonte vedi DACOS - FURLAN I987, p. 24. Per la fauna esotica giunta a Roma nel I5I 4 quale omaggio da parte di Manuele I del Portogallo a papa Leone X, ossia un elefante bianco addestrato prontamente ritratto dagli artisti del tempo, un ghepardo per la caccia, due leopardi, numerosi pappagalli, cani e galline d'India e un pregiato cavallo persiano vedi BEDINI I997, pp. 28, I63-205; PÉREZ DE TUDELA - 
Tra le merci esotiche portate in Italia da Benedetto Dei con l'intento di rivenderle per trarne profitto figurava, nell'elenco accluso alla lettera spedita al fratello Miliano il 4 dicembre I467 dopo essere sbarcato "sano e contento» a Livorno, «I serpente di braccia 8». ${ }^{175}$ Una decina di giorni più tardi Luigi Pulci, a quel tempo residente a Pisa dove aveva incontrato il suo intimo amico, scrivesse a Lorenzo de' Medici: «È qui il tuo Benedetto Dei, et ha uno coccodrillo ch'è lungo braccia otto; in vero un bello animale». ${ }^{176} \mathrm{Si}$ trattava del «serpente di braccia otto di lunghezza, e ba [braccia] quattro di grossezza con cento denti, quattro gambe, intero di tutto" acquistato a Beirut. ${ }^{\mathrm{I} 77} \mathrm{Dal}$ fitto scambio epistolare tra il mercante fiorentino e il fratello, incaricato della vendita del rettile impagliato, trapela il grande interesse suscitato dall'arrivo a Firenze del coccodrillo: un certo "Danese» si impegnò a versare una caparra per assicurarselo ma, a causa del suo temporeggiare, Benedetto Dei lo promise a Giuliano de' Medici che lo voleva per il suo maestro di scherma. ${ }^{78} \mathrm{Nel}$ frattempo anche Miliano condusse delle trattative e, a quanto pare, finì per venderlo a Tommaso Capponi con grande rammarico e disappunto del fratello Benedetto che, oltre a non poter mantenere la promessa fatta a Giuliano de' Medici, avrebbe voluto ricavarne maggior profitto. ${ }^{179}$ Trattative che rivelano il desiderio da parte della classe agiata di possedere un animale esotico da alcuni pellegrini visto sulle rive del Nilo e da altri descritto nei diari di viaggio, come nel caso di Marco Polo, Lionardo Frescobaldi e Ciriaco d'Ancona, autori di testi che i facoltosi mercanti custodivano gelosamente nelle loro biblioteche. ${ }^{\mathrm{I} 80}$ Non solo, a volte questo rettile si trovava sospeso alle navate delle chiese dove, assimilato al dragone simbolo del male, svolgeva la funzione di alludere alla vittoria della religione cristiana sul paganesimo. ${ }^{\text {I8I }}$ Proprio la rarità dell'animale esotico, associata al significato simbolico attribuitogli dai contemporanei, indusse Benedetto Dei, irritato e amareggiato per l'esiguo compenso ricavato dalla vendita del coccodrillo, a rimproverare il fratello scrivendogli: "quell'animale valea e vale oggidì in Italia più di fiorini 200 larghi». ${ }^{182}$

Del resto nel XV secolo i souvenir di animali orientali erano alquanto ambiti. Nel I4O2 il signore di Carrara, appresa la notizia che una delegazione di ambasciatori del Prete Gianni, alias il negus d'Etiopia, era sbarcata a Venezia recando in dono "quatuor leopardos, aromata et certas res placibiles», chiese che gli fossero mandate la "pelle de uno homo saluego» - uno scimmione - e quella «de uno

JORDAN GSCHWEND 2007, pp. 422-423; PARAVICINI BAGLIANI 20I6, p. 88; GROOM 20I8, p. I5.

175. ORVIETO 1969, pp. 252-255. Nella Cronaca Benedetto Dei menziona il coccodrillo: «arechai I serpente a f:Firenze di braccia 8 lungho e 4 piè», PISANI I923, p. 96; DEI I984, p. I22 c. 54 r.

I76. PULCI I886, p. 64; PISANI I923, p. I8. Già nel I440 Milliaduse d'Este, recatosi in pellegrinaggio, acquistò in Egitto la testa di un coccodrillo quale souvenir da riportare in patria vedi Viaggio in Oriente 2005, p. II8.

177. PISANI I923, p. I6.

I78. ORVIETO I969, pp. 262-263, 265, 268.

I79. Ivi, p. 269.

I80. POLO 200I, pp. I85-I86, II 8:5-9; CADORNA 200I, p. 603 ad vocem «colubre»; FRESCOBALDI I99I, p. I38:I8-20; ANCONA I763, p. 56; WEISS I966a, p. 33I.

I8I. CORDEZ 20I6, pp. I90-I96.

I82. ORVIETO I969, p. 269. 
aseno de diuersi colore» - probabilmente una zebra. ${ }^{\text {I83 }}$ Ancora nei primi anni sessanta del XV secolo Alvise Ca' da Mosto, di ritorno dai suoi viaggi in Oriente, aveva omaggiato il re del Portogallo con un piede, parte della proboscide, una zanna e dei peli di elefante, ricavati da una carcassa ricevuta in dono dal sovrano del Gambia, "perché el desiderava molto de haver de queste cosse strane», mentre l'inventario stilato alla morte di Lorenzo de' Medici nel I492 elencava ben quattro "vuova di struzolo", uno in camera sua, due nella cappella del palazzo di via Larga e un altro nella cappella del palazzo di Careggi, perché - come ricordava Niccolò da Poggibonsi - lo struzzo è «l'uccello che fa l'uova così grande le quali noi appicchiamo in alto per le chiese». ${ }^{184}$

\subsection{Animali simulati}

Fu certamente la passione per l'Oriente e la smania di possedere animali rari provenienti dalle terre d'oltremare, oltre alla volontà di rivaleggiare con le corti italiane ed europee che li possedevano in carne e ossa, a indurre $i$ fiorentini a commissionare riproduzioni di bestie esotiche da esibire in occasione di eventi importanti. ${ }^{185}$ La prima notizia risale al I459 quando, per festeggiare l'arrivo in città di papa Pio II e Gian Galeazzo Sforza, fu allestita una serie di spettacoli: una giostra in piazza Santa Croce, un ballo in piazza del Mercato Nuovo, una «caccia» con leoni in piazza dei Signori debitamente recintata e, quale degno epilogo, un'armeggeria lungo via Larga capitanata da un giovanissimo Lorenzo de' Medici. ${ }^{\mathrm{I} 6}$ Il primo maggio I459, davanti agli spalti gremiti di spettatori illustri, nell'arena si affrontarono leoni, tori, mucche, bufali, cinghiali, cavalli e altri animali. ${ }^{187}$ Esibizione cruenta particolarmente amata dall'élite quanto dal popolo fiorentino, che pagava un biglietto per assistervi da dietro il recinto, la «caccia» del I 459 ebbe però un esito disastroso: i leoni, forse intimoriti dal rumore o resi mansueti dalla cattività, si misero in disparte senza attaccare gli altri animali, tanto da indurre Giovanni Cambi a commentare «fu grande aparechio, e di gran chosto, e poco piacere dettono al popolo». ${ }^{188}$ L'insuccesso dello spettacolo fu accortamente interpretato in chiave

I83. CIPOLLA I873, pp. 323-324; MESSEDAGLIA I94I, p. 35; SALVADORE 20I7, p. 25. A questo proposito Pero Tafur riporta che nel I 438 alcune pelli di coccodrillo ricevute in dono dal sultano d'Egitto erano custodite all'interno di un portico del palazzo del doge vedi BEHRENS-ABOUSEIF 20I4, p. I I; TAFUR 20I4, p. I65.

I84. Le navigazioni atlantiche I966, pp. I06-I07; Libro d'inventario I992, pp. 24, 27, I33; POGGIBONSI I990, p. II9, CLXXXIV:ı. Per l'uso di sospendere le uova di struzzo nelle chiese vedi CORDEZ 20I6, pp. I53-I59. Un documento fiorentino con la disposizione «Ova di struzzolo pendenti sopra l'altare di S. Giovanni si rassettino e pulischino" attesta fin dal I338 l'uso di sospendere uova di struzzo sopra gli altari, pratica perpetuata oltre un secolo più tardi nella cappella di Palazzo Medici vedi MEISS I954, p. 94; DAVISSON 200I, pp. I27-I38.

I 85. A questo proposito in occasione di una festa tenutasi a Baghdad nel io95 furono realizzati una giraffa e un elefante finti da far sfilare per le vie della città vedi KRUK 2008, pp. 570-57I.

I86. ANGHIARI 2002, p. I2I; CAMBI I785-I786, vol. 20, pp. 368-37I; MORELLI I785, pp. I77-I78.

I87. Il numero dei leoni varia da cronaca a cronaca oscillando da un minimo di due a un massimo di ventisei vedi CAMBI I785-I786, vol. 20, p. 370; LANDUCCI I969, p. 347; VOLPI I902, p. I8; ANGHIARI 2002, p. I2I; PETRIBONI - RINALDI 200I, p. 468; LUZIO I899; FILARETE - MANFIDI I978, p. 77; DEI I984, p. 67 c. 23 r. I88. RICCIARDI I992, pp. I27, I48; CAMBI I785-I786, vol. 20, p. 370. 
propagandistica: la mitezza dei leoni, simboli di Firenze, rappresentava la volontà di mantenere relazioni amichevoli con il signore di Milano. ${ }^{189}$ Grande novità fu, invece, la presenza di due marchingegni concepiti per aizzare gli animali che Antonio Ricavo, agente a Firenze di Ludovico III Gonzaga, descrisse in una lettera inviata a Mantova nei giorni in cui fervevano i preparativi:

una balla di legname, grossa et sprangata di ferro, dove starà uno dentro, congiegnato in forma che volti la balla a suo modo, che con contrapesi la farà andare dove vorrà lui starà sempre a sedere et sarannoli certe finestrelle per vedere lume, et per andare incitando et riscaldando quelli lioni con uno pungietto, con lo qual li pungierà. Appresso si fa uno animale di legname, grandissimo dove staranno più uomini dentro a muoverlo, et anderà per la piaza, sarà coperto di pelle, qui lo chiamiamo noi la giraffa, con un collo lungo, per far paura et far muovere quelli animali. ${ }^{190}$

Sorprende constatare che alcuni scritti del tempo, pur riportando la presenza della palla in legno, a detta di Benedetto Dei pratica ripresa dall'Oriente, avessero tralasciato di menzionare la giraffa. ${ }^{\text {I9I }} \grave{E}$ assai probabile che un manichino ligneo coperto di pelle e dotato di ruote, sebbene fabbricato con l'intento di riprodurre una giraffa e per questo munito di un lungo collo, all'epoca risultasse alquanto enigmatico a gran parte degli spettatori. ${ }^{192}$ Solo chi aveva letto le descrizioni dell'animale nei diari odeporici o visto una copia della lettera di Ciriaco d'Ancona con il suo disegno poteva in realtà comprendere di cosa si trattasse. I rari testi che accennavano alla presenza della bestia esotica nella «caccia» del I459, senza però specificare che si trattava di un congegno, diedero origine a un fraintendimento perpetuatosi nel tempo: alcuni illustri studiosi della metà del XIX secolo anticiparono la presenza della prima giraffa in carne e ossa a Firenze di quasi un trentennio. ${ }^{193}$

Altro grande evento che comportò la realizzazione di animali finti fu l'elezione a cardinale di Giovanni de' Medici, figlio del Magnifico e futuro papa Leone $\mathrm{X}$, nel marzo I492. In realtà, Lorenzo de' Medici riuscì a ottenere la nomina a cardinale del figlio nel I489, quando Giovanni era ancora tredicenne, ma gli accordi segreti con papa Innocenzo VIII prevedevano che dovessero trascorrere tre

I89. Ricordi di Firenze I907, p. 26; RICCIARDI I992, p. I50.

I90. LUZIO I 899; RICCIARDI I992, p. I49.

I9I. ANGHIARI 2002, p. I2I; PISANI I923, pp. II-I2; DEI I984, pp. 67-68 c. 23 r.

I92. A riportare, più o meno esplicitamente, che si trattasse di un manichino furono, oltre ad Antonio Ricavo: Giovanni Cambi "et una giraffa con 20 uomini», un rimatore anonimo «E una giraffa v'era molto grande / Per far muover le bestie ch'io v'ho detto» e Pagolo di Matteo Petriboni «et una giraffa, con venti huomini», CAMBI I785I786, vol. 20, p. 370; Ricordi di Firenze I907, p. 26; VOLPI I902, p. I7; PETRIBONI - RINALDI 200I, pp. 468469. Vedi anche DONATI I938, pp. 256-257; BEDINI I997, p. 29.

I93. Tra gli studiosi che scambiano il manichino con una giraffa vera vedi BURCKHARDT I980, p. 267 nota I; PERRENS I888, p. I99; LAUFER I928, p. 79. È sorprendente che questo errore si sia perdurato nel tempo nonostante Gustave Loisel avesse già specificato nel I9I2 che si trattava di un manichino, LOISEL I9I2, p. I98. Vedi anche DONATI I938, pp. 256-258. Altri animali finti, una testuggine e un istrice con uomini al loro interno per muoverli e muniti di lance per aizzare le bestie, furono realizzati in occasione della caccia del I5I4 vedi LANDUCCI I969, p. 345; BARCLAY LLOYD I97I, pp. 39-40. 
anni prima della vestizione pubblica. ${ }^{\text {I94 }}$ I festeggiamenti per l'elezione al porporato di un membro della famiglia medicea si protrassero per ben due giorni e furono così imponenti da adombrare - secondo quanto narra Benedetto Dei - qualsiasi evento precedente, persino quelli orchestrati in occasione di visite ufficiali di pontefici e sovrani. ${ }^{195}$ Proprio perché si trattava di un avvenimento di forte valenza politica e sociale a concludere le celebrazioni, quale segno tangibile di potere e magnificenza, furono allestiti due trionfi che sfilarono fino al palazzo mediceo di via Larga, uno dei quali con «uno alefante inghirlandato di ciercchi di razzi». Il pachiderma, con tutta probabilità dotato di ruote per poter deambulare, doveva essere di legno o cartapesta se - come ragguaglia Benedetto Dei - «s'appicchò il fuocho allo trionfo dello alifante e tutto si chonsumò e arsse che mmai si vidde simile cosa né tanto a punto ogni cosa fatta». ${ }^{196}$ Non si trattava certo di una novità, dato che nel I 459 fu realizzato il manichino-giraffa, ma tenuto conto del fatto che un pachiderma vero a Firenze non si era mai visto gli artigiani incaricati della riproduzione dovettero rifarsi alle narrazioni dei viaggiatori e alle immagini che, a differenza della giraffa, dovevano essere disponibili in quantità se alla fine del XIV secolo Lionardo Frescobaldi, a proposito degli elefanti visti al Cairo, scriveva: «de' quali è la forma quasi come si dipingono». ${ }^{197} \mathrm{Si}$ spaziava, infatti, dalle miniature alquanto approssimative che illustravano i bestiari e le rime petrarchesche del Trionfo della Fama a disegni più attinenti alla realtà, come quello eseguito dal vero nella famosa lettera di Ciriaco d'Ancona, fino a quelli nei taccuini degli artisti, forse qualcuno addirittura tratteggiato nel I479 quando un elefante sbarcato a Venezia transitò insieme a una tigre per Milano prima di raggiungere la Francia. ${ }^{198}$ Il passaggio di questi rari animali esotici induce a supporre

I94. ROSSI I786, p. 276; LANDUCCI I969, p. 56; CISERI 2013 , p. 97.

I95. Ivi, pp. 99-IOI; EAD. 20I4, pp. III-II2.

I96. Ivi, p. II5-II6, I I9; LOISEL I9I2, p. 200 (ritiene si tratti di un elefante vero). Riguardo al fuoco Ilaria Ciseri ipotizza che fosse dovuto a congegni pirotecnici sistemati sopra o all'interno dell'animale stesso. Vedi anche TREXLER i980, pp. 455-458.

I97. FRESCOBALDI I99i, p. I 43:34.

I98. LACH I965-I993, vol. 2.I, p. I32; CISERI 20I4, p. I 16; MALAGUZZI VALERI I9I3, p. 742; COCKRAM 20I7, p. 282. A testimoniare il passaggio dell'elefante a Milano nel giugno I479, dono di Alfonso V del Portogallo al re di Francia Luigi XI, è il Registro ducale all'Archivio di Stato di Milano: "Concessae fuerunt litterae passus egregio Equiti Ciprioto D. Jacobo dacha Abram profecturo ad Serenissimum D. Regem Francorum cum elephanto uno, et tigri una, et mauris quattuor ipsa animalia gubernantibus, et cum alijs socijs sive famulis duodecim, annos tres valiturae. Mediolani XI Junij I 479" vedi Il primo elefante I888, p. I06. Alla luce di questo documento la notizia di Doris Behrens-Abouseif, ripresa da Gli elogi (I55I) di Paolo Giovio, che il sultano Qā’it Bey avesse donato al duca Galeazzo Maria Sforza un elefante e una tigre prontamente ritratti nel portico del castello milanese risulta infondata, BEHRENS-ABOUSEIF 20I4, p. I42; GIOVIO I557, pp. I58-I59, libro III. Vedi anche LACH I965-I993, vol. 2.2, p. 23. Per quanto riguarda, invece, il pachiderma secondo alcuni studiosi offerto dal re del Portogallo nel I477 a Renato d'Angiò non è stata trovata traccia della sua presenza nei conti relativi al mantenimento della ménagerie vedi LECOY DE LA MARCHE I969, vol. 2, p. Is nota 3; LOISEL I9I2, p. 255; LACH I965-I993, vol. 2.I, p. I33; BARCLAY LLOYD I97I, p. 49; CUTTLER I99I, p. I63; BEDINI I997, p. II5; Extraits des comptes i873, pp. 27-45. Il primo pachiderma in carne e ossa giunse sulle rive dell'Arno nel I655 vedi HEIKAMP - ROSCAM ABBING 2OI3, pp. 4I, 48. Gustave Loisel, fraintendendo gli scritti quattrocenteschi, diffuse la mendace notizia, poi ribadita da Maria Pisani, di due elefanti posseduti da Lorenzo de' Medici, dando così origine a un errore riportato ancora qualche decennio fa da Robert Delort vedi LOISEL I9I2, p. 200; PISANI I923, p. 60; DELORT 2000, p. I92. 


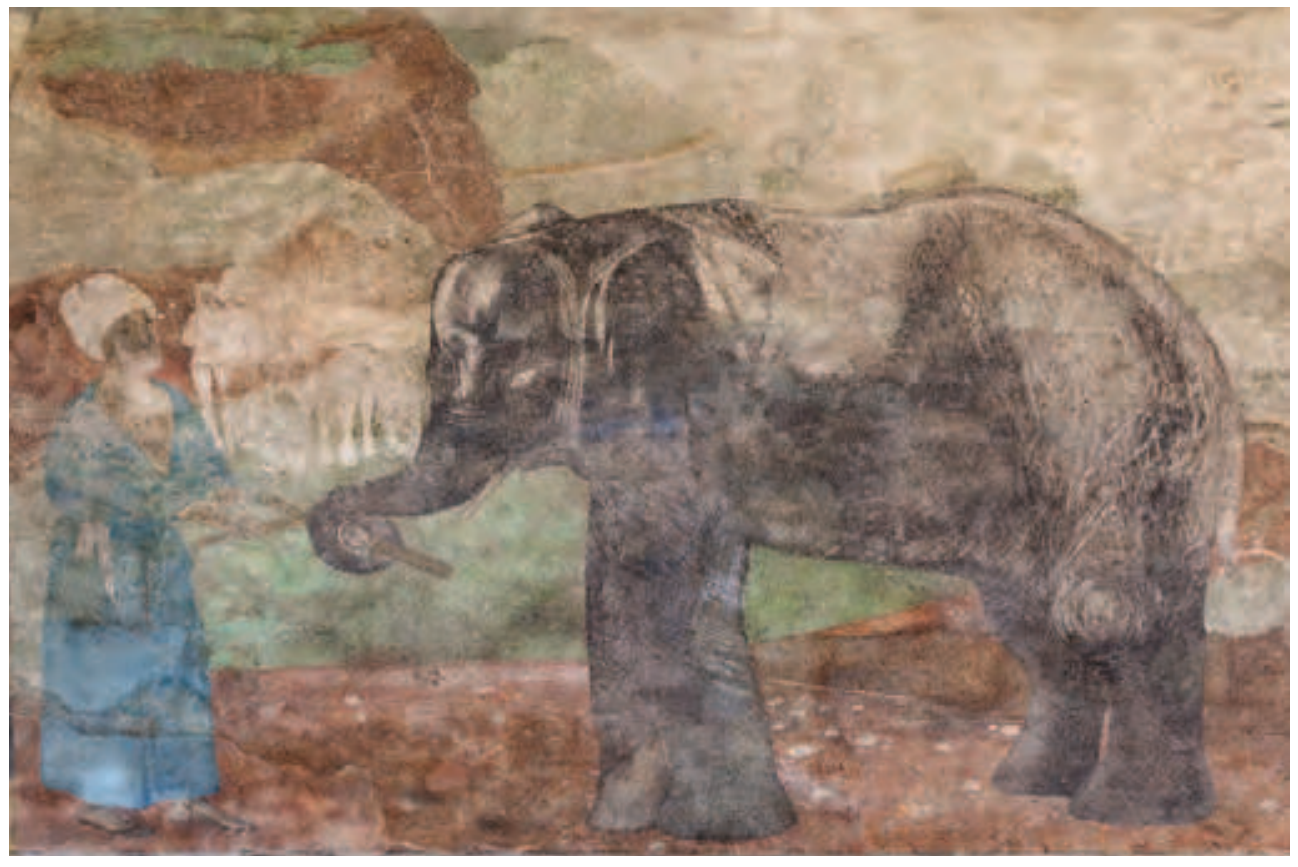

Fig. 2: Artista lombardo,

Elefante, I480-I 490 ca.

Milano, Raccolte d'Arte Antica del Castello Sforzesco 
che il pachiderma affrescato nel portico all'interno del Castello Sforzesco sia l'animale visto in quell'occasione, come sembra confermare la presenza del custode con turbante che lo accompagnava (fig. 2), e l'immagine molto danneggiata nell'arcata attigua con la sagoma di un felino, probabilmente una tigre (fig. 3). ${ }^{199}$ Appena qualche mese prima un certo «missere Jacomo Abram zentilhomo de Vinesia», lo stesso passato da Milano con l'elefante e la tigre, si era recato a Ferrara per proporre a Ercole I d'Este l'acquisto di un cucciolo di elefante al prezzo di I2.000 ducati poi aumentati a 20.000 , motivo per cui il signore estense aveva desistito, mentre l'offerta di un altro pachiderma nel I48I fu declinata per la preoccupazione di doversi impegnare economicamente in una guerra tra stati italiani. ${ }^{200}$ È perciò verosimile ipotizzare, come nel caso di Milano, che la raffigurazione - perduta - di un elefante all'interno di un padiglione nella residenza di Belfiore sia da ricondurre all'arrivo a Ferrara dei pachidermi in vendita. ${ }^{201}$

Sembra che la voga degli spettacoli con la partecipazione di animali simulati fosse assai diffusa nel XV secolo in Italia. Antecedente di rilievo fu certamente "uno elefante grandissimo con lo castello di sopra», all'interno del quale alloggiavano musicisti e cantori vestiti da angeli, realizzato in legno e munito di ruote che sfilò per le vie di Napoli durante la grande giostra organizzata da Alfonso V d'Aragona nell'aprile I423. ${ }^{202}$ Cinquant'anni più tardi le fastose nozze tra Costanzo Sforza e Camilla d'Aragona, celebrate a Pesaro nel I475, furono allietate da numerose rappresentazioni dove figuravano - come ricorda un manoscritto miniato pressoché coevo - animali esotici contraffatti. ${ }^{203}$ Durante il banchetto nuziale, scandito da intermezzi, il regalo offerto dai Giudei dell'Università di Pesaro fu presentato dalla regina di Saba assisa su di un baldacchino trasportato da un elefante "si ben contrafacto, che quasi pareva vero, né si vedeva chi 'l portasse, anci de sé medesimo se vedeva caminare: si bene erano compartite le gambe di li homini, ch'erano dentro cum quello de lo elephante, che impossibile seria scrivere, chi non l'avesse veduto el mirabile artificio d'esso", seguito da altri due pachidermi ciascuno con un castello di legno sulla groppa che ospitava donzelle. ${ }^{204} \mathrm{Il}$ giorno seguente fu la volta del cammello «si ben contrafacto, et cum tanta arte che pareva vivo et era grande, et apriva la bocha et destendeva el collo et colcavasse in terra como fano li veri camelli» che durante la colazione sfilò tra gli ospiti montato da un etiope intento a dispensare ogni sorta di dolci contenuti nelle ceste dorate fissate al dorso dell'animale. ${ }^{205}$ E ancora, nel 1492 a Napoli, per celebrare la

I99. Dai documenti pare che il portico fosse già terminato nel I473, mentre l'affresco è menzionato da Ludovico il Moro nel I 497 vedi Il Castello Sforzesco 2005, pp. I37-I38.

200. ZAMBOTTI I934-I937, pp. 59, 90; CALEFFINI 2006, pp. 304-305. Vedi anche MELI 2009, pp. 244, 269 nota II.

20I. TUOHY I996, p. 346; COCKRAM 20I7, p. 283

202. MAXWELL I992, pp. 847-848; BERTELLI 2006, pp. I2-I3; CISERI 20I4, p. II7.

203. A Renaissance Wedding 2013, pp. IOI, I2I.

204. Le nozze I946, pp. 35-37.

205. Ivi, p. 50. 


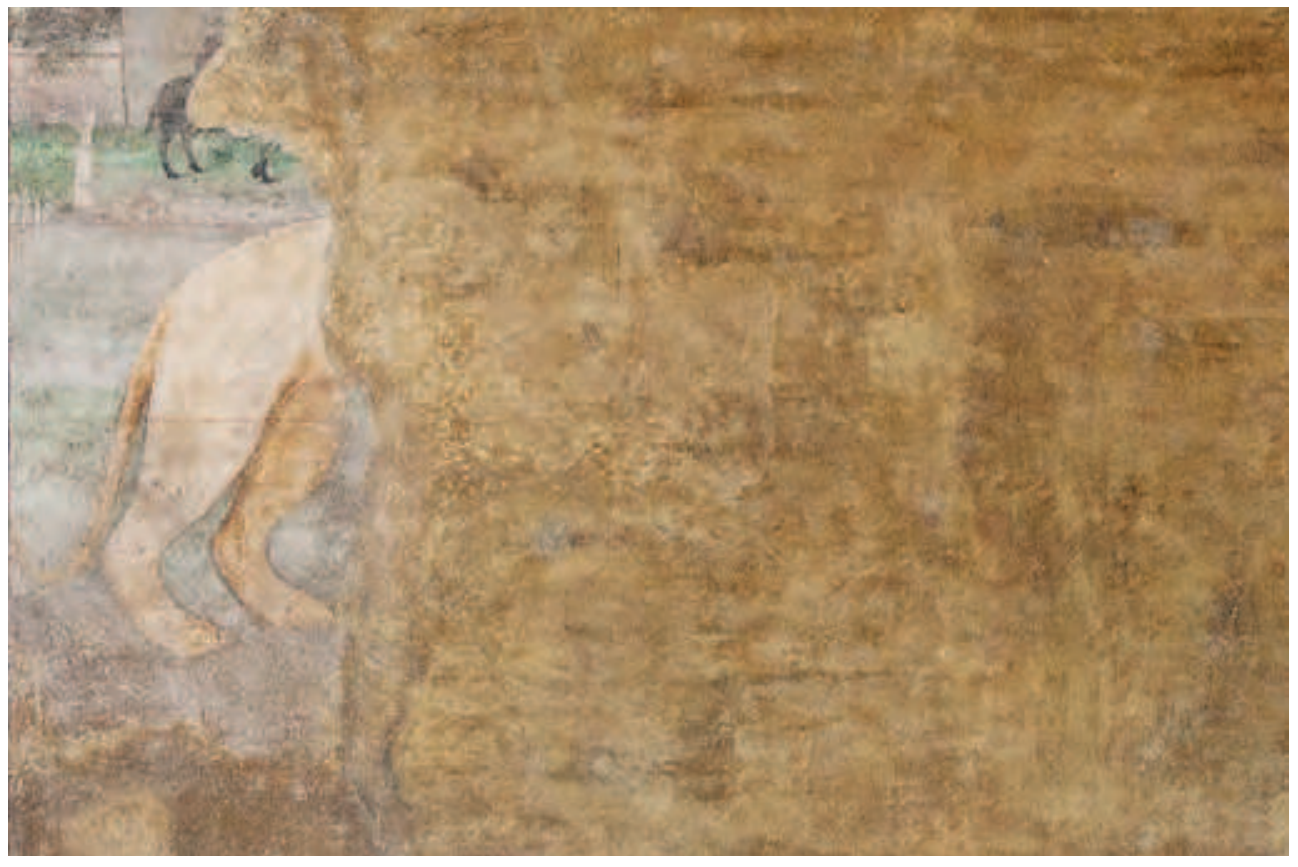

Fig. 3: Artista lombardo,

Tigre (?), I $480-\mathrm{I} 490 \mathrm{ca}$.

Milano, Raccolte d'Arte Antica del Castello Sforzesco 
presa di Granada, fu allestito un carro con il Trionfo della Fama trainato da due elefanti incatenati, in realtà "bufali acconci a guisa di elefanti» tipologia che fu riproposta a Firenze nel I5I3. ${ }^{206}$ Nello stesso anno Baldassarre Castiglione, autore della scenografia degli intermezzi per la commedia Calandrina andata in scena a Urbino, fece realizzare degli struzzi e dei pappagalli «di quelli tanto macchiati di diversi colori» che «mai più si sia finto cosa così simile al vero». ${ }^{207}$

La pratica di impiegare animali simulati fu in uso anche presso le corti europee. Il I7 febbraio I 454 a Lille fu organizzato, per volere di Filippo il Buono, il celebre Banchetto del fagiano, durante il quale gli ospiti giurarono di prendere parte alla crociata progettata da papa Martino V per combattere i musulmani che l'anno precedente si erano impossessati di Costantinopoli. Le quarantotto portate del convivio furono scandite da intermezzi a tema con allegorie che comprendevano, oltre a un leone vivo simbolo del duca di Borgogna e una donna incatenata riferimento alla città bizantina in mani turche, un finto elefante con una donna in preghiera sulla groppa quale personificazione della Chiesa. ${ }^{208}$ Nell'aprile $\mathrm{I} 458$, invece, per festeggiare il solenne ingresso di Filippo il Bello a Gand fu congegnato un automa in forma di elefante con un castello sulla groppa, dentro al quale due uomini e quattro fanciulli con il volto dipinto di nero e abbigliati con vesti esotiche cantavano «Vive Bourgogne! est notre cri», dalla cui proboscide sgorgava del vino. ${ }^{209}$

L'interesse per gli animali esotici nella Firenze nel XV secolo non si limitò, però, agli spettacoli: nei giardini, dove si custodivano gli animali rari in libertà oppure all'interno di gabbie e voliere, i cespugli di bosso si animarono, grazie all'abilità di giardinieri esperti nell'arte topiaria, fino ad assumere le sembianze di «un elefante», nel nuovo palazzo di Cosimo de' Medici in via Larga, oppure di «bertuccie, dragoni, cientauri, chammelli» nel «pratello molto piacevole, circundato di muricioli cum molti bossi e di molti ritratti in figure» nella villa di Giovanni Rucellai a Quaracchi. ${ }^{210}$

206. CISERI 20I4, p. i 77; VASARI I966-I997, vol. 5, p. 3 I2.

207. RUFFINI I986, p. 3 Io.

208. BURCKHARDT I980, p. 347. Vedi anche LACH I965-I993, vol. 2.I, p. I32 (data l'evento al I453).

209. CUTTLER I99i, p. I76 nota I5; ARNADE I996, pp. I36-I37; MARTENS 2002, p. 30.

2 I0. ACIDINI LUCHINAT I996, p. I74; RUCELLAI 20I3, pp. I42-I 43. 



\section{Reminiscenze medievali e riscoperta dei testi antichi}

\section{Enciclopedie medievali}

All'epoca la conoscenza assai limitata degli animali esotici era per lo più dovuta a enciclopedie e bestiari, tra cui un posto di primo piano spettava certamente alla versione latina del Physiologus (II-IV secolo), ancora considerato un testo di riferimento nonostante l'interpretazione in chiave prettamente mistico-allegori$\mathrm{ca}^{2 \text { II }} \mathrm{Ma}$ quale influenza esercitarono le auctoritates sulle descrizioni della fauna esotica fornite dai viaggiatori fiorentini che nel XIV e nel XV secolo in Oriente avevano avuto la possibilità di osservarla dal vero? E in quale misura?

A questo proposito Jacques Le Goff sostiene che i viaggiatori:

ne savent pas regarder, mais sont toujours prêts à écouter et à croire tout ce qu'on leur dit. Or, au cours de leurs voyages, on les abreuve de récits merveilleux et ils croient avoir vu ce qu'ils ont appris, sur place sans doute, mais par ouï-dire. Surtout, nourris au départ de légendes qu'il tiennent pour vérités, ils apportent leurs mirages avec eux et leur imagination crédule matérialise leurs rêves dans des décors qui les dépaysent suffisamment, pour que, plus encore que chez eux, ils soient ces rêveurs éveillés qu'ont été les hommes du Moyen Âge

mentre dall'analisi degli scritti dei fiorentini sembra affiorare un'attitudine, almeno in parte, diversa. ${ }^{212}$ Per comprendere appieno questo fenomeno è indispensabile verificare su quali letture si fondava la loro cultura per poi porla in relazione con le descrizioni degli animali esotici presenti nei loro diari odeporici. Nel XIV e nel XV secolo il testo più diffuso nelle biblioteche dei mercanti fiorentini fu il Tresor di Brunetto Latini, compilazione enciclopedica tardo duecentesca in lingua volgare che comprendeva un vero e proprio bestiario. ${ }^{213}$ Non si trattava certo di un'opera innovativa: nei capitoli dedicati agli animali gran parte delle notizie furono attinte da fonti antiche - la Naturalis historia di Plinio il Vecchio (I secolo), la Collectanea rerum memorabilium di Solino (III secolo) e le Etymologiae di Isidoro da Siviglia (VII secolo) - nelle quali l'impostazione prettamente intellettuale andava a scapito dell'osservazione diretta. ${ }^{214}$ Ancora influenzato dai bestiari -

2 I I. Il Physiologos è un bestiario scritto ad Alessandria tra il II e il IV secolo che riunisce animali reali e fantastici attribuendogli vizi e virtù, opera che nel Medioevo riscosse grandissimo successo.

212. LE GOFF, I970, p. 247. Opinione già avanzata da Rudolf Wittkower, WITTKOWER I987, pp. I29-I32.

2I3. Per il Tresor di Brunetto Latini vedi pagine 6I-62.

2I4. BELTRAMI 2007, p. XVII. Tra la versione francese e quella italiana si riscontra qualche differenza: il passo sull'ibis è accorpato a quello dedicato al cigno, sono stati aggiunti capitoli dedicati al cuculo, al rigolo, al 
avendo incluso la sirena, il basilisco e l'unicorno - che non operavano alcuna distinzione tra animali reali e fantastici, il Tresor appare invece moderno nell'adozione di una prospettiva più zoologica che si discosta dal tradizionale modello della descrizione dell'animale associata a un significato morale. ${ }^{215}$ La cesura tra $i$ bestiari moralizzati e l'enciclopedia di Brunetto Latini trova - secondo Brigitte Roux - una spiegazione:

au changement de destination des encyclopédies: les plus anciennes sont destinées à l'édification d'un public plutôt restreint, des moines ou des nonnes, tandis que les plus récentes, notamment lorsqu'elles sont rédigées dès le départ dans une langue vernaculaire, visent une audience plus large, n'appartenant pas obligatoirement au monde conventuel. Cet élargissement du public va de pair avec une diversification des usages de ces textes. ${ }^{216}$

Proprio sulla scia di questo mutamento, qualche decennio più tardi anche negli scritti dei mercanti fiorentini, e non solo di quelli avventuratisi in Oriente, si affermò una visione più "zoologica" degli animali. Quando nel I33I a Firenze due leoncini furono partoriti in cattività Giovanni Villani nella Cronica annotò:

e' nacquono vivi e non morti come dicono gli autori ne' libri della natura delle bestie, e noi ne rendiamo testimonianza, che con più altri cittadini gli vidi nascere, e incontanente andare a poppare la leonessa

smentendo, sulla base di un'osservazione diretta, una leggenda tramandatasi di bestiario in bestiario fino a Brunetto Latini che, pur specificando di non aver appurato personalmente, aveva accolto nel Tresor:

i leoncini sono così sgomenti che giacciono svenuti per tre giorni, proprio come fossero senza vita; finché alla fine dei tre giorni arriva loro padre, che grida verso di loro alzando così forte la voce che i figli si sollevano e seguono la loro natura. ${ }^{217}$

L'uso di bestiari ed enciclopedie fu quindi duplice: le informazioni contenute furono confrontate con quanto osservato personalmente per verificarne l'attendibilità, come nel caso di Giovanni Villani che negava la credenza dei cuccioli di leone nati morti e portati in vita dalla voce del padre, oppure accolte per conferire attendibilità alle «maraviglie» narrate nei resoconti di viaggio che altrimenti sareb-

picchio e allo «zevere» (per la definizione dell'animale vedi pagina I4 I nota 229), quello sulla pecora eliminato mentre le peculiarità della capra e del becco attribuite al capriolo.

2I5. ROUX 2009, p. 227. Il Libro della natura degli animali - detto anche Bestiario toscano - di autore anonimo e composto nell'Italia settentrionale alla fine del XIII secolo, quindi praticamente coevo al Tresor di Brunetto Latini, ha un carattere ancora marcatamente edificante nel focalizzare l'attenzione su vizi e virtù a scapito delle descrizioni fisiche degli animali vedi Bestiari medievali I996, pp. 425-429.

2I6. ROUX 2009, p. 273.

217. VILLANI I844-I845, vol. 3, p. I66, libro X, CLXXXIII; LATINI 2007, p. 29i, libro I, I74:8; LOISEL I9I 2, p. I52. Credenza che si trova nel Physiologus e nelle Etymologiae di Isidoro da Siviglia, mentre Plinio il Vecchio non ne parla affatto, Il Fisiologo 20I I, p. 40:I; SIVIGLIA 2004, vol. 2, p. 27, libro XII, II:5; PLINIO 20 I I, pp. 5 I-63, libro VIII, XVII-XXI. 
bero apparse inverosimili al lettore. ${ }^{218}$ Forse per questo motivo l'idea ormai consolidata delle gambe dell'elefante prive di giunture, che gli impedivano di inginocchiarsi o sdraiarsi perché altrimenti non sarebbe più stato in grado di rialzarsi, trovò largo seguito anche tra coloro che gli elefanti li avevano visti per davvero. ${ }^{219}$ Non è neppure da escludere che una certa influenza possano averla esercitata i testi religiosi, attraverso la lettura o la predicazione, tra cuil'omelia di Basilio (IV secolo) dedicata alla creazione divina che a proposito dell'elefante asseriva:

le gambe non sono da giuntura alcuna separate, perché come altrettante colonne regger possano al peso. Che se stata gli fosse sottoposta un'ossatura e gracile e pieghevole, spessissimo fuori dalle proprie cavità uscite sarebbero le giunture; sia che la fiera curvasse le ginocchia, sia che sorgesse; né avrebbe bastato a sostener sì gran molte. Quindi vediamo picciola una caviglia, che né presso al nodo discorre né sul ginocchio si torce, annessa al piede dell'elefante; chè altrimenti fora spettacolo a vedersi quel corpulento animale per incostanza e mobilità delle giunture mal reggersi sovr'esse e andar qua e là tentennando.220

È infatti curioso come la maggior parte dei viaggiatori fiorentini tre e quattrocenteschi, pur avendo avuto modo di vedere gli elefanti al Cairo, nelle loro descrizioni avessero continuato a riportare questa informazione errata. ${ }^{22 I}$ Sarà stato per una sorta di rispetto nei confronti delle fonti antiche che non si sentivano all'altezza di contraddire? Oppure perché non avevano avuto l'occasione di osservare gli elefanti inginocchiarsi avendoli nella maggior parte dei casi visti con i piedi legati a dei pali?

Uniche voci fuori dal coro furono quella del mercante Simone Sigoli quando riferiva, a proposito dell'elefante visto al Cairo nel I384, che il guardiano gli grattava il corpo per farlo sedere o sdraiare e quella dell'ambasciatore Felice Brancacci che narrava di aver presenziato, durante il soggiorno al Cairo nel I422, a uno spettacolo con un elefante addestrato che obbediva agli ordini di sdraiarsi e rialzarsi impartitigli dal domatore. ${ }^{222} \grave{E}$ altresì sorprendente constatare, nonostante l'animale avesse inconfutabilmente dimostrato di possedere giunture nelle ginocchia, la reticenza di Simone Sigoli a sconfessare la tradizione letteraria, si era infatti affrettato ad aggiungere, contraddicendosi, «se ssi ponesse in terra a giacere non se ne potrebbe levare, però ch'elli à le ganbe et le coscie quasi d'un pezzo", e quella di Felice Brancacci, che aveva vagamente annotato «non à ginocchio ma piega la gamba su alto alla spalla». ${ }^{223}$ A confermare che i pachidermi fossero dotati

2I8. BUQUET 20I3a, p. 29.

2I9. Vedi pagina IO4 nota 78 .

220. BASILIO i 844 , p. I68. Nella biblioteca di Niccolò Niccoli erano presenti alcuni volumi con i testi di Basilio, mentre una traduzione dell'Hexaemeron con le sue omelie si trovava presso la Badia Fiesolana vedi The Public Library I972, p. 63; VITI 2012, p. I68.

22I. Vedi pagine IOI, IO7-IIO.

222. Vedi pagine Io9-I Io.

223. Ibid. Thierry Buquet ritiene che sottolineando l'abilità dell'elefante a sedersi, sdraiarsi e piegare le ginocchia Felice Brancacci confuti la tradizione, affermazione - a mio avviso - solo in parte veritiera dato che nel descrivere l'animale non tralascia di aggiungere che è privo di giunture nelle ginocchia vedi BUQUET 20 3a, p. 30. 
di giunture nelle ginocchia sarà il mercante e navigatore veneziano Alvise Ca' da Mosto nei primi anni sessanta del XV secolo quando, a proposito degli esemplari visti in Senegal, scriveva:

Dechiarando etiam che li diti alefanti hano zenochi [ginocchia] e desnodase [si piegano] nel andar como ogni altro animal: dico questo, perché avea intesso [sentito] dir avanti che fosse in queste parte, che li alefanti non se podea inzenochiar e che dormia in piè; ch'è una gran bosia [bugia], perché se butano in terra e levanse [si rialza] como ogni altro animal. ${ }^{224}$

Concetto che aveva prontamente ribadito dopo averne osservati altri in Gambia:

Non creda algun che lo elefante non se desnodi ne li zenochi, como altre volte ho aldito [udito] dir avanti che fosse in queste parte; anzi se desnoda e va e gietase zoso [a terra] e suso [si rialza] como li altri animali. 225

Sembra, quindi, di poter cogliere nelle descrizioni degli animali esotici l'affiorare di un approccio diverso, sebbene ancora allo stato embrionale, che prendendo le distanze dalle nozioni per secoli tramandate da bestiari e enciclopedie era ora orientato verso una conoscenza empirica, per quanto possibile, della realtà. Se sullo scorcio del XIV secolo Simone Sigoli, pur avendo visto l'elefante sedersi e sdraiarsi, non aveva osato screditare le auctoritates e, a distanza di qualche decennio, Felice Brancacci aveva preferito mantenersi elusivo, un cinquantennio più tardi Alvise Ca' da Mosto non aveva minimamente esitato a sostenere, poiché verificato di persona, che gli elefanti fossero muniti di giunture nelle ginocchia. ${ }^{226}$

Germogli di questo nuovo orientamento si rintracciano, in forma visiva, in una copia del Tresor di Brunetto Latini, trascritta tra il I3IO e il I320 e miniata alla fine del secolo, dove tra le raffigurazioni poste a corredo dei capitoli dedicati agli animali alla voce "pantera", ossia "piccola bestia macchiata di piccoli cerchi bianchi e neri a forma di piccoli occhi», fu affiancata l'immagine di una zebra forse nel tentativo di far corrispondere alla descrizione un animale assai simile, almeno cromaticamente, presente in natura. ${ }^{27}$ Ancora più interessante è il fatto che l'illustrazione non poteva essere stata suggerita da Brunetto Latini: negli anni in cui il manoscritto fu miniato era già deceduto e, comunque, durante il suo breve soggiorno come ambasciatore presso la corte di Siviglia non ebbe modo di vedere la zebra inviata, insieme ad altri animali esotici, dal sultano egiziano Baybars I ad Alfonso X. Se la data dell'arrivo della fauna esotica in Spagna è incerta, dato che la Crónica de Alfonso X ricorda l'episodio senza però fornire alcuna

224. Le navigazioni atlantiche I966, p. 65 .

225. Ivi, p. 108.

226. In realtà, la prima affermazione sulle ginocchia degli elefanti dotate di giunture si rintraccia nel Liber de quibusdam ultramarinis partibus (I336) del cavaliere tedesco Guglielmo di Boldensele e, per quanto riguarda le auctoritates, nella Naturalis historia di Plinio il Vecchio, BUQUET 20 I3a, pp. 29-30; per il passo pliniano vedi pagina Io4 nota 78 .

227. ROUX 2009, pp. I3I, 338-339; LATINI 2007, p. 32 I, libro I, I93:I e fig. 7. 
indicazione in merito, l'ipotesi più accreditata è quella che lo fa risalire al maggio I26I, vale a dire quando la missione diplomatica di Brunetto Latini era ormai conclusa. ${ }^{228}$ Cronologia che, tra l'altro, giustificherebbe l'assenza nel Tresor delle descrizioni della zebra e della giraffa, animali esotici all'epoca sconosciuti ricevuti in dono dal sovrano spagnolo e raffigurati nelle Cantigas de Santa Maria (fig. 4), che Brunetto Latini avrebbe certamente incluso se avesse avuto l'opportunità di vederli. ${ }^{229}$ È perciò plausibile supporre che nel ritrarre la zebra il miniatore italiano si fosse ispirato al racconto orale di qualche viaggiatore o alla lettura, forse mentre impegnato a decorarne una copia, delle Mirabilia descripta (I329-I330) del frate domenicano Jordan Catala de Sévérac che a proposito di una regione vicino all'Etiopia annotava: "Il y a certains animaux qui ressemblent à des ânes, rayés en travers de noir et blanc, de telle façon qu'une raie est noire et l'autre blanche. Ces animaux sont si beaux que c'en est merveilleux». ${ }^{230}$

Altro testo che rivela l'interesse fiorentino per la conoscenza del regno animale è il De animalibus (I260 ca.) di Alberto Magno, copiato da Vespasiano da Bisticci nella seconda metà del XV secolo per volere di Cosimo de' Medici e presente nell'inventario dei manoscritti posseduti dalla Badia Fiesolana nel I464. ${ }^{23 \mathrm{I}}$ Composta da ben ventisei libri, l'opera redatta dal maestro di teologia domenicano era assolutamente innovativa nel trattare gli animali in maniera analitica: una sorta di manuale scientifico di zoologia che raccoglieva informazioni sulla struttura anatomica, sulla vita e il comportamento degli animali - in gran parte attinte dall'Historia animalium (IV secolo a.C.) di Aristotele e integrate con testi di autori quali Avicenna e Isidoro da Siviglia - a loro volta completate da notizie sulla biologia e la riproduzione che l'autore aveva acquisito attraverso l'osservazione diretta o interrogando chi in prima persona se ne prendeva cura. Risultato delle approfondite ricerche condotte da Alberto Magno fu un testo che, quando fondato sull'esperienza, gli consentì di confutare quanto tramandato da auctoritates

228. BELTRAMI 2007, pp. IX-XI nota I5; BUQUET 20I3c, pp. 38I-382. Di opinione diversa è Joseph O'Callaghan che ritiene di poter datare l'arrivo degli animali esotici alla corte di Siviglia al maggio I260, in concomitanza con la commemorazione della morte del padre di Alfonso X tenuta ogni anno il 3I maggio. Questa datazione è - a mio avviso - da escludere dal momento che alla fine di luglio Brunetto Latini non era ancora partito da Firenze mentre il 4 settembre, di ritorno dalla Spagna, si trovava già nei pressi della città del giglio, pertanto se la fauna esotica fosse stata presente alla corte spagnola durante il suo soggiorno l'avrebbe senza dubbio menzionata vedi O’CALLAGHAN i998, p. 95.

229. BUQUET 20I3b, p. I04; ID. 20I3c, p. 382 . L'animale chiamato "zevere», presente in alcuni manoscritti del Tresor in lingua italiana, è stato da alcuni studiosi identificato con la zebra ma in realtà è un equino selvatico in epoca medievale particolarmente diffuso nella penisola iberica vedi LATINI I9I7, pp. I62-I63, libro V, L; AEBISCHER I959, pp. I65-I75; BUQUET 20I3c, pp. 383-385.

230. GADRAT 2005 , p. 288 n. II5. Se le miniature del manoscritto vaticano sono dovute alla collaborazione tra un artista francese e un artista italiano, la pagina con la figura della zebra è opera di quest'ultimo vedi ROUX 2009 , p. 235. Altro esempio delle difficoltà incontrate dai miniatori nel rendere visivamente animali noti soltanto attraverso i resoconti dei viaggiatori è il Codice Cocharelli dove una giraffa è raffigurata con struttura fisica perfettamente conforme alla realtà ma con manto zebrato, indizio che le informazioni su giraffa e zebra furono confuse (per l'immagine vedi CAMILLE I992, pp. 48, 5I fig. 27). Per il Codice Cocharelli vedi pagine I66-I70.

23I. TAITI 20I4, pp. 94-97. 


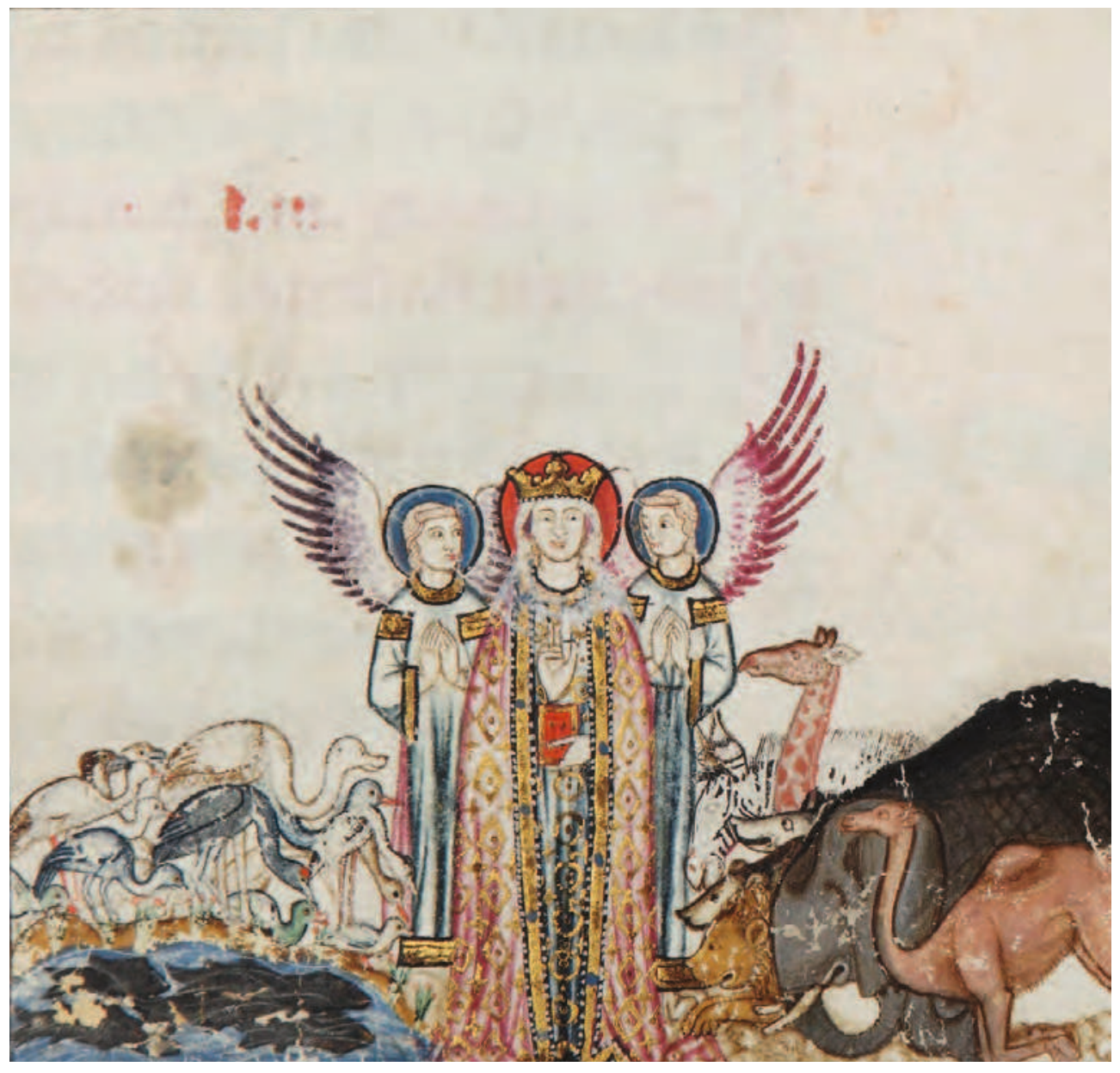

Fig. 4: Miniatore anonimo,

Vergine con animali,

Cantigas de Santa Maria, I270 ca.

Madrid, Biblioteca dell'Escorial (ms. T.I.I, c. 44r) 
del calibro di Aristotele e Plinio il Vecchio, prospettandosi così nel ruolo di anticipatore del metodo basato sulla ricerca scientifica. ${ }^{232}$

\section{Naturalis historia di Plinio il Vecchio}

Se nel XIV e nel XV secolo il ruolo svolto da enciclopedie e bestiari nella conoscenza degli animali esotici non è certo da sottovalutare, quale fu l'influenza della Naturalis historia di Plinio il Vecchio che ampio spazio aveva dedicato alla zoologia?233

La prima copia del testo pliniano completo di tutti e trentasette i libri, ma in forma abbreviata e scorretta, disponibile a Firenze fu quella che Giovanni Boccaccio aveva ricevuto in prestito, forse nel I355, dall'amico e collega Francesco Petrarca, volume della fine del XIII secolo acquistato dal poeta qualche anno prima a Mantova. ${ }^{234}$ Le postille apposte dai due letterati, dopo averlo studiato a fondo, lungo i margini del manoscritto rivelano un interesse prevalentemente focalizzato sulle notizie attinenti al mondo greco-romano e alla geografia, dimostrando scarso interesse per il regno animale. ${ }^{235}$ È possibile che il testo fosse stato consultato, oltre che da Boccaccio, anche da una ristretta cerchia di amici e conoscenti, ma si trattava comunque di un libro in lingua latina che doveva aver avuto una limitatissima circolazione, soprattutto nell'ambiente mercantile fiorentino.

Nel I378 il cancelliere Coluccio Salutati, scoraggiato per non essere riuscito ad accaparrarsi una Naturalis historia, inviò una lettera a Domenico Bandini chiedendo il suo aiuto, ma solo oltre un decennio più tardi riuscì finalmente a procurarsi una copia incompleta, poi passata nelle mani di Leonardo Bruni, Antonio Panormita e, infine, nella biblioteca aragonese di Napoli. ${ }^{236}$ Sempre negli stessi anni il mercante

232. TONGIORGI TOMASI I987, p. 94; TAITI 20I4, pp. 94-97 n. I9. Nei primi decenni del XIII secolo Michele Scoto tradusse dall'arabo in latino l'Historia animalium di Aristotele e il compendio De animalibus di Avicenna dedicandoli al suo protettore Federico II di Svevia vedi MAGNO I999, vol. I, pp. 34-42. È singolare che a proposito dello struzzo, studiato dal vero perché allevato alla corte sveva, Alberto Magno avesse accolto la credenza tramandata dalle auctoritates di un volatile che non covava le uova bensì lasciava che fosse il calore del sole a farle schiudere. Comportamento - a mio avviso - dovuto al fatto che Federico II avesse incluso questa informazione nel De arte venandi cum avibus e Alberto Magno non intendeva certo contraddire il suo protettore vedi D'ELIA 20I5, p. 23; FEDERICO II 2000, p. I27, I:I06.

233. Nella Naturalis historia ben quattro libri (VIII-XI) sono dedicati alla zoologia, ma le informazioni relative agli animali esotici si trovano nel libro VIII. Sembra che fino al XIV secolo non fossero disponibili copie del testo realizzate in Italia vedi REEVE 2007 , p. 158.

234. PASTORE STOCCHI I963, pp. 64-73; DI BENEDETTO I972, p. 439; Firenze e la scoperta I992, pp. 50-53 n. 22; CARRARA 2020, 2.2. Il manoscritto pliniano appartenuto a Petrarca si trova ora alla Bibliothèque Nationale de France di Parigi (ms. Lat. 6802).

235. MCHAM 20I3, pp. 62-64. Per un approfondimento sugli interessi specifici di Petrarca e Boccaccio nei confronti della Naturalis historia vedi CARRARA 2020, 2.2.

236. La copia di Coluccio Salutati, datata al XII secolo e realizzata nella regione mosana, comprendeva solo i libri VI-XXXVII e fu smembrata in data anteriore al I508: i libri VI-XV si trovano ora alla Bodleian Library di Oxford (ms. Auct. T.I.27) e i libri XVI-XXXVII alla Bibliothèque Nationale de France di Parigi (ms. Lat. 6798) vedi SALUTATI I89I-I9I I, vol. i, p. 29I; HUNT I965, p. 77; DI BENEDETTO I972, p. 439; Firenze e la scoperta I992, p. 56 n. 23; DAVIES 2002, p. I27; REEVE 2007, p. I58 nota I08; CORFIATI 20I2, pp. 255-256; VITI 20I2, pp. I55-I56; MARCELLI 2020, 3 . 
e bibliofilo Niccolò Niccoli ne possedeva una copia mutila sulla quale appose numerose annotazioni in gran parte concentrate nella sezione dedicata alla geografia. ${ }^{237}$ Anche il colto mercante e instancabile raccoglitore di libri Antonio Corbinelli, amico di Coluccio Salutati e Niccolò Niccoli, agli inizi del XV secolo custodiva una copia del testo pliniano nella sua fornitissima biblioteca dove fu consultata e postillata dall'umanista veronese Guarino Guarini quando, chiamato a insegnare a Firenze, fu suo ospite dal I4IO al I4I4..$^{238}$

Nonostante la Naturalis historia fosse un'opera molto richiesta Vespasiano da Bisticci - celebre "cartolaio» a capo di una famosa bottega fiorentina specializzata nella vendita e trascrizione di manoscritti destinati a committenti italiani ed europei - nella biografia di Poggio Bracciolini lamentava le difficoltà nel reperirne una copia completa affermando che alla fine degli anni venti del XV secolo «Plinio non era in Italia», per poi aggiustare il tiro in quella di Niccolò Niccoli ammettendo che «Plinio intero non era in Firenze, se non uno framentato». ${ }^{239} \mathrm{E}$, infatti, nei primi decenni del XV secolo Cosimo de' Medici era alla ricerca di una copia il più integra possibile. Dopo aver rifiutato di acquistare per la loro incompletezza i volumi posseduti da Leonardo Bruni e Niccolò Niccoli, dimostrò un vivo interesse per il manoscritto «finito et perfetto» che Ludovico Baglioni, socio di Gherardo Bueri nella filiale tedesca del banco mediceo, gli aveva segnalato presso il monastero domenicano di Lubecca. ${ }^{240}$ Spronato dalle pressanti sollecitazioni di Niccolò Niccoli, grande collezionista di testi antichi, Cosimo il Vecchio incaricò Gherardo Bueri di condurre le trattative, che si conclusero dopo lunghe e complesse negoziazioni nel I 438 con la concessione del prestito della Naturalis historia in cambio di un sostanzioso deposito in denaro e la promessa di restituire l'opera appena terminata la trascrizione. A seguito di alcune controversie sorte con i religiosi, il signore mediceo decise di rinunciare alla cauzione e di tenersi il prezioso manoscritto, primo testimone integro presente in città. ${ }^{24 \mathrm{I}}$

237. Firenze e la scoperta I992, pp. 54-56 n. 23; DAVIES I995, p. 24I; ID. 2002, p. I27; REEVE 2007, pp. I30I3 I; I manoscritti datati della Biblioteca Riccardiana, I997-20I3, vol. I, p. 64 n. II3; MARCELLI 2020, 3. Questa copia del X secolo priva dei libri XIV-XX, XXIII-XXIV e XXXVII, ora alla Biblioteca Riccardiana di Firenze (ms. Riccardiano 488), nel XII secolo si trovava presso il monastero di Saint-Pierre a Beauvais.

238. BEC I967, p. 4I4; BLUM I951, pp. I8, 50-55, 90 n. 5I5, I39 n. 5I5; REEVE 2007, pp. I59-I60; ROLLO 2004, p. 56 nota I; ID. 2005 , p. I5 nota I; MARCELLI 2020, 3 (indica erroneamente ms. Conventi soppressi 230 ). Il manoscritto, ora alla Biblioteca Medicea Laurenziana di Firenze (ms. Conventi soppressi 203), alla morte di Antonio Corbinelli fu lasciato in usufrutto vitalizio, insieme agli altri volumi della biblioteca, all'amico Jacopo di Niccolò Corbizzi e solo dopo la scomparsa di quest'ultimo confluì nella biblioteca della Badia Fiesolana. Per un approfondimento su Antonio Corbinelli e la sua biblioteca vedi ROLLO 2004, pp. 25-95. Per un approfondimento sulla bottega di Vespasiano da Bisticci vedi DE LA MARE I996, pp. I67-207.

239. DI BENEDETTO I972, pp. 437-438; DAVIES I995, p. 240; BISTICCI I970-I976, vol. I, p. 544; vol. 2 , p. 229. Sebastiano Gentile ipotizza che la Naturalis historia frammentaria di cui parla Vespasiano da Bisticci fosse quella di Niccolò Niccoli vedi Firenze la scoperta I992, pp. 54-56 n. 23.

240. HUNT I965, p. 77; STADTER I984, vol. 2, pp. 762-763; VITI 2012, p. I58.

24I. BISTICCI I970-I976, vol. I, pp. 544-545; DI BENEDETTO I972, pp. 437, 439-444; The Public Library I972, p. 70; Firenze e la scoperta I992, pp. 56-58 n. 24; DAVIES I995, pp. 240-24I; REEVE 2007, p. I44; MARCELLI 2020, 3. Il manoscritto di Cosimo il Vecchio, ora alla Biblioteca Medicea Laurenziana (Plut. 82.I-2), fu copiato agli inizi del XIII secolo in nord Europa. 
Erano anni in cui tutti anelavano a possedere una copia del testo pliniano. Nel I 445 Tommaso Tebaldi, segretario di Filippo Maria Visconti, inviò una lettera a Leonello d'Este chiedendo in prestito una Naturalis historia per copiarla, richiesta rifiutata dal duca di Ferrara, che ne possedeva ben due, adducendo come giustificazione il fatto che un volume era stato mandato al signore di Cesena Malatesta Novello e l'altro di grande pregio doveva restare nella biblioteca di corte. ${ }^{242}$ A Firenze, tra i beni posseduti da Piero de' Medici nel ${ }_{45} 6$ figura una Naturalis historia in «libri VI, volumi VI» mentre al $\mathrm{I}_{45} 8$ si datano i due manoscritti riccamente ornati commissionati a Vespasiano da Bisticci, e sempre a un membro della famiglia medicea si deve la copia destinata alla biblioteca della Badia Fiesolana realizzata dalla bottega di Vespasiano tra il 1465 e il I $467 .{ }^{243}$

A testimoniare le difficoltà nel reperire una copia del libro pliniano è una lettera inviata nel I 446 dall'abate e umanista aretino Girolamo Aliotti a un amico per comunicargli la sua intenzione di trascrivere la Naturalis historia e, quindi, la necessità di rivolgersi a Vespasiano da Bisticci perché gli procurasse un esemplare in prestito, ma il suo proposito doveva essere andato miseramente in fumo se nel I 460 si rammaricava del fatto che il testo fosse ancora raro e noto solo a pochi medici. ${ }^{244}$ Ben si comprende, allora, perché con l'avvento della stampa uno dei primi libri a essere pubblicato fu la Naturalis historia, la più grande enciclopedia dell'antichità. L'editio princeps vide la luce a Venezia nel I 469 ma, colma di errori e inesattezze dovute alle difficoltà nel reperire materiale per approntare un'edizione critica, non riscosse alcun successo. ${ }^{245}$ L'anno seguente fu la volta dell'edizione critica a cura del vescovo Giovanni Andrea Bussi, che si avvalse della collaborazione del greco Teodoro Gaza, pubblicata a Roma e ristampata a Venezia nel I472, oggetto di aspre critiche per alcuni interventi emendatori e i numerosi errori. ${ }^{246}$ Per tutta risposta nel I 473 il vescovo Niccolò Perotti presentò una nuova edizione, anche in questo caso non esente da critiche. ${ }^{247}$

242. SAVINO I994, pp. 43-46; MARCELLI 2020, 3. In realtà, nel I389 il milanese Pasquino Capelli, segretario di Giangaleazzo Visconti, possedeva una sontuosa copia della Naturalis historia miniata da Pietro da Pavia; caduto in disgrazia e fatto giustiziare dal duca, non sembra però essere confluita nella biblioteca viscontea poiché assente dagli inventari del I426 e del I459 (Milano, Biblioteca Ambrosiana, ms. E. 24 inf.) vedi ARMSTRONG I983, pp. 26-29.

243. AMES-LEWIS I982, p. I25 n. 75; Inventari medicei I996, p. II3. I due manoscritti appartenuti a Piero de' Medici, ora alla Biblioteca Medicea Laurenziana di Firenze (Plut. 82.3-4), furono copiati dalla Naturalis historia appartenuta al padre Cosimo il Vecchio così come pure il testo destinato alla Badia Fiesolana, ora alla British Library di Londra (ms. Harley 2676) vedi AMES-LEWIS I984, pp. 330 n. 84, 332-333 n. 85 (Plut 82.4 destinato a Giovanni de' Medici e alla sua morte passato al fratello Piero); GARZELLI I985, pp. 56-57, 7I, I32-I34 (Plut. 82.4 destinato a Giovanni de' Medici); DE LA MARE I985, pp. 433, 570D (Plut. 82.4 destinato a Giovanni e alla sua morte passato al fratello Piero); EAD. I996, pp. I88 (indica solo il Plut. 82.3 quale commissione di Piero de' Medici), I92; FANTONI 2005, pp. 309-3IO n. I88 (Plut. 82.4 forse commissionato per il fratello Giovanni); TORTELLI 2005, pp. 470-473 n. I02; ANTONUCCI 2007, pp. 54-55 n. I9; MARCELLI 2020, 3. Nell'inventario stilato nel I 464 si trova un "Plinius de naturalis historia licteris antiquis, coperta crocea $\mathrm{f}$. Ioo", opera che Francis Ames-Lewis ipotizza essere il Plut. 82.3 vedi Inventari medicei I996, p. I55, AMES-LEWIS I984, p. 330.

244. DE LA MARE I996, p. i82; ALIOTTI i769, vol. I, p. 425.

245. Firenze e la scoperta I992, p. 58 n. 25; DAVIES I995, pp. 24I-242; ID. 2002 , p. I28; MCHAM $20 \mathrm{I}_{3}$, p. I 47. Vedi anche MONFASANI I988, p. 4 e in particolare nota 9.

246. Ivi, pp. 3-9; DAVIES 2002, pp. I29-I38; CORFIATI 20I2, pp. 25I-252; MARCELLI 2020, 3.I.

247. DAVIES 2002, pp. I42-I 45; MARCELLI 2020, 3.I. 
Nei decenni successivi l'umanista Angelo Poliziano fu impegnato a postillare un esemplare a stampa di sua proprietà grazie alla collazione delle copie della Naturalis historia disponibili a Firenze e quella, un tempo di proprietà di Coluccio Salutati, ottenuta in prestito dalla biblioteca di Fernando I d'Aragona; lungo lavoro che culminò in un corso dedicato a Plinio il Vecchio tenuto per alcuni studenti inglesi e portoghesi tra il I 489 e il I $490 .{ }^{248}$

La prima traduzione dell'opera pliniana «di lingua latina in fiorentina» fu commissionata da Ferdinando I d'Aragona all'eminente umanista Cristoforo Landino, che la portò a termine nel I475, e data alle stampe l'anno seguente a Venezia in mille esemplari cartacei e venti in pergamena, grazie al contributo elargito della compagnia fiorentina di Filippo e Lorenzo Strozzi che, rifugiatisi nella città partenopea dopo la condanna all'esilio del padre, avevano così voluto ringraziare il sovrano per averli accolti e aiutati. ${ }^{249}$ Una copia in pergamena destinata a Flippo Strozzi fu sontuosamente miniata da Monte di Gherado tra il I 479 e il I483, mentre un'altra fu acquistata dalla famiglia fiorentina Ridolfi. ${ }^{250}$

Risulta quindi evidente che nell'arco cronologico compreso tra la metà del XIV e l'ultimo quarto del XV secolo gran parte delle nozioni sulla fauna esotica contenute nella Naturalis historia furono divulgate tra il ceto mercantile grazie alla mediazione di enciclopedie e bestiari. Infatti - come afferma Francesco Stella:

L'opera di Plinio è a carattere enciclopedico e va analizzata da questo punto di vista, che presuppone non una lettura dell'opera ma una sua consultazione e un suo utilizzo occasionali, mirati e mediati da numerosi strati di escerti, rielaborazioni, aggiornamenti - a partire come si sa da Solino e Isidoro. Il numero di riutilizzi di un suo passo non può dunque essere presentato come 'fortuna di Plinio', un capitolo che forse si apre in senso stretto solo con l'Umanesimo, ma come tradizione delle enciclopedie. ${ }^{251}$

Con l'avvento e l'affermarsi dell'Umanesimo l'interesse per le auctoritates andò sempre più crescendo, ma le difficoltà nel reperire a Firenze copie della Naturalis historia lo avevano reso un volume di difficile consultazione, soprattutto per la classe dei mercanti. Del resto, come trapela dalle loro descrizioni degli animali

248. HUNT I965, p. 78; The Public Library I972, pp. 216-2I7 nn. 79I-793; Firenze e la scoperta I992, p. 56 n. 23; DAVIES I995, pp. 252-256; ID. 2002, pp. I 49-I50; VITI 20I2, pp. I57-I59; MARCELLI 2020, 3.I. L'incunabolo perrottiano del I 473, ora alla Bodleian Library di Oxford (Auct. Q.I.2), è una copia del volume originale postillato perduto vedi CESARINI MARTINELLI I978, pp. XVI nota 27, XXI; DAVIES 2002, pp. I46-I50; VITI 20I2, pp. I58-I59; GUIDA 20I8, pp. 280-293.

249. Firenze e la scoperta I992, pp. 58-59 n. 26; The Douce Legacy I984, p. 84 n. I29; MCHAM 20I3, pp. 9-IO. In realtà, la questione appare assai complessa: alcuni studiosi, rifacendosi all'articolo di Florence Edler de Roover, ritengono che la pubblicazione fu commissionata da Girolamo Strozzi, lontano cugino di Filippo e Lorenzo con i quali aveva lavorato a Napoli e continuava a collaborare, e dal socio Giovanbattista Ridolfi. Non è però - a mio avviso - da escludere che fosse stato stipulato un accordo per fornire a Filippo e Lorenzo Strozzi le lussuose copie in pergamena, mentre quelle cartacee sarebbero spettate a Girolamo Strozzi e al suo socio per la vendita vedi EDLER DE ROOVER I953, pp. IO8-II2; ARMSTRONG 2003, vol. I, pp. 340-34I; MARCELLI 20IIa, pp. I37-I38; EAD. 2020 , 3.I.

250. BORSOOK I970, pp. 7, 20 nn. 70, 73-78; ARMSTRONG 2003, vol. I, p. 348 nota 25. L'incunabolo appartenuto a Filippo Strozzi di trova ora alla Bodleian Library di Oxford (ms. Arch.G b.6).

25I. STELLA 20I2, p. 47. 
esotici, i legami con le notizie zoologiche fornite da Plinio il Vecchio risultano assai modesti e, quando presenti, per lo più recepiti attraverso autori medievali. Di tutt'altro stampo fu, invece, l'approccio degli umanisti fiorentini per quanto riguarda la fauna esotica: il loro interesse non fu tanto mosso dalla ricerca di validità scientifica delle notizie riportate nella Naturalis historia bensì dall'esigenza di acquisire informazioni utili per commentare i testi di autori antichi nei quali gli animali esotici erano menzionati. Solo a seguito dell'arrivo della giraffa a Firenze nel I487 Angelo Poliziano, a quel tempo impegnato nella stesura delle Miscellaneorum Centuria - raccolta di discussioni filologiche - fu stupito nel constatare che tra gli scritti delle auctoritates nessuno, Plinio il Vecchio compreso, avesse menzionato le minuscole corna dell'animale che lui stesso aveva avuto modo di osservare. ${ }^{252}$ Emerge quindi in maniera lampante, almeno per quanto riguarda la fauna esotica, il completo disinteressamento degli intellettuali nei confronti dei resoconti odeporici scritti da mercanti e pellegrini: letteratura minore che in ambito fiorentino aveva avuto una discreta circolazione, ma che con tutta probabilità i letterati non presero in considerazione perché la «troppa devozione all'antichità» impedì loro di "allontanarsi dai suoi paradigmi». ${ }^{253} \mathrm{Se}$ già nel I384 ai mercanti Lionardo Frescobaldi, Giorgio Gucci e Simone Sigoli non erano sfuggite le piccole corna della giraffa vista al Cairo, come pure a Ciriaco d'Ancona nella sua descrizione dal vero corredata da un disegno intorno al I 442, gli umanisti non ne avevano tenuto conto. ${ }^{254}$ A confermare questa attitudine è un passo di Poliziano nelle Miscellaneorum Centuria nel quale si chiede se riguardo alle zampe dell'elefante siano più attendibili Basilio, Ambrogio e il poeta Nonno di Pannoli, che sostengono essere prive di giunture, oppure Aristotele, Plinio il Vecchio ed Eliano, che affermano il contrario. ${ }^{255}$ L'umanista, pur precisando di non voler esprimere alcun giudizio in merito, non si era però trattenuto dall'osservare, mosso dalla reverenza nutrita nei confronti delle auctoritates, che probabilmente Aristotele e Plinio il Vecchio erano più informati dei santi scrittori cristiani. ${ }^{256}$

252. PASTORE STOCCHI 20I4, pp. I23-I26. Da quanto finora emerso, solo nel poema in versi La caccia, dedicato dal poeta greco Oppiano di Apamea (III secolo) a Caracalla, si rintraccia un riferimento alle corna della giraffa: «Dalla metà del capo spuntano dritte due corna, propriamente non sono corna fatte di corno, ma deboli escrescenze che si levano tra le tempie, presso le orecchie» vedi MASPERPO I997, p. I73.

253. TUCCI 2005, pp. 38-39.

254. FANTONI 20I4, pp. 86-87 n. I6. Anche negli scritti dell'ambasciatore spagnolo Ruy González de Clavijo, che all'inizio del XV secolo vide una giraffa durante una tappa del suo viaggio alla volta di Samarcanda, e di Roberto da Sanseverino, che ne osservò una al Cairo nel I 458 quando era diretto in Terrasanta, le due piccole corna rivestire di pelle erano menzionate, GONZÁLEZ DE CLAVIJO I999, pp. I I8-i i9; Felice et divoto I999, p. I83.

255. Riguardo alle informazioni fornite da Aristotele sugli elefanti è da tener presente che nell'Historia animalium afferma essere dotati di giunture nelle ginocchia, mentre nel De partibus animalium scrive: «a causa delle grandi dimensioni e del peso del corpo, i loro arti anteriori servono soltanto a sorreggerlo, ed essendo lenti e inadatti alla flessione non hanno alcuna utilità", asserzioni solo apparentemente contradditorie dato che nel secondo testo il riferimento è limitato agli arti anteriori la cui priorità era di sostenere l'enorme mole del quadrupede, ARISTOTELE I996, pp. 628-629, libro II, 659a. Per la citazione nell'Historia animalium vedi pagina I04 nota 78 .

256. PASTORE STOCCHI 2OI4, p. I25. 
Si delinea quindi con chiarezza l'impatto esercitato sui mercanti fiorentini tre e quattrocenteschi dell'istruzione ricevuta presso le scuole di abaco, che li aveva dotati di una forma mentis indagatrice e incline a quantificare la realtà circostante servendosi dell'unità di misura in uso nell'ambiente commerciale, il braccio. Mossi dal desiderio di conoscere il mondo in prima persona, avevano gradualmente finito per sostituire il valore dell'esperienza diretta all'incondizionata accettazione di quanto tramandato dai testi antichi riguardo al regno animale fino ad arrivare, in alcuni casi, a confutare le auctoritates. È proprio la puntuale analisi delle descrizioni della fauna esotica fornite dai mercanti recatisi in viaggio nelle terre d'oltremare, che nulla o ben poco devono ai testi antichi, a rivelare la loro attitudine a registrare quanto osservato con i propri occhi, così come pure la volontà di trasmettere le fattezze di questi bizzarri animali attraverso paragoni con oggetti o bestie familiari al lettore. A rendere ancora più evidente l'importanza della conoscenza della fauna esotica basata su racconti orali o diari odeporici è l'assenza a Firenze fino al I 438 di una copia completa della Naturalis historia di Plinio il Vecchio, testo ritenuto caposaldo per la conoscenza del regno animale, e di una versione in lingua italiana più facilmente consultabile dai mercanti che sarà data alle stampe solo nel I476. 
PARTE IV

Animali esotici: dalle parole alle immagini 



\section{Raffigurazioni di animali esotici}

\section{Animali "di carta"}

\section{I.I. Mappae mundi e carte geografiche}

I ricchi mercanti fiorentini ancor prima che per gli animali esotici avevano sviluppato uno spiccato interesse per la conoscenza del mondo. Sugli scaffali delle loro biblioteche tre e quattrocentesche non mancavano - accanto a manoscritti come il Milione di Marco Polo, il Memoriale toscano di Odorico da Pordenone e le relazioni di viaggio mercantesche - testi dedicati alla geografia, mappae mundi e portolani, a testimoniare la grande attenzione che nutrivano nei confronti di nuove realtà geografiche. Interesse che nell'ottica mercantile del profitto andava di pari passo con lo sviluppo delle attività commerciali in Oriente.

Il legame tra testi scritti e mappamondi era molto stretto: sovente erano proprio le informazioni su personaggi orientali, eventi biblici, popolazioni mostruose, animali fantastici e fauna esotica dei paesi d'oltremare, in gran parte ricavate

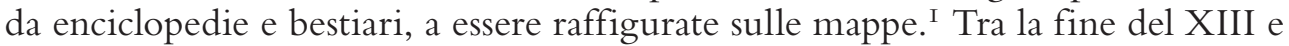
gli inizi del XIV secolo il Mappamondo di Ebstorf e il Mappamondo di Hereford - vere e proprie raffigurazioni su pergamena della terra e dell'ecumene, dove a prevalere era ancora la tradizione religioso-letteraria con la figura di Cristo che attraversa o domina il cosmo e la città di Gerusalemme al centro del mondo - furono realizzati attingendo notizie dalla Bibbia e dagli autori antichi con lo scopo di "confermare, non di creare una conoscenza». ${ }^{2}$ A testimoniare questa attitudine sono i disegni della fauna esotica. Nel Mappamondo di Ebstorf (fig. 5) si individuano un pappagallo nei pressi del Nilo (fig. sa), un cammello nell'area corrispondente alla Terrasanta (fig. 5b), un elefante (fig. 5c) e uno struzzo (fig. $5 \mathrm{~d}$ ) nel continente africano corredati da passi desunti dalle auctoritates - le Etymologiae di Isidoro da Siviglia e il Physiologos - mentre la bestia simile a un cavallo con il corpo punteggiato da macchie che una scritta indica come «camelopardalis» (fig. se) - giraffa - fu probabilmente tratteggiata seguendo le indicazioni della Naturalis historia pliniana oppure di Solino o Isidoro da Siviglia in veste d'intermediari. ${ }^{3}$ Sempre

I. DI PALMA I985, pp. 9I-92.

2. ZUMTHOR I995, pp. 3I6-3I8. Vedi anche SCAFI 2007, pp. I22-I27.

3. HOOGVLIET I997, pp. I92-I96, 206-209; EAD. 2007, pp. I82-I84. Per le fonti antiche vedi SIVIGLIA 2004, vol. 2, pp. I7-I9, libro XII, I:35; 3I-32, libro XII, II:I9; 85, libro XII, VII:20; 87 , libro XII, VII: 24 ; Il Fisiologo 20II, pp. 78-80:43; PLINIO 20II, p. 69, libro VIII, XXVII. Si tratta della più grande mappa mundi medievale nota, con un diametro di quasi 4 metri, scoperta nell'abbazia tedesca di Ebstorf nel I843 e andata distrut- 


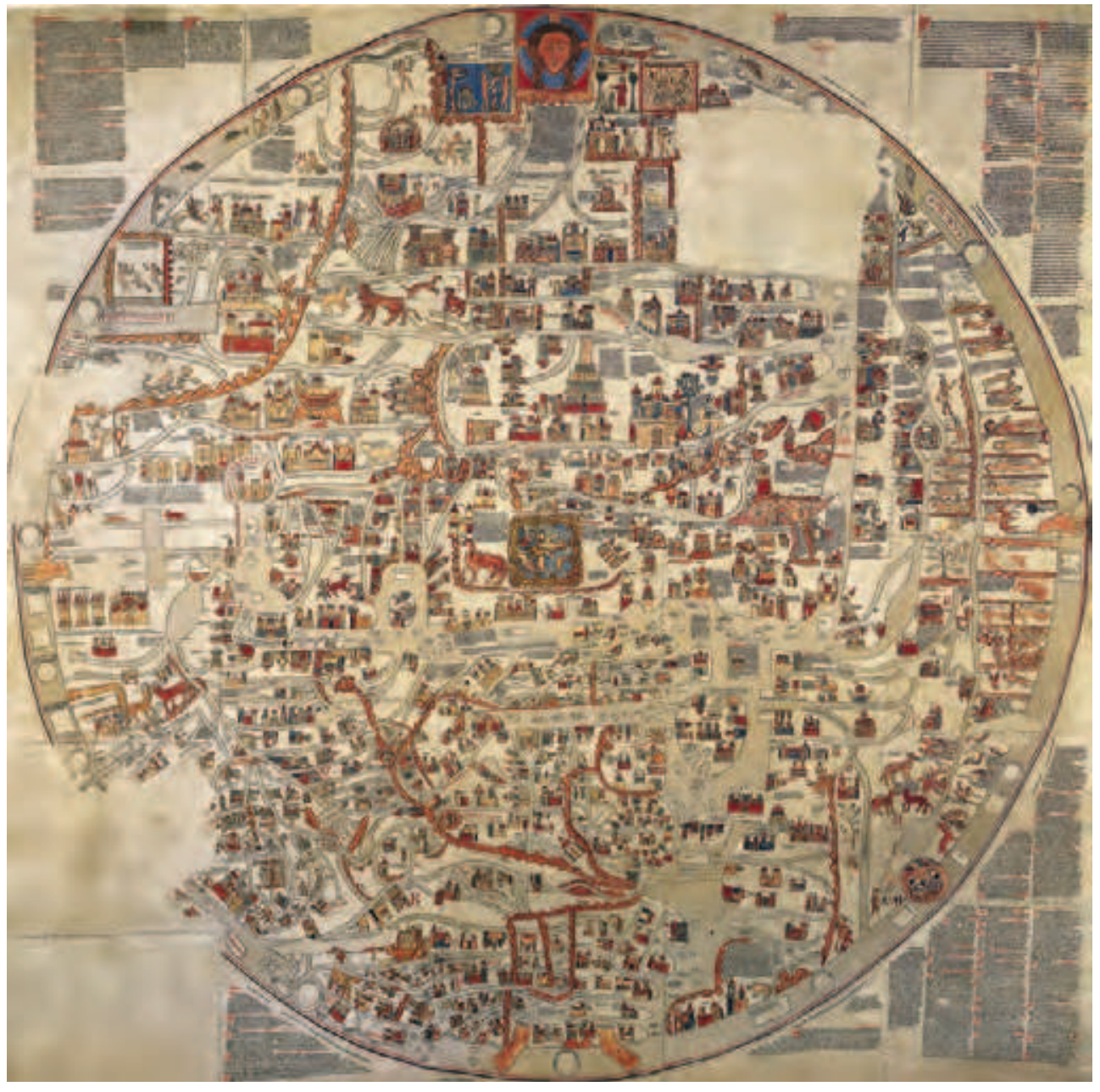

Fig. 5: Mappamondo di Ebsdorf, I300 ca.

Ebsdorf, monastero (facsimile) 


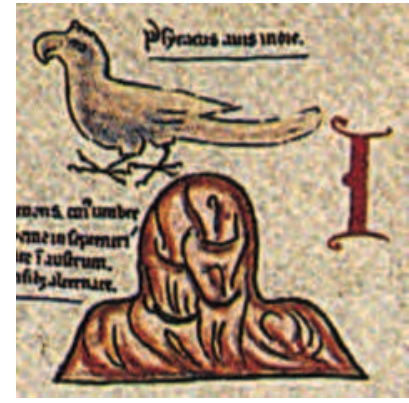

Fig. 5a: Pappagallo (part.)

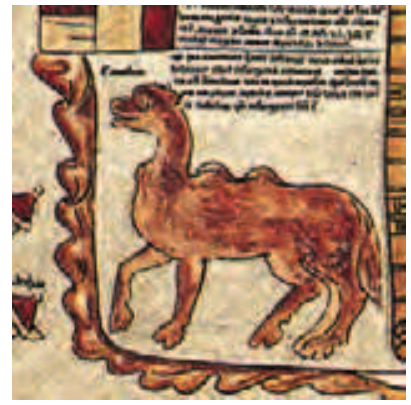

Fig. sb: Cammello (part.)

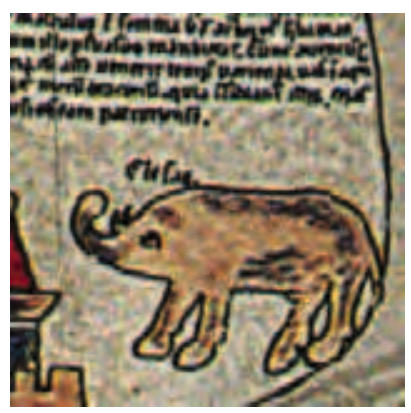

Fig. 5c: Elefante (part.)

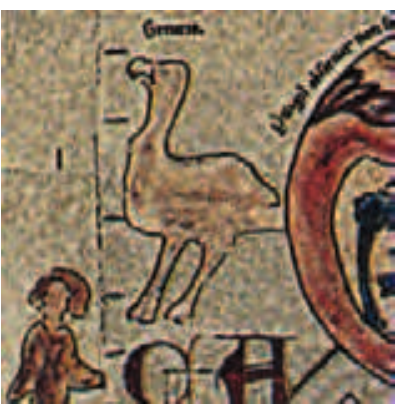

Fig. 5d: Struzzo (part.)

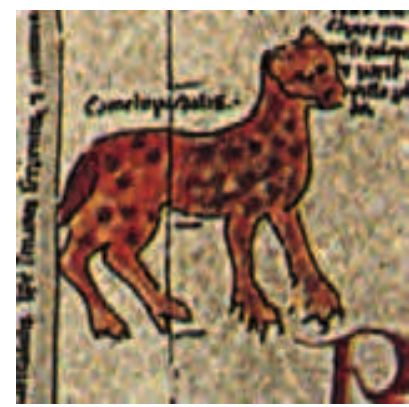

Fig. 5e: Giraffa (part.) 
grazie alle notizie ricavate da testi antichi nel Mappamondo di Hereford (fig. 6) furono raffigurati in Asia un elefante (fig. 6a), un pappagallo (fig. 6b), un improbabile coccodrillo (fig. 6c) e un rinoceronte (fig. 6d), in Africa un inverosimile struzzo (fig. 6e) e nell'area della Battria - odierno Afghanistan - un cammello (fig. 6f). ${ }^{4}$

Se alla fine del XIII secolo il sapere geografico, nel tentativo di dominare l'infinito, concepiva il mondo come uno spazio atemporale e immutabile creato da Dio, con il trascorrere del tempo e l'intensificarsi dei contatti con l'Oriente queste mappe diventarono sempre più aggiornate e attinenti alla realtà. ${ }^{5}$ Non solo le missioni dei religiosi e i viaggi di Marco Polo avevano aperto gli occhi e la mente su nuovi orizzonti quali l'Asia e l'Estremo Oriente, quest'ultimo fino ad allora praticamente ignoto, ma i resoconti odeporici orali e scritti di pellegrini, missionari e mercanti erano diventati, da un lato, strumenti utili per verificare l'attendibilità delle conoscenze fino a quel momento esclusivamente tramandate dalle auctoritates e, dall'altro, fonti per l'acquisizione di nuove informazioni etnografiche, botaniche, zoologiche e geografiche. ${ }^{6}$ Inoltre, negli stessi anni in cui fu scritta la prima pratica di mercatura nota di area toscana, la Memoria de tucte le mercantie (I278), i mercanti svilupparono un altro strumento estremamente utile per i loro commerci: la carta marittima. ${ }^{7} \mathrm{Fu}$ a seguito dell'intensificarsi delle navigazioni, associate alla nuova attitudine a osservare e registrare, che le repubbliche marinare di Genova, Pisa e Venezia approntarono i primi portolani, ossia mappe nautiche in chiave prettamente economica elaborate sulla base di quanto riferito da marinai e mercanti riguardo a distanze, venti, correnti e principali porti del Mediterraneo in modo da consentire a chi si avventurava per mare di compiere viaggi relativamente più sicuri e veloci. ${ }^{8}$

Questo forte desiderio di conoscere e percorrere il mondo non si esauriva certo con i resoconti di mercanti e missionari: già nel I306, o più probabilmente nel I3IO, il prete e cartografo Giovanni da Carignano interrogò a lungo gli ambasciatori etiopi del sedicente Prete Gianni, in attesa d'imbarcarsi nel porto di Genova dopo essersi

ta durante i bombardamenti del 1943 di cui oggi si serba memoria grazie a un facsimile su pergamena realizzato prima della guerra. Gli studiosi sono ancora divisi sulla datazione: alcuni la collocano al I235, mentre studi recenti propendono per la fine del secolo. Si tratta della mappa più antica con l'immagine di un pappagallo vedi BARBER 2006, pp. 23-27; DALTON 20I4, p. 682.

4. KLINE 200I, pp. IO2, IO4-IO7; WESTREM 200I, pp. XVIII, $42-43$ nn. 84-85, I30-I33 nn. 292 e 297,I88I89 n. 447, 76- 77 n. I60; HOOGVLIET 2007, pp. I82-I83; BROTTON 20I2, pp. 84-I02; STR ICKLAND 2019 , pp. 43-46, 49-5I. Vedi anche BARBER 2006, pp. 27-30; HOOGVLIET 2006, pp. I53-I65. Sulla mappa, forse realizzata da Richard Haldingham, lo scriba ha erroneamente indicato "AFFRICA» nell'area geografica europea ed «EUROPA» in quella africana vedi STRICKLAND 2019, p. 4I. Per un approfondimento sul Mappamondo di Hereford vedi KUPFER 2016.

5. Per un approfondimento sui mappamondi del XIII secolo vedi EDSON 2007, pp. II-32.

6. ZUMTHOR I995, pp. 232-235.

7. LOPEZ I98I, p. 465; NURMINEN 20I5, pp. 59-62. Sovente gli studiosi confondono la carta marittima con il portolano: se il contenuto è lo stesso, vale a dire informazioni utili alla navigazione, a cambiare è la forma attraverso la quale sono trasmesse, ovvero visivamente nella carta marittima e in forma scritta nel portolano vedi EDSON 2007, p. 37; VAGNON 2013, p. 445.

8. ZUMTHOR I995, pp. 320-32I; NURMINEN 20I5, pp. 59-62, 74-76. Peculiarità dei portolani è quella d'indicare l'orientamento grazie alla raffigurazione di una bussola e fornire le distanze in scala; uno degli esemplari più antichi è la cosiddetta Carta Pisana, in realtà realizzata a Genova tra il I275 e il I330 vedi EDSON 2007, pp. 33-37. 


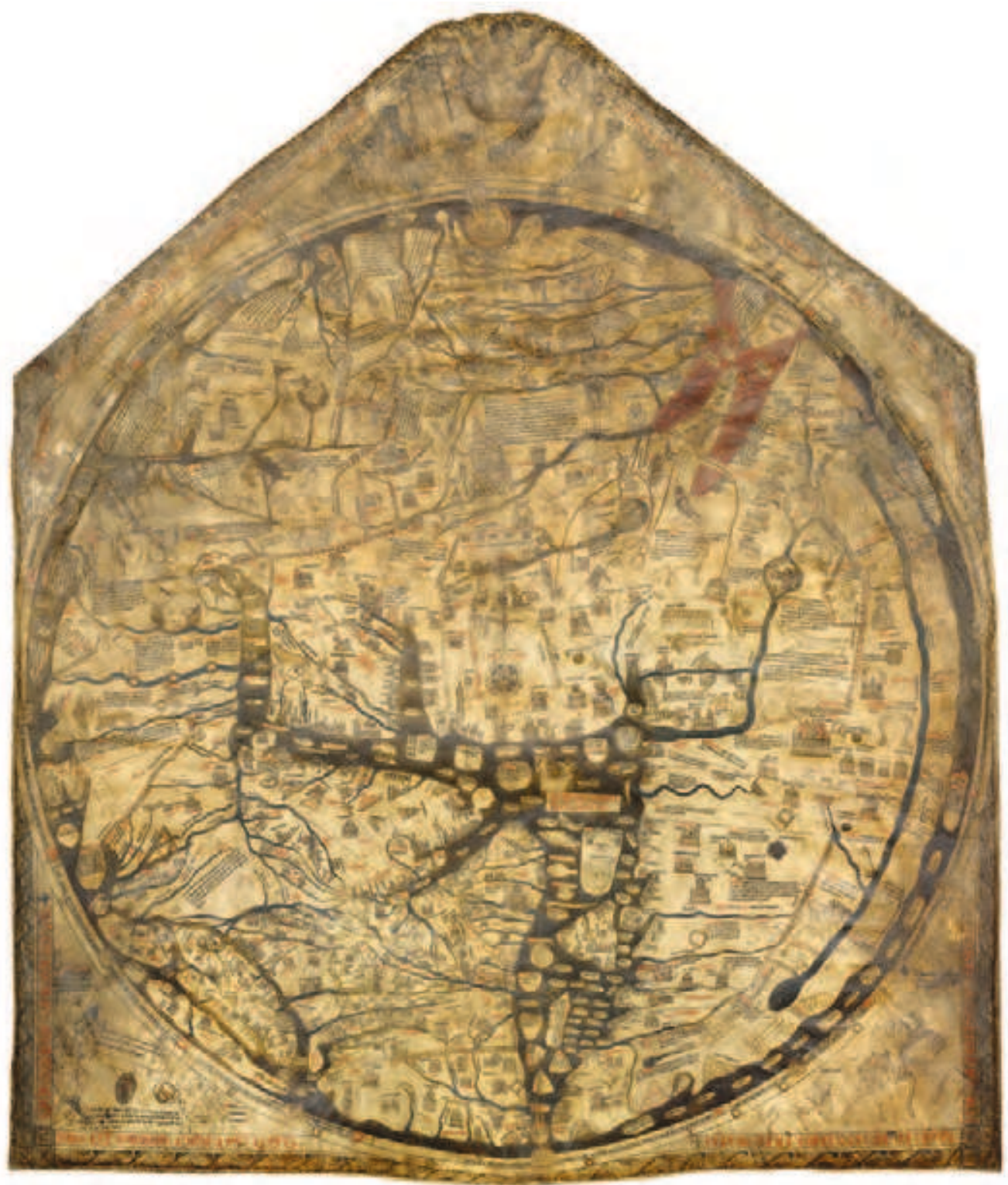

Fig. 6: Mappamondo di Hereford, I300 ca.

Hereford, Tesoro della cattedrale 


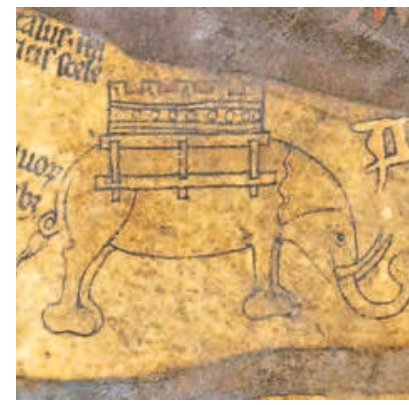

Fig. 6a: Elefante (part.)

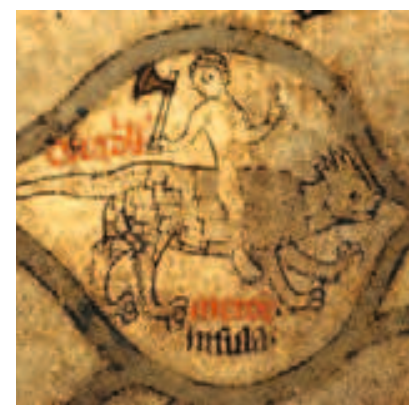

Fig. 6c: Coccodrillo (part.)

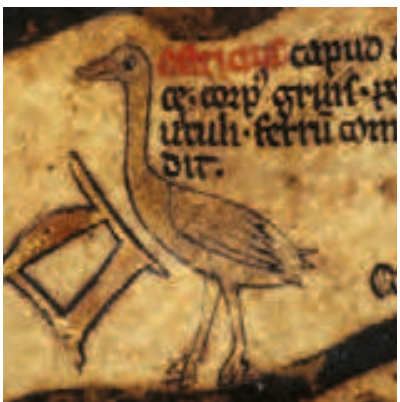

Fig. 6e: Struzzo (part.)

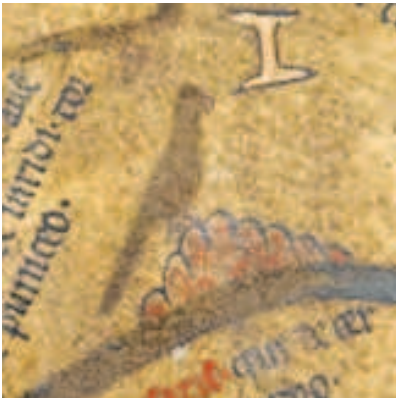

Fig. 6b: Pappagallo (part.)

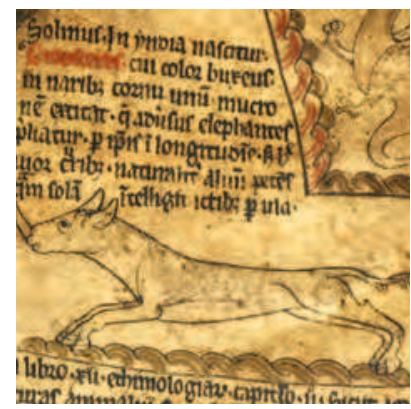

Fig. 6d: Rinoceronte (part.)

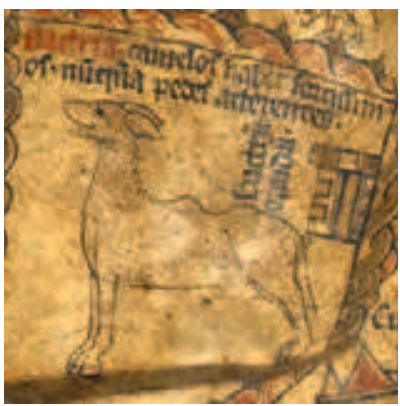

Fig. 6f: Cammello (part.) 
recati in missione ad Avignone da papa Clemente V, apprendendo che nel continente africano esisteva l'Abissinia ed era abitata da "christiani nigri», informazioni poi confluite nella carta marittima disegnata tra il 1320 e il $1325.9^{9}$ Appena un decennio più tardi Angelino Dulcert, operante a Maiorca ma di probabili origini genovesi, portò a termine una mappa con la raffigurazione del mondo all'epoca noto (fig. 7), nella quale era riuscito a coniugare le accurate informazioni delle carte nautiche con le immagini delle mappae mundi di tradizione medievale, le notizie recenti su regioni e sovrani d'oltremare e, nell'area corrispondente all'Africa, le immagini di animali esotici emblematici quali lo struzzo (fig. 7a), il dromedario (fig. 7b), l'elefante (fig. 7c) e il pappagallo (fig. 7 d). ${ }^{\text {IO }}$ Evoluzione che aveva tra l'altro indotto letterati del calibro di Francesco Petrarca e Giovanni Boccaccio, alla metà del XIV secolo impegnati nella stesura di testi dedicati alla geografia, a confrontare le informazioni contenute nelle auctoritates con quanto raffigurato sulle carte geografiche più attuali per verificarne il grado di attendibilità. ${ }^{\text {II }}$ Sempre negli stessi anni pare che Fazio degli Uberti, intento a comporre il Dittamondo, avesse consultato delle mappe con lo scopo di renderne attuale e attendibile la narrazione. ${ }^{\mathrm{I} 2}$

Ancora più innovativo era il famoso Atlante catalano (I375 ca.) (fig. 8) commissionato da Pietro IV d'Aragona al cartografo maiorchino Abraham Cresques, fornitore di mappae mundi della casa reale spagnola, quale dono per Carlo V di Francia, dove lo spazio che si dispiegava dalle isole Atlantiche fino alla Cina e all'isola di Sumatra fu delineato grazie alle notizie, in alcuni casi inserite in didascalie esplicative, attinte da una fonte mercantesca aggiornata come il Milione di Marco Polo con l'obiettivo, pur non tralasciando immagini che ancora evocavano miti della tradizione, di renderlo il più veritiero possibile. ${ }^{13}$ Non mancavano quindi, insieme alla sirene e ai re Magi, gli animali esotici per eccellenza: elefanti (fig. 8a), pappagalli (fig. 8b) e dromedari (fig. $8 c$ ), che lungo la via della Seta formavano una carovana seguita da una comitiva di mercanti a cavallo (fig. 8d). Mutamento, questo, che rivela come l'idea di un mondo che poteva essere indagato grazie all'acume e alla curiosità dei viaggiatori, ai quali si era sempre più propensi a concedere fiducia, si fosse ormai consolidata.

9. GADRAT 2005, p. I82; LEFEVRE i967-I968, pp. 7-8; KAPLAN I985, p. 52. Di questa mappa, conservata all'Archivio di Stato di Firenze e andata distrutta durante un bombardamento nel i943, sopravvive qualche riproduzione vedi BAGROW I985, tav. XXXIII. Per un approfondimento vedi PELLETIER I994, pp. 23-3I; CHIESA 20I8, pp. 63-IOO.

IO. NURMINEN 20I5, p. 65, PUJADES I BATALLER 20I6, pp. I20-I2I. Stessa tipologia è quella della carta nautica eseguita a Venezia da Francesco e Domenico Pizigano nel I367 dove compaiono cammelli, elefanti e uccelli rari vedi GORRERI 2009, pp. I7-23.

I I. Per l'interesse geografico di Petrarca e Boccaccio vedi EDSON 2007, pp. I I5-I I6; Firenze e la scoperta I992, pp. 50-53 n. 22, 65-72 nn. 3I-32; GAUTIER DALCHÉ 2009b, pp. 8I-85.

I2. BOULOUX 20I4, pp. I5-27.

I3. PUJADES I BATALLER 20I6, pp. 9I-93, IIO-III; NURMINEN 20I5, pp. 70-74; DI PALMA I985, p. 98. L'Atlante catalano è una grande mappa indicata con il termine di "atlante" perché, diversamente dalle mappae mundi, non comprende l'estremità settentrionale dell'Europa e quella meridionale dell'Africa e si articola in sei cartelle precedute da due scomparti con informazioni cosmografiche, astronomiche e astrologiche vedi EDSON 2007, pp. 74-86; BRILLI 20I3, pp. I46-I 49. Vedi anche Atlas de cartes marines 2018. 


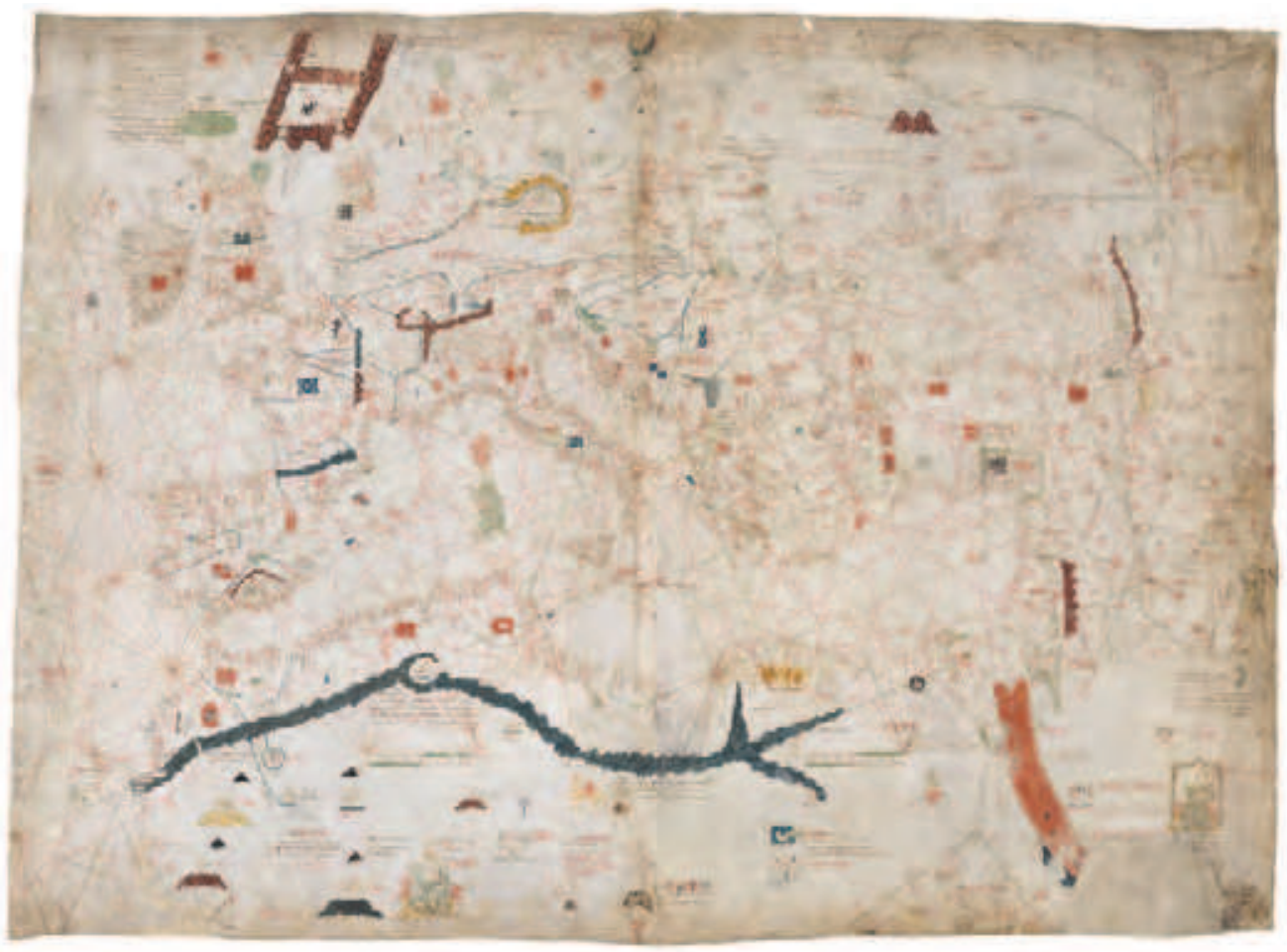

Fig. 7: Angelino Dulcert,

Portolano, I339

Parigi, Bibliothèque nationale de France (CPL GE. B-696) 


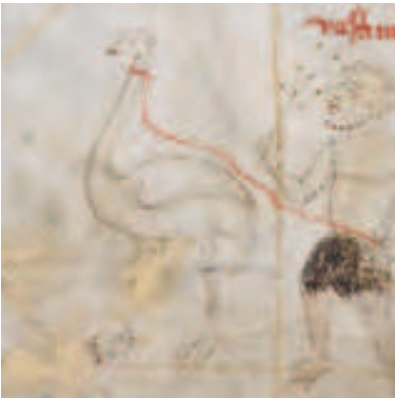

Fig. 7a: Struzzo (part.)

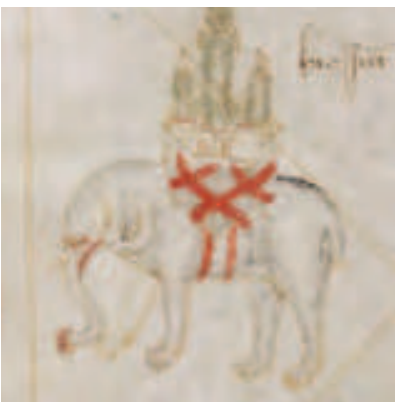

Fig. 7c: Elefante (part.)

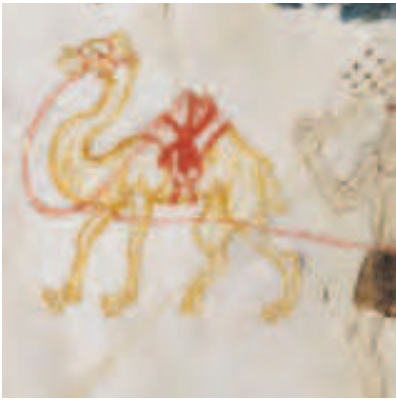

Fig. 7b: Dromedario (part.)

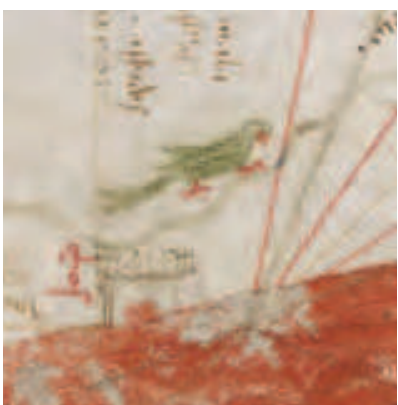

Fig. 7d: Pappagallo (part.) 


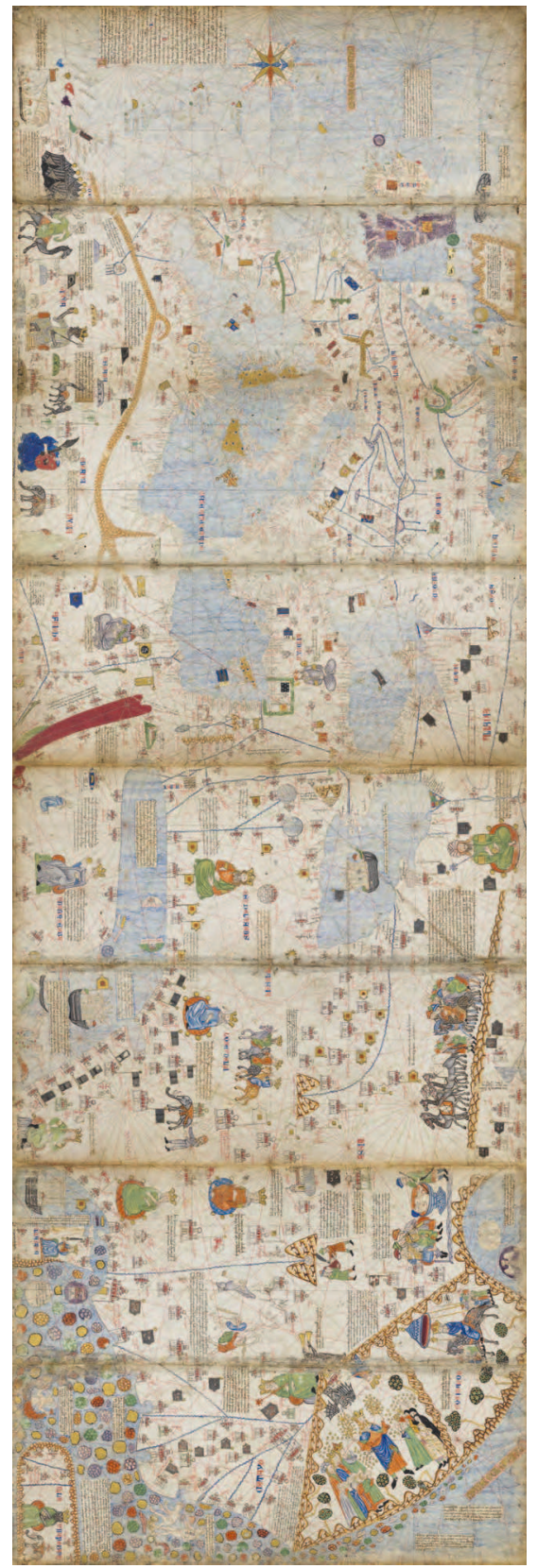

Fig. 8: Abraham Cresques, Atlante catalano, I375 ca. Parigi, Bibliothèque nationale de France (ms. Espagnol 30)

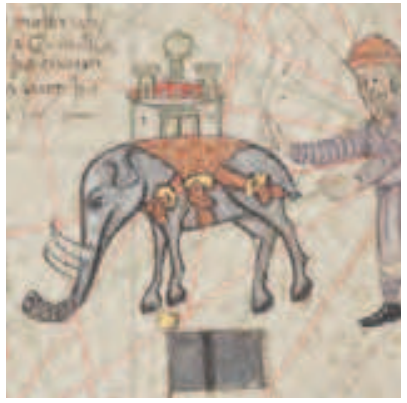

Fig. 8a: Elefante (part.)

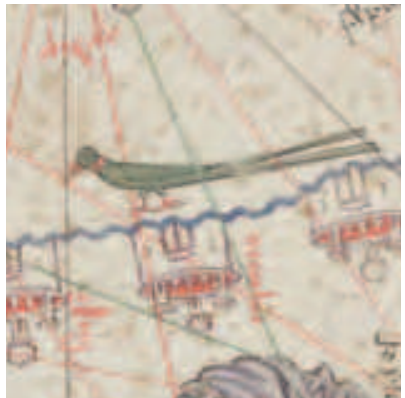

Fig. 8b: Pappagallo (part.)

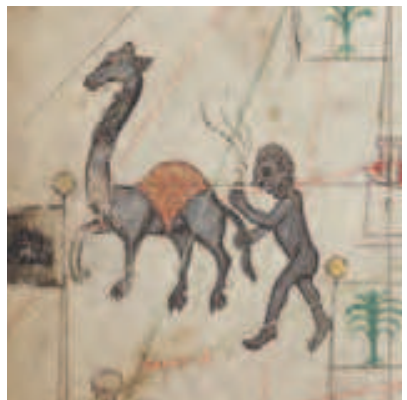

Fig. 8c: Dromedario (part.)

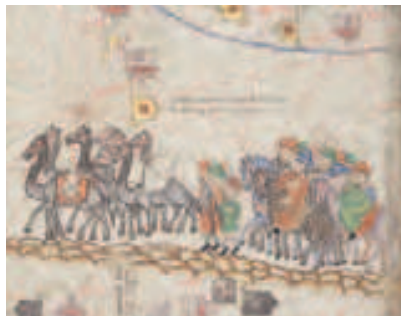

Fig. 8d: Carovana di mercanti (part.) 
L'arrivo a Firenze nel I397 dell'umanista bizantino Emanuele Crisolora, chiamato a insegnare la lingua greca, che recava con sé un esemplare della Cosmographia (II secolo) di Claudio Tolomeo - riscoperta a Costantinopoli nel XIII secolo quando fu corredata da ben ventisei mappe - aveva contribuito a introdurre il concetto di ricerca sistematica in campo geografico ma non, come sostenuto da alcuni studiosi, una vera e propria rivoluzione. ${ }^{\mathrm{I}}$ Tradotto dal greco in latino intorno al I 409 da Jacopo Angeli da Scarperia, che portò a termine l'impresa iniziata da Crisolora, il testo tolemaico con dedica a papa Alessandro $\mathrm{V}$ fu fin da subito oggetto di numerose copie. ${ }^{\text {I5 }}$ Sembra che a distanza di pochi anni la Cosmographia fosse già così diffusa da essere utilizzata non solo dagli umanisti per verificare la corrispondenza dei toponimi antichi con quelli moderni, ma pure da un poeta in volgare come Andrea da Barberino per contestualizzare e rendere più veritiero il peregrinare per il mondo del protagonista nel romanzo cavalleresco Guerrin Meschino. ${ }^{16} \mathrm{Al}$ contrario, il metodo "scientifico" illustrato da Tolomeo, che si serviva di meridiani e paralleli convergenti per elaborare una proiezione geografica del mondo, per lungo tempo non fu applicato a causa di alcuni passi rimasti oscuri nella traduzione. ${ }^{17}$

Il confronto sempre più stretto con mercanti quali Niccolò de' Conti e Ciriaco d'Ancona, che avevano visitato le terre d'oltremare, come pure con personaggi greci, armeni ed etiopi che tra il I439 e il I 443 giunsero a Firenze per partecipare al concilio per l'unione delle due Chiese permise agli umanisti di acquisire nuove informazioni per delineare mappe del mondo con contorni sempre più definiti, mentre mirabilia e mostruosità si andavano via via dissolvendo per lasciare spazio a dati reali. In alcuni casi queste notizie consentirono agli umanisti di emendare alcuni errori: se la commissione di cardinali che nel I44I interrogò su questioni religiose e geografiche alcuni monaci etiopi decise di non prestare fede a quanto riferito perché in disaccordo con il testo tolomeiano, Flavio Biondo li reputò invece attendibili poiché non era la prima volta che si riscontravano errori nella Cosmographia. ${ }^{18}$ Insomma, l'immagine del mondo era in continua evoluzione: le comunicazioni di prima mano avevano permesso di aggiornare la geografia delle

I4. EDSON 2007, pp. II4-I20; Firenze e la scoperta I992, pp. 77-80 nn. 37-38, 88-90 n. 43; GAUTIER DALCHÉ 2009a, pp. I 45-I58. Con l'esilio di Palla Strozzi da Firenze nel i 434 la Cosmographia, ricevuta in dono da Emanuele Crisolora, fu disponibile a Padova, dove il mercante fiorentino aveva trovato rifugio, e nella vicina Venezia, grande centro di produzione cartografica. L'importanza attribuita al testo da Palla si evince dal testamento stilato nel I 462 che proibiva agli eredi di venderlo vedi GENTILE 2003, pp. 5-I5; BEC I972, pp. 238-247. Per un approfondimento sulla Cosmographia vedi anche BROTTON 2012, pp. I7-53.

I5. GAUTIER DALCHÉ 2009a, pp. I9-20, I46-I54; EDSON 2007, pp. II6-I20. A Firenze erano presenti numerose copie della Cosmographia ma a rendere il testo ancora più accessibile fu l'umanista fiorentino Francesco Berlinghieri con la sua traduzione in terza rima volgare vedi GAUTIER DALCHÉ 2009a, pp. 252-255.

I6. Ivi, pp. I58-I60. Per la popolarità tra il ceto mercantile dei testi di Andrea da Barberino vedi ALLAIRE I998, pp. I-8; EAD. 2002, pp. 34-36.

I7. WOODWARD 200I, pp. 259-26I; GAUTIER DALCHÉ 2009a, pp. 335-339; BROTTON 20I2, pp. I60-I62.

I8. Firenze e la scoperta I992, pp. I68-I70 n. 8I; GENTILE 2003, pp. I5-I6; GAUTIER DALCHE 2009 a, pp. I84-I85. Anche il cartografo veneziano Fra' Mauro, scettico riguardo all'attendibilità del testo di Tolomeo, accolse i resoconti orali di esperti marinai e le informazioni fornite da Marco Polo e Niccolò de' Conti vedi EDSON 2007, pp. I53-I55, I64; CATTANEO 2005, pp. I57-202. 
mappe aggiungendo nuove località o modificando le dimensioni dello spazio come pure la conoscenza della fauna esotica.

Raffigurare sulle mappe mundi quanto appreso doveva però risultare alquanto difficoltoso considerato che le novità su personaggi orientali, fauna e flora esotiche riferite oralmente o desunte da testi quali bestiari, enciclopedie, scritti odeporici e letteratura non erano quasi mai corredate da illustrazioni. Fonte primaria per gli animali esotici continuarono a essere le descrizioni dei bestiari, in rari casi illustrate da immagini poco realistiche, mentre i manoscritti delle auctoritates - almeno quelli giunti sino a noi - non presentavano nessun apparato decorativo. ${ }^{\text {I9 }}$

Sarà solo dalla metà del XV secolo, grazie alle informazioni concrete dei viaggiatori, che le immagini della fauna esotica nelle carte geografiche cominciarono, nonostante il perdurare di qualche bestia fantastica, ad assumere una fisionomia più attinente alla realtà, e in rarissimi casi addirittura a liberarsi dei tradizionali attributi, come l'elefante privo di torre lignea (fig. 9a) nella Carta nautica (I455) (fig. 9) del prete e cartografo genovese Bartolomeo Pareto. ${ }^{20}$

Emblematico a questo proposito è il Mappamondo genovese (fig. Io), cosiddetto per la presenza dello stendardo della città marittima, realizzato nel I457 su di una pergamena d'insolita forma ellittica. La raffigurazione di tutto il mondo all'epoca conosciuto fu condotta seguendo criteri molto avanzati rispetto a quelli tolomeiani: le notizie, oltre che da Pomponio Mela e Plinio il Vecchio, furono attinte dai racconti di prima mano di Niccolò de' Conti, confluiti nel IV libro del De varietate fortunae, soprattutto per l'Asia e le sue isole, arrivando in alcuni casi addirittura a trascrivere i passi relativi alle usanze di alcune popolazioni di tatuarsi il corpo o cibarsi di serpenti. ${ }^{21}$ Del resto, l'anonimo cartografo aveva dichiarato le proprie intenzioni in un cartiglio rosso che recava la scritta: «Questa è la vera descrizione dei cosmografi accordata con le carte nautiche ed emendata da racconti frivoli e fantasiosi», motivo per cui sul mappamondo il paradiso terrestre era assente e Gerusalemme non più al centro del mondo. ${ }^{22} \mathrm{Il} \mathrm{ricco}$ apparato iconografico comprendeva, oltre a qualche immancabile essere fantastico, un dromedario in Etiopia (fig. IOa), un coccodrillo (fig. Iob) e un elefante in Nubia (fig. IOc), due scimmie nello spazio compreso tra Mauritania e Libia (fig. Iod) e, sempre nell'area libica, una giraffa assai realistica (fig. Ioe) - a differenza di quella nel Mappamondo di Ebstorf (fig. se) - che probabilmente molto doveva ai racconti di coevi viaggiatori e, forse, a una delle numerose copie del disegno di Ciriaco d'Ancona in

I9. HOOGVLIET I997, pp. 200-20i; CAMILLE I999, pp. 375-377. Unico manoscritto noto corredato da illustrazioni è quello trecentesco delle Collectanea rerum memorabilium di Solino conservato alla Biblioteca Ambrosiana di Milano (ms. C. 246).

20. L'immagine dell'elefante ritratto dal cartografo appare molto simile a quella diffusa da alcune lettere di Ciriaco d'Ancona negli anni quaranta del XV secolo (vedi figg. I9, 2I).

2I. DI PALMA I985, p. IOI; Firenze e la scoperta I992, pp. I73-I75 n. 83; EDSON 2007, pp. I9I-I97. Anche l'anconetano Grazioso Benincasa, divenuto cartografo dopo aver solcato per vent'anni il mare in qualità di marinaio, nella mappa realizzata nel I 468 incluse informazioni aggiornate apprese dal navigatore veneziano Alvise Ca' da Mosto, che tra il I 455 e il I 456 viaggiò in Africa e Asia e nel I464 pubblicò le sue memorie, raffigurando la costa dell'Africa più estesa a sud rispetto alle mappe precedenti vedi EDSON 2007, pp. I35-I36.

22. CATTANEO 2003 , pp. 340-34 I n. I.I. 


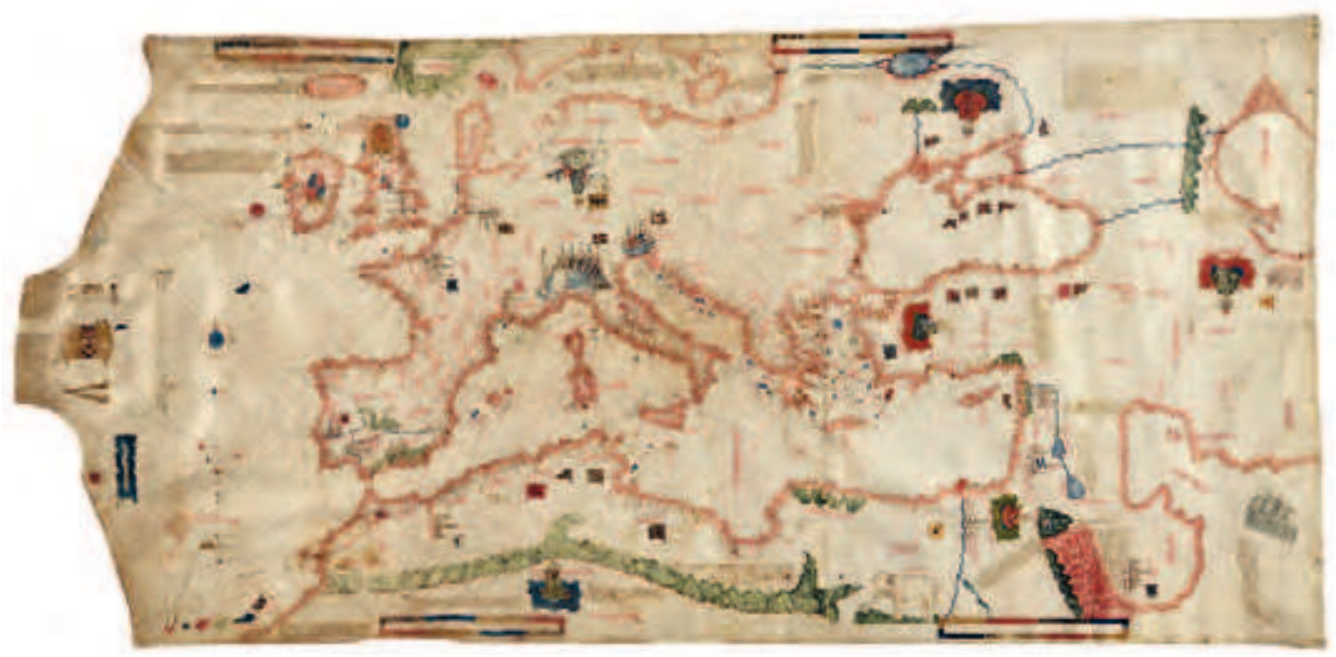

Fig. 9: Bartolomeo Pareto,

Carta Nautica, I455

Roma, Biblioteca Nazionale Centrale (CNI)

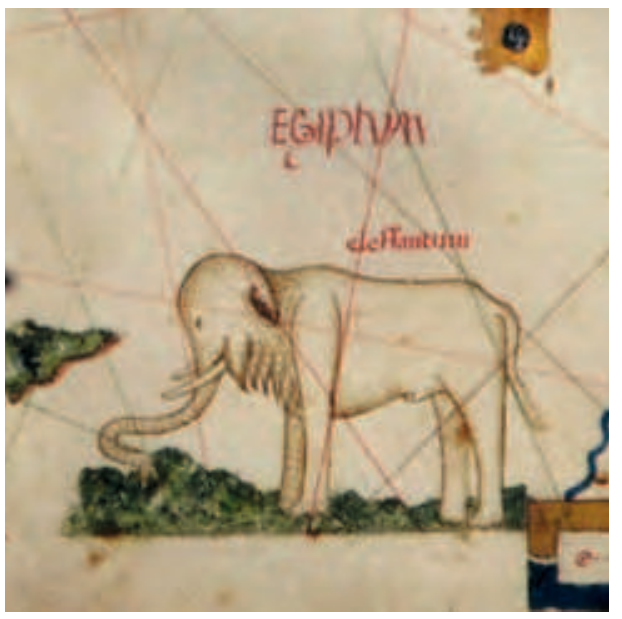

Fig. 9a: Elefante (part.) 


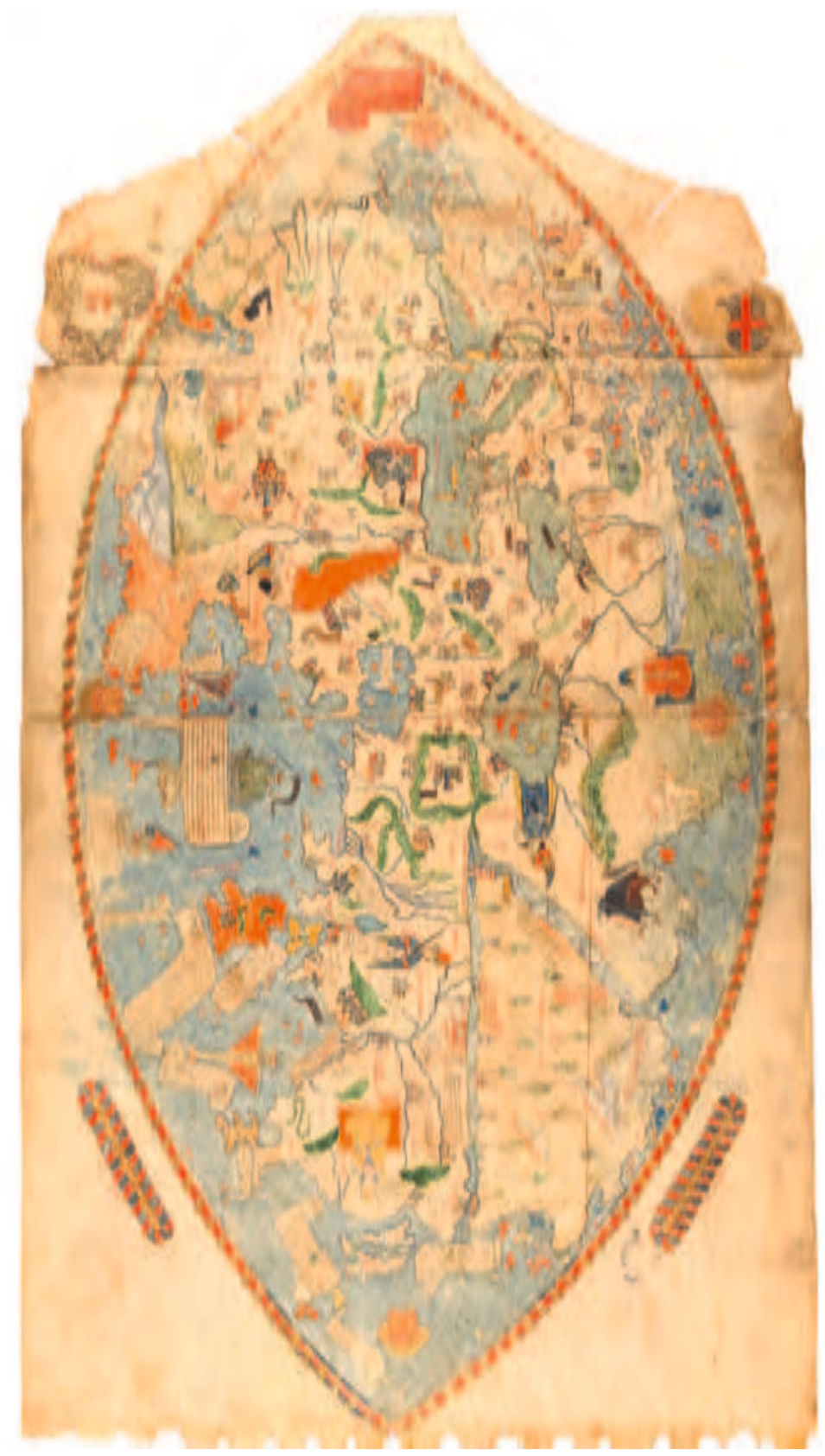

Fig. I0: Mappamondo genovese, I457

Firenze, Biblioteca Nazionale Centrale (Port. I) 


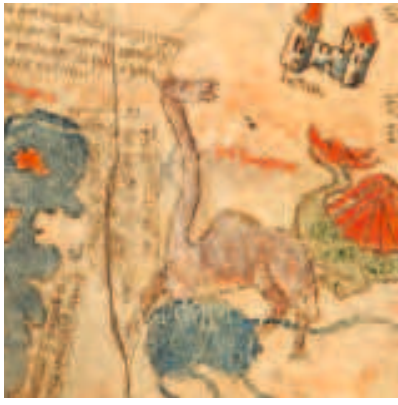

Fig. Ioa: Dromedario (part.)

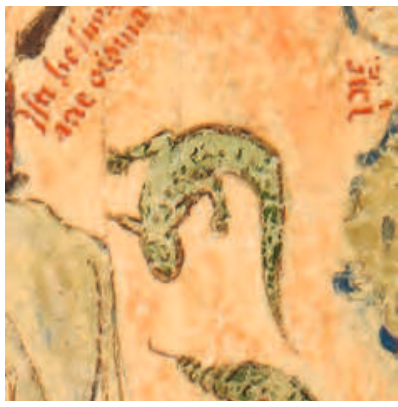

Fig. Iob: Coccodrillo (part.)

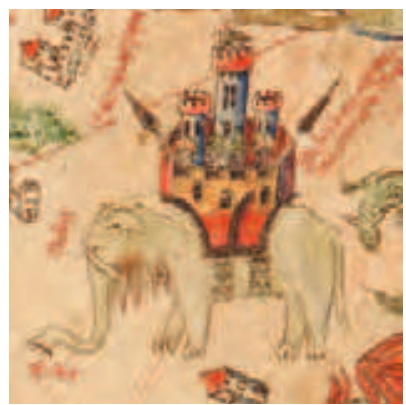

Fig. Ioc: Elefante (part.)

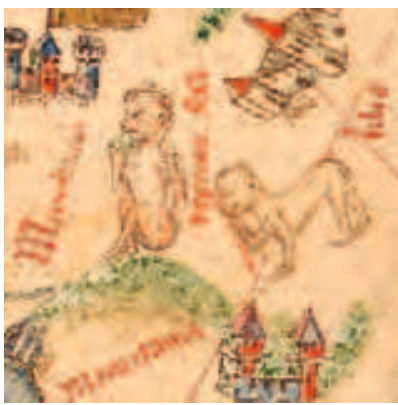

Fig. Iod: Scimmie (part.)

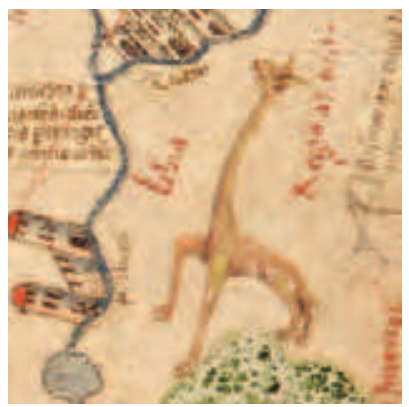

Fig. Ioe: Giraffa (part.) 
circolazione a partire dagli anni quaranta del XV secolo. Pure l'elefante, sebbene ancora sormontato dalla tradizionale torre lignea, si discostava dalle immagini stereotipate dei bestiari per ricalcare lo schizzo dal vero dell'anconetano (figg. I9, 2I) o l'immagine sulla coeva carta nautica di Bartolomeo Pareto (fig. 9a). Si trattava, pertanto, di un mappamondo che poteva a tutti gli effetti essere considerato - come scrive Sebastiano Gentile - «summa delle novità geografiche di metà Quattrocento se non fiorentina, certamente al corrente delle nuove cognizioni acquisite dagli umanisti fiorentini». ${ }^{23}$ Oltre a ciò il Mappamondo genovese si presenta - almeno sulla base di quelli sopravvissuti - come un unicum giacché la raffigurazione di fauna esotica sulle mappe continuava a essere rara e, quando presente, per lo più limitata a dromedari, elefanti o pappagalli, mentre coccodrilli, giraffe e scimmie non comparivano quasi mai. ${ }^{24}$

È interessante osservare come la realizzazione del Mappamondo genovese, nel quale fanno la loro comparsa alcuni animali esotici fino ad allora assenti dalla cartografia, sia probabilmente da ricondurre alla stessa città marittima aperta al mondo dove un secolo prima fu miniato il Codice Cocharelli (figg. II-I3), manoscritto che vanta una straordinaria varietà di fauna esotica resa con un naturalismo descrittivo sorprendente per l'epoca. ${ }^{25}$ Il testo, composto tra il I330 e il I340 da un membro di una facoltosa famiglia di mercanti genovesi che svolgevano la loro attività nell'isola di Cipro, fu concepito quale strumento per trasmettere al figlio Johannes gli insegnamenti appresi dal nonno Pellegrino Cocharelli - da cui il nome del codice - riguardo all'etica del buon mercante e alla nobiltà di spirito. ${ }^{26}$ Le pagine decorate da un anonimo miniatore, forse genovese, si presentano incorniciate da rondelle con al loro interno raffigurazioni realistiche di animali esotici: un leopardo (fig. I Ia), una giraffa (fig. I Ib), un dromedario (fig. I Ic), una zebra (fig. I Id), un pellicano (fig. I2a), uno struzzo (fig. I2b) e delle scimmie (figg. I3a-I3b), tanto da indurre a credere che l'esecutore avesse avuto l'opportunità di osservarli durante un viaggio in Oriente oppure - come ipotizza Otto Pächt: «In uno dei giardini zoologici che esistevano in Italia fin dal tardo XIV secolo e dei quali era un esempio il castello dei Visconti a Pavia. Un'altra possibilità, sebbene più remota, è che abbia copiato alcune raffigurazioni da manoscritti orientali, quali i bestiari arabi o persiani». ${ }^{27}$

La presenza della zebra, all'epoca del tutto sconosciuta in Italia, sembrerebbe però suggerire che il miniatore si fosse recato nelle terre d'oltremare, come pure

23. Firenze e la scoperta I992, pp. I73-I75 n. 83.

24. Nella mappa datata I 439 eseguita da Gabriel de Vallseca si trovano solo cammelli, mentre in quella realizzata nella sua bottega intorno al I440 figurano anche degli elefanti vedi PUJADES I BATALLER 2007, pp. 264265, 270-27I.

25. FABBRI I999, pp. 308-309; PÄCHT 20I I, p. 24. Le pagine del codice - oggi smembrato - si conservano alla British Library di Londra (Add. ms. 27695 e 2884I; Egerton ms. 3 I27 e 378I9), al Museum of Art di Cleveland (J.H. Wade Fund I953.I52) e al Museo Nazionale del Bargello a Firenze (inv. 2065).

26. Per un approfondimento sul testo e le pagine miniate vedi CONCINA 20I6, pp. I89-265; FABBRI I999, pp. 305-320; EAD. 20II, pp. 289-3Iо; EAD. 20I3, pp. 95-I06; DUNLOP 20I6, pp. 228-237.

27. PÄCHT 2OII, p. 24. 


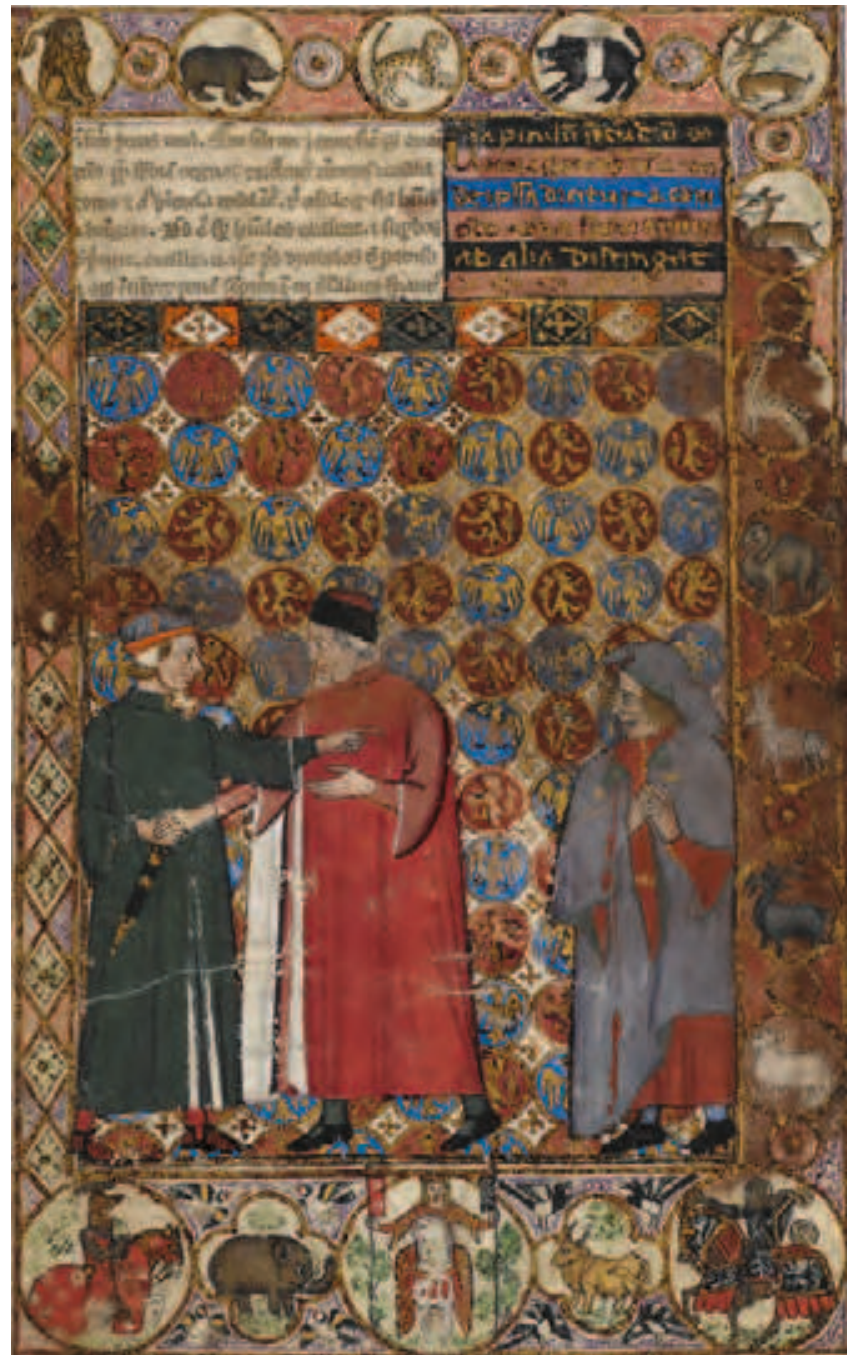

Fig. II: Miniatore genovese (?),

Codice Cocharelli, I330-I340 ca.

Londra, British Library (ms. Add. 27695, c. 3v)

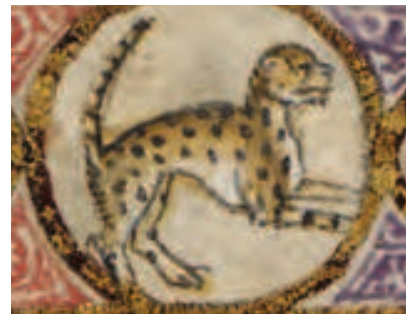

Fig. I Ia: Leopardo (part.)

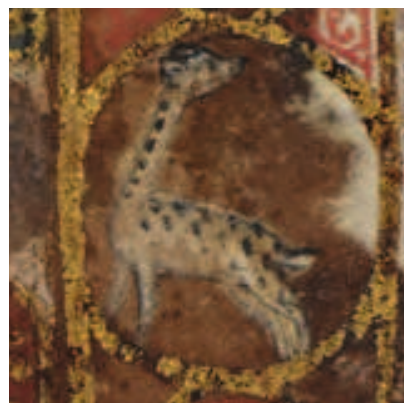

Fig. I Ib: Giraffa (part.)

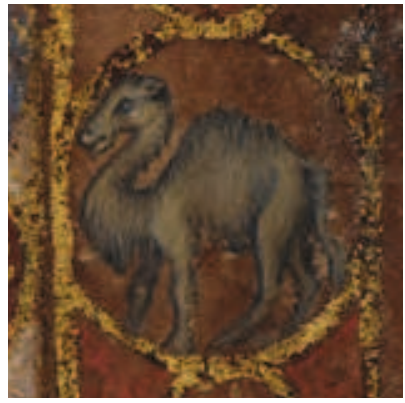

Fig. I Ic: Dromedario (part.)

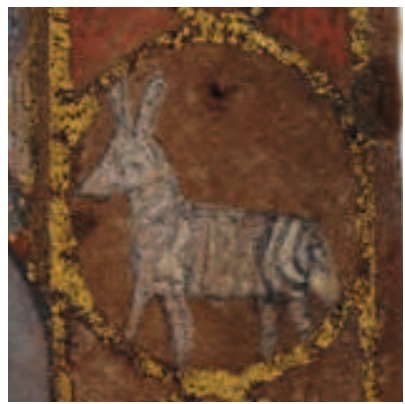

Fig. IId: Zebra (part.) 


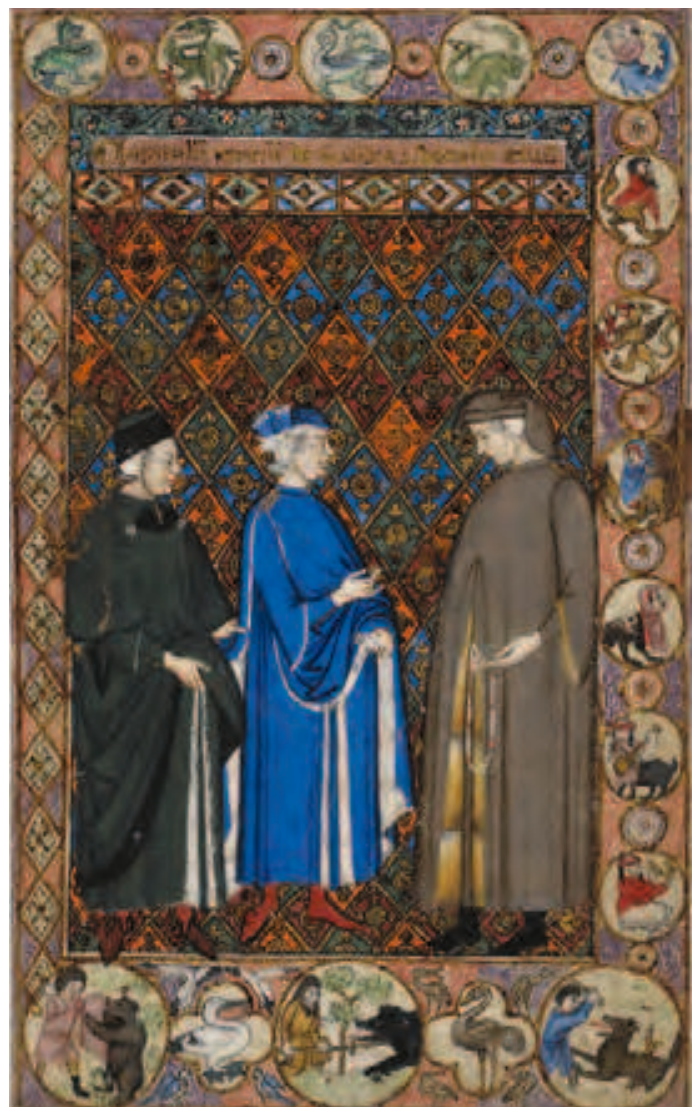

Fig. I2: Miniatore genovese (?),

Codice Cocharelli, I330-I340 ca.

Londra, British Library (ms. Add. 27695, c. 4r)

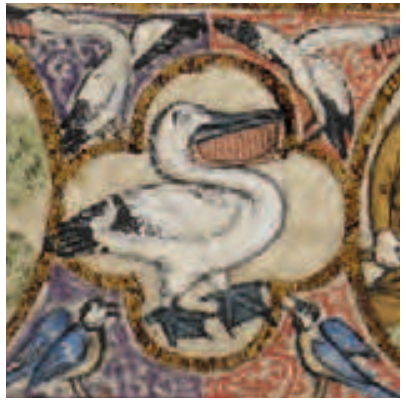

Fig. I2a: Pellicano (part.)

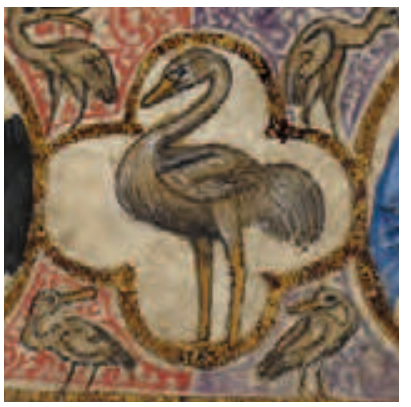

Fig. I2b: Struzzo (part.) 


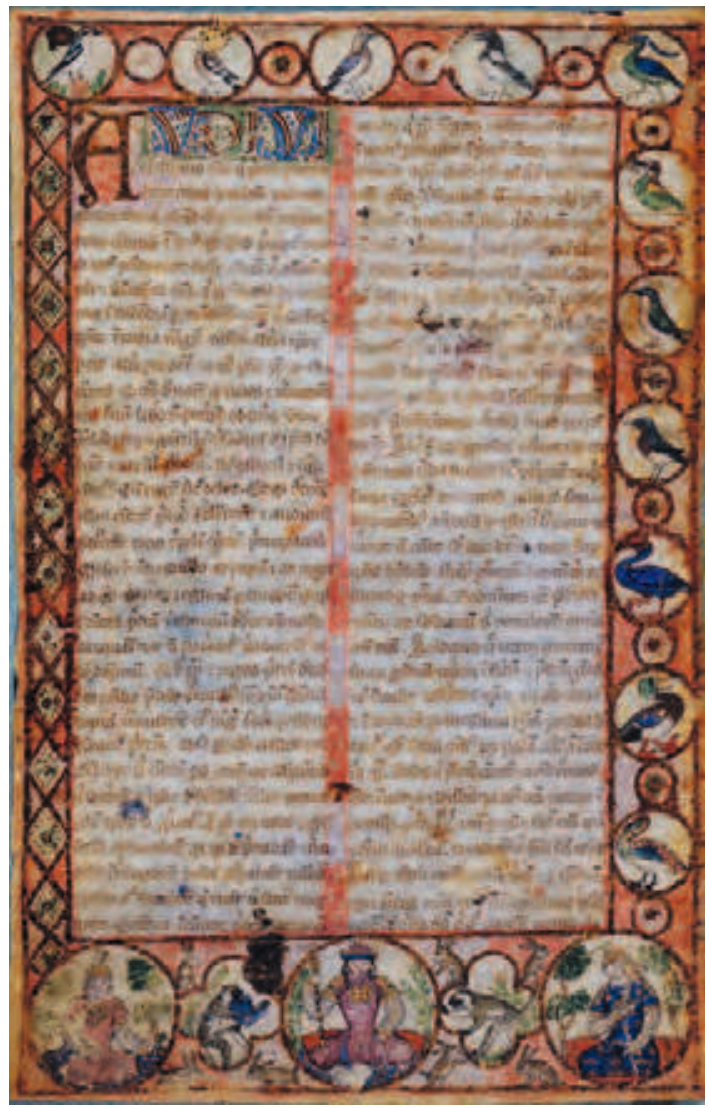

Fig. I3: Miniatore genovese (?),

Codice Cocharelli, I330-I340 ca.

Firenze, Museo Nazionale del Bargello (inv. $2065 \mathrm{Cr}$ )

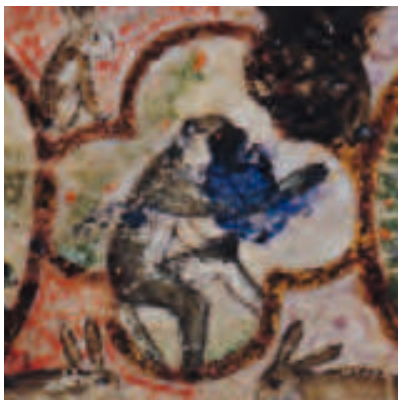

Fig. I3a: Cercopiteco (part.)

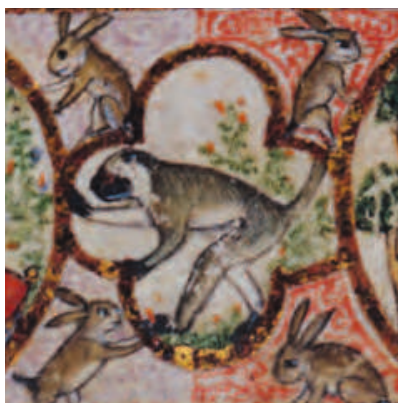

Fig. I3b: Cercopiteco (part.) 
le scelte tematiche e i dettagli decorativi di sapore orientaleggiante profusi a piene mani nelle illustrazioni. ${ }^{28}$

\section{I.2. Scritti di viaggiatori illustrati}

Nel XIV e per buona parte del XV secolo la conoscenza degli animali esotici da parte della classe mercantile fiorentina si basava, oltre che sull'esperienza personale di viaggiatori e pellegrini, sulla lettura di bestiari ed enciclopedie, manoscritti in volgare che tramandavano nozioni in gran parte attinte dalle auctoritates. Si trattava di testi d'impronta ancora marcatamente medievale, nonostante si cominciasse ad avvertire qualche innovazione nel Tresor di Brunetto Latini, nei quali le descrizioni della fauna esotica erano prevalentemente concepite in un'ottica moralizzante a volte accompagnate da miniature stereotipate. È da tener presente che nel Medioevo le immagini degli animali non avevano l'ambizione di ritrarli naturalisticamente, ma piuttosto di renderli facilmente riconoscibili grazie a determinati attribuiti convenzionali conferiti loro dalla tradizione, come le uova di grandi dimensioni per lo struzzo o la proboscide, le zanne e la torre lignea sulla groppa per l'elefante. ${ }^{29}$ Scopo di questi libri era, da un lato, magnificare Dio e la Creazione attraverso le meraviglie della natura e, dall'altro, descrivere le qualità degli animali trasformandoli in exempla di vizi e virtù per il fedele. Non era perciò importante fornire ragguagli sulla loro anatomia, etologia o biologia. Come afferma Michel Pastoureau:

les hommes du Moyen Âge savent très bien observer la faune et la flore. Mais ils n'ont guère idée que l'observation ait un rapport avec le savoir, ni qu'elle puisse les conduire à la vérité. Cette dernière ne relève pas de la physique mais de la métaphysique: le réel est une chose, le vrai est un autre, différente. De même, artistes et imagiers savent fort bien représenter des animaux de manière réaliste, mais ils ne le font guère avant la fin du Moyen Âge parce que les représentations conventionnelles - celles que l'on voit dans nos bestiaires enluminés sont, à leurs yeux, plus importantes, plus véridiques que les représentations naturalistes..$^{30}$

Questa idea moralizzata degli animali doveva essere venuta meno quando i primi viaggiatori trecenteschi recatisi in Oriente si erano trovati davanti agli occhi delle bestie in carne e ossa che poco avevano a che fare con quanto narrato nei testi o con le raffigurazioni dei bestiari. Circostanza che, coniugata con la forma mentis dei mercanti istruitisi nelle scuole d'abaco, aveva dato origine a descrizioni alquanto dettagliate. In genere si limitarono, però, a riferire per iscritto la struttura fisica della fauna esotica, a volte accogliendo incondizionatamente quanto tramandato dalle enciclopedie, come la mancanza di giunture nelle gambe dell'elefante, e a menzionare alcuni attributi tipici, quali la torre lignea sul dorso del

28. FABBRI 20I3, pp. 96-97.

29. PASTOUREAU 2OII, pp. 42-43.

30. Ivi, pp. II-I3. 
pachiderma - per altro pratica diffusa in Oriente - o le grandi uova deposte dallo struzzo che in patria si trovavano sospese alle navate delle chiese.

Assolutamente fuori dal coro - se si considera autografo il manoscritto più antico sopravvissuto - è il Libro d'Oltramare scritto, intorno alla metà del XIV secolo, dal frate Niccolò da Poggibonsi al suo rientro da un lungo viaggio in Oriente. Peculiarità di questo resoconto sono gli schizzi posti a illustrazione delle descrizioni degli animali esotici che più lo avevano colpito. Se i disegni dell'elefante (fig. I4) e dello struzzo (fig. I5) erano già presenti nei bestiari e nelle mappe, quelli di animali come la giraffa (fig. I6), la capra siriana (fig. I7) e la pecora con la "coda grassa" (fig. I8) costituivano delle novità assolute. ${ }^{3 \mathrm{I}}$ Assenti dai bestiari e dai libri di viaggio precedenti, nel Libro d'Oltramare il frate non si era limitato a descrivere gli ovini orientali ma li aveva pure ritratti, anche se in maniera approssimativa, rendendo note ai suoi contemporanei specie diffuse in Oriente. Le capre con folto pelo a ciocche di colore fulvo e orecchie piatte e strette, molto lunghe e pendenti appartengono alla razza siriana (fig.I7a), ovini che ancora un secolo più tardi dovevano aver stupito papa Pio II se nei Commentarii riferiva di averli visti nella residenza del cardinale Ludovico Trevisan ad Albano nel I463. ${ }^{32}$ Le pecore con coda «larga parecchie spanne [...] e tonda a modo d'uno tagliere» sembrano invece corrispondere a esemplari della razza laticauda, dette anche pecore con la "coda grassa" (fig. I8a). ${ }^{33}$ Si tratta di immagini delineate da un frate non particolarmente abile nel disegno ma che, pur nella loro schematicità, ben illustravano la morfologia degli animali reali. Del resto, il suo elefante non differiva molto da quello raffigurato da un anonimo miniatore lombardo un secolo più tardi nel Tractatus de herbis (I440 ca.), raccolta di immagini botaniche e zoologiche corredate da indicazioni sulle loro proprietà terapeutiche. ${ }^{34}$ È probabile che, una volta rientrato in patria, il frate avesse realizzato i disegni basandosi su quanto annotato nel corso del lungo viaggio e

3I. Thierry Buquet ha rintracciato qualche rarissima raffigurazione della giraffa nell'Histoire universelle de la Genèse à l'Histoire romaine jusqu'à Pompée datata al terzo quarto del XIII secolo e nella Bible massorétique della fine del XIII secolo, mentre nell'inventario della biblioteca privata dei Medici stilato nel I 495 figura una copia, probabilmente realizzata a Costantinopoli nell'XI secolo, della Topographia christiana attribuita al viaggiatore Cosma di Indicopleuste (VI secolo) dove tra gli animali miniati compare anche una giraffa - indicata come camelopardalis - ben poco attinente alla realtà. L'animale si trova, poi, in una miniatura delle Très riches heures del duca di Berry eseguita dai Fratelli de Limbourg intorno al I4Io, secondo Charles Cuttler elaborato sulla base di modelli italiani o di contatti con un artista bizantino. A mio parere, invece, la scarsa somiglianza dell'animale con una giraffa sembra piuttosto suggerire la trasposizione in miniatura di un racconto orale oppure di informazioni contenute in un resoconto odeporico o nelle auctoritates vedi BUQUET 20I2, p. 80 figg. I2-I4; SPER ANZI 20I4, pp. $90-93$ n. I8; CUTTLER I99i, pp. I63-I66 fig. 3.

32. Pio II nei suoi Commentarii riferisce di aver visto "animali di varie specie, fra cui pavoni e galline d'India e capre portate dalla Siria, che hanno orecchie lunghissime e larghe, pendenti sui due lati del capo e che coprono tutt'e due le guance». E ancora nel maggio I 493 l'ambasciatore sforzesco a Venezia scrisse a Ludovico il Moro che certi mercanti giunti a Venezia dal Levante avevano portato «uno sorzo [topo] de Faraone [mangusta] molto domestico et certe capre de Barbaria» che, essendogli parse «bestiole nove», aveva deciso di acquistare vedi PICCOLOMINI 2008, vol. 2, p. 223I, libro XI:22; MALAGUZZI VALERI I9I3, p. 742. Vedi anche MASSETI 20I5, pp. I49-I5I.

33. Gli ovini orientali con la "coda grassa" saranno descritti, un quarantennio più tardi, anche dal mercante Lionardo Frescobaldi vedi pagina II I.

34. COLLINS 2000 , p. 279. 


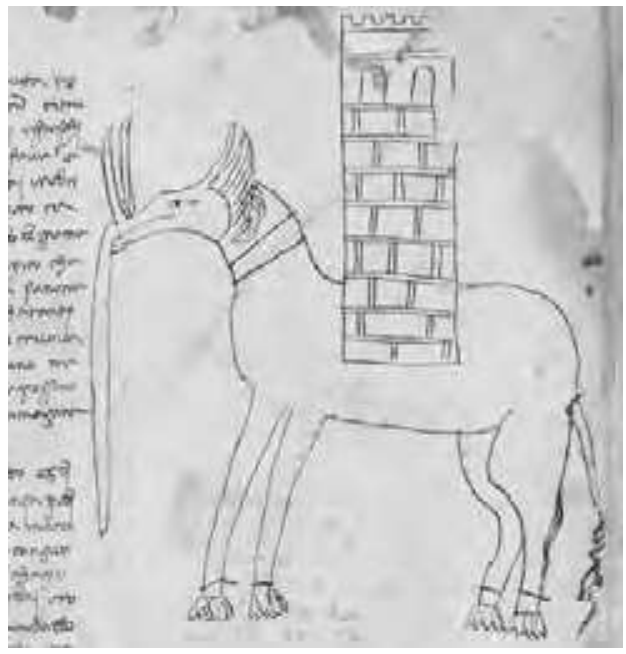

Fig. I4: Niccolò da Poggibonsi,

Elefante (part.), Libro d'Oltramare, I346-I350 ca. Firenze, Biblioteca Nazionale Centrale (ms. II.IV. IOI, c. 4Ir)

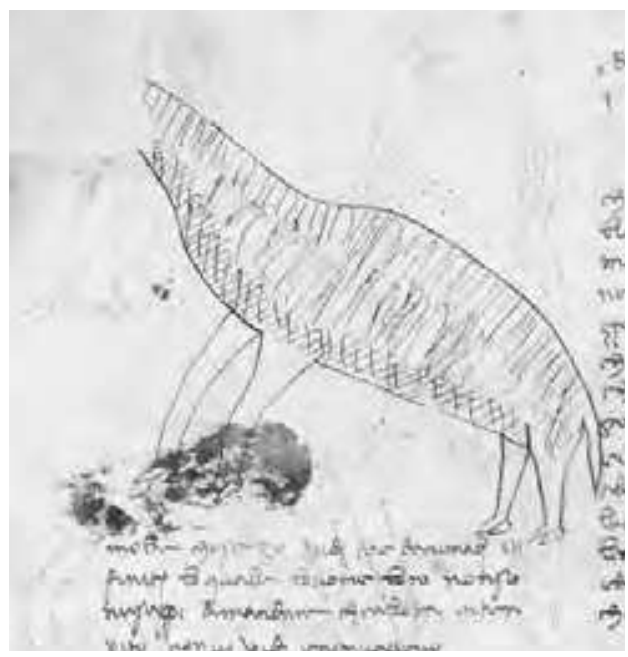

Fig. I6: Niccolò da Poggibonsi,

Giraffa (part.), Libro d'Oltramare, I346-I350 ca. Firenze, Biblioteca Nazionale Centrale (ms. II.IV. IOI, c. 4IV)

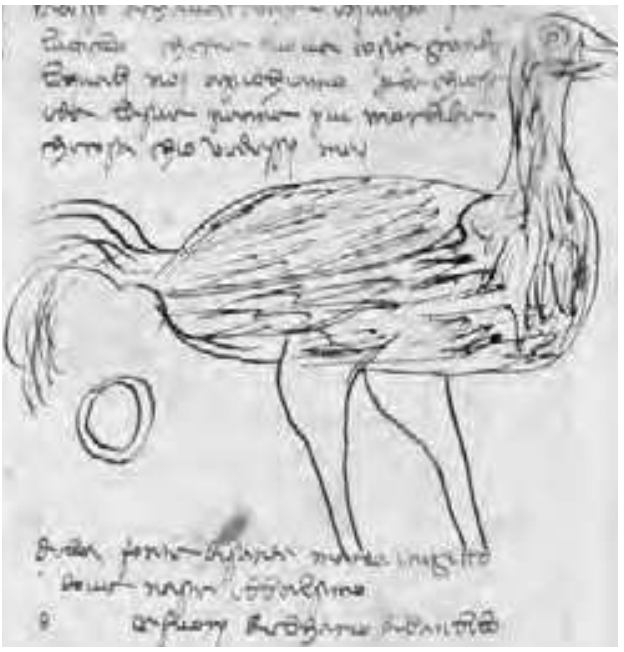

Fig. I5: Niccolò da Poggibonsi,

Struzzo (part.), Libro d'Oltramare, I346-I350 ca. Firenze, Biblioteca Nazionale Centrale (ms. II.IV. IOI, C. 4IV)

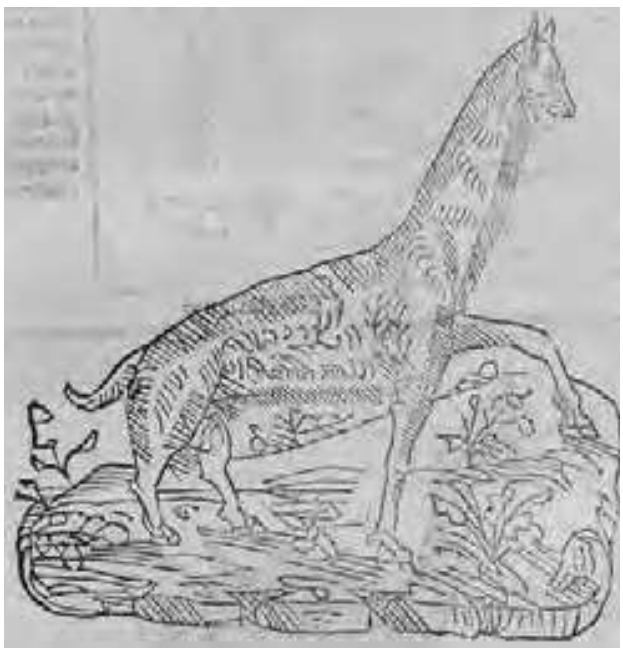

Fig. I6a: Niccolò da Poggibonsi, Giraffa (part.),

Viazo da Venesia al Sancto Iherusalem, et al Monte Sinai...,

Giustiniano da Rubiera, Bologna, I50o Venezia, Fondazione Cini (FOAN TES 9I3, c. Mir) 


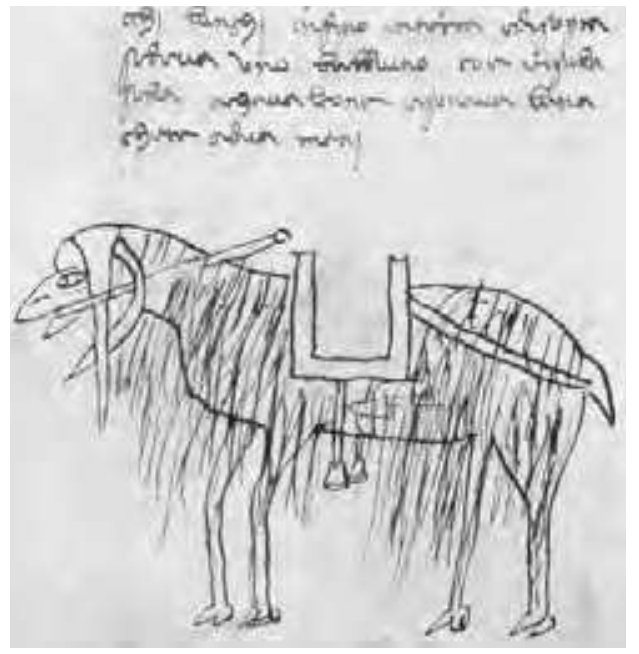

Fig. I7: Niccolò da Poggibonsi,

Capra siriana (part.), Libro d'Oltramare, I346-I350 ca. Firenze, Biblioteca Nazionale Centrale (ms. II.IV. IOI, c. 4IV)

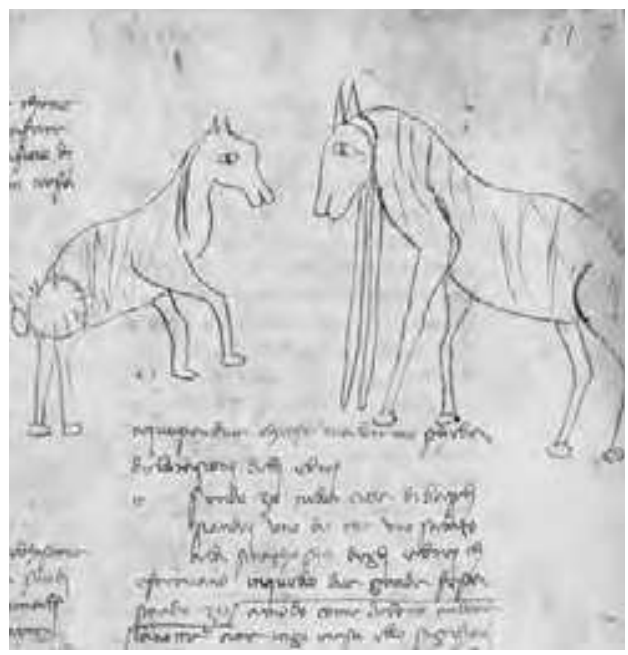

Fig. I8: Niccolò da Poggibonsi, Pecore con la "coda grassa",

Libro d'Oltramare, I346-I350 ca.

Firenze, Biblioteca Nazionale Centrale (ms. II.IV. IOI, c. 54r)

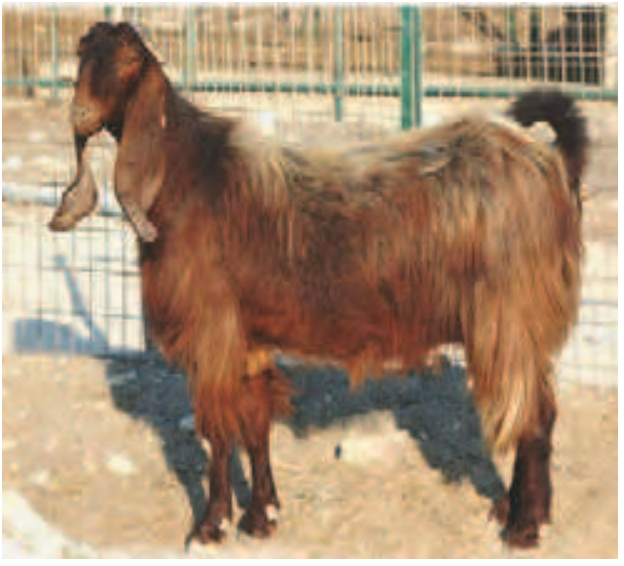

Fig. I7a: Capra siriana (Capra hircus)

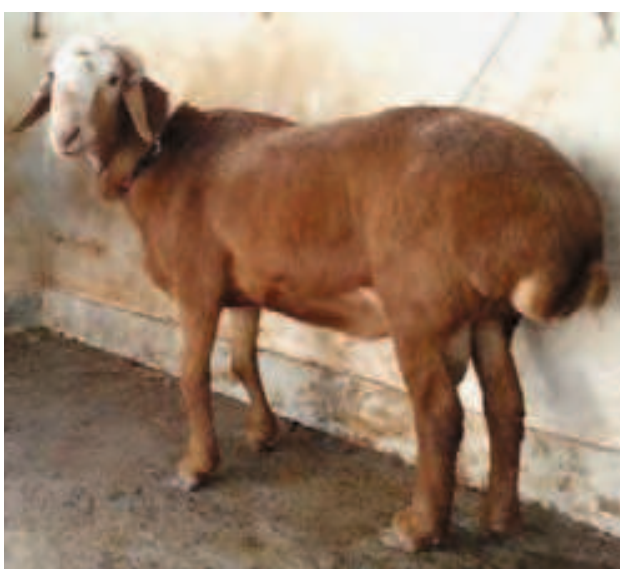

Fig. I8a: Pecora con la "coda grassa" (Ovis aries steatopyga) 
sui ricordi, forse un poco affievoliti, di quanto aveva visto, motivo per cui le orecchie del pachiderma finirono per assumere la «forma d'ale di draco» come appuntato nel diario. La giraffa - nel manoscritto ora mutila della testa - doveva apparire come nella cinquecentesca edizione a stampa del testo (fig. I6a), dove le immagini, anche se leggermente rimaneggiate, in larga parte corrispondevano a quelle schizzate da Niccolò da Poggibonsi, quindi con lungo collo e capo alquanto verosimile considerata la sua scarsa attitudine al disegno. ${ }^{35}$ Nell'evenienza in cui non si tratti di un manoscritto autografo e che i disegni siano opera di un copista - che avrebbe però calibrato con maggior accortezza lo spazio da destinare alle raffigurazioni - dovevano essere stati elaborati seguendo le indicazioni fornite nel testo.

Sarà solo un secolo più tardi, grazie al mercante e umanista Ciriaco d'Ancona, che in Italia cominciarono a circolare immagini realistiche della giraffa e dell'elefante, animali che nel corso dei suoi viaggi in Oriente aveva avuto modo di osservare al Cairo. Le raffigurazioni, corredate da una descrizione scritta, figurano in una lettera inviata nel I 442 al fiorentino Andrea Stagi e in quelle recapitate, nel giro di pochi anni, ad altri illustri destinatari tra cui Filippo Maria Visconti, Alfonso V d'Aragona, il veronese Iacopo Rizzon, il padovano Iacopo Zeno, l'imperatore bizantino Giovanni VIII Paleologo, conosciuto e frequentato durante il concilio fiorentino, e un senese di nome Mariano. ${ }^{36} \mathrm{La}$ lettera di Ciriaco d'Ancona fu poi ampiamente diffusa grazie a numerose copie di cui due riconducibili ad area fiorentina: quella di Pierfilippo Pandolfini destinata alla sua biblioteca (figg. I9-20) e quella approntata da Bartolomeo Fabio per Francesco Sassetti (fig. 2I). ${ }^{37}$

Nella missiva inviata il I gennaio I 443 a Filippo Maria Visconti l'Anconetano riferiva:

vidimus Zorophan sic enim indigenae feram vocitant: peregrinum quippe animal, \& mirabile visu; nam informe longitudinis collo, \& anteriori parte sesquitertia, posteriore cruribus altius eminebat; cetera vero a capite ad extremas pedum \& ungularum partes, dorsumque,

35. Viazo da Venesia I972, s.p. Vedi anche TEDESCO 20I9, pp. III, I26-I28, I32-I33.

36. FANTONI 20I4, pp. 86-87 n. I6. Il destinatario della missiva - come evidenzia Paolo Galluzzi - non doveva essere Mariano di Iacopo detto il Taccola: nel I433 il suo trattato De ingeneis con disegni di animali esotici era già concluso e se avesse avuto a disposizione la lettera di Ciriaco d'Ancona con il disegno della giraffa non l'avrebbe certo raffigurata come appare nel suo libro. La lettera doveva invece essere indirizzata a Mariano Sozzini, grande umanista senese e amico di Enea Silvio Piccolomini. Nella lunga lettera spedita nel I 442 a papa Eugenio IV - nota come Itinerarium - Ciriaco pur accennando ai dromedari, alla giraffa, all'elefante e ai terrificanti coccodrilli visti lungo il Nilo non incluse nessun disegno vedi BERTALOT - CAMPANA, I939, pp. 365-366; MITCHELL I962, p. 385; GALLUZZI I991, p. 23; DEGENHART - SCHMITT I96820I0, vol. 2.4, tav. 48a; WEISS I966a, pp. 33I, 335; ANCONA I742, p. 5I; WILLIAMS LEHMANN I977, p. 30 nota 77 .

37. La copia appartenuta a Pierfilippo Pandolfini si trova ora alla Biblioteca Medicea Laurenziana di Firenze (ms. Ashb. II74 cc. I42V-I 43v) e quella di Francesco Sassetti alla Bodleian Library di Oxford (ms. Lat. misc. d.85 cc.72v-73r); altre copie dell'epistola sono conservate alla Biblioteca Capitolare di Treviso (ms. I.I38 c. I73r -v), alla Bodleian Library di Oxford (ms. Canon Lat. misc. 280 c. 69Ar) e alla Biblioteca Estense di Modena (cod. Gr. I 44, c. I79v) vedi Firenze e la scoperta I992, pp. I77-I80 n. 85; WILLIAMS LEHMANN I977, pp. 9-I 2 figg. 30-35; CASU 2007 , p. 477. 


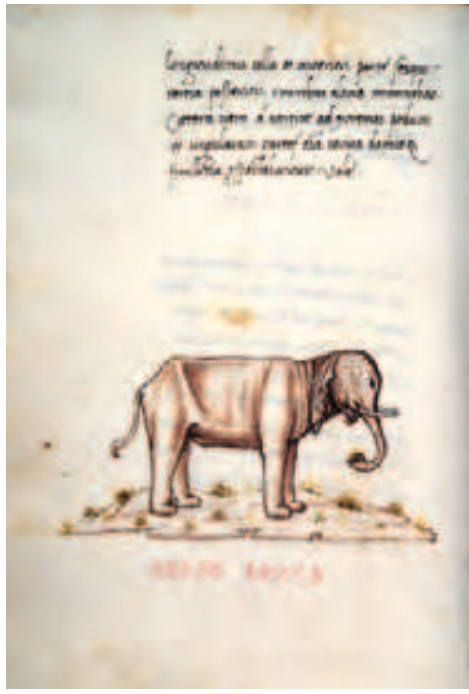

Fig. I9: Pierfilippo Pandolfini,

Elefante, Silloge di iscrizioni e disegni in parte derivati da originali di Ciriaco d'Ancona, ultimo quarto XV secolo Firenze, Biblioteca Medicea Laurenziana (ms. Ashb. II74, c. I42v)

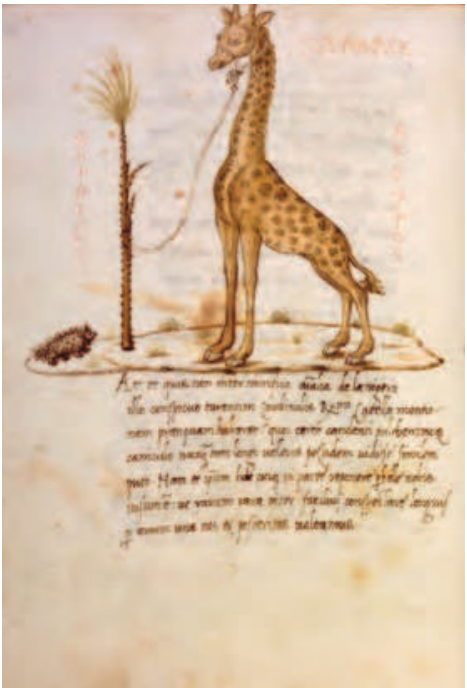

Fig. 20: Pierfilippo Pandolfini, Giraffa con cagnolino, Silloge di iscrizioni e disegni in parte derivati da originali di Ciriaco d'Ancona, ultimo quarto XV secolo Firenze, Biblioteca Medicea Laurenziana (ms. Ashb. II 74, c. I 43r)
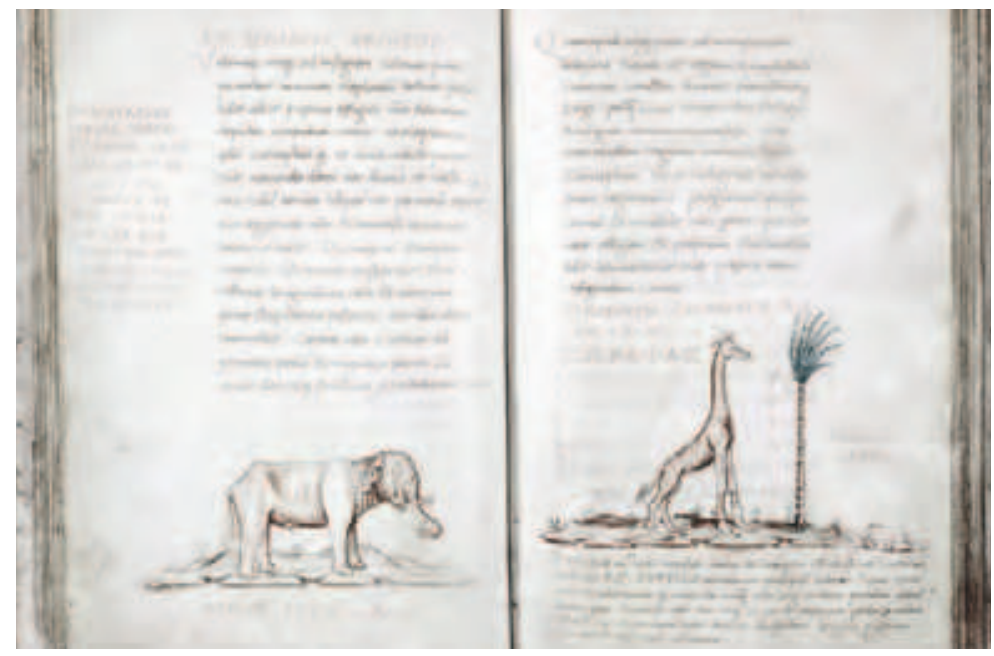

Fig. 2I: Bartolomeo Fazio (copia da Ciriaco d'Ancona),

Elefante e giraffa, Codex Ashmolensis, fine XV secolo Oxford, Bodleain Library (ms. Lat. misc. d.85, cc.7 2v-73r) 
\& maculosi tegminis color, omnia cervis, damisque simillima videbantur. Vidimus \& inibi magnas, immanesque elephantum belluas, ac antea per Nilum monstruosos illos, \& anguigenos crocodillos. ${ }^{38}$

Se la descrizione dell'animale strano e meraviglioso che gli indigeni chiamano giraffa, così come pure le indicazioni su elefanti enormi e mostruosi coccodrilli potevano risultare assai sintetiche, molto più eloquenti dovevano essere i disegni eseguiti dal vero con piglio estremamente realistico, attitudine riconducibile alla sua forma mentis di stampo mercantile, in modo che il signore visconteo potesse farsi un'idea della fauna esotica senza dover abbandonare il suo castello. ${ }^{39}$

Di tutt'altra natura appaiono, invece, gli animali esotici nel fittizio diario di viaggio intitolato Dimostrazione dell'andata o viaggio al Santo Sepolcro e al monte Sinai scritto dall'orafo fiorentino Marco di Bartolomeo Rustici alla metà del XV secolo. Non avendo mai compiuto il pellegrinaggio, l'autore doveva aver attinto le informazioni da qualche resoconto orale, da diari odeporici - in particolare quello di Niccolò da Poggibonsi e forse Felice Brancacci - e da altri libri tra cui anche qualche bestiario. ${ }^{40}$ In realtà le uniche immagini di fauna esotica che si rintracciano nel manoscritto sono quelle del cammello (fig. 22), abbozzato nel tondo con l'illustrazione del sesto giorno della Creazione, e un pellicano poco realistico accompagnato dalla didascalia «anitrocho» (fig. 23) che asseriva di aver visto lungo il Nilo. ${ }^{4}$ Per quanto riguarda, poi, il tondo con i Quattro Elementi, raffigurato nella pagina consacrata alla complessione dell'uomo, Marco di Bartolomeo Rustici proponeva un'iconografia insolita: i pesci quale simbolo dell'acqua e le talpe della terra, animali a lui ben noti, un quadrupede accovacciato avvolto dalle fiamme con la didascalia «samandra» - salamandra - per il fuoco e un altro circondato da nubi con la scritta "cameleon» per l'aria (fig. 24). ${ }^{42}$ Proprio per la sua peculiarità è possibile ipotizzare che l'immagine fosse stata ripresa dall'affresco - oggi perduto - con i Quattro Elementi eseguito da Paolo Uccello tra il I 432 e il I 434 nella volta della loggia di Palazzo Peruzzi, dove - come ricorda con grande ilarità Giorgio Vasari - nella quadratura corrispondente all'aria il pittore aveva ritratto:

il camaleonte che ne vive e piglia ogni colore; e perché ne aveva mai veduti, fece un cammello che apre la bocca et inghiottisce aria empiendosene il ventre: simplicità certo grandis-

38. ANCONA 1763 , pp. 55-56.

39. CASU 2007, p. 468; GAUTIER DALCHÉ 2009a, p. I85. Pare che la lettera indirizzata a Filippo Maria Visconti - purtroppo perduta - contenesse, oltre al disegno della giraffa e dell'elefante, anche quello di un coccodrillo vedi BERTALOT - CAMPANA I939, p. 366.

40. NEWBIGIN 20I5, pp. 46-47.

4I. ACIDINI - GURRIERI 20I5, pp. 63 c. Iv 7, 70 c. IO2r (I44). Riguardo al pellicano Marco di Bartolomeo Rustici riferiva: «andando sù per lo detto Nilo, trovamo uccegli tutti bianchi grandi. Aveano sì grande il beco, quando i marinai possono avere, con quello vòtano le navi. Chiamasi 'grochi', e noi gli chiamiamo 'anicrochi'", RUSTICI 2015 , p. 217.

42. ACIDINI - GURRIERI 20I5, p. 64 c. 4v 36. Nella recente edizione del testo alle curatrici sembra essere sfuggita la discrepanza tra la scritta «camaleon» e l'animale raffigurato. 


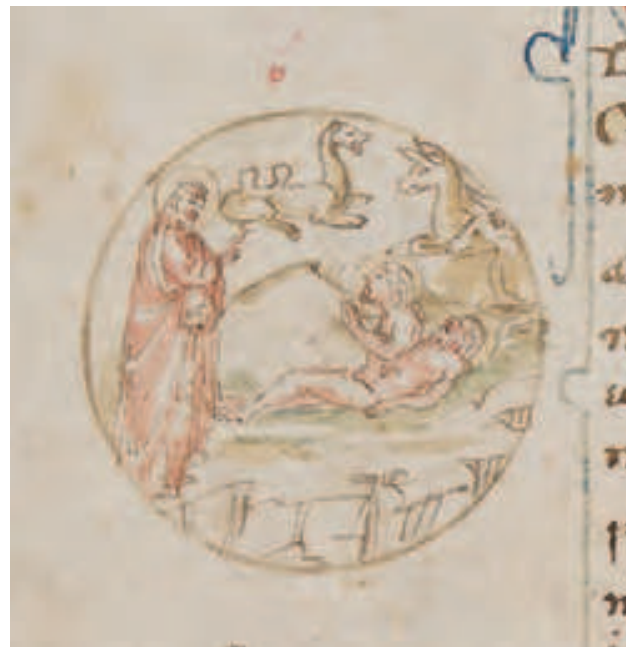

Fig. 22: Marco di Bartolomeo Rustici,

Creazione con Dio e Adamo ed Eva (part.), Dimostrazione dell'andata o viaggio al Santo Sepolcro $e$ al monte Sinai, I $448-\mathrm{I} 453 \mathrm{ca}$.

Firenze, Biblioteca del Seminario Arcivescovile Maggiore (c. IV)

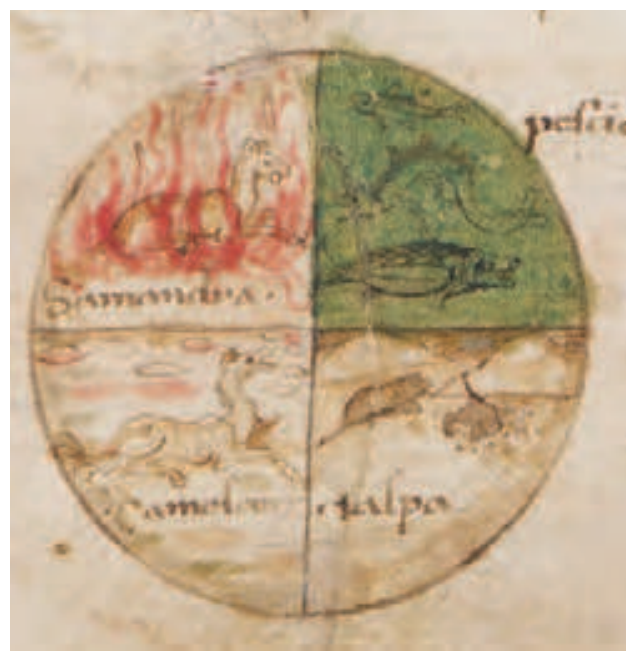

Fig. 24: Marco di Bartolomeo Rustici, Quattro Elementi (part.),

Dimostrazione dell'andata o viaggio al Santo Sepolcro $e$ al monte Sinai, I $448-\mathrm{I} 453$ ca.

Firenze, Biblioteca del Seminario Arcivescovile Maggiore (c. 4v)

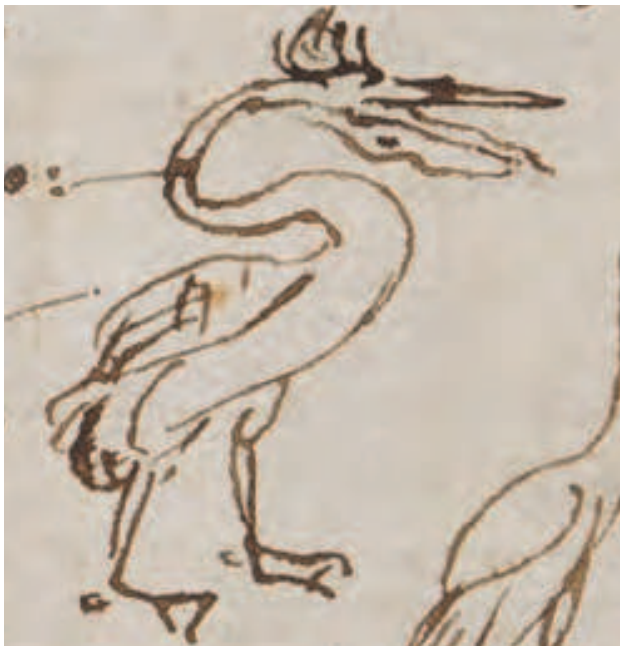

Fig. 23: Marco di Bartolomeo Rustici, Pellicano (part.),

Dimostrazione dell'andata o viaggio al Santo Sepolcro $e$ al monte Sinai, I $448-1453$ ca.

Firenze, Biblioteca del Seminario Arcivescovile Maggiore (c. I02r) 
sima, alludendo per lo nome del cammello a un animale che è simile a un ramarro, secco e piccolo, col fare una bestiaccia disadatta e grande..$^{43}$

Errore, a quanto pare, giustificabile con il fatto che la prima notizia sulla presenza di un camaleonte nella città del giglio risale al $\mathrm{I} 467$, quando il mercante fiorentino Benedetto Dei ne riportò uno dal suo viaggio in Oriente. Negli stessi anni Masolino da Panicale, impegnato a Roma ad affrescare la Sala Theatri di Palazzo Orsini a Montegiordano, nel dipinto con i Quattro Elementi (I432) - ora perduto - aveva raffigurato un dromedario quale simbolo dell'aria, quasi certamente rifacendosi a un modello iconografico che all'epoca doveva essere assai diffuso. ${ }^{44} \mathrm{La}$ confusione tra il quadrupede e il rettile è probabilmente da imputare alle notizie tramandate da alcuni bestiari ed enciclopedie dove il camaleonte, dotato della capacità di mutare colore, era a volte indicato, accogliendo una spiegazione in chiave allegorica, con il nome "camaleon», ossia il frutto dell'accoppiamento tra un cammello e una leonessa. ${ }^{45}$ Uno tra questi è il Bestiario latino della metà del XIII secolo dove il camaleonte miniato si presenta in forma di quadrupede con striature policrome sul corpo in modo da suggerire visivamente la capacità di mutare colore. ${ }^{46}$ A ulteriormente conferma del fatto che Paolo Uccello non avesse mai visto un camaleonte è l'affresco con la Creazione degli animali (I43I ca.) nel chiostro Verde della chiesa di Santa Maria Novella a Firenze, dove l'animale ritratto en trompe-l'oil appare più simile a un cane di piccola taglia che al rettile cangiante (fig. $74 \mathrm{C}$ ). ${ }^{47}$

L'errore commesso da Paolo Uccello nella loggia dei Peruzzi sembra essere stato perpetuato da Marco di Bartolomeo Rustici che, pur affermando di aver scritto il resoconto del pellegrinaggio compiuto in Terrasanta, rivela di non averlo mai intrapreso, altrimenti si sarebbe accorto, quando a proposito del Cairo scriveva "trovamo mandriani che aveano di molto bestiami e camegli», che i camelidi non si nutrono d'aria. ${ }^{4}$ Oltre a ciò, non si spiegherebbe come una persona così attenta nell'illustrare quanto narrato nel libro, fino al punto da disegnare chiese e monumenti fiorentini e animali diffusi in Toscana ben noti ai lettori, avesse invece tralasciato di corredare d'immagini le descrizioni, a volte molto accurate, dei numerosissimi animali esotici che sosteneva di aver osservato nel corso del suo

43. VASARI i966-I997, vol. 3, pp. 69-70; POPE-HENNESSY I950, pp. I72-I73. Per il legame tra le due iconografie e il fatto che Paolo Uccello si fosse ispirato a Masolino vedi BORSI I992, pp. 26, $295-296$ n. 7; CICCUTO 2000, p. 47; GAGLIARDO 2002, pp. 40, 49.

44. Ivi, pp. 36-64. Vedi anche PARRONCHI I962, pp. 64-67. Per un approfondimento sul ciclo pittorico di Palazzo Orsini vedi CAVALLARO 200I, pp. 23-24.

45. A questo proposito Giorgio Vasari ipotizza un malinteso dovuto alla somiglianza tra i nomi dei due animali vedi pagine I76-I78. Vedi anche GALIARDO 2002, pp. 49, 54-55.

46. PASTOUREAU 20II, p. 2 II.

47. GIURA 20I6, pp. I2O-I32. È interessante notare come nell'affresco nel chiostro Verde il camaleonte, sebbene poco realistico, sia in qualche modo attinente alla realtà, mentre quello realizzato a distanza di pochi anni nella loggia dei Peruzzi assume le fattezze di un dromedario.

48. RUSTICI 20I5, p. 2 I9. 
viaggio: pellicani, ovini orientali, coccodrilli, ippopotami, testuggini, dromedari, elefanti, giraffe, scimmie e galline d'India. ${ }^{49}$

\section{I.3. Taccuini di disegni}

\section{Tra la fine del XIV e gli inizi del XV secolo un ruolo di primo piano nella rap- presentazione dal vero degli animali spetta alla Lombardia dove - come scrive Enrico Castelnuovo:}

La rappresentazione della natura è una grande scoperta. Si esce da un mondo simbolico ripetibile e semplicemente catalogabile per entrare in un universo plurimo, diverso e diversificato. [...] Il nuovo modo di guardare alla natura e di rappresentarla, che comportava non solo una nuova attenzione e un nuovo modo di raffigurare, ma un nuovo rapporto tra l'uomo e il mondo..$^{\circ}$

49. Ivi, pp. 2 I 8 «E nella detta città [Damietta] vedemo certe bestie travisate, fra lle quali erano capre ch'aveano le corna dua ispanne lunghe. E castroni che si nutricavano a mano, che aveano sì grande coda che no·lla potea portare, ma era posta isun una carretta e in quel modo andava»; 2I9 «E ancora vedemo una calcatrice [ippopotamo] nel detto fiume, la quale correva per pigliare un camello. Era grande braccia sei o piùe. La sua testa er'a modo d'un cavallo, più ritonda e grossa quanto una vitella, andante in sù quatro gambe non tropo alte. Il suo colore è nerognolo di sotto, e di sopra a modo di colore bigerognelo. [...] E anco vedemo in detto luogo testugini grandi che 'l coperchio del dosso si faceva targoni [scudi] per gente d'arme. Erano di grandeza due braccia o inna‘n zi magiori. [...] vedemo [al Cairo] un dormendario [dromedario], il quale era grande quanto un camello, il quale cavalcava un saraino [saraceno]. La sua fazione era con una testa come di camello, quasi somigliava una vitella, di colore di camello, con un collo lungo poco minore di camello, e ttutto velloso i sua crini del collo e anco il petto e il dosso. E in sulle reni avea uno scrigno [gobba] o vuo' dire dua iscrigni alti dua terzi di braccio, in forma pareva una sella antica di legname, e nel mezzo vi stava e·cavalcatore, quello saraino»; 22I «Ed in que-luogo [al Cairo] vedemo parechi liofanti. [...] E·liofante è tutto nero quasi di colore d'una bufola [bufalo], tutto quasi pelato e tanto grande che pare un monte a vedere. Dicesi che nonn ha congiuntura ne le sua gambe né ginochia, e a vederlo andare pare che così sia, tanto vàe intero, ma gli ha congiunture quasi intere. Il capo suo è grande e gli ochi sono piccoli. Egli ha dua denti maestri, son grandi e quegli si chiamano 'avorio'. Son di peso di quatrocento o di secento libre li dua denti, son di peso secondo la grandeza del liofante. E il suo naso o vuo' dire grifo [muso] va insino in terra e nella fine del naso ha una presa e piglia la vivanda e riducela in boca. E i sua orechi son fatti pendenti a modo d'alie di dragone. La coda è picola, i sua piedi sono ritondi. [...] Ancora in que luogo vi fu condotto un liofante venuto dall'isola di Taprobana [Sri Lanka], il quale liofante era bianco tutto e maraviglioso con quelle fazioni che quello che noi vedemo ch'era nera, il quale fu mandato al soldano di Bambilonia [Babilonia]. [...] detti ci fue da mercanti che lo vidono. [...] E ancora vedemo uno animale chiamato girafa, e 'l capo suo è fatto com'un capo di scorpione e 'l suo corpo è lavorato come stàe una rete. Gli piedi di drieto ha corti e que' dinanzi ha grandi. E il collo suo è lungo in modo che quando lo diriza pare una maraviglia tanto è lungo. [...] Quivi sono babuini e gatti mamoni, papagalli asai, topi di Faraone [manguste], bertucce e divariati animali. [...] E in que-luogo vedemo una capra, la quale avea una sella e briglia da cavalcare. La sua lana agiugneva insino in terra, le sua corne agiugnevano per lungheza dua ispanne, tutte vergate come d'uno serpente. I sua orechi agiugnevano sotto le mascelle infino in terra e di sopra a questa capra sedeva uno babuino, il quale sonava le nachere a dua mani. Ed anco vedemo galline indiane non trope grandi. Aveano il capo tondo sanza penne di sopra e ttutta la persona erano belle penne di divariati colori, travisati quasi come uno pagone [pavone]». Se la descrizione della capra orientale è ripresa pedissequamente da Niccolò da Poggibonsi, quella accurata dell'animale chiamato "dormendario» - in realtà un cammello per la presenza delle due gobbe - è probabilmente da collegare alla presenza in città di un cammello mandato in dono da Francesco Sforza nel I 452, mentre l'informazione sull'elefante bianco potrebbe essere stata ricavata dai ricordi di viaggio di Niccolò de' Conti immortalati su carta da Poggio Bracciolini e disponibili a partire dal I 448 se non addirittura qualche anno prima. È infine singolare che chiami «calcatrice» l'ippopotamo, termine in genere usato per indicare il leggendario serpente marino ritenuto capace di uccidere il coccodrillo oppure il coccodrillo stesso vedi LATINI 2007, p. 235, libro I, I3 I:2 e 4; PORDENONE vedi pagina IOo; BRACCIOLINI 2004, p. I07; Viaggio in Oriente 2005, p. I18; Le navigazioni atlantiche 1966, p. I08.

5o. CASTELNUOVO $201 \mathrm{I}$, p. XXIV. Unico precedente è il De arte venandi cum avibus, trattato di falconeria composto alla metà del XIII secolo da Federico II e quindi riconducibile all'Italia meridionale, illustrato lungo i mar- 
Non deve quindi stupire se iniziatore di questo movimento fu Giovannino de' Grassi - poliedrico artista lombardo attivo presso la corte milanese in qualità di architetto, scultore, pittore e miniatore - che probabilmente aveva avuto la possibilità di osservare gli animali, tra cui anche quelli rari ed esotici, custoditi nei parchi dei castelli viscontei e, soprattutto, in quello pavese costruito per volere di Galeazzo II Visconti nel $1365 .{ }^{51}$ A lui e alla sua bottega si deve il celeberrimo Taccuino di disegni (I385-I400 ca.), raccolta di studi quasi "scientifici" di animali ritratti dal vero, nonostante il persistere di qualche reminiscenza medievale quali le figure fantastiche dell'unicorno e della pantera, al quale attingere a piene mani quando il suo atelier era chiamato a realizzare affreschi e miniature..$^{52}$ Lo studio degli animali riprodotti su pergamena con l'accuratezza di un naturalista, indagati fin nei minimi dettagli del pelo, del piumaggio e della postura, costituiva una novità assoluta per l'epoca: la resa accurata della loro anatomia, che si poneva in netto contrasto con i disegni statici e stereotipati della tradizione medievale, costituiva un mezzo per conoscere la realtà attraverso l'osservazione diretta. ${ }^{53}$ Esemplari a questo riguardo sono le immagini di animali esotici quali lo struzzo (fig. 25), volatile presente alla corte viscontea fin dal $\mathrm{I} 342$, le bertucce e i cercopitechi (fig. 26) all'epoca pure presenti, i ghepardi e i leopardi (figg. 26-29) mantenuti dai Visconti fin dal I368, il pappagallo (fig. 30), la capra nubiana corredata dalla didascalia "uno becho salvaticho» (fig. 3I) e la faraona indicata come "galina de india» (fig. 32). ${ }^{54}$ Il disegno - come sottolinea Maria Grazia Recanati: «ora si preoccupa di restituire esattamente il dato di natura, come avveniva al tempo nei testi medici o negli erbari, conquistando attraverso quest'ansia di definizione pre-scientifica una sua autonoma giustificazione, un suo valore cognitivo di incalcolabile portata culturale». 55

gini da numerosissime miniature di uccelli e definito «il primo trattato zoologico scritto con lo spirito critico della scienza moderna» vedi PÄCHT 20II, pp. 26-28. Nei bestiari medievali la pantera non è il felino di colore nero come lo intendiamo oggi bensì una piccola bestia maculata che dalla bocca emanava un profumo così dolce e soave in grado di attirare tutti gli animali ad eccezione del drago vedi LATINI 2007, p. 32 I n. I93; BUQUET 20I I, pp. 23-24.

5I. MESSEDAGLIA I94I, p. 35; ROSSI I995, p. 47; MALACARNE I998, p. I03. Joanna Woods-Marsden ritiene, invece, che gli animali minuziosamente ritratti dagli artisti lombardi fossero morti, opinione accolta da Maria Clara Ruggieri Tricoli, WOODS-MARSDEN I992, pp. 68-69; RUGGIERI TRICOLI 2004, pp. I45-I46.

52. ROSSI I995, pp. 45-6I, II3; TOESCA I905, pp. 332-336; ID. I9I2, pp. 298-307; SCHELLER, I963, pp. I42I54 n. 2I; Il taccuino I997, pp. I5-37; RECANATI I998, pp. 2I-43; ROSSI 20I5, p. I56 n. II.2; BUQUET 201 I, pp. 23-24. Antonio Cadei attribuisce a Giovannino solo parte dei disegni del primo fascicolo con la firma «Johaninus de grassis designavit» e non li considera elementi di una raccolta di modelli o di studi preparatori bensi antesignani del disegno moderno, CADEI I970, pp. I7-36. Per un sunto delle vicende critiche vedi RECANATI I998, pp.I8-2I.

53. Ivi, pp. 26-27; EAD. 2005, p. II6.

54. Le didascalie sono un'aggiunta databile tra il I450 e il I470: quella che recita «uno struzo che padisse lo ferro" riprende la credenza tramandata dai bestiari che il volatile fosse in grado di mangiare e digerire il ferro, mentre la scritta "leon pardo" indistintamente impiegata per designare ghepardi e leopardi è dovuta al fatto che fino alla fine del XVI secolo le due tipologie di felini furono accomunate e tra loro confuse vedi BRAVI I998, p. I I LATINI 2007, p. 287, libro I, I72:4; BUQUET 20I I, p. 29. La capra selvatica che Maria Grazia Recanati ritiene un animale fantastico in realtà corrisponde a una specie di ovino orientale, come a suo tempo già indicato da Robert Scheller, RECANATI I998, pp. 22, 28; SCHELLER I963, p. I47 n. 2 I.

55. RECANATI 2005 , p. I32. 


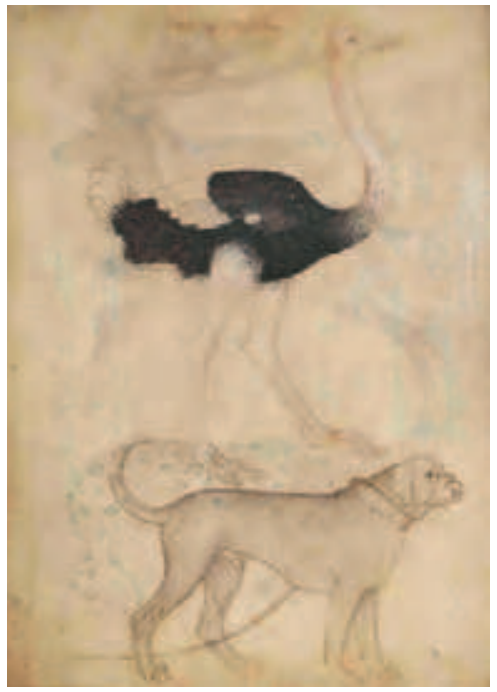

Fig. 25: Giovannino de’ Grassi, Struzzo e mastino,

Taccuino di disegni, I385-I400 ca. Bergamo, Biblioteca Civica Angelo Mai (Cassaf. I.2I, C. 2V)

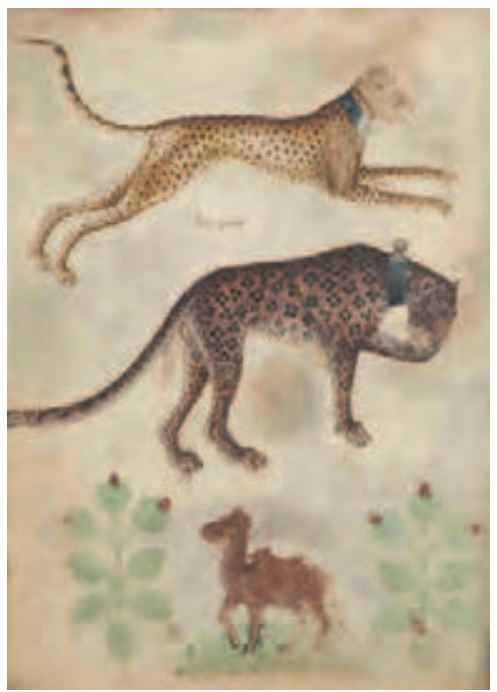

Fig. 27: Giovannino de' Grassi, Ghepardo, leopardo e cammello, Taccuino di disegni, I385-I400 ca. Bergamo, Biblioteca Civica Angelo Mai (Cassaf. I.2I, c. I5V)

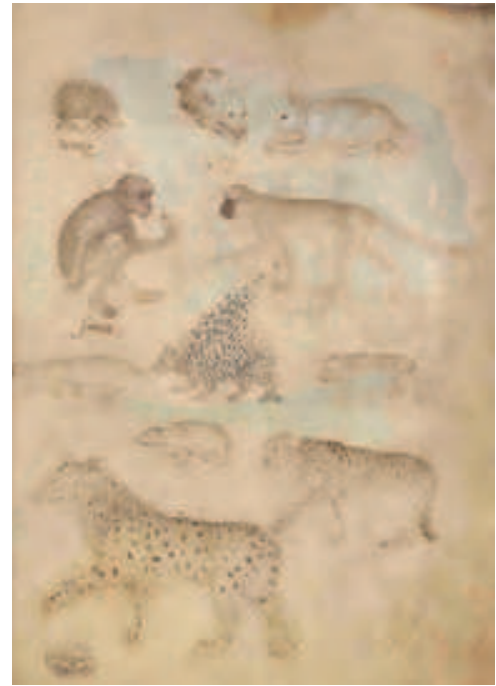

Fig. 26: Giovannino de' Grassi,

Porcospino, conigli, bertuccia, cercopiteco, mangusta, istrice, iena, leopardo, pantera (fantastica),

Taccuino di disegni, I385-I400 ca.

Bergamo, Biblioteca Civica Angelo Mai (Cassaf. I.2 I, c. 5r)

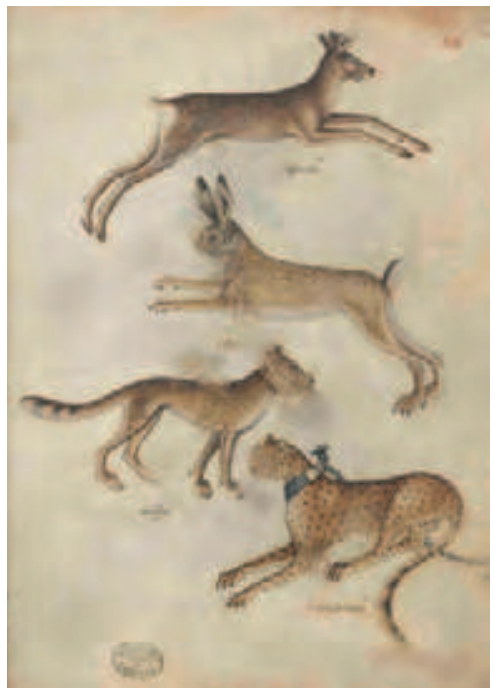

Fig. 28: Giovannino de' Grassi,

Capriolo, lepre, volpe, ghepardo,

Taccuino di disegni, I385-I $400 \mathrm{ca}$.

Bergamo, Biblioteca Civica Angelo Mai (Cassaf. I.2I, c. I6r) 


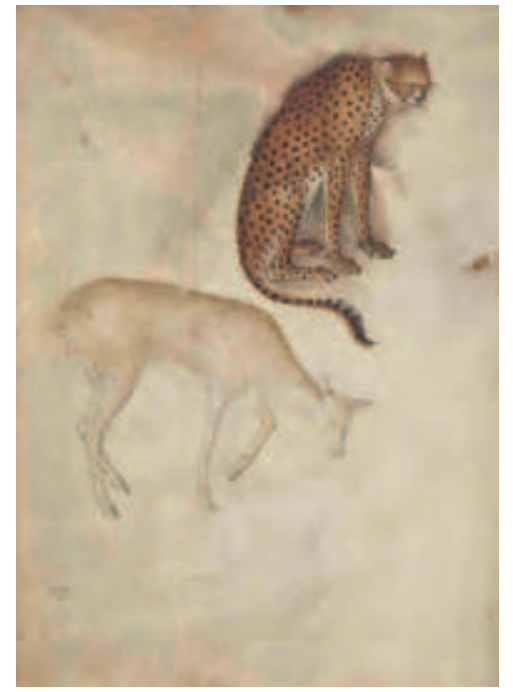

Fig. 29: Giovannino de' Grassi, Ghepardo e capriolo,

Taccuino di disegni, I385-I400 ca.

Bergamo, Biblioteca Civica Angelo Mai

(Cassaf. I.2I, c. 2IV)

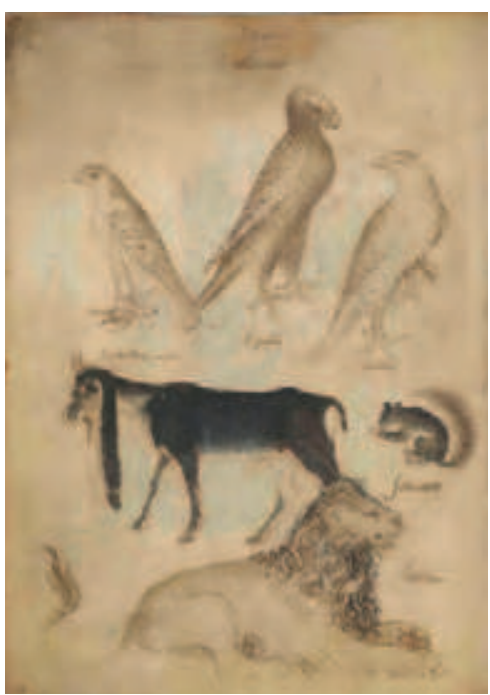

Fig. 3 I: Giovannino de' Grassi,

Falconi, capra nubiana, scoiattolo e leone, Taccuino di disegni, I385-I400 ca.

Bergamo, Biblioteca Civica Angelo Mai (Cassaf. I.2 I, c. 4V)

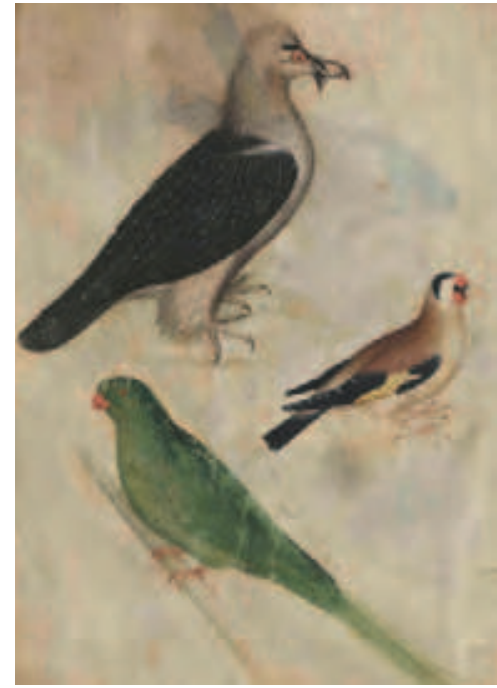

Fig. 30: Giovannino de' Grassi, Gipeto, cardellino, pappagallo,

Taccuino di disegni, I385-I400 ca. Bergamo, Biblioteca Civica Angelo Mai (Cassaf. I.2I, c. I3v)

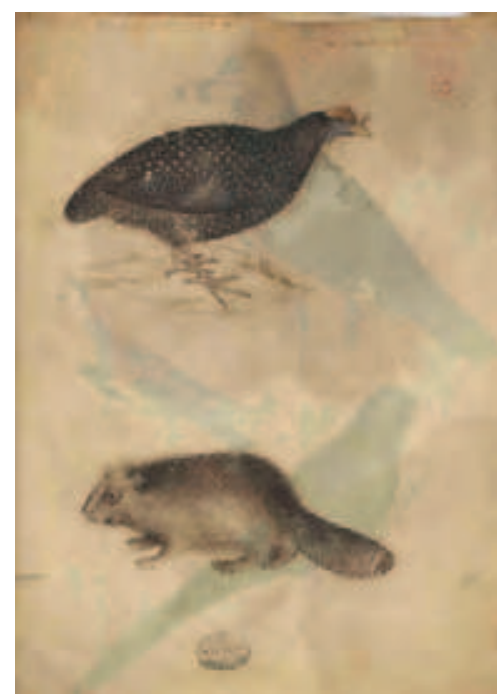

Fig. 32: Giovannino de' Grassi, Gallina d'India e castoro,

Taccuino di disegni, I385-I400 ca.

Bergamo, Biblioteca Civica Angelo Mai (Cassaf. I.2I, c. I3r) 
All'ambito della scuola di Giovannino de' Grassi è stata pure attribuita l'Historia plantarum (I395-I400 ca.), testo corredato da numerose miniature commissionato da Gian Galeazzo Visconti con il proposito di offrirlo a Venceslao IV re di Boemia e Germania quale omaggio per averlo incoronato duca di Milano nel $1395 .{ }^{56}$ Peculiare di questo prezioso manoscritto di farmacopea, che oltre alle proprietà delle piante menzionate nel titolo illustrava anche quelle attribuite alle sostanze medicinali ricavate da minerali e animali, è la totale assenza del rapporto testoimmagine: le raffigurazioni naturalistiche delle bestie prive di descrizione figurano accostate a testi esclusivamente focalizzati sulle loro proprietà terapeutiche. Se le immagini di animali esotici quali lo struzzo (fig. 33), il ghepardo e il leopardo (fig. 34) risultano fedelmente riprese dal taccuino degrassiniano appartenuto ai Visconti, quelle con la scimmia (fig. 35) che sembra ritrarre una bertuccia d'insolite dimensioni, dell'elefante (fig. 36) e del coccodrillo (fig. 37) appaiono ancora legate alla tradizione dei bestiari medievali, forse perché animali all'epoca ancora assenti dai parchi viscontei: l'unico elefante in carne e ossa visto in area lombarda fu quello inviato da Federico II a Cremona nel I235, e due anni più tardi trasferito a Pontevico nel bresciano per celebrare la vittoria facendolo sfilare con «una torre di legno alla maniera del carroccio dei Lombardi» issata sul dorso "ed era quadrata e bene legata e aveva quattro bandiere, in ogni angolo una, e in mezzo un grande gonfalone, e, dentro, il conduttore della bestia, con molti Saraceni». 57 Particolare era pure la miniatura con marcato intento naturalistico del dromedario (fig. 38), assente dal Taccuino di disegni dove un approssimativo cammello fu aggiunto in epoca più tarda (fig. 27) da qualcuno che lo aveva probabilmente osservato dal vero..$^{8}$

Altra produzione tipicamente lombarda, se non addirittura da ricondurre a commissioni viscontee, erano i tacuina sanitatis della fine del XIV secolo, alcuni dei quali ricondotti alla cerchia di Giovannino de' Grassi e del figlio Salomone, con la traduzione latina di un testo arabo redatto intorno alla metà dell'XI secolo dal medico cristiano Ibn Butlān, nei quali oltre a scene di vita quotidiana erano illustrate le proprietà mediche e dietetiche di vegetali e animali corredate da miniature che in rari casi comprendevano animali esotici, ripresi dal Taccuino di disegni, quali il dromedario (fig. 39) e il cercopiteco (fig. 40).59

56. TOESCA I9I2, pp. 334-339; PÄCHT 20II, pp. I2, 67-69; RECANATI 1998, p. 27; COLLINS 2000, pp. 275-278; SEGRE RUTZ 2002a, pp. 69-I22.

57. SALIMBENE I987, pp. I32:400, I34:405; LATINI 2007, p. 313, libro I, I87:2. Per le immagini vedi Historia plantarum 2002-2004, vol. 2, pp. I55 c. 89v, 229-230 c. I 4Ir (entrambi identificati come leopardi nonostante le differenti maculature), 390 c. $243 \mathrm{v}, 405-406$ c. 253v, 42 I c. $263 \mathrm{r}$.

58. RECANATI I998, p. 2I.

59. SEGRE RUTZ 2002b, pp. I23-170. Per il gruppo di tacuina sanitatis tardo trecenteschi prodotti per la cerchia viscontea, tra cui quello appartenuto a Verde Visconti (Parigi, Bibliothèque nationale de France, ms. NAL I673) vedi TOESCA I9I2, pp. 337-367; PÄCHT 20II, pp. 67-73; SEGRE 2000; EAD. 20I5, p. I57 n. II.5; Das Hausbuch I979. Per un approfondimento sull'origine e la funzione del tacuinun sanitatis vedi HOENIGER 2006, pp. 5I-8I. 


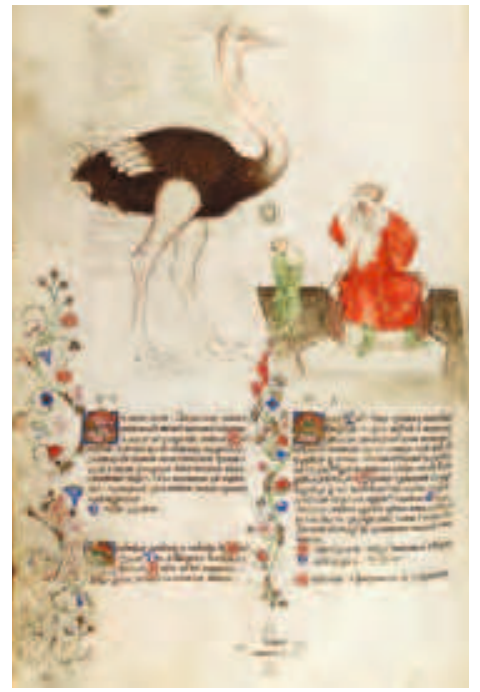

Fig. 33: Bottega di Giovannino de' Grassi, Struzzo e sudore,

Historia plantarum, I395-I400 ca.

Roma, Biblioteca Casanatense (ms. 459, c. 253v)

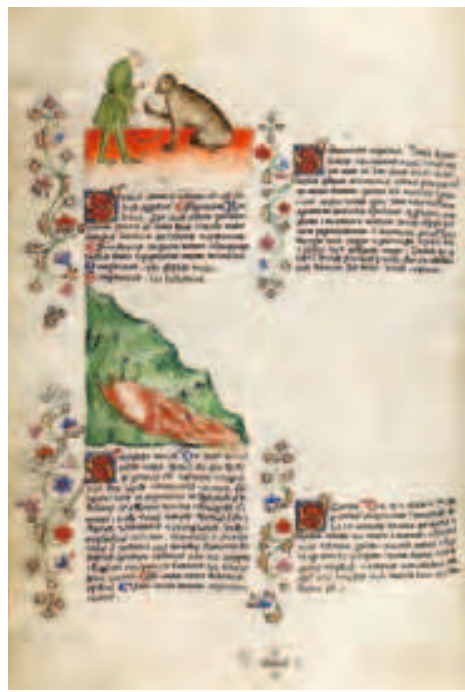

Fig. 35: Bottega di Giovannino de' Grassi, Bertuccia,

Historia plantarum, I395-I400 ca.

Roma, Biblioteca Casanatense (ms. 459, c. 243v)

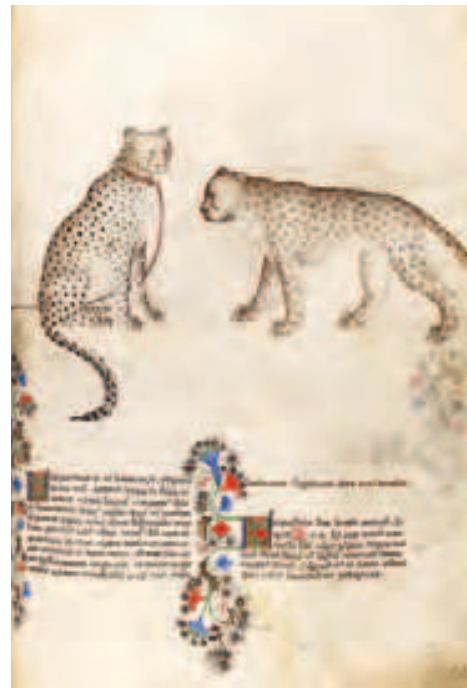

Fig. 34: Bottega di Giovannino de' Grassi, Ghepardo e leopardo,

Historia plantarum, I395-I400 ca.

Biblioteca Casanatense (ms. 459, c. I4Ir)

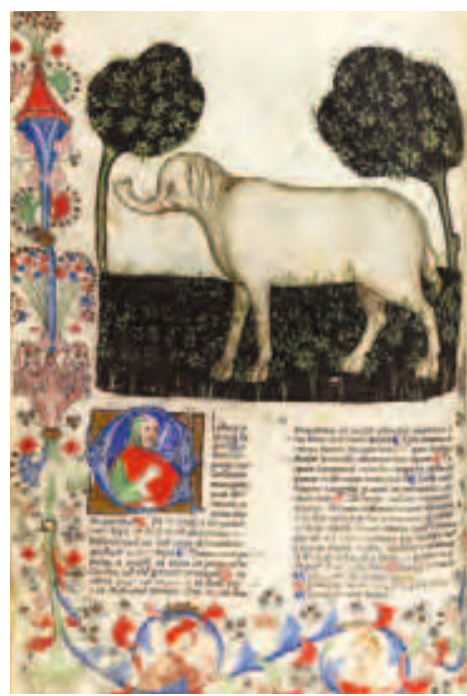

Fig. 36: Bottega di Giovannino de' Grassi, Elefante,

Historia plantarum, I395-I400 ca.

Roma, Biblioteca Casanatense (ms. 459, c. 89v) 


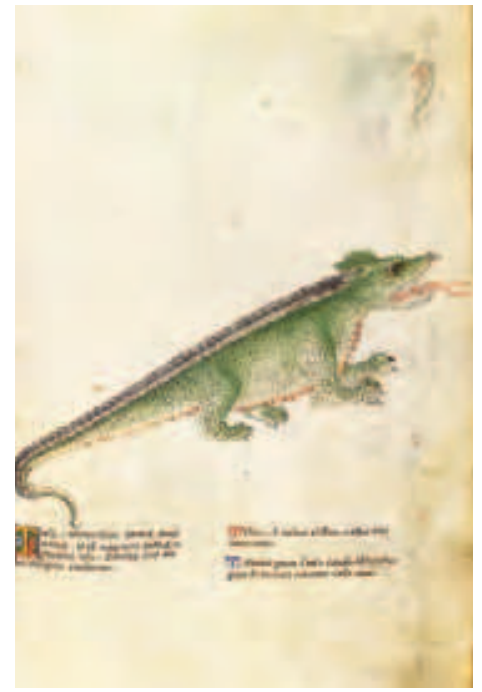

Fig. 37: Bottega di Giovannino de' Grassi, Coccodrillo,

Historia plantarum, I395-I400 ca.

Roma, Biblioteca Casanatense (ms. 459, c. 263r)

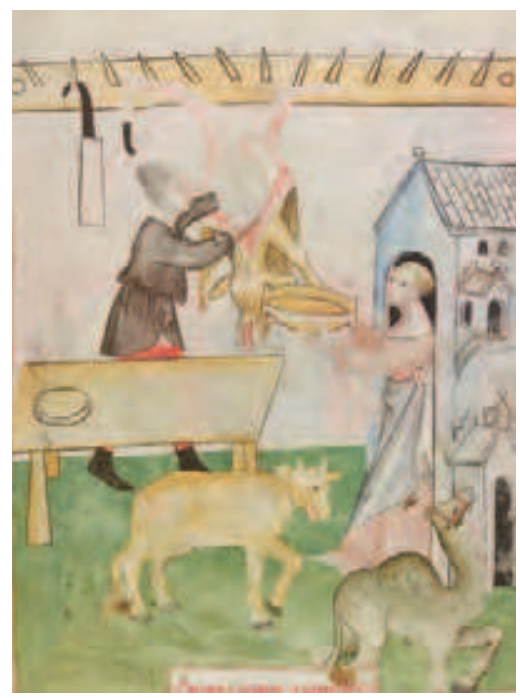

Fig. 39: Bottega di Giovannino de' Grassi, Carne vaccina e di cammello,

Tacuinum sanitatis, I $390 \mathrm{ca}$.

Parigi, Bibliothèque nationale de France (ms. NAL I673, c. 63r)

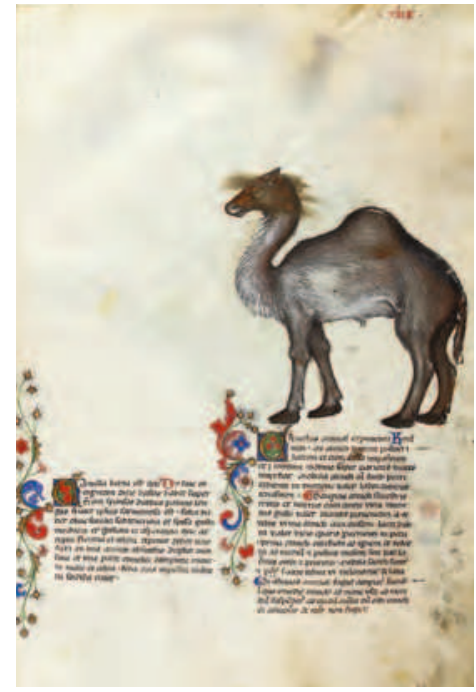

Fig. 38: Bottega di Giovannino de' Grassi, Dromedario,

Historia plantarum, I395-I400 ca.

Roma, Biblioteca Casanatense (ms. 459, c. 49r)

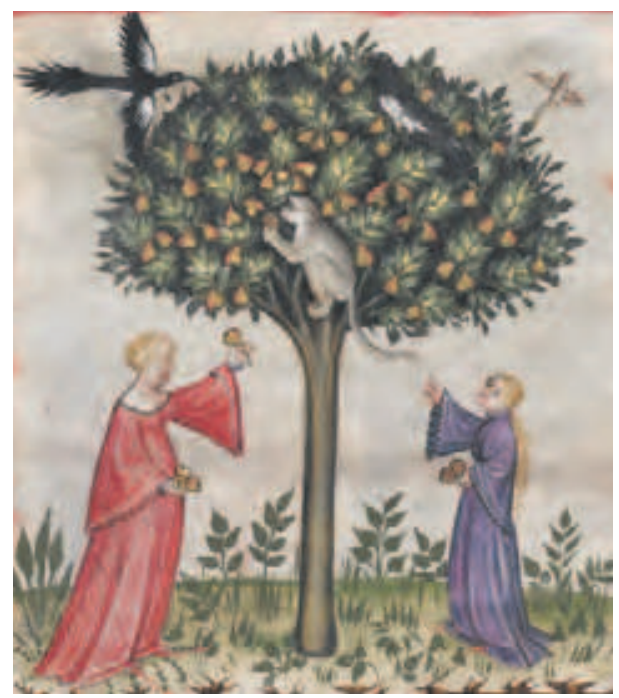

Fig. 40: Bottega dell'Italia settentrionale, Albero di pere e cercopiteco,

Tacuinum sanitatis, I380-I400 ca. Vienna, Österreichische Nationalbibliothek (Ser. n. 2644, c. 6v) 
La raffigurazione dal vero degrassiniana fu un'innovazione fin da subito accolta da gran parte degli artisti lombardi che diedero vita a una vera e propria corrente "zoologica" e, nello stesso tempo, all'uso di libri di modelli all'interno degli atelier di pittori e miniatori. ${ }^{60}$ Scopo di questi repertori di immagini - inizialmente eseguiti su costose e resistenti pagine in pergamena nel corso del tempo sostituite da ben più economici e fragili fogli di carta - era predisporre un catalogo al quale attingere quando chiamati a realizzare affreschi, dipinti e miniature. ${ }^{61}$ Ampiamente diffusi nel XIV e nel XV secolo, questi taccuini ad uso di bottega si tramandavano di generazione in generazione grazie a copie eseguite, quale parte integrante della loro formazione, da assistenti e praticanti quando gli originali cominciavano a essere consunti, motivo per cui sovente si avverte l'intervento di più mani oppure, nei disegni ormai divenuti mere ripetizioni, una cristallizzazione rispetto ai prototipi. ${ }^{62}$ Questi cataloghi d'immagini non erano però esclusivamente limitati all'atelier di produzione ma circolavano tra gli artisti: era infatti assai consueto il prestito tra pittori, miniatori, orafi e incisori che quando li avevano a disposizione non perdevano l'occasione per eseguirne una copia da serbare in bottega.

Tra i primi seguaci di Giovannino de' Grassi è certamente da annoverare l'artista anonimo di area lombarda che agli inizi del XV secolo approntò un repertorio di disegni di animali - il Libro di modelli di animali di Weimar - desunti da disparati taccuini tra cui anche quello degrassiniano al quale sono certamente da ricondurre i ghepardi (fig. 4I), la bertuccia e il cercopiteco (fig. 42). ${ }^{63} \mathrm{La}$ capra siriana con lunghe e folte ciocche di pelo (fig. 43), così diversa da quella nubiana a pelo corto ritratta da Giovannino de' Grassi (fig. 3I) e nelle copie del suo disegno (fig. 44), porta invece a ipotizzare un'altra origine, forse il Libretto degli Anacoreti della bottega di Michelino da Besozzo (fig. 49). ${ }^{64}$ Si trattava di una razza ovina inconsueta per il tempo: descritta e schizzata alla metà del XIV secolo da frate Niccolò da Poggibonsi nel Libro d'Oltramare quale novità vista al

60. PÄCHT 20II, pp. II-I9. Vedi anche GROOM 20I5, p. I47.

6I. Per un approfondimento sull'uso della pergamena, della carta e delle tecniche del disegno vedi KÁRPÁTI 2004, pp. 83-85; CHAPMAN 20Iоa, pp. 35-46. Riguardo all'uso di taccuini di modelli nell'esecuzione di dipinti e miniature vedi ZENTAI I973, pp. 25-39.

62. CHAPMAN 2010a, pp. 2 I, 27-29; ELEN 2012, pp. 36-40. Se Il libro dell'arte (i 400 ca.) di Cennino Cennini raccomandava di esercitarsi nel disegno in modo da apprendere a coordinare mano e occhio, l'idea fu ribadita nel I 435 da Leon Battista Alberti nel De pictura, CENNINI I99I, p. 2I; ALBERTI I950, p. 82.

63. Per un approfondimento su questo libro di modelli, scoperto e pubblicato da Annegrit Schmitt che per l'artista coniò il nome di Maestro del libro di modelli di animali di Weimar, e altri disegni fiorentini con la raffigurazione di fauna esotica vedi SCHMITT I997, pp. 7-33, tavv. VII-VIII, XV-XVI; CHAPMAN $2010 b$, pp. 90-9I; TASSO 20I5, pp. I82, 223 n. III.r. Vedi anche RECANATI i998, pp. 27-28.

64. Les dessins italiens I960, n. 203. Un elefante molto simile a quello del Musée Bonnat-Helleu di Bayonne si trova in un disegno attribuito ad artista lombardo attivo tra il I40o e il I4 I5, ora alle Gallerie dell'Accademia a Venezia (inv. n. 8), di recente ricondotto al Maestro delle Vitae imperatorum con datazione intorno al 1420 vedi RUGGERI I982, p. 20 n. 8; PERISSA TORRINI I999, pp. 22-24; DELLE FOGLIE 20I9, p. I7. In entrambi i casi, la resa poco naturalistica, soprattutto della proboscide, delle zampe e della coda sembra indicare quale modello un bestiario, tenuto conto del fatto che l'unico pachiderma visibile su suolo lombardo era stato quello di Federico II nella prima metà del XIII secolo. 


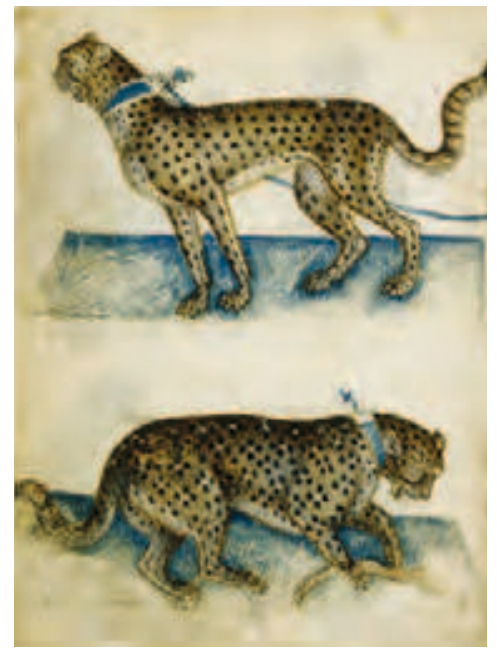

Fig. 4I: Maestro del libro di Weimar, Ghepardo e leopardo,

Libro di modelli di animali di Weimar, I400 ca. Weimar, Klassik Stiftung, Museums (inv. KK $8805 \mathrm{v}$ )

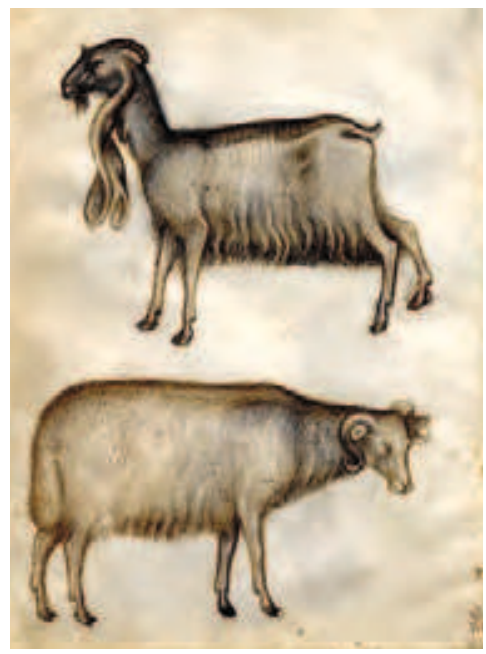

Fig. 43: Maestro del libro di Weimar, Capra siriana e pecora con la "coda grassa", Libro di modelli di animali di Weimar, I $400 \mathrm{ca}$. London, British Museum (inv. I895-I2-I494v)

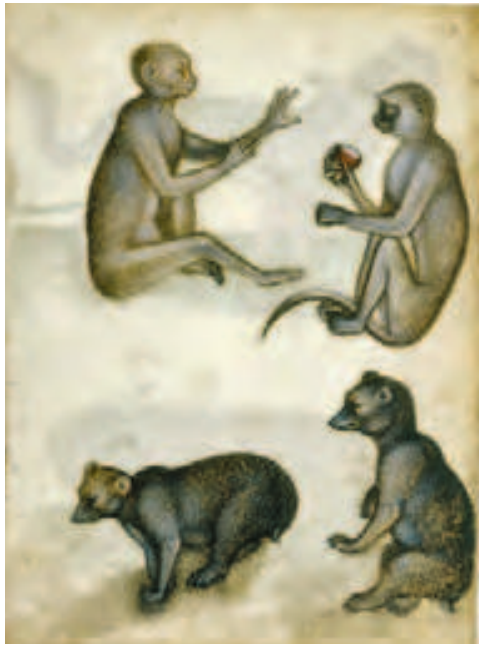

Fig. 42: Maestro del libro di Weimar, Bertuccia, cercopiteco e orsi,

Libro di modelli di animali di di Weimar, I $400 \mathrm{ca}$ Weimar, Klassik Stiftung, Museums (inv. KK 8805 r)

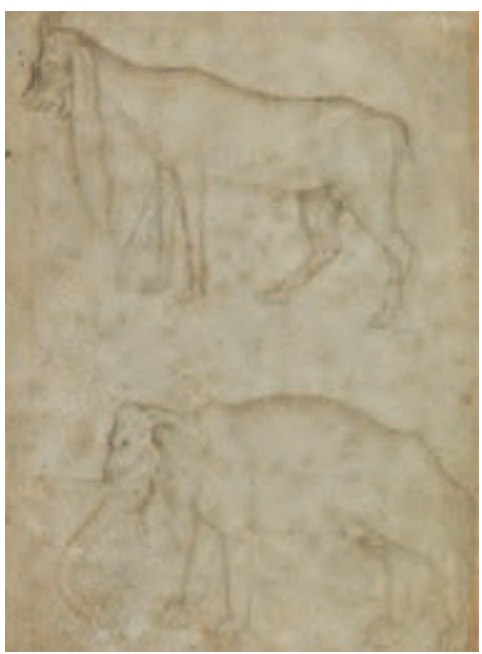

Fig. 44: Bottega lombarda, Capra nubiana ed elefante, primo quarto XV secolo Bayonne, Musée Bonnat-Helleu (inv. I4I bis) 
Cairo (fig. I7), ancora nel I487 gli esemplari inviati a Lorenzo de' Medici dal sultano d'Egitto avevano suscitato grande stupore tra i fiorentini. ${ }^{65}$

A questo filone di artisti inclini a osservare la natura con piglio pseudo-scientifico appartiene pure il lombardo Michelino da Besozzo, pittore e miniatore prediletto dalla corte dei Visconti forse formatosi nella bottega di Giovannino de' Grassi, celebrato dai suoi contemporanei per l'abilità nel ritrarre «animali verissimi» che poteva aver osservato nel parco visconteo mentre affrescava nel I388 il chiostro di San Pietro in Ciel d'Oro a Pavia. ${ }^{66}$ Abilità ancora lodata nel I530 da Marcantonio Michiel quando nella casa del veneziano Gabriele Vendramin aveva potuto ammirare un quadernetto in pergamena - oggi perduto - «con li animali coloriti fu de mano di Michelino milanese»; repertorio zoologico, insieme ad altri fogli sparsi con disegni dal vero di un ghepardo (fig. 45) e di una gazzella (fig. 46), ai quali Michelino da Besozzo e la sua bottega attingevano per realizzare opere pittoriche e miniature. ${ }^{67} \mathrm{La}$ critica si è invece divisa nell'attribuire all'artista il Libretto degli Anacoreti, considerato un repertorio di bottega realizzato nei primi decenni del XV secolo, con scene della vita di sant'Antonio abate e alcuni disegni di animali, tra $i$ quali ghepardi e leopardi (fig. 47), un dromedario (fig. 48) e una capra siriana (fig. 49) tratteggiati con sensibilità naturalistica nonostante un certo schematismo. ${ }^{68}$

Fu durante il lungo soggiorno in Veneto, databile nei primi decenni del XV secolo, che l'artista contribuì a diffondere il naturalismo zoologico di matrice lombarda attraverso i contatti con quelli che di lì a poco sarebbero diventati i grandi maestri della pittura italiana quattrocentesca: il veronese Pisanello e il marchigiano Gentile da Fabriano, che in laguna lavorarono al ciclo di affreschi nella sala del Maggior Consiglio a Palazzo Ducale quando anche Michelino da Besozzo vi prestava la sua opera. ${ }^{69}$ L'attrazione di Gentile da Fabriano per l'in-

65. Vedi pagine IOI-IO2, I23.

66. BOSKOVITS i988, p. Io; ALGERI I987, pp. 53-55; CASTELFRANCHI i996, pp. i 6-I27; CAIRATI 20I3, pp. 334-335.

67. MICHIEL I 884, p. 22 I; PÄCHT 20II, pp. 5-IO. Se la critica si è divisa riguardo all'attribuzione del disegno con il ghepardo di profilo, alternativamente assegnato a Pisanello o a Michelino da Besozzo, gli studi più recenti sono per lo più propensi a ricondurlo a quest'ultimo, mentre alla sua cerchia è stato assegnato il disegno di gazzella vedi CORDELLIER I996, pp. 343-344 n. 226; FOSSI TODOROW I966, p. I88 n. 409; DEGENHART - SCHMITT ig68-20io, vol. 3.I, p. 53; BOLLATI 2006, p. 84 n. I.I2; CAMPAGNA 20i5, pp. I36, I63-I64 n. II.20; The Robert Lehman I987-20I2, vol. 5, pp. 25-27 cat. 9.

68. SCHELLER I963, pp. I55-I59 n. 22; TOESCA I966, pp. I90-I9I fig. 387; COGLIATI ARANO I988, pp. 90-93; SCHELLER I995, pp. 292-298; ELEN I995, p. I88-I90 n. I2; RECANATI I998, p. 28; DELLE FOGLIE 2006, pp. 55-62; EAD. 20I9, pp. I3-I5, I8-I9, 24, 85-86 n. 2I, 87 n. 25. Nel disegno con i felini l'uso della maculatura circolare oppure "a rosetta" ha la mirata funzione di distinguere i ghepardi dai leopardi ritratti con corporatura - contrariamente a quanto avviene in natura - simile. Per quanto riguarda invece il disegno del dromedario, dalla studiosa ritenuto particolarmente naturalistico fino al punto da affermare che solo a distanza di decenni Pisanello e la sua bottega eseguiranno uno studio così dettagliato, un esemplare di estremo naturalismo si rintraccia già tra la fine del XIV e gli inizi del XV nell'Historia plantarum illustrata dalla bottega di Giovannino de' Grassi (vedi fig. 38). Infine, se Anna Delle Foglie accomuna giustamente la capra dalle lunghe orecchie a quella nel Libro di modelli di animali di Weimar (vedi fig. 43), il parallelo con il disegno dell'ovino nel Taccuino di Bergamo (vedi fig. 3I) e con quello di Bayonne (vedi fig. 44) risulta errato trattandosi di una tipologia di capra orientale diversa, ossia quella nubiana a pelo raso.

69. FOSSI TODOROW I966, pp. 5-6; CHRISTIANSEN I987, pp. iI9-I22; Pisanello 200I, pp. 8-io; CHRISTIANSEN 2006 , pp. 28-29. 


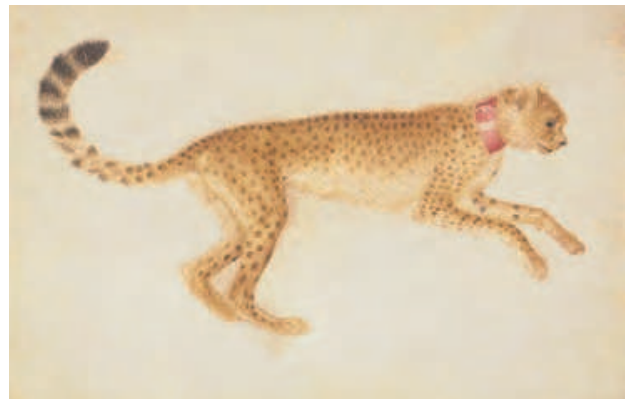

Fig. 45: Michelino da Besozzo, Ghepardo, I $400 \mathrm{ca}$.

Parigi, Musée du Louvre, D.A.G (inv. 2426r)

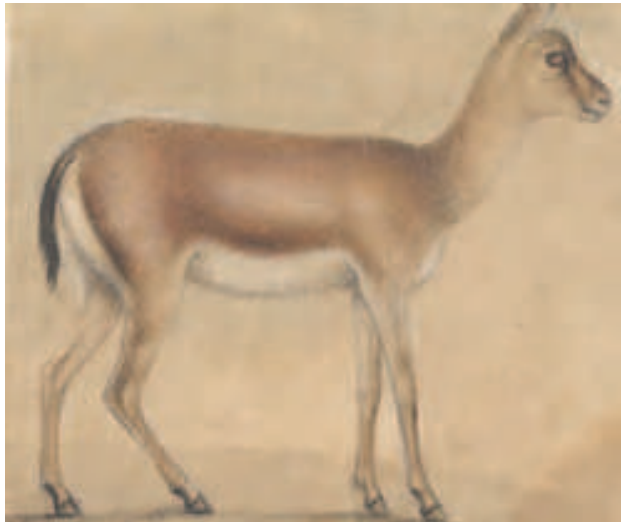

Fig. 46: Cerchia di Michelino da Besozzo, Gazzella, I4IO-I420 ca.

New York, Metropolitan Museum of Art (inv. I975.I.402)

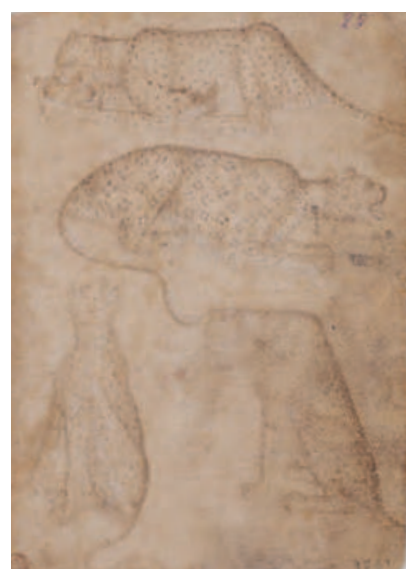

Fig. 47:

Bottega di Michelino da Besozzo, Tre ghepardi e un leopardo, Libretto degli Anacoreti, I $420-\mathrm{I} 430 \mathrm{ca}$.

Roma, Istituto Centrale per la Grafica (F.N. 2858r)

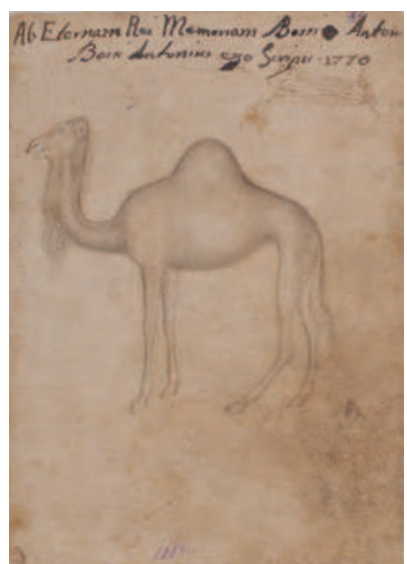

Fig. 48:

Bottega di Michelino da Besozzo, Dromedario,

Libretto degli Anacoreti, I $420-\mathrm{I} 43 \mathrm{O} \mathrm{ca}$.

Roma, Istituto Centrale per la Grafica (F.N. 2854r)

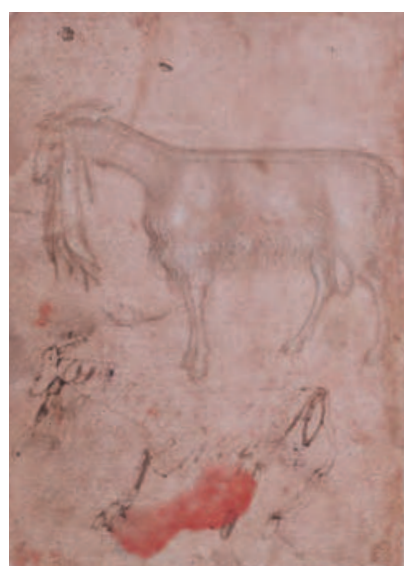

Fig. 49:

Bottega di Michelino da Besozzo, Capra siriana,

Libretto degli Anacoreti, I $420-\mathrm{I} 430 \mathrm{ca}$.

Roma, Istituto Centrale per la Grafica (F.N. 2858v) 
dagine naturalistica aveva un antecedente nei precoci contatti con l'arte lombarda della cerchia di Giovannino de' Grassi, quando sullo scorcio del XIV secolo si era formato tra Milano e Pavia, per poi consolidarsi nei primi decenni del XV secolo a Venezia, dove lavorò a stretto contatto con Michelino da Besozzo, e infine manifestarsi pienamente nella Pala Strozzi dipinta a Firenze tra il I420 e il I $23 .{ }^{70}$ Probabilmente fu proprio lui, al quale sono stati ascritti alcuni disegni di animali, a introdurre sulle rive dell'Arno il gusto per la raffigurazione della fauna esotica. ${ }^{7 \mathrm{I}}$ Non è neppure da escludere che l'artista marchigiano avesse avuto l'opportunità, giunto a Firenze nell'estate del I420, di vedere e forse ritrarre dal vero il cammello di Martino $\mathrm{V}$, ricevuto in dono l'anno precedente, prima della sua partenza per Roma il 9 settembre..$^{72}$

Numerosi sono i disegni pisanelliani giunti sino a noi in forma di taccuini e fogli sciolti che tra $i$ vari soggetti annoverano anche animali esotici ritratti con intenso naturalismo: alcuni sono schizzi veloci volti a catturare con avida curiosità il dinamismo e la vitalità delle bestie, altri disegni eseguiti con acume e precisione oggettiva che il maestro e i suoi assistenti usavano nell'esecuzione di affreschi e dipinti. ${ }^{73}$ Se l'ipotesi di Claudio Bismara che considera il prezioso mappamondo acquistato da Pisanello nel I430 «un repertorio di animali esotici realmente esistenti: il dromedario, l'elefante, il leone, il ghepardo, la scimmia, la giraffa o il coccodrillo; tutti soggetti dai quali [...] l'artista dalla curiosità inquieta, può aver tratto ispirazione per alcuni dei suoi disegni» è certamente da escludere, sia perché le immagini di animali realistici faranno la loro comparsa sulle mappe più tardi sia perché continueranno a essere assai approssimative, determinanti dovevano invece essere stati i soggiorni dell'artista nelle più sofisticate corti italiane: Venezia, Pavia, Roma, Ferrara e Napoli dove i signori custodivano animali esotici nei loro palazzi e giardini. ${ }^{74}$ Sembrerebbe, poi, che Filippo Maria Visconti tra il I427 e il I430 gli avesse affidato il compito di affrescare una sala del castello pavese - ora perduta - con soggetti di vita cortese e animali; occasione che gli aveva probabilmente offerto l'opportunità di ammirare il

70. DE MARCHI 2006b, pp. I6-55; CHRISTIANSEN 2006, pp. 25-29; DE MARCHI 2006a, pp. 62-63.

7I. KÁRPÁTI 20I2, p. 5 I.

72. CHRISTIANSEN I982, pp. 3-4; DE MARCHI 2006b, p. I62; BIANCA 2008, p. 282. Per la possibilità che Gentile da Fabriano si trovasse a Firenze poco prima della partenza di papa Martino V vedi DAVISSON I980, pp. 759-763.

73. SCHELLER I963, pp. I76-I88 n. 26; FOSSI TODOROW I966, pp. I5-I7, 43-46; Pisanello 200I, pp. 2634, I9I-202. Riguardo al naturalismo dei disegni pisanelliani Michel Pastoureau, discostandosi dalla maggior parte degli studiosi, considera la maniera esatta e descrittiva fin nei dettagli uno dei tanti modi per rappresentare la natura ma non per questo: "plus 'vraie' que la stylisation expressionniste du bestiaire héraldique ou que la faune allégorique de la poésie animale. L'exact n'est pas le vrai. Il serait en effet anachronique de croire que, dans l'Italie de la première moitié du XVe siècle, l'observation et la représentation réaliste de la nature soient pensées comme des moyens plus nobles ou plus efficaces que d'autres pour accéder à la connaissance et à la vérité. Non seulement parce que les problèmes de la ressemblance ne se posent pas ainsi dans la sensibilité et dans l'idéologie de cette période - l'adéquation parfaite entre une forme dessinée et une forme vivante n'est pas de l'ordre de la ressemblance - mais aussi et surtout parce que la vérité des êtres et des choses est à chercher dans les mots qui désignent ces êtres et ces choses, pas dans leur réalité vivante et encore moins dans leur réalité figurée», PASTOUREAU I996, p. 22.

74. BISMARA 20I2, pp. 2I-24; LOISEL I9I2, p. 205; Pisanello 200I, pp. I6, 254-257. 
taccuino di Giovannino de' Grassi, e forse anche i disegni di Michelino da Besozzo, e di visitare il parco con numerose specie animali tra cui anche quelle esotiche. ${ }^{75} \mathrm{E}$ infatti sorprendente notare come alcuni dei suoi disegni ripropongano assai fedelmente esemplari di fauna esotica già presenti nel taccuino degrassiniano: il ghepardo (fig. 50) e il pappagallo (fig. 5I), forse impoverito dalla coloritura a opera di un allievo di bottega, e la gallina d'India. ${ }^{7}$ È altresì vero che durante i suoi frequenti soggiorni nelle corti italiane aveva certamente potuto osservare dal vero e immortalare su carta felini (fig. 52) e cercopitechi (fig. 53), mentre il cammello (fig. 54) e il dromedario (fig. 55) poteva averli ritratti nel corso della sua visita milanese del I440, quando Filippo Maria Visconti possedeva due cammelli ricevuti in dono l'anno precedente e, sembrerebbe, anche dei dromedari. ${ }^{77}$

A Firenze, invece, la raffigurazione di animali esotici dal vero sembra essersi affermata - considerando i disegni giunti sino a noi - molto più tardi, forse proprio in relazione al fatto che fino all'ascesa del casato mediceo, e in particolare di Lorenzo il Magnifico, non esisteva un vero e proprio signore con l'ambizione di palesare ricchezza e potere attraverso il possesso di fauna esotica. Una prima menzione riguardo a un libro di disegni nel quale figuravano degli animali - ma non sappiamo se esotici - si deve a Giorgio Vasari che nella vita di Paolo Uccello narrava:

avendo disegnato tanto che lasciò a' suoi parenti, secondo che da loro medesimo ho ritratto, le casse piene di disegni. Ma se bene il disegnar è assai, meglio è nondimeno mettere in opera, poiché hanno maggior vita l'opere che le carte disegnate. E se bene nel nostro libro de' disegni sono assai cose di figure, di prospettive, d'uccelli e d'animali belli a maraviglia..$^{8}$

Passione, quella dell'artista per gli animali e in particolare gli uccelli - da cui il suo soprannome -, forse sviluppata durante il soggiorno a Venezia nel I425, città dove lavorarono Michelino da Besozzo, Pisanello e Gentile da Fabriano.79 A sua volta Lorenzo Ghiberti possedeva delle "charte degli uccelli», alle quali si era probabilmente ispirato per l'esecuzione dei volatili lungo le cornici e in alcuni pannelli della Porta del Paradiso (I425-I452) per il battistero fiorentino, che aveva concesso in prestito all'orafo senese Goro di Neroccio. ${ }^{80}$ Altro artista fiorentino che aveva approntato un

75. FOSSI TODOROW i966, pp. 6-8, 45-46; Pisanello 200i, pp. i6, 254; DELMORO 2006, p. 63. Stefania Buganza data gli affreschi pisanelliani al I440, anno in cui un documento attesta il passaggio a Milano dell'artista, così come molti studiosi reputano la medaglia in bronzo con il ritratto di Filippo Maria Visconti eseguita tra il I 440 e il I44I vedi BUGANZA 20I5, p. 254; CORDELLIER I996, p. 2 I 4 n. I25.

76. Ivi, pp. 258-259 n. I59. Se per il disegno con il ghepardo e tre colonne tortili Milvia Bollati ha proposto un generico artista milanese con datazione intorno al I40o e per quello con la faraona - erroneamente indicata come quaglia - Maria Fossi Todorow indica la bottega di Pisanello, nel catalogo on-line del Louvre figurano entrambi attribuiti a quest'ultimo vedi BOLLATI 2006, p. 85 n. I.I3; FOSSI TODOROW I966, p. I90 n. 4I8.

77. MESSEDAGLIA i94I, pp. 43, 62; Pisanello 200I, p. 256; MONTANO i75 I, p. 439. Per i disegni di scimmie, dromedari e cammelli ricondotti a Pisanello o alla sua bottega vedi Pisanello I996, pp. 7I-72 nn. 3I-32, I77 n. 95, 208 n. II7, 302-3I2 nn. I96-I98, 3I 4-3I6 nn. 202-203, 33 I-332 n. 2 I 8.

78. VASARI I966-I997, vol. 3, p. 70. Per il Libro de’ Disegni appartenuto a Giorgio Vasari vedi KURZ I937, pp. I-6; RAGGHIANTI COLLOBI I974, vol. I, pp. 46-48; DEGENHART - SCHMITT I968-20Io, vol. I.2, pp. $628-638$.

79. VASARI I966-I997, vol. 3, p. 65.

80. BRENZONI I952, p. 2I5; KÁRPÁTI 20I2, p. 5 I. 


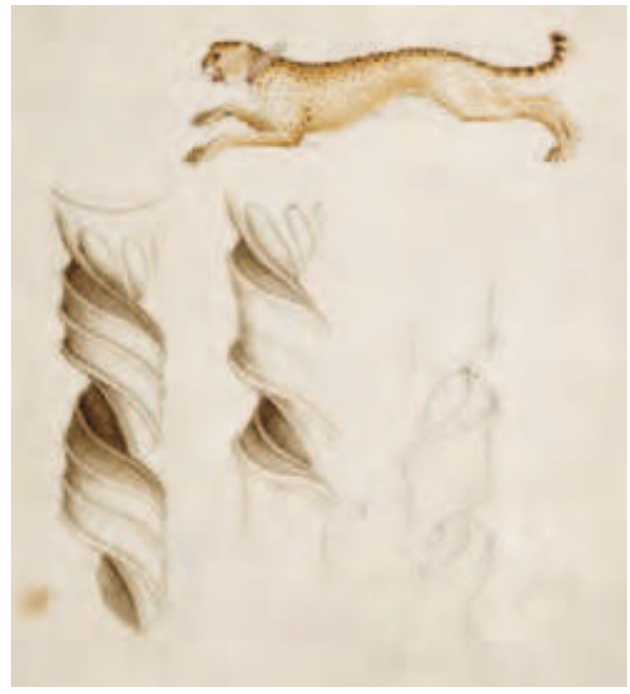

Fig. 50: Pisanello (?),

Ghepardo e tre colonne tortili, I $430 \mathrm{ca}$.

Parigi, Musée du Louvre, D.A.G (inv. 2425r)

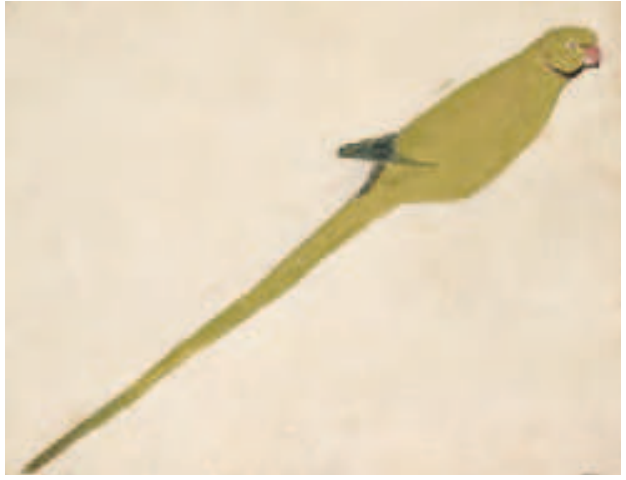

Fig. 5I: Bottega di Pisanello, Pappagallo, I435-I $445 \mathrm{ca}$.

Parigi, Musée du Louvre, D.A.G (inv. 2456r)

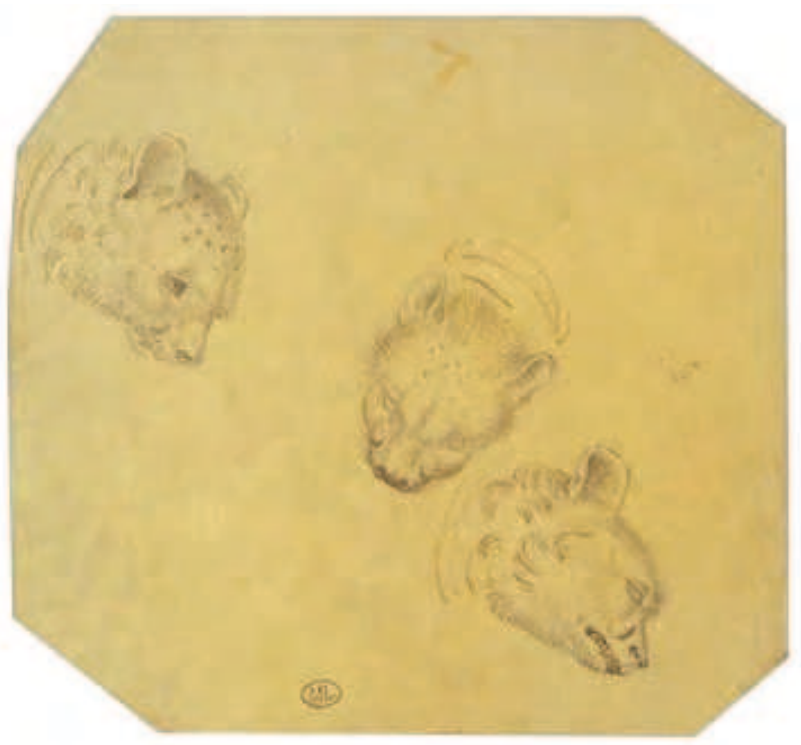

Fig. 52: Pisanello,

Teste di ghepardo, I $435-\mathrm{I} 445 \mathrm{ca}$.

Parigi, Musée du Louvre, D. A.G (inv. 2488r) 


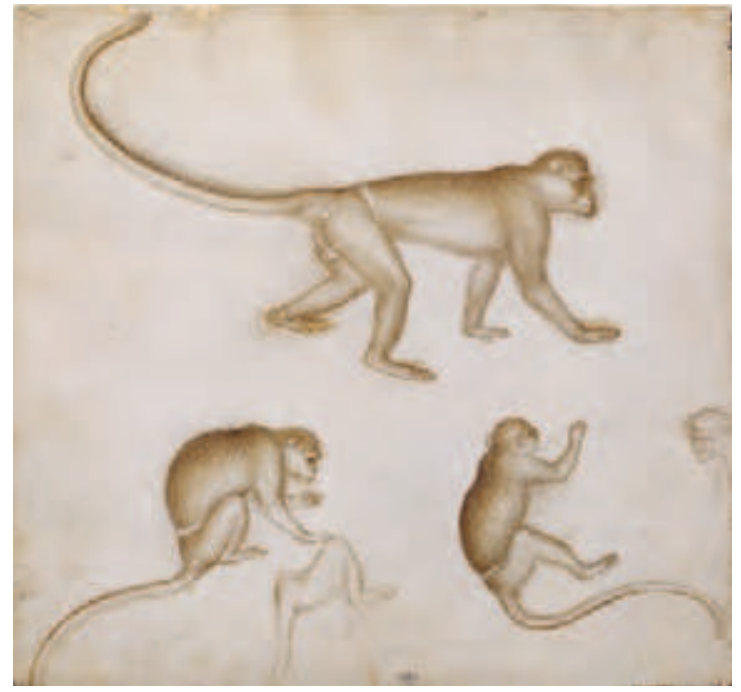

Fig. 53: Pisanello,

Cercopitechi, I 435-I 445 ca.

Parigi, Musée du Louvre, D.A.G (inv. 2394r)

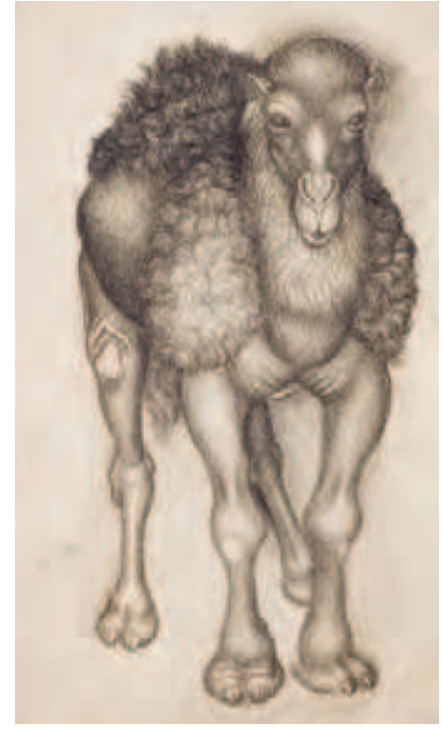

Fig. 54: Pisanello,

Cammello (?), I437-I $440 \mathrm{ca}$.

Parigi, Musée du Louvre, D.A.G (inv. 2399r)

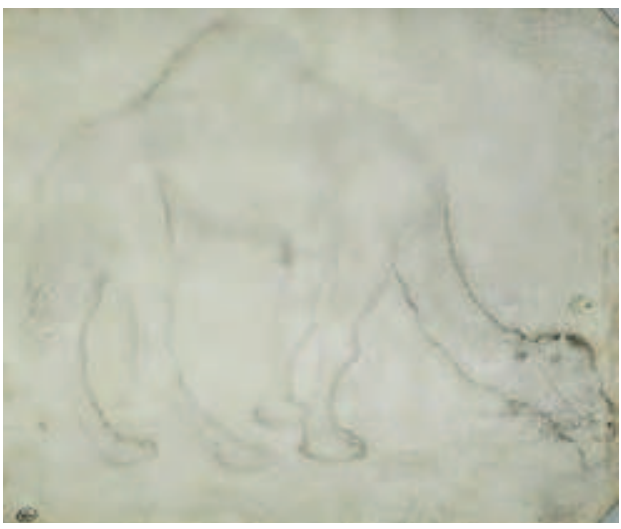

Fig. 55: Pisanello,

Dromedario, I437-I440 ca.

Parigi, Musée du Louvre, D.A.G (inv. 240or) 
libro di disegni con soggetti che spaziavano dagli animali alle figure, dai motivi ornamentali ai dettagli architettonici - di cui restano alcuni fogli dagli studiosi reputati per lo più copie eseguite da allievi di bottega negli anni sessanta del XV secolo - fu Benozzo Gozzoli. ${ }^{8 \mathrm{I}}$ Tra le specie esotiche degne d'interesse spicca la raffigurazione naturalistica di un cammello (fig. 56), erroneamente indicato da una didascalia come «dromedario", forse copiato da un disegno di Pisanello giunto a Firenze in occasione del concilio oppure - data la scarsa attinenza con l'immagine pisanelliana - ritratto dal vero nel I447 a Roma dove, recatosi con Beato Angelico, poteva aver visto l'esemplare offerto qualche anno prima a papa Eugenio IV o nel I 452 quando Francesco Sforza, per sbarazzarsi del cammello «tanto possente» ricevuto in dono dal re di Tunisi, lo aveva inviato nella città del giglio. ${ }^{82}$ La pagina con un improbabile elefante (fig. 57), certamente dovuto alla mano di un apprendista di bottega poco dotato, attesta il perdurare dell'influenza dei bestiari nella raffigurazione di animali esotici che nel XIV e nella prima metà del XV secolo non si erano ancora visti a Firenze; influenza in particolar modo evidente nella proboscide più simile a un olifante che a una parte anatomica del pachiderma, mentre l'epidermide con striature che disegnano un motivo a losanghe ricorda quella di alcuni elefanti scolpiti sui sarcofagi antichi come pure l'esemplare raffigurato da Lorenzo Ghiberti nella Porta del Paradiso (I425-I452) quando, per l'appunto, si avvalse della collaborazione di Benozzo. ${ }^{83}$

A una bottega fiorentina con datazione al secondo quarto del XV secolo si deve il prezioso Libro di modelli Rothschild con animali selvatici, domestici, creature fantastiche e qualche bestia esotica ritratti con attenzione naturalistica. I raffinati disegni di animali eseguiti su pergamena si ispirano all'arte grafica attribuita a Gentile da Fabriano e alla sua cerchia, all'opera pittorica di Benozzo Gozzoli e Piero di Cosimo e alle incisioni fiorentine del tempo. ${ }^{84}$ In questo repertorio è interessante riscontrare, oltre alle consuete scimmie (fig. 58), la presenza di due capre nubiane (fig. 59) che sembrano più da ricondurre a un libro di modelli che a un ritratto dal vero.

Sempre ad ambito fiorentino appartiene il cosiddetto Libro di modelli di animali di Budapest, la più cospicua raccolta fiorentina quattrocentesca giunta sino a noi, con disegni in parte riconducibili a un atelier operante alla metà del XV secolo e in

8I. POPHAM I930, pp. 53-58; SCHELLER I963, pp. 207-2 i n n. 30; ELEN 20i2, pp. 43-44. Per il disegno quale pratica di apprendistato nelle botteghe quattrocentesche vedi AMES-LEWIS I990, pp. 657-685.

82. Francis Ames-Lewis, ritenendo l'allora diciannovenne Benozzo Gozzoli troppo giovane per aver avuto accesso a un disegno di Pisanello, ipotizza che si fosse rifatto a una copia eseguita da Paolo Uccello o Domenico Veneziano quando l'artista veronese si trovava a Firenze. Il cammello ricevuto dal pontefice nel I 444, che non si sa per quanto tempo sopravvisse o restò nella città eterna, fu prontamente raffigurato da Filarete nella porta bronzea in San Pietro (I433-I445) e menzionato dal contemporaneo mercante viterbese Niccolò della Tuccia vedi AMES-LEWIS I998, p. 28; VASARI I966-I997, vol. 3, p. 368; GHINZONI I875, p. I62 nota I; MALAGUZZI VALERI I9I3, p. 739; DELLA TUCCIA vedi pagina I26; SCAFI 20I2, pp. I48-I50; Il primo elefante I888, p. I05. Diane Cole Ahl ritiene il disegno del cammello nel taccuino d Benozzo Gozzoli opera dello stesso assistente che lo affrescò nella cappella dei Magi, COLE AHL i996, p. io8. Vedi DEGENHART - SCHMITT I968-20Io, vol. I.2, p. 483 n. 447 ; vol. I.4, tav. 330b; ELEN I995, pp. 222-226 n. 23;

83. Per il disegno dell'elefante nel taccuino di Benozzo Gozzoli vedi POPHAM I930, p. 55 (fol. I8); DEGENHART - SCHMITT I968-20I0, vol. I.2, p. 483 n. 445; vol. I.4, tav. 329 h.

84. SCHELLER I963, pp. I9I-20I n. 28; AMES-LEWIS I987, pp. 3-4; LOISEL 2009, pp. 70-80 n. 23. 


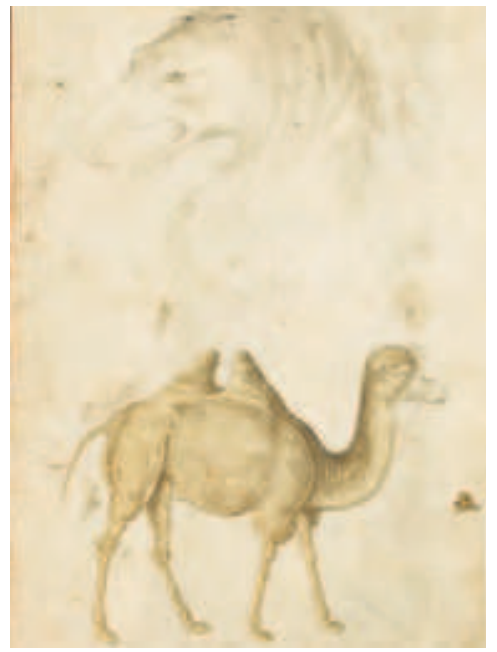

Fig. 56: Bottega di Benozzo Gozzoli, Testa di aquila e cammello, Taccuino di Rotterdam, I $459-\mathrm{I} 462 \mathrm{ca}$

Rotterdam, Museum Boijmans Van Beuningen (inv. I 562, c. I4v)

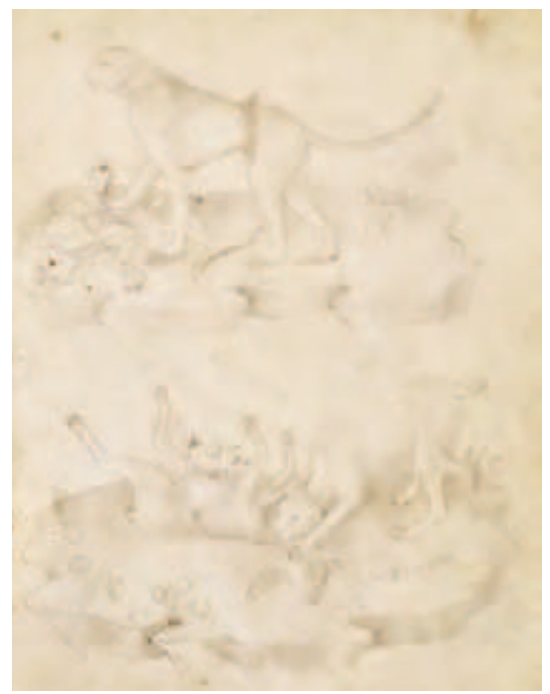

Fig. 58: Bottega fiorentina,

Cercopiteco e felino con capriolo, Libro di modelli Rothschild, I425-I45O ca. Parigi, Musée du Louvre, D.A.G (inv. $760 \mathrm{DR}$ recto)

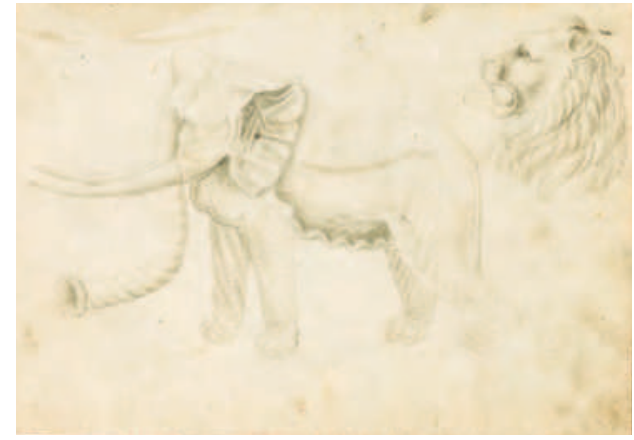

Fig. 57: Bottega di Benozzo Gozzoli, Elefante e testa di leone, Taccuino di Rotterdam, I $459-\mathrm{I} 462 \mathrm{ca}$.

Rotterdam, Museum Boijmans Van Beuningen (inv. I 562, c. I8r)

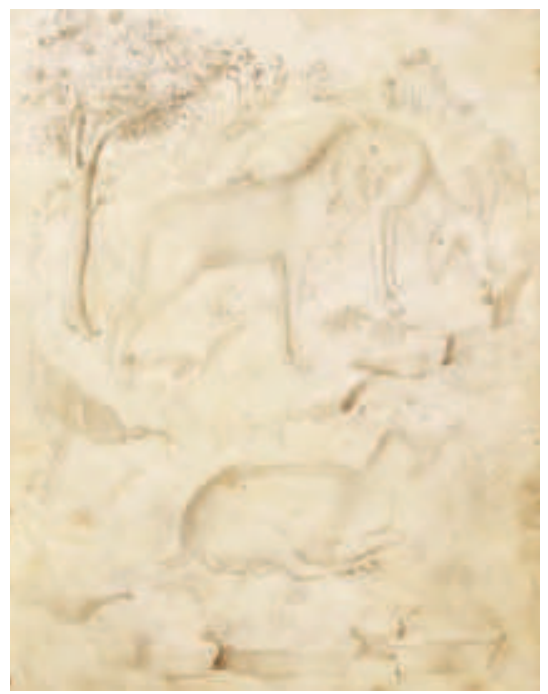

Fig. 59: Bottega fiorentina, Due capre nubiane e becco, Libro di modelli Rothschild, I425-I450 ca. Parigi, Musée du Louvre, D.A.G (inv. $756 \mathrm{DR}$ recto) 
parte a un artista attivo agli inizi di quello successivo. Le immagini risultano riprese da taccuini e disegni di area lombarda, veneta e romana, che all'epoca circolavano con frequenza all'interno delle botteghe, da fogli con incisioni, a partire dagli anni sessanta del XV secolo più facili da reperire e a minor costo, come pure da miniature e dipinti fiorentini. ${ }^{85}$ Il repertorio comprende ghepardi e leopardi (fig. 6o) di ascendenza degrassiniana (fig. 34), ma delineati in maniera assai stereotipata tanto da far ipotizzare a Zoltán Kárpáti che il libro di modelli appartenesse a una bottega orafa, bertucce (fig. 6I) - quella in posizione frontale praticamente identica all'esemplare raffigurato da Benozzo Gozzoli nella cappella dei Magi (fig. 77b), uno struzzo (fig. 62) privo di qualsiasi attinenza con quello di Giovannino de' Grassi (fig. 33), e un coccodrillo assai realistico (fig. 63), con tutta probabilità ritratto dal vero dato che a partire dal I467 a Firenze si trovava l'esemplare impagliato che Benedetto Dei aveva portato dall'Oriente. ${ }^{86}$

A questa tipologia di modelli eseguiti da artisti fiorentini nella seconda metà del $\mathrm{XV}$ secolo, in parte ancora legati ai bestiari medievali, sono da ricondurre l'incisione con ventiquattro rondelle che racchiudono animali di vario genere tra cui bestie esotiche (fig. 64), il disegno con un cammello cavalcato da un fanciullo e una bestia fantastica (fig. 65), quello con un cervo, un'aquila, un ghepardo, un immancabile unicorno e un elefante con le orecchie «a modo d'ale di draco» (fig. 66) e quello con un cercopiteco, una bertuccia e un ghepardo intento ad azzannare un cervo (fig. 67). ${ }^{87}$

Sempre a Vasari si deve la notizia dell'esistenza di un «libro d'animali [...] bellissimi e biz‘z’arri, tratteggiati di penna diligentissimamente e con una pazienza inestimabile condotti» eseguito dal pittore Piero di Cosimo - oggi perduto - posseduto da Cosimo I de' Medici. ${ }^{88}$ Non è dato sapere se il libro contenesse anche disegni di animali esotici, ma è assai probabile considerata l'attenzione dedicata dall'artista, lodato da Vasari per la sua abilità nel ritrarre «di naturale molto eccellentemente», nel raffigurare animali rari e bizzarri come una giraffa (fig. 84) e una bertuccia (fig. 85a) nei suoi dipinti. ${ }^{89}$

85. KÁRPÁTI 2004, p. 9I; ID. 20I2, pp. 5I-73.

86. Per il coccodrillo di Benedetto Dei vedi pagina 28.

87. ZUCKER I994, pp. I35-I36; HIND I938-I948, vol. I., pp. 44-45 n. 48; vol. 2, tav. 47. L'attribuzione dei disegni a Paolo Uccello e Giuliano da Sangallo proposta nel I963 da Bernhard Degenhart e Annegrit Schmitt, in parte modificata nel I968, fu rigettata da John Pope-Hennessy così come pure dalla critica successiva propensa a ricondurli a generica scuola fiorentina o toscana della seconda metà del XV secolo, mentre nel $200 \mathrm{I}$ Per Bjurström ha nuovamente sostenuto per i disegni di Stoccolma l'attribuzione a Paolo Uccello e al suo atelier vedi DEGENHART - SCHMITT I963, pp. IOI-IO8; IDD. I968-20Io, vol. I.2, p. 388 n. 304; 625 nn. 630, 633; vol. I.4, tavv. 279b, 442g, 443c; POPE-HENNESSY I950, pp. 4, I68; BELTRAME QUATTROCCHI I979, pp. 26-27 n. 8b; TONGIORGI TOMASI I992, p. I83 n. 9.4; ELEN I995, pp. 203-204 n. I7; BELLOSI 2000, p. I82; BJURSTRÖM 200I, nn. I068, I069, I07I. A testimoniare la diffusione di repliche dei disegni è il foglio conservato all'Albertina di Vienna (inv. 27) praticamente uguale, tranne per l'aggiunta in alto di un ghepardo che assale un daino e alcune didascalie, a quello dell'Istituto Centrale per la Grafica di Roma vedi DEGENHART - SCHMITT I968-20Io, vol. I.2, p. 396 n. 3II; vol. I.4, tav. $282 \mathrm{c}$.

88. VASARI I966-I997, vol. 4, p. 66; GERONIMUS 2006, p. I26.

89. VASARI I966-I997, vol. 4, p. 60. 


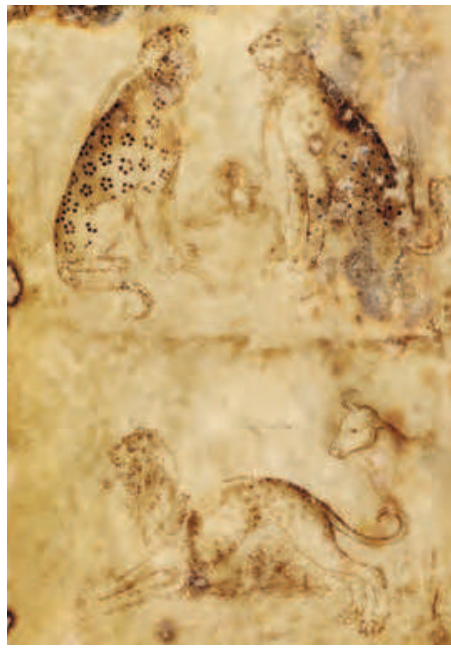

Fig. 6o: Bottega fiorentina, primo atelier, Ghepardi, leopardi e animali fantastici,

Libro di modelli di animali di Budapest, I45O ca. Budapest, Szépmüvészeti Múzeum (inv. I9I8 482, c. $5 \mathrm{v}$ )

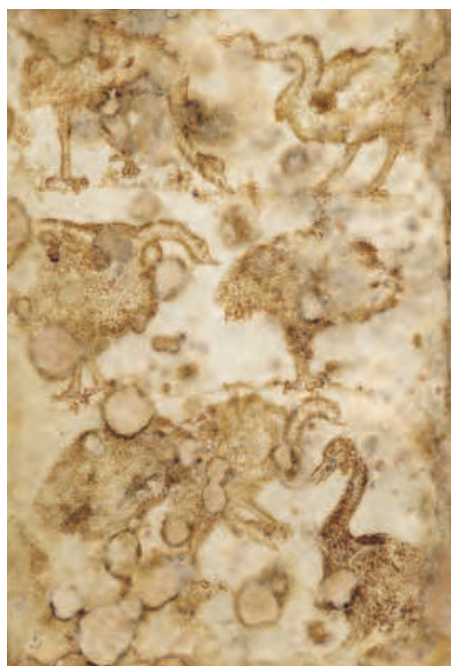

Fig. 62: Bottega fiorentina, Maestro del secondo atelier, Struzzo e volatile.

Libro di modelli di animali di Budapest, I450-I520 ca. Budapest, Szépmüvészeti Múzeum (inv. I9I8 482, c. Iv)

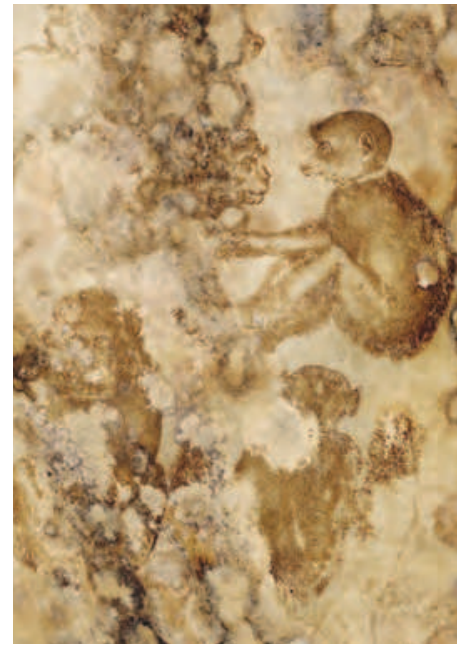

Fig. 6I: Bottega fiorentina, Maestro del secondo atelier, Bertucce,

Libro di modelli di animali di Budapest, I450-I520 ca. Budapest, Szépmüvészeti Múzeum (inv. I9I8 482, c. I3r)

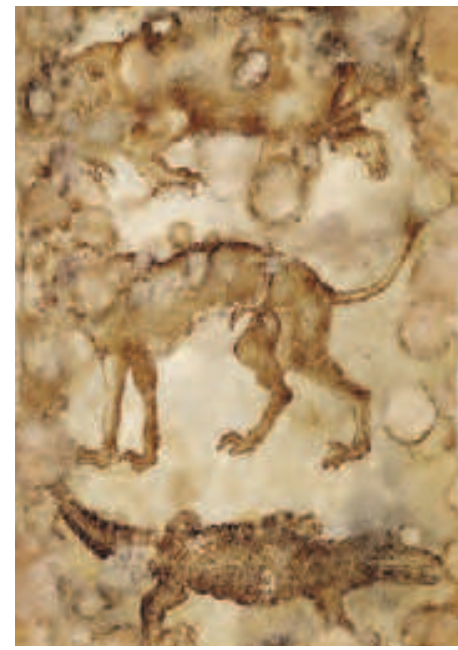

Fig. 63: Bottega fiorentina,

Maestro del secondo atelier,

Animale ignoto, cercopiteco (?) e coccodrillo,

Libro di modelli di animali di Budapest, I450-I520 ca. Budapest, Szépmüvészeti Múzeum (inv. I9I 8482 , c. I6r) 


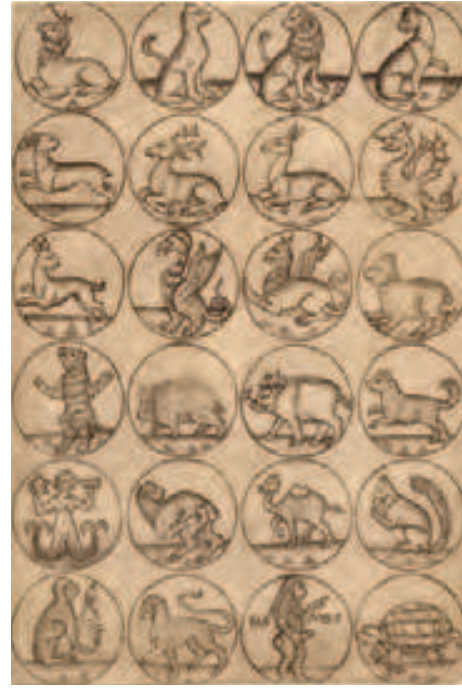

Fig. 64: Bottega fiorentina,

Rondelle con animali, I460-I $470 \mathrm{ca}$.

Londra, British Museum (inv. I933 OII9.I)

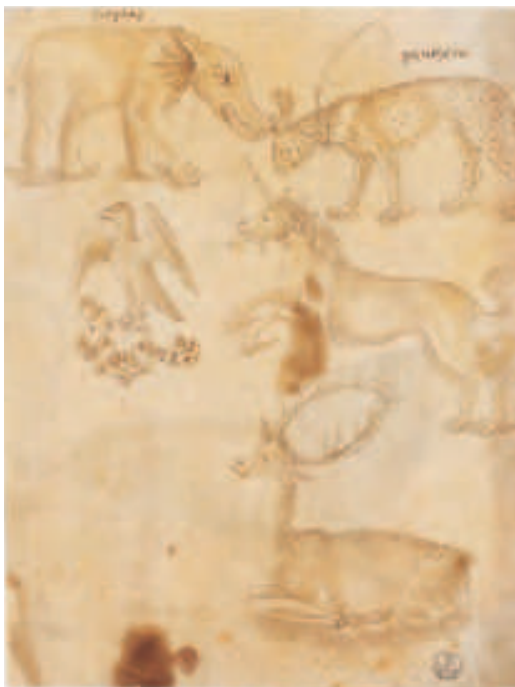

Fig. 66: Bottega fiorentina,

Elefante, aquila, ghepardo, unicorno e cervo, I $460-\mathrm{I} 470 \mathrm{ca}$.

Firenze, Gallerie degli Uffizi, GDSU (inv. $14503 \mathrm{~F}$ )

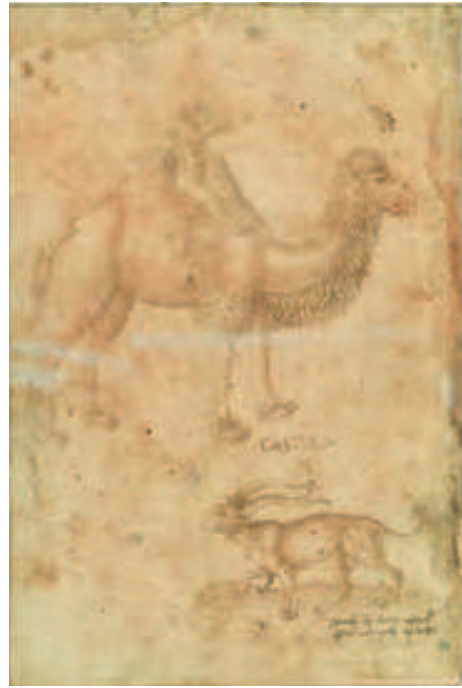

Fig. 65: Bottega fiorentina,

Cammello e animale fantastico, I $450-1500 \mathrm{ca}$. Stoccolma, Nationalmuseum (inv. $\mathrm{NMH}_{45} \mathrm{a} / \mathrm{I} 863$ )

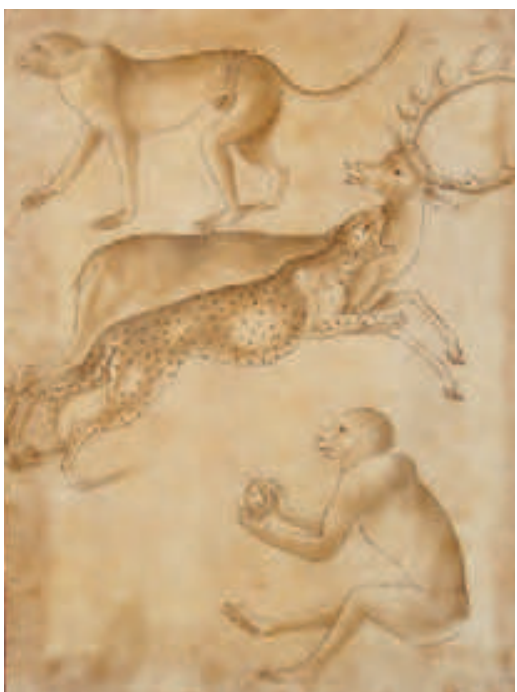

Fig. 67: Bottega fiorentina,

Cercopiteco, ghepardo che azzanna un cervo e bertuccia, I $460-I 470 \mathrm{ca}$.

Roma, Istituto Centrale per la Grafica (F.C. I30530) 


\section{Animali dipinti}

\section{I. Gentile da Fabriano e gli animali esotici}

Punto di partenza per la diffusione delle immagini di animali esotici nella pittura fiorentina sembra essere stata l'opera di un artista forestiero: il marchigiano Gentile da Fabriano giunto in città nel I420 per dipingere la pala d'altare con l'Adorazione dei Magi (I423) commissionatagli da Palla Strozzi (fig. 68). ${ }^{90}$ Iniziati da Onofrio Strozzi, i lavori della cappella e della sagrestia nella chiesa di Santa Trinita furono portati a termine, dopo la sua morte nel I4I8, dal figlio Palla, mercante e banchiere che a detta di papa Pio II «eccelleva su ogni altro per ricchezze» e che il catasto del I427 conferma essere l'uomo più facoltoso di Firenze. ${ }^{9 \mathrm{I}}$ Per manifestare pubblicamente tutta la sua agiatezza e il suo potere Palla Strozzi, uomo di raffinata cultura umanistica e promotore della venuta a Firenze del bizantino Emanuele Crisolora, richiese la collaborazione degli artisti di maggior spicco: Lorenzo Ghiberti, orafo-scultore impegnato a realizzare la Porta Nord (I403-I424) del battistero fiorentino, in veste di consulente per la parte architettonica e Gentile da Fabriano, pittore più famoso della penisola, per dipingere la pala d'altare. ${ }^{92}$ Se le aspirazioni del banchiere e mercante erano quelle di convogliare allo spettatore, con un semplice colpo d'occhio, il prestigio sociale di cui godeva, il ruolo politico che esercitava e le risorse economiche di cui disponeva, le sue aspettative non andarono certo deluse. La scelta dell'iconografia dell'Adorazione dei Magi, a quel tempo inusuale per il milieu fiorentino, e l'incarico affidato a un raffinato pittore come Gentile da Fabriano diedero origine a una sontuosa scena di soggetto sacro proposta in chiave "profana", fenomeno del tutto inconsueto per una città come Firenze. ${ }^{93}$ Il fabrianese, formatosi in giovane età presso la sofisticata corte dei Visconti, aveva infatti saputo infondere al dipinto un'ambientazione cortese improntata alle battute di caccia signorili, come rivela il dettaglio dell'uomo con un corno da caccia a tracolla, pervenendo, da un lato, a conferire risalto al committente ritratto in compagnia del figlio Lorenzo al seguito dei Magi con un falcone in pugno, suo emblema personale ma anche volatile impiegato per la caccia, e, dall'altro, a permeare il dipinto con quel tono di opulenza tipico delle corti orientali. ${ }^{94}$ Del resto, il tema richiesto dal committente ben si prestava a questo sfoggio: se nelle Sacre Scritture si afferma la provenienza

90. Sulla cornice della predella il pittore apposte un'iscrizione con firma e data «OPUS GENTILIS DE FABRIANO. MCCCCXXIII MENSIS MAII». Per un approfondimento sul dipinto, ora alle Gallerie degli Uffizi di Firenze, vedi DE MARCHI 2006b, pp. I64-I99.

9I. MARTINES i963, p. 372; PICCOLOMINI 2008, vol. I, p. 353. Per un approfondimento sulla figura di Palla Strozzi vedi BELLE I972.

92. BELLOSI 2000, p. IOI; DE MARCHI 2006b, pp. I62-I63.

93. CHRISTIANSEN I982, pp. 97-98.

94. Ivi, pp. 31, 74, 98; DE MARCHI 2006b, p. 182. 


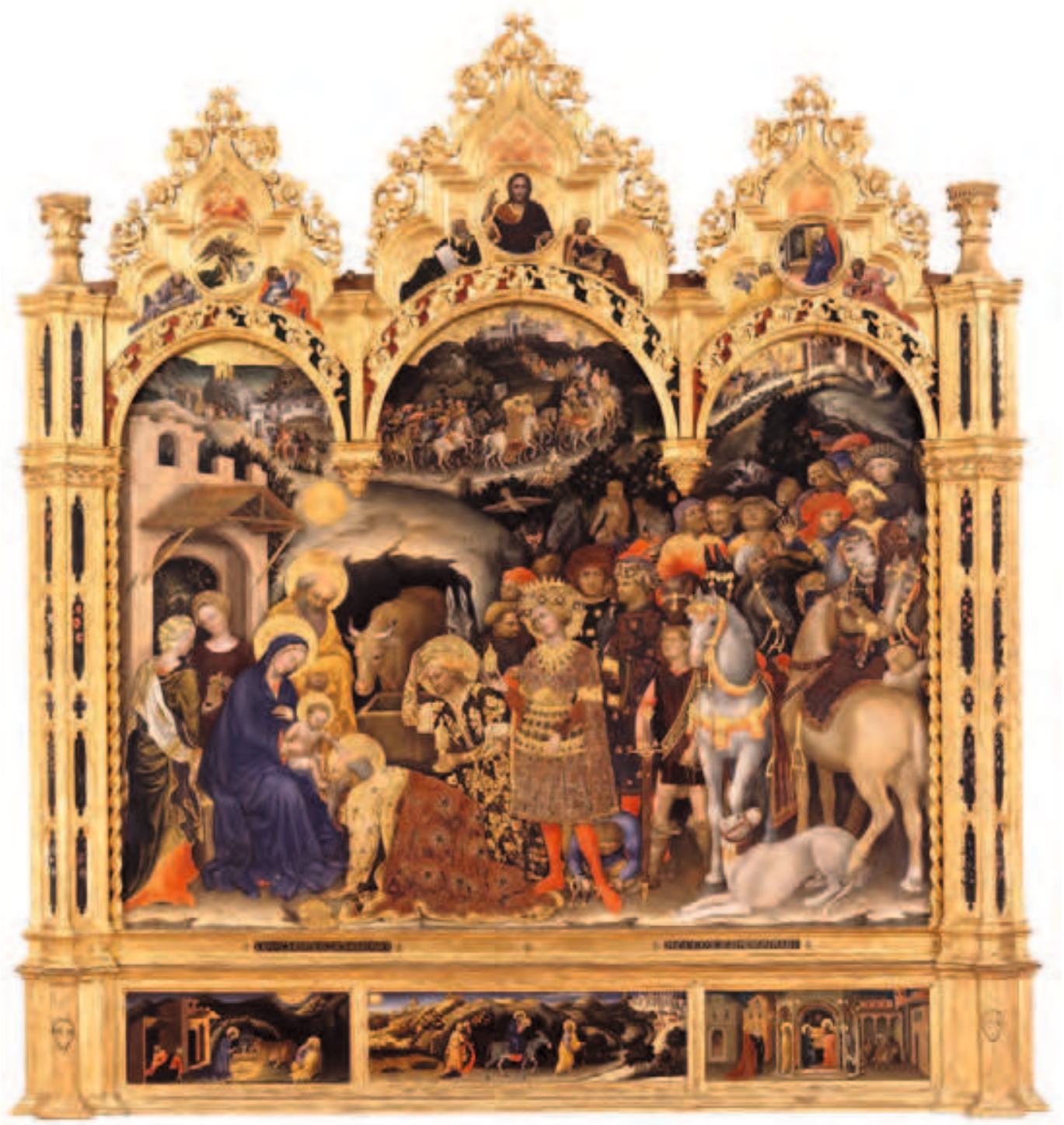

Fig. 68: Gentile da Fabriano,

Adorazione dei Magi, I423

Firenze, Gallerie degli Uffizi,

Galleria delle Statue e delle Pitture 
orientale dei Magi, a volte nelle mappae mundi effigiati in Asia intenti a seguire la stella che li avrebbe condotti a Betlemme, non da meno erano gli scritti dei viaggiatori che a partire da Marco Polo narravano essere partiti dalla Persia. ${ }^{95}$ Gentile da Fabriano non aveva poi risparmiato dettagli narrativi volti a evocare le terre d'oltremare e il lusso delle corti dei sultani: turbanti, tappeti, preziosi tessuti e, non da ultimo, animali esotici. Fu la sensibilità per lo studio dal vero degli animali, maturata dal fabrianese in area padana e veneta prima di giungere sulle rive dell'Arno, che gli consentì di raffigurare fauna esotica di estremo naturalismo: cammelli, leopardi, ghepardi e scimmie che, sebbene ormai presenti in tutte le corti più sofisticate d'Italia dove poteva averli osservarti e disegnati, non avevano certo perso il potere di evocare paesi lontani..$^{6}$ La resa naturalistica degli animali, colti in pose spontanee, si discostava dalle precedenti raffigurazioni, ancora influenzate dai bestiari medievali, palesando una conoscenza diretta anziché mediata da libri di modelli. Non è semplice determinare se i camelidi con scimmie sulla gobba nella scena centrale (fig. 68a) e quelli più approssimativi nella lunetta destra (fig. 68b), in parte occultati dalla cornice, siano cammelli o dromedari, è però indiscutibile la somiglianza con esemplari reali (fig. 69) tanto da far supporre che a Firenze l'artista avesse avuto modo di osservare il cammello di papa Martino V. ${ }^{97}$ Anche i leopardi (figg. 68c-68e) - con capo leonino, corporatura possente e manto fulvo realisticamente punteggiato da macchie "a rosetta" - e i ghepardi (figg. 68f- 68g) - con testa piccola, fisico snello e pelame fulvo disseminato di minuscole macchie nere circolari - sembrano più debitori a una visione diretta (figg. 70-7I) che al ricorso a taccuini di disegni..$^{98} \mathrm{Il}$ fatto, poi, che nella Pala Strozzi i leopardi, animali feroci impossibile da addestrare, siano utilizzati al pari dei ghepardi per la caccia sembra da imputare alla confusione generata da taccuini e testi, che indicavano entrambi i felini con il generico termine «leopardi», piuttosto che a una mancanza di conoscenza zoologica. 99

95. POLO 200I, pp. 4I-43, 30:2-II.

96. Il gusto per il naturalismo di Gentile da Fabriano, memore dei disegni di Giovannino de' Grassi, trapela anche dall'attenzione posta nella resa dei tessuti, della lucertola sul muro della stalla, simile a quella di Lorenzo Ghiberti sul telaio della Porta nord del battistero, e dei fiori all'interno delle monofore lungo i montanti della cornice. Ai dettagli naturalistici Keith Christiansen attribuisce un significato simbolico-religioso, ossia interpreta la natura quale celebrazione dell'Epifania di Cristo, CHRISTIANSEN 2006, pp. 33-36. Per una lettura in chiave religiosa della Pala Strozzi vedi anche DAVISSON I97I, pp. 29I-379. Un precedente toscano nella raffigurazione di animali esotici, ossia cammelli e scimmie, privi però di naturalismo si trova nella pala con l'Adorazione dei Magi (I375-I385) dipinta da Bartolo di Fredi ora alla Pinacoteca di Siena.

97. Vedi pagina I90.

98. BUQUET 2OI , p. I4. Il cane con museruola in primo piano sulla sinistra si ritrova nel Libro di modelli Rothschild attribuito a bottega fiorentina e datato al secondo quarto del XV secolo, così come pure in un disegno di Maso Finiguerra, ora al Gabinetto dei Disegni e delle Stampe degli Uffizi (inv. 753 O), vedi DEGENHART SCHMITT I968-20I0, vol. I.I, p. 258; SCHELLER I995, pp. 337-338; LOISEL 2009, pp. 70-80 n. 23.

99. BUQUET 20I I, pp. 40-43. Già nel Taccuino di disegni di Giovannino de' Grassi un ghepardo con maculatura circolare e un leopardo con maculatura "a rosette", entrambi muniti di collare, sono corredati dalla didascalia «leon pardo" (vedi fig. 27). Immagini che dovevano aver generato una certa confusione nelle copie e nei libri di modelli di animali successivi, dove a volte felini con struttura fisica slanciata e testa minuscola del ghepardo presentano un mantello con la tipica maculatura "a rosette" del leopardo (figg. 4I, 47). Basandosi sui disegni degras- 


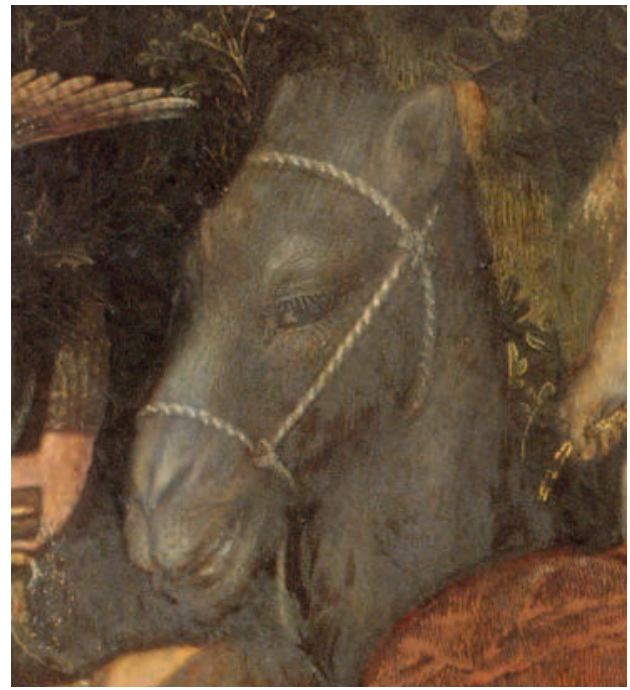

Fig. 68a: Dromedario (?) (part.)

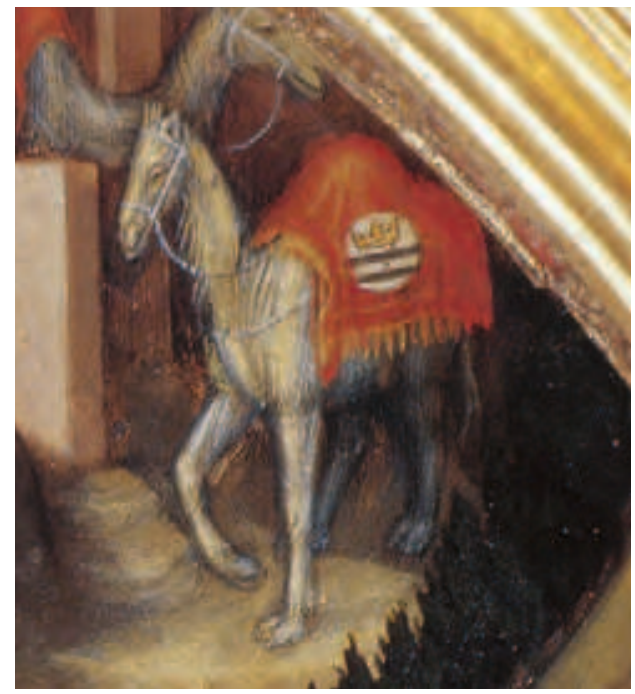

Fig. 68b: Dromedario (part.)

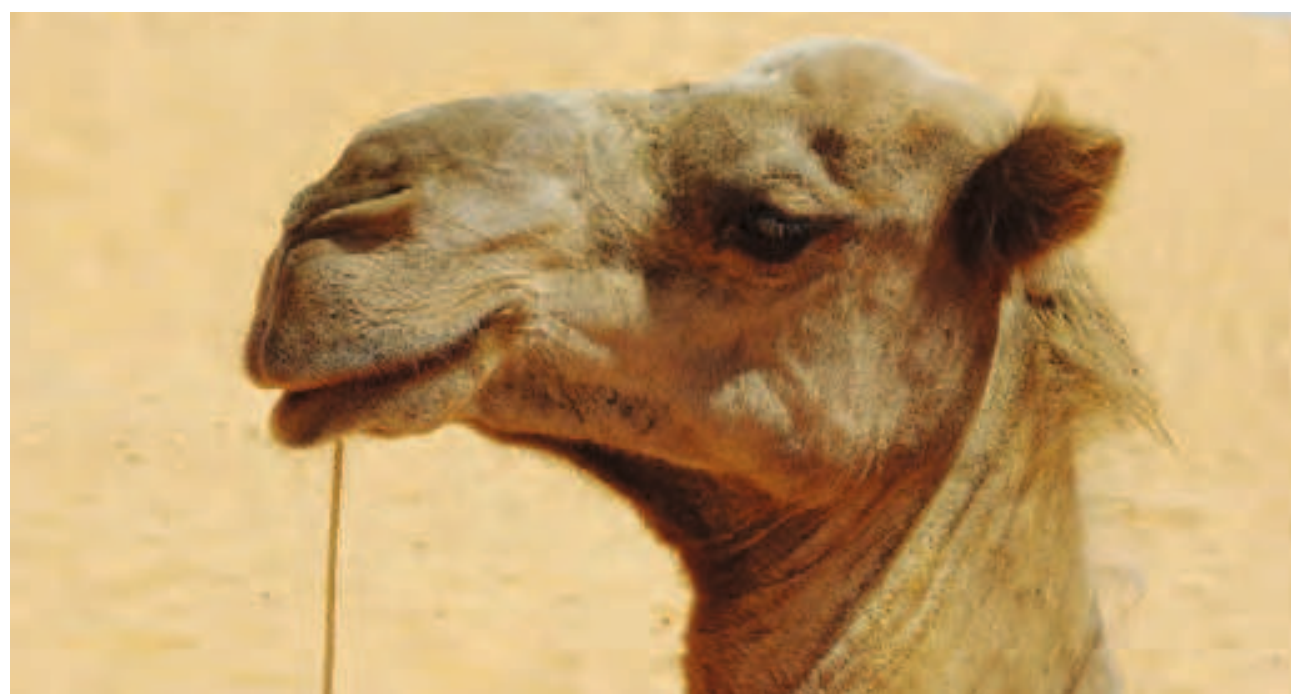

Fig. 69: Dromedario (Camelus dromedarius) 


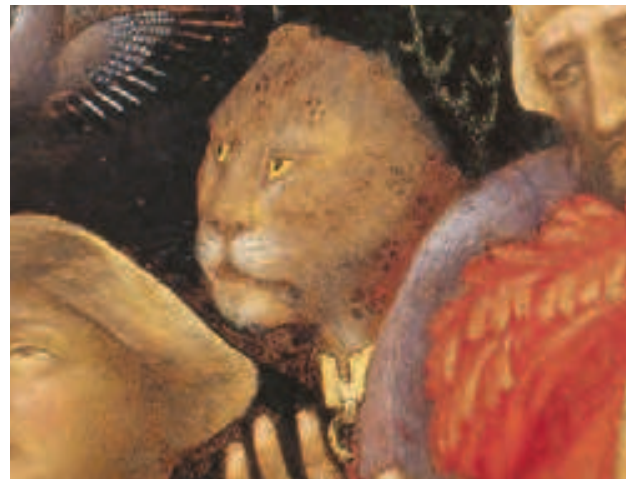

Fig. 68c: Leopardo (part.)

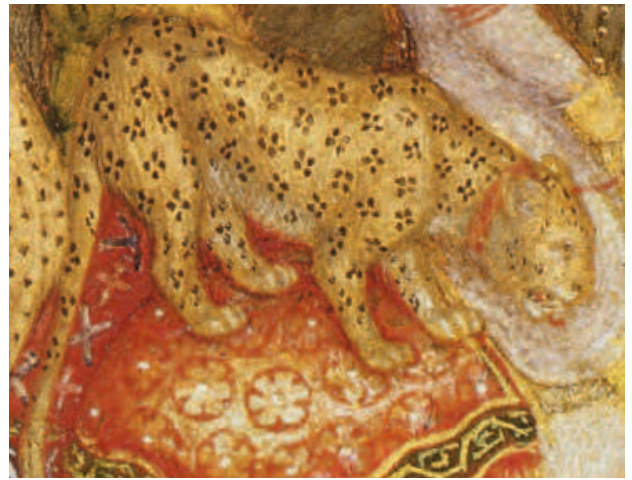

Fig. 68d: Leopardo (part.)

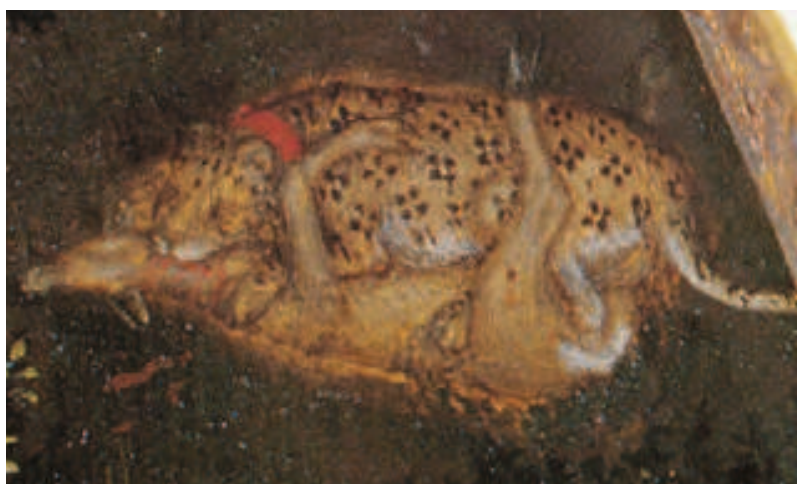

Fig. 68e: Leopardo (part.)

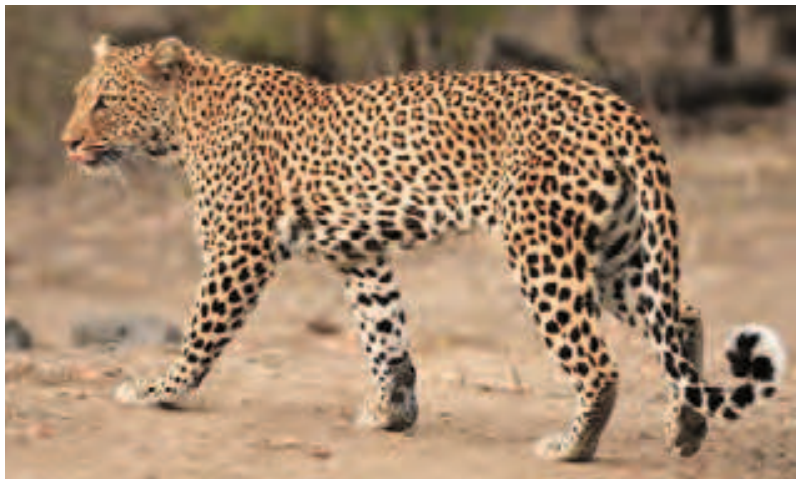

Fig. 70: Leopardo (Panthera pardus) 


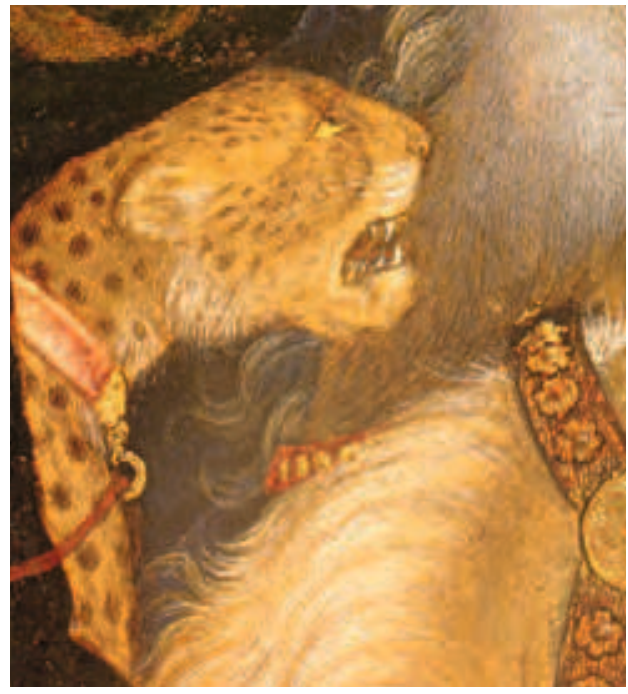

Fig. 68f: Ghepardo (part.)

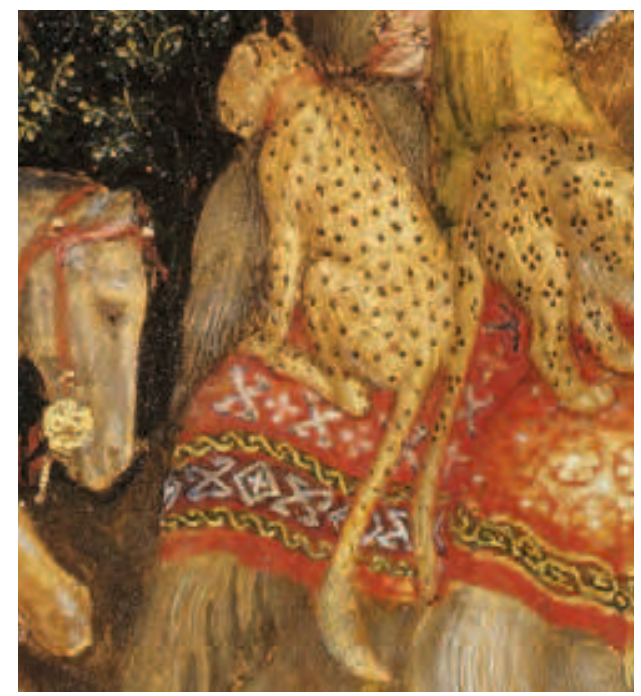

Fig. 68g: Ghepardo (part.)

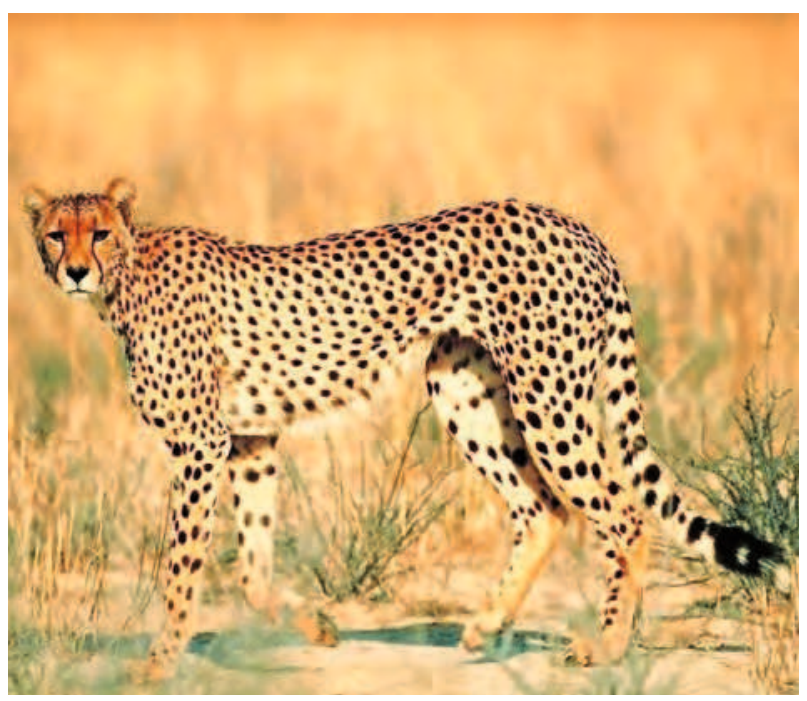

Fig. 7I: Ghepardo

(Acinonyx jubatus) 
Peculiari sono pure le scimmie (figg. 68h-68i) con preziose catene legate in vita e al collo dipinte in maniera così accurata da palesare la loro appartenenza a specie diverse: la bertuccia (Macaca sylvanus) tipica dell'Africa nord-occidentale (fig. 72) e il cercopiteco - forse gialloverde (Chlorocebus sabaeus) - diffuso in Africa tropicale ed equatoriale (fig. 73), che Gentile da Fabriano poteva aver visto a Firenze oppure in Lombardia, dove già alla fine del XIV secolo questi primati furono ritratti nel Taccuino di disegni di Giovannino de' Grassi (fig. 26). ${ }^{\text {Ioo }}$

Poiché sulle rive dell'Arno la conoscenza dell'Oriente era per lo più limitata alle esperienze vissute da mercanti, missionari e pellegrini e alla lettura delle loro relazioni o diari di viaggio, l'opera pittorica di Gentile da Fabriano risultò assolutamente innovativa: il contatto vero e proprio con i popoli orientali avverrà, infatti, solo tre lustri più tardi con le delegazioni giunte in città per partecipare al concilio per l'unione delle due Chiese. A contribuire alla magnificenza della scena erano soprattutto le scimmie, animali da compagnia ricercate dalle classi abbienti quale segno di status symbol, e il leopardo raffigurato nella Pala Strozzi nell'atto di azzannare un cervo. Osservando la pala il ricordo della narrazione poliana, testo particolarmente diffuso tra la classe mercantile fiorentina, del Gran Khan che disponeva di «leopardi assai, e che tutti sono buoni da cacciare e da prendere bestie» e che, come appare nel dipinto, portava "un leopardo in sulla groppa del cavallo; e quando egli vuole fare pigliare alcuna di queste bestie, lascia andare lo leopardo» (fig. 94) doveva evocare nello spettatore tutto lo splendore delle corti orientali, così come pure quello dei sovrani europei che dalle terre d'oltremare avevano ripreso questa modalità venatoria. ${ }^{\text {IOI }}$ Pratica che sembra essere stata introdotta in Italia, prima nazione in Europa, già al tempo di Federico II e ritornata in auge alla fine del XIV secolo presso la corte viscontea, dove il duca Gian Galeazzo: «appassionato per la caccia, volendosi divertire con equipaggi più nobili di quelli che usavano gli altri principi, non si accontentava delle belle mute di cani [...] egli volle anche dei leopardi ed altre bestie strane per lanciarle, contro quelle dei campi e delle foreste». ${ }^{102}$

siniani, gli storici dell'arte hanno sostenuto che per distinguere le due specie feline gli artisti fecero ricorso all'espediente di raffigurare le macchie del ghepardo di forma circolare e quelle del leopardo "a rosetta", tipologie che in realtà - come già accennato da Luigi Messedaglia - corrispondono a quelle degli animali in natura (figg. 70-7I) vedi BUQUET 20II, pp. 28-43; MESSEDAGLIA I94I, pp. 63-64. Di tutt'altra opinione - che non condivido - è Marco Masseti che ritiene tutti i felidi raffigurati nella Pala Strozzi dei ghepardi, in quanto dotati di collare e impiegati per la caccia, e interpreta la differenza nella maculatura uno strumento "di narrazione pittorica" adottato dall'artista per indicare fasi successive dell'azione venatoria, espediente che sarebbe poi stato ripreso da Benozzo Gozzoli nella cappella dei Magi vedi MASSETTI 20I7, pp. I29-I30.

Iоo. Ivi, pp. I33-I39.

Iог. POLO 200I, pp. I09, 74:6; I40, 9г: . Per le origini orientali di questa pratica venatoria vedi ALLSEN 2006.

I02. BORSA I924, p. I24. Vedi anche MESSEDAGLIA I94I, pp. 3I-34; ID. I947, pp. I9-2I; BUQUET $20 I$ I, p. 26. 


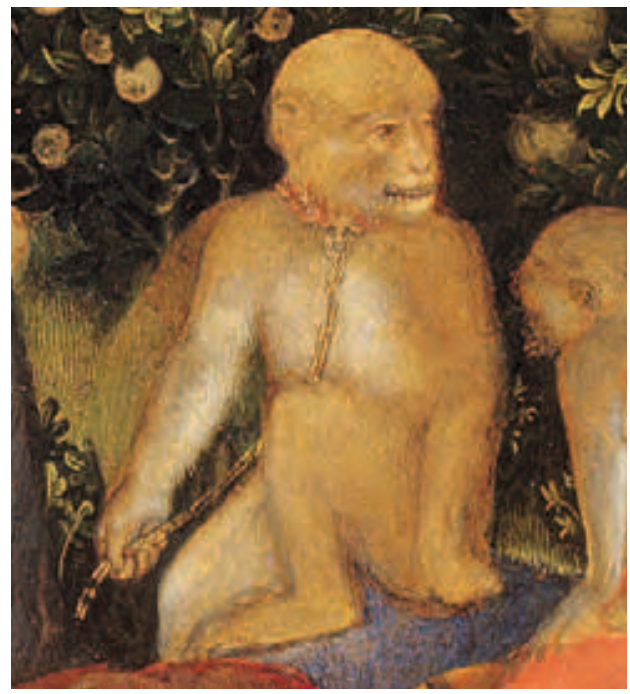

Fig. 68h: Bertuccia (part.)

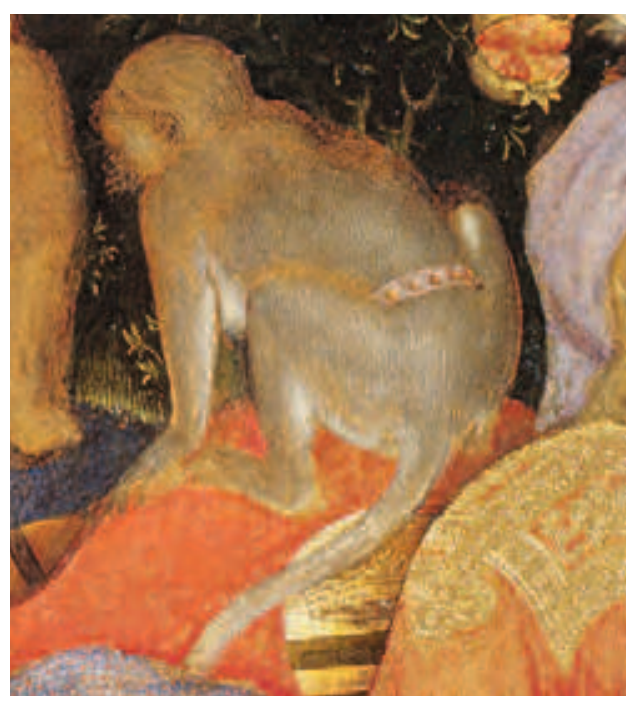

Fig. 68i: Cercopiteco (part.)

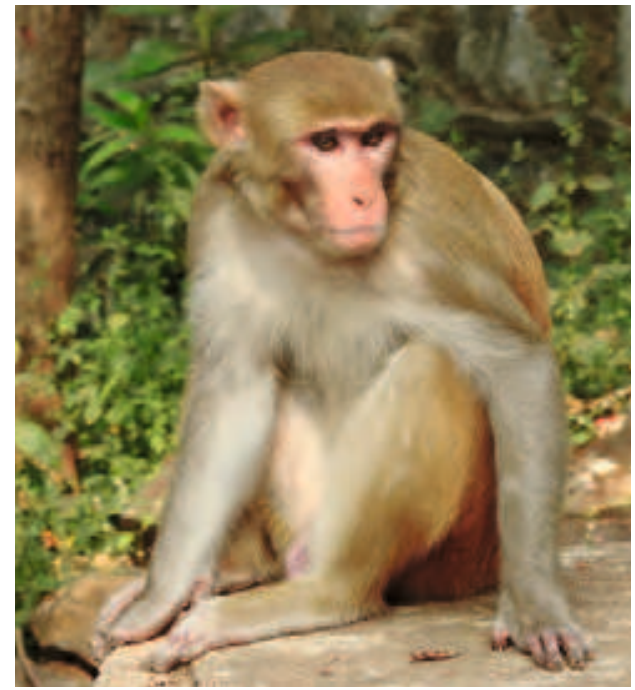

Fig. 72: Bertuccia (Macaca sylvanus)

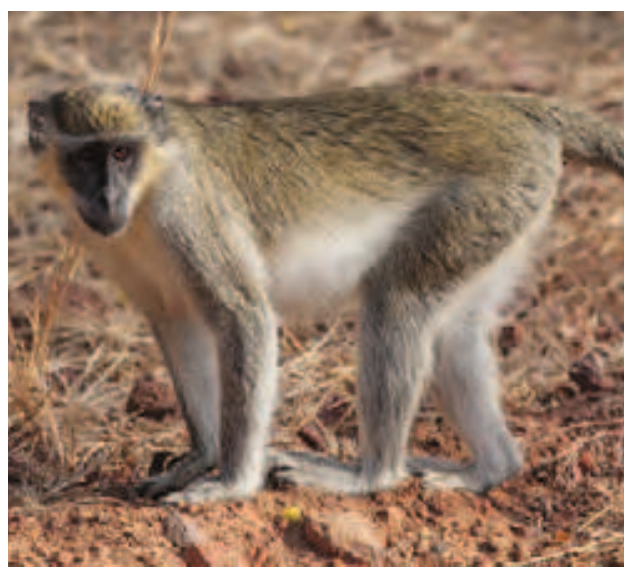

Fig. 73: Cercopiteco gialloverde (Chlorocebus sabaeus) 


\subsection{Animali esotici nella pittura fiorentina post I423}

Di tutt'altra natura erano gli animali esotici raffigurati da Paolo Uccello nel ciclo di affreschi con le Storie della Genesi nel chiostro Verde della chiesa di Santa Maria Novella. Nonostante Giorgio Vasari avesse tessuto le lodi dell'artista nel dipingere gli animali «de' quali sempre si dilettò, e per fargli bene vi mise grandissimo studio; e che è più, tenne sempre per casa dipinti uccelli, gatti, cani e d'ogni sorte di animali strani che potette aver disegno, non potendo tenere de' vivi per esser povero", le pitture murali eseguite nel complesso domenicano intorno al I43I rivelano le difficoltà incontrate dall'artista nel dare forma ad animali esotici che all'epoca non si erano mai visti a Firenze. ${ }^{\text {I03 }}$ Il pachiderma (fig. 74a), che s'intravvede nell'affresco con la Creazione degli animali (fig. 74), appare alquanto stilizzato e ancora debitore a modelli di disegni o a immagini di bestiari, così come pure la testa di scimmia (fig. 74b), nonostante all'epoca qualche primate doveva già essere presente a Firenze. ${ }^{\text {I04 }}$ Del tutto fantasioso e per nulla realistico risulta, poi, il camaleonte (fig. 74c) ritratto en trompe-l'œil sulla cornice bicroma, rettile presente in città solo a partire dal $1467 .^{\text {IO5 }}$

Nonostante la grande impressione che l'opera di Gentile da Fabriano doveva aver suscitato tra i pittori e i cittadini fiorentini, la raffigurazione di animali esotici sembra essere rimasta estremamente limitata e sporadica negli anni immediatamente successivi alla Pala Strozzi, forse a causa della scarsa fauna esotica presente in città, ma probabilmente anche per una sorta di reticenza da parte dell'emergente ceto dei facoltosi mercanti e banchieri fiorentini ad autocelebrarsi in maniera così esplicita come aveva fatto Palla Strozzi. ${ }^{106}$ Attitudine che sembra affiorare dall'affresco con il Risanamento dello storpio e la Resurrezione di Tabita (I425) eseguito da Masolino da Panicale su incarico di Felice Brancacci - che nel I433 sposerà la figlia di Palla Strozzi - nella cappella di famiglia della chiesa di Santa Maria del Carmine. Al centro della scena, che separa i miracoli compiuti da Pietro, due giovani abbigliati con lussuose vesti che passeggiano conversando amabilmente rappresentano un accenno di «cronaca mondana», ma potrebbero pure alludere velatamente - come ipotizza Dale Kent - alla professione del committente arricchitosi con il commercio della seta. ${ }^{107}$ Unica traccia di animali esotici è la presenza

I03. VASARI I966-I997, vol. 3, p. 65.

I04. AMES-LEWIS I987, pp. 5-6. La disposizione "a ventaglio" degli animali ricorda l'affresco di Bartolo di Fredi con Dio che indica ad Adamo il paradiso terrestre (I367) nella collegiata di San Gimignano.

I05. Per il camaleonte vivo presente a Firenze vedi pagina I27.

Io6. Keith Christiansen ipotizza che Palla Strozzi avesse scelto l'iconografia dell'Adorazione dei Magi per offrire ai fiorentini un surrogato virtuale delle processioni dei Magi quando tra il I4I9 e il I428 furono sospese per volere della Signoria, che reputava le confraternite pericolosi centri di attività politica, CHRISTIANSEN 2006, p. 34-35. Per le processioni dei Magi a Firenze vedi anche HATFIELD I970; TREXLER I980, p. 298.

I07. LONGHI I940, p. I58; KENT 2007, p. 55. Per un approfondimento sulla figura di Felice Brancacci vedi ECKSTEIN 20I4, pp. 69-73. 


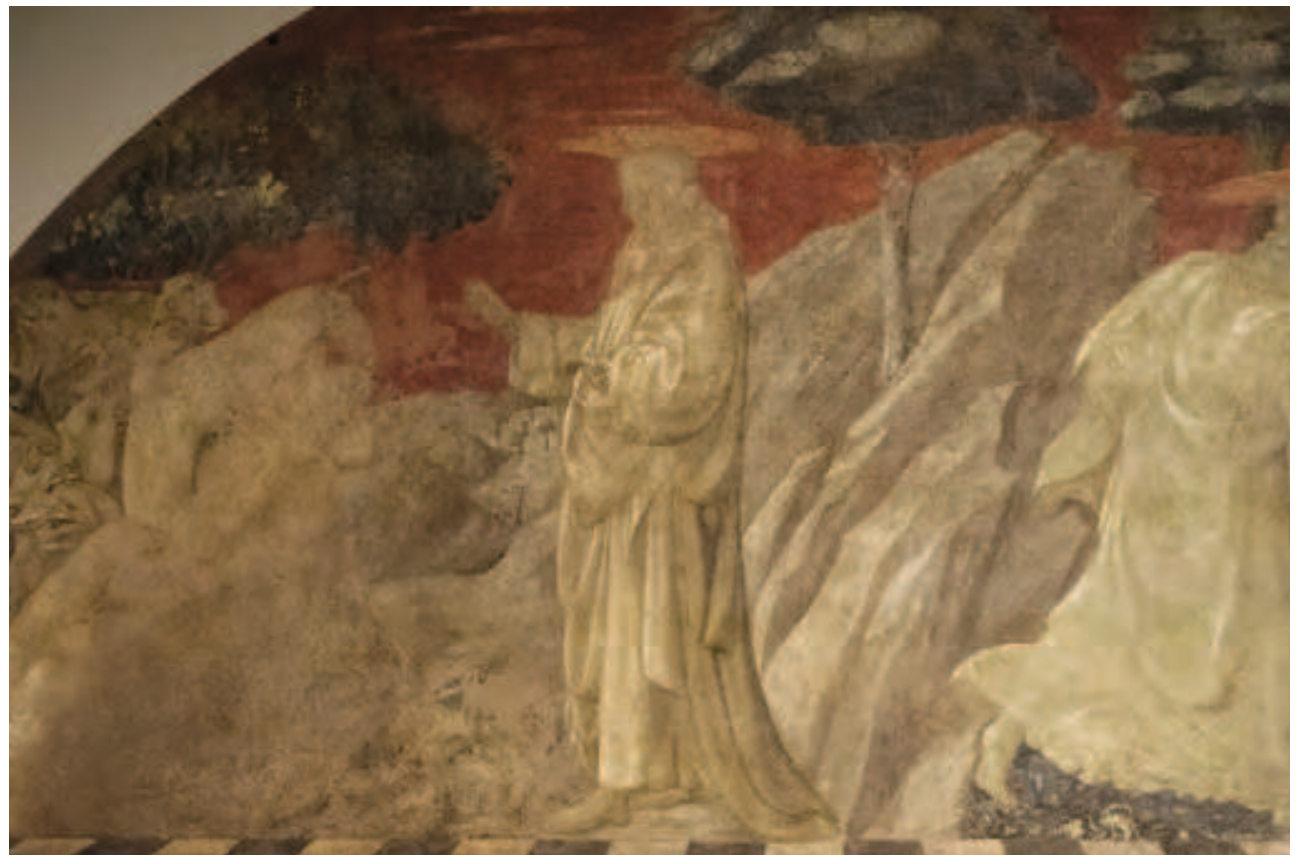

Fig. 74: Paolo Uccello,

Creazione degli animali, I43I ca.

Firenze, chiesa di Santa Maria Novella, chiostro Verde

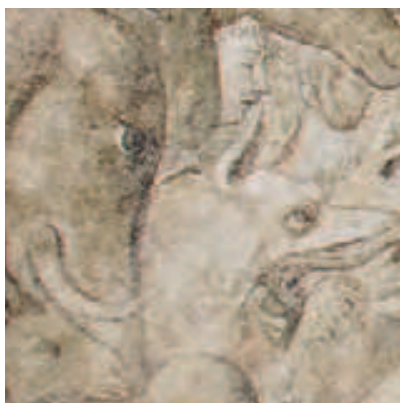

Fig. 74a: Elefante (part.)

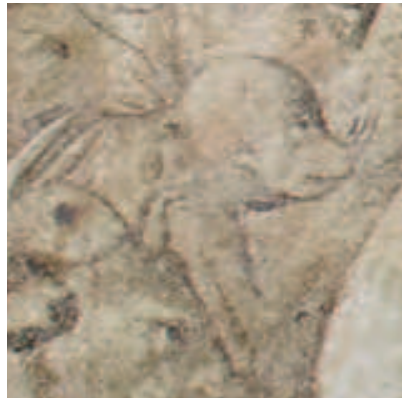

Fig. 74b: Scimmia (part.)

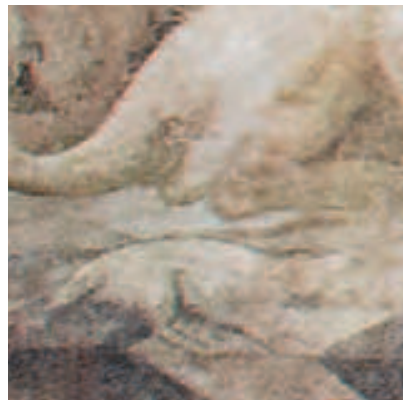

Fig. 74c: Camaleonte (part.) 
di due scimmie assicurate con lunghi guinzagli, una intenta a camminare lungo il cornicione di una finestra e l'altra pacificamente assisa su di un'asta dell'infisso, che alla scena in fondo un tono giocoso più che un vero e proprio senso di esotismo. Assente invece qualsiasi riferimento all'incarico che qualche anno prima la Signoria aveva conferito a Felice Brancacci in qualità di ambasciatore inviato presso il sultano d'Egitto per negoziare un trattato commerciale, missione che gli aveva fornito l'opportunità, come accuratamente descritto nel suo diario di viaggio, di osservare con i propri occhi un elefante. ${ }^{108} \mathrm{La}$ mancanza nell'affresco di dettagli che rimandino al mondo orientale e a un evento straordinario come la visione ravvicinata di un pachiderma, animale ritenuto esotico per eccellenza, sarà forse da imputare al fatto che nel I422 Felice Brancacci aveva vissuto l'esperienza del viaggio in maniera poco piacevole? ${ }^{109}$

È evidente che fino alla metà del XV secolo gli animali esotici figuravano nei dipinti unicamente in forma di dettagli volti a suggerire un'ambientazione o una provenienza orientale dei personaggi. Anche nel caso di un soggetto come l'Adorazione dei Magi (I439-I44I ca.) (fig. 75) dipinto da Domenico Veneziano su commissione di Piero de' Medici che ben si sarebbe prestato all'inserimento di fauna esotica, soprattutto perché eseguito negli anni in cui a Firenze era in corso il concilio che aveva portato in città personaggi e delegazioni orientali con tutta probabilità accompagnati da qualche esemplare esotico, l'attento naturalismo dell'artista si era limitato a descrivere accuratamente due cammelli, di cui uno cavalcato da un paggio africano, in posizione defilata e in parte occultati dalla capanna con la Vergine e il Bambino (fig. 75 a). ${ }^{\text {IIO }}$ Se l'eleganza e il tono fiabesco che permeano l'opera, come pure il dettaglio del personaggio con un falcone in pugno da identificare con il committente, furono certamente ispirati dalla pala di Gentile da Fabriano esposta nella chiesa di Santa Trinita, i cammelli assai realistici lasciano supporre - nonostante finora non siano stati rintracciati documenti - che al seguito degli orientali giunti in città per il concilio ve ne fosse qualcuno. ${ }^{\text {III }}$

Anche in alcuni dipinti dovuti al pennello di Beato Angelico quali la scena con l'Adorazione dei Magi (I425-I427 ca.) nella predella dell'Annunciazione per la chiesa di San Domenico a Fiesole e il Tondo Cook (I445- I460 ca.) con la stessa iconografia, forse eseguito per i Medici in collaborazione con Filippo Lippi, s'intravvedono in secondo piano lunghi colli e teste di camelidi assai realistici nonostante le ridotte dimensioni. ${ }^{\mathrm{II} 2}$ Un grande dromedario si staglia, invece, sullo sfon-

I08. Vedi pagine I09-III.

I09. Vedi TRIPODI 20I0, pp. 4I5-4I8.

IIO. AMES-LEWIS I979, pp. 78-90; OLSON 2000, pp. I69-170. Nell'inventario stilato alla morte di Lorenzo il Magnifico nel I 492 l'opera, erroneamente attribuita a Pesellino, risulta ancora nel palazzo di via Larga vedi Libro d'inventario I992, p. 57 c. 3I.

I I. Lorenzo de' Medici 2013 , pp. 20-2I. Francis Ames-Lewis ritiene, invece, i cammelli copiati da un libro di modelli, AMES-LEWIS I987, p. 5 .

II2. BOSKOVITS I995, p. 56; KANTER 2005, pp. 98-I00 n. I7; VERDON 20I5, pp. I29-I30. Diane Cole Ahl evidenzia come nell'Annunciazione per la chiesa di San Domenico le figure di Adamo ed Eva cacciati dal para- 


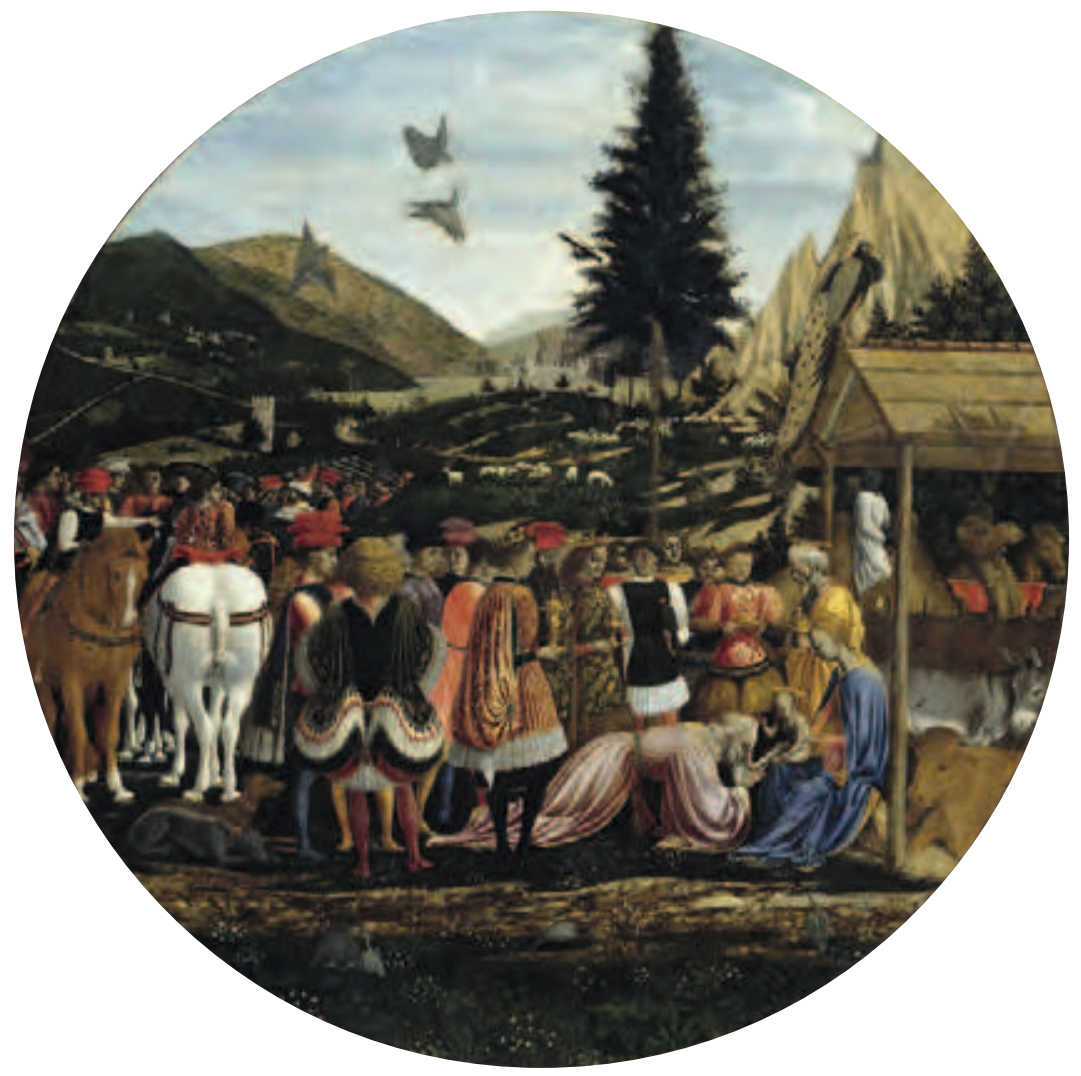

Fig. 75: Domenico Veneziano,

Adorazione dei Magi, I439-I44I ca.

Berlino, Staatliche Museen, Gemäldegalerie

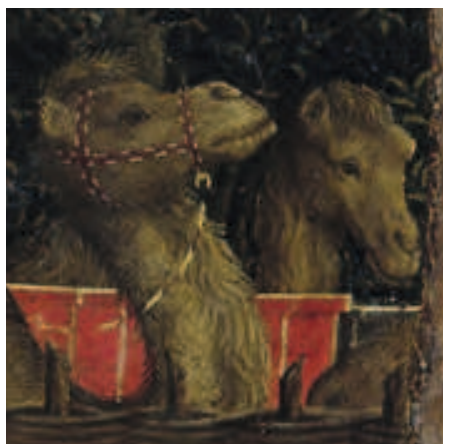

Fig. 75a: Cammelli (part.) 
do della Sepoltura dei santi Cosma e Damiano e dei loro fratelli (I440-I443 ca.), nella predella della pala destinata all'altare maggiore della chiesa fiorentina di San Marco (fig. 76), dove la facciata del convento domenicano è raffigurata come doveva apparire prima dei lavori di restaurato finanziati da Cosimo de' Medici e terminati alla fine del $\mathrm{I}_{442}{ }^{\mathrm{II} 3}$ È interessante che nelle iconografie con i re Magi i camelidi risultino dipinti con intento naturalistico: nella predella di San Domenico modellati sulla base di quelli ritratti nella Pala Strozzi o forse del cammello di papa Martino $\mathrm{V}$ che tra il I4I9 e il I 420 si trovava in città, mentre nel più tardo Tondo Cook punto di riferimento potrebbero essere stati un disegno, l'affresco benozzoliano con la Cavalcata dei Magi oppure il cammello inviato da Francesco Sforza ai Medici nel I452. ${ }^{\text {II } 4}$ Nella predella della pala di San Marco, invece, il dromedario, forse dovuto alla mano di un collaboratore, sembra rifarsi a quello miniato dalla bottega di Giovannino de' Grassi nell'Historia plantarum (fig. 38) e probabilmente diffuso da repliche nei numerosi taccuini di modelli in circolazione. ${ }^{\text {II }}$

Quando nel luglio I459 Benozzo Gozzoli intraprese il ciclo di affreschi nella cappella del nuovo palazzo mediceo affacciato su via Larga il ricordo della pala dipinta da Gentile da Fabriano per Palla Strozzi, acerrimo nemico di Cosimo il Vecchio che rientrato a Firenze nel I 434 lo aveva fatto bandire dalla città, doveva essere ancora vivo. ${ }^{\mathrm{II} 6}$ Riproporre nel proprio sacello, dove era solito ricevere ospiti e personaggi illustri, un'iconografia introdotta dall'avversario condannato all'esilio implicava un palese messaggio: ricordare agli spettatori il fondamentale ruolo raggiunto dai Medici nella scena politica fiorentina. ${ }^{17}$ Se un primo velato riferimento politico affiora già dal tondo con l'Adorazione dei Magi (I439-I44I ca.) dove Piero di Cosimo si presenta, al pari di Palla Strozzi nella chiesa di Santa Trinita, sontuosamente abbigliato al fianco dei re orientali con un falcone in pugno, nella cappella medicea l'allusione risulta ancora più marcata. ${ }^{\text {II } 8}$ E poiché

diso terrestre risultino essere una citazione degli affreschi di Masaccio nella chiesa del Carmine, stabilendo quale termine ante quem il I425, mentre per la scena nella predella con l'Adorazione dei Magi ritiene che l'Angelico si fosse ispirato all'opera di Gentile da Fabriano nella chiesa di Santa Trinita, COLE AHL 20o8, pp. 46-47. Per il Tondo Coock vedi BOSKOVITS I995, pp. 33-68; KANTER 2005, pp. 282-283; VERDON 20I5, p. 369. Quest'opera, elencata come «di mano di Fra Giovanni» nell'inventario stilato nel I 492 alla morte del Magnifico, si trovava nella "camera di Lorenzo» e fu stimata l'esorbitante somma di Ioo fiorini vedi Libro d'inventario I992, p. I2 c. 6.

II3. KANTER 2005, pp. I90-I99 n. 34; SCUDIERI 2009, pp. II3-II4; VERDON 20I5, pp. 215-226. La nuova pala di Beato Angelico per la chiesa di San Marco fu mostrata al pubblico il 6 gennaio I 443 quando, al termine dei lavori di restauro, l'edificio fu nuovamente consacrato vedi KENT 2005 , p. 388 .

I 4. Per i cammelli presenti a Firenze vedi pagina 125 .

II5. In questo caso è la storia dei santi martiri cristiani Cosma e Damiano, fratelli e medici che in Oriente prestavano le loro cure gratuitamente, a richiedere la presenza del cammello (all'epoca confuso con il dromedario): secondo la tradizione, dopo essere stati arrestati e giustiziati, quando stavano per essere seppelliti distanti tra loro per rispettare la richiesta di Cosma, irato con il fratello Damiano che aveva accettato da una donna delle uova come ricompensa per averla risanata, comparve un cammello che per volontà divina pronunciò la frase «Nolite eos separare a sepoltura, quia non sunt separati a merito» e fu così deciso d'inumare i santi nella stessa fossa.

II6. Per un approfondimento sul ciclo di affreschi vedi Benozzo Gozzoli I993; COLE AHL I996, pp. 8I-I 2.

II7. O'GRODY I989, pp. 83-84, 86.

II 8. GOMBRICH I973, p. 73. Il falcone, oltre che volatile impiegato per la caccia, era l'emblema personale di Palla Strozzi poi adottato, forse non casualmente, da Piero de' Medici vedi CARDINI i992b, pp. 67-70. 


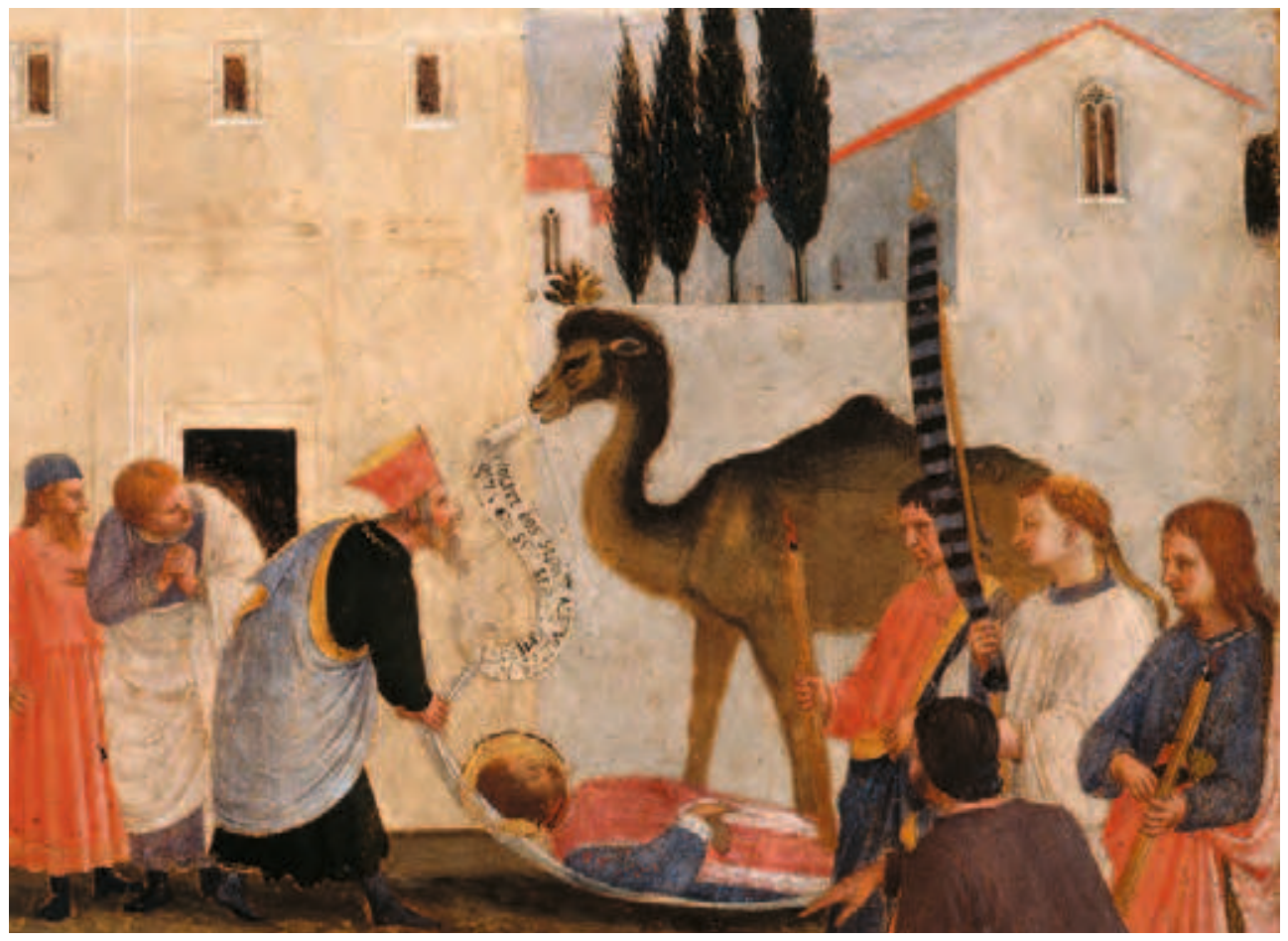

Fig. 76: Beato Angelico,

Sepoltura dei santi Cosma e Damiano e dei loro fratelli, I440-I $443 \mathrm{ca}$.

Firenze, Museo di San Marco 
all'opera del fabrianese si deve l'introduzione nella città del giglio degli animali esotici naturalisticamente ritratti, nella Cavalcata dei Magi (fig. 77) Benozzo Gozzoli cercò di uguagliarlo, a volte addirittura riproponendo gli stessi modelli: sulla parete occidentale, summa di motivi ripresi dalla Pala Strozzi, un ghepardo da caccia seduto sulla groppa del cavallo coperta da un tappeto e tenuto alla catena da un elegante giovane (fig. 77a), all'estremità destra una bertuccia assisa sul dorso di un destriero (fig. 77 b) e nella boscaglia in secondo piano un ghepardo e un leopardo che inseguono e azzannano prede (figg. 77c-77d). ${ }^{\text {II9 }}$ Anche il corteo sullo sfondo, composto da dignitari orientali, paggi e schiavi con al seguito asini, cavalli, dromedari e cammelli, che s'inerpica lungo un sentiero roccioso sembra ripreso dal fabrianese, mentre a Benozzo Gozzoli si deve la figura del guardiano in primo piano - nei documenti del tempo indicato come "pardiere» - colto nell'atto di smontare da cavallo tenendo saldamente al laccio quello che sembrerebbe essere un leopardo (fig. 77e). ${ }^{\mathrm{I} O}$ Proprio all'ascendente esercitato dall'opera di Gentile da Fabriano, oltre che ai taccuini di disegni, sarebbe da ricondurre la confusione tra ghepardi e leopardi indistintamente ritratti quali animali da caccia. Per quanto riguarda, invece, la resa naturalistica dei felini quello assiso sulla groppa del cavallo corrisponde a un ghepardo, sia per il cranio di ridotte dimensioni e le caratteristiche striature nere ai lati del muso sia per le macchie nere di forma circolare che punteggiano il pelo fulvo, mentre l'esemplare tenuto dal "pardiere», con corporatura più massiccia, macchie del manto disposte "a rosetta" e ciuffi di pelo ai lati del muso, non trova piena corrispondenza con la realtà. ${ }^{\mathrm{I} I}$ A Gentile da Fabriano rimanda pure la bertuccia che, forse in virtù delle maggiori dimensioni, nell'affresco benozziolano appare ancora più realistica. ${ }^{\text {I22 }}$ Tra $i$ camelidi del corteo raffigurati con sensibilità naturalistica è possibile distinguere dromedari (fig. 77f) e cammelli (fig. $77 \mathrm{~g}$ ), questi ultimi con personaggi africani sulla groppa probabile citazione dal tondo di Domenico Veneziano (fig. 75a) opera commissionata da Piero di Cosimo e quindi conservata nello stesso Palazzo Medici - e fattezze che rimandano pedissequamente a un disegno dell'animale schizzato dalla bottega di Benozzo Gozzoli (fig. 56). ${ }^{\mathrm{I23}}$

I I9. MESSEDAGLIA I94I, pp. 63-64; O’GRODY I989, pp. 80-82; COLE AHL i996, p. 86.

I 20. Per le fattezze africane del "pardiere» è stato ipotizzato quale modello lo schiavo appartenuto al cardinale del Portogallo, morto a Firenze nel I 459 durante il viaggio per partecipare alla dieta di Mantova vedi KAPLAN I985, p. I 4 .

I 2I. Per il felino con il manto grigiastro, che Thierry Buquet ipotizza essere un ghepardo appartenente a una sottospecie, è probabile che Benozzo Gozzoli si fosse ispirato a una copia del Taccuino di disegni di Giovannino de' Grassi (vedi fig. 27) dove, per l'appunto, si trova un felide, forse un leopardo, con il manto più scuro rispetto a quello del ghepardo nella stessa pagina vedi BUQUET 20 I I, p. 38.

I22. Ivi, pp. 37-38; MASSETI 20I7, p. I39.

I23. SALMI I930, p. 90; POPHAM I930, pp. 55 (fol. I4B), 57; COLE AHL I996, pp. Io8, i Io fig. I32. Nello stesso foglio si trova una testa di aquila corrispondente a quella dipinta sulla parete d'altare quale simbolo di san Giovanni. L'uso di disegni preparatori da parte di Benozzo Gozzoli trova testimonianza in un foglio della collezione Woodner con un cane che insegue una lepre molto simili a quelli affrescati nella cappella di Palazzo Medici. A questo proposito il disegno agli Uffizi (I4504 F) e quello al Musée des Beaux-Arts di Digione (inv. I745) con un leopardo intento ad azzannare un bovino corrispondono a un dettaglio nello sfondo dell'affresco benozzoliano vedi KANTER 


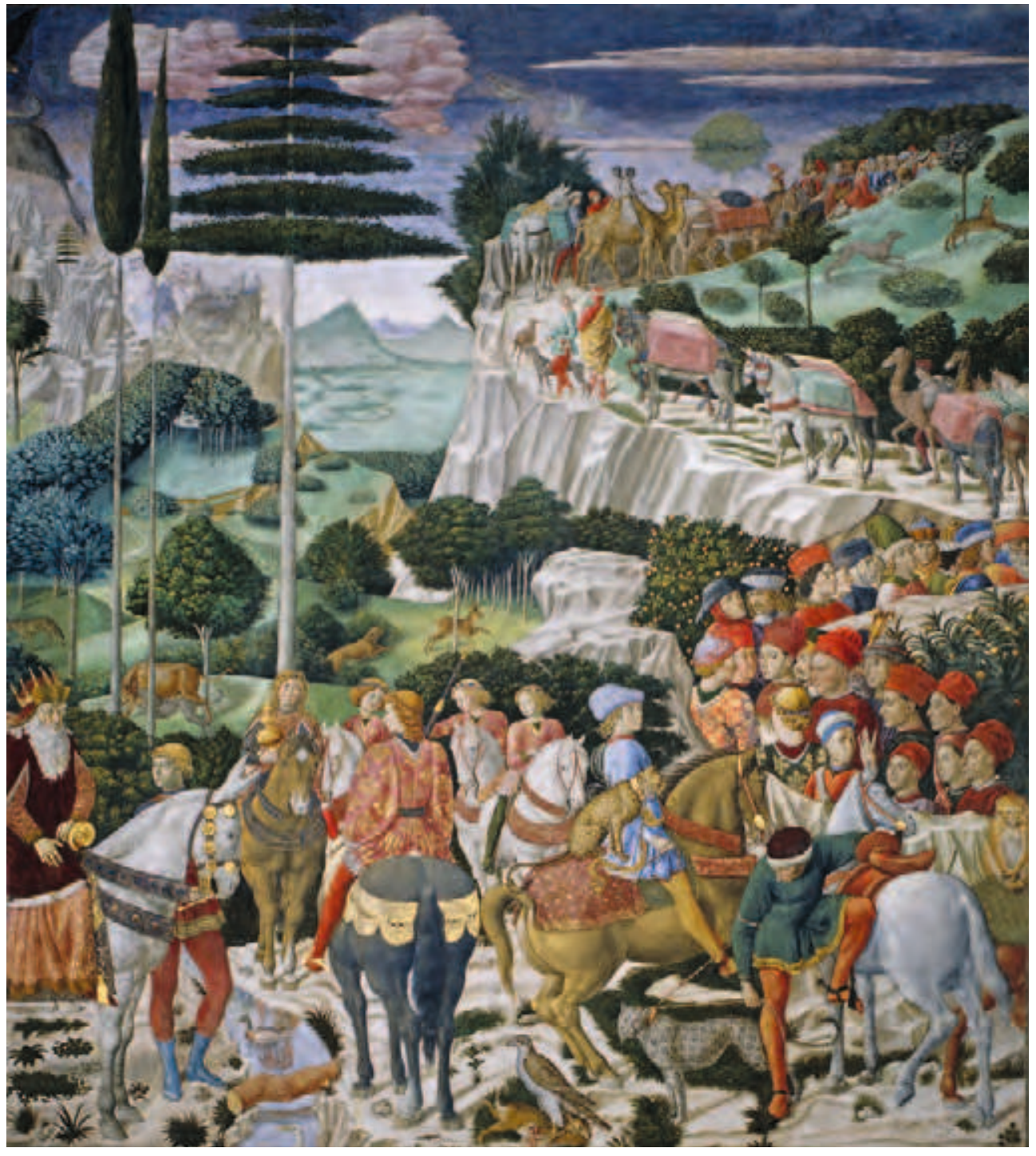

Fig. 77: Benozzo Gozzoli,

Cavalcata dei Magi (parete est), I459

Firenze, Palazzo Medici Riccardi, cappella dei Magi 


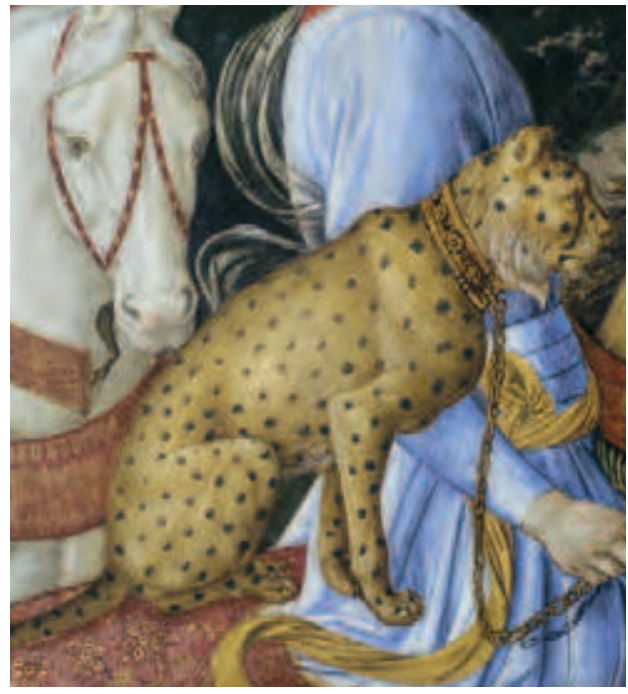

Fig. 77a: Ghepardo (part.)

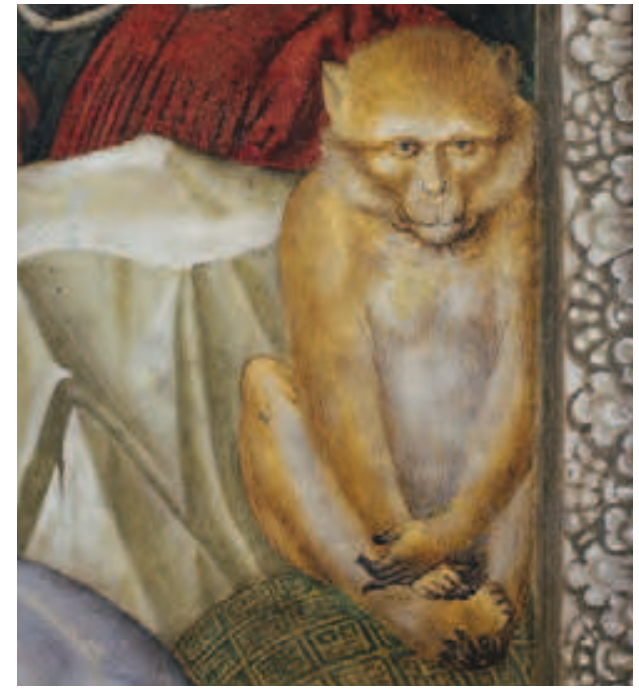

Fig. 77b: Bertuccia (part.)

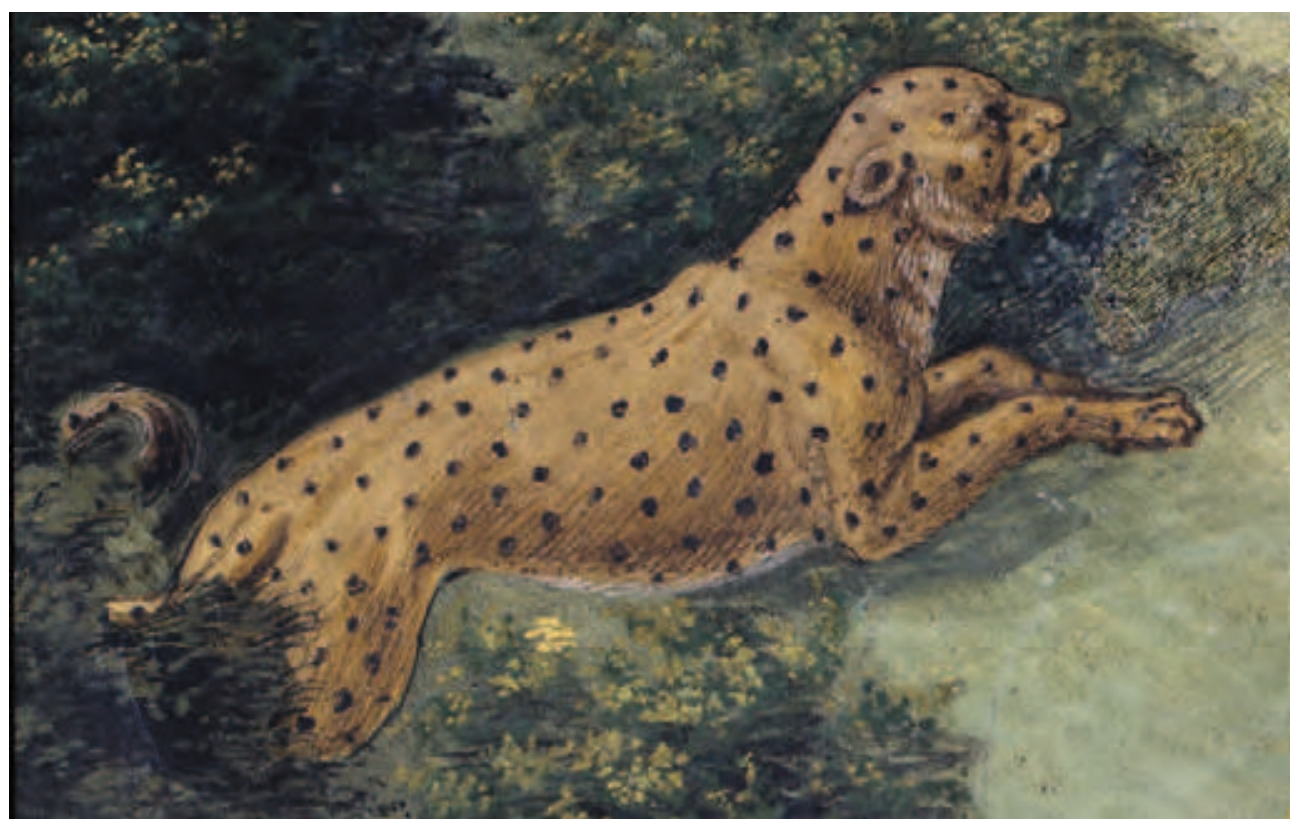

Fig. 77C: Ghepardo (part.) 


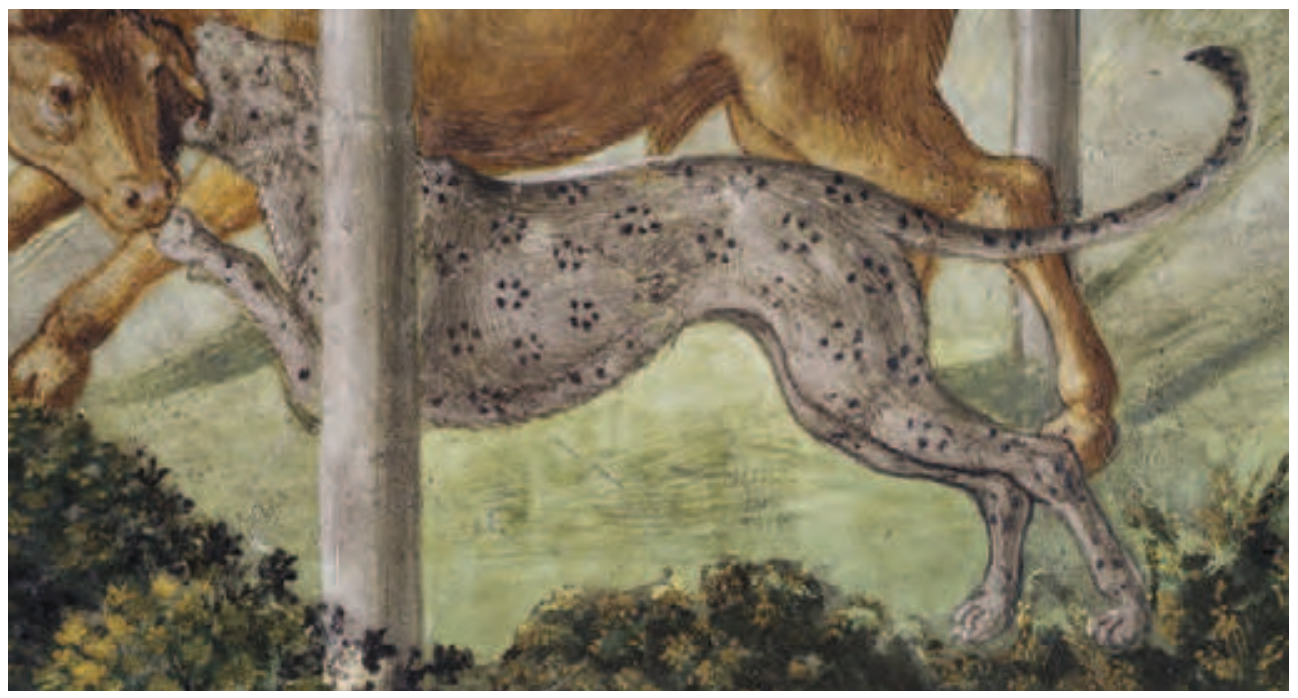

Fig. 77d: Leopardo (part.)

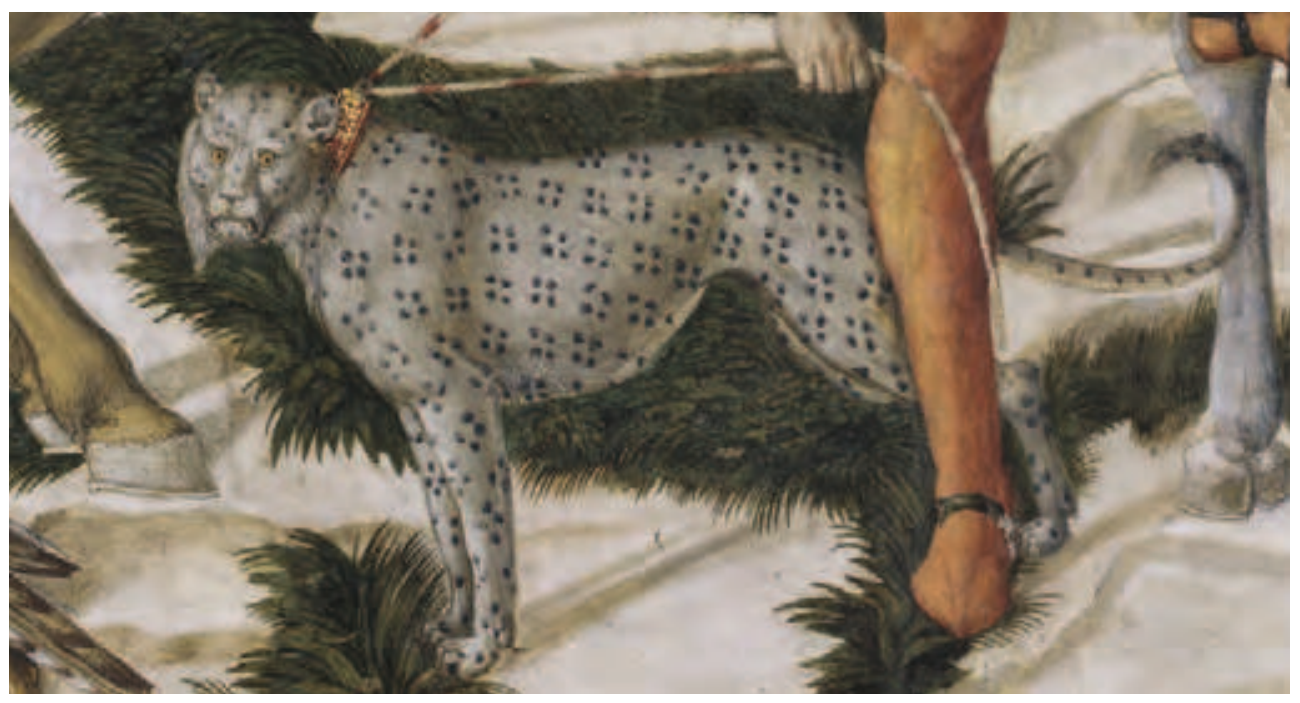

Fig. 77e: Leopardo (part.) 


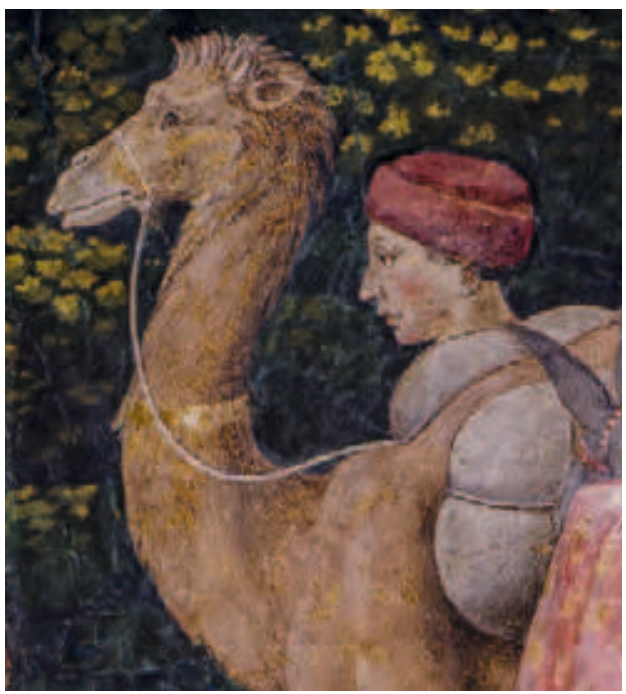

Fig. 77f: Dromedario (part.)

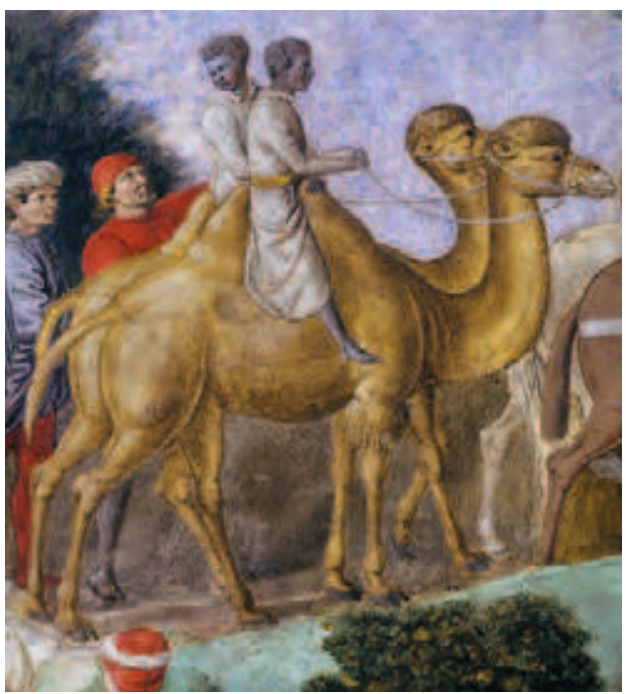

Fig. 77g Cammelli (part.) 
Quello che emerge dall'analisi degli affreschi benozzoliani è la tendenza, nonostante l'artista avesse con tutta probabilità potuto osservare gran parte di questi animali dal vivo, a servirsi di disegni ripresi da libri di modelli all'epoca molto diffusi e confluiti nel libro approntato nel suo atelier. Se a un primo e superficiale sguardo gli animali esotici ritratti dal pittore e dai suoi collaboratori appaiono alquanto realistici, un'osservazione più accurata rivela invece un'esecuzione poco attinente alla realtà. Anche quando le specie appartengono alla fauna indigena, come nel caso del gipeto e del cardellino nell'affresco con l'Adorazione degli angeli, sembrano rifarsi a una copia del Taccuino di disegni di Giovannino de' Grassi (fig. 30) piuttosto che a uno studio dal vero. ${ }^{\text {I24 }}$ Per quanto riguarda invece la bertuccia, l'animale più naturalistico dell'affresco, potrebbe essere stata ritratta dal vero; è però da escludere che si potesse trattare delle due scimmie regalate da Pio II al giovane Galeazzo Maria Sforza durante il loro incontro a Firenze nel I459 - anno di esecuzione dell'affresco - trattandosi di cercopitechi. ${ }^{\text {I25 }}$

Sandro Botticelli, estremamente parco nella raffigurazione di animali esotici anche nelle iconografie che ne avrebbero giustificata la presenza, sembra aver avuto una particolare predilezione per le scimmie e, soprattutto, una grande conoscenza delle varie specie che nella seconda metà del XV secolo dovevano essere presenti a Firenze. Sul lato posteriore della tavola con il Ritorno di Giuditta a Betulia (I469-I470 ca.) (fig. 78) - parte di un dittico di ridotte dimensioni - sono raffigurate due scimmie: una di profilo con lunga coda e il canonico guinzaglio fissato in vita e un'altra seduta molto danneggiata da identificare con dei cercopitechi all'epoca detti "gatti mammoni» (fig. 79). ${ }^{\mathrm{I} 26}$ Sempre negli stessi anni nell'Adorazione dei Magi (I470-I472 ca.) (fig. 80), forse di proprietà della famiglia Pucci, l'artista dipinse un babbuino (figg. 80a, 8I) e una bertuccia, quest'ultima accuratamente descritta fin nel dettaglio delle natiche prive di pelo (fig. 8ob). ${ }^{127}$ Anche nella coeva Adorazione dei Magi (I 475 ca.) (fig. 82) di Cosimo Rosselli, forse proveniente dall'omonima Compagnia patrocinata dai Medici, tra le zampe dei cavalli s'in-

I995, pp. 44-47 n. 6; DEGENHART - SCHMITT I963, pp. IIo-I I ; MELLI 2002, p. I28. Per i disegni degli Uffizi e di Digione vedi DEGENHART - SCHMITT I968-20Io, vol. I.2, p. 395 n. Io, 625 n. 63 I; vol. I.4, tavv. 282 d, 443 a. I24. AMES-LEWIS I987, pp. 6-7; MASSETI 20I7, pp. I68-I70.

I25. Per le scimmie regalate al giovane Sforza vedi pagina II8. La stretta affinità tra la bertuccia dipinta e un disegno nel Libro di modelli di animali di Budapest, datato tra la seconda metà del XV e i primi decenni del XVI secolo, rende plausibile l'ipotesi che sia stata copiata dall'affresco benozzoliano.

I 26. ZOLLNER 2009, p. I88 n. 8b. Nell'iconografia del tempo Giuditta, oltre che simbolo della vittoria del debole sul forte, era considerata emblema della virtù femminile. In questo contesto l'immagine sul verso con la scimmia e due cervi potrebbe costituire un'allegoria amorosa: la lotta tra il cervo, avversario del vizio e del peccato, e la scimmia, personificazione del diavolo e della lussuria, vedi IMPELLUSO 2003, pp. 244-245, JANSON I952, pp. I3-7I. Una stessa versione del dittico, però privo di raffigurazioni nella parte posteriore e ritenuto opera successiva, si trova alle Gallerie degli Uffizi di Firenze (inv. I890, n. I484). Ronald Lightbown a proposito della resa degli animali raffigurati ipotizza che Botticelli tenesse un taccuino di disegni in bottega, LIGHTBOWN I989, pp. 36-38. Vedi anche ZÖLLNER 2009, p. I87 n. 7a.

I27. Ivi, pp. I92-I94 n. I7; MASSETI 2015, p. I48; ID. 20I7, pp. I39-I42. 


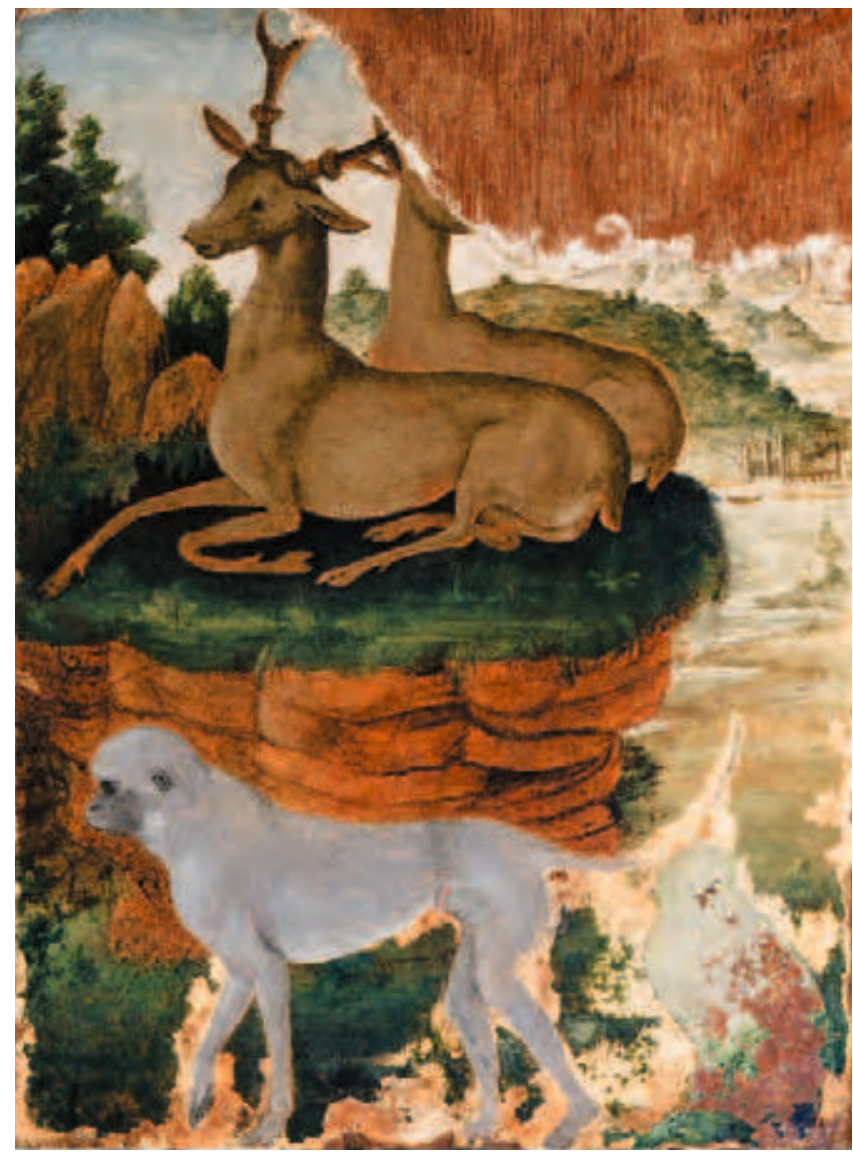

Fig. 78: Sandro Botticelli,

Cervi e cercopitechi, I469-I $470 \mathrm{ca}$.

Cincinnati, Art Museum

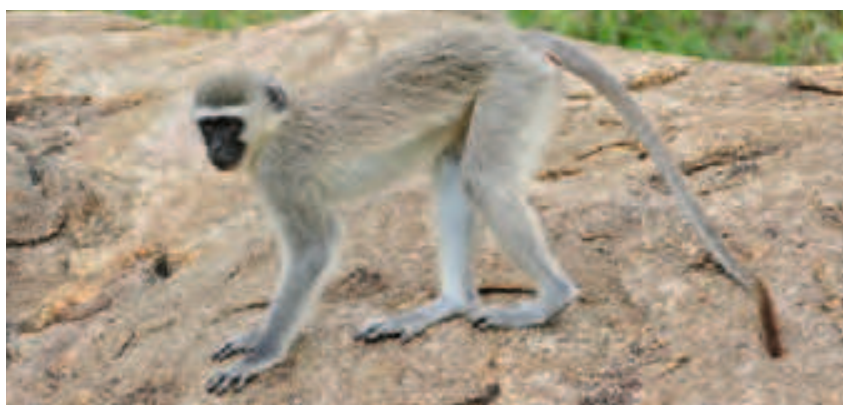

Fig. 79: Cercopiteco grigioverde (Chlorecebus aethiops) 


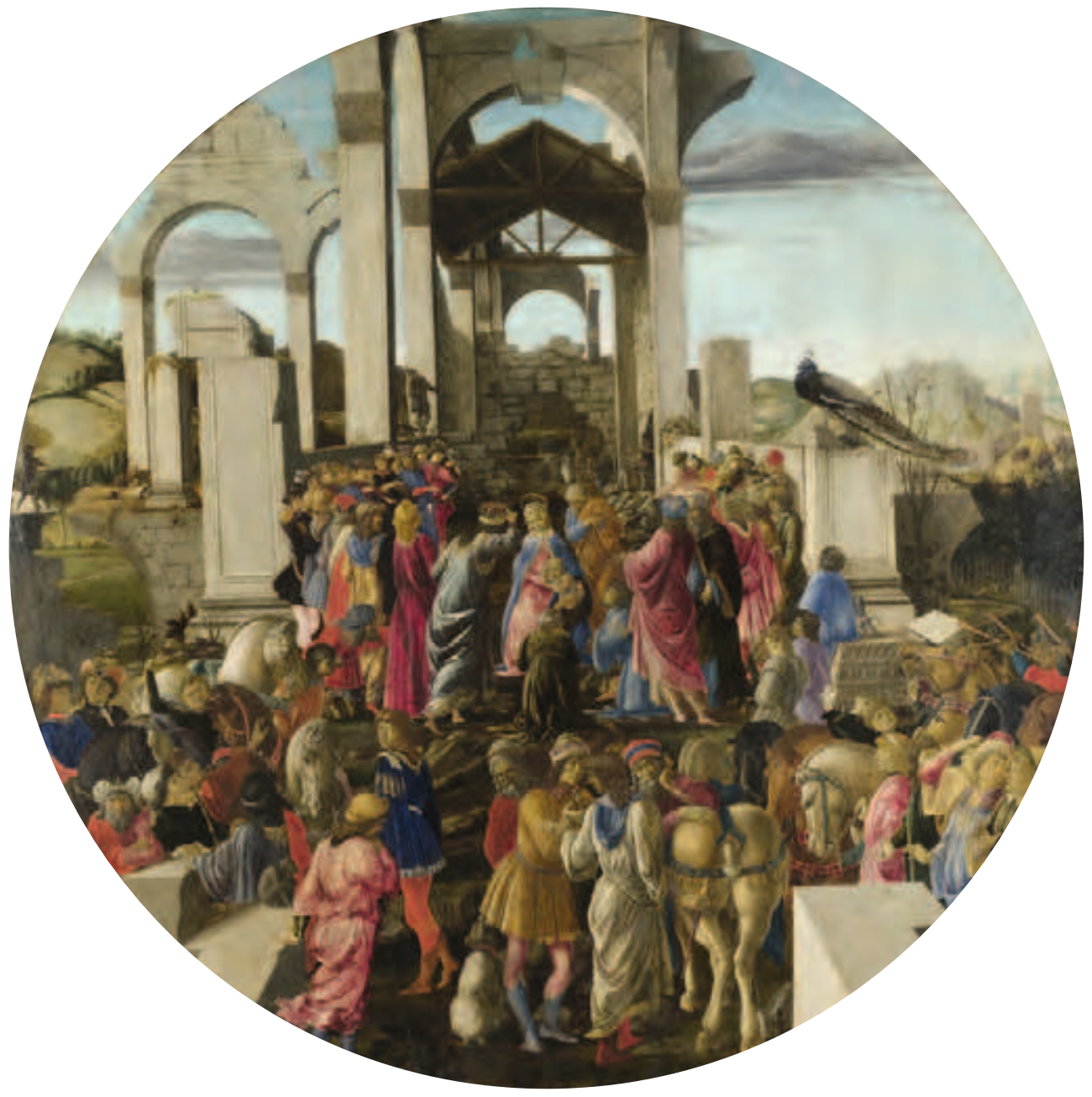

Fig. 80: Sandro Botticelli,

Adorazione dei Magi, I470-I472 ca.

Londra, National Gallery 


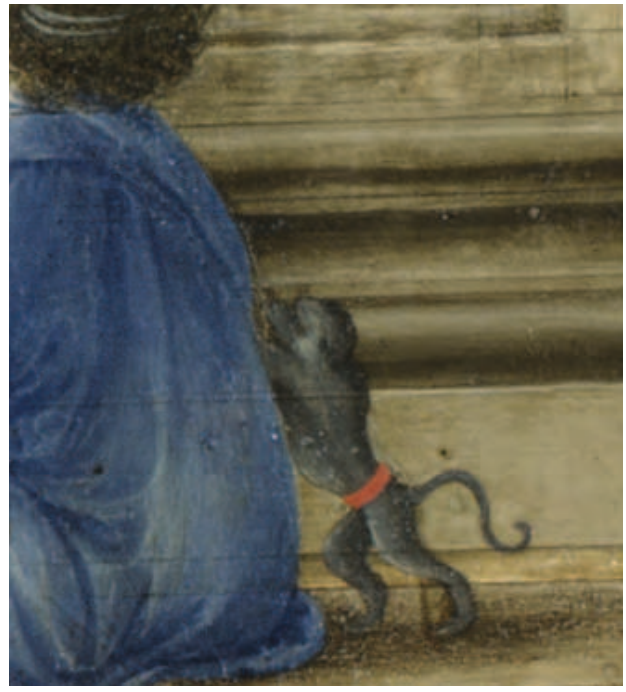

Fig. 8oa: Babbuino (part.)

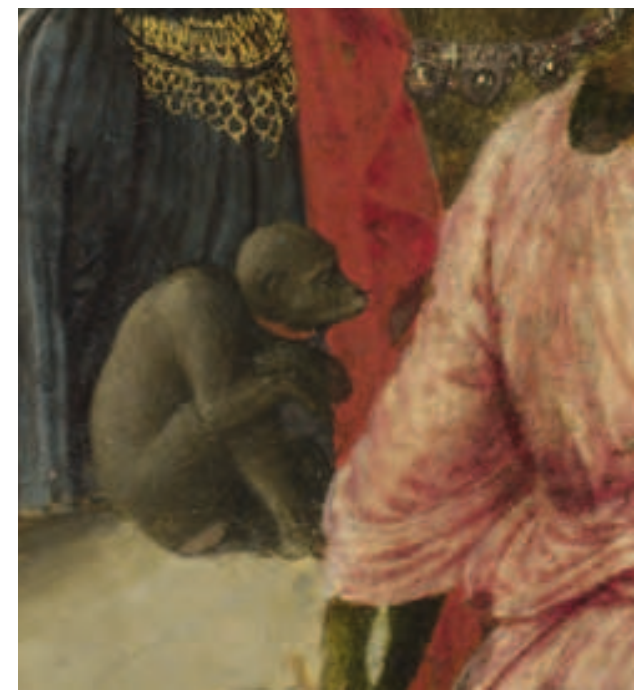

Fig. 8ob: Bertuccia (part.)

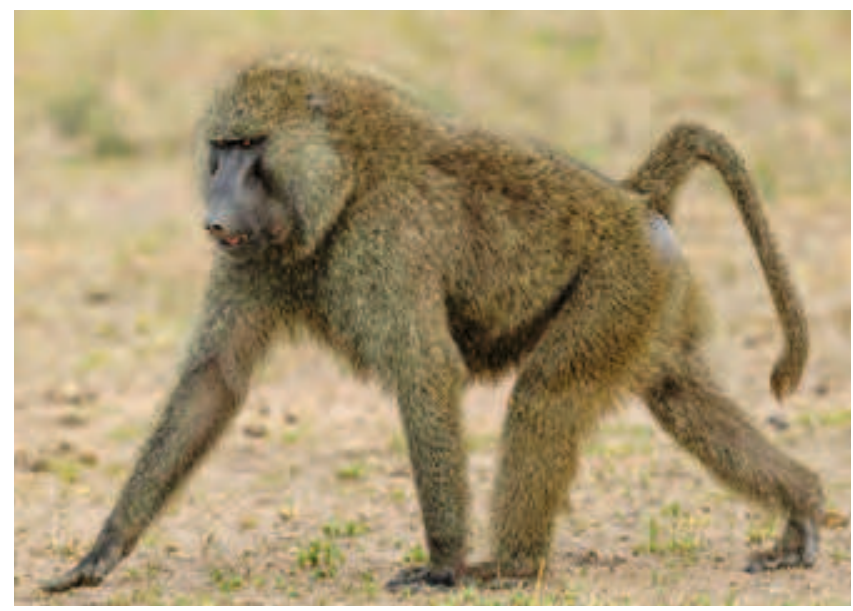

Fig. 8I: Babbuino verde (Papio anubis) 
travvede un cercopiteco accucciato assicurato con un lungo laccio al gomito di un palafreniere (fig. 82a). ${ }^{\text {I28 }}$

Svolta decisiva per la raffigurazione dell'animale esotico per eccellenza fu l'arrivo a Firenze della giraffa che nel 1487 il sultano d'Egitto aveva inviato, per accattivarsi i favori di Lorenzo de' Medici, quale dono diplomatico, e che tanto stupore suscitò nella popolazione. Il bizzarro animale non solo aveva destato meraviglia e ammirazione in tutta la città e i suoi dintorni, ma ben presto diventò celebre in tutta la penisola e oltre confine, fino al punto da indurre la reggente di Francia Anne de Beaujeu a inviare una lettera al Magnifico pregandolo di mandargli l'animale perché era la bestia che più desiderava vedere dal vero. ${ }^{\text {I29 }} \mathrm{Il}$ sensazionale arrivo della giraffa, fino ad allora nota unicamente attraverso gli scritti di mercanti e pellegrini che l'avevano vista al Cairo o il disegno schizzato da Ciriaco d'Ancona negli anni quaranta del XV secolo, finì per contagiare anche i pittori o, per lo meno, i loro committenti se - come annota Luca Landucci nel Diario - «com'ella fussi fatta se ne può vedere i' molti luoghi in Firenze dipinte». ${ }^{\text {I30 }}$ Tra i primi a immortalare l'animale fu Domenico Ghirlandaio nel grandioso ciclo di affreschi con scene della vita della Vergine e del Battista commissionatogli da Giovanni Tornabuoni, ricco e colto banchiere oltre che uomo di fiducia della famiglia me-

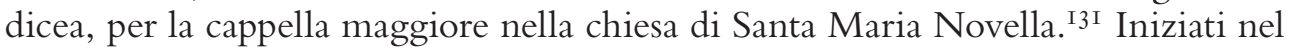
maggio I 486, i lavori furono portati a termine il 22 dicembre I490 quando - sempre secondo Luca Landucci - «si scoprì la cappella di Santa Maria Novella, cioè la cappella maggiore. L'aveva dipinta Domenico del Girillandaio; e fecela dipingere Giovanni Tornabuoni». ${ }^{132}$ Nella scena con l'Adorazione dei Magi (fig. 83) si scorge, lungo il sentiero che discende dalla collina, una giraffa accompagnata da due guardiani e seguita da alcuni personaggi orientali a cavallo (fig. 83a): una sorta di "fotografia istantanea" di quanto avvenuto in città durante l'esecuzione degli affreschi, ossia l'arrivo l'i I novembre I487 di un'ambasciata del sultano d'Egitto che recava la giraffa offerta al Magnifico. ${ }^{\mathrm{I} 33}$ Anche in questo caso, sebbene l'iconografia dei Magi ben si prestasse alla raffigurazione della fauna esotica, cammelli e dromedari sono assenti mentre la giraffa, relegata in secondo piano, sembra voler alludere a un evento di "cronaca cittadina" carico di riferimenti simbolici per Giovanni Tornabuoni, committente dell'opera e zio di Lorenzo de' Medici.

La visione dell'animale doveva aver particolarmente colpito anche Piero di Cosimo, artista eccentrico che a detta di Giorgio Vasari «recavasi spesso a vedere

I28. GABRIELLI 2007, pp. I55-I57 n. 37.

I29. Vedi pagina 79.

I30. LANDUCCI I969, p. 52.

I3I. Per le vicende relative al passaggio di patronato della cappella da Francesco Sassetti a Giovanni Tornabuoni vedi HATFIELD I996, pp. II2-II7; MARTELLI 20I6, pp. I55-I60.

I32. LANDUCCI I969, p. 60. La datazione per il completamento degli affreschi fornita da Luca Landucci risulta degna di fede, a differenza del $\mathrm{I}_{4} 8 \mathrm{5}$ indicato da Giorgio Vasari quando la giraffa non era ancora giunta a Firenze vedi VASARI I966-I997, vol. 3, p. 482.

I33. Vedi pagina 78 . 


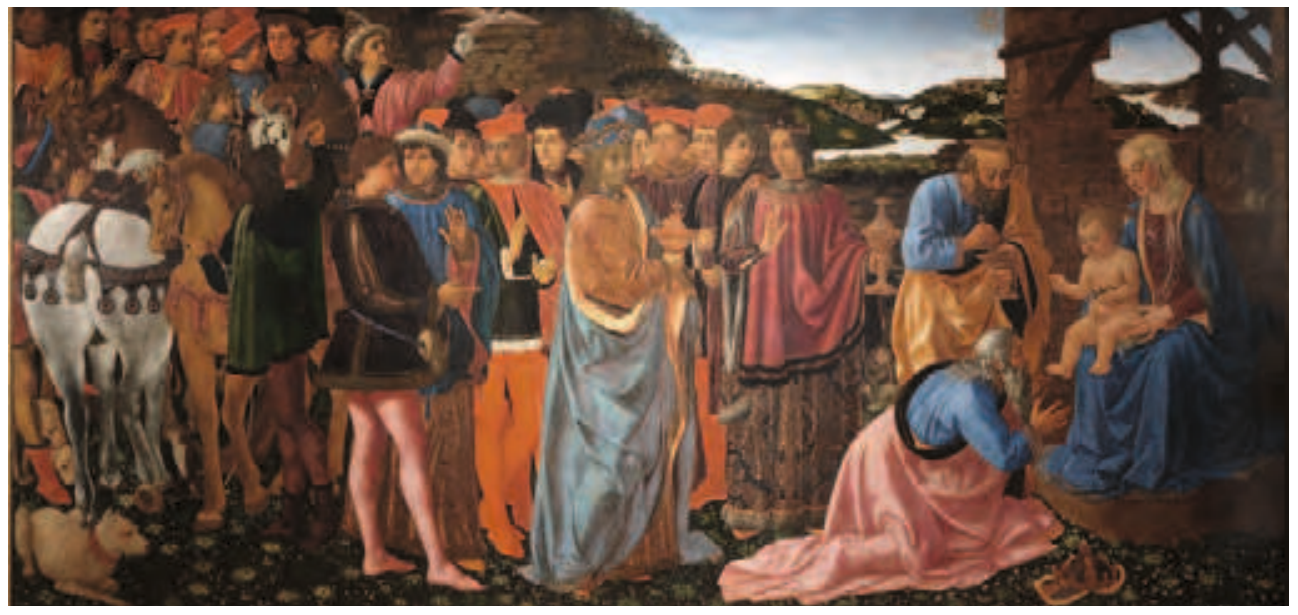

Fig. 82: Cosimo Rosselli,

Adorazione dei Magi, I475 ca.

Firenze, Gallerie degli Uffizi,

Galleria delle Statue e delle Pitture

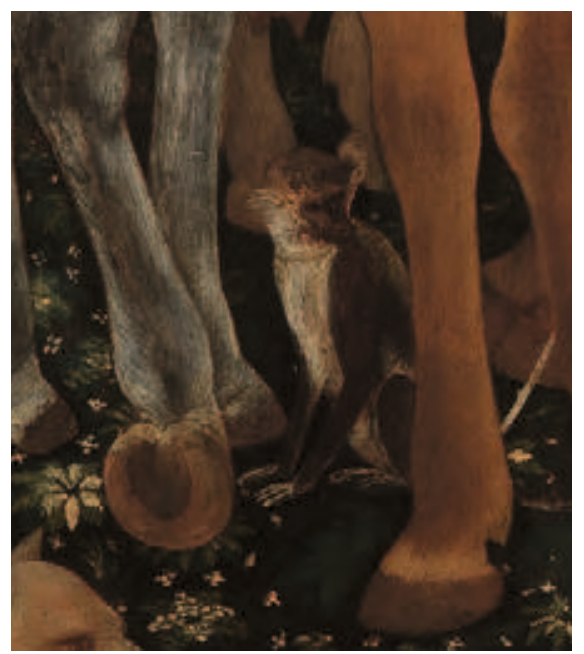

Fig. 82a: Cercopiteco (part.) 


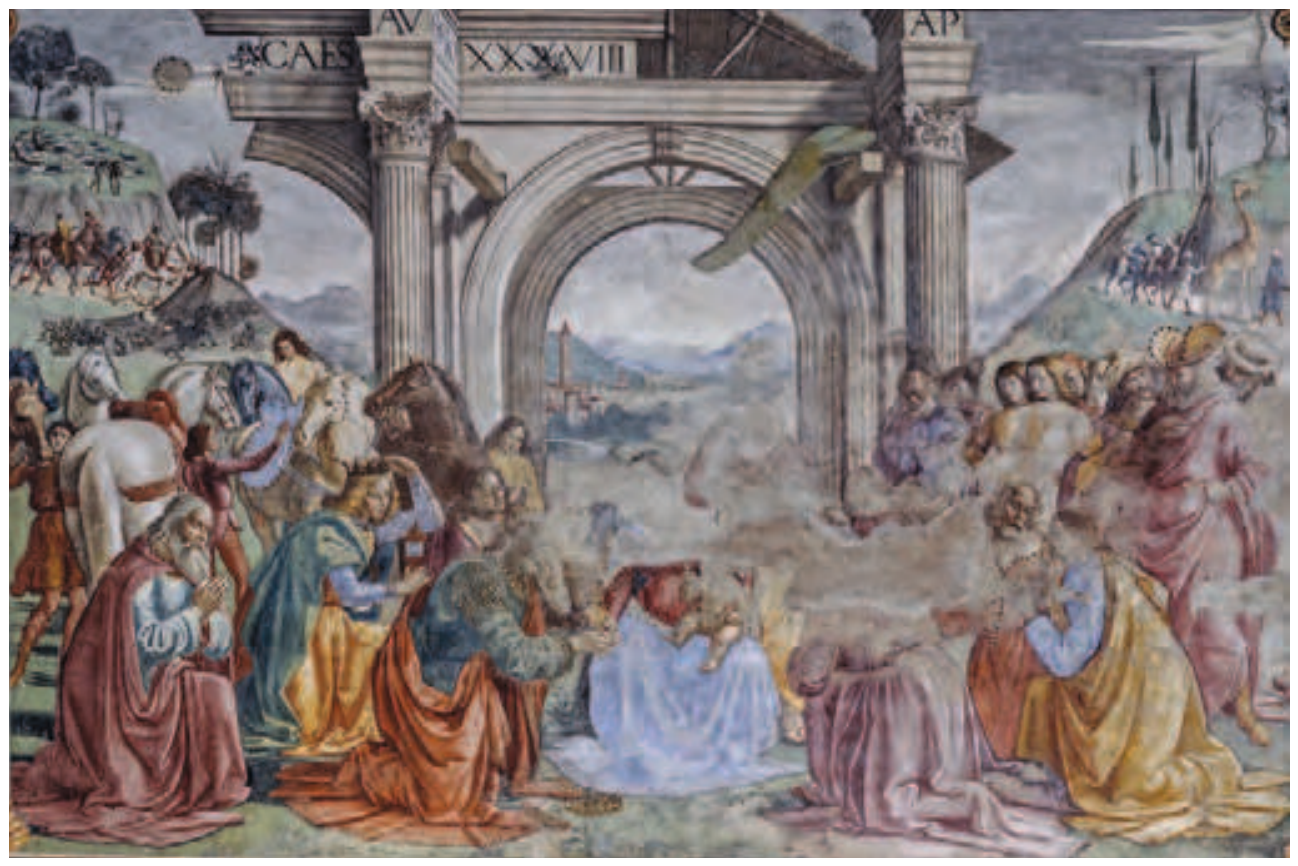

Fig. 83: Domenico Ghirlandaio e bottega, Adorazione dei Magi, I486-I $490 \mathrm{ca}$.

Firenze, chiesa di Santa Maria Novella, cappella Tornabuoni

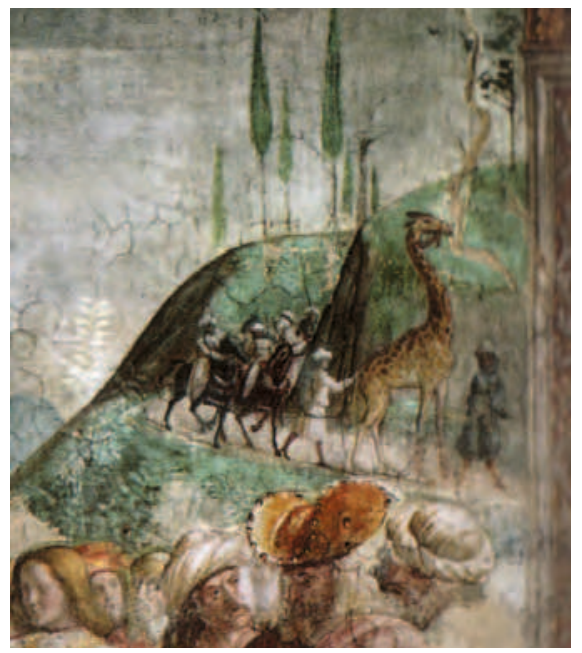

Fig. 83a: Giraffa (part.) 
o animali o erbe o qualche cose che la natura fa per istranezza o da caso di molte volte e ne aveva un contento e una satisfazione che lo furava tutto di se stesso». ${ }^{\text {I3 }}$ Non aveva quindi perso l'occasione per inserire nella tela con Vulcano ed Eolo (I490-I500 ca.) (fig. 84) una giraffa dipinta con estrema fedeltà accompagnata da due cuccioli e un cammello, nonostante la scarsa attinenza con il soggetto rappresentato. ${ }^{\mathrm{I} 5} \mathrm{Il}$ gusto per gli animali trapela pure dal dipinto con la primordiale Scena di caccia (I485-I500 ca.) (fig. 85) probabilmente commissionata, insieme al suo pendant con il Ritorno dalla caccia, dal ricco mercante fiorentino Francesco del Pugliese per decorare le pareti di una camera del suo palazzo. La singolare iconografia, interpretata quale illustrazione di due stadi nell'evoluzione dell'uomo primitivo dopo la scoperta del fuoco, si prospetta come un unicum nel panorama della pittura rinascimentale. ${ }^{136} \mathrm{La}$ critica recente, pur non scartando quale fonte d'ispirazione il De architectura libri decem di Vitruvio e il De rerum natura di Lucrezio, ha proposto di ricondurre il soggetto al crescente interesse, stimolato dalle coeve esplorazioni portoghesi della costa occidentale dell'Africa, per le popolazioni che vivevano allo stato primitivo, argomento senza dubbio di estrema attualità se nel I486 Lorenzo di Giovanni Tornabuoni scriveva all'amico Benedetto Dei:

Io udì istamane, sendo in piazza a cerchio con molti nobili citadini, infra quali era Zanobio Del Nero, el quale legea una lettera da Portogallo venuta da uno certo suo amico che gli scriveva che in questi andirivieni à fatti quel serenissimo Re con quelli huomini di Ghinea haver tanto facto per mezo di certi sua che hanno indotto uno gran signore di que' Ghinei che lui con suo regno, che à grandissimo, s'è batizato e che 'l re v'à mandato molti huomini experti a insegnare loro el linguaggio di Portogallo e amaestrali in costumi e mandatovi molte di quelle gallee leggere cariche di tutte merce a parte a ridurli alla vita humana et non bestiale, e che di que' Ghinei ne viene una quantità per imbasceria al papa a chiedere titolo per loro Singnore et esser esser accetati fra sua fideli et offrirli ho[nore e] fedeltà. ${ }^{\mathrm{I}}{ }^{37}$

Pratica che doveva essere ben nota al mercante e viaggiatore in quegli anni impegnato a inviare a conoscenti e amici lettere dense di notizie riguardo alle terre e alle popolazioni incontrate durante i suoi viaggi in Oriente, missive che

I34. VASARI I966-I997, vol. 4, p. 62. Vedi anche BELOZERSKAYA 2019, pp. 76- 78; OLSON 2019, pp. I03-I29.

I35. Italian Paintings I993, pp. 49-52; GERONIMUS 2006, pp. I45-I50. Adolfo Venturi propone come pendant a questo dipinto quello con il Ritrovamento di Vulcano (Hartford, Wadsworth Atheneum Museum of Art), ipotesi unanimemente accolta, mentre di recente Dennis Geronimus ha aggiunto a questa coppia di tele il pannello con Giasone e la regina (collezione privata), VENTURI 1927, pp. 69-70; GERONIMUS 2006, pp. I50-I6I.

I36. Erwin Panofsky ipotizza che queste due tavole, insieme a quella con l'Incendio nella foresta (Oxford, Ashmoleam Museum) e alle tele con il Ritrovamento di Vulcano e Vulcano ed Eolo, appartenessero a un unico ciclo decorativo realizzato per Francesco del Pugliese. In un secondo tempo Federico Zeri ha aggiunto la tavola con la Costruzione di un edificio (Sarasota, John and Mable Ringling Museum), tesi da molti studiosi, tra cui Sharone Fermor e Dennis Geronimus, ritenuta infondata per l'eterogeneità dei dipinti ma di recente accolta da Elena Capretti, PANOFSKY 1937, pp. I2-30; ZERI I959, p. 44; FERMOR 1993, pp. 62-8I; GERONIMOUS 2006, pp. I24-I35, I6I; CAPRETTI 20I5, pp. 220-223 n. 9. Vedi anche FARINELLA 20I5, pp. I07-I2I; CHRISTIANSEN 20I5, pp. 2I6-2I9 n. 8.

I37. BROWN 200I, pp. 37-62; VERDE I973-2010, vol. 3.I, p. 576. 


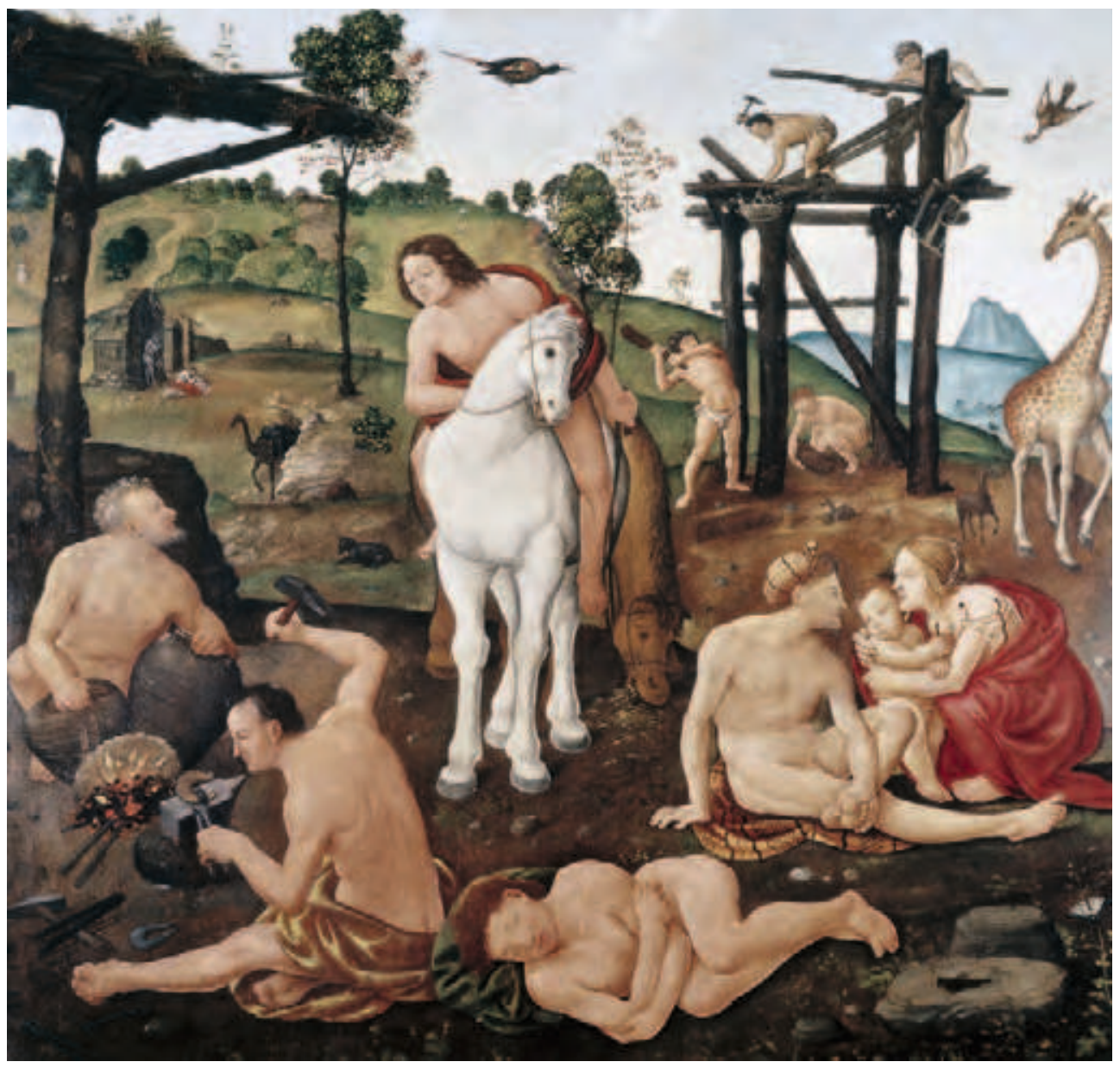

Fig. 84: Piero di Cosimo,

Vulcano ed Eolo, I490-I500 ca.

Ottawa, National Gallery of Canada 


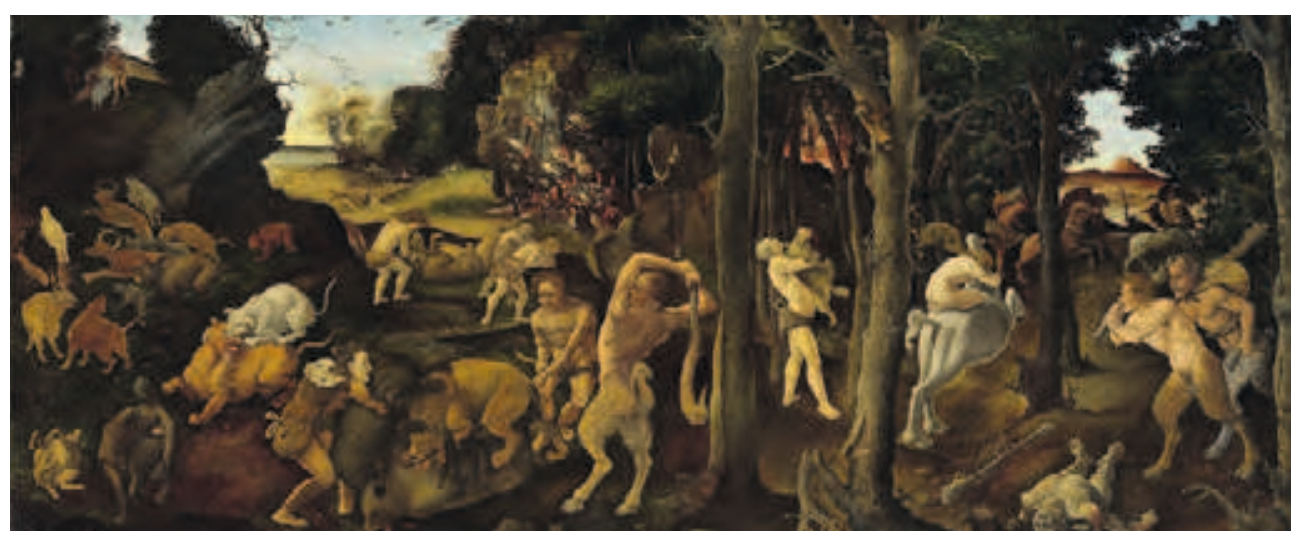

Fig. 85: Piero di Cosimo,

Scena di caccia, I485-1500 ca.

New York, Metropolitan Museum of Art

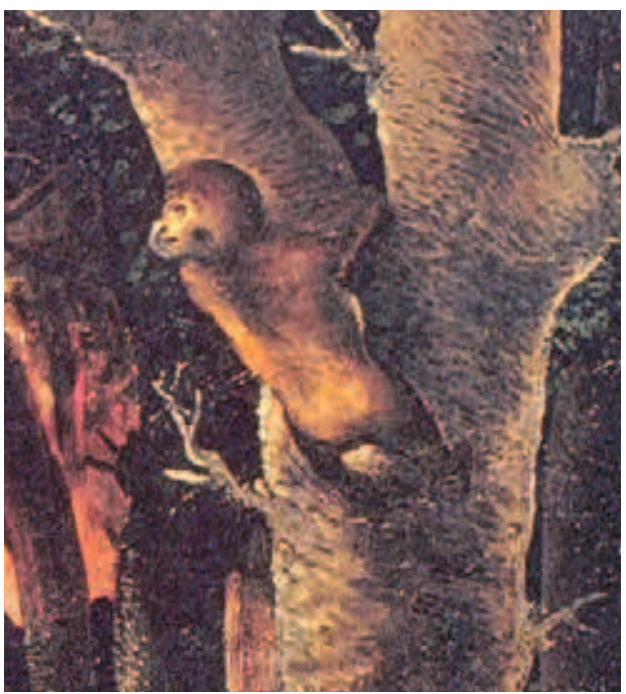

Fig. 85a: Bertuccia (part.) 
oltre a essere lette pubblicamente furono copiate e fatte circolare tanto era la curiosità e l'attenzione da parte dei fiorentini e non solo. Alessandro Braccesi lo aveva informato che le sue epistole facevano fare «la processione a Siena» e Pandolfo della Stufa che appena giungevano a Cortona si affrettava a copiarle perché la richiesta era così pressante che non riusciva a tenerle presso di sé per più di mezz'ora. Conscio dell'effetto suscitato dal suo carteggio, Benedetto Dei si era quindi premurato di assicurare al marchese di Mantova «E da.mme ogni sabato arete le nuove e d'Asia e d'Africa e d'Europia sempre». ${ }^{138}$ Del resto, fin dal XIV secolo le notizie relative alle scoperte geografiche e alle popolazioni sconosciute avevano appassionato i fiorentini fervidi lettori di relazioni e diari odeporici, della Cosmographia di Tolomeo e possessori di mappae mundi e carte geografiche.

Sebbene il tema del dipinto con la Scena di caccia continui a rimanere oscuro, tra i numerosi animali raffigurati da Piero di Cosimo si scorge aggrappata al ramo di un albero una bertuccia (fig. 85a) ritratta con piglio naturalistico. Primate che il pittore poteva aver visto a Firenze oppure durante il suo soggiorno romano, trattandosi di un animale esotico particolarmente richiesto da papi e prelati, quando tra il I48I e il I482 lavorò come assistente nella bottega di Cosimo Rosselli impegnata nell'esecuzione di alcuni affreschi della cappella Sistina. ${ }^{\mathrm{I} 9}$ Vivo interesse, quello di Piero di Cosimo per il mondo animale, che lo aveva portato a realizzare un libro con disegni «bellissimi e bizızıarri tratteggiati di penna diligentissimamente». ${ }^{\text {I }}{ }^{\circ}$

Memoria dell'arrivo della giraffa a Firenze si trova anche nell'Adorazione dei Magi con i santi Paolo, Francesco e Giovanni Battista (I490-I495 ca.) (fig. 86) dipinta dal Maestro dell'Epifania di Fiesole, anch'esso gravitante nella cerchia di Cosimo Rosselli, dove l'animale compare in posizione defilata quasi a voler annunciare l'arrivo dei Magi che la seguono a cavallo (fig. 86a). ${ }^{\text {I4I }}$ Anche Raffaello Botticini, in giovane età assistente nella bottega di Domenico Ghirlandaio, ammaliato come tutti i fiorentini dall'insolito animale nel tondo con l'Adorazione dei Magi (I495 ca.) (fig. 87) raffigurò una giraffa tenuta al laccio da un guardiano membro di una delegazione di africani a cavallo (fig. 87a), immagine che sembra voler evocare l'ambasciata del I $487 .{ }^{\mathrm{I}}{ }^{2} \mathrm{Il}$ suo gusto per l'esotico lo portò a includere, in quella che

I38. ORVIETO I969, pp. 222-223.

I39. Per la presenza di scimmie nella città eterna vedi pagina I 18 .

I40. Vedi pagina I96.

I4I. FILIPPINI I992, pp. I63-I64 n. 5.7. Per l'autore del dipinto - di proprietà delle Gallerie degli Uffizi di Firenze (inv. I890, n. 3935) ma in deposito dal I907 presso la chiesa di San Francesco a Fiesole - Everett Fahy ha coniato l'appellativo di Maestro dell'Epifania di Fiesole e proposto di identificarlo con Filippo di Giuliano, attribuzione accolta da Anna Padoa Rizzo, FAHY I967, p. I33; PADOA RIZZO I989, pp. 2i-22. Per un ampliamento del corpus di opere riconducibili a questo artista vedi FAHY 200I-2002, pp. I7-29. Lisa Venturini ipotizza invece che il Maestro dell'Epifania di Fiesole fosse un collaboratore di Raffaello Botticini, artista che pure aveva inserito una giraffa in un suo dipinto, VENTURINI I994, p. 8I.

I42. Italian Paintings I993, pp. 49-53; OLSON 2000, p. 239. Lisa Venturini sottolinea la scarsa inventiva dell'artista influenzato da Domenico Veneziano, Sandro Botticelli, Domenico Ghirlandaio e Piero di Cosimo, pittori questi ultimi due che avevano a loro volta raffigurato la giraffa, VENTURINI I994, p. I7. 


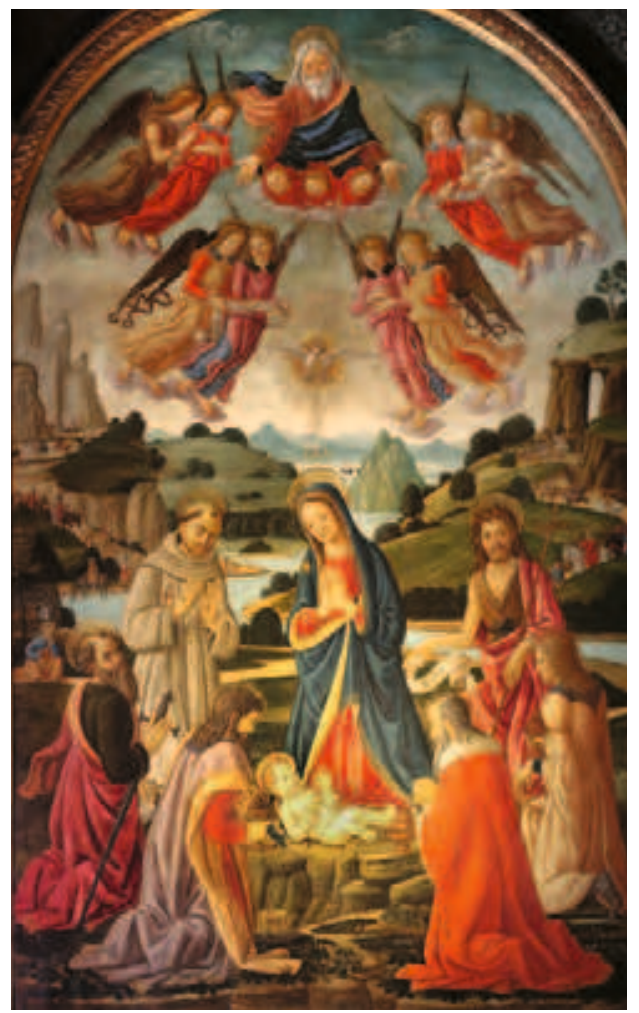

Fig. 86: Maestro dell'Epifania di Fiesole, Adorazione dei Magi con i santi Paolo,

Francesco e Giovanni Battista, I490-I 495 ca.

Fiesole, chiesa di San Francesco

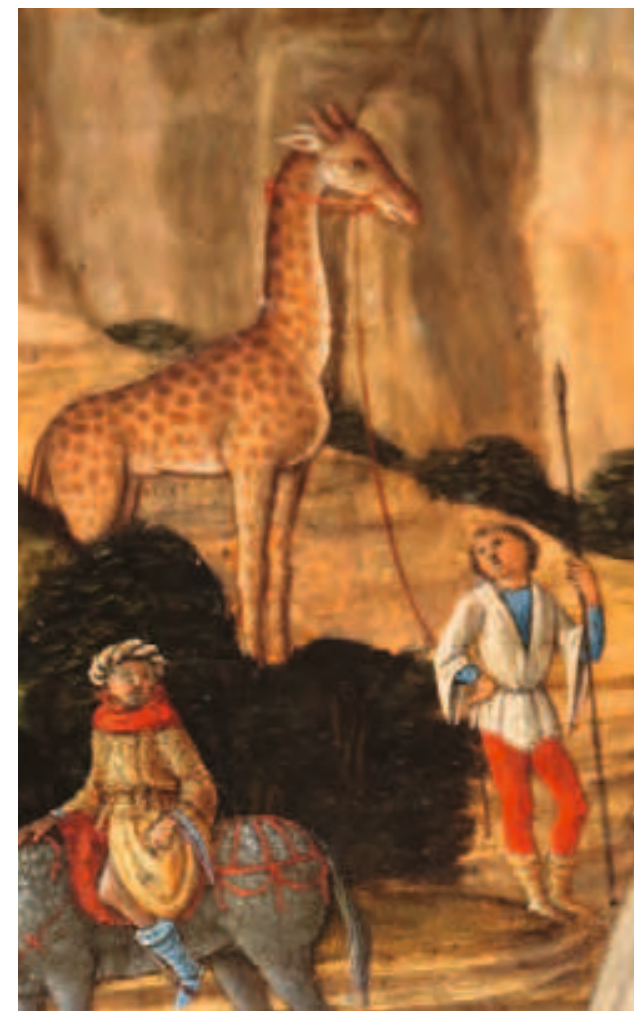

Fig. 86a: Giraffa (part.) 


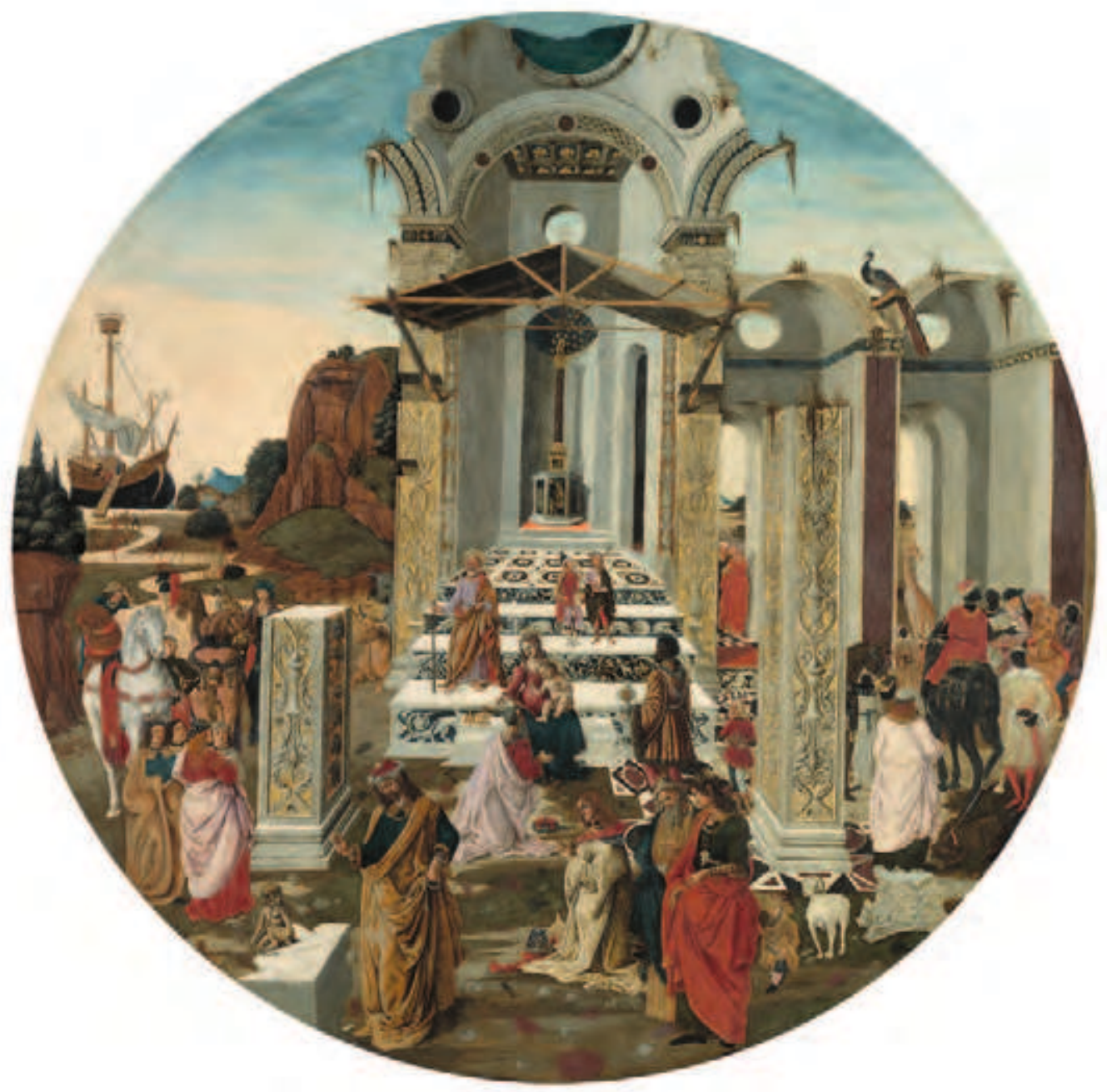

Fig. 87: Raffaello Botticini,

Adorazione dei Magi, I $495 \mathrm{ca}$.

Chicago, Art Institute 


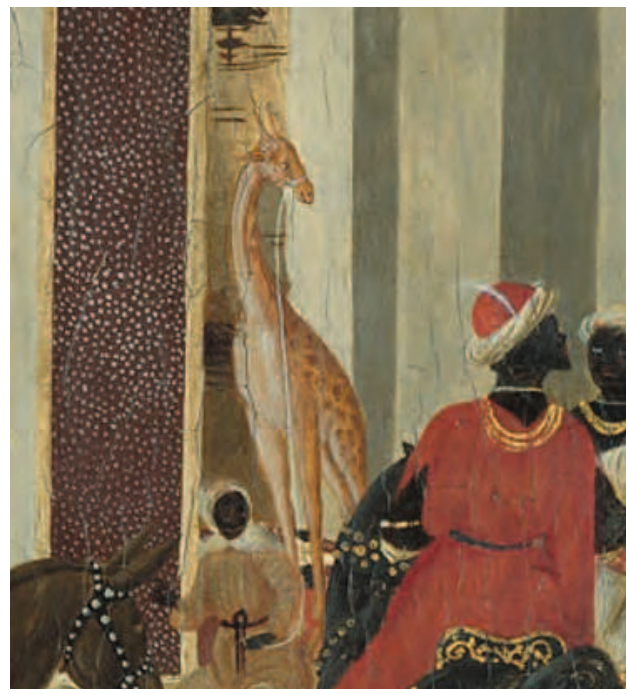

Fig. 87a: Giraffa (part.)

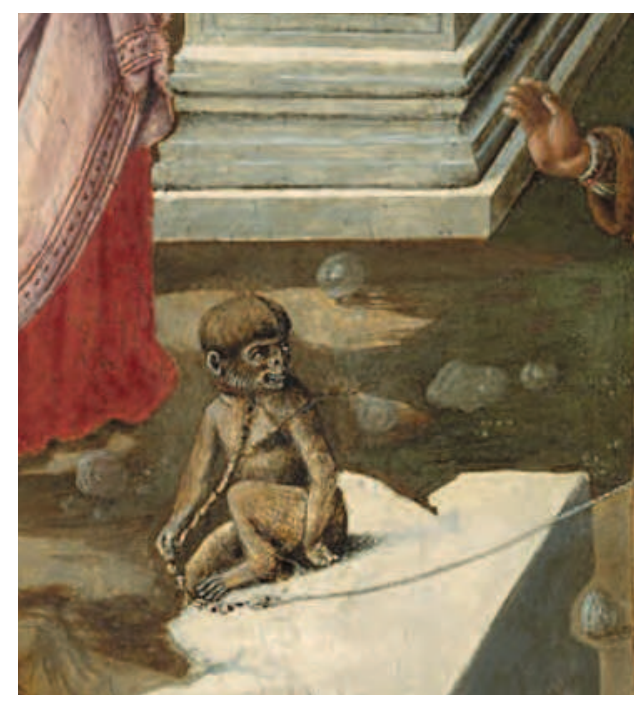

Fig. 87b: Bertuccia (part.)

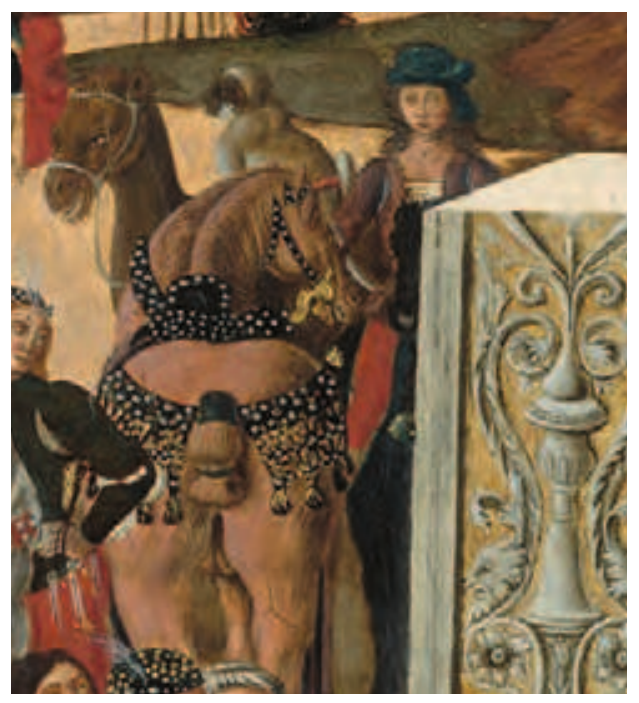

Fig. 87c: Babbuino (?) e camelide (part.)

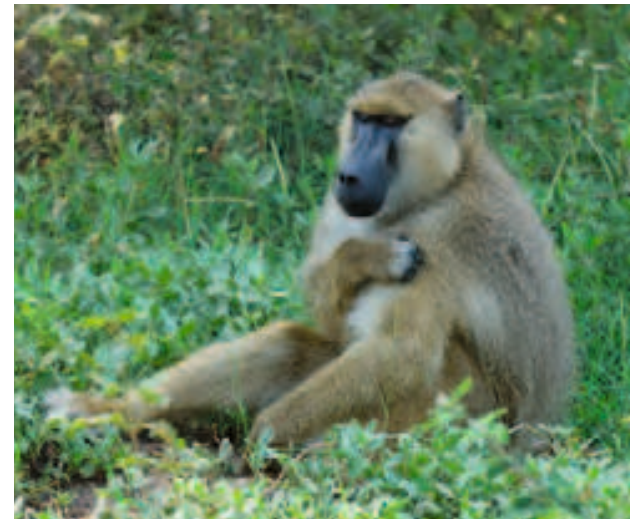

Fig. 88: Babbuino giallo (Papio Cynocephalus) 
si configura come una scena di corte vera e propria per la presenza di musici e gnomi, numerosi personaggi orientali inturbantati, una bertuccia legata con un lungo guinzaglio (fig. 87b) e un camelide con quello che sembra essere un babbuino (fig. 88) sul dorso (fig. 87c), tutti animali le cui fattezze sembrano rimandare a taccuini di modelli più che una visione diretta. L'immagine di una giraffa tratteggiata con spiccata sensibilità naturalistica (fig. 89a), insieme a numerosi dromedari (fig. 89b), compare pure in uno dei due pannelli - presumibilmente spalliere - con la Storia di Giuseppe (fig. 89) realizzati da Biagio d'Antonio e Bartolomeo di Giovanni, presen$\mathrm{za}$ che ha reso possibile stabilire come termine post quem per l'esecuzione il I 487 . $^{\mathrm{I}}{ }^{3}$

Di tutt'altra natura furono, tranne qualche rara eccezione, gli animali esotici raffigurati su spalliere e pannelli di cassone quattrocenteschi dipinti da forzierinai fiorentini: cammelli, dromedari e a volte elefanti che per la loro mancanza di naturalismo attestano la dipendenza da bestiari o taccuini di disegni di mediocre qualità. Fu probabilmente per sopperire all'impossibilità di osservare dal vero gli esemplari di fauna esotica posseduti dalla famiglia medicea o dalle più raffinate corti italiane, così come pure l'assenza di pachidermi nella penisola, che artisti minori come Domenico di Zanobi e Giovanni di ser Giovani detto lo Scheggia fecero ricorso a raccolte di modelli. ${ }^{\mathrm{I} 44}$ Anche Francesco di Stefano detto il Pesellino, pittore che «tanto prese piacere del contrafare animali [...] che e' fece quegli sì pronti e vivaci che in quella professione non ebbe alcuno nel suo tempo che gli facesse paragoni», per la raffigurazione di una capra orientale sul fronte di cassone con la Storia di Davide e Golia (I445-I455 ca.) si rivela ancora debitore di un taccuino di disegni dato che gli ovini giunsero a Firenze solo nel I $487 .{ }^{\text {I4 }}$

Eccezione in questo panorama di pittori dediti alla decorazione di arredi sembra essere Jacopo del Sellaio, influenzato dall'arte di Filippo Lippi, Domenico Ghirlandaio e Sandro Botticelli, impegnato anche nella realizzazione di dipinti e pale d'altare. Nella spalliera con Orfeo e le fiere (I 490 ca.) (fig. 90), pendant di altre due tavole che componevano la Storia di Orfeo ed Euridice, spiccano numerosi animali esotici: un elefante (fig. 90a) simile a quello affrescato da Paolo Uccello nel chiostro Verde (fig. 74a), una bertuccia e un cercopiteco (fig. 9ob) resi con estremo realismo forse perché osservati dal vero, mentre i due felini poco naturalistici sono probabilmente da ricondurre a un taccuino di modelli o a quelli benozzoliani nella cappella dei Magi (figg. 77a, 77c). ${ }^{\mathrm{I}} 46$

Sembra che il fiorire dell'attenzione naturalistica nei confronti degli animali e soprattutto quelli esotici avesse avuto inizio, stimolata dai racconti di viaggiatori che narravano le "meraviglie» d'Oriente, nelle maggiori corti italiane e in particolare a Milano dove nei parchi viscontei erano custoditi esemplari di fauna esotica. A Firenze, invece, la conoscenza di questi animali fu favorita, da un lato,

I43. DE FRANCOVICH I926-I927, pp. 65-92; BARTOLI I999, p.I62; Bartolomeo di Giovanni 2004, pp. 20-2I. I 44. STADERINI 20Io, pp. 236-239 n. 24; Il fratello di Masaccio I999, pp. 84-88 n. 23 d.

I45. VASARI I966-I997, vol. 3, p. 37I; STADERINI 20Io, pp. 246-25I n. 26.

I46. PONS 20Io, pp. 216-2I9 n. I8. 


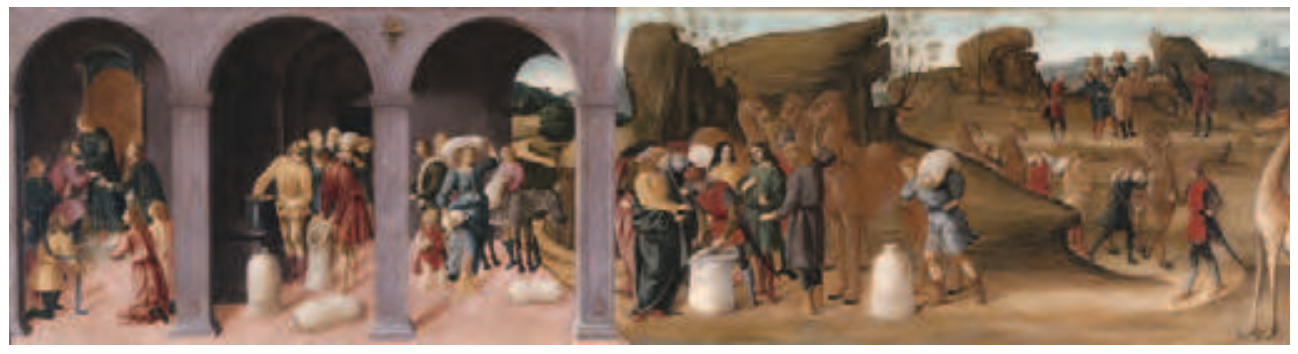

Fig. 89: Biagio d'Antonio e Bartolomeo di Giovanni, Storie di Giuseppe, post 1487

Cambridge, Fitzwilliam Museum

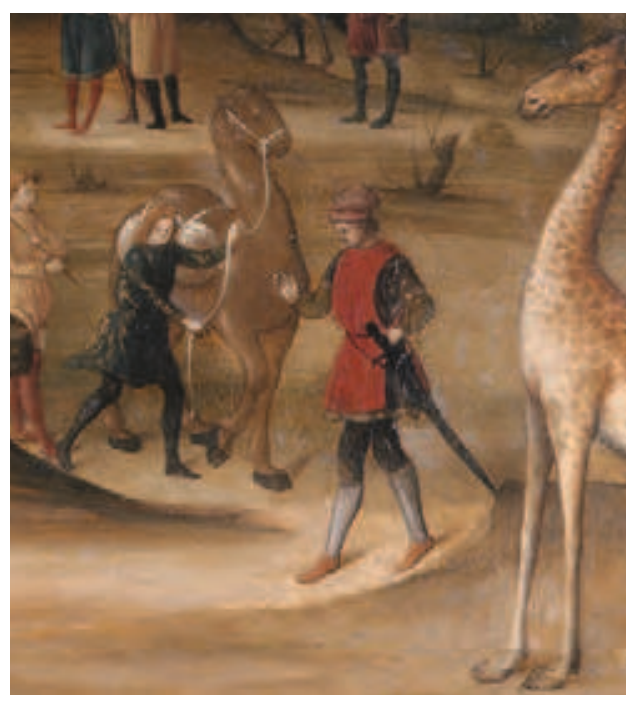

Fig. 89a: Giraffa (part.)

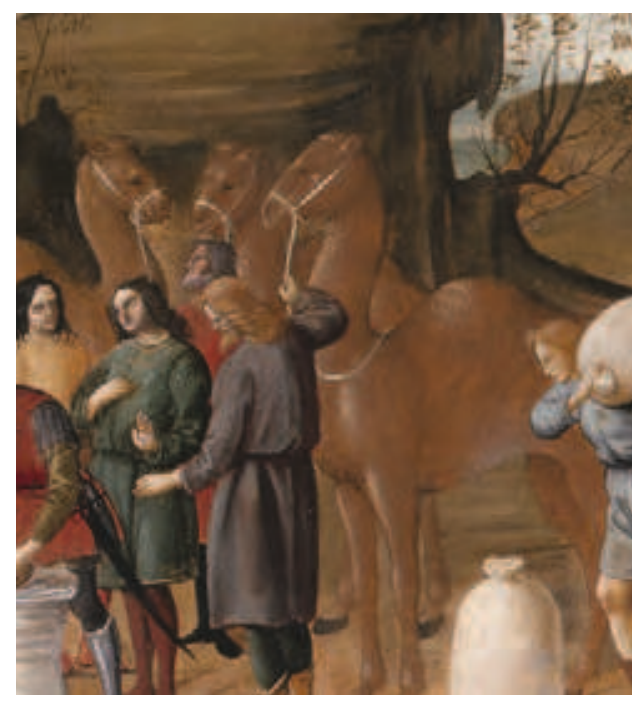

Fig. 89b: Dromedari (part.) 


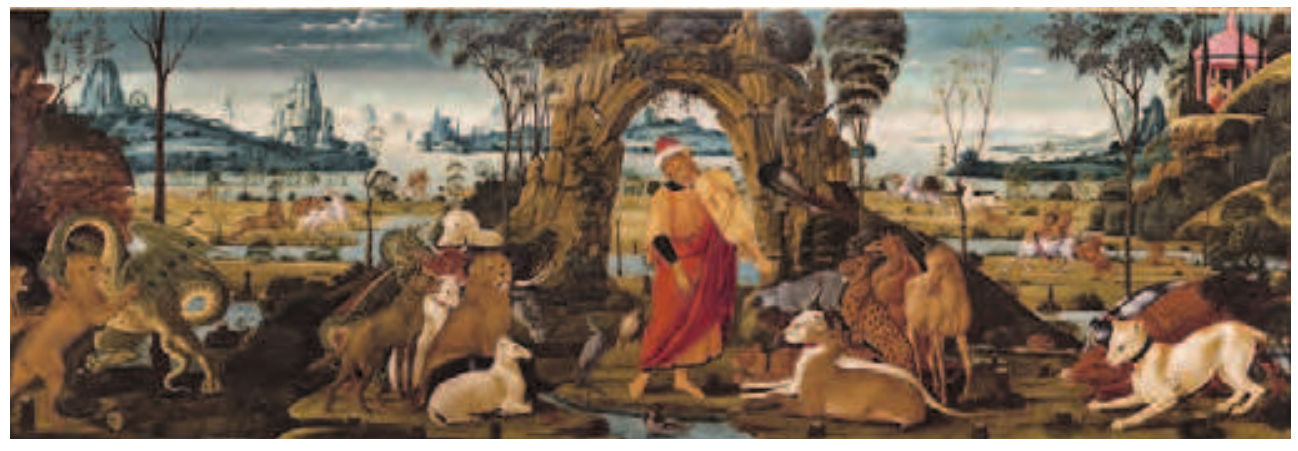

Fig. 90: Jacopo del Sellaio,

Orfeo e le fiere, I $490 \mathrm{ca}$.

Cracovia, Castello Reale di Wavel, Collezione Nazionale d'Arte

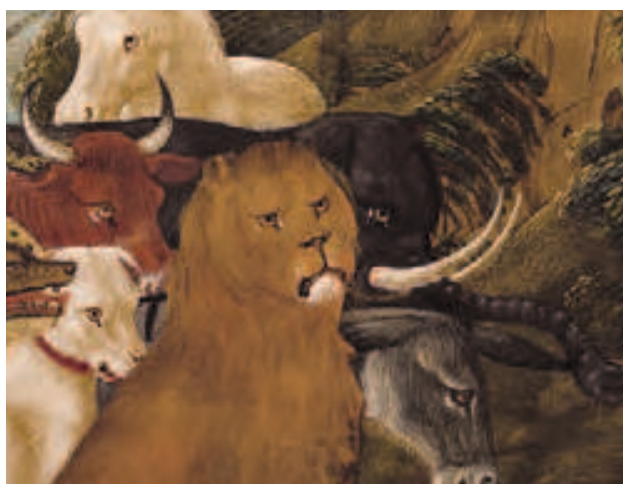

Fig. 90a: Elefante (part.)

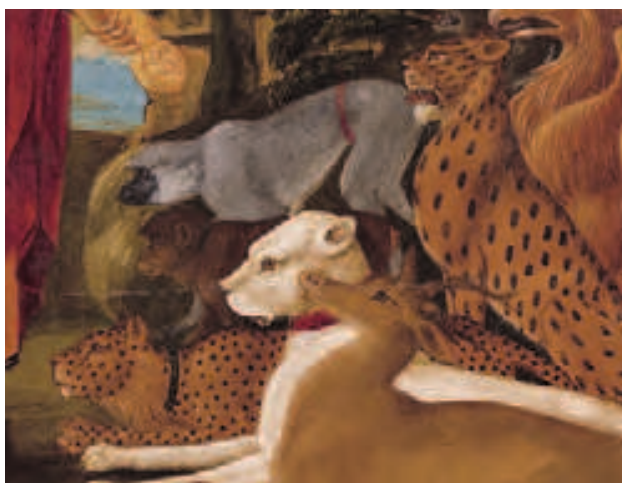

Fig. 9ob: Leopardi, bertuccia, cercopiteco (part.) 
dall'arrivo di artisti come Gentile da Fabriano e Pisanello che innescarono la produzione di taccuini di disegni e la loro circolazione all'interno delle botteghe di artisti e, dall'altro, dalla comparsa in città di esemplari esotici in carne e ossa come il cammello e gli struzzi ricevuti in dono da papa Martino V nel I4I9, il camelide inviato ai Medici da Francesco Sforza nel I452, il camaleonte vivo e il coccodrillo imbalsamato recati dal mercante fiorentino Benedetto Dei di ritorno dall'Oriente nel I467, gli ovini orientali e la giraffa offerti dal sultano d'Egitto a Lorenzo il Magnifico nel I487. Diretta conseguenza di questi eventi fu la comparsa di fauna esotica nei dipinti e negli affreschi del tempo a volte ritratta con estremo naturalismo e altre rifacendosi a libri di modelli. 

PARTE V

Animali esotici e potere 



\section{Valenza simbolica degli animali esotici}

\section{Segni di potere e ricchezza}

\section{I.I. Animali esotici come doni diplomatici}

Quando nel I447 Giovanni Montano si apprestò a scrivere l'orazione funebre per Filippo Maria Visconti tra i molti ricordi volti a magnificare il duca di Milano vi era quello dell'onore tributatogli dai sultani d'Oriente tramite l'invio di fauna esotica:

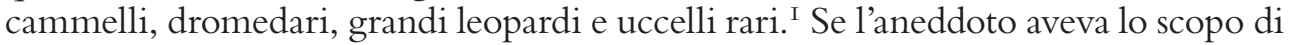
evidenziare il ruolo politico raggiunto a livello internazionale dal signore visconteo destinatario di tali omaggi, nel contempo testimoniava il perdurare nel XV secolo di un'antica tradizione di origine orientale. ${ }^{2}$ Offrire a sostenitori e alleati animali insoliti e difficili da reperire era infatti un'usanza che aveva radici lontane nel tempo e nello spazio. In uso fin dall'epoca mesopotamica ed ellenistica, quando dalle popolazioni sconfitte o assoggettate si esigevano tributi in forma di schiavi e animali rari da esibire nel corso delle parate organizzate per celebrare la vittoria, questa consuetudine fu ripresa dal mondo islamico e da quello romano di età imperiale. ${ }^{3} \mathrm{Fu}$ soprattutto in relazione ai rapporti diplomatici intessuti tra bizantini e musulmani nel corso del Medioevo che la fauna esotica - insieme a tessuti serici broccati in oro, gioielli e pietre preziose, spezie ed essenze, manoscritti, armi, schiavi, cavalli, cani e falconi per la caccia - entrò a pieno titolo tra i beni di lusso che gli ambasciatori erano soliti offrire al regnante con il quale si apprestavano a intavolare trattative. ${ }^{4}$ Nel 549 un principe indiano omaggiò Giustiniano I con un elefante, nel Io53 una delegazione fatimide recapitò un pachiderma e una giraffa alla corte di Costantino IX Monomaco suscitando grande stupore nella popolazione, nel iı87 Șalāh al-Dīn donò un elefante all'imperatore Isacco II Angelo seguito, l'anno dopo, da un cucciolo di elefante, uno struzzo, cinque leopardi e uno zibetto. ${ }^{5}$

I. MONTANO I75I, p. 439.

2. Per un approfondimento sull'origine orientale dell'offerta di doni quale pratica politica vedi MORONY 20II, pp. 33-49; BLOOM 20II, pp. 95-I09;

3. MIZIUR 20I3, pp. 462-463; MIZIUR-MOZDZIOCH 20I5, p. I6; BUQUET 20I3b, pp. II3-II4; ID. 2015 , p. 2. Per il perdurare in epoca medievale dei tributi in animali esotici offerti al sultano del Cairo vedi ID. 20I3c, pp. 379-380.

4. DROCOURT 2004, pp. 87-9I; CUTLER 20II, pp. 79-9I. Per un approfondimento sul valore politico attribuito ai doni diplomatici vedi BEHRENS-ABOUSEIF 20I4, pp. I7-25.

5. Ivi, pp. 69-70; KRUK 2008, p. 576; KINOSHITA 20I2, p. 49 nota 3I; BUQUET 20I3c, pp. 385-386, 388; CUTLER 200I, pp. 253, 260. 
Molteplici erano i significati, più o meno reconditi, attribuiti all'omaggio di esemplari di fauna esotica. Se offrire animali rari aveva innanzitutto lo scopo di lusingare il destinatario, che poteva così ostentarli pubblicamente aumentando il suo prestigio, ancora più importante era il ritorno d'immagine dell'offerente che, tanto generoso e nobile d'animo da privarsene, doveva essere molto influente se aveva la possibilità di procurarsi tali mirabilia. Nel caso, poi, di animali selvaggi il significato simbolico era ancora più strettamente connesso alla propaganda di potere: esibire un animale per sua natura feroce che si era riusciti a rendere mansueto addomesticandolo alludeva apertamente alla forza e alle capacità del signore di dominare la natura e il mondo, vale a dire una sorta di legittimazione politica. ${ }^{6}$

A seguito delle crociate e dell'intensificarsi dei rapporti diplomatici e commerciali con i paesi d'oltremare la politica dei doni in forma di animali bizzarri ed esotici penetrò anche in Europa, e soprattutto nella penisola dove i legami con l'Oriente erano particolarmente stretti. Grande risonanza aveva avuto l'arrivo in Europa nell'8or dell'elefante Abul Abbas offerto dal califfo di Baghdad Hārūn al-Rashīd a Carlo Magno, che non perdeva occasione di esibirlo pubblicamente quale segno del suo potere imperiale. ${ }^{7}$ Il pachiderma, in virtù della sua mole così come pure delle qualità di intelligenza, forza e castità attribuitegli dalle auctoritates e dai bestiari, rientrava tra $i$ doni regali per eccellenza in grado di evocare nell'immaginario le pompe e i trionfi di Alessandro Magno. Motivo per cui, dopo essere sbarcato nel porto di Marsiglia, l'imperatore lo aveva esibito come star del corteo che dalla città francese lo condusse fino ad Aquisgrana, suscitando grande impressione nella gente accorsa per ammirarlo poiché da quattro secoli non se ne vedeva uno su suolo europeo. ${ }^{8}$ Ancora nel I252 il re francese Luigi IX, promotore della sfortunata settima crociata, mentre si apprestava a rientrare dal Vicino Oriente aveva ricevuto in dono dal sultano mamelucco Aybak (r. I250-I257) un elefante per sancire la loro alleanza. ${ }^{9}$ Poco amante degli animali, il sovrano francese se n'era ben presto sbarazzato regalandolo al suocero Enrico III d'Inghilterra, con il quale si era da poco riconciliato, che da tempo anelava a possederne uno. ${ }^{\mathrm{IO}}$ Durante il tragitto da Parigi a Londra al pachiderma furono riservati grandi onori: scortato dal primogenito del conte di Savoia, in ogni città fu ricevuto alla stregua di un regnante, in quel di Beauvais il vescovo in persona gli impartì la benedizione e, una volta giunto a destinazione, fu oggetto di lunghi festeggiamenti. ${ }^{\text {II }}$ Esemplare che Matthew Paris, storico e miniatore di corte, immortalò prontamente in un disegno eseguito dal vero (fig. 9I). ${ }^{\mathrm{I} 2} \mathrm{E}$

6. DROCOURT 2004, pp. 80-82.

7. BEHRENS-ABOUSEIF 20I4, p. I9.

8. Vedi pagina IoI nota 69.

9. BUQUET 20I3c, pp. 386-387.

Io. PARIS I872-I883, vol. 5, p. 489; LACH I965-I993, vol. 2.I, p. I30.

II. PASTOUREAU 2002 , pp. II5-II9.

I2. LEWIS I987, pp. 2I2-2 I6; BUQUET 20I3c, pp. 386-387. Il disegno, insieme a quello nel Liber additamentorum (British Library, ms. Cotton Nero D.I, c. I69v), testimonia come la visione diretta degli animali consentisse 


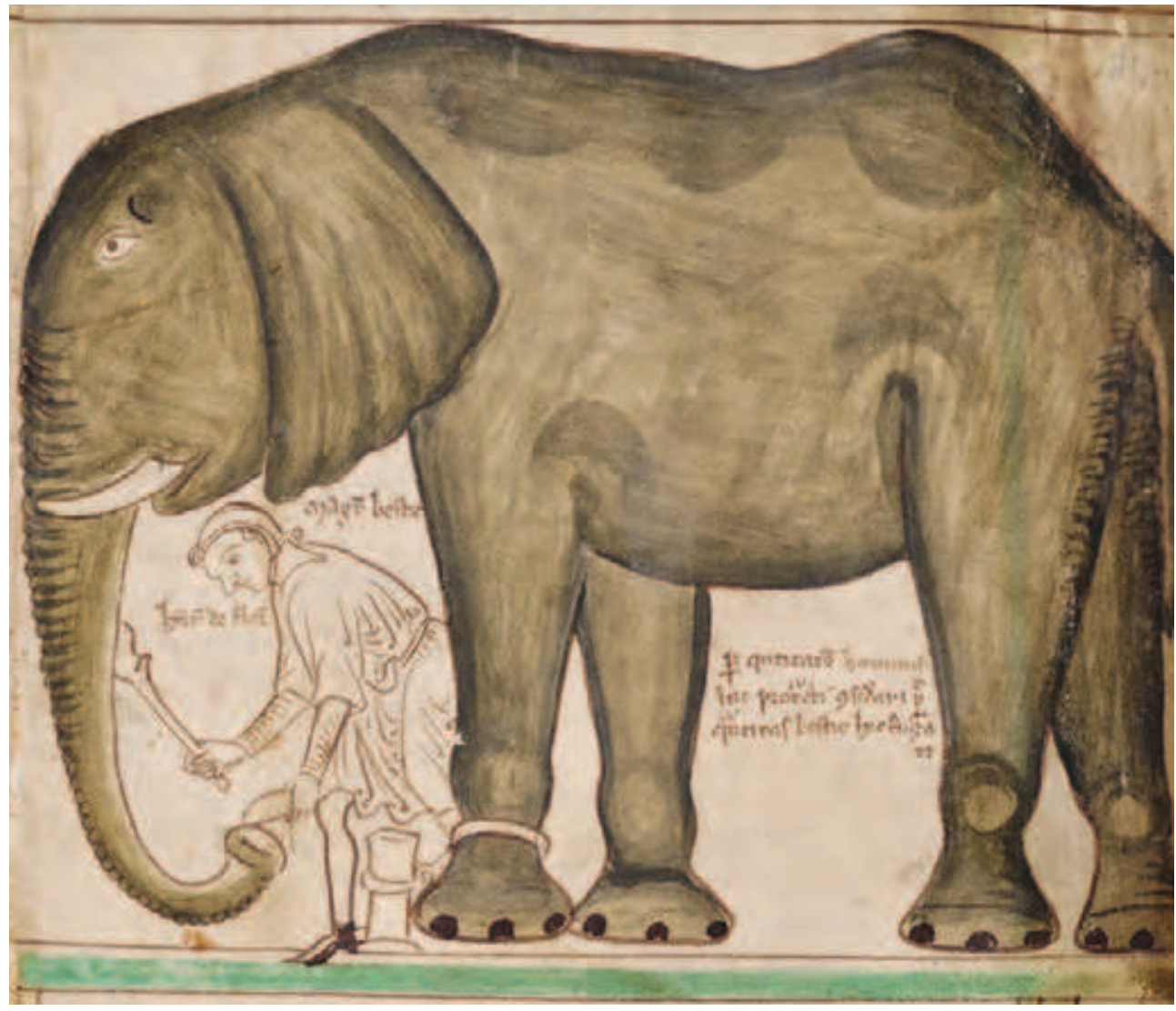

Fig. 91: Matthew Paris,

Elefante di Enrico III,

Chronica Maiora, I255 ca.

Cambridge, Corpus Christi College (ms. I6.I, c. 2r) 
assai probabile che la smania di Enrico III di poter includere un elefante nel suo serraglio fosse dettata dalla volontà di emulare Federico II, fin dal gennaio I228 proprietario di un pachiderma inviatogli dal sultano ayyubide al-Kāmil (r. I2I8-I238) per sugellare i loro accordi riguardo al riconoscimento del titolo di re di Gerusalemme e, qualche mese più tardi, di un secondo esemplare offertogli al suo arrivo ad Acri. ${ }^{\mathrm{I3}}$ L'imperatore svevo, orgoglioso del suo animale esotico, non perdeva occasione per esibirlo nel corso dei suoi spostamenti o per celebrare una vittoria, come quando nel I237, dopo aver sconfitto i nemici, lo aveva fatto sfilare a Pontevico con una torre lignea issata sul dorso e il mese seguente, per festeggiare la disfatta della Lega Lombarda a Cortenuova, gli aveva fatto trainare il carroccio dei milanesi con il capo delle truppe prigioniero. ${ }^{\mathrm{I}}$ Sempre nel I228 al-Kāmil aveva offerto a Federico II una giraffa che per volere del sovrano fu immortalata, insieme a un pachiderma, su di una teca eburnea destinata alla cappella Palatina. ${ }^{\text {Is }}$ Nell'ottica degli omaggi diplomatici volti a dimostrate potere e magnificenza sono pure da annoverare il raro pavone bianco e l'orso polare, ricevuto dal re di Norvegia, che nel I234 il sovrano svevo fece recapitare all'emiro di Damasco al-Ashraf Musa (r. I229-I237). ${ }^{\text {I6 }}$ Quando, invece, nel I235 si recò a Worms per convolare a nozze con la terza moglie Isabella d'Inghilterra, sorella di Enrico III, Federico II viaggiò con un fastoso corteo di sapore orientale al seguito, massima espressione di pompa imperiale, che tra i molti animali comprendeva dromedari, cammelli, scimmie e leopardi. ${ }^{\mathrm{I}} 7$

Fu a partire dalla seconda metà del XIII secolo, in larga parte a opera del sultano mamelucco Baybars I, che si andò sempre più affermando l'uso di offrire meravi-

agli artisti di raffigurarli con estremo realismo mentre, sempre nella Chronica Maiora, l'illustrazione dell'accoglienza trionfale riservata da Federico II a Riccardo di Cornovaglia eseguita qualche anno prima sulla base di descrizioni orali rivela tutta la sua dipendenza dai bestiari (ms. I6.II, c. I52v) vedi LEWIS I987, pp. 280-28I.

I3. Il primo elefante fu consegnato a Berardo, arcivescovo di Palermo inviato da Federico II in qualità di ambasciatore presso il sultano, quando si apprestava a fare rientro a Palermo, mentre il secondo era l'unico esemplare sopravvissuto tra quelli che al-Kāmil aveva ricevuto, insieme a una zebra, dal sovrano dello Yemen vedi PARIS I872-I883, vol. 3, p. I79; MANDALÀ 20II, pp. 426, 428-429; BUQUET 20I3c, p. 386 nota 90. Nel I225 Federico II sposò Isabella di Brienne che portava in dote il titolo di re di Gerusalemme, riconosciutogli da al-Kāmil nel marzo I229 quando gli consegnò la città vedi AMARI I933-I939, vol. 3.2, pp. 62 I-622, 648-660; MANDALÀ 20II, pp. 423-424.

I4. Il frate contemporaneo Salimbene de Adam ricorda che nel mese di novembre l'elefante sfilò a Pontevico, mentre Pier della Vigna, basandosi però su di un resoconto anonimo, riferisce che agli inizi di dicembre Federico II fece un trionfale ingresso a Cremona seguito da un elefante che trainava il carroccio con Pietro Tiepolo, podestà di Treviso e capo delle truppe lombarde sconfitte, legato. Fu sempre questo elefante, con una torre lignea sul dorso che ospitava musici e giocolieri, a sfilare nel corso dei festeggiamenti organizzati a Cremona nel I24I per accogliere Riccardo di Cornovaglia vedi SALIMBENE I987, p. I34:405; BOCCIA 20I4, pp. 260-264; PARIS I872-I883, vol. 4, p. I67; AMARI I933-I939, vol. 3.2, p. 655 e in particolare nota 2; LACH I965-I993, vol. 2.I, p. I30; BEDINI I997, p. 30 (per una svista indica la data I2I4); MANDALÀ 20II, pp. 430-43I; KINOSHITA 20I2, pp. 5I-52; LEWIS I987, pp. 280-28I; BUQUET 20I3b, pp. II5-II6; ID. 20I3c, p. 386 nota 93. Vedi anche pagina I83.

I5. OLMI I992, p. 43; BUQUET 2013b, pp. 98, II3-II4.

I6. LOISEL I9I2, p. I46; AMARI I933-I939, vol. 3.2, pp. 662-663; BUQUET 20I3c, p. 380; ID. $2013 \mathrm{~b}$, p. I 4; BEHERENS-ABOUSEIF 2OI4, pp. I3I-I32. La maggior parte degli studiosi indica quale destinatario del dono il sultano d'Egitto al-Kāmil, mentre Thierry Buquet riferisce che si trattava del fratello, il sultano di Damasco vedi BUQUET 20I3c, p. 380 nota 46.

I7. LOISEL I9I2, p. I46; BUQUET 20I3b, p. I 6. 
gliosi animali esotici a regnanti orientali ed europei con il mirato scopo di ottenere in cambio favori. Sembra, infatti, che il sultano d'Egitto disponesse di una grande quantità di giraffe, animale al pari dell'elefante considerato dono regale per eccellenza poiché alla spettacolarità dell'aspetto si associava la leggenda della sua origine ibrida, vale a dire frutto dell'accoppiamento tra un cammello e un leopardo da cui l'antico nome di "camelopardalis». ${ }^{8} \mathrm{Nel}$ I 260 una giraffa fu inviata alla corte sivigliana di Alfonso X, nel i26I fu la volta di quella - descritta dallo storico bizantino Giorgio Pachimere - regalata all'imperatore Michele VIII Paleologo confidando di assicurarsi il suo aiuto riguardo al commercio di schiavi importati dall'Eurasia centrale, mentre nel 1262 un esemplare fu recapitato a Manfredi, figlio di Federico II, in Sicilia. ${ }^{\text {I9 }}$ Lo stesso anno Baybars I dispose di mandare una giraffa nell'Orda d'Oro - insieme a un elefante, una zebra, dromedari, scimmie, e altri beni di lusso - con lo scopo di ottenere l'appoggio del capo mongolo Berke (r. I257-I267) nel contrastare i tartari che occupavano la Persia. Nel corso del viaggio, però, una sosta forzata protrattasi per ben quindici mesi nel porto di Costantinopoli, imposta da Michele VIII per evitare di inimicarsi la delegazione persiana che soggiornava alla sua corte, causò il decesso di gran parte degli animali suscitando le rimostranze del destinatario del dono. ${ }^{20} \mathrm{~A}$ sua volta, Baybars I aveva ricevuto dal sultano yemenita cavalli, elefanti e una zebra nel I267 e ancora nel I275 un elefante, un rinoceronte e una zebra. ${ }^{2 \mathrm{I}}$

Nonostante alla metà del XIV secolo nei De rimedi de l'una, et l'altra fortuna (I354I366) Francesco Petrarca avesse deplorato la sfrenata passione dei suoi contemporanei per la fauna esotica intesa come segno di nobiltà d'animo, questa voga continuò a perdurare in Italia e all'estero. ${ }^{22}$ In ambito orientale nella prima metà del XIV secolo il signore yemenita al-Mujāhid 'Alī (r. I32I-I363) fece recapitare a un sultano mamelucco un elefante, una giraffa, una tigre, una zebra e uno zibetto, nel I360 il re del Mali inviò a Fes una giraffa per il sultano del Marocco, nel I385 il principe di Dalahk - arcipelago del Mar Rosso presso la costa eritrea, all'epoca sotto il controllo dello Yemen - omaggiò il sultano yemenita con un elefante e altre bestie selvatiche con la speranza di ottenere la sua protezione nei commerci e due anni più tardi inviò una seconda delegazione con un elefante, una giraffa e uno struzzo, mentre nel I392 offrì una giraffa al sultano egiziano Barqūq (r. I382-I389 e I390-I399). ${ }^{23}$

All'ambasciatore spagnolo Ruy González de Clavijo, inviato da Enrico III di Castiglia e di León a Samarcanda per incontrare Timur Beg (r. I370-I405), si deve

I8. ID. $2013 \mathrm{~d}$, pp. I25-I 47. A questo proposito è interessante, anche se di qualche anno successivo, il patto stipulato nel I 275 tra Baybars I e il re nubiano che aveva l'obbligo annuale di fornirgli giraffe, altri animali e schiavi vedi KRUK 2008, p. 578; BEHRENS-ABOUSEIF 20I4, p. 52. Per la leggenda tramandata nei bestiari dell'origine ibrida della giraffa vedi BUQUET $204_{4}$.

I9. VISMARA I950, pp. 6I-62; BUQUET 20I3c, pp. 388, 39I-392; BEHRENS-ABOUSEIF 20I4, pp. 95-96 (data l'arrivo degli animali esotici a Siviglia al I26I).

20. VISMAR A I950, p. 62; BUQUET 20I2, pp. 7I-73; ID. 20I3c, p. 389, BEHRENS-ABOUSEIF 20I4, pp. 28,62 .

2I. KURK 2008, p. 572; BUQUET 20I3c, p. 384; BEHRENS-ABOUSEIF 20I4, p. 39.

22. PETRARCA I584 pp. IIOv-II2r, libro I, LX-LXI; BUQUET 20I3b, p. III.

23. BEHRENS-ABOUSEIF 2OI4, pp. 21, 42, 54, I42; KRUK 2008, pp. 578-579; CONTI ROSSINI I923, p. 456. 
la notizia che il 5 giugno I 404 nella città di Khoy - attuale Azarbaijan occidentale - incontrò un emissario del sultano mamelucco Faraj (r. I392-I4I2) che recava una ventina di cavalli, quindici cammelli carichi di doni, sei struzzi e «un animale chiamato giraffa» destinati al condottiero mongolo, forse per contraccambiare l'elefante ricevuto in dono l'anno precedente. ${ }^{24} \mathrm{E}$ ancora nel I4I4 una giraffa fu offerta dal sultano bengalese all'imperatore cinese Yongle (r. I4O2-I424), animale che riscosse grande attenzione alla corte di Nanchino dove, scambiato per il mitico unicorno, fu prontamente ritratto in un rotolo dipinto, mentre nel I4IS fu la volta dell'esemplare inviato dal re di Malindi e quattro anni più tardi quello giunto da Aden.25

In Italia, invece, nel I402 a Venezia sbarcò una delegazione inviata dal negus d'Etiopia, all'epoca identificato con il famoso quanto fantomatico Prete Gianni, che tra i molti doni diplomatici recava quattro leopardi, due dei quali destinati a Gian Galeazzo Visconti. ${ }^{26}$ Tra gli animali provenienti dall'Oriente che più suscitarono clamore figura la zebra, animale mai visto prima in Italia, che nell'ultimo quarto del XV secolo il sultano d'Egitto Qā’it Bey inviò alla corte partenopea di Ferdinando I d'Aragona. ${ }^{27}$ Unico precedente in Europa fu l'esemplare offerto nel I26I dal sultano mamelucco Baybars I, insieme a una giraffa e a un elefante, al re spagnolo Alfonso X e prontamente ritratta, insieme ad altri animali esotici

24. All'ambasciatore spagnolo si deve un'accurata descrizione: «Un animale chiamato giraffa, il quale è fatto nel modo seguente: il corpo è grande come quello del cavallo, ha un collo molto lungo e le zampe davanti più alte di quelle di dietro. Il piede somiglia a quello del bue, diviso da una fenditura. Dallo zoccolo fino al culmine dal dorso è alto circa sedici palmi e altrettanto dalla spalla alla testa. Il collo è sottile come quello del cervo e può allungarsi in modo stupefacente. Le gambe posteriori sono a tal punto più corte di quelle anteriori che chi non l'avesse ben osservato potrebbe pensare che sta seduto anche quando sta in piedi. La groppa è inclinata verso il basso come quella del bufalo, il ventre è bianco, mentre il corpo ha un colore giallo dorato traversato da lunghe strisce bianche. Il muso è simile a quello del cervo, il collo è alto e sottile, gli occhi sono molto grandi e rotondi, le orecchie somigliano a quelle del cavallo ed hanno vicino due piccoli cornetti rotondi coperti di peluria simili a quelli appena spuntati del cerbiatto. Il collo di questo animale è talmente alto ed estensibile che, se lo vuole, può raggiungere il cibo sopra un muro alto cinque o sei tapie e può mangiare le foglie che spuntano sui rami più alti degli alberi, cosa che fa assai spesso. Chi, come noi, non l'aveva mai vista prima, rimane pieno di meraviglia», GONZÁLEZ DE CLAVIJO i999, pp. I I8-i I9. Nel resoconto si trova anche una lunga e dettagliata descrizione degli elefanti visti a Samarcanda alla corte di Timur Beg vedi ivi, pp. I97-I99. Tra le miniature che illustrano il Zafarnāma, manoscritto commissionato da Ibrahim-Sultān nel I 436 per celebrare le imprese politiche e militari compiute dal nonno Timur Beg, si trova quella con la giraffa offerta dal sultano egiziano nel I 404 vedi KOMAROFF 2OI I, p. 288 n. 2 I9; BEHRENS-ABOUSEIF 20I4, pp. 73-74. Per un approfondimento sulla genesi del testo Zafarnāma vedi EVRIM BINBAŞ 20I6, pp. 2I9-223. Per l'elefante inviato da Faraj vedi BEHRENS-ABOUSEIF 20I4, p. 73.

25. LAUFER I928, p. 44; CHURCH 2004, pp. I-3, 2I-26, 30 nota 79, 34-37; RINGMAR 2006, p. 378 (confonde l'esemplare con quello inviato l'anno successivo dal re di Malindi); OVERTON 20I I, p. 288 n. 220 ; BEHRENS-ABOUSEIF 20I 4, p. 38; AL-MASUM 20I7, pp. 60-6I. Sembra che tra il i 430 e il I 438 altre giraffe furono inviate in Cina vedi LAUFER I928, p. 46; CHURCH 2004, p. 30.

26. MESSEDAGLIA I947, p. 23; LEFEVRE I967-I968, pp. II-I2, I4; KAPLAN I985, pp. I2, 57.

27. Nel De magnificentia (I 499-I500) Giovanni Pontano, intellettuale di spicco della corte aragonese, scrive: «Poco tempo fa il re di Siria mandò fra gli altri doni a Ferdinando una giraffa ed un asino, che risulta portato dalle più lontane regioni dell'Oriente. Cosa c'è di più vile di un asino? Eppure molti sono venuti da luoghi lontanissimi a vederlo. Una cosa poi lo rendeva particolarmente interessante, che, avendo il pelo screziato, mostrava il corpo tutto segnato di strisce uguali e di diverso colore. Fra i doni vi erano molti oggetti preziosi, ma questi due animali resero il dono anche più eccellente per la loro stranezza, per il fatto di essere stati mai visti prima», PONTANO I999, pp. 213-2 I5. Riguardo al dono della giraffa vedi pagina 245 nota 30. 
probabilmente appartenenti al serraglio sivigliano, in una miniatura delle Cantigas de Santa Maria (fig. 4). ${ }^{28}$

A Firenze fu la giraffa dono del sultano Qā’it Bey nel I487 per Lorenzo de' Medici a riscuotere grande ammirazione. ${ }^{29}$ Bizzarro animale al seguito dell'ambasciatore egiziano Mohamed Ibn-Mahfuz giunto in città con un duplice scopo: negoziare accordi commerciali e chiedere appoggio riguardo a una delicata questione politica, ossia il trasferimento del principe ottomano Djem dalla corte francese, dov'era tenuto prigioniero per volere del fratello Bayezid II, a quella papale più compiacente a Qå'it Bey che intendeva strumentalizzarlo per intimorire il suo rivale. Offrire a Lorenzo de' Medici un animale così raro e spettacolare come la giraffa, che in Italia non si era più vista da oltre due secoli, aveva pertanto una forte connotazione diplomatica: riconoscere e legittimare a livello internazionale il prestigio di cui godeva il signore fiorentino. ${ }^{30}$ Ben conscio del valore simbolico dell'omaggio, il Magnifico aveva saputo sfruttare abilmente l'arrivo della giraffa: non aveva perso occasione per esibirla pubblicamente con il mirato intento di ribadire ad alleati, nemici e cittadini il suo ruolo politico e dimostrare che, nonostante la congiura

28. BUQUET 20I3c, pp. 38I-382; BEHRENS-ABOUSEIF 20I4, pp. 95-96. Vedi anche pagine I 40-I 42. Alla luce di queste informazioni l'asserzione che la prima zebra importata in Europa dai tempi dell'antichità fu quella regalata nel I555 da Caterina d'Asburgo, regina del Portogallo, al nipote Carlos, figlio di Filippo II di Spagna, risulta infondata vedi JORDAN GSCHWEND 2004, p. 43; PÉREZ DE TUDELA - JORDAN GSCHWEND 2007 , p. 428.

29. KRUK 2008, p. 577; BEHRENS-ABOUSEIF 20I4, pp. II3-II5.

30. L'affermazione che intorno al I 474 Federico da Montefeltro possedeva una giraffa è da imputare a un errore di lettura di un documento da parte di James Dennistoun: nei Memoirs of the Dukes of Urbino (I85I) tra gli stipendiati della corte urbinate include un «Keeper of the camel-leopard», mentre il documento riporta «Per il LeonPardo Christofaro del Belluccio» (Roma, Biblioteca Apostolica Vaticana, ms. Urb. lat. 829, c. 56Ir). Ancora di recente Una Roman D'Elia riporta questa informazione errata, mentre la versione aggioranta del libro di Dennistoun, pur rifacendosi a un altro documento, emenda l'errore citando la seguente voce: "Addetto al leopardo o pantiera" (Roma, Biblioteca Apostolica Vaticana ms. Urb. lat. I204, c. I Ior) vedi DENNISTOUN I85I, vol. I, p. I43; ID. 20Io, vol. I, p. I26 (riporta ms. Urb. lat. 829 mentre la voce si trova nel ms. Urb. lat. I204); D’ELIA 20I5, p. 45. Secondo quanto riferito da Giovanni Pontano e Sigismondo Tizio intorno al I 480 , quindi ancora prima che al Magnifico, Qā’it Bey aveva offerto una giraffa al re di Napoli Ferdinando I d'Aragona quale ringraziamento per avergli fornito armature, armi e polvere da sparo ignorando le disposizioni papali in merito vedi PONTANO I999, pp. 213-2I5; DONATI I938, pp. 248, 254; FORCELLINI i9i4, p. i80; BEHRENS-ABOUSEIF 2014 , pp. I06; I 42 . Per gli studiosi che menzionano la presenza della giraffa nel serraglio napoletano vedi BURKHARDT I980, pp. 267-268; LOISEL I9I2, p. 20I; LAUFER I928, p. 79; BARCLAY LLOYD I97I, p. 47; OLMI I992, p. 43; BUQUET 20I3c, p. 385 ; MASSETI 20I5, p. I6I (segnala anche giraffe di proprietà del duca di Calabria e di Ercole I d'Este). È alquanto singolare, considerato lo stupore suscitato dalla giraffa ricevuta nel I487 da Lorenzo de' Medici, la quasi assoluta mancanza di tracce documentarie, pittoriche o letterarie relative all'esemplare napoletano. Unico indizio potrebbe essere la scena - purtroppo perduta - commissionata dalla duchessa Eleonora d'Aragona, figlia del re di Napoli convolata a nozze con Ercole I d'Este nel I473, al pittore di corte Giovanni Bianchini detto Trullo che sulla parete di una delle stanze in Castel Vecchio a Ferrara nel I 485 affrescò en trompe-l'œil «Napoli, zoè la cità, retrato dal naturale como el molo e como lo Castelo Novo et como la terra de San Vizenzo e como lo Castelo de l'Ovo, e como nave et gale et como la marina retrata, e como figurine che pare che sia zente che sia dentro ala citade, et como la zirafa, como l'axino de Ierusaleme, como uno bo [bue] puiexe [pugliese] et uno montone de stranio paise retrato..." vedi FRANCESCHINI I993-I997, vol. 2.I, pp. 339-340 doc. 489 ff. Vedi anche TUOHY I996, pp. Ioo-IoI, 4I6-4I7 doc. 2i; CONDORELLI 2006, pp. 83-86; FOLIN 2008, p. 496. Per quanto riguarda, invece, la giraffa vista a Fano da Antonio Costanzi nel I487, che si era apprestato a descrivere e ritrarre in una lettera indirizzata al signore di Faenza Galeotto Manfredi, è plausibile ipotizzare che si trattasse dell'esemplare destinato a Lorenzo de' Medici forse sbarcato sulla costa adriatica per poi raggiungere Firenze. Per l'Epistola ad Galeottum Manfredum de camelopardali di Antonio Costanzi vedi DONATI I938, p. 264. 
dei Pazzi ordita ai suoi danni nel I 478 costata la vita al fratello Giuliano e il perdurare di complotti volti a destabilizzarlo, il suo potere non era stato minimamente scalfitto. Non solo, se n'era pure servito per accattivarsi i favori della reggente francese Anne de Beaujeu che, desiderosa di possedere tale rarità, lo aveva pregato d'inviarle l'esemplare esotico. Richiesta che il signore di Firenze accolse senza indugio con lo scopo di renderla accondiscendente alla richiesta di Qā'it Bey, ma che non aveva potuto soddisfare per la prematura morte dell'animale. Il valore politico dell'offerta della giraffa suscitò un tale impatto che, a distanza di oltre mezzo secolo dalla morte del signore mediceo, Giorgio Vasari scelse d'immortalare sul soffitto del Quartiere di Leone X a Palazzo Vecchio la scena in cui Lorenzo de' Medici riceve gli omaggi dagli ambasciatori (I556-I558 ca.) (fig. 92), dove tra i doni spicca l'animale esotico dal lungo collo. ${ }^{3 \mathrm{I}}$ Ancora più pregnante doveva essere il significato della sua presenza nell'affresco con il Tributo a Cesare (I5I9-I52I ca.) (fig. 93) eseguito da Andrea del Sarto qualche decennio prima nel salone della villa medicea di Poggio a Caiano, quindi destinato a un contesto privato e familiare, dove il parallelo tra il potere del dittatore romano, rientrato dalla vittoriosa campagna d'Africa esibendo l'animale esotico, e quello del Magnifico doveva risultare assai palese agli occhi dello spettatore. ${ }^{32} \mathrm{La}$ giraffa non solo era entrata a far parte dell'immaginario fiorentino, ma addirittura assurta a simbolo di propaganda politica per i successori di Lorenzo de' Medici. ${ }^{33}$

\section{I.2. Animali esotici come status symbol}

È indubbio che la pala d'altare con l'Adorazione dei Magi dipinta da Gentile da Fabriano nel I423 per Palla Strozzi, il più ricco e potente mercante e banchiere fiorentino, doveva aver impresso un segno indelebile nella città del giglio. Formatosi nell'Italia settentrionale e influenzato dalla raffinata corte dei Visconti, dove regnava un mondo signorile e aristocratico, il pittore fabrianese ben conosceva gli strumenti visivi per comunicare allo spettatore, in maniera semplice e diretta, il peso politico ed economico del committente. Strumenti che, associati a un'iconografia a quel tempo inusuale per i fiorentini, dovevano aver esercitato un forte

31. JOOST-GAUGIER I987, pp. 9I-99; LAZZARO I995, pp. 224-225; La natura dipinta, 2018, pp. 78-79. Per l'affresco vedi ALLEGRI - CECCHI I980, pp. I36-I42.

32. LAZZARO I995, p. 223. Nell'affresco figurano le capre esotiche dono del sultano d'Egitto a Lorenzo de' Medici nel 4887 così come pure pappagalli, scimmie, un camaleonte e uno zibetto fatti recapitare dal re del Portogallo a papa Leone X, secondogenito del Magnifico, nel I5I4. Già un decennio prima Andrea del Sarto, formatosi nella bottega di Piero di Cosimo, nell'affresco con il Corteo dei Magi (I5II) nel chiostro dei Voti della chiesa della Santissima Annunziata aveva inserito una giraffa vedi KLIEMANN I985, pp. I99-200; CAPRETTI 20I3, pp. I62-I65; MASSETI 20I5, pp. I48-I49; ID. 20I8, pp. 42-44, 48; CONTI - GERMANI - POPPLE 20I62017, pp. 77-78. Quando un cinquantennio più tardi, per volere di Francesco I de' Medici, Alessandro Allori portò a termine gli affreschi nella villa di Poggio a Caiano, rimasti incompiuti alla morte del committente Leone X, nella scena con Siface re di Numidia riceve Scipione (I582) non tralasciò d'inserire un elefante, allusione all'animale inviato dal re del Portogallo a papa Leone X nel is I4 vedi pagina io i nota 69.

33. Per un approfondimento sul ciclo di affreschi commissionati da Leone $\mathrm{X}$ quale celebrazione del casato mediceo vedi MEDRI I992, pp. 59-65. 


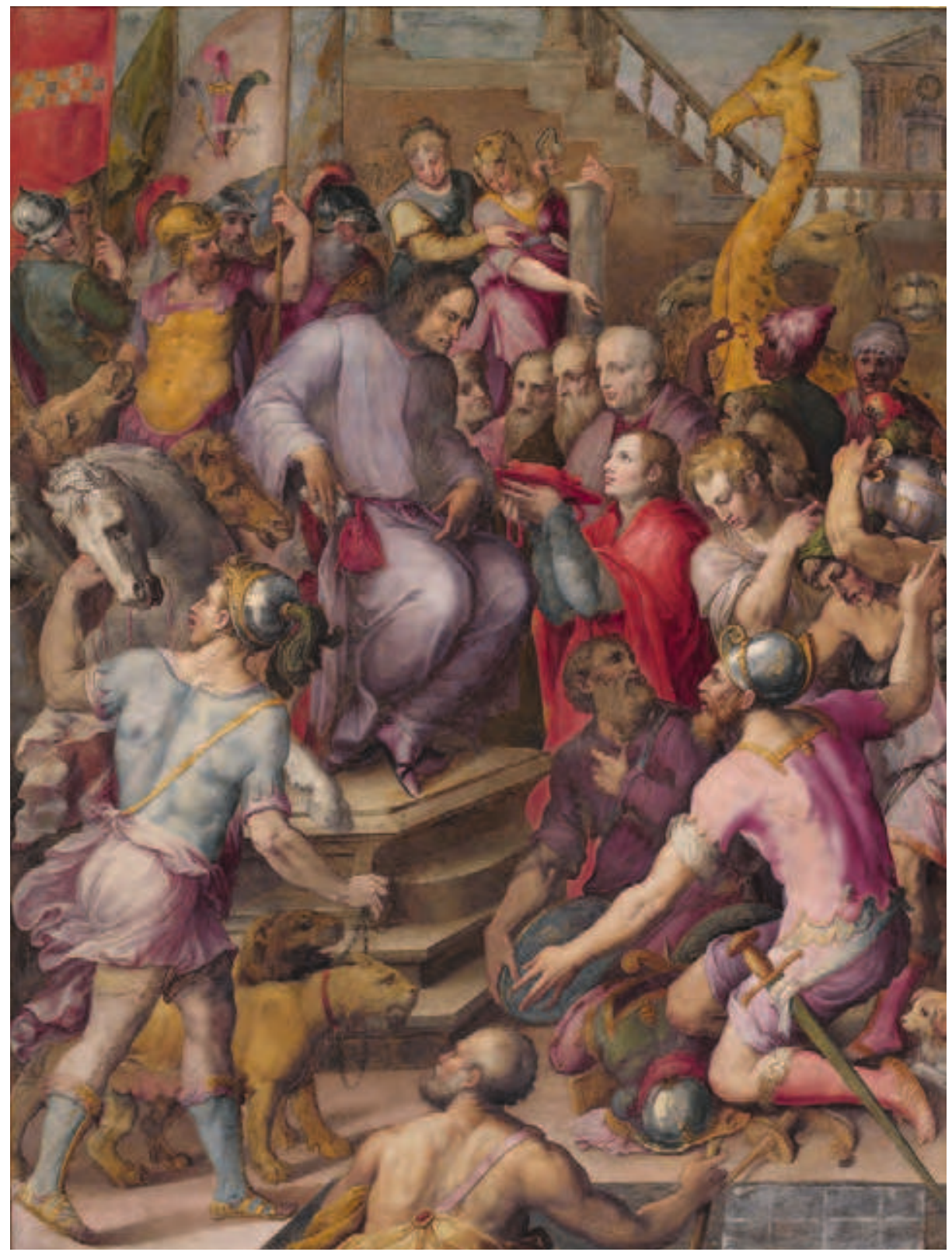

Fig. 92: Giorgio Vasari e Marco Faenza,

Lorenzo de' Medici riceve gli omaggi dagli ambasciatori, I556-I558 ca.

Firenze, Palazzo Vecchio, Quartiere di Leone X, sala Lorenzo il Magnifico 


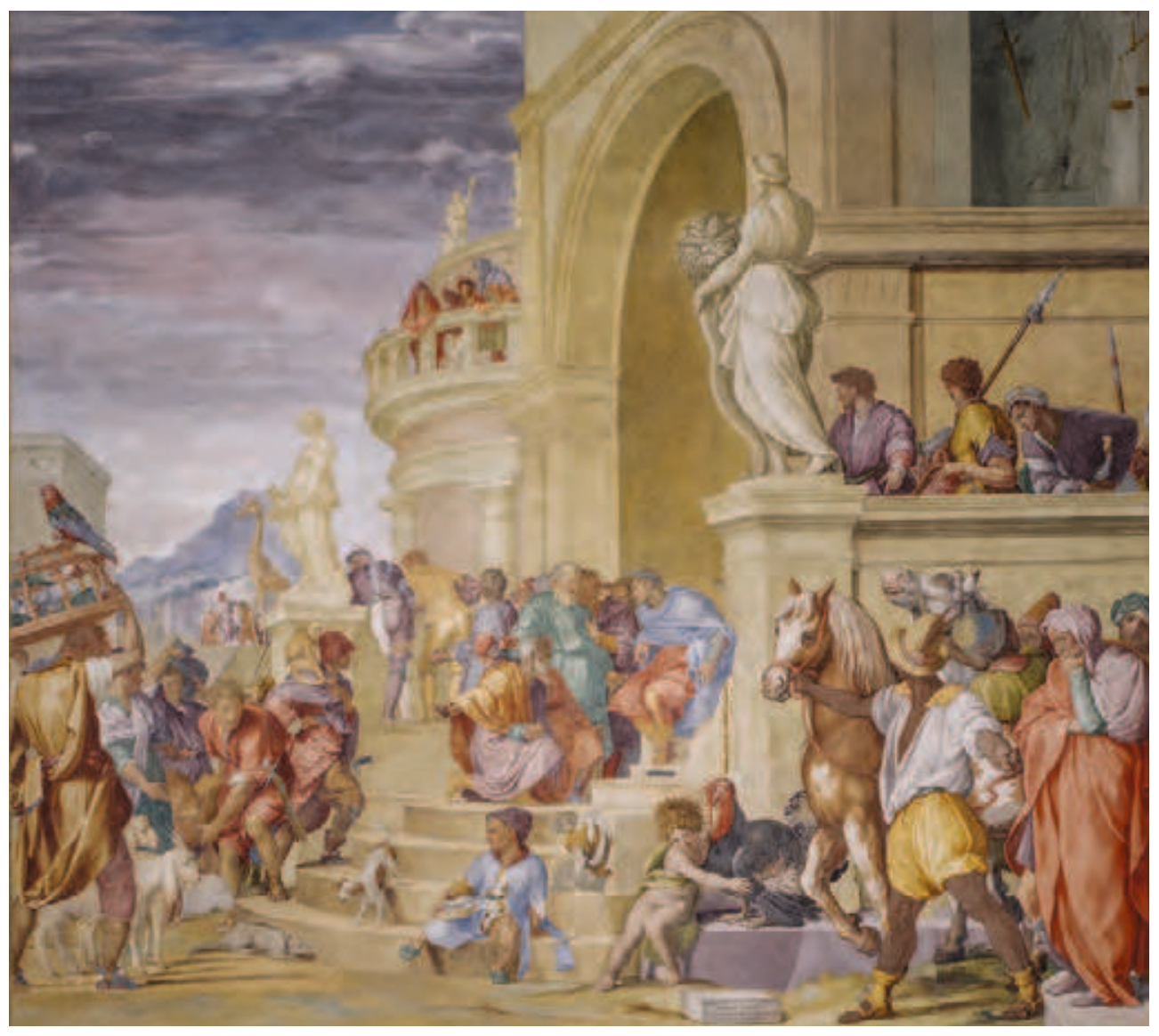

Fig. 93: Andrea del Sarto,

Tributo a Cesare, I5I9-I52I ca.

Poggio a Caiano, Villa medicea, salone di Leone X 
impatto in una città profondamente repubblicana e, quindi, non avvezza alle atmosfere e alla magnificenza del milieu nobiliare. ${ }^{34}$

Inoltre Gentile da Fabriano, straordinario osservatore della natura, era riuscito a rendere unico il suo dipinto arricchendolo con dettagli, animali esotici compresi, ritratti con un tale naturalismo da renderli "granelli di vero». ${ }^{55}$ Se la raffigurazione di stoffe sontuose, messaggio ben comprensibile in una società che doveva gran parte della sua prosperità al commercio dei tessuti, e la profusione di oro contribuivano ad accentuare il senso intensamente profano dell'opera, non da meno era la presenza della fauna esotica. Animali che avevano il potere di sollecitare ricordi e associazioni mentali sulla scorta delle letture amate dai mercanti, nelle quali si narrava di sultani e sovrani orientali che come segno di prestigio ricercavano, possedevano e offrivano in omaggio ad amici e alleati bestie esotiche. Tra questi testi è certamente da annoverare il Milione di Marco Polo che descriveva il meraviglioso palazzo fatto edificare dal Gran Khan a Giandu odierna Xanadu nella Mongolia interna - provvisto di un grande parco dove:

quando 'l Grande Kane vae per questo prato murato, porta uno leopardo in sulla groppa del cavallo; e quando egli vuole fare pigliare alcuna di queste bestie [cervi, daini, caprioli], lascia andare lo leopardo, e-leopardo la piglia e falla dare agli suoi gerfalchi ch'egli tiene i-muda; e questo fae per diletto. ${ }^{36}$

Scena di caccia, quella descritta dal mercante veneziano, tradotta visivamente in una miniatura posta a illustrazione del prezioso manoscritto Livre des merveilles (fig. 94) commissionato da Giovanni senza Paura nel I4I3. ${ }^{37} \mathrm{Fu}$ attraverso i contatti con il Vicino Oriente nel corso delle prime crociate che in Europa giunse notizia della caccia con ghepardi praticata in Siria, usanza già illustrata nel XIII secolo dal vescovo di Acri Jacques de Vitry quando scriveva:

et leopardi, sic dicti, quasi leonibus similes in capite et disposicione membrorum, licet non sint tam magni, nec tam robusti: adeo etiam mansueti sunt ab hominibus, quod eis sicut canibus utuntur ad venandum: non enim currendo predam capiunt, sed saltus faciendo, et si in tercio saltu predam non ceperint, eam prorsus dimittunt sibi indignando. ${ }^{38}$

Pratica venatoria, pare, in un primo tempo introdotta nelle colonie europee dell'Asia minore e nell' isola di Cipro, dove era ancora in voga nel XV secolo, e successi-

34. Otto Pächt ipotizza che l'iconografia dell'Adorazione dei Magi in chiave orientaleggiante sia da far risalire agli inizi del XV secolo quando Michelino da Besozzo, esperto nella raffigurazione di animali, fu influenzato dai resoconti della sacra rappresentazione tenutasi a Milano nel I336 con «simiae, babuini, diversa genera animalium», PÄCHT 201 I, pp. 85-86.

35. LONGHI I940, p. I9I. Luciano Bellosi propone di posticipare l'esecuzione delle Très riches heures du Duc de Berry intorno al I450, datazione che rivaluterebbe Gentile da Fabriano quale punta più avanzata in direzione naturalistica del gotico internazionale europeo, BELLOSI I993, p. I5.

36. POLO 200I, pp. 108-109, 74:4-6.

37. ID. 2002, pp. 7, 47.

38. MESSEDALIA I947, p. I7. 


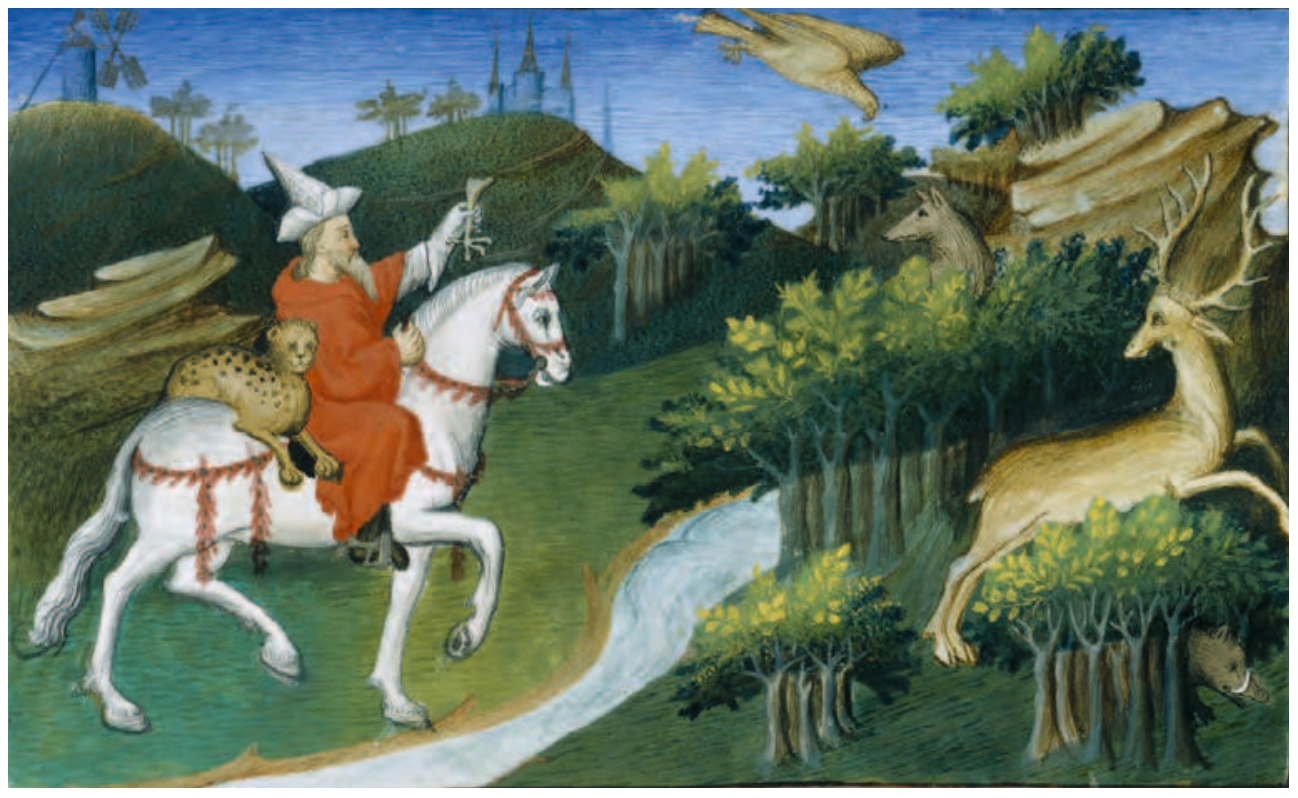

Fig. 94: Maestro di Boucicaut, Gran Khan a caccia,

Livre des merveilles, I4IO-I4I 2 ca.

Parigi, Bibliothèque nationale de France (ms. Fr. 28Io, c. 3Iv) 
vamente adottata in Occidente. Se nel Liber de quibusdam ultramarinis partibus (I336I337), resoconto del suo pellegrinaggio a Gerusalemme, il domenicano tedesco Guglielmo di Boldensele riferiva di aver assistito in quel di Cipro alla caccia di pecore selvatiche con l'impiego di cani e ghepardi, nel I4I3 il marchese Nicolò d'Este, anch'esso diretto al Santo Sepolcro, raccontava di essere stato ricevuto con tutti gli onori dal principe di Lusignano che gli aveva offerto falconi, levrieri e un ghepardo addestrato per la caccia. ${ }^{39}$

Fu con tutta probabilità sulla scorta dei numerosi racconti che alla fine del XIV secolo Gian Galeazzo Visconti, con l'espresso intento di emulare i fasti del meraviglioso mondo dei signori orientali, introdusse la caccia con felini alla sua corte. ${ }^{40} \mathrm{Nel}$ I39I per allietare la visita di Luigi di Valois duca di Touraine - marito della figlia Valentina e fratello del re di Francia - il signore visconteo orchestrò una serie di eventi e spettacoli tra cui una caccia nell'immenso parco del castello pavese nel corso della quale stupì gli ospiti esibendo ghepardi seduti sulla groppa dei cavalli che al comando del «pardiere» si lanciavano all'inseguimento delle prede per afferrarle e ucciderle. ${ }^{4 \mathrm{I}} \mathrm{Al}$ biografo di Carlo VI di Francia si deve la notizia che il duca milanese «appassionato della caccia, volendosi divertire con equipaggi più nobili di quelli che usavano gli altri principi, non si accontentava delle belle mute di cani $[\ldots]$ egli volle anche dei leopardi». ${ }^{42}$

La caccia con i felini fu uno sport esclusivamente riservato all'élite: acquistare ghepardi importati dall'Oriente era oneroso, come pure il loro mantenimento e stipendiare un addestratore altamente specializzato capace d'insegnargli a cavalcare sulla groppa del cavallo e a balzare all'inseguimento della preda per ghermirla. ${ }^{43}$ Non solo, ostentare di avere familiarità con animali in natura selvaggi che erano stati addomesticati equivaleva a una manifestazione di dominio che contribuiva ad aumentare il proprio carisma. Proprio perché il possesso di queste fiere fu considerato un segno di grande prestigio, i signori delle più raffinate corti italiane si prodigarono nel procurarsi ghepardi addestrati da poter esibire pubblicamente. Se a Milano Filippo Maria Visconti - come riporta Pier Candido Decembrio - «non si stancava di far cercare leopardi in tutto l'Oriente e d'insistere per averne presso il sultano degli Arabi» e il successore Francesco Sforza amava servirsi di felini per la caccia al cervo o al capriolo, non da meno erano i Gonzaga a Mantova o gli Este a Ferrara. ${ }^{44}$ Nel 1459 la marchesa di Mantova Barbara Hohenzollern ebbe in prestito dalla duchessa di Milano Bianca Maria Sforza un ghepardo accompagnato dal suo "pardiere» per offrire svaghi venatori agli ospiti

39. Ibid.; MEREGALLI 2005, p. I9I; CAMPO 20II, pp. 242-243.

40. MALACARNE I998, p. I73. Il signore visconteo adottò il ghepardo come suo emblema personale e, nel corso degli anni, altri membri del suo casato continuarono a fregiarsene vedi pagina II7 nota II8.

4I. BORSA I924, p. I24.

42. Ibid. Vedi anche SAINTE-PALAYE I759-I78I, vol. 3, pp. 289-290.

43. Per l'addestramento dei felini vedi ALLSEN 2006, pp. 76-79.

44. DECEMBRIO ig83, p. I i . 
illustri convenuti in città per partecipare alla dieta indetta da papa Pio II, mentre tre anni più tardi il figlio Federico I scriveva al padre Ludovico III Gonzaga informandolo di aver ricevuto in dono tre leprotti vivi che gli mandava perché li usasse per la caccia con il ghepardo. ${ }^{45}$ A Ferrara la presenza di felini si rintraccia, invece, nei libri di conti estensi: nel I 469 una stoffa fu usata per «frodare e vero coprire il sedere de li tapedi de li pardi» mentre nel I474 il "pardiere» Battista Battaglino richiese a Marco Galeotto, addetto al guardaroba di corte, un tappeto «per portare insuxo la gropa del cavalo sotto li piedi de uno lionpardo quando va in campagna». ${ }^{46}$ Se è probabile che Ercole I avesse affidato a questo "pardiere» l'incarico di consegnare alla corte di Francia il ghepardo abile nella caccia alla lepre richiesto da Luigi XI nel I476, non vi sono dubbi - come attesta un documento di pagamento - che tre anni più tardi fu proprio lui a recapitare al sovrano francese un secondo felino, provvisto di un "mantelletto» del quale si era personalmente occupata la moglie del duca Eleonora d'Aragona. ${ }^{47}$ Richieste certamente da ricondurre alla ben nota passione di Ercole I per i felini addestrati che non perdeva occasione di portare con sé anche quando prendeva parte a battute di caccia che si tenevano fuori dai suoi territori. Unica eccezione per quanto riguarda la pratica cinegetica con i ghepardi sembra essere stata la città di Firenze, almeno fino all'ascesa di Lorenzo il Magnifico, dove, forse in relazione all'accorta politica di Cosimo il Vecchio volta a mantenere un basso profilo consono a un regime repubblicano, sembra essere stata meno diffusa rispetto alle corti estensi e viscontee..$^{8}$

Con la raffigurazione di felini da caccia nella Pala Strozzi, alcuni seduti sulla groppa dei cavalli e uno colto nell'atto di azzannare un capriolo, così come pure di un "canattiere» con corno a tracolla e cane al guinzaglio Gentile da Fabriano era riuscito a trasformare un'iconografia per eccellenza religiosa come quella dell'Adorazione dei Magi in una scena di ambientazione cortese volta a equiparare lo stile di vita del committente, stagliato in primo piano con vesti sfarzose, a quello dei signori d'Oriente e della più raffinata corte d'Italia, quella viscontea. ${ }^{49}$ Se il dipinto con fauna esotica e scene di venatio esposto nella cappella di famiglia all'interno della chiesa di Santa Trinita costituiva un messaggio rivolto a tutti i fedeli, di tutt'altro tenore era quello dell'affresco realizzato un ventennio più tardi da Benozzo Gozzoli all'interno delle mura del palazzo mediceo (fig. 77). La visione della Cavalcata dei Magi, popolata da membri del lignaggio, alleati, soste-

45. MALACARNE I998, pp. I74-I75. Dal testo della missiva destinata alla duchessa di Milano si evince che la marchesa di Mantova aveva avuto in prestito sia la "parda" che il "pardiere», è infatti assai probabile che ogni ghepardo avesse il proprio addestratore.

46. BERTONI I9I9, p. 236. Nel I260 Federico II, possessore di numerosi ghepardi da caccia, ordinò ben 60 tappeti per questo uso vedi BUQUET 20I3 b, p. IO5.

47. BERTONI I9I9, p. 236; MESSEDAGLIA I94I, pp. 70-72, I03; ID. I947, pp. 25-26; TUOHY I996, p. 246; COCKRAM 20I7, p. 290; BUQUET 2020, pp. 3I-33.

48. Un primo accenno a una possibile caccia con il ghepardo risale al i 475 vedi pagina I 6.

49. Il "canattiere» era la persona incaricata di accudire i cani e durante le battute di caccia d'indirizzarli e guidarli con il suono del corno vedi MALACARNE I998, pp. 50-52. 
nitori e animali esotici che si snodava lungo le pareti della cappella, era invece riservata a una cerchia ristretta: famigliari, conoscenti e ospiti di riguardo che Cosimo il Vecchio era solito ricevere nel suo sacello privato. Poco importava se all'epoca i Medici fossero dediti o meno all'ars venandi con i felini, la raffigurazione di animali rari aveva lo scopo di equiparare nell'immaginario lo stile di vita della potente famiglia di mercanti e banchieri a quello delle grandi corti nobiliari. Oltre a ciò, se l'intento del dipinto commissionato da Palla Strozzi era quello di evocare potere e ricchezza, gli affreschi medicei con l'immagine di un corteo affollato di individui appartenenti alla famiglia e personaggi illustri intendeva espressamente ostentare, alludendo al concilio tenutosi a Firenze nel I439, il prestigio politico raggiunto dal casato mediceo nella scena politica cittadina, italiana e internazionale.

Introdotta nella città del giglio dal capolavoro di Gentile da Fabriano, l'iconografia dei Magi d'ambientazione cortese riscosse ben presto grande successo. A Domenico Veneziano si deve il primo tondo con l'Adorazione dei Magi (fig. 75) commissionato da Piero de' Medici proprio negli anni in cui il lignaggio aveva acquisito notevole rilevanza politica: nel I 434 Cosimo il Vecchio fu richiamato dall'esilio veneziano impostogli l'anno precedente, mentre nel I439 grazie al suo intervento il concilio per l'unione delle due Chiese fu trasferito da Ferrara a Firenze. ${ }^{50}$ Far proprio un modello pittorico che l'immaginario cittadino identificava con quello commissionato dal ricchissimo Palla Strozzi, acerrimo nemico di Cosimo che al suo rientro dall'esilio si era premurato di far bandire dalla città, equivaleva a ribadire il livello del potere raggiunto dalla famiglia medicea. E se in un primo tempo l'iconografia richiesta da Piero de' Medici, dove le citazioni si limitavano al ritratto del committente con vesti lussuose e un falcone in pugno, era destinata a una fruizione privata, qualche decennio più tardi per volere di Cosimo il Vecchio fu riproposta in maniera ben più esplicita, fino al punto da includere la fauna esotica e la caccia con i felini, nella cappella medicea che, sebbene confinata all'interno del palazzo di famiglia, svolgeva la funzione di sala di rappresentanza del signore occulto di Firenze. Sempre agli stessi anni risale il cosiddetto Tondo Cook, opera di notevoli dimensioni con la raffigurazione di un'affollata Adorazione dei Magi che Beato Angelico, all'epoca pittore più acclamato di Firenze, dipinse per i Medici. ${ }^{5 \text { I }}$

Dopo essere stato accolto dalla famiglia più potente di Firenze, il soggetto dell'Adorazione dei Magi d'ambientazione aristocratica per lo più raffigurato su tondi «da camera» - tipologia di formato esclusivamente destinata alle dimore private - cominciò a essere richiesto anche dai loro alleati e sostenitori. ${ }^{52}$ Nell'opera eseguita da Sandro Botticelli per Antonio Pucci (fig. 80), uno dei più fedeli affiliati della famiglia medicea, tra la folta folla di personaggi vestiti alla moda si

50. BOSKOVITS I995, p. 67 nota 60.

5 I. Vedi pagina 2I I nota I 2.

52. KENT 2005, p. 380 ; EAD. 2009, pp. 77-78. 
scorgono due scimmie munite di guinzaglio e collare. Bertucce e cercopitechi costituivano, da un lato, un espediente per conferire una connotazione esotica e orientale alla scena e, dall'altro, segni di status symbol trattandosi di costosi animali da compagnia provenienti da paesi lontani che solo i ceti più abbienti potevano permettersi; cammelli e dromedari, solitamente raffigurati per suggerire la provenienza orientale dei Magi, risultano invece assenti.

Ancora più significativa appare negli ultimi decenni del XV secolo la presenza di una giraffa, per lo più relegata in secondo piano, nell'iconografia tanto amata dai Medici quando a detenere il potere fu il Magnifico con la sua corte principesca. L'arrivo a Firenze nel I 487 del raro animale aveva colpito l'immaginario di pittori e committenti: i primi lo ritrassero quale allusione a un fatto di cronaca contemporanea, i secondi richiesero espressamente la sua raffigurazione per l'intrinseco significato politico. È infatti probabile che la giraffa inserita nei dipinti realizzati per le più importanti famiglie fiorentine del tempo avesse la funzione di esternare, più o meno velatamente, un legame con il casato mediceo. Trattandosi di un dono diplomatico ufficialmente inviato dal sultano del Cairo alla Signoria fiorentina ma in realtà destinato a Lorenzo de' Medici il riferimento al suo ruolo di signore della città doveva risultare assai palese. ${ }^{53}$ Nell'Adorazione dei Magi (fig. 83) affrescata da Domenico Ghirlandaio nella cappella di Giovanni Tornabuoni il messaggio destinato ai frequentatori della chiesa di Santa Maria Novella doveva apparire alquanto esplicito poiché il committente, oltre che abile uomo d'affari incaricato di gestire per conto del banco mediceo le transazioni con la Santa Sede, era zio del Magnifico. Sempre ad ambito religioso era destinata la pala con l'Adorazione dei Magi (fig. 86) nel convento fiorentino delle Murate posto sotto il patronato di Lorenzo de' Medici e dei suoi alleati. ${ }^{54}$ Anche in questo caso la presenza della giraffa sullo sfondo si prospetta come un accenno al legame che doveva unire l'anonimo committente e la famiglia più potente della città. Questo animale esotico, plausibile segno di affiliazione medicea, si ritrova pure in due dipinti destinati ad ambito privato: la tela con Vulcano ed Eolo (fig. 84) realizzata da Piero di Cosimo per il ricco mercante fiorentino Francesco del Pugliese, legato alla famiglia Medici fino a quando, dopo essere diventato seguace di Gerolamo Savonarola, nel I5I3 fu condannato a otto anni di esilio per aver pubblicamente definito Lorenzo de' Medici duca di Urbino «el Magnifico merda», e il tondo con l'Adorazione dei Magi (fig. 87) di Raffaello Botticini di cui

53. Vedi pagina I23.

54. Catalogo I933, p. I7I (scuola di Cosimo Rosselli); PAATZ I940-I954, vol. 4, p. 348 (scuola di Cosimo Rosselli); WEDDLE I997, pp. 308, 340 (scuola di Cosimo Rosselli); FAHY 200I-2002, p. I9 (Maestro dell'Epifania di Fiesole); LOWE 2003, pp. 347-350 (attribuito a scuola di Cosimo Rosselli, confonde questo dipinto con quello di Lorenzo di Credi, ora alla Galleria dell'Accademia (inv. I89o, n. 866I), e di conseguenza ne attribuisce la committenza a Niccolò Capponi per l'oratorio del convento); NICCOLINI 20II, pp. I2-I6, 326 (menziona il dipinto con la Natività commissionato da Niccolò Capponi a Lorenzo di Credi per il convento, ma non quello con lo stesso soggetto del Maestro dell'Epifania di Fiesole). Vedi anche pagina 228. 
resta ignota la committenza. ${ }^{55}$ È altresì vero che per queste ultime tre opere è stata proposta una datazione oscillante tra il I 490 e il I500, ossia gli ultimi anni della vita di Lorenzo de' Medici e quelli in cui il figlio Piero il Fatuo fu cacciato dalla città. Si potrebbe allora ipotizzare che la presenza della giraffa nei dipinti sia piuttosto da interpretare come un omaggio postumo al grande signore di Firenze oppure un mezzo per esprimere, in ambito privato, il proprio sostegno alla dinastia ormai in esilio. 



\title{
Secolarizzazione di un'iconografia religiosa
}

\author{
I. Magi, Oriente e animali esotici \\ I.I. Festa dei Magi
}

La prima notizia riguardo alla celebrazione della festa dei Magi nella città di Firenze risale al 1390 quando un anonimo cronista nel suo Diario aveva annotato:

A dì VI di genaio si fe' in Firenze una solenne e magnia festa alla chiesa de' frati di Sancto Marcho, de' santi Magj e della stella. I Magj andorono per tutta la città, molto orevolemente [onorevolmente] vestiti et chon chavaglj e cho·molta conpagnia et co-molte novità. I-re 'Rode istette a Santo Giovannnj i-sun uno palcho molto bene adornato, chon sua gente. E passando da Santo Giovannj, salirono i-su'palcho dov'era Erode e quivj disputorono del fanciullo che andavano ad adorare e promettendo di tornare a Erode. E fatta l'oferta i Magj al banbino e non tornando ad Erode, Erode gli perseghuitò e fe' ucidere molti fanciulli contrafatti in braccio alle madri e balie, e chon questo finì la sera la festa alle 23 ore. ${ }^{56}$

La messa in scena dell'evento religioso consisteva in una cavalcata capeggiata da tre membri della Compagnia dei Magi vestiti da re orientali che il giorno dell'Epifania sfilavano, accompagnati da un folto corteo di figuranti, per le vie della città seguendo un percorso scandito da alcune tappe fondamentali: la partenza dalla chiesa di San Marco, la sosta presso il battistero di San Giovanni dov'era allestita la reggia di Erode a Gerusalemme per comunicargli che si stavano recando ad adorare Gesù, l'arrivo alla chiesa di San Marco immaginaria capanna di Betlemme per offrire oro, incenso e mirra al Bambino e quale epilogo la strage degli Innocenti, inscenata in piazza del duomo con l'impiego di fantocci per renderla più cruenta, ordinata dall'irato re dei Giudei per il mancato ritorno dei Magi.57 Spettacolo ufficialmente riconosciuto dalla Signoria nel I408, quando al Tribunale di Mercanzia e ai Consoli delle Arti fu imposto l'obbligo di onorare la

56. HATFIELD i970, pp. Io8, I44 doc. i; Alle bocche I986, p. 89 . Il 6 gennaio era una data importante per Firenze anche per un altro motivo: san Giovanni Battista, patrono della città, aveva battezzato Cristo nel Giordano.

57. VENTRONE 20I6, pp. 87-88. Sulla scorta delle ricerche di Richard Trexler sono state avanzate alcune ipotesi riguardo al punto di origine del corteo del I390: Raimondo Guarino e Paola Ventrone ritengono che la Compagnia dei Magi avesse sede nella casa di Baldassarre degli Ubriachi, appena fuori le mura di Porta San Frediano, e da lì si dirigesse verso il battistero per poi passare dalla cappella dei Magi, patrocinata dal ricco mercante, all'interno della chiesa di Santa Maria Novella e giungere, infine, alla chiesa di San Marco; Franco Cardini indica invece come punto di partenza la chiesa di Santa Maria Novella, TREXLER I987, pp. 75-I67; ID. I988, pp. I05-I06; GUARINO I988, pp. I05-I06; VENTRONE 20I6, pp. 87-88 e in particolare nota I99; CARDINI I99Ib, pp. 64-66. 
festività con l'offerta di ceri alla chiesa di San Marco associata al culto dei Magi..$^{8}$ Quasi un decennio più tardi, nel I4I7, la Signoria accolse la richiesta avanzata dalla Compagnia dei Magi di poter disporre di fondi pubblici, ricavati da una tassa imposta agli usurai ebrei, quale contributo per gli elevati costi sostenuti per organizzare la festa dell'Epifania per «onore di Dio e fama della città».59

Un sostanziale cambiamento nella messa in scena della festa dei Magi si verificò nel I429 quando l'itinerario percorso dei tre re orientali fu ampliato, l'immaginario palazzo di Erode dislocato dal battistero a piazza dei Signori e la scena con il massacro degli Innocenti omessa, mentre il corteo con settecento uomini a cavallo lussuosamente abbigliati che sfilavano lungo via Larga, suscitando grande ammirazione tra gli spettatori seduti su palchetti costruiti per l'occasione, assunse un carattere marcatamente terreno. ${ }^{60}$ Lo spettacolo dei Magi si era così tramutato da sacra rappresentazione in opulento corteo di sapore profano. ${ }^{6 \mathrm{I}} \grave{\mathrm{E}}$ stato ipotizzato che l'evoluzione in senso cavalleresco della festa dei Magi fosse da ricondurre al ricordo delle cavalcate con scopo di propaganda politica organizzate dalla raffinata corte viscontea, come quella splendida e di sapore esotico tenutasi a Milano nel I336 quando - come riporta Galvano Fiamma, frate domenicano e storiografo di corte - tra i figuranti comparivano musici, mimi, scimmie, babbuini e altri animali; spettacolo che riscosse un tale successo da decretarne la cadenza annuale. ${ }^{62}$ Memore delle sfilate milanesi, Gentile da Fabriano dipinse l'Adorazione dei Magi per Palla Strozzi, all'epoca forse affiliato all'omonima confraternita, gremita di personaggi lussuosamente abbigliati e animali esotici introducendo nella città del giglio, per tradizione repubblicana e quindi estranea ai fasti delle corti sofisticate, la prima versione laico-aristocratica dell'iconografia che suscitò grande sensazione. ${ }^{63}$ Per quanto riguarda, invece, la sfilata vera e propria sia il trasferimento della reggia di Erode in piazza dei Signori, centro del potere comunale, sia la presenza nel corteo di un carro con un figurante nei panni di «Davitttj [Davide], che uccise il giughante [gigante] colla fronbola

58. Il Tribunale di Mercanzia, composto da sei giudici scelti tra le fila delle cinque Arti maggiori di Firenze, aveva il compito di dirimere le contese tra mercanti, categoria che aveva come patroni i re Magi.

59. HATFIELD I970, pp. IO9-IIO, I45 doc. 3; VENTRONE 20I6, pp. 9I-92.

60. PETRIBONI - RINALDI 200I, p. 2I6; VENTRONE 20I6, pp. 92-93.

6I. Le feste dei Magi, ispirate dal Vangelo di Matteo (I:I-I2), nel corso dei secoli furono soggette a contaminazioni vedi CARDINI I99ib, pp. 35-60.

62. FIAMMA I938, p. 22; D’ANCONA I97I, vol. I, pp. 97-98; GUARINO I988, pp. 27-28; TREXLER I997, pp. 88-89; PIACENTI 20I7, p. I9I. A indicare una relazione tra la sfilata milanese e quella fiorentina sono le analogie del circuito percorso dai tre re orientali. A Milano la festa dei Magi era connessa alle loro ossa, vere o presunte, conservate nella chiesa domenicana di Sant'Eustorgio fino al i I64, quando furono requisite come bottino di guerra da Federico Barbarossa e fatte trasportare a Colonia. Per il percorso del corteo milanese vedi HOFMANN I975, pp. I3I,I54-I55; CARDINI 20I7, pp. I50-I53. Per le vicende relative alle reliquie dei Magi vedi MACCHIA 2017 , pp. $65-78$.

63. Per la possibilità che tra il I390 e il I434 la famiglia Strozzi fosse affiliata alla Compagnia dei Magi vedi CARDINI i99ib, p. 75; VENTRONE 20i6, pp. 94-95. Se così fosse, l'appropriazione da parte dei Medici dell'iconografia dei Magi e del patronato sulla Compagnia avrebbe un significato ancora più profondo mosso da proposito di annientare la figura di Palla Strozzi. Per la devozione di Palla Strozzi nei confronti dei Magi anche durante il suo esilio vedi CHRISTIANSEN 2005, p. 34. 
[fionda]", nell'immaginario fiorentino simbolo civico per eccellenza del trionfo della libertas sulla tirannide, testimoniano la volontà di infondere allo spettacolo una connotazione marcatamente politica. ${ }^{64}$

Furono soprattutto i Medici a nutrire una particolare devozione nei confronti dei tre re orientali. A partire dal I434, dopo il rientro di Cosimo il Vecchio dall'esilio veneziano, la Compagnia dei Magi passò sotto il suo controllo annoverando tra gli affiliati membri delle più importanti famiglie fiorentine a lui fedeli. ${ }^{65}$ Influenza ulteriormente consolidatasi con il patronato di Cosimo sulla chiesa di San Marco, sede della confraternita, ristrutturata a sue spese insieme all'annesso convento e riconsacrata il 6 gennaio I443 da papa Eugenio IV. Oltre che al santo titolare, l'edificio era dedicato a Cosma e Damiano, fratelli martiri e medici di epoca paleocristiana, i cui nomi evocavano quelli del signore mediceo e del gemello morto in tenera età, mentre le loro doti terapeutiche alludevano al cognome del casato. ${ }^{66}$ Significativa in questo senso fu la scelta di consacrare la chiesa non il giorno in cui si festeggiava il santo patrono e neppure quello dedicato ai santi Cosma e Damiano, bensì la data in cui si celebravano i tre re orientali, affrescati da Beato Angelico anche nella cella del convento riservata a Cosimo il Vecchio. ${ }^{67}$

La festa dei Magi organizzata nel I447, dotata di cospicui finanziamenti da parte della Signoria e passata a cadenza quinquennale, fu descritta da Lionardo Morelli come "una cosa maravigliosa, e di grande dispendio» e da Giusto d'Anghiari come una «bella festa e saria stata più bella se 'l vento non l'avesse guasta». ${ }^{68}$ Tra $i$ «festaioli» incaricati dell'organizzazione e degli apparati scenografici figuravano Giovanni de' Medici, secondogenito di Cosimo, e l'architetto di famiglia Michelozzo, responsabile della ristrutturazione del convento di San Marco e in quegli anni impegnato nei lavori di edificazione del palazzo mediceo. ${ }^{69} \mathrm{Nel}$ gennaio I45I Cosimo il Vecchio prese parte alla cavalcata, sfilando lungo via Larga dove la sua imponente residenza era in fase di costruzione, abbigliato con una «bella ciop[p]a a la polacca di martore e zibellini», dono dell'amico aretino

64. HATFIELD i970, pp. i 2, I46 doc. 5b. Vedi anche PETRIBONI - RINALDI 20oi, p. 2i6. Rab Hatfield interpreta la presenza di Davide un riferimento ai salmi a lui dedicati e associati alla festa dell'Epifania, mentre Franco Cardini ritiene che nel corteo furono introdotti elementi carnevaleschi e allegorici privi di un diretto riferimento ai Magi, HATFIELD I970, p. II2 nota 27; CARDINI 20I7, p. I6I. Riguardo a un possibile riferimento politico: nel I4I6 una statua di David, scolpita da Donatello tra il I408 e il i 409, fu spostata dalla sua originaria collocazione presso il duomo a Palazzo dei Signori. L'immagine di un carro trionfale con Davide vittorioso su Golia si ritrova sia in ambito religioso, nella formella della Porta del Paradiso (I 425-I 452) di Lorenzo Ghiberti, sia in ambito profano, nel fronte di cassone dipinto da Pesellino con il Trionfo di David (I452-I457) vedi DONATO I99I, pp. 96-98; ROGERS I996, p. 293; The Gates of Paradise 2007, pp. IIO-II7; STADERINI 20Io, pp. 246-25I.

65. HATFIELD I970, pp. I35-I4I; VENTRONE 20I6, p. 205 e in particolare nota 373.

66. HATFIELD I970, p. I37; CARDINI I99ib, pp. 69-70; KENT 2005, pp. 29, 388 . Per i lavori di ristrutturazione della chiesa di San Marco vedi SCUDIERI 2000, pp. Io-I3.

67. Riguardo agli affreschi dipinti da Beato Angelico nel convento di San Marco vi sono opinioni discordanti: la critica recente propende per una partecipazione di Benozzo Gozzoli, mentre Miklós Boskovits ha fortemente ribadito l'autografia angelichiana, soprattutto per l'Adorazione dei Magi nella cella 39, BOSKOVITS 2002, pp. 43-44.

68. MORELLI I785, p. I73; ANGHIARI 2002, p. 9I.

69. KENT 2005 , p. 388. 
Rosello Rosselli che - secondo quanto riferito dalla moglie Contessina al figlio Giovanni - sostituì la sopravveste in drappo d'oro degli anni precedenti. ${ }^{70}$

Si trattava di uno spettacolo pubblico, organizzato da una ristretta cerchia di fiorentini autorevoli riuniti sotto la Compagnia dei Magi, con le vie della città come scenografia e il mirato scopo, pur mantenendo un sostrato religioso, di allietare e allo stesso tempo ammaliare la popolazione evocando un contesto sontuoso e cavalleresco del tutto inusuale sulle rive dell'Arno. Il fasto trapelava, oltre che dagli abiti dei Magi e del loro seguito per quel giorno esonerati dal dover rispettare le leggi suntuarie, dalla reggia di Erode che nel I429 comprendeva un «driççatoio di valuta assai degli arienti che su v'erano", ossia l'immancabile credenza dei banchetti ufficiali con l'esposizione di preziosi oggetti in oro e argento quale segno tangibile di ricchezza. ${ }^{\text {I }} \mathrm{Nel}$ I469, ultima edizione nota della festa, la magnificenza della residenza del re dei Giudei raggiunse livelli ancora più elevati: nei pressi del convento di San Marco fu eretto un palazzo ligneo di notevoli dimensioni con la facciata scandita da colonne e un porticato costruito sospendendo panni azzurri punteggiati di stelle, mentre le stanze interne furono arredate con cortine in seta, arazzi alle pareti, pregiati tappeti a coprire i pavimenti e suppellettili preziose. Alla pompa contribuirono anche gli ambasciatori inviati dai Magi alla corte di Erode: partiti dagli accampamenti dislocati in tre diversi quartieri, percorsero le vie della città - secondo quanto riportato nei Libri de temporibus suis (I480-I482) dal teologo domenicano Giovanni Caroli - con al seguito paggi, servi e schiavi in abiti orientali, musici, bestie da soma cariche di casse e bagagli, animali selvatici ed esotici e altri "contraffatti» così come pure cani e uccelli addestrati per la caccia..$^{72}$ Pare che ogni quartiere, memore «dei passaggi papali e regali e della trasfusione dei loro connotati nelle ambizioni aristocratiche del Comune e soprattutto delle sue grandi famiglie», si fosse prodigato per superare in magnificenza e ricchezza le altre delegazioni in una sorta di competizione che, transitando per tutte le piazze, aspirava a contribuire alla fama della città. ${ }^{73}$ È probabile che una certa suggestione in questo senso l'avesse suscitata, tra i molti cortei che nel corso del tempo giunsero a Firenze, quello dell'imperatore Federico III nel I 452 così descritto da un contemporaneo:

begli huomini, bene adobbati di vestimenta, coperti d'oro e d'ariento et di perle et di pietre pretiose, con grandissima quantità di belle collane d'oro et perle et gio[i] e di gran valimento [...] et con tante argenterie d'oro et d'ariento da tavola et da altare ed altre magnificençe che

70. HATFIELD I970, pp. I36-I37 nota I42; KENT 2005, pp. 388-389, 404 nota 49. La costruzione di Palazzo Medici, poco distante dalla "casa vecchia» pure in via Larga, iniziò nel I 444 e si protrasse fino al I 458 vedi SAALMAN -MATTOX I985, pp. 329-345.

7I. PETRIBONI - RINALDI 200i, p. 2i6; HATFIELD I970, pp. II2, I 46 doc. 5b; VENTRONE 20 I6, pp. 93, 2I2. Il termine "driççatoio», da Rab Hatfield dubitativamente interpretato come copricapo, è stato di recente chiarito da Paola Ventrone.

72. HATFILED I970, pp. II4-II8, I48-I5 I doc. 9b; TREXLER I997, p. 9I; VENTRONE 20I6, pp. 2II215. Il palazzo di Erode costruito per la festa del I 469 era alto poco meno di 9 metri, lungo 23 e profondo 7.

73. TREXLER i980, pp. 297-299; GUARINO I988, p. 3I; TREXLER I997, p. 9I. 
sserebbe impossibile a racchontare. Et furono per numero di cavagli $\star \star \star$, sì bbene a ordine d'uomini et di begli et grossi cavagli che sarebbe dificile a poterne raccoççare in [I]Talia altrettanti et di tanta riccheçça [...] Et aveva con detta conpagnia moltissimi falchoni e astori et gram magnificentia di cani da chaccia et altri animali da prenderne diletto in quantità [...] Et in detta conpagnia aveva gran quantità di nobili trombetti et pifferi et d'ogni generationi di suoni, et dimolti araldi et giuchulari et buffoni, come si richiede a ssi fatta baronia. Et avevano gran quantità di some di lor cariaggi di loro vestimenti et di loro adornamenti che valevano uno tesoro, et era bella cosa. ${ }^{74}$

Riflesso dell'evoluzione in tono sempre più marcatamente sfarzoso e profano della festa dei Magi si rintraccia nei dipinti commissionati dai membri dell'élite fiorentina; quelli invece realizzati su incarico delle istituzioni religiose sembrano aver conservato un carattere prettamente sacro dove dettagli come animali esotici volti a evocare il mondo delle corti risultano del tutto assenti, tranne i camelidi la cui presenza trovava piena giustificazione nella Bibbia e nella Legenda aurea. ${ }^{75}$ Illuminante, a questo proposito, è il pensiero espresso da Antonino Pierozzi - priore del convento di San Marco e nel I446 nominato da papa Eugenio IV arcivescovo di Firenze - nella Summa theologica (I440-I459) quando deplora i «curiosa» dipinti di soggetto sacro destinati alle chiese con la raffigurazione di abiti sfarzosi, cani che cacciano lepri e scimmie, ossia particolari a suo avviso del tutto inutili per la devozione. ${ }^{76}$

Alle commissioni della famiglia medicea, e alla loro particolare venerazione nei confronti dei re orientali, sono da ricondurre gran parte delle Adorazioni dei Magi dipinte nell'arco cronologico compreso tra il i 434, anno del rientro di Cosimo il Vecchio dall'esilio, e il I 492, anno della morte di Lorenzo il Magnifico. Se l'inventario di Giovanni di Bicci, padre di Cosimo il Vecchio, stilato nel I4I8 non comprendeva immagini dei Magi, negli anni successivi tra $i$ beni posseduti dai suoi discendenti figurano una "storia di Magi leghata in ariento dorato» di Piero di Cosimo, due arazzi con l'Adorazione dei Magi e almeno quattro dipinti su tavola con la stessa iconografia, alcuni eseguiti da prestigiosi pittori del tempo quali Domenico Veneziano e Beato Angelico. ${ }^{77}$ In queste opere, così come pure in quelle commissionate da illustri famiglie fiorentine gravitanti nell'orbita del potente casato, la crescente influenza esercitata dalle sfarzose sfilate patrocinate dai Medici, alle quali partecipavano insieme ai loro affiliati, si fece sempre più eviden-

74. PETRIBONI - RINALDI 200I, pp. 365-366.

75. Vangelo di Matteo (2:I-I2). Alla Legenda aurea di Iacopo da Varazze si deve la notizia che per percorrere il lungo viaggio dall'Oriente a Betlemme in così breve tempo i re Magi "giunsero in sella a dromedari, che sono animali velocissimi che corrono in un sol giorno quanto un cavallo in tre giorni», VARAZZE 2007 , pp. I57-I58. Nell'Adorazione dei Magi del Maestro dell'Epifania di Fiesole il corteo e gli animali esotici sono assenti, unica eccezione è la giraffa di ridotte dimensioni in secondo piano, probabile riferimento all'affiliazione medicea del committente vedi pagina 228 .

76. STRELHKE 2005 , p. 52; GILBERT I988, p. I74.

77. HATFILED i970, p. I37; COLE AHL i996, p. 86; Inventari medicei I996, p. 96; Libro d'inventario I992, p. I2, 23, 33, 68, 78, I 6. Nell'inventario il tondo dipinto da Domenico Veneziano fu attribuito a Pesellino vedi pagina 209 nota IIO. 
te: il seguito dei Magi diventò più affollato di personaggi elegantemente abbigliati, il numero di cavalli accresciuto a scapito della presenza dei camelidi, la fauna esotica inserita quale segno tangibile di status symbol come pure i musici, gli gnomi e i paggi africani. L'iconografia dell'Adorazione dei Magi si era così trasformata da evento sacro in vera e propria scena di raffinata vita signorile traendo ispirazione dai cortei che il giorno dell'Epifania allietavano la città di Firenze.

\section{I.2. Valenza simbolica dei Magi nella Firenze oligarchica}

Le origini dell'introduzione del culto dei Magi nella città del giglio restano ancora incerte. Richard Trexler, sulla scorta dei documenti rintracciati, propone di ricondurle allo spettacolo messo in scena il 6 gennaio I390 dal ricco mercante e banchiere fiorentino Baldassarre degli Ubriachi per celebrare il suo omonimo patrono..$^{78}$ A lui è pure da ricondurre, tra il ${ }_{3} 365$ e il $\mathrm{I} 378$, il patrocinio per la costruzione di una cappella intitolata ai tre re orientali nella chiesa di Santa Maria Novella, dove desiderava essere sepolto. ${ }^{79}$ Ulteriore attestazione della sua devozione ai Magi si rintraccia nel Diario di Bartolomeo del Corazza che in data 22 giugno I 434 annotava l'arrivo a Firenze di papa Eugenio IV nel «luogo che fu di Baldassare Ubriachi, dove sono i Magi, sopra la porta a piè di Monte Uliveto, in su la strada fuori della Porta a San Friano». ${ }^{80}$

Uomo di mondo che aveva ricoperto le prestigiose cariche di ambasciatore e agente al servizio dei più grandi signori del tempo - Martino I d'Aragona, Riccardo II d'Inghilterra, Jean de Valois duca di Berry e Gian Galeazzo Visconti - e viaggiato al seguito dell'imperatore Carlo IV che nel I369 gli conferì l'onorificenza di conte Palatino, Baldassarre degli Ubriachi ben doveva conoscere i fasti e le sontuose cerimonie delle raffinate corti italiane ed europee. ${ }^{8 \mathrm{I}}$ È quindi plausibile - come ipotizza Paola Ventrone - che una volta rientrato a Firenze il facoltoso fiorentino con aspirazioni signorili e ambizioni politiche avesse finanziato e organizzato la festa dei Magi del I390, forse con un triplice scopo: manifestare pubblicamente il prestigio del suo casato, accattivarsi l'ammirazione dei suoi concittadini e, non da ultimo, assicurarsi qualche voto in vista dello scrutinio che l'anno seguente avrebbe decretato i candidati eleggibili per i tre Maggiori Uffici. Ambizioni andate deluse ma che gli garantirono un riconoscimento all'interno dell'élite di governo e la stima della popolazione

78. TREXLER 1987, pp. 75-I67. Raimondo Guarino reputa suggestiva la tesi di Richard Trexler, mentre Franco Cardini e Paola Ventrone la ritengono plausibile vedi GUARINO I988, p. 28; CARDINI I99Ib, pp. 6366; VENTRONE 20I6, pp. 85-86.

79. TREXLER I987, pp. 84-88.

80. CORAZZA I 894 , pp. 284-285. Un riferimento a Monte Oliveto si rintraccia anche nella Historia trium regum (I370 ca.) di Giovanni da Hildesheim: «Balthasar, re di Godolia e di Saba, giunse per il cammino che aveva seguito, insieme con il suo esercito, e si fermò nelle tenebre, presso il Monte Oliveto, in un villaggio che ivi chiamano Galilea", HILDESHEIM I966, p. I44.

8I. GOLDTHWAITE 20I3, pp. 243-244. 
che aveva assistito allo spettacolo. ${ }^{82}$ A lui sarebbe pertanto da ricondurre l'introduzione sulle rive dell'Arno di uno strumento di propaganda politica senza precedenti, ispirato alle pompe regali, che tanta presa aveva avuto sull'intera città.

Se - come ritiene Richard Trexler - la cavalcata dei Magi organizzata a Milano nel 1336 rientrava nella strategia di affermazione dei Visconti quale strumento per emulare l'aristocrazia e legittimarsi così agli occhi della collettività, senza per altro destare sospetti trattandosi di uno spettacolo ammantato di sacralità, questa necessità venne meno nel $\mathrm{I} 395$ quando Venceslao IV re di Boemia e Germania conferì a Gian Galeazzo Visconti il titolo di duca. ${ }^{83}$ A Firenze, invece, città eminentemente mercantile governata da un regime repubblicano sprovvisto di un cerimoniale diplomatico in grado di competere con quello delle corti italiane ed europee, la festa dei Magi costituì il pretesto per manifestare e ostentare ricchezza senza alimentare fraintendimenti. Oltre a ciò, allestire uno spettacolo con un folto corteo popolato da personaggi sfarzosamente abbigliati che sfilavano in sella a possenti destrieri per le strade cittadine era un modo per evocare le ambasciate fiorentine che si erano recate presso le più importanti corti italiane e straniere offrendo, alla stregua dei Magi, doni a sovrani e sultani.

In quest'ottica ben si comprende il sapore marcatamente cortese-profano e il tocco esotico che Gentile da Fabriano aveva infuso nell'Adorazione dei Magi commissionata da Palla Strozzi, banchiere fiorentino più volte chiamato a ricoprire una tra le cariche più ambite dalla classe mercantile: quella di ambasciatore inviato dalla Signoria presso la corte pontificia e nelle città di Venezia, Ferrara, Siena e Napoli. ${ }^{84} \mathrm{Fu}$ proprio in occasione della missione diplomatica presso la corte partenopea, tra la fine del I4Is e gli inizi del I4I6, che Giacomo II di Borbone gli conferì gli speroni d'oro nominandolo cavaliere, onorificenza celebrata dalla Signoria al suo rientro in città con l'omaggio "di pennone e di sopravveste d'uomo, di cavallo, e di targa». ${ }^{85}$ A partire da quel momento Palla Strozzi, fiero di tale carica che lo elevava di rango, fece seguire alla sua firma la lettera «K» abbreviazione del titolo di «Kavaliere». ${ }^{86}$ Allusione a questo onore si ritrova nella pala d'altare dove in primo piano è raffigurato un paggio nell'atto di liberare dagli speroni d'oro il magio Baldassarre, mentre alle sue spalle si stagliano Palla Strozzi e il figlio Lorenzo, prima volta, sembrerebbe, che in ambito fiorentino il committente appare ritratto al centro del dipinto e non, come di consuetudine, in posizione defilata e di profilo. ${ }^{87}$

82. TREXLER I987, pp. IOO-IO2; VENTRONE 2016 , p. 86.

83. TREXLER I997, p. 89.

84. Sebbene gli ambienti di corte padani fossero ben noti a Gentile da Fabriano, Raimondo Guarino ipotizza che la presenza a Firenze nel I4I9 di papa Martino V con il suo seguito possa aver influenzato l'artista giunto in città per dipingere la Pala Strozzi vedi GUARINO I988, pp. 29-3I. Vedi pagina I90.

85. STREHLKE 2005, pp. 42-43; TOGNETTI 2009, p. 42; VENTRONE 20I6, p. 94; CORAZZA I894, p. 255.

86. BELLE I972, p. ii 8; STREHLKE 2005, p. 43.

87. Paola Ventrone, rifacendosi allo studio di Darrell Davisson, identifica le figure con Palla Strozzi e il padre Nofri, mentre le ricerche attuali sono più propense a riconoscervi Palla Strozzi e il figlio Lorenzo, VENTRONE 20I6, p. 95. Vedi anche DE MARCHI 2006b, p. I82 e in particolare nota 45. 
Sarà pure da tener presente che in quegli anni Leonardo Bruni, intimo amico di Palla Strozzi, aveva composto e dedicato a Rinaldo degli Albizzi, insignito del titolo di cavaliere nel I4I8, il De militia (I42I) nel quale illustrava le origini della cavalleria e gli obblighi dei cavalieri repubblicani fiorentini senza per altro tralasciare l'importanza dell'abito e degli speroni aurei; testo che Palla Strozzi aveva copiato di proprio pugno per conservarne una copia nella sua biblioteca ${ }^{88}$ Infine, la profusione di oro, i tessuti pregiati, l'opulenza delle vesti, i cavalli splendidamente bardati e la presenza di animali esotici, tra cui felini addestrati per uno sport elitario come la venatio, contribuivano a rendere la pala del fabrianese «un po' scena di caccia in un paesaggio agreste, un po' pellegrinaggio cortese», ossia strumento capace di conferire lustro al committente così come lo era prendere parte alla sfilata dei Magi il giorno dell'Epifania. ${ }^{89}$

Si trattava quindi di un mezzo di propaganda che Palla Strozzi, appartenente a uno dei più importanti casati del reggimento oligarchico pre-mediceo, aveva accortamente adottato per sottolineare il prestigio di cui godeva. Membro del clan familiare fiorentino più potente della città, Palla Strozzi dimostrava di avere gusti:

sicuramente più evoluti e cosmopoliti di quelli paterni, [che] parevano poco tipici della cultura borghese e mercantile della Firenze primo quattrocentesca. Con i suoi caratteri aristocratici, elitari ed edonistici, l'Adorazione dei Magi di Gentile da Fabriano si confaceva piuttosto all'estetica cavalleresca di un nobile mecenate o di un raffinato signore padano. ${ }^{90}$

Non sarà quindi una mera coincidenza se decise d'ingaggiare il celeberrimo Gentile da Fabriano, artista che papa Martino V, dopo averne ammirato nel I4I8 gli affreschi realizzati a Brescia per Pandolfo Malatesta, aveva caldamente invitato a prestare la sua opera presso la corte papale di Roma. ${ }^{9 \mathrm{I}}$ L'esilio padovano inflittogli da Cosimo de' Medici non affievolì certo l'interesse di Palla Strozzi nei confronti della cappella di famiglia, conscio del fatto che agli occhi dei fiorentini equivaleva all'immagine pubblica del suo casato. Nel primo testamento redatto nel I447, oltre ad augurarsi di essere sepolto sotto l'altare che ospitava la pala con l'Adorazione dei Magi, impartì disposizioni alla moglie Marietta di vendere tutti i suoi abiti tranne un «hucco [lucco] di vellutato in cremisi» con il quale far confezionare una pianeta da mandare «alla chiesa di Sancta Trinita alla capella nostra nuova che Nofri mio padre lasciò si facesse. E così io feci. E la stia insieme con l'altre cose e fornimenti ch'io feci fare in ornamento di quella capella, continuamente». ${ }^{92} \mathrm{Al}$ Trattato politico-morale del contemporaneo Giovanni Cavalcanti si deve invece la notizia che,

88. STREHLKE 2005, pp. 43, 52; BELLE 1972, p. 174 n. 6 «Leonardus Aretinus De militia di mano di m. Palla di Nofri degli Strozzi».

89. CARDINI I99ib, p. 75. Per l'importanza delle vesti lussuose indossate durante le feste organizzate da compagnie e confraternite fiorentine vedi PERI 2000, pp. 25-47.

90. TOGNETTI 2009, pp. 4I-42. Per la personalità di Palla Strozzi vedi anche CHRISTIANSEN 2005, pp. 20-2I.

9i. Ivi, p. I3.

92. Ivi, p. 21; JONES i984, pp. 92-94 doc. I39a e I39b. 
dopo il bando di Palla Strozzi, la cappella era diventata luogo di ritrovo per la fazione anti-medicea fino al I444, quando fu sventata la «sacramentata congiura» ordita da "quatordici ciptadini, nella capella di messere Palla in Sancta Trinita».93

Nella ricerca di una nuova identità in grado di nobilitare $i$ grandi casati fiorentini e, di conseguenza, conferire lustro alla città, non deve sorprendere se personaggi del calibro di Baldassarre Ubriachi e Palla Strozzi, che per aver svolto il ruolo di ambasciatori ben conoscevano il cerimoniale e la cultura delle più raffinate corti italiane ed europee, si fossero prodigati per introdurre a Firenze, sulla scorta di quanto avvenuto nel I336 a Milano, uno spettacolo e un'iconografia dedicati ai tre re orientali. Non solo, la comparsa nella città del giglio dell'Adorazione dei Magi raffigurata in chiave marcatamente cortese-cavalleresca è con tutta probabilità da interpretare quale risposta alle ostilità che tra il I4I9 e il I 425 la Signoria manifestò nei confronti delle confraternite, tra cui anche quella organizzatrice della festa dei Magi che tra gli affiliati probabilmente annoverava Palla Strozzi, minacciandone la dissoluzione perché ritenute spazi sociali di potere consortile alternativo al Comune. ${ }^{94}$ Oltre a ciò, chi meglio dei tre re orientali considerati patroni di mercanti e viaggiatori avrebbe potuto incarnare nell'immaginario fiorentino la ricca classe mercantile che attraverso i commerci con l'Oriente era riuscita ad accumulare enormi ricchezze?

\section{I.3. Valenza simbolica dei Magi in epoca medicea}

Negli anni successivi al rientro dall'esilio di Cosimo il Vecchio, di pari passo con il consolidarsi del suo potere, il legame tra il casato mediceo e il culto dei Magi si fece sempre più stretto. Il cripto-signore di Firenze alla ricerca di un mezzo che gli consentisse di palesare pubblicamente il prestigio di cui godeva e desideroso di crearsi un carisma personale, evitando però l'insorgere di contrasti e sospetti da parte del regime repubblicano, adottò scaltramente uno spettacolo già inserito nel contesto della cerimonialità cittadina e, quindi, ormai ritualizzato. Appropriarsi del culto dei Magi doveva essergli sembrato il modo più semplice per raggiungere il suo scopo. La festa urbana si prospettava, infatti, come un momento d'integrazione nel quale si celebrava l'unità del gruppo comunitario ma, al tempo stesso, affioravano gerarchie di potere, divisioni dei ruoli, meccanismi dei consensi. Per di più il fasto e la spettacolarità del corteo dei Magi consentiva largo sfoggio di vesti lussuose e cavalli riccamente bardati, e forse anche di animali esotici, atti a suggerire prestigio, potere e ricchezza. In quest'ottica non sarà da sottovalutare il ruolo esercitato dalla pala con l'Adorazione dei Magi in chiave cortese-profana commissionata da Palla Strozzi, uomo più facoltoso di Firenze insignito del titolo di

93. The Trattato I973, p. I96.

94. HATFIELD I970, pp. IIo-Iii; GUARINO I988, p. I7; CHRISTIANSEN 2005, p. 35; VENTRONE 20I6, pp. 94-95. 
cavaliere: sfilare in un corteo che evocava l'iconografia per la prima volta introdotta in città dal suo rivale aveva il potere di generare un mirato messaggio sull'influenza esercitata in campo politico da Cosimo il Vecchio che aveva fatto bandire il suo antagonista. Non è neppure da escludere un'allusione al concilio per l'unione delle due Chiese che, grazie ai cospicui finanziamenti elargiti dal signore mediceo, nel 4439 fu trasferito da Ferrara a Firenze, comportando l'arrivo in città di numerose delegazioni orientali, bizantine, armene, copte ed etiopi, il cui splendore ed esotismo dovettero impressionare i fiorentini. Appena qualche anno più tardi, il 6 gennaio I443, giorno dedicato ai tre re orientali, la chiesa di San Marco posta sotto il patrocinio del casato mediceo, e sede della confraternita dei Magi, fu riconsacrata da papa Eugenio IV che per l'occasione concesse indulgenze anche ai fedeli che negli anni successivi vi si fossero recati per la ricorrenza dell'Epifania. ${ }^{95}$ Oltre ai legami con il culto dei Magi, alcuni significati simbolici attribuiti ai re orientali erano particolarmente consoni al casato mediceo: patroni di viaggiatori e mercanti, tra i doni recati dall'Oriente vi erano oro e mirra, ossia metallo che alludeva alle attività bancarie dei Medici e sostanza vegetale usata nella professione che onomasticamente evocava il loro cognome. ${ }^{96}$

Nel I 447 Giovanni de' Medici si occupò dell'organizzazione del corteo dei Magi, nel I 45 I Cosimo il Vecchio sfilò sfarzosamente abbigliato insieme ai figuranti e nel I469 l'allestimento del palazzo di Erode, col trascorrere del tempo sempre più principesco, fu dislocato da piazza dei Signori a piazza San Marco, area posta sotto l'influenza medicea e prossima al palazzo di famiglia che ben si prestava a una vasta gamma di simbolismi personali. ${ }^{97}$ Tutto questo sfoggio di magnificenza trovava piena giustificazione negli ideali politici propugnati da Matteo Palmieri, personaggio gravitante nell'orbita medicea e dal I444 cancelliere della Repubblica, che nella Vita civile (I430-I440) scriveva:

Magnificenza è posta nelle grandi spese dell'opere maravigliose e notabili; per questo tale virtù non può essere operata se non da' richi et potenti; et poveri et mezani non supperiscono a quella, et se si sforzassino in dimonstrarsi in alcune opere magnifici, sarebbe di cose piccole, in elle quali sopraspendere sarebbe matta sciocheza. Le spese magnifiche vogliono essere grandi et convenienti in degne opere in modo che l'opera paia mirabile et meriti la facta spesa et ogni cosa sia bene allogato in essa. Le spese del magnifico vogliono essere in cose honorifice e piene di gloria, non private ma publice, come in edificii et ornamenti di

95. HATFEILD I970, p. I36.

96. CARDINI 20I7, p. I63. In relazione alle ricchezze medicee e alla loro devozione nei confronti dei Magi, Paola Ventrone ipotizza un legame con Giovanni di Bicci, padre di Cosimo il Vecchio, che al tempo di papa Giovanni XXIII, al secolo Baldassarre Cossa e quindi omonimo di un magio, svolgeva la funzione di banchiere della Santa Sede. Deposto come antipapa al concilio di Costanza e tenuto prigioniero da Ludovico di Baviera, Baldassarre Cossa fu liberato nel I4I9 grazie all'intervento del neoeletto papa Martino V e a lunghe trattative condotte da un agente di Giovanni di Bicci seguite dal pagamento di un ingente riscatto; si stabili poi a Firenze dove, morto dopo pochi mesi, fu inumato nel battistero vedi VENTRONE 20I6, pp. 205-206.

97. Da un sonetto di Niccolò d'Arezzo indirizzato «ai Capitani della festa de' Magi a dì 6 di novembre I 435 , perché s'aparecchiavano a fare la festa" si ricava la notizia che già nel I 436, quindi poco dopo il rientro dall'esilio di Cosimo il Vecchio, si svolse una festa dei Magi vedi VENTRONE 20I6, pp. 206-207. 
templi, theatri, logge, feste publice, giuochi, conviti: et in così facte magnificentie non computare né fare conto di quanto si spenda, ma in che modo sieno quanto più si può maravigliose et bellissime.

Opera che riscosse grande successo tra i contemporanei se, negli anni immediatamente successivi la stesura, almeno sette copie erano di proprietà di fiorentini e due di queste recavano sulla legatura lo stemma mediceo..$^{8}$

In relazione alla connotazione esotica della festa dei Magi sarà, poi, da tener presente che all'epoca il mitico Prete Gianni, sovrano orientale di fede cristiana ritenuto discendente dei Magi e a capo di un immenso regno posto al confine con il paradiso terrestre dove abbondavano ricchezze, mirabilia e un'infinità di animali esotici, godeva di grande popolarità. ${ }^{99}$ Noto soprattutto attraverso la letteratura e alcuni resoconti odeporici come il Milione di Marco Polo e l'immaginario Livre des merveilles du monde di Jean de Mandeville, alcuni viaggiatori e missionari avevano cercato di identificare il Prete Gianni con regnanti asiatici o africani, ma la sua fama era soprattutto legata alla famosa lettera - in realtà un falso - che nella seconda metà del XII secolo avrebbe inviato all'imperatore bizantino Manuele I Comneno, ben presto diffusa in tutta Europa attraverso numerose copie, nella quale decantava la sua superiorità e l'opulenza delle sue terre. Nel corso del XV secolo alcuni sovrani europei tentarono invano di fargli pervenire missive con richieste di aiuto per arginare la sempre più pressante avanzata dell'Islam, così come pure papa Eugenio IV che nel I 438 affidò al frate francescano Alberto da Sarteano una lettera - mai recapitata - con la richiesta di inviare alcuni rappresentanti al concilio. ${ }^{\mathrm{IOO}}$ A Firenze fu soprattutto noto grazie ai numerosi volgarizzamenti toscani della Lettera del Prete Gianni arricchita, rispetto alla versione originale in latino, da ragguagli su popolazioni e animali bizzarri in modo da soddisfare appieno il gusto per l'esotismo dei lettori tre e quattrocenteschi. Tra le sue carte personali Michele del Giogante, intimo amico di Cosimo il Vecchio, ne custodiva una copia eseguita intorno al I454 di suo pugno che recava l'annotazione «chose maravigliose del presto Giovanni». ${ }^{\text {IOI }}$ Non solo, alcune opere letterarie degli inizi del XV secolo quali il Guerrin Meschino e la Storia di Ugone d'Alvernia di Andrea da Barberino, presenti nelle biblioteche dei mercanti fiorentini e recitate dall'autore stesso sulla piazza di San Martino, narravano l'immenso potere e ricchezze del regno del Prete Gianni fino a farlo assurgere a «modello sociale alternativo». ${ }^{\mathrm{IO} 2} \mathrm{La}$ curiosità e l'interesse per questo sovrano orientale furono tali che nel I44I il segretario di Cosimo il Vecchio scrisse a Giovanni de' Medici, secondogenito del

98. PALMIERI I982, p. I47; VENTRONE 20I6, p. 204. Per i manoscritti con trascrizioni del testo di Matteo Palmieri vedi PALMIERI I982, pp. IX-XIX.

99. DI NOLA i966, pp. 47-50.

Ioo. Vedi pagina 59 .

IOI. KENT 2005, p. 387 e in particolare nota 40; BARTOLUCCI 200I, p. 93

I02. ZAGANELLI I995, p. 255; BARTOLUCCI I995, pp. 222-227. Per Andrea da Barberino vedi pagina 65 
signore mediceo, per informarlo che al concilio di Firenze era giunta una delegazione etiope inviata dal Prete Gianni, mentre l'immagine del suo regno non mancava mai dalle mappae mundi, dapprima collocato in Asia e con l'accrescersi delle conoscenze geografiche spostato in Africa, terra poco nota dove era ancora possibile credere avesse sede. ${ }^{\mathrm{10} 3}$

A sua volta, il vivo interesse nutrito dal ceto mercantile per la geografia svolse un'influenza rilevante nella messa in scena della festa dei Magi. In occasione del corteo la città fu percepita dall'immaginario collettivo quale proiezione della Terrasanta con la città di Gerusalemme idealmente rappresentata dal palazzo di Erode, in un primo tempo allestito presso il battistero e successivamente dislocato in piazza dei Signori, e Betlemme simboleggiata dalla mangiatoia con il Bambino all'interno della chiesa di San Marco.${ }^{\mathrm{IO}}$ Luoghi orientali, tra l'altro, ben noti a mercanti e pellegrini fiorentini che nelle terre d'oltremare si erano recati per davvero, così come pure a quelli che, non avendo potuto affrontare il viaggio, si erano dedicati alla lettura di diari odeporici e resoconti di pellegrinaggio.

Per la festa dei Magi tenutasi nel i469, dopo che Piero de' Medici era riuscito a sedare la congiura politica ordita da alcuni membri dell'oligarchia nel tentativo di ridimensionare il potere mediceo, il significato politico e la geografia simbolica della città assunsero una connotazione ancora più marcata. ${ }^{\text {IOS }}$ Per ribadire pubblicamente il controllo esercitato dai Medici sulla città e consolidare la posizione di Firenze agli occhi delle signorie italiane, il 6 gennaio fu organizzato uno splendido corteo che superava di gran lunga quelli precedenti. Se tanta magnificenza e regalità si proponevano di comunicare autorità - per altro confermata dalla concessione da parte di Luigi XI d'inserire il giglio di Francia nello stemma mediceo - la presenza al seguito dei Magi dei figli degli oligarchi filo-medicei con il viso coperto da maschere che riproducevano le fattezze dei padri e addestrati a imitarne i gesti costituiva un palese messaggio riguardo alla fedeltà non solo della classe dirigente ma anche della nuova generazione che gli sarebbe succeduta. ${ }^{\mathrm{IO}}$ Il fatto, poi, che la principesca reggia di Erode e la capanna di Betlemme, luoghi salienti dello spettacolo, fossero collocati in un'area di pertinenza medicea sembra sottintendere un'ulteriore testimonianza in favore di questa fazione. Non solo, l'attenta regia che aveva dislocato gli accampamenti dei Magi in tre diversi quartieri cittadini, dai quali erano partiti con le loro delegazioni per recarsi a San Marco, sembra voler sottintendere un preciso messaggio sul dominio dei Medici ormai esteso a tutta la città trasformata in una nuova

I03. KENT 2005, p. 387. Vedi anche pagine 59-60.

I04. CARDINI I99Ib, p. 64; VENTRONE 20I6, pp. 88, 92-93.

IO5. RUBINSTEIN i97I, pp. 2 I I-276. Nella sua descrizione della festa dei Magi del i469 Giovanni Caroli ritiene che lo scopo fosse rilanciare l'immagine pubblica di Firenze dopo il fallimento, tra la fine del I464 e la prima metà del I465, di alcune imprese commerciali di proprietà di autorevoli casati vedi VENTRONE 20I6, pp. 2I6-2I8.

I06. HATFIELD I970, p. I50; VENTRONE 20I6, pp. 2i 8-2i9. Richard Trexler considera, invece, la presenza dei giovani impegnati a impersonare i loro padri una sorta di esercizio a comportarsi in pubblico in vista di un possibile incarico nel ruolo di ambasciatori, TREXLER I997, p. 92. 
Gerusalemme. In relazione a questo fatto non sarà neppure da escludere una tappa, lungo il percorso della sfilata, presso la cappella annessa alla chiesa di San Pancrazio edificata per volere del ricco mercante Giovanni Rucellai nelle immediate adiacenze del suo imponente palazzo in via della Vigna, all'interno della quale si trovava un tempietto in scala del «sancto Sipolcro a similitudine di quello di Gierusalem del Nostro Signore Yesu Christo». ${ }^{107}$ Realizzato su progetto di Leon Battista Alberti, al quale fu affidato pure l'incarico di realizzare il palazzo di famiglia e la facciata della chiesa di Santa Maria Novella, il tempietto terminato nel I 467 presentava pareti ornate da pregiate tarsie marmoree con motivi geometrici che comprendevano, oltre allo stemma con la vela spiegata al vento dei Rucellai, alcuni emblemi medicei: il mazzocchio con le tre piume di Cosimo il Vecchio, l'anello diamantato con due piume di Piero e i tre anelli intrecciati con diamante di Lorenzo. Riferimento da ricondurre alle fastose nozze celebrate l'anno precedente tra Bernardo Rucellai, figlio di Giovanni, e Nannina de' Medici, figlia di Piero, per sancire l'alleanza tra le due potenti famiglie. ${ }^{108}$ Sottolineare questo legame con una tappa al sacello poteva quindi costituire un forte messaggio politico indirizzato alla popolazione negli anni immediatamente successivi alla sventata congiura anti-medicea.

A conferma delle sovrapposizioni tra fantasia e realtà che connotavano geograficamente la città di Firenze durante il corteo dei re orientali è una lettera inviata dalla Compagnia dei Magi situata «nelle partj d'orjente», ossia presso la chiesa di San Marco, alla Compagnia di San Bartolomeo, con sede nel quartiere di Santa Croce, tra il I469 e il I 470 per scusarsi di non poter partecipare alla «nuova festa e trjunfo" che si apprestavano a organizzare perché impegnati a trasformare i loro «regnj - et maximamente Egjpto, Ethiopja e Nubja, Arabja, Sabea, Jndja, Madja e ll'una e ll'altra, e 'rmenja - per tanto è jmpossjbile assentarcj”. ${ }^{\text {I09 }}$ Si trattava - secondo quanto annotato da Giusto d'Anghiari - della rappresentazione della Passione di san Bartolomeo svoltasi il 22 agosto I47I in piazza Santa Croce e del corteo con «due re, un nero e un bianco, con molte belle veste contrafatte, e delle vere e di valuta» che sfilò per le vie della città. ${ }^{\text {IIO }}$ Sebbene non siano stati finora rintracciati documenti relativi alla localizzazione dei regni orientali all'interno dello spazio urbano fiorentino, tranne l'Armenia collocata nell'area della parrocchia di San

I07. RUCELLAI 2013, p. I39. La replica del sacello di Gerusalemme commissionata da Giovanni Rucellai e il suo desiderio di esservi sepolto sono idealmente da ricondurre all'aspirazione comune a ogni pellegrino, ossia essere inumato a Gerusalemme in modo da resuscitare nelle immediate vicinanze del luogo del Giudizio. Per un approfondimento sulla cappella Rucellai e il tempietto del Santo Sepolcro vedi BELLUZZI 2009b, pp.IO3-I34.

I08. Giovanni Rucellai, unitosi in matrimonio con la figlia di Palla Strozzi nel i 428 e membro della Balìa responsabile dell'esilio di Cosimo il Vecchio, fu - come appuntato nel suo Zibaldone - «non acetto ma sospetto allo stato anni 27, cioè dal I 434 al I46I», vale a dire dal ritorno in città del signore mediceo fino alla stipula degli accordi con Piero de' Medici per unire i loro figli in matrimonio, RUCELLAI 20I3, p. 552.

I09. HATFIELD i970, pp. I20-I2I, I48 doc. 94; TREXLER I980, pp. 396-398, 402-403; KENT 2005 , pp. 389-390. Richard Trexler ha invece proposto di datare la lettera al I 47I, TREXLER I980, p. 40 I e in particolare nota I6I; ID. I997, pp. 9I-92.

IIO. ANGHIARI 2002, p. I68. 
Lorenzo e quindi sotto la diretta influenza del casato mediceo, Richard Trexler ipotizza di poter situare l'Arabia nella zona di Sant'Ambrogio, all'epoca comunemente indicata come "Città Rossa", e l'India nelle adiacenze del Mercato Vecchio, dove sorgeva la chiesa di San Tommaso apostolo che nella città indiana di Madras - attuale Chennai - subì il martirio. ${ }^{\text {III }}$

Con l'ascesa al potere di Lorenzo de' Medici, succeduto al padre Piero nel dicembre I469, la funzione ostentatoria del corteo orientaleggiante dei Magi, ispirato a un culto popolare medievale, andò scemando: sia perché non più conforme al gusto del tempo, sia perché in questo modo erano drasticamente ridotte le possibilità offerte ai facoltosi casati che vi prendevano parte di esibire pubblicamente le loro ricchezze. Gli spettacoli cittadini di epoca laurenziana, connotati da un palese intento ideologico-politico, ambivano a mettere in scena trionfi e allegorie ispirati a modelli dell'antichità, temi che, da un lato, rispondevano appieno alla nuova cultura umanistica e, dall'altro, consentivano al Magnifico, pur inserendosi nel tradizionale calendario della cerimonialità cittadina, di trasmettere alla popolazione mirati messaggi propagandistici riguardo al suo potere e alle aspirazioni personali: le sue doti politiche erano ora apertamente equiparate a quelle dei grandi e vittoriosi condottieri romani. ${ }^{\mathrm{II}}$

\section{I.4. La Cavalcata dei Magi di Benozzo Gozzoli}

Nel giugno I459 Cosimo il Vecchio commissionò a Benozzo Gozzoli un ciclo pittorico, realizzato in poco più di sette mesi, con la raffigurazione di una summa di episodi salienti per il suo casato: il concilio per l'unione delle due Chiese tenutosi a Firenze tra il I 439 e il I 443, la visita di Galeazzo Maria Sforza e papa Pio II nel I 459 e la cavalcata dei Magi, rito cittadino posto sotto il patrocinio mediceo. ${ }^{\text {II3 }}$ Committenza rivelatrice del potere acquisito da Cosimo che nel proprio sacello, dove era solito ricevere ospiti e personaggi illustri, ostentava uno sfavillante corteo popolato da membri del lignaggio, alleati e sostenitori per ricordare agli astanti il fondamentale ruolo raggiunto dai Medici nella scena politica. ${ }^{\mathrm{II}} 4 \mathrm{Del}$ resto, negli stessi anni Giovanni Rucellai lo aveva così descritto nel suo Zibaldone:

III. TREXLER I980, pp. 400-403; KENT 2005, p. 389; EAD. 2008, p. 362. Per i legami che univano la famiglia medicea alla chiesa intitolata a san Tommaso, missionario che, secondo quanto narrato nella Legenda aurea, in Oriente battezzò i Magi vedi KENT 2005, pp. 253-256.

i 2. ACIDINI LUCHINAT I990, p. 86; VENTRONE I992, pp. 29-32; EAD. 20i6, pp. 224-225. Lorenzo de' Medici, a differenza del nonno Cosimo e del padre Piero che preferirono operare nell'ombra, assunse con sempre maggior frequenza alte cariche della repubblica.

II3. VENTRONE. I992, pp. 22-26. Anna Padoa Rizzo, valutando l'iconografia e le continue pressioni esercitate dal committente, ipotizza che il ciclo pittorico fosse terminato entro Natale dello stesso anno, mentre altri studiosi sono più propensi a una generica datazione compresa tra il I 459 e il I 463-I 464, anno della partenza dell'artista da Firenze vedi PADOA RIZZO I993, p. 359; COLE AHL I996, p. 8I.

I I 4. Diversamente dal rivale Palla Strozzi, incorso in aspre critiche quando sull'altare della cappella di famiglia espose l'Adorazione dei Magi rifulgente di dettagli dorati, il signore mediceo preferì accortamente riservare la visione di una tale ostentazione di potere e ricchezza a una ristretta élite che godeva del privilegio di accedere alla sua cappella privata. 
cipttadino ricchissimo più che avessi mai la nostra cipttà e forte più che mai fosse in tutta Italia, huomo di grandissimo naturale, potentissimo cipttadino e di gran seguito e di grandissima riputazione dentro e di fuori, più che mai avesse la nostra cipttà per forma, che al tenpo suo disponeva del governo della cipttà come se proprio ne fussi stato singniore. ${ }^{\mathrm{II}}$

Filo conduttore della narrazione affrescata sulle pareti della cappella di famiglia era la Cavalcata dei Magi, tema strettamente connesso al casato che ormai da decenni patrocinava l'omonima Compagnia impegnata nell'organizzazione della festa dedicata ai tre re orientali. Se a prima vista la scelta iconografica sembra evocare l'episodio religioso del viaggio intrapreso dai Magi per giungere a Betlemme dove rendere omaggio a Gesù, in realtà si rivela permeata da una fitta rete di allusioni visive tese a esaltare e glorificare fatti politici di particolare rilievo per il committente, primo tra tutti il concilio per l'unione delle Chiese d'Oriente e d'Occidente tenutosi un ventennio prima a Firenze che, oltre a richiamare in città delegazioni europee e orientali, grande risonanza doveva aver avuto nelle terre d'oltremare speranzose in un aiuto per arginare la sempre più pressante avanzata turca. ${ }^{\text {II6 }}$ Un lustro dopo essere rientrato dall'esilio Cosimo de' Medici, grazie a un cospicuo finanziamento e allo stretto rapporto che lo legava al papa, aveva dato prova della sua influenza e abilità diplomatica nel concertare il trasferimento della sede del concilio da Ferrara a Firenze, dove nel 1439 in veste di gonfaloniere di Giustizia accolse con tutti gli onori il pontefice Eugenio IV, il patriarca di Costantinopoli Giuseppe II e l'imperatore bizantino Giovanni VIII Paleologo. ${ }^{17}$ In un analogo contesto di rappresentanza e di relazioni diplomatiche si andava a inserire la fastosa accoglienza riservata nel I459, anno di esecuzione degli affreschi, a Galeazzo Maria Sforza inviato dal padre Francesco, intimo amico e alleato di lunga data di Cosimo il Vecchio, con l'incarico di rendere omaggio a papa Pio II e scortarlo oltre l'Appennino nell'ultimo tratto di viaggio alla volta di Mantova, dove si sarebbe svolta la dieta da lui indetta per assicurarsi l'appoggio delle potenze cristiane nel promuovere una guerra santa volta ad arginare la sempre più minacciosa espansione musulmana dopo la conquista di Costantinopoli. ${ }^{\text {II8 }}$ I complessi e solenni festeggiamenti ebbero inizio il 29 aprile con una giostra in piazza Santa Croce, il giorno seguente si tenne un lussuoso ballo in piazza del Mercato Nuovo quando, per onorare il giovane Sforza

II5. RUCELLAI 20I3, p. I8I.

I 6 . Illuminante sulla simbologia all'epoca attribuita ai tre re orientali e a una possibile connessione con il concilio è un passo della lettera inviata da papa Pio II a Filippo di Borgogna: "Guarda, i Magi sono venuti dall’Oriente verso la stella $[. .$.$] portando non mirra, non oro, non incenso [...] ma cose molto più importanti e durature,$ ovvero l'unione tra le chiese e la pacificazione della chiesa cristiana» vedi RONCHEY 2009, p. I38.

II7. FUBINI I994, p. 27; MOLHO I994, pp. 90-9I; CORAZZA I894, pp. 296-297; MORELLI I785, pp. I69-I70; ANGHIARI 2002, p. 56. Dal I 434 al I 444 papa Eugenio IV soggiornò a Firenze, dove aveva trasferito la corte papale per sfuggire agli intrighi orditi dalla potente famiglia romana dei Colonna.

II 8. ILARDI I989, p. 228. Lo stretto legame che univa il signore milanese e quello mediceo trova testimonianza in una poesia in volgare che nel 1450 Cosimo de' Medici dedicò a Francesco Sforza da poco riconosciuto duca di Milano vedi KENT 2005, p. 38; Lirici toscani I975, vol. 2, pp. 55-56. 
e contribuire al prestigio della città, gli invitati fecero largo sfoggio di abiti in pregiati tessuti serici e costosi gioielli, mentre il primo maggio fu bandita una "caccia» in piazza dei Signori per l'occasione trasformata, con steccati alle vie d'accesso e palchetti destinati agli spettatori illustri, in un'arena dentro la quale si affrontarono leoni, tori, cavalli, cinghiali, altri animali e un manichino in forma di giraffa. ${ }^{119} \mathrm{La}$ sera, a concludere il rutilante susseguirsi di esibizioni, Lorenzo de' Medici, allora poco più che decenne, capitanò un'armeggeria lungo via Larga, cosparsa di sabbia e illuminata da una miriade di torce, in onore del giovane Sforza che presenziò affacciato a una finestra del palazzo mediceo. ${ }^{\mathrm{I} 20}$ Spettacoli che per la loro magnificenza furono descritti in numerosi libri di ricordi, cronache e «istorie» ed eternati da due poemetti encomiastici in volgare di autore anonimo dedicati a Cosimo il Vecchio. ${ }^{\text {I2I }}$

Fatti storici che, grazie a una sapiente regia, erano armoniosamente confluiti nell'intrinseco simbolismo politico dell'affresco benozzoliano. All'interno del sacro sacello il fregio pittorico si sviluppava con continuità lungo tre pareti - la quarta si apriva su una scarsella dove era alloggiato l'altare con l'Adorazione del Bambino dipinta da Filippo Lippi - ciascuna riservata a uno dei tre re orientali che, accompagnati dal loro seguito, si prospettavano come protagonisti incontrastati della narrazione. ${ }^{\text {I22 }}$ Il paesaggio raffigurato in secondo piano si presentava, invece, più simile $\mathrm{a}$ un fondale scenico che a uno spazio vero e proprio, tanto da far ipotizzare uno stretto legame con la precedente esperienza di Benozzo Gozzoli nella realizzazione di apparati scenografici destinati alle sacre rappresentazioni allestite dalle confraternite. ${ }^{23}$ Il fatto, poi, che ciascun magio avesse al suo seguito undici accompagnatori personali, formando un gruppo composto da dodici individui tipico delle «brigate», contribuiva ulteriormente a rimandare a un contesto ludico e politico nello stesso tempo. ${ }^{\text {I24 }}$

I I9. Vedi pagine I29-I30.

I20. LURATI 20I2, pp. 38-39.

I2 I. I poemetti encomiastici, conservati alla Biblioteca Nazionale Centrale di Firenze, si intitolano Ricordi di Firenze dell'anno I459 (ms. Magliabechiano XXV. 24) e Terze rime in lode di Cosimo de' Medici e de' figli e dell'honoranza fatta l'anno 1458 [sic] al figliuolo del duca di Milano et al Papa nella loro venuta a Firenze (ms. Magliabechiano, VII. I I I). Per la relativa bibliografia vedi LURATI 2012, p. 55 nota 53. A Firenze il genere letterario con descrizioni in forma laudativa di spettacoli, già diffuso nelle corti rinascimentali, sembra essere stato inaugurato proprio in occasione delle feste del I 459 con i Medici come protagonisti vedi VENTRONE 2006, p. 20 I.

I22. Nel I422 papa Martino V concesse al giovane Cosimo de' Medici e alla moglie Contessina de' Bardi il privilegio di possedere un altare portatile che li autorizzava a far celebrare la messa nel loro palazzo privato vedi SAALMAN - MATTOX i985, pp. 343 Appendix VI, 344-345 Appendix IX.

I23. PADOA RIZZO I972, pp. 57-58; EAD. I993 pp. 359-360. Sempre in relazione al potere della famiglia medicea, durante il concilio la sacra rappresentazione dell'Annunciazione fu ambientata nella chiesa di San Marco, posta sotto il suo patrocinio, e l'incarico della realizzazione degli innovativi apparati scenici con tutta probabilità affidato da Cosimo de' Medici a Filippo Brunelleschi. Grazie a una nuova traduzione italiana dei manoscritti russi del prelato ortodosso Abramo di Souzdal, che aveva assistito al dramma, Paola Ventrone ha potuto dimostrare che fu inscenato nella chiesa di San Marco e non, come precedentemente ipotizzato, in quella di San Felice o della Santissima Annunziata, VENTRONE 200I, pp. 43-44.

I24. ACIDINI LUCHINAT I993a, pp. 39-40. I potenti lignaggi fiorentini con aspirazioni istituzionali si servivano delle brigate, associazioni di giovani appartenenti all'élite fiorentina preposti all'organizzazione di giochi e spettacoli, per accrescere la loro popolarità agli occhi della popolazione, ma anche per consolidare un sistema di alleanze utili a tutelare la propria posizione politica vedi RICCIARDI I992, pp. 7I-83. 
La cavalcata aveva inizio sulla parete est con un edificio merlato in aperta campagna, forse allusione alle residenze medicee di Cafaggiolo e del Trebbio, quale punto di partenza del lungo e affollato corteo che si snodava fino a raggiungere il magio Gaspare in primo piano, abbigliato con ricche vesti e in sella a un destriero bianco, scortato da una comitiva di membri, amici e alleati del casato mediceo. ${ }^{\text {I25 }}$ Tra i volti ritratti si ravvisavano quelli di Cosimo il Vecchio e dei figli Piero, Giovanni - morto nel I463 - e l'illegittimo Carlo, con carnagione scura e lineamenti esotici ereditati dalla madre schiava circassa, mentre in posizione più arretrata quelli dei nipoti Lorenzo e Giuliano, figli di Piero forse in compagnia del loro precettore Gentile de' Becchi, Cosimino, figlio di Giovanni - morto all'età di sei anni nel novembre I 459 - e con tutta probabilità Giovanni Tornabuoni, cognato di Piero e direttore della filiale romana del banco mediceo. ${ }^{26}$ Se la scena sembra riproporre una delle sfilate che il giorno dell'Epifania si tenevano in città, alle quali i Medici e la loro cerchia erano soliti prendere parte, in realtà la presenza al fianco di Cosimo il Vecchio di Sigismondo Pandolfo Malatesta e Galeazzo Maria Sforza giunti in visita nel I459 convogliava un forte messaggio politico. ${ }^{\text {I27 }}$ Era soprattutto la figura del figlio del duca di Milano ad assumere un valore di rilevanza eccezionale riguardo al sodalizio che legava i Medici agli Sforza al di là e al di sopra degli interessi della città: alcuni mesi prima il casato milanese aveva assicurato, in caso di necessità e «in grandissimo segreto», il sostegno armato per contrastare il tentativo di rivolta ordito dalla fazione anti-medicea nell'agosto I 458. A quella data lo stretto legame che univa le due famiglie era già di pubblico dominio dopo l'offerta da parte di Francesco Sforza di un edificio da destinare a sede milanese del banco mediceo. ${ }^{\mathrm{I} 8}$ I festeggiamenti e gli onori che nella primavera 1459 furono tributati all'illustre ospite milanese rientravano pertanto negli strumenti di propaganda e, nel contempo, trasmettevano un avvertimento inequivocabile ai nemici. Non solo, la scelta di eleggere l'adolescente Lorenzo de' Medici a «messere» della brigata impegnata nell'armeggeria aveva il palese intento di presentarlo pubblicamente quale legittimo successore a capo della consorteria medicea nella guida di Firenze. ${ }^{\mathrm{I} 29}$ Nella fitta stratificazione di rimandi simbolici, e al tempo stesso concreti, indirizzati alla cittadinanza il più eloquente fu la con-

I25. KENT 2005, p. 39I. Per le ricche vesti broccate in oro dei tre Magi e la possibile influenza delle narrazioni di viaggiatori e mercanti, primo tra tutti Marco Polo, con descrizioni di sovrani orientali abbigliati con vesti in drappo d'oro vedi DUITS 2008, pp. 209-2II.

I26. ACIDINI LUCHINAT I990, pp. 86-88; CARDINI I99ib, pp. I44-I53; ACIDINI LUCHINAT I993b, pp. 364-367; EAD. 2003, pp. IO-I I; KENT 2005, pp. 39I-392. Poiché alla metà del XV secolo la presenza di ritratti nella pittura murale fiorentina era per lo più limitata a scene di soggetto religioso all'interno di edifici sacri, dove i committenti figuravano in posizione defilata e di profilo, la cappella medicea si prospetta come un caposaldo nell'affermarsi del ritratto di gruppo vedi ACIDINI LUCHINAT 2003, p. I I.

I27. DESPOTAKIS 2009, pp. IO3-IO4. Opinione discordante è quella di Francesca Vaglienti che nella figura finora unanimemente identificata con il signore di Rimini propone di riconoscervi Galeazzo Maria Sforza, VAGLIENTI 2006, pp. 37-54.

I28. MARTINIS 2003, pp. 37-38. Vedi anche BERNSTEIN I992, pp. 346-349.

I29. VENTRONE 2006, p. 201. 
segna al giovane Medici di un bastone di comando, come si soleva fare con i signori delle città. Considerate queste implicazioni appare allora del tutto plausibile identificare il giovane magio Gaspare quale immagine idealizzata del futuro Magnifico, come sembrano del resto suggerire l'arbusto di alloro - richiamo onomastico a «Laurentius-laurus» - che incornicia il suo profilo e la bardatura del cavallo ornata da motivi araldici medicei. ${ }^{\mathrm{I}}{ }^{30}$ Specchio della politica cosimiana si rivela il dettaglio del volto arcigno di Pio II ritratto in lontananza tra una moltitudine di visi, addirittura arretrato di qualche fila rispetto a Benozzo Gozzoli, autore dell'affresco immortalatosi tra la folla. ${ }^{\mathrm{I}}{ }^{\mathrm{I}} \mathrm{La}$ posizione defilata alludeva ai rapporti poco cordiali che intercorrevano tra il pontefice e il signore mediceo: se per il mancato incontro nell'aprile I 459 il papa nella sua biografia aveva malignamente annotato «si finse malato", nella sosta di ritorno da Mantova il suo disappunto fu ancora maggiore non avendo ottenuto garanzie di appoggio per il progetto di crociata contro i turchi. ${ }^{\mathrm{I} 32}$

La sfilata proseguiva sulla parete sud con il magio Baldassarre, ritratto a grandezza naturale dell'imperatore bizantino Giovanni VIII Paleologo, scortato da un numero esiguo di paggi per poi concludersi sulla parete ovest con l'anziano magio Melchiorre, da identificare con il patriarca di Costantinopoli Giovanni II, in sella a una mula e preceduto da un corteo che s'inerpica su di una collina rocciosa. ${ }^{\mathrm{I} 33} \mathrm{Al}$ contesto conciliare sembrerebbe da ricondurre anche la figura del giovane in primo piano, dagli studiosi genericamente indicato come guardiacaccia, con capiglia-

I30. CARDINI I99ib, pp. I22-I25, I40-I44; ACIDINI LUCHINAT I993a, p. 43; VENTRONE 20 I6, p. 2 I9. Tra gli studiosi che non condividono l'identificazione con Lorenzo de' Medici vi sono Diane Cole Ahl e, di recente, Anna Padoa Rizzo che negli anni precedenti aveva invece accolto l'idea del magio Gaspare quale immagine idealizzata del giovane Medici, COLE AHL I996, p. 95, PADOA RIZZO 2009, p. II4; EAD. I972, p. 58; EAD. 2003 , p. I06. La tesi ottocentesca che interpretava la Cavalcata dei Magi quale immagine allegorica del concilio fiorentino del I 439 fu abbandonata negli anni sessanta del XIX secolo, dopo che Ernst Gombrich dichiarò irragionevole pensare che si potesse trattare della raffigurazione di un evento occorso vent'anni prima e per di più rivelatosi fallimentare; sulla scia di questa interpretazione ancora oggi gran parte degli studiosi si limita a interpretare i Magi quali tipi ideali vedi GOMBRICH, I960, pp. 300-30I; ACIDINI LUCHINAT I993b, p. 366 ; KENT 2005 , p. 39I. Opinioni discordanti sono quelle di Eleftherios Despotakis, che interpreta l'affresco in chiave politica, e Silvia Ronchey, che propone di riconoscere nella figura del giovane magio Demetrio Paleologo - fratello minore dell'imperatore bizantino - giunto a Firenze per partecipare al concilio, tesi secondo la studiosa avvalorata dal corteo alle sue spalle popolato da ritratti di eminenti intellettuali greci intervenuti per dibattere questioni filosofiche, DESPOTAKIS 2009, pp. IOI-I07; RONCHEY 2006, pp. I70-I72; EAD. 2009, pp. I38-I43. A mio avviso, invece, le posizioni fortemente anti-unioniste di Demetrio Paleologo e il suo essersi schierato proprio nel I 459 a favore di Mehmed II non sembrano giustificarne l'inserimento in un affresco volto a celebrare il potere e il successo di Cosimo de Medici vedi RONCHEY 2009, p. I48.

I3I. MÄRTL 2000, pp. I55-I83; ACIDINI LUCHINAT 2003, p. Io. L'autoritratto di Benozzo Gozzoli compare almeno due volte: nella parete est con berretto rosso che lungo il bordo reca la scritta dorata «OPUS BENOTII D", forse in origine completata da "E LESE», e in quella ovest con abito rosso e berretto azzurro cinto da una fascia bianca; è stato inoltre ipotizzato che la figura con un cappello da viaggio possa essere un terzo autoritratto dell'artista vedi ACIDINI LUCHINAT I993b, pp. 367, 369.

I32. EAD. 2003 , p. Io. Nei volti con la barba, tratto distintivo dei greci, Silvia Ronchey propone di riconoscere alcuni intellettuali bizantini presenti al concilio: Giorgio Gemisto Pletone, Giovanni Argiropulo, Teodoro Gaza, Isidoro da Kiev e forse Bessarione, RONCHEY 2006, pp. I2I-I25; EAD. 2009, pp. I4I-I43. Vedi anche PADOA RIZZO I972, pp. 56-57. Per la proposta d'indentificare tra i ritratti anche Marsilio Ficino, Lugi Pulci e forse Gentile da Fabriano vedi RONCHEY 2006, pp. II4-II5. Per la barba quale segno orientale di dignità di intellettuali e religiosi vedi CHASTEL I999, pp. I98-I99.

I33. RONCHEY 2006, pp. I04-I06; EAD. 2009, pp. I39-I40, I4I nota I9. 
tura bionda e veste e copricapo azzurri che monta un cavallo con un ghepardo da caccia sulla groppa, per il quale è stato proposto il nome di Tommaso Paleologo, ultimogenito di Manuele II e fratello minore di Giovanni VIII. Congettura che sembra trovare piena giustificazione negli avvenimenti: se per il concilio del I439 Tommaso giunse a Firenze in via ufficiosa, vent'anni più tardi, divenuto despota di Mistrà, fu al centro delle questioni affrontate durante la dieta di Mantova dato che, attivamente impegnato nella difesa di quello che restava dell'impero bizantino dopo la caduta di Costantinopoli, gli sarebbe spettato di diritto il trono se la crociata promossa da Pio II fosse riuscita nell'intento di spodestare gli usurpatori ottomani. ${ }^{\mathrm{I}}{ }^{34}$ Anche qui, tra $i$ volti del corteo si scoprono individui gravitanti nell'orbita del casato: Neri Capponi, oppositore di Rinaldo degli Albizzi e tiepido alleato di Cosimo, Bernardo Giugni, ambasciatore e intimo amico del capofamiglia mediceo, probabilmente Francesco Sassetti, direttore delle filiali del banco mediceo di Ginevra e Lione richiamato a Firenze nel $\mathrm{I} 458$ con l'incarico di vice-direttore generale, Agnolo Tani, direttore della filiale di Bruges, Dietisalvi Neroni, alleato dei Medici che di lì a qualche anno si sarebbe tramutato in nemico, e Roberto di Niccolò Martelli, direttore del banco mediceo presso il concilio di Basilea e successivamente a Ferrara e a Firenze. ${ }^{135}$

A enfatizzare il tono fiabesco ed esotico erano la carovana in secondo piano popolata da paggi, servi, schiavi - alcuni con fisionomie, vesti e copricapi orientali -, cammelli e dromedari carichi di casse, probabile allusione al fasto delle delegazioni bizantine giunte in città in occasione del concilio. ${ }^{136}$ Sempre in questa scena, tesa a celebrare l'egemonia di Cosimo de' Medici così abile da far trasferire il concilio a Firenze e così ricco da finanziare i fasti e le pompe riservate ai bizantini, si concentra la presenza di animali esotici. In realtà all'epoca la fauna esotica, e in particolare il possesso di questi animali da parte del casato mediceo, era ancora assai limitato rispetto ad altre corti italiane ed europee: le numerose descrizioni in rima e in prosa della caccia organizzata in piazza dei Signori per rendere omaggio a Galeazzo Maria Sforza nel I 459 non menzionano né leopardi né ghepardi e l'unico animale fuori dal comune risulta essere una giraffa in forma di manichino. ${ }^{I 37}$ Non sono state neppure rintracciate testimonianze sull'uso di cacciare con l'impiego di felini, mentre è altamente probabile che i dignitari bizantini giunti nel I 439 così come pure il giovane Sforza ospite nel I459 avessero al loro seguito questi predatori: si trattava di un tipo di pratica venatoria di origine orientale adottata presso la corte viscontea fin dalla fine del XIV seco1o. ${ }^{\mathrm{I} 3} 8 \mathrm{Se}$ è indubbio che la fauna esotica affrescata nella cappella medicea avesse la

I34. Ivi, pp. I44-I 49. Ipotesi condivisa anche da Giovanna Lazzi vedi LAZZI 2009, pp. I25-I26.

I35. ACIDINI LUCHINAT I993b, pp. 367-368; EAD. 2003, p. II.

I36. VENTRONE 20I6, pp. 209-2II. Vedi anche EAD. I99I, pp. II-I3. Silvia Ronchey propone invece d'interpretare questa scena come il «passaggio a occidente» della tradizione bizantina in tutto il suo splendore culturale e artistico, RONCHEY 2006, pp. I07-IO9.

I37. Vedi pagine I29-I30.

I38. Vedi pagine 249-25I. 
funzione di contribuire all'ambientazione orientale della storia dei Magi, ancora più spiccato doveva essere il proposito di esaltare l'onore mediceo accentuando il tono principesco delle scene attraverso l'illustrazione di animali rari in Europa e presenti unicamente nelle corti più raffinate dove, giunti in qualità di doni diplomatici inviati dai sultani d'Oriente, erano assurti a emblemi di status symbol. L'affresco commissionato da Cosimo il Vecchio e dipinto da Benozzo Gozzoli, sotto l'attenta supervisione di Piero de' Medici, rientra pertanto tra le molteplici strategie adottate dalla ricchissima famiglia di mercanti-banchieri che all'epoca teneva saldamente le redini della città per dimostrare - come osserva lo storico Sergio Tognetti - che «la ricchezza accumulata con la mercatura [...] non era affatto oggetto di disprezzo e di discredito, purché però fosse utilizzata quale trampolino di lancio verso la dimensione aristocratica, meta ultima di ogni scalata sociale degna di questo nome». ${ }^{\mathrm{I} 9}$

Sulla scorta di letture dedicate all'Oriente e dell'intensificarsi dei contatti con le terre d'oltremare, le corti italiane avevano prontamente assimilato la pratica orientale di ostentare il possesso di animali esotici quale segno di magnificenza e potere oppure di offrirli in dono in cambio di favori politici. In questo contesto s'inserisce l'uso di fauna esotica, dipinta o in carne e ossa, da parte dei Medici per convogliare eloquenti messaggi riguardo al loro ruolo politico in una città solo apparentemente governata da una repubblica. Animali esotici che a Firenze ben si prestavano a essere associati al popolare corteo dei Magi, rito cittadino in uso fin dalla fine del XIV secolo, posto sotto il patrocinio mediceo e allestito con il mirato intento di ostentare potere, suscitate stupore e ammirazione negli spettatori e, non da ultimo, rendere memorabile l'evento, fino al punto da diventare il soggetto dell'affresco commissionato per decorare le pareti nella cappella del palazzo di famiglia.

I39. TOGNETTI 20I7, p. I49. A rendere ancora più forte il messaggio riguardo al potere dei Medici doveva essere stata la novità dell'introduzione di un cospicuo numero di ritratti di membri e affiliati del casato in un affresco di soggetto religioso vedi NAJEMY 2006, p. 330. 


\section{Conclusioni}

Quello che emerge con evidenza da questa ricerca è l'importanza di uno studio condotto in chiave interdisciplinare per comprendere appieno gli interessi, le conoscenze e la cultura dei fiorentini tra la fine del XIV e quella del XV secolo. In una città repubblicana ma di fatto dominata da una ricca classe mercantile l'interesse nei confronti della fauna esotica è da ricondurre ai frequenti contatti con il Vicino e Medio Oriente, in gran parte dovuti alle attività dei mercanti che, mossi dall'ambizione di ampliare il raggio dei loro affari, si erano avventurati nelle terre d'oltremare. Pertanto questa indagine focalizza l'attenzione su temi tra loro strettamente connessi: da un lato, il ruolo svolto dalla classe mercantile nel favorire l'interazione tra Firenze e l'Oriente e, dall'altro, la portata dell'influenza esercitata da questi contatti nell'immaginario e, di conseguenza, sulla cultura fiorentina, inserendosi a pieno titolo sia nel filone dei cross-cultural studies sia in quelli della storia sociale, economica e culturale.

Proprio ai mercanti, abituati a osservare e quantificare, si deve gran parte dei resoconti odeporici che avevano ampiamente contribuito ad alimentare la fascinazione dei fiorentini per l'Oriente. E tra le molte informazioni di prima mano non mancavano certo quelle relative alla fauna esotica, la sua morfologia e la valenza simbolica attribuitagli dalla cultura orientale. In una città come Firenze dove fino al I 438 non fu disponibile una versione completa della Naturalis historia di Plinio il Vecchio, le notizie basate sull'osservazione diretta degli animali esotici furono accolte quale complemento alle informazioni tramandate da auctoritates e bestiari fino al punto, a volte, d'insinuare dubbi sulla loro veridicità o addirittura confutarle.

Il mercante - spesso sottovalutato o ignorato a causa del retaggio burckhardtiano - diventa pertanto una figura chiave per comprendere l'interesse dei fiorentini nei confronti della fauna esotica, della sua raffigurazione e della sua funzione quale segno di prestigio. ${ }^{\mathrm{I}}$ Istruito, curioso di scoprire nuove realtà e dotato di una forma mentis improntata alla conoscenza e all'acquisizione di dati concreti, il mercante occupa un ruolo decisivo nel passaggio dalla conoscenza della fauna esotica ancorata a quanto riferito per lo più in latino dalle auctoritates a quella in volgare di matrice pseudo-scientifica. ${ }^{2}$ Cambiamento di mentalità che a sua vol-

I. BURCKHARDT I980. Anni più tardi, in una lettera indirizzata all'amico Bernhard Kugler, Jacob Burckhardt ammise con rammarico di aver tralasciato nel suo studio un aspetto importante quale l'economia vedi BURKE 2014 , p. 36.

2. Per l'importanza della relazione tra economia e sviluppo culturale con l'imprenditore nel ruolo di promotore di una nuova mentalità vedi TRIVELLATO 20I9, pp. 403-4IO. 
ta aveva dato origine all'esigenza di una raffigurazione "naturalistica" di questi animali grazie all'osservazione diretta, quando possibile, oppure all'uso di taccuini di disegni, pratica alquanto diffusa nelle botteghe degli artisti. Non solo, il modello orientale della fauna esotica intesa quale segno di magnificenza, quando offerta in dono, e di potere, quando posseduta e ostentata, fu assimilato dalla pittura fiorentina, soprattutto in relazione a un'iconografia tanto amata in città e intrisa di valori simbolici e politici come quella dei Magi. Pratica, appresa nel corso dei viaggi o in occasione dell'arrivo di delegazioni diplomatiche orientali in città, penetrata nell'immaginario quale manifestazione di potere e munificenza fino al punto da essere trasposta in pittura dando vita ad una variante sontuosa e d'impronta marcatamente cortese dell'iconografia dei Magi. ${ }^{3}$

In quest'ottica il Rinascimento concepito, secondo una visione eurocentrica, quale riscoperta intellettualizzata dell'antichità greco-romana dovrà essere in parte ridimensionato per lasciare spazio all'influenza esercitata dai contatti e dagli scambi commerciali, politici e culturali con altre civiltà in un momento storico in cui gli orizzonti del mondo si andavano sempre più ampliando. ${ }^{4} \mathrm{Nel}$ contesto fiorentino tre e quattrocentesco l'orientalismo assume quindi una nuova prospettiva: la forte fascinazione esercitata dall'Oriente nell'immaginario collettivo fu assimilata dalla classe dominante, ben conscia delle potenzialità suscitate da un mondo «maraviglioso» traboccante di ricchezze e fauna esotica, per convogliare espliciti messaggi di potere e opulenza. L'Oriente, percepito come lontano, esotico e colmo di mirabilia, finì così per assurgere a modello da emulare - sottraendosi, quindi, al concetto di superiorità europea illustrato da Edward Said - nell'uso degli animali esotici quali espliciti segni di status symbol. 5 In una città mercantile come Firenze i frequenti viaggi e gli intensi rapporti commerciali con le terre d'oltremare avevano contribuito, grazie ai mercanti nel ruolo di intermediari, ad alimentare l'immaginario, ispirare la letteratura, influenzare il gusto e plasmare la cultura e l'arte del tempo. ${ }^{6}$ Perché - come ricorda Fernand Braudel - bisogna diffidare di coloro che «negano tutti gli influssi di una civiltà sull'altra, mentre in Mediterraneo si scambia ogni cosa: gli uomini, i pensieri, le arti di vivere, le credenze, i modi di amare». ${ }^{7}$

3. Atteggiamento che a distanza di qualche decennio muterà completamente quando la fauna esotica, reale o figurata, pur continuando a mantenere il significato di espressione di potere sarà contestualizzata in iconografie ispirate all'antichità classica vedi LAZZARO I995, pp. I97-227. Anche in questo caso, però, è da tener presente che i trionfi con animali esotici tanto amati dagli imperatori romani furono ripresi dalla cultura orientale.

4. Fondamentale su questo argomento è il testo Reframing the Renaissance. Visual Culture in Europe and Latin America I450-I650 (I995), seguito da molti altri tra cui Global Interests. Renaissance Art between East and West vedi FARAGO I995; JARDIN - BROTTON 2000.

5. SAID 20I9, pp. I7, 63-66.

6. Vedi HORODOWICH 20I7, pp. I90-I93; MARCOCCI 20I5, pp. 50-52.

7. BRAUDEL $201 \mathrm{I}$, p. 805. 


\section{Bibliografia}

ACIDINI LUCHINAT 1990

ACIDINI LUCHINAT I993a

ACIDINI LUCHINAT I993b

ACIDINI LUCHINAT 1996

ACIDINI LUCHINAT 2003

ACIDINI LUCHINAT $20 I$

ACIDINI 2019

ACIDINI - GURRIERI 2015

\section{AEBISCHER I959}

AGRIESTI I990

AIRALDI 2007

ALBERTI I946

ALBERTI I950

ALGERI I987
CRISTINA ACIDINI LUCHINAT, La cappella medicea attraverso cinque secoli, in Il palazzo Medici Riccardi di Firenze, a cura di Giovanni Cherubini e Giovanni Fanelli, Firenze, Giunti, I990, pp. 82-97.

CRISTINA ACIDINI LUCHINAT, Il viaggio dei Magi, in Benozzo Gozzoli. La Cappella dei Magi, a cura di Cristina Acidini Luchinat, Milano, Electa, I993, pp. 39-263.

CRISTINA ACIDINI LUCHINAT, Medici e cittadini nei cortei dei Re Magi. Ritratto di una società, a cura di Cristina Acidini Luchinat, Milano, Electa, I993, pp. 363-370.

CRISTINA ACIDINI LUCHINAT, Il giardino di Palazzo Medici in via Larga, in Giardini medicei. Giardini di palazzo e di villa nella Firenze del Quattrocento, a cura di Cristina Acidini Luchinat, Milano, Motta, I996, pp. I73-I 85 .

CRISTINA ACIDINI LUCHINAT, Viaggio nel sacro. Ritratti di Medici e d'altri contemporanei nella Cappella dei Magi, in Stanze segrete. Raccolte per caso. I Medici Santi - Gli arredi celati, catalogo di mostra (Firenze, Palazzo Medici Riccardi 25 marzo - 26 settembre 2003), a cura di Cristina Giannini, Firenze, Olschki, 2003, pp. 3-24.

CRISTINA ACIDINI LUCHINAT, Cosimo, Piero, Lorenzo. Dai danari ai maestri, in Denaro e bellezza. I banchieri, Botticelli e il rogo delle vanità, catalogo di mostra (Firenze, Palazzo Strozzi I7 settembre 20 I - 22 gennaio 20I2), a cura di Ludovica Sebregondi e Tim Parks, Firenze, Giunti, 2OII, Pp. IO3-II7.

CRISTINA ACIDINI, Firenze come Gerusalemme: il pellegrinaggio di Marco di Bartolomeo Rustici entro le mura della sua città, in "Ad Stellam». Il Libro d'Oltramare di Niccolò da Poggibonsi e altri resoconti di pellegrinaggio in Terra Santa fra Medioevo ed Età moderna, Atti della giornata di studi (Milano, Biblioteca Nazionale Braidense 5 dicembre 20I7), a cura di Edoardo Barbieri, Firenze, Olschki, 20I9, pp. 25-3I.

CRISTINA ACIDINI - ELENA GURRIERI, Didascalie alle immagini del Codice Rustici, in MARCO DI BARTOLOMEO RUSTICI, Codice Rustici. Dimostrazione dell'andata o viaggio al Santo Sepolcro e al monte Sinai, a cura di Elena Gurrieri, Kathleen Olive e Nerida Newbigin, vol. 2, Firenze, Olschki, 20I5, pp. 63-7I.

PAUL AEBISCHER, Le zebro 'âne sauvage' de la Péninsule Ibérique et Brunetto Latini, in "Boletim de Filologia", I6, I956-I957, pp. I65-I75. LIBERATO AGRIESTI, L'evoluzione storica dei modi d'uso della tenuta, in Le Cascine di Tavola a Prato dal Rinascimento al nuovo Rinascimento, a cura di Liberato Agriesti, Giuliana Campioni e Guido Ferrara, Empoli, Ibiskos, I990, pp. I-3I.

GABRIELLA AIRALDI, Dall'Eurasia al Nuovo Mondo. Una storia italiana (secc. XI-XVI), Genova, Fratelli Frilli, 2007.

LEON BATTISTA ALBERTI, I primi tre libri della famiglia, a cura di Francesco Carlo Pellegrini e R affaele Spongano, Firenze, Sansoni, I946. LEON BATTISTA ALBERTI, Della pittura, a cura di Luigi Malle, Firenze, Sansoni, I950.

GIULIANA ALGERI, La pittura in Lombardia nel primo Quattrocento, in La pittura in Italia. Il Quattrocento, a cura di Federico Zeri, vol. I, Milano, Electa, I987. 


\section{ALINEI 20I5}

\section{ALIOTTI 1769}

ALIPRANDI I9IO

ALLAIRE I994

ALLAIRE I998

ALLAIRE 2002

ALLAIRE 2006

Alle bocche 1986

ALLEGRI - CECCHI I980

ALLSEN 2006

ALMAGIÀ I955

AL-MASUM 2017

AMARI I933-I939

AMES-LEWIS I979

AMES-LEWIS I982

AMES-LEWIS I984

AMES-LEWIS 1987

AMES-LEWIS I990

AMES-LEWIS 1998

ANCONA I 742

ANCONA 1763

ANDREOSE 2012
MARIO ALINEI, Dante rivoluzionario borghese. Per una lettura storica della Commedia, Velletri, PM, 2015.

GIROLAMO ALIOTTI, Epistola et Opuscola, 2 voll., a cura di Gabriel Maria Scarmalli, Arezzo, Michaelis Bellotti, I769.

BONAMENTE ALIPRANDI, "Aliprandina" o Cronica de Mantua, a cura di Antonio Nerli, in Rerum Italicarum Scriptores, vol. 24.I3, Città di Castello, Lapi, I9Io, pp. I9-I83.

GLORIA ALLAIRE, Un ignoto manoscritto di Guerrino il Meschino di Andrea da Barberino nella Biblioteca Apostolica Vaticana, in "La Bibliofilia», 3, I994, pp. 233-24I.

GLORIA ALLAIRE, A Fifteenth-Century Florentine Community of Readers and the Romance of Chivalry, in "Essays in Medieval Studies», I5, I998, pp. I-8.

GLORIA ALLAIRE, Animal Descriptions in Andrea da Barberino's Guerrino Meschino, in «Romance Philology», 56, 2002, pp. 23-39.

GLORIA ALLAIRE, The Narrative World of Andrea da Barberino, in Firenze alla vigilia del Rinascimento. Antonio Pucci e $i$ suoi contemporanei, Atti del convegno della McGill University (Montreal, 22-23 ottobre 2004), a cura di Maria Bendinelli Predelli, Fiesole, Cadmo, 2006, pp. I I-20.

Alle bocche della piazza. Diario di anonimo fiorentino (I382-I4OI), a cura di Anthony Molho e Franek Sznura, Firenze, Olschki, I986.

ETTORE ALLEGRI - ALESSANDRO CECCHI, Palazzo Vecchio e i Medici. Guida storica, Firenze, SPES, I980.

THOMAS T. ALLSEN, The Royal Hunt in Eurasian History, Philadelphia, University of Pennsylvania Press, 2006.

ROBERTO ALMAGIÀ, Marco Polo, in Nel VII centenario della nascita di Marco Polo, Venezia, Palazzo Loredan, I955, pp. 7-49.

ABDULLAH AL-MASUM, China-Bengal Interactions in the Early Fifteenth Century. A Study on Ma Huan's and Fei Shin's Travels Accounts, in China's Development from a Global Perspective, a cura di María Dolores Elizalde e Wang Jianlang, Newcastle, Cambridge Scholars Pulishing, 20I7, pp. 57-72.

MICHELE AMARI, Storia dei musulmani di Sicilia. Seconda edizione modificata e accresciuta dall'autore, 3 voll., Catania, Romeo Prampolini, I933-I939.

FRANCIS AMES-LEWIS, Domenico Veneziano and the Medici, in «Jahrbuch der Berliner Museen", 21, I979, pp. 67-90.

FRANCIS AMES-LEWIS, The Inventories of Piero di Cosimo de' Medici's Library, in "La Bibliofilia», 2, I982, pp. I03-I42.

FRANCIS AMES-LEWIS, The Library and Manuscripts of Piero di Cosimo de' Medici, New York, Garland Publishing, I984.

FRANCIS AMES-LEWIS, Model-book Drawings and the Florentine Quattrocento Artist, in "Art History", IO, I, I987, pp. I-I I.

FRANCIS AMES-LEWIS, Il disegno nella pratica di bottega del Quattrocento, in La pittura nel Veneto. Il Quattrocento, a cura di Mauro Lucco, vol. 2, Milano, Electa, I990, pp. 657-685.

FRANCIS AMES-LEWIS, Training and Practice in the Early Renaissance Workshop. Observations on Benozzo Gozzoli's Rotterdam Sketchbook, in Drawing I400-I600. Invention and Innovation, a cura di Stuart Currie, Aldershot, Ashgate, I998, pp. 26-44.

CIRIACO D'ANCONA, Itinerarium Nunc Primum ex Ms. Cod. in Lucem Erutum ex Bibl. Illus. Clarissimique Baronis Philippi Stosch, a cura di Laurentius Mehus, Firenze, Tipografia Giovanni Paolo Giovannelli, I742.

CIRIACO D'ANCONA, Commentariorum Cyriaci Anconitani. Nova fragmenta notis illustrata, a cura di Annibale degli Abati Olivieri, Pisauri, Aedibus Gavelliis, I763.

ALVISE ANDREOSE, La strada, la Cina, il cielo. Studi sulla Relatio di Odorico da Pordenone e sulla sua fortuna romanza, Soveria Mannelli, Rubbettino, 2012. 
ANGHIARI 2002

ANTONUCCI 2007

Appunti e notizie I887

ARDUINI 2015

A Renaissance Wedding $20 \mathrm{O} 3$

ARISTOTELE 1996

ARMSTRONG I983

ARMSTRONG 2003

ARNADE 1996

BABINGER I957

BABINGER I963

BAGROW I985

BALESTRACCI 2008

BAMBACH 2004

BARBER 2006

BARBERINO 2005

BARBIERI 2019

BARCLAY LLOYD I97I

BARSANTI I905

BARTOLETTI 2004
GIUSTO D'ANGHIARI, I Giornali (I437-I482), a cura di Nerida Newbigin, in «Letteratura Italiana Antica», 3, 2002, pp. 4I-246.

EUGENIA ANTONUCCI, Scheda, in La Biblioteca in mostra. Animali fantastici, catalogo di mostra (Firenze, Biblioteca Medicea Laurenziana I aprile - 3I dicembre 2007), Firenze, Mandragora, 2007, pp. 54-55. Appunti e notizie, Pio II e gli Sforza a Mantova, in "Archivio Storico Lombardo", 3, I887, pp. 630-63I.

BEATRICE ARDUINI, Boccaccio and his Desk, in The Cambridge Companion to Boccaccio, a cura di Guyda Armstrong, Rhiannon Daniels e Stephen J. Milner, Cambridge, Cambridge University Press, 2015 , pp. $20-35$.

A Renaissance Wedding. The Celebrations at Pesaro for the Marriage of Costanzo Sforza \& Camilla Marzano d'Aragona 26-30 May I474, a cura di Jane Bridgeman, London-Turhout, Harvey Miller, 20I3.

ARISTOTELE, Opere biologiche, a cura di Diego Lanza e Mario Vegetti, Torino, Unione Tipografico-Editrice Torinese, I996.

LILIAN ARMSTRONG, The Illustration of Pliny's Historia naturalis. Manuscripts before I43O, in "Journal of the Warburg and Courtauld Institutes", 46, I983, pp. I9-39.

LILIAN ARMSTRONG, Studies of Renaissance Miniaturists in Venice, 2 voll., London, Pindar Press, 2003.

PETER ARNADE, Realms of Ritual. Burgundian Ceremony and Civic Life in Late Medieval Ghent, Ithaca (N.Y.)-London, Cornell University Press, I996.

FRANZ BABINGER, Maometto il Conquistatore e il suo tempo, Torino, Einaudi, I957 [ed. originale Mehmed der Eroberer und seine Zeit: Weltenstürmer einer Zeitenwende, München, F. Bruckmann, I953].

FRANZ BABINGER, Lorenzo de' Medici e la corte ottomana, in "Archivio Storico Italiano", 439, I963, pp. 305-36I.

LEO BAGROW, History of Cartography, a cura di R.A. Skelton, Chicago, Precedent, I985 [ed. originale Cambridge, Harvard University Press, I964].

DUCCIO BALESTRACCI, Terre ignote strana gente. Storie di viaggiatori medievali, Roma-Bari, Giuseppe Laterza \& Figli, 2008.

CARMEN BAMBACH, Scheda, in Byzantium. Faith and Power (I26II557), catalogo di mostra (New York, Metropolitan Museum of Art 23 marzo - 4 luglio 2004), a cura di Helen C. Evans, New York, Metropolitan Museum of Art, 2004, pp. 527-534.

PETER BARBER, Medieval Maps of the World, in The Hereford World Map. Medieval World Maps and their Context, a cura di P.D.A. Harvey, London, British Library, 2006, pp. I-44.

ANDREA DA BARBERINO, Il Guerrin Meschino. Edizione critica secondo l'antica vulgata fiorentina, a cura di Mauro Cursietti, RomaPadova, Antenore, 2005 .

EDOARDO BARBIERI, L'editio princeps bolognese del Viazo da Venesia al sancto Iherusalem riduzione del Libro d'Oltramare di Niccolò da Poggibonsi, in "Ad Stellam». Il Libro d'Oltramare di Niccolò da Poggibonsi e altri resoconti di pellegrinaggio in Terra Santa fra Medioevo ed Età moderna, Atti della giornata di studi (Milano, Biblioteca Nazionale Braidense, 5 dicembre 2017), a cura di Edoardo Barbieri, Firenze, Olschki, 20I9, pp. 7I-IO6.

JOAN E. BARCLAY LLOYD, African Animals in Renaissance Literature and Art, Oxford, Clarendon Press, I97I.

PAOLO BARSANTI, Il pubblico insegnamento in Lucca. Dal secolo 14 alla fine del secolo I8, Lucca, Marchi, I905.

GUGLIELMO BARTOLETTI, Scheda, in Rappresentare e misurare il mondo. Da Vespucci alla modernità, catalogo di mostra (Firenze, Istituto Geografico Militare 30 ottobre 2004 - I5 gennaio 2005), a cura di 


\section{BARTOLI I999}

\section{BARTOLINI I99I}

Bartolomeo di Giovanni 2004

BARTOLUCCI I995

BARTOLUCCI 200I

BASILIO I 844

BASSI 2014

BAXANDALL 1978

BEC 1967

BEC 1972

BEC I975-1976

BEC I98 I

BEC 1983

BEC I984

BECDELIÈVRE 2018

BECDELIÈVRE 2019

BEDINI I999

BEDINI 2007

BEDINI 2010

BEDINI I997
Andrea Cantile, Giovanna Lazzi e Leonardo Rombai, Firenze, Polistampa, 2004, pp. 108-I09.

ROBERTA BARTOLI, Biagio d'Antonio, Milano, Federico Motta, I999.

GABRIELLA BARTOLINI, Il testo, in GABRIELLA BARTOLINI - FRANCO CARDINI, "Nel nome di Dio facemmo vela». Viaggio in Oriente di un pellegrino medievale, Roma-Bari, Laterza, I99I, pp. 99-I 23. Bartolomeo di Giovanni collaboratore di Ghirlandaio e Botticelli, catalogo di mostra (Firenze, Museo di San Marco 24 aprile - 5 giugno 2004), a cura di Nicoletta Pons, Firenze, Polistampa, 2004.

LIDIA BARTOLUCCI, L'Oriente nelle versioni italiane della Lettera del Prete Gianni, in Medioevo romanzo e orientale. Oralità, scrittura, modelli narrativi, Atti del 2. Colloquio Internazionale (Napoli, I7-I9 febbraio I994), a cura di Antonio Pioletti e Francesca Rizzo Nervi, Soveria Mannelli, Rubbettino, pp. 22 I-234.

LIDIA BARTOLUCCI, Qualche nota sulla lettera del prete Gianni nella versione italiana $N_{I}$ (ms. 2.2.39, Biblioteca Nazionale Centrale, Firenze), in "Quaderni di Lingue e Letterature», 26, 200I, pp. 89-94.

BASILIO, L'Esamerone volgarizzato dall'abate Jacopo Bernardi, Venezia, Giovanni Cecchini, I844.

SIMONETTA BASSI, Natura, magia e scienza nel Rinascimento, in Storia della filosofia occidentale. Medioevo e Rinascimento, a cura di Giuseppe Cambiano, Luca Fonnesu e Massimo Mori, vol. 2, Bologna, Il Mulino, 20I4, pp. 32I-374.

MICHAEL BAXANDALL, Pittura ed esperienze sociali nell'Italia del Quattrocento, Torino, Einaudi, I978 [ed. originale Painting and Experience in Fifteenth Century Italy, Oxford, Oxford University Press, I972].

CHRISTIAN BEC, Les marchands écrivains à Florence. Affaire et humanisme 1375-I434, Paris, Mouton, I967.

CHRISTIAN BEC, La bibliothèque d'un grand bourgeois florentin, Francesco d'Agnolo Gaddi (I496), in «Bibliothèque d'Humanisme et Renaissance», 34, I972, pp. 239-247.

CHRISTIAN BEC, Sur la lecture de Boccace à Florence au Quattrocento, in «Studi sul Boccaccio», 9, I975-I976, pp. 247-260.

CHRISTIAN BEC, Cultura e società a Firenze nell'età della rinascenza, Roma, Salerno, I98I.

CHRISTIAN BEC, I mercanti scrittori, in Letteratura italiana, a cura di Alberto Asor Rosa, vol. 2, Torino, Einaudi, I983, pp. 269-297.

CHRISTIAN BEC, Les livres des florentins (I4I3-I608), Firenze, Olschki, I984.

VÉRONIQUE DE BECDELIÈVRE, Espagnol 30 :

$<$ https://archivesetmanuscrits.bnf.fr/ark:/I 2 I 48/cc78545v>

[accesso: giugno 2020]

VÉRONIQUE DE BECDELIÈVRE, Français 2810 :

<https://archivesetmanuscrits.bnf.fr/ark:/I 2 I 48/cc77943x> [accesso: dicembre 2020]

ALESSANDRO BEDINI, Testimone a Gerusalemme. Il pellegrinaggio di un fiorentino del Trecento, Roma, Città Nuova, I999.

ALESSANDRO BEDINI, Un pellegrino del Trecento "agente" dei servizi angioini: Lionardo di Niccolò Frescobaldi, in I fiorentini alle crociate. Guerre, pellegrinaggi e immaginario "orientalistico" a Firenze tra Medioevo ed Età Moderna, a cura di Silvia Agnoletti e Luca Mantelli, Firenze, Meridiana, 2007, pp. 259-266.

ALESSANDRO BEDINI, Un pellegrino in Terrasanta. Il «resoconto di viaggio» di messer Giorgio di Guccio Gucci, in "Come l'orco della fiaba». Studi per Franco Cardini, a cura di Marina Montesano, Firenze, SISMEL Edizioni del Galluzzo, 2010, pp. 37-48.

SILVIO A. BEDINI, The Pope's Elephant, Manchester, Carcanet Press, I997. 
BEHRENS-ABOUSEIF 2014

BELLE I972

BELLOSI I993

BELLOSI 2000

BELLUZZI 2009a

BELLUZZI 2009b

BELOZERSKAYA 2006

BELOZERSKAYA 2019

BELTRAME QUATTROCCHI I979

BELTRAMI 2007

BENDINELLI 1978

BENEDETTO I930

Benozzo Gozzoli 1993

BERNSTEIN I992

BERTALOT - CAMPANA I939

BERTELLI I999

BERTELLI 2006
DORIS BEHRENS-ABOUSEIF, Practising Diplomacy in the Mamluk Sultanate. Gifts and Material Culture in the Medieval Islamic World, LondonNew York, Tauris, 20I4.

LAWRENCE W. BELLE, A Renaissance Patrician. Palla di Nofri Strozzi, I372-I462, Ph.D Dissertation, Rochester, University of Rochester, 1972 .

LUCIANO BELLOSI, Gentile da Fabriano e il Polittico di Valle Romita, in Gentile da Fabriano. Il Polittico di Valle Romita, catalogo di mostra (Milano, Pinacoteca di Brera 3I marzo - 25 aprile I993), a cura di Matteo Ceriana ed Emanuela Daffra, Milano-Firenze, Charta, I993, pp. II-24.

LUCIANO BELLOSI, Come un prato fiorito. Studi sull'arte tardogotica, Milano, Jaka Book, 2000.

AMEDEO BELLUZZI, Il serraglio dei leoni e la cavallerizza, in La sede della Sapienza a Firenze. L'Università e l'Istituto Geografico Militare a San Marco, a cura di Amedeo Belluzzi ed Emanuela Ferretti, Firenze, IGM, 2009, pp. 99-II5.

AMEDEO BELLUZZI, La cappella Rucellai e il tempietto del Santo Sepolcro, in Leon Battista Alberti. Architetture e committenti, Atti dei convegni internazionali del Comitato nazionale VII centenario della nascita di Leon Battista Alberti (Firenze-Rimini, I2-I6 ottobre 2004), a cura di Arturo Calzona, Joseph Connors, Francesco Paolo Fiore e Cesare Vasoli, vol. I, Firenze, Olschki, 2009, pp. I03-I34.

MARINA BELOZERSKAYA, The Medici Giraffe. And other Tales of Exotic Animals and Power, New York, Little, Brown and Company, 2006.

MARINA BELOZERSKAYA, Real or Imagined? Exotic Animals in Piero di Cosimo's Mythologies, in Piero di Cosimo. Painter of Faith and Fables, a cura di Dennis Geronimus e Michael W. Kwakkelstein, Leiden, Brill, 20I9, pp. 6I-8I.

ENRICHETTA BELTRAME QUATTROCCHI, Disegni toscani e umbri del primo Rinascimento dalle collezioni del Gabinetto Nazionale delle Stampe, Roma, De Luca, I979.

PIETRO G. BELTRAMI, Introduzione, in BRUNETTO LATINI, Tresor, a cura di Pietro G. Beltrami, Torino, Einaudi, 2007, pp. VIIXXVI.

MARIA LIVIA BENDINELLI, Volgarizzamenti italiani della Lettera del Prete Gianni, in Testi e interpretazioni. Studi del seminario di filologia romanza dell'Università di Firenze, Milano-Napoli, Riccardo Ricciardi, I978, pp. 43-64.

LUIGI F. BENEDETTO, Perché fu chiamato Milione il libro di Marco Polo, in «Il Marzocco», 35, I4 settembre I930, pp. I-2.

Benozzo Gozzoli. La Cappella dei Magi, a cura di Cristina Acidini Luchinat, Milano, Electa, I993.

JOANNE G. BERNSTEIN, The Portal of the Medici Bank in Milan, in Verrocchio and Late Quattrocento Italian Sculpture, a cura di Steven C. Bule, Alan P. Darr e F. Superbi Gioffredi, Firenze, Le Lettere, I992, pp. 345-352.

LODOVICO BERTALOT - AUGUSTO CAMPANA, Gli scritti di Iacopo Zeno e il suo elogio di Ciriaco d'Ancona, in «La Bibliografia», 4 I, I939, pp. 356-376.

SANDRO BERTELLI, Un nuovo testimonio del Viaggio ai Luoghi Santi di Giorgio Gucci, in "Medioevo e Rinascimento", I0, I999, pp. 295-300.

SANDRO BERTELLI, Giovanna e Alfonso, Antonio e Ferrante, in GIANCARLO ALISIO - SERGIO BERTELLI - ANTONIO PINELLI, Arte e politica tra Napoli e Firenze. Un cassone per il trionfo di Alfonso d'Aragona, Modena, Panini, 2006, pp. 9-32. 
BERTI 2009

\section{BERTOLINI I984}

BERTOLINI I985

BERTOLUCCI PIZZORUSSO I994

\section{BERTONI I9I9}

BESCHI 2004

Bestiari medievali 1996

BIANCA 2008

BIONDO I963

BISMARA 2012

BISTICCI I970-I976

BJURSTRÖM $200 \mathrm{I}$

BLACK 2007

BLAIR MOORE 2009

BLAIR MOORE 2010

BLAIR MOORE 2013

BLAIR MOORE 2017

BLAIR MOORE 2019

BLOOM 20I I

BLUM I95I

BOCCACCIO I992
MARCELLO BERTI, Alcune note sulle pratiche di mercatura (secoli XIIIXVIII): dalla Memoria pisana ai manuali del perfetto mercante, in La contabilità nel bacino del Mediterraneo (secc. XIV-XIX), a cura di Paola Pierucci, Milano, FrancoAngeli, 2009, pp. 29-83.

LUCIA BERTOLINI, L'attribuzione della Sfera del Dati nella tradizione manoscritta, in Studi offerti a Gianfranco Contini dagli allievi pisani, Firenze, Le Lettere, I984, pp. 33-43.

LUCIA BERTOLINI, Censimento dei manoscritti della Sfera del Dati, in "Annali della Scuola Normale Superiore di Pisa», I5, 3, I985, pp. 889-940. VALERIA BERTOLUCCI PIZZORUSSO, Lingue e stili nel Milione, in L'epopea delle scoperte, a cura di Renzo Zorzi, Firenze, Olschki, I994, pp. 6I-73.

GIULIO BERTONI, L'Orlando furioso e la Rinascenza a Ferrara, Modena, Umberto Orlandini, I9I9.

LUIGI BESCHI, Giovanni VIII Paleologo del Pisanello: note tecniche ed esegetiche, in "Museio Mpenake», 4, 2004, pp. II7-I32.

Bestiari medievali, a cura di Luigina Morini, Torino, Einaudi, I996.

CONCETTA BIANCA, Martino $V$, in Dizionario biografico degli Italiani, a cura di Mario Caravale, vol. 7I, Roma, Treccani, 2008, pp. 277-287.

FLAVIO BIONDO, Le Decadi, a cura di Achille Crespi, Forlì, Comune di Forlì, I963.

ClAUdiO BISMARA, Pisanello, Pietro da Sacco, due mappae mundi e una ecclesiola di legno a Verona nel I430, in "Nuovi Studi», I8, 20I2, pp. II -35 .

VESPASIANO DA BISTICCI, Le vite, 2 voll., a cura di Aulo Greco, Firenze, Istituto Nazionale di Studi sul Rinascimento, I970-I976.

PER BJURSTRÖM, Italian Drawings from the Collection of Giorgio Vasari, Stockholm, National Museum, 200I.

ROBERT BLACK, Education and Society in Florentine Tuscany. Teachers, Pupils and Schools, c. I250-I500, vol. I, Leiden, Brill, 2007.

KATHRYN BLAIR MOORE, Seeing Through Text: The Visualization of Holy Land Architecture in Niccolò da Poggibonsi's Libro d'Oltramare, I4th-I5th Centuries, in «Word \& Image», 4, 2009, pp. 402-4I5.

KATHRYN BLAIR MOORE, Textual Transmission and Pictorial Transformations: The Post-Crusade Image of the Dome of the Rock in Italy, in "Muqarnas», 27, 2010, pp. 5I-78.

KATHRYN BLAIR MOORE, The Disappearance of an Author and the Emergence of a Genre: Niccolò da Poggibosi and Pilgrimage Guidebooks between Manuscript and Print, in "Renaissance Quarterly», 2, 2013, pp. 357-4II.

KATHRYN BLAIR MOORE, The Architecture of the Christian Holy Land. Reception from Late Antiquity through the Renaissance, Cambridge, Cambridge University Press, 2017.

KATHRYN BLAIR MOORE, Premessa, in "Ad Stellam». Il Libro d'Oltramare di Niccolò da Poggibonsi e altri resoconti di pellegrinaggio in Terra Santa fra Medioevo ed Età moderna, Atti della giornata di studi (Milano, Biblioteca Nazionale Braidense, 5 dicembre 20I7), a cura di Edoardo Barbieri, Firenze, Olschki, 20I9, pp. VII-IX.

JONATHAN BLOOM, Fatimid Gifts, in Gifts of the Sultan. The Arts of Giving at the Islamic Courts, catalogo di mostra (Los Angeles, County Museum of Art 5 giugno - 5 settembre 20I I), a cura di Linda Komaroff, New Haven-London, Yale University Press, 201 I, pp. 95-Io9.

RUDOLF BLUM, La biblioteca della Badia Fiorentina e i codici di Antonio Corbinelli, Città del Vaticano, Biblioteca Apostolica Vaticana, I95I. GIOVANNI BOCCACCIO, Decameron, 2 voll., a cura di Vittore Branca, Torino, Einaudi, I992 [I980]. 
BOCCACCIO 20II-20I7

BOCCIA 20I4

BODART 1998

BOEHRER 2004

BOEHRER 2007

BOEHRER 2010

BOLLATI 2006

BOLOGNA 1987

BORLANDI I963

BORLANDI 1936

BORLANDI 1962

BORSA I924

BORSI I992

BORSOOK I970

BOSCHETTO 2013

BOSKOVITS I9 88

BOSKOVITS I995

BOSKOVITS 2002

BOULOUX 2002

BOULOUX 2014
GIOVANNI BOCCACCIO, Genealogy of the Pagan Gods, a cura di Jon Solomon, 2 voll., Cambridge, Harvard University Press, 20II2017.

ALESSANDRO BOCCIA, Libro II. Scontro tra Impero e Comuni, in L'epistolario di Pier della Vigna, a cura di Edoardo D’Angelo, Soveria Mannelli, Rubettino, 20I4, pp. 249-433.

DIANE H. BODART, Tiziano e Federico II Gonzaga. Storia di un rapporto di committenza, Roma, Bulzoni, I998.

BRUCE BOEHRER, Parrot Culture. Our 250o-Year-Long Fascination with the World's Most Talkative Bird, Philadelphia, University of Pennsylvania Press, 2004.

BRUCE BOEHRER, Introduction. The Animal Renaissance, in $A$ Cultural History of Animals in the Renaissance, a cura di Bruce Boehrer, vol. 3, Oxford, Berg, 2007.

BRUCE BOEHRER, Animal Characters. Nonhuman Beings in Early Modern Literature, Philadelphia, University of Pennsylvania Press, 2010.

MILVIA BOLLATI, Scheda, in Gentile da Fabriano e l'altro Rinascimento, catalogo di mostra (Fabriano, Spedale di Santa Maria del Buon Gesù 2I aprile - 23 luglio 2006), a cura di Laura Laureati e Lorenza Mochi Onori, Milano, Electa, p. 85 .

CORRADO BOLOGNA, La letteratura dell'Italia settentrionale nel Duecento, in Letteratura italiana, a cura di Alberto Asor Rosa, vol. I, Torino, Einaudi, I987, pp. I79-I88.

ANTONIA BORLANDI, Il manuale di mercatura di Saminiato de' Ricci, Genova, Di Stefano, I963.

FRANCO BORLANDI, El libro di mercatantie et usanze de' paesi, Torino, S. Lattes \& C., I936.

FRANCO BORLANDI, Alle origini del libro di Marco Polo, in Studi in onore di Amintore Fanfani, a cura di Gino Barbieri, vol. I, Milano, Giuffrè, I962, pp. I05-I 47.

MARIO BORSA, La caccia nel milanese dalle origini ai giorni nostri, Milano, Hoepli, I924.

FRANCO e STEFANO BORSI, Paolo Uccello, Milano, Leonardo Editore, I992 [ed. originale Paris, Hazan, I992].

EVE BORSOOK, Documenti relativi alle cappelle di Lecceto e delle selve di Filippo Strozzi, in "Antichità viva», 3, I970, pp. 3-20.

LUCA BOSCHETTO, Società e cultura a Firenze al tempo del concilio. Eugenio IV tra curiali mercanti e umanisti (1434-1443), Roma, Edizioni di Storia e Letteratura, 20I3.

MIKLÓS BOSKOVITS, Arte lombarda del primo Quattrocento: un riesame, in Arte in Lombardia tra Gotico e Rinascimento, catalogo di mostra (Milano, Palazzo Reale I988) a cura di Miklós Boskovits, Milano, Fabbri, I988, pp. IO-49.

MIKLÓS BOSKOVITS, Attorno al Tondo Cook. Precisazioni sul Beato Angelico su Filippo Lippi e su altri, in «Mitteilungen des Kunsthistorisches Institutes in Florenz", 39, I, I995, pp. 33-68.

MIKLÓS BOSKOVITS, Il Beato Angelico e Benozzo Gozzoli. Problemi ancora aperti, in Benozzo Gozzoli allievo a Roma, maestro in Umbria, catalogo di mostra (Montefalco, Chiesa-Museo di San Francesco 2 giugno - 3I agosto 2002), a cura di Bruno Toscano e Giovanna Capitelli, Cinisello Balsamo, 2002, pp. 4I-55.

NATHALIE BOULOUX, Culture et savoirs géographiques en Italie au $X I V^{e}$ siècle, Turnhout, Brepols, 2002.

NATHALIE BOULOUX, Carte marine et culture visuelle chez Giovanni Villani et Fazio degli Uberti, in Pour une histoire de l'espace au Moyen Âge. Textes et cartes, Cahiers électroniques d'histoire textuelle du LAMOP, 2014 , pp. I-27. 
BOURDIEU 2010

BRACCIOLINI I993

BRACCIOLINI 2004

BRANCA I958-I99I

BRANCA I96I

BRANCA I98I

BRANCA 1992

BRAUDEL 20 I I

BRAVI 1998

BRENZONI I952

BRILLI 2OI3

BROTTON 2012

BROWN I960

BROWN 200I

BRUCKER I968

BRUCKER 1977

BUDD 2006

BUDINI GATTAI 2010

BUFFON I770-I785

BUGANZA 2015
PIERRE BOURDIEU, Distinction. A Social Critique of the Judgement of Taste, London-New York, Routledge, 20 Io [ed. originale La distinction. Critique sociale du jugement, Paris, Minuit, I979].

POGGIO BRACCIOLINI, De Varietate Fortunae, a cura di Outi Merisalo, Helsinki, Soumaleinen Tiedeakatemia, I993.

POGGIO BR ACCIOLINI, De l'Inde. Les voyages en Asie de Niccolò de' Conti, a cura di Michèle Guéret-Laferté, Turnhout, Brepols, 2004.

VITTORE BRANCA, Tradizione delle opere di Giovanni Boccaccio, 2 voll., Roma, Edizioni di Storia e Letteratura, I958-I99I.

VITTORE BRANCA, Copisti per passione, tradizione caratterizzante, tradizione di memoria, in Studi e problemi di critica testuale, Convegno di studi di filologia italiana nel centenario della Commissione per i Testi di Lingua (Bologna, 7-9 aprile I960), Bologna, Commissione per i Testi di Lingua, I96I, pp. 69-83.

VITTORE BRANCA, Boccaccio medievale e nuovi studi sul Decameron, Firenze, Sansoni, I98I [I956].

VITTORE BRANCA, Una chiave di lettura per il Decameron. La vita e le opere di Giovanni Boccaccio, in GIOVANNI BOCCACCIO, Decameron, 2 voll., a cura di Vittore Branca, Torino, Einaudi, I992, pp. VII-LXXVI [I980].

FERNAND BRAUDEL, Civiltà e imperi del Mediterraneo nell'età di Filippo II, 2 voll., Torino, Einaudi, 2or I [ed. originale La Méditerranée et le monde méditerranéen à l'époque de Philippe II, Paris, Armand Colin, I949].

GIULIO ORAZIO BRAVI, Taccuino dei disegni di Giovannino de Grassi, in Taccuino di disegni di Giovannino de Grassi. Cassaf. I.2I della Civica Biblioteca Angelo Mai di Bergamo. Commentario, Modena, Il Bulino, I998, pp. 7-I5.

RAFFAELLO BRENZONI, Pisanello pittore, Firenze, Olschki, 1952. ATTILIO BRILLI, Mercanti avventurieri. Storie di viaggi e di commerci, Bologna, Il Mulino, 20I3.

JERRY BROTTON, A History of the World in Twelve Maps, London, Allen Lane, 2012.

ALISON M. BROWN, Priorista of Angelo and Francesco Gaddi, in «The British Museum Quarterly", 3/4, I960, pp. 62-64.

ALISON M. BROWN, Lucretius and the Epicureans in the Social and Political Context of Renaissance Florence, in «I Tatti Studies», 9, 200I, pp. II-62.

GENE A. BRUCKER, The Ciompi Revolution, in Florentine Studies. Politics and Society in Renaissance Florence, a cura di Nicolai Rubinstein, London, Faber \& Faber, I968, pp. 3I4-356.

GENE A. BRUCKER, The Civic World of Early Renaissance Florence, Princeton, Princeton University Press, I977.

DENISE M. BUDD, Leonardo, Medici Ephemera, and the Art of the Pazzi Conspiracy, in Watching Art. Writings in Honor of James Beck, a cura di Lynn Catterson e Mark Zucker, Todi, Ediart, 2006, pp. I03-I Io.

NICOLÒ BUDINI GATTAI, La percezione del mondo greco del XIV secolo tra incomprensioni culturali e topoi letterari, in Boccaccio geografo. Un viaggio nel Mediterraneo tra le città, i giardini e... il "mondo" di Giovanni Boccaccio, a cura di Roberta Morosini, Firenze, Mauro Pagliai, 20io, pp. IO3-I3I.

GEORGES LOUIS BUFFON, Histoire naturelle des oiseaux, I 8 voll., Paris, Imprimerie Royale, I770-I785.

STEFANIA BUGANZA, Note su Filippo Maria Visconti committente d'arte, in Il ducato di Filippo Maria Visconti, I4I2-I447. Economia, politica, cultura, a cura di Federica Cengarle e Maria Nadia Covini, Firenze, Firenze University Press, 20I5, pp. 247-284. 
BUQUET 2008

BUQUET 2OI I

BUQUET 2012

BUQUET 20I3a

BUQUET 20I3b

BUQUET 20I3C

BUQUET 2OI3d

BUQUET 2OI4

BUQUET 2015

BUQUET 2020

BURCKHARDT I980

BURKE 2004

BURKE 2OI4

CADEI I970

CADORNA 2001

CAIRATI 2013

CALEFFINI 2006

CAMBI I785-I 786
THIERRY BUQUET, La girafe, belle inconnue des bibles médiévales. Camelopardalis: un animal philologique, in "Anthropozoologica», 43,2, 2008, pp. 47-68.

THIERRY BUQUET, Le guépard médiéval, ou comment reconnaître un animal sans nom, in "Reinardus», 23, 20I I, pp. I2-47.

THIERRY BUQUET, La belle captive. La girafe dans les ménageries princières au Moyen Âge, in La bête captive au Moyen Âge et à l'époque moderne, Actes des deuxièmes rencontres internationales Des bêtes et des hommes (Valenciennes, 8-9 novembre 2007), a cura di Corinne Beck e Fabrice Guizard, Amiens, Encrage, 2012, pp. 65-90.

THIERRY BUQUET, "Animalia extranea et stupenda ad videndum». Describing and Naming Exotic Beasts in Cairo Sultan's Menagerie, in Animals and Otherness in the Middle Ages. Perspectives across Disciplines, a cura di Francisco de Asís García García, Mónica Ann Walker Vadillo e María Victoria Chico Picaza, Oxford, Archaepress, 2013, pp. 25-34. THIERRY BUQUET, Les animaux exotiques dans les ménageries médiévales, in Fabuleuses histoires des bêtes et des hommes, a cura di Jacques Toussaint, Namur, Société Archéologique de Namur, 20I3, pp. 97-I2I. THIERRY BUQUET, Nommer les animaux exotiques de Baybars, d'Orient en Occident, in Les non-dits du nom. Onomastique et documents en terres d'Islam. Mélanges offerts à Jacqueline Sublet, a cura di Christian Müller e Muriel Roiland-Rouabah, Beirut, Ifpo, 2013, pp. 375-402. THIERRY BUQUET, Preventing "Monkey Business". Fettered Apes in the Middle Ages, in Medieval Animal Data - Network, 23 giugno 2013 <https://mad.hypotheses.org/37> [accesso: dicembre 2020]

THIERRY BUQUET, Les légendes relatives à l'origine hybride et à la naissance des girafes selon les autres arabes, in "Bulletin d'Etudes Orientales», 62, 2014 , pp. I $25-\mathrm{I} 47$.

THIERRY BUQUET, Arab and Ottoman Menagerie, in Medieval Animal Data-Network, 22 giugno 2015 <https://mad.hypotheses.org/620> [accesso: dicembre 2020].

THIERRY BUQUET, Hunting with Cheetahs at European Courts. From the Origins to the End of a Fashion, in Animals and Courts. Europe, c. I200-I800, a cura di Mark Hengerer e Nadir Weber, Berlin-Boston, De Gruyter, 2020, pp. I7-42.

JACOB BURCKHARDT, La civiltà del Rinascimento in Italia, Firenze, Sansoni, I980 [ed. originale Die Kultur der Renaissance in Italien, Basel, Schweighauser, I860]

JILL BURKE, Changing Patrons. Social Identity \& the Visual Arts in Renaissance Florence, Pennsylvania, Pennsylvania State University Press, 2004 .

PETER BURKE, The Italian Renaissance. Culture \& Society in Italy, Princeton-Oxford, Princeton University Press, 20I4 [ed. originale Culture and Society in Renaissance Italy, I420-1540, London, Batsford, I972].

ANTONIO CADEI, Giovannino de Grassi nel taccuino di Bergamo, in "Critica d'Arte», I09, I970, pp. I7-36.

GIORGIO R. CADORNA, Indice ragionato, in MARCO POLO, Milione, a cura di Valeria Bertolucci Pizzorusso, Milano, Adelphi, 200I, pp. 490-76I [I975].

CARLO CAIRATI, Il polittico trecentesco, ancona dell'altar maggiore: ipotesi e problemi, in San Pietro in Ciel d'Oro a Pavia mausoleo santuario di Agostino e Boezio. Materiali antichi e problemi attuali, a cura di Maria Teresa Mazzilli Savini, Pavia, Comitato Pavia Città di Sant'Agostino, 20I3, pp. 330-35I. UGO CALEFFINI, Croniche I47I-I494, Ferrara, Deputazione Provinciale Ferrarese di Storia Patria, 2006.

GIOVANNI CAMBI, Istorie, in Delizie degli eruditi toscani, 24 voll., a cura di Ildefonso di San Luigi, I785-I786. 
CAMILLE 1992

CAMILLE I999

CAMPAGNA 2015

CAMPANA I950

CAMPO $201 \mathrm{I}$

CAMPORI I874

CANTILE 2010

CAPRETTI 2013

CAPRETTI 2015

CARDINI I983

CARDINI I985

CARDINI i99Ia

CARDINI I99Ib

CARDINI I99IC

CARDINI I992a

CARDINI I992b

CARDINI I993
MICHAEL CAMILLE, Image on the Edge. The Margins of Medieval Art, London, Reaktion Books, I992.

MICHAEL CAMILLE, Bestiary or Biology? Aristotle's Animals in Oxford, Merton Collge, Ms. 27I, in Aristotle's Animals in the Middle Ages and Renaissance, a cura di Carlos Steel, Guy Guldentops e Pieter Beullens, Liegi, Liegi University Press, I999, pp. 355-396.

CLAUDIA CAMPAGNA, Scheda, in Arte lombarda dai Visconti agli Sforza. Milano al centro dell'Europa, catalogo di mostra (Milano, Palazzo Reale I2 marzo - 28 giugno 20I5), a cura di Mauro Natale e Serena Romano, Skira, Milano, 2015, pp. I63-I64.

AUGUSTO CAMPANA, Il camaleonte di Leone $X$, in «Strenna dei Romanisti», XI, I950, pp. 225-227.

LUCHINO DAL CAMPO, Viaggio del marchese Nicolò d'Este al Santo Sepolcro (I4I3), a cura di Caterina Brandoli, Firenze, Olschki, 20 I. GIUSEPPE CAMPORI, Tiziano e gli Estensi, in "Nuova Antologia», 27, II, I874, pp. 58I-620.

ANDREA CANTILE, Fantasia e misura nella imago mundi: note sull'eredità cartografica e sulla rappresentazione dell'ecumene nel basso Medioevo, in Boccaccio geografo. Un viaggio nel Mediterraneo tra le città, i giardini e...il "mondo" di Giovanni Boccaccio, a cura di Roberta Morosini, Firenze, Polistampa, 20Io, pp. 39-52.

ELENA CAPRETTI, Feste, carri trionfali e il salone di Poggio a Caiano: i fasti della restaurazione medicea fra storia mito e allegoria, in Nello splendore mediceo. Papa Leone Xe Firenze, a cura di Nicoletta Baldini e Monica Bietti, Livorno, Sillabe, 2013, pp. I53-167.

ELENA CAPRETTI, Scheda, in Piero di Cosimo I462-I522. Pittore eccentrico fra Rinascimento e Maniera, catalogo di mostra (Firenze, Galleria degli Uffizi 23 giugno - 27 settembre 2015), a cura di Elena Capretti, Anna Forlani Tempesti, Serena Padovani e Daniela Parenti, Firenze, Giunti, 2015, pp. 220-223.

FRANCO CARDINI, Orizzonti geografici e orizzonti mitici nel Guerrin Meschino, in «Imago Mundi»: la conoscenza scientifica nel pensiero bassomedievale, Convegni del Centro di studi sulla spiritualità medievale (Todi, II-I4 ottobre I98I), Todi, Accademia Tudertina, I983, pp. I83-22I.

FRANCO CARDINI, Il viaggio in Terrasanta di ser Mariano da Siena, in Renaissance Studies in Honor of Craig Hugh Smyth, a cura di Andrew Morrogh, Fiorella Superbi Gioffredi, Piero Morselli ed Eve Borsook, Firenze, Giunti Barbera, I985, pp. 43-5I.

FRANCO CARDINI, Gerusalemme d'oro, di rame, di luce. Pellegrini, crociati, sognatori d'Oriente fra XI e XV secolo, Milano, Il Saggiatore, I99I. FRANCO CARDINI, La cavalcata d'Oriente. I Magi di Benozzo a palazzo Medici, Roma, Tomo, I99I.

FRANCO CARDINI, Viaggiar nel Trecento, in GABRIELLA BARTOLINI - FRANCO CARDINI, "Nel nome di Dio facemmo vela». Viaggio in Oriente di un pellegrino medievale, Roma-Bari, Laterza, I99I, pp. 5-95.

FRANCO CARDINI, "In terra di Soldano». Firenze come osservatorio sulla Terrasanta tra la caduta di San Giovanni d'Acri e il Concilio ferraresefiorentino (I29I-I44I), in Europa e Mediterraneo tra Medioevo e prima Età Moderna: l'osservatorio italiano, a cura di Sergio Gensini, Pisa, Pacini, I992, pp. 363-373.

FRANCO CARDINI, Le insegne laurenziane, in Le tems revient'l tempo si rinuova. Feste e spettacoli nella Firenze di Lorenzo il Magnifico, catalogo di mostra (Firenze, Palazzo Medici Riccardi 8 aprile - 30 giugno I992), a cura di Paola Ventrone, Firenze, Silvana, I992, pp. 55-74. FRANCO CARDINI, Alla cerca del Paradiso, in Columbeis V. Relazioni di viaggio e conoscenza del mondo fra Medioevo e Umanesimo, Atti del convegno internazionale di studi dell'Associazione per il Medioevo e 
CARDINI 200I

CARDINI 2002a

CARDINI $2002 b$

CARDINI 2009

CARDINI 2015

CARDINI 2017

CARDONA I986

CARILE I977

CARILE 2008

CARRARA 2020

CASTELFRANCHI I996

CASTELLI I986

CASTELNUOVO 20 I I

CASU 2007

Catalogo I933

CATTANEO 2003
l'Umanesimo latini (Genova, I2-I5 dicembre I99I), a cura di Stefano Pittaluga, Genova, Dipartimento di Archeologia, Filologia Classica e loro Tradizioni, I993, pp. 67-88.

FRANCO CARDINI, Il viaggio in Asia fra realtà e immaginario, in Firenze, il Giappone e l'Asia orientale, Atti del convegno internazionale di studi (Firenze, 25-27 marzo I999), a cura di Adriana Boscaro e Maurizio Bossi, Firenze, Olschki, 200I, pp. I7-46.

FRANCO CARDINI, In Terrasanta. Pellegrini italiani tra Medioevo e prima età moderna, Bologna, Il Mulino, 2002.

FRANCO CARDINI, Pellegrini toscani in Terrasanta fra Tre e Quattrocento. Note sul testo di Lionardo Frescobaldi, in Il cammino di Gerusalemme, Atti del II convegno internazionale di studio (Bari-Brindisi-Trani, I8-22 maggio I999), a cura di Maria Stella Calò Mariani, Bari, Mario Adda, 2002, pp. 7I-I32.

FRANCO CARDINI, Firenze e l'Oriente nel Quattrocento, in La stella e la porpora. Il corteo di Benozzo e l'enigma del Virgilio Riccardiano, Atti del convegno di studi (Firenze, I7 maggio 2007), a cura di Giovanna Lazzi e Gerhard Wolf, Firenze, Polistampa, 2009, pp. 73-Ioo.

FRANCO CARDINI, Da Firenze a Firenze, via Gerusalemme, in MARCO DI BARTOLOMEO RUSTICI, Codice Rustici. Dimostrazione dell'andata o viaggio al Santo Sepolcro e al monte Sinai, a cura di Elena Gurrieri, Kathleen Olive e Nerida Newbigin, vol. 2, Firenze, Olschki, 20I5, pp. I7-23.

FRANCO CARDINI, I Re Magi. Leggenda cristiana e mito pagano tra Oriente e Occidente, Venezia, Marsilio, 2017 [ed. originale 2000].

GIORGIO RAIMONDO CARDONA, I viaggi e le scoperte, in Letteratura italiana, a cura di Alberto Asor Rosa, vol. 5, Torino, Einaudi, I986, pp. 687-7I6.

ANTONIO CARILE, Territorio e ambiente nel Divisament dou monde di Marco Polo, in «Studi Veneziani», I, I977, pp. I3-36.

ANTONIO CARILE, La caduta di Costantinopoli nella cultura europea, in L'Europa dopo la caduta di Costantinopoli: 29 maggio 1453, Atti del XLIV convegno storico internazionale (Todi, 7-9 ottobre 2007), Spoleto, Fondazione Centro italiano di studi sull'alto Medioevo, 2008, pp. I-53. ELIANA CARRARA, La trasmissione della Naturalis Historia di Plinio dalla tarda Antichità al Medioevo, in ELIANA CARRARA NICOLETTA MARCELLI, La fortuna di Plinio dalla tarda antichità all'epoca moderna, luglio 2020, <http://www.oltreplinio.it/it/carrara-marcelli/> [accesso: dicembre 2020].

LIANA CASTELFRANCHI, La formazione e gli esordi di Michelino da Besozzo miniatore, in "Prospettiva», 83-84, I996, pp. II6-I27.

MARCELLA CASTELLI, Storie di santi nella pittura a Firenze, Firenze, Bonechi, I986.

ENRICO CASTELNUOVO, Introduzione, in OTTO PÄCHT, La scoperta della natura. I primi studi italiani, a cura di Fabrizio Crivello, Torino, Einaudi, 201 I, pp. XIII-XXX.

STEFANO CASU, Attinenze albertiane nelle frequentazioni antiquarie di Ciriaco d'Ancona, in Alberti e la cultura del Quattrocento, Atti del convegno internazionale del Comitato nazionale VI centenario della nascita di Leon Battista Alberti (Firenze, I6-I8 dicembre 2004), a cura di Roberto Cardini e Mariangela Regoliosi, vol. I, Firenze, Polistampa, 2007, pp. 467-494.

Catalogo delle cose d'arte e di antichità d'Italia. Fiesole, a cura di Odoardo H. Giglioli, Roma, La Libreria dello Stato, I933.

ANGELO CATTANEO, Scheda, in Umanesimo e cartografia: Tolomeo nel XV secolo, in La cartografia europea tra primo Rinascimento e fine dell'Illuminismo, Atti del convegno internazionale The making of European cartography (Firenze, I3-I5 dicembre 200I), a cura di Diogo Ramada 


\section{CATTANEO 2005}

CAVALLARO 200 I

CAZZOLA I99I

\author{
CENNINI I99I \\ CENTANNI 2017
}

CERULLI I933

CESARINI MARTINELLI I978

CESSI - ALBERTI I934

CHAMBERS I984

CHAMBERS 1992

CHAPMAN 20I0a

CHAPMAN 2OIob

CHASTEL I985

CHASTEL I999

CHAUDHURI 2009

CHIESA 20I 8

CHRISTIANSEN I982

CHRISTIANSEN I987

CHRISTIANSEN 2005

CHRISTIANSEN 2006
Curto, Angelo Cattaneo e André Ferrand Almeida, Firenze, Olschki, 2003, pp. 340-34I.

ANGELO CATTANEO, Scritture di viaggio e scrittura cartografica. La Mappamundi di Fra Mauro e i racconti di Marco Polo e Niccolò de' Conti, in «Itineraria», 3-4, 2004-2005, pp. I57-202.

ANNA CAVALLARO, La pittura rinascimentale a Roma da Martino $V$ ad Alessandro VI (I42O-I5O3), Roma, Lithos, 200I.

FRANCO CAZZOLA, L'orto di Belfiore, la villa, il barco. Una campagna per diletto, in Le muse e il principe. Arti di corte nel Rinascimento padano. Saggi, catalogo di mostra (Milano, Museo Poldi Pezzoli 20 settembre - I dicembre I991), a cura di Alessandra Mottola Molfino e Mauro Natale, Modena, Panini, I99I, pp. 203-222.

CENNINO CENNINI, Il libro dell'arte, a cura di Mario Serchi, Firenze, Le Monnier, I99I.

MONICA CENTANNI, Fantasmi dell'antico. La tradizione classica nel Rinascimento, Rimini, Guaraldi, 2017.

ENRICO CERULLI, Eugenio IV e gli Etiopi al concilio di Firenze, in "Atti della Reale Accademia Nazionale dei Lincei. Rendiconti della Classe di Scienze Fisiche, Matematiche e Naturali», 9, I933, pp. 347-368.

LUCIA CESARINI MARTINELLI, Introduzione, in ANGELO POLIZIANO, Commento inedito alle Selve di Stazio, a cura di Lucia Cesarini Martinelli, Firenze, Sansoni, I978, pp. IX-XXVI.

ROBERTO CESSI - ANNIBALE ALBERTI, Rialto. L'isola - Il ponte - Il mercato, Bologna, Zanichelli, I934.

DAVID S. CHAMBERS, Giovanni Pietro Arrivabene (I439-I504). Humanistic Secretary and Bishop, in "Aevum", 58, 3, I984, pp. 397-438. DAVID S. CHAMBERS, A Renaissance Cardinal and his Worldly Goods. The Will and Inventory of Francesco Gonzaga (I444-I483), London, Warburg Institute, I992.

HUGO CHAPMAN, Introduction, in Fra Angelico to Leonardo. Italian Renaissance Drawings, catalogo di mostra (London, British Museum 25 aprile - 25 luglio 20I0), a cura di Hugo Chapman e Marzia Faietti, London, British Museum Press, 2010, pp. I5-75.

HUGO CHAPMAN, Scheda, in Fra Angelico to Leonardo. Italian Renaissance Drawings, catalogo di mostra (London, British Museum 25 aprile - 25 luglio 20I0), a cura di Hugo Chapman e Marzia Faietti, London, British Museum Press, 20Iо, pp. 90-9I.

ANDRÉ CHASTEL, Cronaca della pittura italiana I280-I580, Roma, Fratelli Palombi, I985 [ed. originale Chronique de la peinture italienne à la Renaissance (I280-I580), Friburgo (CH), Office du Livre, I983].

ANDRÉ CHASTEL, L'Italie et Byzance, Paris, Fallois, I999.

SUPRIYA CHAUDHURI, India Recognita. The Travels of Nicolo de' Conti, in Oriente e Occidente nel Rinascimento, Atti del XIX convegno internazionale (Chianciano Terme-Pienza, I6-I9 luglio 2007), a cura di Luisa Secchi Tarugi, Firenze, Franco Cesati, 2009, pp. 263-278.

PAOLO CHIESA, Galvano Fiamma e Giovanni da Carignano. Una nuova fonte sull'ambasceria etiopica a Clemente $V$ e sulla spedizione oceanica dei fratelli Vivaldi, in «Itineraria», I7, 2018, pp. 63-I07.

KEITH CHRISTIANSEN, Gentile da Fabriano, London, Chatto \& Windus, I982.

KEITH CHRISTIANSEN, La pittura a Venezia e in Veneto nel primo Quattrocento, in La pittura in Italia. Il Quattrocento, a cura di Federico Zeri, vol. I, Milano, Electa, I987, pp. II9-I46.

KEITH CHRISTIANSEN, L'Adorazione dei Magi di Gentile da Fabriano, in Gentile da Fabriano agli Uffizi, a cura di Alessandro Cecchi, Cinisello Balsamo, Silvana, 2005, pp. I I-40.

KEITH CHRISTIANSEN, L'arte di Gentile da Fabriano, in Gentile da Fabriano e l'altro Rinascimento, catalogo di mostra (Fabriano, Spedale di 
CHRISTIANSEN 2015

CHURCH 2004

CIANO I964

CIAPPELLI 200I

CICCAGLIONI 2009

CICCUTO 2000

\section{CIOCCI 2003}

CIPOLLA I873

CISERI 2013

CISERI 2014

CLARK I95I

CLASSEN 2013

CLEMENS 2008

\section{CLOULAS I984}

COCKRAM 2017

Codici latini I99I

COGLIATI ARANO I988
Santa Maria del Buon Gesù 2 I aprile - 23 luglio 2006), a cura di Laura Laureati e Lorenza Mochi Onori, Milano, Electa, pp. I9-5I.

KEITH CHRISTIANSEN, Scheda, in Piero di Cosimo I462-I522. Pittore eccentrico fra Rinascimento e Maniera, catalogo di mostra (Firenze, Galleria degli Uffizi 23 giugno - 27 settembre 20I5), a cura di Elena Capretti, Anna Forlani Tempesti, Serena Padovani e Daniela Parenti, Firenze, Giunti, 2015, pp. 216-2I9.

SALLY K. CHURCH, The Giraffe of Bengal. A Medieval Encounter in Ming China, in "The Medieval History Journal», 7, I, 2004, pp. I-37.

CESARE CIANO, La pratica di mercatura datiniana (secolo XIV), Milano, Giuffrè, I964.

GIOVANNI CIAPPELLI, Biblioteche e lettura a Firenze nel Quattrocento, in Libri, lettori e biblioteche dell'Italia medievale (secoli IX-XV). Fonti, testi, utilizzazione del libro, Atti della tavola rotonda italo-francese (Roma, 7-8 marzo I997), a cura di Giuseppe Lombardi e Donatella Nebbiai Dalla Guarda, Roma, ICCU, 200I, pp. 425-439.

GIOVANNI CICCAGLIONI, Il mare a Firenze. Interazioni tra mutamenti geografici, cambiamenti istituzionali e trasformazioni economiche nella Toscana fiorentina del '400, in "Archivio Storico Italiano», 619, 2009, pp. 9I-I25.

MARCELLO CICCUTO, Con la storia o contro: le Cronache Universali illustrate nel Quattrocento, in Percorsi tra parole e immagini (I4OO-I600), a cura di Angela Guidotti e Massimiliano Rossi, Lucca, Maria Pacini Fazzi Editore, 2000, pp. 37-50.

ARGANTE CIOCCI, Luca Pacioli e la matematizzazione del sapere nel Rinascimento, Bari, Cacucci, 2003.

CARLO CIPOLLA, Prete Jane e Francesco Novello da Carrara, in "Archivio Veneto", 6, II, I873, pp. 323-324.

ILARIA CISERI, Io marzo I492. Cerimonie e feste per la prima entrata a Firenze del cardinale Giovanni de' Medici, in Nello splendore mediceo. Papa Leone Xe Firenze, a cura di Nicoletta Baldini e Monica Bietti, Livorno, Sillabe, 20I3, pp. 97-IOI.

ILARIA CISERI, Il «trionfo dello alifante». Immagini inedite dalle feste per Giovanni de' Medici cardinale, in "Annali di Storia di Firenze», 9, 20I4, pp. III-I22.

KENNETH CLARK, Piero della Francesca, London, Phaidon, I95I. ALBRECHT CLASSEN, Introduction, in East Meets West in the Middle Ages and Early Modern Times. Transcultural Experiences in the Premodern World, a cura di Albrecht Classen, Berlin-Boston, De Gruyter, 20I3, pp. I-2I7.

RAYMOND CLEMENS, Medieval Maps in a Renaissance Context: Gregorio Dati and the Teaching of Geography in Fifteenth-Century Florence, in Cartography in Antiquity and the Middle Ages. Fresh Perspectives, New Methods, a cura di Richard J.A. Talbert e Richard W. Unger, Leiden, Brill, 2008 , pp. 237-256.

IVAN CLOULAS, Un caprice d'Anne de Beaujeu: la girafe de Laurent le Magnifique, in Anne de Beaujeu et ses énigmes, Acte du colloque national (Villefranche-en-Beaujolais, 28 maggio I983), Villefranche-sur- Saône, Hassler, I984, pp. 73-82.

SARAH COCKRAM, Interspecies Understanding. Exotic Animals and their Handlers at the Italian Renaissance Court, in "Renaissance Studies», 3I, 2, 20I7, pp. 277-296.

Codici latini del Petrarca nelle biblioteche fiorentine, catalogo di mostra (Firenze, Biblioteca Medicea Laurenziana I9 maggio - 30 giugno I99I), a cura di Michele Feo, Firenze, Le Lettere, I99I.

LUISA COGLIATI ARANO, Scheda, in Arte in Lombardia tra Gotico e Rinascimento, catalogo di mostra (Milano, Palazzo Reale I988) a cura di Miklós Boskovits, Milano, Fabbri, I988, pp. 90-93. 
COLE AHL I996

COLE AHL 2008

COLLINS 2000

Compendio I739

CONCINA 2016

CONCINA 2018

CONDORELLI 2006

CONTE 2OII

CONTI - GERMANI - POPPLE

20I6-20I7

CONTI ROSSINI I923

CORAZZA I 894

CORDELLIER 1996

CORDEZ 2016

CORFIATI 2012

CORSI 2008

CORTI 1958

COSTANZI I5O2

COX 1967

CRISTINA I999

CRITCHLEY I992

CURSI I998

CURSI 2007
DIANE COLE AHL, Benozzo Gozzoli, New Haven-London, Yale University Press, I996.

DIANE COLE AHL, Beato Angelico, London, Phaidon, 2008.

MINTA COLLINS, Medieval Herbals. The illustrative Traditions, London, British Library, 2000.

Compendio del vocabolario degli accademici della Crusca, 5 voll., Firenze, Domenico Maria Manni, I739.

CHIARA CONCINA, Unfolding the Cocharelli Codex: Some Preliminary Observation about the Text, with a Theory about the Order of the Fragments, in "Medioevi», 2, 20I6, pp. I89-265.

CHIARA CONCINA, Da Pechino ad Avignone e oltre. La corrispondenza tra Benedetto XII, il "qaghan" Toghon-Temür e i principi Alani nella traduzione francese di Jean le Long (I35I), in «Itineraria», I 7, 2018, pp. I09-I59. ADELE CONDORELLI, Appendice. A proposito della tavola Strozzi, in Antonello e la pittura del Quattrocento nell'Europa mediterranea, a cura di Maria Antonietta Malleo, Palermo, Kalos, 2006, pp. 82-89.

ROSA CONTE, Il leggendario "Prete Gianni" tra Oriente e Occidente, in "Orientalia Parthenopea», II, 20II, pp. 3I-62.

CRISTIANA CONTI - GIOIA GERMANI - ALESSANDRA POPPLE, Andrea del Sarto alla Santissima Annunziata. Il Corteo dei Magi (ISII) e la Madonna del Sacco (I525), in «Kermes», I04-IO5, ottobre 2016 - marzo 20I7, pp. 77-90.

CARLO CONTI ROSSINI, Aetiopica, in "Rivista degli Studi Orientali", 9, I923, pp. 449-468.

BARTOLOMEO DEL CORAZZA, Diario fiorentino anni I405-I438, a cura di Giuseppe O. Corazzini, in "Archivio Storico Italiano", I96, I894, pp. 233-298.

DOMINIQUE CORDELLIER, Scheda, in Pisanello. Le peintre aux sept vertus, catalogo di mostra (Paris, Musée du Louvre 6 maggio - 5 agosto I996), a cura di Dominique Cordellier e Paola Marini, Paris, Réunion des Musées Nationaux, I996, pp. 2I3-2I4.

PHILIPPE CORDEZ, Trésor, mémoire, merveilles. Les objets des églises au Moyen Âge, Paris, EHESS, 2016

CLAUDIA CORFIATI, Lettori della Naturalis historia di Plinio a Napoli nel Rinascimento, in La Naturalis historia di Plinio nella tradizione medievale e umanistica, a cura di Vanna Maraglino, Bari, Cacucci, 20I2, pp. 25 I-276.

PASQUALE CORSI, Fine di Bisanzio, fine del Medioevo?, in L'Europa dopo la caduta di Costantinopoli: 29 maggio I453, Atti del XLIV convegno storico internazionale (Todi, 7-9 ottobre 2007), Spoleto, Fondazione Centro italiano di studi sull'alto Medioevo, 2008, pp. 55- 7I.

GINO CORTI, Relazione di un viaggio al Soldano d'Egitto e in Terra Santa, in "Archivio Storico Italiano", 4I8, I958, pp. 247-266.

ANTONIO COSTANZI, Epigrammatum libellus. Ode excitans christianorum principes in Turcum. Ode ad Federicum tertium Caesarem Iacobi Constantii epigrammata quaedam. Eiusdem epicedion in Tadaeam matrem, Fano, Gerolamo Soncino, I5O2.

EUGENE L. COX, The Green Count of Savoy. Amadeus VI and Transalpine Savoy in the Fourteenth Century, Princeton, Princeton University Press, I967.

GIOVANNI CRISTINA, Un panegirico del professore pavese Baldassarre Rasini per Francesco Sforza pronunciato davanti all'Università di Pavia, in "Bollettino della Società Pavese di Storia Patria», LI, I999, pp. 25-I I6. JOHN CRITCHLEY, Marco Polo's Book, Aldershot, Variorum, I992. MARCO CURSI, Produzione, tipologia, diffusione del Decameron fra Tre e Quattrocento. Note paleografiche e codicologiche, in «Nuova Rivista di Letteratura Italiana", I, 2, I998, pp. 463-55I.

MARCO CURSI, Il Decameron: scritture, scriventi, lettori. Storia di un testo, Roma, Viella 2007. 


\section{CURSIETTI I999}

\section{CURSIETTI 2005}

CUTLER 200I

CUTLER 2OII

CUTTLER I99I

DACOS - FURLAN 1987

DALTON 2014

D'ANCONA I97I

DANIELS 2009

DANIELS 2013

Das Hausbuch 1979

DATI 1902

DAVIDSOHN I896-I908

DAVIDSOHN 1929

DAVIDSOHN I956-I968

DAVIES I995

DAVIES 2002

DAVISSON I97I

DAVISSON I980

DAVISSON 200I

DECEMBRIO I925
MAURO CURSIETTI, Indagine sulla tradizione manoscritta del Guerrin Meschino di Andrea da Barberino. Materiali per un'edizione critica, Tesi di dottorato di ricerca in Studi storici di letteratura italiana (X ciclo), Università degli Studi di Roma Tre, Tutor Prof. Enzo Esposito, I999. MAURO CURSIETTI, Introduzione, in ANDREA DA BARBERINO, Il Guerrin Meschino. Edizione critica secondo l'antica vulgata fiorentina, a cura di Mauro Cursietti, Roma-Padova, Antenore, 2005, pp. XIII-XXIX.

ANTHONY CUTLER, Gifts and Gifts Exchange as Aspects of Byzantine, Arab, and Related Economies, in "Dumbarton Oaks Papers", 55, 200I, pp. 247-278.

ANTHONY CUTLER, The Enduring Present. Gifts in Medieval Islam and Byzantium, in Gifts of the Sultan. The Arts of Giving at the Islamic Courts, catalogo di mostra (Los Angeles, County Museum of Art 5 giugno - 5 settembre 20II), a cura di Linda Komaroff, New HavenLondon, Yale University Press, 201 i, pp. 79-9I.

CHARles D. CUTTler, Exotics in Post-Medieval European Art. Giraffes and Centaurs, in "Artibus et Historiae", 23, I99I, pp. I6I-I79. NICOLE DACOS - CATERINA FURLAN, Giovanni da Udine I487-I56I, Udine, Casamassina, I987.

HEATHER DALTON, A Sulphur-Crested Cokatoo in Fifteenth-Century Mantua. Rethinking Symbols and Sanctity and Patterns of Trade, in "Renaissance Studies», 5, 2014, pp. 676-694.

ALESSANDRO D'ANCONA, Origini del teatro italiano, 2 voll., Roma, Bardi, I97I [ed. originale Torino, Loescher I89I].

RHIANNON DANIELS, Boccaccio and the Book. Production and Reading in Italy 1340-1520, London, Legenda, 2009.

TOBIAS DANIELS, La congiura dei Pazzi: $i$ documenti del conflitto fra Lorenzo de' Medici e Sisto IV. Le bolle di scomunica, la Florentina Synodus, e la Dissentio insorta tra la Santità del Papa e i Fiorentini, Firenze, Edifir, $20 \mathrm{OI}$. Das Hausbuch der Cerruti. Nach der Handschrift in der Österreichischen Nationalbibliothek, a cura di Franz Unterkircher, Dortmund, Harenberg Kommunikation, I979.

GREGORIO DATI, L'Istoria di Firenze dal I380 al I405, a cura di Luigi Pratesi, Norcia, Tonti Cesare, I902.

ROBERT DAVIDSOHN, Forschungen zur älteren Geschichte von Florenz, 4 voll., Berlin, Mittler, I896-I908.

ROBERT DAVIDSOHN, Firenze ai tempi di Dante, Firenze, Bemporad, I929.

ROBERT DAVIDSOHN, Storia di Firenze, 8 voll., Firenze, Sansoni, I956-I968 [ed. originale Geschichte von Florenz, Berlin, Mittler, I896I927].

MARTIN DAVIES, Making Sense of Pliny in the Quattrocento, in «Renaissance Studies», 2, I995, pp. 240-257.

MARTIN DAVIES, Per l'esegesi di Plinio nel Quattrocento, in Nel mondo delle postille. I libri a stampa con note manoscritte. Una raccolta, a cura di Edoardo Barbieri, Milano, Edizioni C.U.S.L., 2002, pp. I25-I52.

DARRELLDAVISSON, The advent of the Magi. A study of the Transformations in Religious Images in Italian Art I260-I425, Ph.D. Dissertation, Baltimore, John Hopkins University, I97I.

DARRELL DAVISSON, New Documents on Gentile da Fabriano's Residence in Florence, I42O-I422, in "The Burlington Magazine», 932, I980, pp. 759-763.

DARRELL DAVISSON, Magician Ars medica, Liturgical Devices, and Eastern Influences in the Medici Palace Chapel, in «Studies in Iconography», 22, 200I, pp. III-I62.

PIER CANDIDO DECEMBRIO, Opuscola historica, a cura di Attilio Butti, Felice Fossati e Giuseppe Petraglione, in Rerum Italicarum Scriptores, vol. 20.I, Bologna, Zanichelli, I925, pp. 3-438. 
DECEMBRIO I983

DE FRANCOVICH I926-I927

DEGENHART - SCHMITT I963

DEGENHART - SCHMITT I968-20IO

DEI 1984

DE LA MARE I973

DE LA MARE I985

DE LA MARE 1996

D'ELIA 2015

DELFIOL I982

DELLA TUCCIA I 852

DELLE FOGLIE 2006

DELLE FOGLIE 2019

DELLO MASTRO I9I 2

DEL MIGLIORE I976

DELMORO 2006

DELORT 2000

\section{DEL TREPPO I972}

DELUZ I987
PIER CANDIDO DECEMBRIO, Vita di Filippo Maria Visconti, a cura di Elio Bartolini, Milano, Adelphi, I983.

GÉZA DE FRANCOVICH Nuovi aspetti della personalità di B. di Giovanni, in "Bollettino d'Arte», 6, I926-I927, pp. 65-91.

BERNHARD DEGENHART - ANNEGRIT SCHMITT, Uccello. Wiederherstellung einer Zeichnung, in "Albertina Studien", 2, I963, pp. IOI-II7.

BERNHARD DEGENHART - ANNEGRIT SCHMITT, Corpus der Italienischen Zeichnungen I300-I450, 3 voll., Berlin, Mann, I968-20I0. BENEDETTO DEI, La Cronica dall'anno I 400 all'anno I50o, a cura di Roberto Barducci, Firenze, Francesco Papafava, I984.

ALBINIA C. DE LA MARE, The Shop of a Florentine cartolaio in I426, in Studi offerti a Roberto Ridolfi, a cura di Berta Maracchi Biagiarelli e Dennis E. Rhodes, Firenze, Olschki, I973, pp. 237-48.

ALBINIA C. DE LA MARE, New Research on Humanistic Scribes in Florence, in Miniatura fiorentina del Rinascimento (I44O-I525). Un primo censimento, a cura di Albinia C. de La Mare, vol. I, Firenze, La Nuova Italia, I985, pp. 395-600.

ALBINIA C. DE LA MARE, Vespasiano da Bisticci as Producer of Classical Manuscripts in Fifteenth-Century Florence, in Medieval Manuscripts of the Latin Classics. Production and Use, Proceedings of the Seminar in the History of the Book to I500 (Leiden, I993), a cura di Claudine A. Chavannes-Mazel e Margareth M. Smith, Anderson-Lovelace, Red Gull Press, I966, pp. I66-207.

UNA ROMAN D'ELIA, Raphael's Ostrich, University Park, Pennsylvania State University Press, 2015.

RENATO DELFIOL, Su alcuni problemi codicologico-testuali concernenti le relazioni di pellegrinaggio fiorentine del 1384 , in Toscana e Terrasanta nel Medioevo, a cura di Franco Cardini, Firenze, Alinea, I982, pp. I39I 76.

NICCOLÒ DELLA TUCCIA, Cronaca inedita de' principali fatti d'Italia dall'anno I4I7 al I468, a cura di Francesco Orioli, Roma, Tipografia della Belle Arti, I852.

ANNA DELLE FOGLIE, Un taccuino tardogotico lombardo. Studi sul Libretto degli Anacoreti, in "Arte Lombarda", I-3, 2006, pp. 55-62.

ANNA DELLE FOGLIE, Il Libretto degli Anacoreti e il Libro di Giusto. Due taccuini di disegni tra Tardogotico e Rinascimento, Roma, De Luca Editori d'Arte, 20I9.

PAOlO Dello MASTRO, Il Memoriale di Paolo di Benedetto di Cola dello Mastro del rione di Ponte, a cura di Francesco Isoldi, in Rerum Italicarum Scriptores, vol. 24. 2, Città di Castello, Lapi, I9I2, pp. 8I-Ioo.

FERDINANDO LEOPOLDO DEL MIGLIORE, Firenze città nobilissima illustrata, Sala Bolognese, Forni, I976 [ed. originale Firenze, Stella, I684].

ROBERTA DELMORO, Per gli affreschi perduti della "salla grande dale caze» del Castello Visconteo di Pavia: modelli decorativi del tardo Trecento, in "Arte Lombarda", I-3, 2006, pp. 63-72.

ROBERT DELORT, Le prince et la bête, in Guerre, pouvoir et noblesse au Moyen Âge. Mélanges en l'honneur de Philippe Contamine, a cura di Jacques Paviot e Jacques Verger, Paris, Presses de l'Université de ParisSorbonne, 2000, pp. I84-I95.

MARIO DEL TREPPO, I mercanti catalani e l'espansione della Corona d'Aragona nel secolo XV, Napoli, L'Arte Tipografica, I972.

CHRISTIANE DELUZ, Le Livre de Jehan de Mandeville, autorité géographique à la Renaissance, in Voyager à la Renaissance, Actes du colloque du Centre d'études supérieures de la Renaissance (Tours, 30 giugno -I3 luglio I983), a cura di Jean Ceard e Jean-Claude Margolin, Paris, Maisonneuve et Larose, I987, pp. 205-220. 
DELUZ 2007

DE MARCHI 2006a

DE MARCHI $2006 \mathrm{~b}$

DENNISTOUN I85I

DENNISTOUN 2010

DE ROOVER I970

DESPOTAKIS 2009

Diario di anonimo I876

Diario di Felice Brancacci I88 I

DI BENEDETTO 1972

DIENER I967

DI FEBO 2016

DINI 1980

DINI 1998

DI NOLA 1966

DI PALMA I985

Documenti sulle relazioni I879

DONATI I938

DONATO I99I
CHRISTIANE DELUZ, L'originalité du Livre de Jean de Mandeville, in Jean de Mandeville in Europa. Neue Perspektiven in der Reiseliteraturforschung, a cura di Ernst Bremer e Susanne Röhl, München, Wilhelm Fink, 2007, pp. II-I8.

ANDREA DE MARCHI, Alla corte di Gian Galeazzo Visconti: l'anconetta di Pavia, in Gentile da Fabriano e l'altro Rinascimento, catalogo di mostra (Fabriano, Spedale di Santa Maria del Buon Gesù 2 I aprile - 23 luglio 2006), a cura di Laura Laureati e Lorenza Mochi Onori, Milano, Electa, 2006, pp. 62-9I.

ANDREA DE MARCHI, Gentile da Fabriano. Un viaggio nella pittura italiana alla fine del gotico, Milano, Federico Motta, 2006 [I992].

JAMES DENNISTOUN, Memoirs of the Dukes of Urbino, 3 voll., London, Longman, Brown, Greeb and Longmans, I85I.

JAMES DENNISTOUN, Memorie dei Duchi d'Urbino (I440-I630), 3 voll., a cura di Giorgio Nonni, Urbino, QuattroVenti, 20 Iо.

RAYMOND DE ROOVER, Il Banco Medici. Dalle origini al declino (I397I494), Firenze, La Nuova Italia, I970 [ed. originale The Rise and Decline of the Medici Bank (I397-I494), Cambridge, Harvard University Press, I963]. ELEFTHERIOS DESPOTAKIS, Il corteo dei Magi di Benozzo nel contesto politico del I459, in La stella e la porpora. Il corteo di Benozzo e l'enigma del Virgilio Riccardiano, Atti del convegno di studi (Firenze, I7 maggio 2007), a cura di Giovanna Lazzi e Gerhard Wolf, Firenze, Polistampa, 2009, pp. IOI-IO7.

Diario di anonimo fiorentino dall'anno 1358 al I389, in Cronache dei secoli $X I I I$ e XIV, a cura di Alessandro Gherardi, Firenze, Cellini, I876, pp. 207-48I.

Diario di Felice Brancacci ambasciatore con Carlo Federighi al Cairo per il Comune di Firenze (1422), a cura di Dante Catellacci, in «Archivio Storico Italiano", 22, I88I, pp. I57-I88.

FRANCESCO DI BENEDETTO, Il Plinio laurenziano proveniente veramente da Lubecca, in Studi classici in onore di Quintino Cataudella, vol. 3, Catania, Edigraf, I972, pp. 437-445.

HERMANN DIENER, Die Camera Pappagalli im Palast des Papstes. Papageien als Hausgenossen der Päpste, Könige und Fürsten des Mittelalters und der Renaissance, in "Archiv für Kunstgeschichte», 49, I967, pp. 43-97.

MARTINA DI FEBO, Jean de Mandeville sulle tracce di Alessandro: dal Roman d'Alexandre al Livre des merveilles dou monde, in Forme letterarie del Medioevo romanzo: testo, interpretazione e storia, Atti dell'XI congresso della Società Italiana di Filologia Romanza (Catania, 22-26 settembre 20I5), a cura di Antonio Pioletti e Stefano Rapisarda, Soveria Mannelli, Rubbettino, 20I6, pp. I73-I87.

BRUNO DINI, Una pratica di mercatura in formazione (1394-1395), Firenze, Le Monnier, I980.

BRUNO DINI, I circuiti del commercio internazionale nel tardo Medioevo, in Prodotti e tecniche d'oltremare nelle economie europee secc. XIII-XVIII, a cura di Simonetta Cavaciocchi, Firenze, Le Monnier, I998, pp. 635-669.

ALFONSO M. DI NOLA, Introduzione, in GIOVANNI DI HILDESHEIM, La storia dei Re Magi, a cura di Alfonso M. di Nola, Firenze, Vallecchi, I966, pp. 9-58.

MARIA TERESA DI PALMA, Cartografia medievale, in L'Oriente. Storie di viaggiatori italiani, Milano, Electa, I985, pp. 88-I07.

Documenti sulle relazioni delle città toscane coll'Oriente cristiano e coi Turchi fino all'anno MDXXXI, a cura di Giuseppe Müller, Firenze, Cellini, I879.

LAMBERTO DONATI, Città del Vaticano - Biblioteca - La giraffa, in «Maso Fininguerra», 3, I938, pp. 247-268.

MARIA MONICA DONATO, Hercules and David in the Early Decoration of the Palazzo Vecchio. Manuscript Evidence, in «Journal of the Warburg and Courtauld Institutes", 54, I991, pp. 83-98. 
DONI GARFAGNINI 2002

DROCOURT 2004

DRONKE I997

DUITS I999

DUITS 2008

DUNLOP 20I6

ECO 200I

$\mathrm{ECO} 2005$

ECKSTEIN 2OI4

EDLER DE ROOVER I953

EDLER DE ROOVER I999

EDSON 2005

EDSON 2007

ELEN I995

ELEN 2012

ERODOTO 2013

ESCH 2000

EVRIM BINBAŞ 2016
MANUELA DONI GARFAGNINI, Il teatro della storia fra rappresentazione e realtà. Storiografia e trattatistica fra Quattrocento e Seicento, Roma, Edizioni di storia e letteratura, 2002.

NICOLAS DROCOURT, Les animaux comme cadeaux d'ambassade entre Byzance et ses voisins (VIIe-XIIe siècle), in Byzance et ses périphéries. Hommage à Alain Ducellier, a cura di Bernard Doumerc e Christophe Picard, Toulouse, CNRS Université de Toulouse-Le Mirail, 2004, pp. 67-93.

PETER DRONKE, Introduzione, in Alessandro nel Medioevo occidentale, a cura di Piero Boitani, Corrado Bologna, Adele Cipolla e Mariantonia Liborio, Roma-Milano, Fondazione Lorenzo Valla-Arnoldo Mondadori, I997, pp. XV-LXXV.

REMBRANDT DUITS, Figured Riches. The Value of Gold Brocades in Fifteenth-Century Florentine Painting, in "Journal of the Warburg and Courtauld Institutes", 62, I999, pp. 60-92.

REMBRANDT DUITS, Gold Brocade and Renaissance Painting. A Study in Material Culture, London, Pindar Press, 2008.

ANNE DUNLOP, Ornament and Vice. The Foreign, the Mobile, and the Cocharelli Fragments, in Histories of Ornament from Global to Local, a cura di Gülru Necipoğlu e Alina Payne, Princeton, Princeton University Press, 20I6, pp. 228-237.

UMBERTO ECO, Sugli specchi e altri saggi. Il segno, la rappresentazione, l'illusione, l'immagine, Milano, Bompiani, 200 I [1985].

UMBERTO ECO, Kant e l'ornitorinco, Milano, Bompiani, 2005 [I997].

NICHOLAS A. ECKSTEIN, Painted Glories. The Brancacci Chapel in Renaissance Florence, New Haven-London, Yale University Press, 2014.

FLORENCE EDLER DE ROOVER, Per la storia dell'arte della stampa in Italia. Come furono stampati a Venezia tre dei primi libri in volgare, in «La Bibliofilia", 2, I953, pp. IO7-II7.

FLORENCE EDLER DE ROOVER, L'arte della seta a Firenze nei secoli XIV e XV, a cura di Sergio Tognetti, Firenze, Olschki, I999.

EVELYN EDSON, Mapping the Middle Ages: The Imaginary and the Real Universe of the Mappaemundi, in Monsters, Marvels and Miracles: Imaginary Journeys and Landscapes in the Middle Ages, a cura di Leif Søndergaard e Rasmus Thorning Hansen, Odense, University Press of Southern Denmark, 2005, pp. I I-25.

EVELYN EDSON, The World Map, I300-I492: The Persistence of Tradition and Transformation, Baltimore, Johns Hopkins University Press, 2007.

ALBERT J. ELEN, Italian Late-Medieval and Renaissance Drawing-Books. From Giovannino de' Grassi to Palma il Giovane. A codicological approach, Ph.D Dissertation, Leiden, Rijksuniversiteit, I995.

ALBERT J. ELEN, Drawing Evolution or Revolution? From Workshop ModelBook to Personal Sketch-Book, in From Pattern to Nature in Italian Renaissance Drawing. Pisanello to Leonardo, a cura di Michael W. Kwallelstein e Lorenza Melli, Firenze, Centro Di, 2012, pp. 35-49.

ERODOTO, Le storie. Libro III: la Persia, a cura di David Asheri e Silvio M. Medaglis, vol. 3, Milano, Fondazione Lorenzo VallaArnoldo Mondadori, 20I3 [I990].

ARNOLD ESCH, Navi nel porto di Roma. Esempi di carichi di merci nei registri doganali del Quattrocento, in Medioevo nel Mediterraneo. Studi in onore di Mario Del Treppo, a cura di Gabriella Rossetti e Giovanni Vitolo, 2 voll., Napoli, Liguori, 2000, pp. 93-I03.

ILKER EVRIM BINBAS,, Intellectual Networks in Timurid Iran, Sharaf al-Dìn 'Alì Yazdī and the Islamicate Republic of Letters, Cambridge, Cambridge University Press, 20I6. 
Extraits des comptes 1873

FABBRI I999

FABBRI 2OII

FABBRI 2OI3

FAHY I967

FAHY 200I-2002

FALCHETTA 2016

FANTACCI I970

FANTONI 2005

FANTONI 2014

FARAGO I995

FARINELLA 2015

FEDERICO II 2000

Felice et divoto I999

FERMOR 1993

FIAMMA I938
Extraits des comptes et mémoriaux du roi René pour servir à l'histoire des arts $d u$ XVe siècle, a cura di Albert Lecoy de la Marche, Paris, Picard, I873. FRANCESCA FABBRI, Il "Cocharelli". Osservazioni e ipotesi per un manoscritto genovese del XIV secolo, in Tessuti, oreficerie, miniature in Liguria $X I I I-X V$ secolo, Atti del convegno internazionale di studi (GenovaBordighera, 22-25 maggio I997), a cura di Anna Rosa Calderoni Masetti, Clario Di Fabio e Mario Marcenaro, Bordighera, Istituto internazionale di studi liguri, I999, pp. 305-320.

FRANCESCA FABBRI, Il codice Cocharelli fra Europa, Mediterraneo e Oriente, in La pittura in Liguria. Il Medioevo, secoli XII-XIV, a cura di Giuliana Algeri e Francesca Fabbri, Genova, De Ferrari, 20ı i, pp. 289-3I0.

FRANCESCA FABBRI, Vizi e virtù in due codici realizzati a Genova nel Trecento fra seduzioni d'Oriente e apporti toscani, in «Storia della Miniatura", I7, 20I3, pp. 95-106.

EVERETT FAHY, Some Early Italian Pictures in the Gambier-Parry Collection, in «The Burlington Magazine», 768, I967, pp. I28-I39.

EVERETT FAHY, The Este Predella Panels and other Works by the Master of the Fiesole Epiphany, in «Nuovi Studi», 9, 200I-2002, pp. I7-29.

PIERO FALCHETTA, Storia del mappamondo di Fra' Mauro. Con la trascrizione integrale del testo, Rimini, Imago, 2016.

LILIANA FANTACCI, La Pratica di mercatura Acciaioli secolo XIV. (Con trascrizione del codice Tordi n. I39 della Biblioteca Nazionale Centrale di Firenze), Tesi di laurea in Economia, Università degli studi di Firenze, Tutor Prof. Federigo Melis, I970.

ANNA RITA FANTONI, Scheda, in Mythologica et Erotica. Arte e Cultura dall'Antichità al XVIII secolo, catalogo di mostra (Firenze, Palazzo Pitti, Museo degli Argenti 5 ottobre 2005 - I5 maggio 2006), a cura di Ornella Casazza e Riccardo Gennaioli, Livorno Sillabe, 2005, pp. 309-3 I0.

ANNA RITA FANTONI, Scheda, in Animalia. Gli nomini e la cura degli animali nei manoscritti della Biblioteca Medicea Laurenziana, catalogo di mostra (Firenze, Biblioteca Medicea Laurenziana I4 aprile - I4 giugno 20I4), a cura di Donatella Lippi, Firenze, Mandragora, 20I4, pp. $86-87$.

CLAIRE FARAGO, Introduction. Reframing the Renaissance, in Reframing the Renaissance. Visual Culture in Europe and Latin America I45O-I65O, a cura di Claire Farago, New Haven-London, Yale University Press, I995, pp. I-20.

VINCENZO FARINELLA, "Il dolce miele delle muse». Piero di Cosimo e la tradizione lucreziana a Firenze, in Piero di Cosimo I462-1522. Pittore eccentrico fra Rinascimento e Maniera, catalogo di mostra (Firenze, Galleria degli Uffizi 23 giugno - 27 settembre 20I5), a cura di Elena Capretti, Anna Forlani Tempesti, Serena Padovani e Daniela Parenti, Firenze, Giunti, 2015, pp. I07-I2I.

FEDERICO II DI SVEVIA, De arte venandi cum avibus. L'arte di cacciare con gli uccelli. Edizione e traduzione del ms. lat. 7 I 7 della Biblioteca Universitaria di Bologna collazionato con il ms. Pal. lat. Io7 I della Biblioteca Apostolica Vaticana, a cura di Anna Laura Trombetti Budriesi, RomaBari, Laterza, 2000.

Felice et divoto ad Terrasancta viagio facto per Roberto de Sancto Severino (I458-I459), a cura di Mario Cavaglià e Alda Rossebastiano, Alessandria, Edizioni dell'Orso, I999.

SHARONE FERMOR, Piero di Cosimo. Fiction, Invention and Fantasì, London, Reaktion Books, I993.

GALVANO FIAMMA, Opusculum de rebus gestis ab Azone, Luchino et Johanne Vicecomitibus ab anno MCCCXXVIII usque ad annum MCCCXLI, a cura di Carlo Castiglioni, in Rerum Italicarum Scriptores, vol. I2.4, Bologna, Nicola Zanichelli, I938. 
FILARETE - MANFIDI I978

FILIPPINI I992

FIORILLA 2013

Firenze e il concilio I994

Firenze e la scoperta 1992

FOLIN 2008

FORCELLINI I9I4

FOSSI TODOROW I966

FOSTER I969

FOSTER 1974

FRANCESCHI I993

FRANCESCHI I995

FRANCESCHI 2008

FRANCESCHI 2014

FRANCESCHI 2015

FRANCESCHINI I993-I997

FRANCI 1998

FRANCI - TOTI RIGATELLI 2002
FRANCESCO FILARETE - ANGELO MANFIDI, The Libro cerimoniale of the Florentine Republic, a cura di Richard C. Trexler, Ginevra, Droz, I978.

CECILIA FILIPPINI, Scheda, in Maestri e botteghe. Pittura a Firenze alla fine del Quattrocento, catalogo di mostra (Firenze, Palazzo Strozzi I6 ottobre I992 - Io gennaio I993), a cura di Mina Gregori, Antonio Paolucci e Cristina Acidini Luchinat, Cinisello Balsamo, Silvana, I992, p. I63.

MAURIZIO FIORILLA, Decameron, in Boccaccio autore e copista, catalogo di mostra (Firenze, Biblioteca Medicea Laurenziana I I ottobre 2013 - II gennaio 20I4), a cura di Teresa De Robertis, Carla Maria Monti, Marco Petoletti, Giuliano Tanturli e Stefano Zamponi, Firenze, Mandragora, 2013, pp.I29-136.

Firenze e il concilio del I439, Convegno di studi (Firenze, 29 novembre - 2 dicembre I989), 2 voll., a cura di Paolo Viti, Firenze, Olschki, I994.

Firenze e la scoperta dell'America. Umanesimo e geografia nel '4oo fiorentino, catalogo di mostra (Firenze, Biblioteca Medicea Laurenziana 4 maggio - 30 giugno I992), a cura di Sebastiano Gentile, Firenze, Olschki, I992.

MARCO FOLIN, La corte della duchessa. Eleonora d'Aragona a Ferrara, in Donne di potere nel Rinascimento, a cura di Letizia Arcangeli e Susanna Peyronel, Roma, Viella, 2008, pp. 48I-5I2.

FRANCESCO FORCELLINI, Strane peripezie d'un bastardo di casa d'Aragona, in "Archivio Storico per le Province Napoletane», 39, I, I9I 4, pp. I72-2I 4 .

MARIA FOSSI TODOROW, I disegni del Pisanello e della sua cerchia, Firenze, Olschki, I966.

PHILIP E. FOSTER, Lorenzo de' Medici's Cascina at Poggio a Caiano, in «Mitteilungen des Kunsthistorisches Institutes in Florenz", I4, I, I969, pp. 47-56.

PHILIP E. FOSTER, A Study of Lorenzo de' Medici's Villa at Poggio a Caiano, Ph.D Dissertation, New Haven, Yale University, I974.

FRANCO FRANCESCHI, Oltre il «Tumulto». I lavoratori fiorentini dell'Arte della lana fra Tre e Quattrocento, Firenze, Olschki, I993.

FRANCO FRANCESCHI, Florence and Silk in the Fifteenth Century: The Origins of a Long and Felicitous Union, in «Italian History \& Culture», I, I995, pp. 3-22.

FRANCO FRANCESCHI, I "Ciompi» a Firenze, Siena e Perugia, in Rivolte urbane e rivolte contadine nell'Europa del Trecento. Un confronto, a cura di Monique Bourin, Giovanni Cherubini e Giuliano Pinto, Firenze, Firenze University Press, 2008, pp. 277-303.

FRANCO FRANCESCHI, Il ruolo dell'allume nella manifattura tessile toscana dei secoli $X I V-X V$, in «Mélanges de l'École Française de Rome. Moyen Âge», I26, I, 2014 , pp. I59-I70.

FRANCO FRANCESCHI, Medici Economic Policy, in The Medici. Citizens and Masters, a cura di Robert Black e John E. Law, Cambridge, Villa I Tatti, The Harvard University Center for Italian Renaissance Studies, 20I5, pp. I29-I54.

ADRIANO FRANCESCHINI, Artisti a Ferrara in età umanistica e rinascimentale. Testimonianze archivistiche dal I472 al I492, 2 voll., FerraraRoma, Gabriele Corbo, I993-I997.

RAFFAELLA FRANCI, La trattatistica d'abaco nel Quattrocento, in Luca Pacioli e la matematica del Rinascimento, Atti del convegno internazionale di studi (Sansepolcro, I3-I6 aprile I994), a cura di Enrico Giusti, Città di Castello, Petruzzi, I998, pp. 6I-75.

RAFFAELLA FRANCI - LAURA TOTI RIGATELLI, L'eredità di Leonardo Fobonaci, in Fibonacci tra arte e scienza, a cura di Luigi A. Radicati di Brozolo, Cinisello Balsamo, Silvana, 2002, pp. 45-67. 
FRESCOBALDI 1990

FRESCOBALDI I99I

FRIEDMAN 2016

FUBINI I994

FUBINI 1996

GABRIELLI 2007

GADRAT 2005

GADRAT-OUERFELLI 2015

GAGLIARDO 2002

GAI I982

GALLETTI I996

GALLO I955

GALLUZZI I99I

GAMBA 2008

GANDINI I89I

GARZELLI I985

GATTESCHI 2008

GAUTIER DALCHÉ 2009a

GAUTIER DALCHÉ 2009 b
LIONARDO FRESCOBALDI, Viaggio in Terrasanta, a cura di Antonio Lanza, in Pellegrini scrittori. Viaggiatori toscani del Trecento in Terrasanta, a cura di Antonio Lanza e Marcellina Troncarelli, Firenze, Ponte alle Grazie, I990, pp. I67-2I5.

LIONARDO FRESCOBALDI, Viaggio in Egitto e in Terra Santa, a cura di Gabriella Bartolini, in GABRIELLA BARTOLINI - FRANCO CARDINI, "Nel nome di Dio facemmo vela". Viaggio in Oriente di un pellegrino medievale, Roma-Bari, Laterza, I991, pp. I24-I96.

JOHN BLOCK FRIEDMAN, Coats, Collars, and Capes. Royal Fashions for Animals in the Early Modern Period, in "Medieval Clothing and Textiles", I2, 20I6, pp. 6I-94.

RICCARDO FUBINI, Italia quattrocentesca. Politica e diplomazia nell'età di Lorenzo il Magnifico, Milano, FrancoAngeli, I994.

RICCARDO FUBINI, Quattrocento fiorentino. Politica, diplomazia, cultura, Ospedaletto, Pacini, I996.

EDITH GABRIELLI, Cosimo Rosselli. Catalogo ragionato, Torino, Umberto Allemandi, 2007.

CHRISTINE GADRAT, Une image de l'Orient an XIV siècle. Les Mirabiblia descripta de Jordan Catala de Sévérac, Paris, École des Chartes, 2005.

CHRISTINE GADRAT-OUER FELLI, Lire Marco Polo au Moyen Âge. Traduction, diffusion et réception du Devisement du monde, Turnhout, Brepols, 20I5.

MATILDE GAGLIARDO, I "Quattro Elementi» della Sala Theatri nel palazzo romano del cardinale Giordano Orsini, in «Prospettiva», Io8, 2002, pp. 36-64.

LUCIA GAI, La Dimostrazione dell'andata del Santo Sepolcro di Marco di Bartolommeo Rustici fiorentino (I44I-42), in Toscana e Terrasanta nel Medioevo, a cura di Franco Cardini, Firenze, Alinea, I982, pp. I89-233. GIORgIO GALletTI, Il giardino della villa a Poggio a Caiano, in Giardini medicei. Giardini di palazzo e di villa nella Firenze del Quattrocento, a cura di Cristina Acidini Luchinat, Federico Motta, I996, pp. I95-200. RODOlfo GAllo, La fortuna del libro di Marco Polo, in Nel VII centenario della nascita di Marco Polo, Venezia, Palazzo Loredan, I955, pp. I26-I6I.

PAOLO GALLUZZI, Le macchine senesi. Ricerca antiquaria, spirito di innovazione e cultura del territorio, in Prima di Leonardo. Cultura delle macchine a Siena nel Rinascimento, catalogo di mostra (Siena, Magazzini del Sale 9 giugno - 30 settembre I99I), a cura di Paolo Galluzzi, Milano, Electa, pp. I5-44.

ENRICO GAMBA, Piero della Francesca e la tradizione della matematica d'abaco. La "forma mentis" dell'ambiente abachistico, in "I 492", I-2, 2008 , pp. 93-99.

LUIGI ALBERTO GANDINI, Saggio degli usi e delle costumanze della corte di Ferrara al tempo di Niccolò III (I393-I442), in "Atti e Memorie della R. Deputazione di Storia Patria per le Provincie di Romagna", 9, I89I, pp. I48-I69.

ANNAROSA GARZELLI, Le immagini, gli autori, i destinatari, in Miniatura fiorentina del Rinascimento (I440-I525). Un primo censimento, a cura di Annarosa Garzelli, vol. I, Firenze, La Nuova Italia, I985, pp. 5-39I.

ALBERTO GATTESCHI, Il concilio di Ferrara-Firenze e gli stati italiani, in L'Europa dopo la caduta di Costantinopoli: 29 maggio I453, Atti del XLIV convegno storico internazionale (Todi, 7-9 ottobre 2007), Spoleto, Fondazione Centro italiano di studi sull'alto Medioevo, 2008, pp. 289-354.

PATRICK GAUTIER DALCHÉ, La Géographie de Ptolémée en Occident (IVe-XVIe siècle), Turnhout, Brepols, 2009.

PATRICK GAUTIER DALCHÉ, Usages critiques et scientifiques de la carte marine au XIV siècle: Pétrarque, Boccace, Paolo dell'Abaco, in Aufsicht - Ansicht-Einsicht. Neue Perspektiven auf die Kartographieon der Schwelle 
GAUTIER DALCHÉ 2019

\section{GEBHART I 887}

GENTILE 2008

GENTILE 2019

GENTILE 2003

GERONIMUS 2006

GHERARDI I975

GHINZONI I875

GIAGNACOVO 2014

GIARDINI 2016

GILBERT 1988

GILL I967

GINZBURG I994

GINZBURG 2009

Giochi matematici 2006

GIOLA 2006

GIOLA 2019 zur Frühen Neuzeit, a cura di Tanja Michalsky, Felicitas Schmieder e Gisela Engel, Berlin, Trafo, 2009, pp. 8I-92.

PATRICK GAUTIER DALCHE, Les cartes marines comme source de réflexion géographique au XV siècle, in Maps and Travel in the Middle Ages and the Early Modern Period. Knowledge, Imagination, and Visual Culture, a cura di Ingrid Baumgärtner, Nirit Ben-Aryeh Debby e Katrin KogmanAppel, Berlin-Boston, de Gruyter, 2019, pp. I65-188.

ÉMILE GEBHART, La Renaissance et la philosophie de l'histoire, Paris, Léopold Cerf, I887.

GUIDO GENTILE, Dall'esperienza del pellegrinaggio in Terra Santa ai Sacri Monti, in Viaggi e pellegrinaggi fra Tre e Ottocento, a cura di Claudio Sensi e Patrizia Pellizzari, Atti del convegno (Torino, 26 marzo 2007), Alessandria, Edizioni dell'Orso, 2008, pp. 77-I2I.

GUIDO GENTILE, Dall'immaginario del pellegrinaggio all'evocazione della Terra Santa nei Sacri Monti, in «Ad Stellam». Il Libro d'Oltramare di Niccolò da Poggibonsi e altri resoconti di pellegrinaggio in Terra Santa fra Medioevo ed Età moderna, Atti della giornata di studi (Milano, Biblioteca Nazionale Braidense, 5 dicembre 20I7), a cura di Edoardo Barbieri, Firenze, Olschki, 20I9, pp. I6I-I78.

SEBASTIANO GENTILE, Umanesimo e cartografia: Tolomeo nel XV secolo, in La cartografia europea tra primo Rinascimento e fine dell'Illuminismo, Atti del convegno internazionale The Making of European Cartography (Firenze, I3-I5 dicembre 200I), a cura di Diogo Ramada Curto, Angelo Cattaneo e André Ferrand Almeida, Firenze, Olschki, 2003, pp. 3-I8. DENNIS GERONIMUS, Piero di Cosimo. Visions Beautiful and Strange, New Haven-London, Yale University Press, 2006.

GIOVANNI GHERARDI, Paradiso degli Alberti, a cura di Antonio Lanza, Roma, Salerno, I975.

PIETRO GHINZONI, Un ambasciadore del soldano d'Egitto alla corte milanese nel I476, in "Archivio Storico Lombardo", 2, I875, pp. I55-I78.

MARIA GIAGNACOVO, Appunti di metrologia mercantile genovese. Un contributo della documentazione aziendale Datini, Firenze, Firenze University Press, $20 \mathrm{I} 4$.

MARCO GIARDINI, Figure del regno nascosto. Le leggende del Prete Gianni e delle dieci tribù perdute d'Israele fra Medioevo e prima Età Moderna, Firenze, Olschki, 2016.

CREIGHTON E. GILBERT, L'arte del Quattrocento nelle testimonianze coeve, Firenze-Vienna, IRSA, I988.

JOSEPH GILL, Il concilio di Firenze, Firenze, Sansoni, I967 [ed. originale The Council of Florence, Cambridge, Cambridge University Press, I959].

CARLO GINZBURG, Indagini su Piero. Il Battesimo, il ciclo di Arezzo, la Flagellazione di Urbino, Torino, Einaudi, I994.

CARLO GINZBURG, Il formaggio e $i$ vermi. Il cosmo di un mugnaio del '500, Torino, Einaudi, 2009 [I985].

Giochi matematici del Medioevo. I "conigli di Fibonacci" e altri rompicapi liberamente tratti dal Liber abaci, a cura di Nando Geronimi, Milano, Bruno Mondadori, 2006.

MARCO GIOLA, Sul volgarizzamento italiano del Trésor di Brunetto Latini, Tesi di dottorato di ricerca in Modelli, linguaggi e tradizioni della cultura occidentale (XIX ciclo), Università degli Studi di Ferrara, Tutor Prof. Paolo Fabbri, 2006.

MARCO GIOLA, Primi appunti sul Libro d'Oltramare di Niccolò da Poggibonsi: i manoscritti e le forme del testo, in "Ad Stellam». Il Libro d'Oltramare di Niccolo da Poggibonsi e altri resoconti di pellegrinaggio in Terra Santa fra Medioevo ed Età moderna, Atti della giornata di studi (Milano, Biblioteca Nazionale Braidense, 5 dicembre 2017), a cura di Edoardo Barbieri, Firenze, Olschki, 20I9, pp. I-23. 
GIOVIO I557

GIURA 2016

GIUSTI 2002

GIUSTINIANI I667-I675

GOLDTHWAITE I985

GOLDTHWAITE 2013

GOLUBOVICH I906-I927

GOMBRICH I960

GOMBRICH 1973

GONZÁLEZ DE CLAVIJO I999

GORRERI 2009

Grande dizionario 196I-2002

GRAF I 892

GREPPI 2010

GROOM 2015

GROOM 2018

GROSSATO I994a

GROSSATO I994b

GUARINO I988

GUCCI I990
PAOLO GIOVIO, Gli elogi. Vite brevemente descritte d'huomini illustri di guerra, antichi et moderni, Venezia, Giovanni dei Rossi, I557.

GIOVANNI GIURA, La seconda età della pittura in Santa Maria Novella, in Santa Maria Novella. La basilica e il convento, a cura di Andrea de Marchi, vol. 2, Firenze, Mandragora, 20I6, pp. 97-I53.

ENRICO GIUSTI, Matematica e commercio nel Liber abaci, in Un ponte sul Mediterraneo. Leonardo Pisano, la scienza araba e la rinascita della matematica in Occidente, a cura di Enrico Giusti, Firenze, Polistampa, 2002, pp. 59-I20.

MICHELE GIUSTINIANI, Lettere Memorabili, 3 voll., Roma, Tinassi, I667-I675.

RICHARD A. GOLDTHWAITE, The Renaissance Economy: The Preconditions for Luxury Consumption, in Aspetti della vita economica medievale, Atti del convegno di studi nel $\mathrm{X}$ anniversario della morte di Federigo Melis (Firenze-Pisa-Prato, IO-I 4 marzo I984), Firenze, Università degli Studi di Firenze, pp. 659-675.

RICHARD A. GOLDTHWAITE, L'economia della Firenze rinascimentale, Bologna, Il Mulino, $20 \mathrm{I}_{3}$ [ed. originale The Economy of Renaissance Florence, Baltimore, Johns Hopkins University Press, 2009].

GIROLAMO GOLUBOVICH, Biblioteca bio-bibliografica della Terra Santa e dell'Oriente francescano, 5 voll., Firenze, Barbera, I906-I927.

ERNST H. GOMBRICH, The Early Medici as Patrons of Art, in Italian Renaissance Studies. A Tribute to the Late Cecilia M. Ady, a cura di Ernest F. Jacob, London, Faber \& Faber, I960, pp. 279-3 I I.

ERNST H. GOMBRICH, Norma e forma. Studi sull'arte del Rinascimento, Torino, Einaudi, I973 [ed. originale Norm and Form. Studies in the Art of the Renaissance, London, Phaidon Press, I966].

RUY GONZÁLEZ DE CLAVIJO, Viaggio a Samarcanda I403-I406. Un ambasciatore spagnolo alla corte di Tamerlano, a cura di Paola Boccardi Storoni, Roma, Viella, I999.

SILVANA GORRERI, Scheda, in Carte per navigare. La raccolta di portolani della Biblioteca Palatina di Parma, catalogo di mostra (Parma, Biblioteca Palatina 28 maggio - 25 giugno 2009), Parma, MUP, 2009, pp. I7-23.

Grande dizionario della lingua italiana, 21 voll., a cura di Salvatore Battaglia, Torino, UTET, I96I-2002.

ARTURO GRAF, Il mito del paradiso terrestre, in ARTURO GRAF Miti, leggende e superstizioni del Medio Evo, 2 voll., Torino, Loescher, I892.

CLAUDIO GREPPI, Il dizionario geografico di Boccaccio. Luoghi e paesaggi nel De Montibus, in Boccaccio geografo. Un viaggio nel Mediterraneo tra le città, i giardini e... il "mondo" di Giovanni Boccaccio, a cura di Roberta Morosini, Firenze, Mauro Pagliai, 2010, pp. 89-Io2.

ANGELICA GROOM, Early Modern Natural Science as an Agent for Change in Naturalist Painting. Jacopo Ligozzi's Zoological Illustrations as a Case Study, in Knowing Nature in Early Modern Europe, a cura di David Beck, London, Pickering \& Chatto, 2015, pp. I39-I63.

ANGELICA GROOM, Exotic Animals in the Art and Culture of the Medici Court in Florence, Leiden, Brill, 2018.

ALESSANDRO GROSSATO, L'India di Niccolò de' Conti. Un manoscritto del Libro IV del De Varietate Fortunae di Francesco Poggio Bracciolini da Terranova (Marc. 2560), Padova, Programma, I994.

ALESSANDRO GROSSATO, Navigatori e viaggiatori veneti sulla rotta per l'India. Da Marco Polo ad Angelo Legrenzi, Firenze, Olschki, I994. RAIMONDO GUARINO, Introduzione, in Teatro e culture della rappresentazione. Lo spettacolo in Italia nel Quattrocento, a cura di Raimondo Guarino, Bologna, Il Mulino, I988, pp. 9-66.

GIORGIO GUCCI, Viaggio ai Luoghi Santi, a cura di Marcellina Troncarelli, in Pellegrini scrittori. Viaggiatori toscani del Trecento in Terrasanta, a cura di Antonio Lanza e Marcellina Troncarelli, Firenze, Ponte alle Grazie, I990, pp. 257-3I 2. 
GUÉRIN DALLE MESE 1989

GUÉRIN DALLE MESE I99I

GUICCIARDINI 2010

GUIDA 20I8

HATFIELD I970

HATFIELD I996

HAW 2006

HEERS I993

HEIKAMP - ROSCAM ABBING 2013

HERLIHY - KLAPISCH-ZUBER I978 DAVID HERLIHY - CHRISTIANE KLAPISCH-ZUBER, Les

HIGGINS 1997

HILDESHEIM I966

HIND I938-I948

Historia plantarum 2002-2004

HOENIGER 2006

HOFMANN 1975

HOLMES I968

HOOGVLIET I997

HOOGVLIET 2006 Toscans et leurs familles. Une étude du catasto florentin $d u$ I427, Paris, Fondation nationale des sciences politiques, I978.

JEANNINE GUÉRIN DALLE MESE, Io o lui? (il problema del narratore in alcune relazioni di viaggio del Trecento-Quattrocento), in La letteratura di viaggio dal Medioevo al Rinascimento. Generi e problemi, Alessandria, Edizioni dell'Orso, I989, pp. 7-I7.

JEANNINE GUERIN DALLE MESE, Égypte la mémoire et le rêve. Itinéraires d'un voyage, I320-I60I, Firenze, Olschki, I99I.

FRANCESCO GUICCIARDINI, Storie fiorentine dal I378 al I509, a cura di Alessandro Montevecchi, Milano, Rizzoli, 20 o.

AUGUSTO GUIDA, Plinio il Vecchio, un postillato polizianeo e un progetto per Winckelmann, in "Prometheus», I, 20I8, pp. 280-293.

RAB HATFIELD, The Compagnia de' Magi, in «Journal of the Warburg and Courtauld Institutes", 33, I970, pp. IO7-I6I.

RAB HATFIELD, Giovanni Tornabuoni, i fratelli Ghirlandaio e la cappella maggiore di Santa Maria Novella, in Domenico Ghirlandaio I449-I494, Atti del convegno internazionale (Firenze, I6-I8 ottobre I994), a cura di Wolfram Prinz e Max Seidel, Firenze, Centro Di, I996, pp. II2-II7.

STEPHEN G. HAW, Marco Polo's China. A Venetian in the Realm of Khubilai Khan, London-New York, Routledge, 2006.

JACQUES HEERS, Pèlerinages et connaissance du monde. Jérusalem et l'Orient, in Columbeis V. Relazioni di viaggio e conoscenza del mondo fra Medioevo e Umanesimo, Atti del convegno internazionale di studi dell'Associazione per il Medioevo e l'Umanesimo latini (Genova, I2-Is dicembre I99I), a cura di Stefano Pittaluga, Genova, Dipartimento di Archeologia, Filologia Classica e loro Tradizioni, I993, pp. 7-28.

DETLEF HEIKAMP - MICHIEL ROSCAM ABBING, Epitaffio per un elefante morto nella Loggia dei Lanzi, in Diafane passioni. Avori barocchi dalle corti europee, catalogo di mostra (Firenze, Museo degli Argenti i6 luglio -3 novembre 20I3), a cura di Eike D. Schmidt e Maria Sframeli, Livorno, Sillabe, 20I3, pp. 40-7I.

IAIN MACLEOD HIGGINS, Writing East. The Travels of Sir John Mandeville, Philadelphia, Pennsylvania University Press, I997.

GIOVANNI DI HILDESHEIM, La storia dei Re Magi, a cura di Alfonso M. di Nola, Firenze, Vallecchi, I966.

ARTHUR M. HIND, Early Italian Engravings. A Critical Catalogue with Complete Reproductions of all the Prints Described, 7 voll., London, Bernard Quaritch, I938-I948.

Historia Plantarum, 2 voll., a cura di Vera Segre Rutz, Modena, Franco Cosimo Panini, 2002-2004.

CATHLEEN HOENIGER, The Illuminated Taccuinum sanitatis Manuscripts from Northern Italy ca. I380-I400. Sources, Patrons, and Creation of a New Pictorial Genre, in Visualizing Medieval Medicine and Natural History, I200-I550, a cura di Jean A. Givens, Karen M. Reeds e Alain Touwaide, Aldershot, Ashgate, 2006, pp. 5I-8I.

HANS HOFMANN, Die Heiligen Drei Könige. Zur Heiligenverehrung im kirchlichen, gesellschaftlichen und politischen Leben des Mittelalters, Bonn, Rörscheid, I975.

GEORGE HOLMES, How the Medici Became the Pope's Bankers, in Florentine Studies. Politics and Society in Renaissance Florence, a cura di Nicolai Rubinstein, London, Faber \& Faber, I968, pp. 357-380.

MARGRIET HOOGVLIET, «De ignotis quarumdam bestiarium naturis». Texts and Images from Bestiary on Medieval Maps of the World, in Animals and the Symbolic in Medieval Art and Literature, a cura di L.A.J.R. Houwen, Groningen, Egbert Forsten, 1997, pp. I89-208.

MARGRIET HOOGVLIET, Animals in Context. Beast on the Hereford Map and Medieval Natural History, in The Hereford World Map. Medieval 
HOOGVLIET 2007

HORODOWICH 2017

HOSHINO I980

HOSHINO 2001

HOUSLEY 20I3

HUMBOLT I 845 -I 862

HUNT I994

HUNT I965

Iddio ci dia buon viaggio 2006

I diplomi arabi $\mathrm{I} 863$

ILARDI I989

Il Castello Sforzesco 2005

Il Fisiologo $20 \mathrm{II}$

Il fratello di Masaccio I999

Il primo elefante I 888

Il Taccuino I997

I manoscritti datati del fondo Acquisti 2004

I manoscritti datati del fondo Palatino 2003

I manoscritti datati della Biblioteca Nazionale 2 OI I

I manoscritti datati della Biblioteca Riccardiana I997-20I3
World Maps and their Context, a cura di P.D.A. Harvey, London, British Library, 2006, pp. I53-I65.

MARGRIET HOOGVLIET, Pictura et Scriptura: textes, images et herméneutique des mappae mundi (XIII ${ }^{e}-X V I^{e}$ siècle), Turnhout, Brepols, 2007. ELIZABETH HORODOWICH, The Wider World. Foreigners, Travels, and Geography, in Italian Renaissance Diplomacy. A Sourcebook, a cura di Monica Azzolini e Isabella Lazzari, Toronto, Pontifical Institute of Medieval Studies, 20I7, pp. I90-2I3.

HIDETOSHI HOSHINO, L'Arte della lana in Firenze nel basso Medioevo. Il commercio della lana e il mercato dei panni fiorentini nei secoli XIII-XV, Firenze, Olschki, I980.

HIDETOSHI HOSHINO, Industria tessile e commercio internazionale nella Firenze del tardo Medioevo, a cura di Franco Franceschi e Sergio Tognetti, Firenze, Olschki, 200I.

NORMAN HOUSLEY, Crusading and the Ottoman Threat, I453-I505, Oxford, Oxford University Press, 2013.

ALEXANDER VON HUMBOLT, Kosmos. Entwurf einer physischen Weltbeschreibung, 5 voll., Stuttgart-Tübingen, Cotta, I845-1862.

EDWIN S. HUNT, The Medieval Super-Companies. A Study of the Peruzzi Company of Florence, Cambridge, Cambridge University Press, I994.

RICHARD WILLIAM HUNT, A Manuscript from the Library of Coluccio Salutati, in Calligraphy and Palaeography. Essays Presented to Alfred Fairbank on his $70^{\text {th }}$ Birthday, a cura di Arthur S. Osley, London, Faber \& Faber, I965, pp. $75-79$.

"Iddio ci dia buon viaggio e guadagno». Firenze, Biblioteca Riccardiana ms. I9Io (Codice Vaglienti), a cura di Luciano Formisano, Firenze, Polistampa, 2006.

I diplomi arabi del Reale Archivio fiorentino. Testo originale, a cura di Michele Amari, Firenze, Felice Le Monnier, I863.

VINCENT ILARDI, The Banker-Statesman and the Condottiere-Prince. Cosimo de' Medici and Francesco Sforza (I45O-I464), in Florence and Milan. Comparisons and Relations, Atti di convegno (Firenze, Villa I Tatti I982I984), a cura di Sergio Bertelli, Nicolai Rubinstein e Craig H. Smyth, Firenze, vol. 2, La Nuova Italia, I989, pp. 217-239.

Il Castello Sforzesco di Milano, a cura di Maria Teresa Fiorio, Milano, Skira, 2005 .

Il Fisiologo, a cura di Francesco Zambon, Milano, Adelphi, 20I I [I975].

Il fratello di Masaccio, catalogo di mostra (San Giovani Valdarno, Casa Masaccio I4 febbraio - I6 maggio I999), a cura di Laura Cavazzini, Siena, Maschietto \& Musolino, I999.

Il primo elefante in Milano?..., in "Bollettino Storico della Svizzera Italiana", 5-6, I888, pp. I05-I07.

Il Taccuino di Giovannino de' Grassi della Biblioteca Civica di Bergamo: tecnica di esecuzione e restauro, in "OPD", 9, I997, pp. I5-37.

I manoscritti datati del fondo Acquisti e doni e dei fondi minori della Biblioteca Medicea Laurenziana di Firenze, a cura di Lisa Fratini e Stefano Zamponi, Firenze, SISMEL - Edizioni del Galluzzo, 2004.

I manoscritti datati del fondo Palatino della Biblioteca Nazionale Centrale di Firenze, a cura di Simona Bianchi, Firenze, SISMEL - Edizioni del Galluzzo, 2003.

I manoscritti datati della Biblioteca Nazionale Centrale di Firenze. III, a cura di Susanna Pelle, Anna Maria Russo, David Speranzi e Stefano Zamponi, Firenze, SISMEL - Edizioni del Galluzzo, 20 I I.

I manoscritti datati della Biblioteca Riccardiana di Firenze, 4 voll., a cura di Teresa De Robertis e Rosanna Miriello, Firenze, SISMEL - Edizioni del Galluzzo, I997-20I3. 
I manoscritti della letteratura 2002

I manoscritti della letteratura $20 \mathrm{II}$

\section{IMPELLUSO 2003}

Indagini I 875 -I 879

Inventari medicei 1996

Italian Paintings 1993

Itinerario di Ludovico 2012

I viaggi $\mathrm{I} 883$

JACOBY 2006

JANSON I952

JARDIN - BROTTON 2000

JOLY - LAVOCAT I 840

JONES I984

JOOST-GAUGIER I987

JORDAN GSCHWEND 2004

JORDAN GSCHWEND 2010

JORDAN GSCHWEND 2015

KANTER I995

KANTER 2005

KAPLAN 1985
I manoscritti della letteratura italiana delle origini. Firenze Biblioteca Nazionale Centrale, a cura di Sandro Bertelli, Tavarnuzze, SISMEL - Edizioni del Galluzzo, 2002.

I manoscritti della letteratura italiana delle origini. Firenze Biblioteca Medicea Laurenziana, a cura di Sandro Bertelli, Tavarnuzze, SISMEL Edizioni del Galluzzo, 20 I I.

LUCIA IMPELLUSO, La natura e $i$ suoi simboli. Piante, fiori e animali, Milano, Electa, 2003.

Indagini storiche, artistiche e bibliografiche sulla Libreria Visconteo-Sforzesca del Castello di Pavia, a cura di Gerolamo d'Adda, 2 voll., Milano, Brignola, I 875 -I 879 .

Inventari medicei (I4 I7-I465). Giovanni di Bicci, Cosimo e Lorenzo di Giovanni, Piero di Cosimo, a cura di Marco Spallanzani, Firenze, SPES, I996.

Italian Paintings before I600 in The Art Institute of Chicago: A catalogue of the Collection a cura di Christopher Lloyd, Princeton, Princeton University Press, I993.

Itinerario di Ludovico de Varthema bolognese, a cura di Eugenio Lo Sardo, Roma, De Luca Editori d'Arte, 2012.

I viaggi di Nicolò de' Conti. Riscontrati ed illustrati con proemio storico, documenti originali e carte geografiche, a cura di Vincenzo Bellemo, Milano, A. Brignola \& C., I883.

DAVID JACOBY, Marco Polo, his Close Relatives, and his Travel Account: Some New Insights, in "Mediterranean Historical Review», 2 I, 2006, pp. I93-2I8.

HORST W. JANSON, Apes and Ape Lore in the Middle Ages and the Renaissance, London, Warburg Institute, I952.

LISA JARDIN - JERRY BROTTON, Global Interests. Renaissance Art between East \& West, Ithaca (N.Y), Cornell University Press, 2000. NICOLAS JOLY - ACHILLE LAVOCAT, Recherches historiques, zoologiques, anatomiques et paléontologiques sur la girafe, in Mémoires de la société du museum d'histoire naturelle de Strasbourg, vol. 3, Paris, PitoisLevrault, I840, pp. I-I23.

ROGER JONES, Palla Strozzi e la sagrestia di Santa Trinita, in «Rivista d'arte», 4, I, I984, pp. 9-IO6.

CHRISTIANE L. JOOST-GAUGIER, Lorenzo the Magnificent and the Giraffe as Symbol of Power, in "Artibus et Historiae», I6, I987, pp. 9I-99.

ANNEMARIE JORDAN GSCHWEND, Animals in SixteenthCentury Europe, in Encounters. The Meeting of Asia and Europe I5OOI800, a cura di Anna Jackson e Amin Jaffer, London, V\&A Publications, pp. 4I-43.

ANNEMARIE JORDAN GSCHWEND, The Story of Süleyman. Celebrity Elephants and Other Exotica in Renaissance Portugal, Zürich, Pachyderm Production, 2010.

ANNEMARIE JORDAN GSCHWEND, Schede, in Echt tierisch! Die Menagerie des Fürsten, catalogo di mostra (Innsbruck, Schloss Ambras, I 8 giugno - 4 ottobre 2015), a cura di Sabine Haag, Vienna, Kunsthistorisches Museum, 20II, pp. I52-I53, I64-I65.

LAURENCE B. KANTER, Scheda, in The Touch of the Artist. Master Drawings from the Woodner Collections, catalogo di mostra (Washington, National Gallery of Art I ottobre I995 - 28 gennaio I996), a cura di Margaret Morgan Grasselli, New York, Abrams, I995, pp. 44-47.

LAURENCE B. KANTER, Schede, in Fra Angelico, a cura di Laurence Kanter e Pia Palladino, catalogo di mostra (New York, Metropolitan Museum of Art 26 ottobre 2005 - 29 gennaio 2006), New York, Metropolitan Museum of Art, 2005, pp. 98-I00, I90-I99, 282-283. PAUL H.D. KAPLAN, The Rise of the Black Magus in Western Art, Ann Arbor, UMI Research Press, I985. 
KÁRPÁTI 2004

KÁRPÁTI 2012

KELLY 2016

KENT I978

KENT 2005

KENT 2007

KENT 2008

KENT 2009

KINOSHITA 2012

KLIEMANN I985

KLINE 200I

KOMAROFF 2OI I

KÖNIG-LEIN 1997

KRAIS - GEBAUER 2009

KRUK 2008

\section{KUPFER 2016}

KURZ I937

LACH 1965-I993

LANDUCCI 1969

La lettera 1992
ZOLTÁN KÁRPÁTI, The Budapest Animal Model-Book. Codicological Analysis and Reconstruction, in "Bulletin du Musée Hongrois des Beaux-Arts», I00, 2004, pp. 79-II7.

ZOLTÁN KÁRPÁTI, Survival of a Tradition. The Budapest Animal Model-Book, in From Pattern to Nature in Italian Renaissance Drawing, a cura di Michael W. Kwakkelstein e Lorenza Melli, Firenze, Centro Di, 20I2, pp. 5I-73.

SAMANTHA KELLY, Ewostateans at the Council of Florence (I44I). Diplomatic Implications between Ethiopia, Europe, Jerusalem and Cairo, in "Afriques», Varia, 29 giugno 20I6, <https://journals.openedition.org/ afriques/1858> [accesso: dicembre 2020].

DALE KENT, The Rise of the Medici: Faction in Florence (I426-I434), Oxford, Oxford University Press, I978.

DALE KENT, Il committente e le arti. Cosimo de' Medici e il Rinascimento fiorentino, Milano, Electa, 2005 [ed. originale Cosimo de' Medici and the Florentine Renaissance, New Haven, Yale University Press, 2000].

DALE KENT, The Brancaci Chapel Viewed in the Context of Florence's Culture of Artistic Patronage, in The Brancacci Chapel. Form, Function and Setting, a cura di Nicholas A. Eckstein, Firenze, Olschki, 2007, pp. 53-7I. DALE KENT, $A$ Widow on Cosimo de' Medici, Paterfamilias and Politician, from within his Own Household. The Letters of his Personal Assistant, Ser Alesso Pelli, in Florence and Beyond. Culture, Society and Politics in Renaissance Italy. Essays in Honor of John M. Najemy, a cura di David S. Peterson e Daniel E. Bornstein, Toronto, Centre for Reformation and Renaissance Studies, 2008 , pp. 355-367.

DALE KENT, Friendship, Love, and Trust in Renaissance Florence, Cambridge, Harvard University Press, 2009.

SHARON KINOSHITA, Animals and the Medieval Culture of Empire, in Animal, Vegetable, Mineral. Ethics and Objects, a cura di Jeffrey Jerome Cohen, Washington D.C., Oliphaunt Books, 20I2, pp. 35-63.

JULIAN KLIEMANN, Il pensiero di Paolo Giovio nelle pitture eseguite sulle sue "invenzioni", in Paolo Giovio. Il Rinascimento e la memoria, Atti del convegno (Como, 3-5 giugno 1983), Como, New Press, I985, pp. I97-223.

NAOMI REED KLINE, Maps of Medieval Thought. The Hereford Paradigm, Woodbridge, Boydell Press, 200I.

LINDA KOMAROFF, Scheda, in Gifts of the Sultan. The Arts of Giving at the Islamic Courts, catalogo di mostra (Los Angeles, County Museum of Art 5 giugno - 5 settembre 20II), a cura di Linda Komaroff, New Haven-London, Yale University Press, 20II, p. 288.

SUSANNE KÖNIG-LEIN, «Simile alla natura». Die Darstellung exotischer Tiere in der Florentiner Malerei des Quattrocento, Weimar, Verlag und Datenbank für Geisteswissenschaften, I997.

BEATE KRAIS - GÜNTER GEBAUER, Habitus, Roma, Armando, 2009 [ed. originale Habitus, Bielefeld, transcript Verlag, 2002]

REMKE KRUK, Encounters with the Giraffe, from Paris to the Medieval Islamic World, in Classic Arabic Humanities in their Own Terms. Festschrifts for Wolfhart Heinrichs on his $65^{\text {th }}$ Birthday Presented by his Students and Colleagues, a cura di Beatrice Gruendler, Leiden, Brill, 2008, pp. 568-592.

MARCIA KUPFER, Art and Optics in the Hereford Map. An English Mappa Mundi, c. I300, New Haven-London, Yale University Press, 2016.

OTTO KURZ, Giorgio Vasari's Libro de' Disegni, in "Old Master Drawings», 45, I937, pp. I-I5

DONALD F. LACH, Asia in the Making of Europe, 3 voll., Chicago, University Chicago Press, I965-1993.

LUCA LANDUCCI, Diario fiorentino dal 1450 al I5I6, a cura di Iodoco Del Badia, Firenze, Studio Biblos, I969 [I883].

La lettera del Prete Gianni, a cura di Gioia Zaganelli, Parma, Pratiche Editrice, I992 [I990]. 
La natura dipinta 2018

LARNER 1999

La scienza a corte 1979

LATINI I9I7

LATINI 2007

LAUFER I928

LAZZARO I995

LAZZI I994

LAZZI 2004

LAZZI 2008

LAZZI 2009

Le Consulte I 896-I898

LECOY DE LA MARCHE I969

LEFEVRE I967-I968

LE GOFF I970

LE GOFF I972

LE GOFF I977

Le navigazioni atlantiche 1966

Le nozze 1946

Les dessins italiens 1960
La natura dipinta. Piante, fiori e animali nelle rappresentazioni di Palazzo Vecchio a Firenze, a cura di Maria Adele Signorini e Valentina Zucchi, Sansepolcro, Aboca, 2018.

JOHN LARNER, Marco Polo and the Discovery of the World, New Haven-London, Yale University Press, I999.

La scienza a corte. Collezionismo eclettico natura e immagine a Mantova fra Rinascimento e Manierismo, Roma, Bulzoni, I979.

BRUNETTO LATINI, Libri naturali del Tesoro emendati colla scorta de' codici, a cura di Guido Battelli, Firenze, Le Monnier, I9I7.

BRUnetTO LATINI, Tresor, a cura di Pietro G. Beltrami, Paolo Squillacioti, Plinio Torri e Sergio Vatteroni, Torino, Einaudi, 2007. BERTHOLD LAUFER, The Giraffe in History and Art, Chicago, Field Museum of Natural History, I928.

ClAUDiA LAZZARO, Animals as Cultural Signs. A Medici Menagerie in the Grotto at Castello, in Reframing the Renaissance. Visual Culture in Europe and Latin America I450-I650, a cura di Claire Farago, New HavenLondon, Yale University Press, I995, pp. I97-227.

GIOVANNA LAZZI, Novità e persistenze nelle tipologie vestimentarie al tempo del concilio: dalla moda «alla franciosa» a quella «all'orientale», in Firenze $e$ il concilio del I439, Convegno di studi (Firenze, 29 novembre - 2 dicembre I989), a cura di Paolo Viti, vol. I, Firenze, Olschki, I994, pp. 389-407.

GIOVANNA LAZZI, Scheda, in Rappresentare e misurare il mondo. Da Vespucci alla modernità, catalogo di mostra (Firenze, Istituto Geografico Militare 30 ottobre 2004 - I5 gennaio 2005), a cura di Andrea Cantile, Giovanna Lazzi e Leonardo Rombai, Firenze, Polistampa, 2004, pp. I06-I07.

GIOVANNA LAZZI, Trattato di aritmetica di Lorenzo il Magnifico, Roma, Editalia, 2008.

GIOVANNA LAZZI, Enea sull'Arno: un sogno greco e un messaggio illustrato, in La stella e la porpora. Il corteo di Benozzo e l'enigma del Virgilio Riccardiano, Atti del convegno di studi (Firenze, I7 maggio 2007), a cura di Giovanna Lazzi e Gerhard Wolf, Firenze, Polistampa, 2009, pp. II9-I33.

Le Consulte della Repubblica fiorentina dall'anno MCCLXXX al MCCXCVIII, 2 voll., a cura di Alessandro Gherardi, Firenze, Sansoni, I896-I898.

ALBERT LECOY DE LA MARCHE, Le roi René. Sa vie son administration ses travaux artistiques et littéraires, 2 voll., Genève, Slatkine Reprints, I969 [Paris I 875].

RENATO LEFEVRE, Presenze etiopiche in Italia prima del concilio di Firenze del I439, in "Rassegna di Studi Etiopici», 23, I967-I968, pp. 5-26.

JACQUES LE GOFF, L'Occident médiévale et l'Océan Indien: un horizon onirique, in Mediterraneo e Oceano Indiano, Atti del VI colloquio internazionale di storia marittima (Venezia, 20-29 settembre I962), a cura di Manlio Cortelazzo, Firenze, Olschki, I970, pp. 243-263.

JACQUES LE GOFF, La civilisation de l'Occident médiéval, Paris, Arthaud, I972 [1964].

JACQUES LE GOFF, Nel Medioevo. Tempo della Chiesa e tempo del mercante, in Tempo della Chiesa e tempo del mercante. E altri saggi sul lavoro e la cultura del Medioevo, Torino, Einaudi, I977, pp. 3-23 [ed. originale Au Moyen Âge: Temps de l'Église et temps du marchand, in "Annales E.S.C.", I5, I960, pp. 4I7-433].

Le navigazioni atlantiche del veneziano Alvise da Mosto, a cura di Tullia Gasparrini Leporace, Roma, Istituto poligrafico dello Stato, I966.

Le nozze di Costanzo Sforza e Camilla d'Aragona celebrate a Pesaro nel maggio I475, a cura di Tammaro De Marinis, Firenze, Vallecchi, I946. Les dessins italiens de la collection Bonnat, a cura di Jean Bean, Paris, Réunion des Musées Nationaux, I960. 
LESTER 2009

\section{LETTS I953}

LEVI D'ANCONA 200 I

LEVI DELLA VIDA 1959

LEWIS I987

Libro d'inventario 1992

LIGHTBOWN I989

Lirici toscani 1975

LOISEL 2009

LOISEL I9I 2

LONGHI I940

LOPEZ I98I

LOPEZ - AIRALDI I983

Lorenzo de' Medici 2013

LOWE 2003

LUGLI 2017

LURATI 2012

LURATI 2018

LUZIO I 899

MACCHIA 2017

MAESTRO MARTINO 200 I
TOBY LESTER, The Fourth Part of the World. The Race to the Ends of the Earth, and the Epic Story of the Map that Gave America Its Name, New York, Free Press, 2009.

MALCOLM LETTS, Mandeville's Travels. Text and Translations, 2 voll., London, The Hakluyt Society, I953.

MIRELLA LEVI D'ANCONA, Lo zoo del Rinascimento. Il significato degli animali nella pittura italiana dal XIV al XVI secolo, Lucca, Maria Pacini Fazzi, 200I.

GIORGIO LEVI DELLA VIDA, Fazio degli Uberti e l'Egitto medievale, in Studi in onore di Angelo Monteverdi, vol. I, Modena, Società Tipografica Editrice Modenese, I959, pp. 443-454.

SUZANNE LEWIS, The Art of Matthew Paris in the Chronica Majora, Aldershot, Scholar Press, I987.

Libro d'inventario dei beni di Lorenzo il Magnifico, a cura di Marco Spallanzani e Giovanna Gaeta Bertelà, Firenze, SPES, I992.

RONALD LIGNTBOWN, Sandro Botticelli. Life and Work, London, Thames and Hudson, I989.

Lirici toscani del Quattrocento, a cura di Antonio Lanza, 2 voll., Roma, Bulzoni, I975.

CATHERINE LOISEL, Scheda, in Il Rinascimento italiano nella collezione Rothschild del Louvre, catalogo di mostra (Firenze, Casa Buonarroti 27 maggio - I4 settembre 2009), a cura di Catherine Loisel, Firenze, Mandragora, 2009, pp. 70-80.

GUSTAVE LOISEL, Histoire des ménageries de l'Antiquité à nos jours. Moyen Âge - Renaissance, Paris, O. Doin, I9I2.

ROBERTO LONGHI, Fatti di Masolino e di Masaccio, in «La Critica d'Arte» 3-4, I940, pp. I45-I9I.

ROBERTO S. LOPEZ, Il più antico manuale italiano di pratica della mercatura, in Produttività e tecnologie nei secoli XII-XVII, a cura di Sara Mariotti, Atti della III settimana di studio (Prato, 23-29 aprile I97I), Firenze, Le Monnier, I98I, pp. 46I-469.

ROBERTO S. LOPEZ - GABRIELLA AIRALDI, Il più antico manuale italiano di pratica della mercatura, in Miscellanea di Studi Storici, II, Genova, Istituto di paleografia e storia medievale, I983, pp. 99-I33.

Lorenzo de' Medici at Home. The Inventory of the Palazzo Medici in I492, a cura di Richard Stapleford, Pennsylvania, Pennsylvania State University Press, 20I3.

KATE J. LOWE, Nun's Chronicles and Convent Culture in Renaissance and Counter-Reformation Italy, Cambridge, Cambridge University Press, 2003.

EMANUELE LUGLI, Linking the Mediterranean. The Construction of Trading Networks in $14^{\text {th }}$ and $15^{\text {th }}$-Century Italy, in The Globalization of Renaissance Art. A Critical Review, a cura di Daniel Savoy, Leiden, Brill, 20I7, pp. I58-I 85 .

PATRICIA LURATI, "In Firenze non si fe' mai simile festa». A proposito del cassone di Apollonio di Giovanni con scena di Giostra alla Yale University Art Gallery, in "Annali di Storia di Firenze», 7, 20I2, pp. 35-7I.

PATRICIA LURATI, "The Merchant eye". A New Perception of Exotic Animals, in Into the Wild. Kunst und Architektur im globalen Kontext Herausgeberschaft, a cura di Antonie Bassing-Kontopidis, Laura Hindelang, Charlotte Matter e Filine Wagner, München, Metzel, 20 I8, pp. 8I-88.

ALESSANDRO LUZIO, Curiosità storiche. Una caccia di leoni, in «Gazzetta di Mantova", 7-8 agosto I899.

GIOAVANNI MACCHIA, Le reliquie pellegrine, in La luce della stella. I Re Magi fra arte e storia, a cura di Alessandro Bedini, Giovanni Macchia, Paolo Ognibene, Antonio Panaino e Andrea Piras, Milano-Udine, Mimesis, 20I7, pp. 65-78.

MAESRTO MARTINO, Libro de arte coquinaria, a cura di Luigi Ballerini e Jeremy Parzen, Milano, Guido Tommasi Editore, 20oI. 
MAGNO I999

MALACARNE I998

MALAGUZZI VALERI I9I3

MALLET I967

MANDALÀ 20 I

MANDEVILLE I982

MANDEVILLE 2000

MARCELLI 2OIIa

MARCELLI 2OI Ib

MARCELLI 2020

MARCOCCI 2015

MARCOZZI 2010

MARTELLI 2016

MARTENS 2002

MARTINES I963

MARTINIS 2003

MÄRTL 2000

MÄRTL 2004
Alberto MAGNO, On Animals. A Medieval Summa Zoologica, 2 voll., a cura di Kenneth F. Kitchell Jr. e Irven Michael Resnik, Baltimore, I999.

GIANCARLO MALACARNE, Le cacce del principe. L'ars venandi nella terra dei Gonzaga, Modena, Il Bulino, I998.

FRANCESCO MALAGUZZI VALERI, La corte di Ludovico il Moro. La vita privata e l'arte a Milano nella seconda metà del Quattrocento, vol. I, Milano, Hoepli, I9I3.

MICHAEL E. MALLET, The Florentine Galleys in the Fifteenth Century with the Diary of Luca di Maso degli Albizi Captain of the Galleys I429I430, Oxford, Clarendon Press, I967.

GIUSEPPE MANDALÀ, Un ambasciatore di Federico II in visita alle piramidi. Berardo arcivescovo di Palermo (a. I227), in "Aevum», 85, 20I I, pp. 4I7-438.

JOHN MANDEVILLE, Viaggi ovvero Trattato delle cose più meravigliose e più notabili che si trovano al mondo, a cura di Ermanno Barisone, Milano, Il Saggiatore, I982.

JEAN DE MANDEVILLE, Le livre des merveilles du monde, a cura di Christiane Deluz, Paris, CNRS, 2000.

NICOLETTA MARCELli, La Naturalis historia di Plinio nel volgarizzamento di Cristoforo Landino, in "Archives Internationales d'Historie et des Sciences", 6I, 20II, pp. I37-I6I.

NICOLETTA MARCELLI, La Novella del picchio senese di Luigi Pulci. Studio ed edizione, in «Filologia italiana», 8, 20I I, pp. 77-IOI.

NICOLETTA MARCELLI, Tradizione manoscritta e circolazione del testo pliniano nel Quattrocento, in ELIANA CARRARA - NICOLETTA MARCELLI, La fortuna di Plinio dalla tarda antichità all'epoca moderna, luglio $2020,<$ http://www.oltreplinio.it/it/carrara-marcelli/> [accesso: dicembre 2020$]$.

GIUSEPPE MARCOCCI, Renaissance Italy Meets South Asia. Florentines and Venetians in a Cosmopolitan World, in Cosmopolitismes en Asie du Sud. Sources, itinéraires, langues $\left(X V I^{e}-X V I I I^{e}\right.$ siècle), a cura di Corinne Lefèvre, Ines G. Zupanov e Jorge Flores, Paris, EHESS, 2015, pp. 45-69.

LUCA MARCOZZI, Raccontare il viaggio: tra itineraria ultramarina $e$ dimensione dell'immaginario, in Boccaccio geografo. Un viaggio nel Mediterraneo tra le città, i giardini e... il "mondo" di Giovanni Boccaccio, a cura di Roberta Morosini, Firenze, Mauro Pagliai, 20I0, pp. I59-I77.

CECILIA MARTELLI, Uno spettacolo per i Tornabuoni, regista Domenico Ghirlandaio. Affreschi e vetrate, spalliere e pala d'altare, in Santa Maria Novella. La basilica e il convento, a cura di Andrea de Marchi, vol. 2, Firenze, Mandragora, pp. I55-205.

MAXIMILIAAN P.J. MARTENS, Festive Decorations for Triumphant Entries in the Burgundian Netherlands, in Polyptiek. Een veelluik van Groninger bijdragen aan de kunstgeschiedenis, a cura di Victor M. Schmidt, Joost M. Keizer e Henk Th. Van Veen, Zwolle, Waanders, 2002, pp. 27-3I.

LAURO MARTINES, The Social World of the Florentine Humanists I390-I460, London, Routledge \& Kegan Paul, I963.

ROBERTA MARTINIS, Il palazzo del Banco Mediceo. Edilizia e arte della diplomazia a Milano nel XV secolo, in "Annali di Architettura», I5, 2003, pp. 37-57.

CLAUDiA MÄRTL, Papst Pius II (1458-I464) in der Kapelle des Palazzo Medici Riccardi zu Florenz. Ein Beitrag zu Ikonographie und Zeremoniell der Päpste in der Renaissance, in "Concilium Medii Aevi», 3, 2000, pp. I55-I83. CLAUDIA MÄRTL, Von Mäusen und Elefanten. Tiere am Papsthof im I5. Jahrhundert, in "Deutsches Archiv für Erforschung des Mittelalters», 6o, 2004, pp. I83-200. 
MASI I906

MASPERO I997

MASPERO - GRANTA I999

MASSETI 2002

MASSETI 2009

MASSETI 2015

MASSETI 2016

MASSETI 2017

MASSETI 2018

MASSING I99I

MATARRESE 1992

MAXWELL I992

MAZZI I997

MCHAM 2013

MEDICI I977-20II

Medieval Islamic 2006

MEDRI I992

MEISS I954
BARTOLOMEO MASI, Ricordanze di Bartolomeo Masi calderaio fiorentino dal 1478 al I526, a cura di Odoardo Corazzini, Firenze, Sansoni, I906.

FRANCESCO MASPERO, Bestiario antico. Gli animali-simbolo e il loro significato nell'immaginario dei popoli antichi, Casale Monferrato, Piemme, I997.

FRANCESCO MASPERO - ALDO GRANATA, Bestiario Medievale, Casale Monferrato, Piemme, I999.

MARCO MASSETI, Uomini e (non solo) topi. Gli animali domestici e la fauna antropocora, Firenze, Firenze University Press, 200 I.

MARCO MASSETI, Pictorial Evidence from Medieval Italy of Cheetahs and Caracals, and their Use in Hunting, in "Archives of Natural History", 36, 2009, pp. 37-47.

MARCO MASSETI, La fattoria di Lorenzo il Magnifico. Gli animali domestici e selvatici delle Cascine di Poggio a Caiano (Prato): un esperimento pilota nella gestione delle risorse agrosilvopastorali della Toscana del XV secolo, Poggio a Caiano, Comune di Poggio a Caiano, 2015.

MARCO MASSETI, Carpaccio's Parrots and the Early Trade in Exotic Birds between the West Pacific Islands and Europe, in "Annali dell'Università degli Studi di Ferrara. Museologia Scientifica e Naturalistica", I2, I, 20I6, pp. 259-266.

MARCO MASSETI, Fiere esotiche e selvaggina nostrana. La raffigurazione zoologica nelle Adorazioni dei Magi fra Tardo Gotico e il primo Rinascimento italiani, con particolare riferimento alle opere di Gentile da Fabriano e Benozzo Gozzoli, in La luce della stella. I Re Magi fra arte e storia, a cura di Alessandro Bedini, Giovanni Macchia, Paolo Ognibene, Antonio Panaino e Andrea Piras, Milano-Udine, Mimesis, 2017, pp. I I9-I76.

MARCO MASSETI, New World and Exotic Animals in the Italian Renaissance. The Menageries of Lorenzo Il Magnifico and his Son, Pope Leo $X$, in Naturalists in the Field. Collecting, Recording and Preserving the Natural World from the Fifteenth to the Twenty-First Century, a cura di Arthur Mac Gregor, Leiden, Brill, 2018, pp. 40-75.

JEAN MICHEL MASSING, Observations and Beliefs: The World of the Catalan Atlas, in Circa I492. The Art in the Age of Exploration, catalogo di mostra (Washington D.C, National Gallery of Art I2 ottobre I99I - I2 gennaio I992), a cura di Jay A. Levenson, New Haven, Yale University Press, I991, pp. 27-33.

SABATINA MATARRESE, Cultura volgare a corte all'epoca del concilio, in Ferrara e il concilio I438-I439, Atti del convegno di studi nel $550^{\circ}$ anniversario del concilio dell'unione delle due Chiese d'Oriente e d'Occidente (Ferrara, 23-24 novembre I989), a cura di Patrizia Castelli, Ferrara, Università degli Studi, I992, pp. 57-7I.

HOPE MAXWELL, "Uno elefante grandissimo con lo castello di sopra». Il trionfo aragonese del I423, in "Archivio Storico Italiano", 553, I992, pp. 847-875.

MARIA SERENA MAZZI, Oltre l'orizzonte. In viaggio nel Medioevo, Torino, Gribaudo, I997.

SARA B. MCHAM, Pliny and the Artistic Culture of the Italian Renaissance. The Legacy of the Natural History, New Haven-London, Yale University Press, 20I3.

LORENZO DE' MEDICI, Lettere, a cura di Nicolai Rubinstein, I6 voll., Firenze, Giunti-Barbera, I977-20I I.

Medieval Islamic Civilization: An Encyclopedia, 2 voll., a cura di Josef W. Meri, New York-London, Routledge, 2006.

LITTA MARIA MEDRI, Il mito di Lorenzo il Magnifico nelle decorazioni della villa di Poggio a Caiano, Firenze, Medicea, I992.

MILLARD MEISS, Ovum Struthionis. Symbol and Allusion in Piero della Francesca's Montefeltro Altarpiece, in Studies in Art and Literature for 
MELI 2009

MELIS I972

MELLI 2002

Mercanti scrittori I986

MEREGALLI 2005

MERISALO I993

MESSEDAGLIA I94I

MESSEDAGLIA I947

METZGER 2015

MEYERS 2008

MICHIEL I 884

MIZIUR 2013

MIZIUR-MOŹDZIOCH 2015

MITCHELL I962

MOLHO I994

MONACO I978-I979

MONFASANI I988

MONTANO I75I
Belle da Costa Greene, a cura di Dorothy Miner, Princeton, Princeton University Press, I954, pp. 92-IOI.

PATRIZIA MELI, Firenze di fronte al mondo islamico. Documenti su due ambasciate (I487-I489), in "Annali di Storia di Firenze», 4, 2009, pp. 243-273.

FEDERIGO MELIS, Documenti per la storia economica dei secoli XIIIXVI, Firenze, Olschki, I972.

LORENZA MELLI, Il disegno per Benozzo, in Benozzo Gozzoli allievo a Roma, maestro in Umbria, catalogo di mostra (Montefalco, Chiesa-Museo di San Francesco 2 giugno - 3I agosto 2002), a cura di Bruno Toscano e Giovanna Capitelli, Cinisello Balsamo, 2002, pp. I I7-I 29.

Mercanti scrittori. Ricordi nella Firenze tra Medioevo e Rinascimento, a cura di Vittore Branca, Milano, Rusconi, I986.

ANDREA MEREGALLI, La descrizione degli animali nel Niederrheinischer Orientbericht, in Testi cosmografici, geografici e odeporici del Medioevo germanico, Atti del XXXI convegno dell'Associazione italiana di filologia germanica (Lecce, 26-28 maggio 2004), a cura di Dagmar Gottschall, Louvain-la-Neuve, FIDEM, 2005, pp. I87-205.

OUTI MERISALO, Niccolò Conti e la realtà dell'Oriente, in Columbeis V. Relazioni di viaggio e conoscenza del mondo fra Medioevo e Umanesimo, Atti del convegno internazionale di studi dell'Associazione per il Medioevo e l'Umanesimo latini (Genova, I2-I5 dicembre I99I), a cura di Stefano Pittaluga, Genova, Dipartimento di Archeologia, Filologia Classica e loro Tradizioni, I993, pp. 433-439.

LUIGI MESSEDAGLIA, Il pardo da caccia nella poesia, nella storia, nell'arte, in "Atti e Memorie della Accademia di Agricoltura, Scienze e Lettere di Verona", I9, I94I, pp. I-78.

LUIGI MESSEDAGLIA, Nuovi appunti sul pardo da caccia nella poesia, nella storia, nell'arte, in "Atti e Memorie della Accademia di Agricoltura, Scienze e Lettere di Verona», 23, I947, pp. I-32.

CHRISTOF METZGER, Scheda, in Echt tierisch! Die Menagerie des Fürsten, catalogo di mostra (Innsbruck, Schloss Ambras I 8 giugno - 4 ottobre 2015), a cura di Sabine Haag, Vienna, Kunsthistorisches Museum Vienna, 20I5, pp. I29-I3I.

JEAN MEYERS, Le "rhinocéros» de Frère Félix Fabri. Autopsie d'un passage de l'Evagatorium (II, 7, fol. 39 B-4o A), in «Rursus», 3, 2008, <https:// journals.openedition.org/rursus/22I $>$ [accesso dicembre 2020]

MARCANTONIO MICHIEL, Notizia d'opere di disegno pubblicata e illustrata da D. Jacopo Morelli, a cura di Gustavo Frizzoni, Bologna, Zanichelli, I884.

MAJA MIZIUR, Exotic Animals as Manifestation of Royal Luxuria. Rulers and their Menageries: From the Pompe of Ptolemy II Philadelphus to Aurelian, in «Phasis», I 2, 20I3, pp. 45I-467.

MAJA MIZIUR-MOŹDZIOCH, Bestial Rivalry. Animal Propaganda in the Hellenistic Kingdoms, in «EOS», I02, 2015, pp. 7-28.

CHARLES MITCHELL, Ex libris kiriaci anconitani, in «Italia Medioevale e Umanistica", 5, I962, pp. 283-298.

ANTHONY MOLHO, Fisco ed economia a Firenze alla vigilia del concilio, in Firenze e il concilio del I439, Convegno di studi (Firenze, 29 novembre - 2 dicembre I989), a cura di Paolo Viti, vol. I, Firenze, Olschki, I994, pp. 59-94.

LUCIO MONACO, I volgarizzamenti italiani della relazione di Odorico da Pordenone, in «Studi Mediolatini e Volgari», 26, I978-I979, pp. I79-2 I9. JOHN MONFASANI, The First Call for Press Censorship: Niccolo Perotti, Giovanni Andrea Bussi, Antonio Moreto and the Editing of Pliny's Natural History, in «Renaissance Quarterly», I, I988, pp. I-3 I.

GIOVANNI MONTANO, Oratio funebris in morte Philippi Mariae Vicecomitis, Mediolani Ducis, in Rerum Italicarum Scriptores, vol. 25, Mediolani, Ex typographia Societas Palatinae in Regia Curia, I75I, pp. 433-442. 
MONTE DI CROCE 2005

MONTEMAGNO CISERI 2009

MONTEMAGNO CISERI 2OI2-20I3

MONTESANO 2007

\author{
MONTESANO 2010 \\ MONTESANO 2OI I \\ MONTESANO 2014 \\ MORELLI I986
}

MORELLI I 785

MORONY 2OII

MOROSINI 2006

MOROSINI 2010

MOROSINI 2OII

MOSCO I985

MOTTA 2006

Motto del pappagallo $20 \mathrm{IS}$

Motto di Bernabò Visconti 2015

MÜNKLER 200I

MUZZARELLI 1996
RICCOLDO DA MONTE DI CROCE, Libro della peregrinazione. Epistole alla Chiesa trionfante, a cura di Davide Cappi, Genova-Milano, Marietti, 2005.

LORENZO MONTEMAGNO CISERI, Note di teratologia classica nel Tresor di Brunetto Latini, in «Schede Umanistiche», 23, 2009, pp. 5-32. LORENZO MONTEMAGNO CISERI, Camelopardalis. Storia naturale e straordinaria della giraffa di Lorenzo il Magnifico, in "Interpres», 3 I, 2OI2-2OI3, pp. 35I-372.

MARINA MONTESANO, In missione dal Sultano: ambascerie e pellegrinaggi alla fine del XV secolo, in I fiorentini alle crociate. Guerre, pellegrinaggi e immaginario "orientalistico" a Firenze tra Medioevo ed età moderna, a cura di Silvia Agnoletti, Firenze, Meridiana, 2007, pp. 282-29I.

MARINA MONTESANO, Da Figline a Gerusalemme. Viaggio del prete Michele in Egitto e in Terrasanta (I489-I490), Roma, Viella, 20 Io.

MARINA MONTESANO, Invenzioni, obliterazioni e accorpamenti. Geografia e toponomastica tra Egitto e Terrasanta nei diari dei pellegrini italiani bassomedievali, in «Itineraria», IO, 20I I, pp. I4I-I57.

MARINA MONTESANO, Marco Polo, Roma, Salerno, 2014.

GIOVANNI MORELLI, Ricordi, in Mercanti scrittori. Ricordi nella Firenze tra Medioevo e Rinascimento, a cura di Vittore Branca, Milano, Rusconi, I986, pp. IOI-337.

LIONARDO MORELLI, Cronaca originale dal I347 al I520, in Delizie degli eruditi toscani, a cura di Ildefonso di San Luigi, vol. I9, Firenze, Cambiasi, I785, pp. I65-249.

MICHAEL MORONY, Gift Giving in the Iranian Tradition, in Gifts of the Sultan. The Arts of Giving at the Islamic Courts, catalogo di mostra (Los Angeles, County Museum of Art 5 giugno - 5 settembre 20II), a cura di Linda Komaroff, New Haven-London, Yale University Press, 20II, pp. 33-49.

ROBERTA MOROSINI, $A$ «Literary" Muhammed: The Poet of Islam in the Cosmography of Fazio degli Uberti, in Firenze alla vigilia del Rinascimento. Antonio Pucci e $i$ suoi contemporanei, Atti del convegno della McGill University (Montreal, 22-23 ottobre 2004), a cura di Maria Bendinelli Predelli, Fiesole, Cadmo, 2006, pp. I99-2 I 8.

ROBERTA MOROSINI, Introduzione, in Boccaccio geografo. Un viaggio nel Mediterraneo tra le città, i giardini e... il "mondo" di Giovanni Boccaccio, a cura di Roberta Morosini, Firenze, Mauro Pagliai, 20Io, pp. 9-38. ROBERTA MOROSINI, The Alexander Romance in Italy, in A Companion to Alexander Literature in the Middle Ages, a cura di Z. David Zuwiyya, Leiden, Brill, 20II, pp. 329-364.

MARILENA MOSCO, Natura viva in casa Medici, in Natura viva. Dipinti di animali dai depositi di Palazzo Pitti con esemplari del Museo Zoologico La Specola, catalogo di mostra (Firenze, Palazzo Pitti I4 dicembre I985 - I3 aprile I986), a cura di Marilena Mosco, Firenze Centro Di, I985, pp. II-23.

ATTILIO MOTTA, Le regine (d'Oriente) di Pucci, in Firenze alla vigilia del Rinascimento. Antonio Pucci e i suoi contemporanei, Atti del convegno della McGill University (Montreal, 22-23 ottobre 2004), a cura di Maria Bendinelli Predelli, Fiesole, Cadmo, 2006, pp. 2I9-24I.

Motto del pappagallo di Lorenzo il Magnifico, a cura di Serena Modena, 20I5, <http://www.rialfri.eu/rialfriWP/opere/motto-del-pappagallo-di-lorenzo-il-magnifico> [accesso: dicembre 2020].

Motto di Bernabò Visconti, a cura di Serena Modena, 2015, <https:// www.rialfri.eu/rialfriW P/opere/motto-di-bernabo-visconti> [accesso: dicembre 2020].

MARINA MÜNKLER, Marco Polo. Vita e leggenda, Milano, Vita e Pensiero, 200I.

GIUSEPPINA MUZZARELLI, Gli inganni delle apparenze. Disciplina di vesti e ornamenti alla fine del Medioevo, Torino, Scriptorium, I996. 
NAJEMY 2006

NASTASI 2006

NEBBIAI DALLA GUARDA 2006

NEWBIGIN 2015

NICOLINI 1924

NICCOLINI 20II

NURMINEN 2015

O'CALLAGHAN 1998

O'DOHERTY 2009

O'DOHERTY 2013

O'GRODY 1989

OLIVE 2009

OLIVE 2OIS

OLMI 1992

OLSCHKI 1937

OLSCHKI I957

OLSON 1982

OLSON 2000

OLSON 2019

ORLANDELLI I959

ORVIETO I969
JOHN M. NAJEMY, A History of Florence I200-I575, Oxford, Blackwell, 2006.

PIETRO NASTASI, Leonardo Pisano detto Fibonacci. Un commerciante matematico ai tempi di Federico II, in Giochi matematici del Medioevo. I "conigli di Fibonacci" e altri rompicapi liberamente tratti dal Liber abaci, a cura di Nando Geronimi, Milano, Bruno Mondadori, 2006, pp. IX-XXV. DONATELLA NEBBIAI DALLA GUARDA, Letture e circoli eruditi tra Quattro e Cinquecento: a proposito dell'ex-libris "et amicorum", in I luoghi dello scrivere da Francesco Petrarca agli albori dell'età moderna, Atti del convegno internazionale di studio dell'Associazione italiana di paleografi e diplomatisti (Arezzo, 8-I I ottobre 2003), a cura di Caterina Tristano, Marta Calleri e Leonardo Magionami, Spoleto, Fondazione Centro italiano di studi sull'alto Medioevo, 2006, pp. 375-393.

NERIDA NEWBIGIN, Mappare il mondo: l'itinerario intellettuale di Marco di Batolomeo Rustici, in MARCO DI BARTOLOMEO RUSTICI, Codice Rustici. Dimostrazione dell'andata o viaggio al Santo Sepolcro e al monte Sinai, a cura di Elena Gurrieri, Kathleen Olive e Nerida Newbigin, vol. 2, Firenze, Olschki, 20I5, pp. 45-48.

FAUSTO NICOLINI, La lettera di Giovanni Boccaccio a Franceschino de' Bardi, in "Archivio Storico italiano", 3II, I924, pp. 5-99.

GIUSTINA NICCOLINI, The Chronicle of Le Murate, a cura di Saundra Weddle, Toronto, Iter, 20 I I.

MARJO T. NURMINEN, The Mapmakers' World: A Cultural History of the European World Map, Oxford, The Pool of London Press, 2015. JOSEPH O'CALlaghan, Alfonso $X$ and the Cantigas de Santa Maria. A Poetic Biography, Leiden, Brill, 1998.

MARIANNE O'DOHERTY, The Viaggio in Inghilterra of a Viaggio in Oriente: Odorico da Pordenone's Itinerarium from Italy to England, in "Italian Studies", 2, 2009, pp. I98-220.

MARIANNE O'DOHERTY, The Indies and the Medieval West: Thought, Report, Imagination, Turnhout, Brepols, 2013.

JEANNINE A. O'GRODY, Echoes of the Strozzi Altarpiece in Benozzo Gozzoli's Frescoes in the Medici Chapel, in Siracuse University Graduate Studies in Florence, Firenze, I989, pp. 80-90.

KATHLEEN OLIVE, The Codex Rustici and the Fifteenth-Century Florentine Artisan, in «Renaissance Studies», 5, 2009, pp. 593-608.

KATHLEEN OLIVE, Alla ricerca di Marco di Bartolomeo Rustici, in MARCO DI BARTOLOMEO RUSTICI, Codice Rustici. Dimostrazione dell'andata o viaggio al Santo Sepolcro e al monte Sinai, a cura di Elena Gurrieri, Kathleen Olive e Nerida Newbigin, vol. 2, Firenze, Olschki, 20I5, pp. $4 \mathrm{I}-44$.

GIUSEPPE OLMI, Linventario del mondo. Catalogazione della natura e luoghi del sapere nella prima età moderna, Bologna, Il Mulino, 1992.

LEONARDO OLSCHKI, Storia letteraria delle scoperte geografiche. Studi e ricerche, Firenze, Olschki, I937.

LEONARDO OLSCHKI, L'Asia di Marco Polo. Introduzione alla lettura e allo studio del Milione, Firenze, Sansoni, I957.

GLENDING OLSON, Literature as Recreation in the Later Middle Ages, Ithaca (N.Y.), Cornell University Press, 1982.

ROBERTA J.M. OLSON, The Florentine Tondo, Oxford, Oxford University Press, 2000.

ROBERTA J.M. OlSON, Rara Avis. Piero di Cosimo and the Birds He Painted, in Piero di Cosimo. Painter of Faith and Fables, a cura di Dennis Geronimus e Michael W. Kwakkelstein, Leiden, Brill, 2019, pp. I03-I29. GIANFRANCO ORLANDELLI, Osservazioni sulla scrittura mercantesca nei secoli XIV e XV, in Studi in onore di Riccardo Filangieri, Napoli, L'Arte Tipografica, 1959, pp. 445-460.

PAOLO ORVIETO, Un esperto orientalista del '400. Benedetto Dei, in «Rinascimento", 9, I969, pp. 205-275. 
OVERTON 2OII

PAATZ I940-I954

PÄCHT 2OI I

PADOA RIZZO I972

PADOA RIZZO I989

PADOA RIZZO I993

PADOA RIZZO 2003

PADOA RIZZO 2009

PALMIERI I982

PANOFSKY I937

PANOFSKY 2014

PARAVICINI BAGLIANI 2016

PARAVICINI BAGLIANI 2017

PARIS I $872-1883$

PARRONCHI 1962

PASTOR I96I

PASTORE STOCCHI I963

PASTORE STOCCHI I967

PASTORE STOCCHI I986a

PASTORE STOCCHI i986b
KEELAN OVERTON, Scheda, in Gifts of the Sultan. The Arts of Giving at the Islamic Courts, catalogo di mostra (Los Angeles, County Museum of Art 5 giugno - 5 settembre 20II), a cura di Linda Komaroff, New Haven-London, Yale University Press, $201 \mathrm{I}$, p. 288.

WALTER e ELISABETH PAATZ, Die Kirchen von Florenz. Ein kunstgeschichtliches Handbuch, 6 voll., Frankfurt am Main, Klostermann, I940-I954

OTTO PÄCHT, La scoperta della natura. I primi studi italiani, a cura di Fabrizio Crivello, Torino, Einaudi, 20I I [ed. originale Early Italian Nature Studies and the Early Calendar Landscape, in «Journal of the Warburg and Courtauld Insititutes», I3,I950, pp. I3-47].

ANNA PADOA RIZZO, Benozzo Gozzoli, pittore fiorentino, Firenze, Edam, I972.

ANNA PADOA RIZZO, L'altare della Compagnia dei Tessitori in San Marco a Firenze. Dalla cerchia di Cosimo Rosselli al Cigoli, in "Antichità viva», 4, I989, pp. I7-24.

ANNA PADOA RIZZO, La Cappella dei Magi nell'attività di Benozzo Gozzoli, in Benozzo Gozzoli. La Cappella dei Magi, a cura di Cristina Acidini Luchinat, Milano, Electa, I993, pp. 357-362.

ANNA PADOA RIZZO, Benozzo Gozzoli. Un pittore insigne, "pratico di grandissima invenzione», Cinisello Balsamo, Silvana, 2003.

ANNA PADOA RIZZO, Benozzo e la cavalcata dei Magi, in La stella e la porpora. Il corteo di Benozzo e l'enigma del Virgilio Riccardiano, Atti del convegno di studi (Firenze, I7 maggio 2007), a cura di Giovanna Lazzi e Gerhard Wolf, Firenze, Polistampa, 2009, pp. Io9-II7.

MATTEO PALMIERI, Vita civile, a cura di Gino Belloni, Firenze, Sansoni, I982.

ERWIN PANOFSKY, The Early History of Man in a Cycle of Paintings by Piero di Cosimo, in "Journal of the Warburg and Courtauld Institute», I, I937, pp. I2-30.

ERWIN PANOFSKY, Architettura gotica e filosofia scolastica, a cura di Francesco Starace, Milano, Abscondita, 20I4 [ed. originale Gothic Architecture and Scholasticism, Latrobe, Archabbey Press, I95I].

AGOSTINO PARAVICINI BAGLIANI, Il bestiario del papa, Torino, Einaudi, 2016.

AGOSTINO PARAVICINI BAGLIANI, Il pappagallo del papa. "Volatile parlante" e specchio di sovranità, in Animali parlanti. Letteratura, teatro, canzoni, a cura di Caterina Mordeglia, Firenze, SISMEL Edizioni del Galluzzo, 20I7, pp. 69-84.

MATTHEW PARIS, Chronica majora, 7 voll., a cura di Henry Richards Luard, London, Longman, I872-I883.

ALESSANDRO PARRONCHI, Cammello per camaleonte, in "Paragone», I53, I962, pp. 64-67.

LUDWIG PASTOR, Storia dei papi dalla fine del Medio Evo, a cura di Angelo Mercati, vol. 2, Roma, Desclée \& Editori Pontifici, I96r [ed. originale Geschichte der Päpste seit dem Ausgang des Mittelalters, Freiburg im Briesgau, Herder, I894].

MANLIO PASTORE STOCCHI, Tradizione medievale e gusto umanistico nel De Montibus del Boccaccio, Padova, Cedam, I963.

MANLIO PASTORE STOCCHI, Note su alcuni itinerari in Terrasanta dei secoli $X I V$ e $X V$, in "Rivista di Storia e Letteratura Religiosa", I967, pp. I85-202.

MANLIO PASTORE STOCCHI, Itinerari in Asia nei secoli XIII e $X I V$, in Dizionario critico della letteratura italiana, a cura di Vittore Branca, vol. 2, Torino, UTET, I986, pp. 5I7-520.

MANLIO PASTORE STOCCHI, Itinerari in Terrasanta nei secoli XIII e XIV, in Dizionario critico della letteratura italiana, a cura di Vittore Branca, vol. 2, Torino, UTET, I986, pp. 520-523. 
PASTORE STOCCHI 2014

PASTOUREAU I996

PASTOUREAU I999

PASTOUREAU 2000

PASTOUREAU 2002

PASTOUREAU 20 I I

PEGOLOTTI I766

\section{PEGOLOTTI I936}

Pellegrini scrittori 1990

PELLETIER I994

PÉREZ DE TUDELA JORDAN GSCHWEND 2007

PERI 2000

PERISSA TORRINI I999

PERRENS I 888

PETRARCA I584

PETRARCA I979

PETRARCA I990

PETRARCA I993

PETRARCA 2002

Petrarch's Guide 2002
MANLIO PASTORE STOCCHI, Pagine di storia dell'Umanesimo italiano, Milano, FrancoAngeli, $20 \mathrm{O} 4$.

MICHEL PASTOUREAU, Un peintre italien en son temps: nordique, héraldique, mélancolique, in Pisanello. Le peintre aux sept vertus, catalogo di mostra (Paris, Musée du Louvre 6 maggio - 5 agosto I996), a cura di Dominique Cordellier e Paola Marini, Paris, Réunion des Musées Nationaux, I996, pp. I9-23.

MICHEL PASTOUREAU, L'animal et l'historien du Moyen Âge, in L'animal exemplaire au Moyen Âge ( $V^{e}-X V^{e}$ siècles), a cura di Jacques Berlioz e Marie Anne Polo de Beaulieu, Rennes, Presses Universitaires de Rennes, I999, pp. I3-26.

MICHEL PASTOUREAU, Pourquoi tant de lions dans l'Occident médiéval?, in «Micrologus», 8, 2000, pp. II-30.

MICHEL PASTOUREAU, Les animaux célèbres, Paris, Bonneton, 2002.

MICHEL PASTOUREAU, Bestiaires $d u$ Moyen Âge, Paris, Seuil, 2 o I I. FRANCESCO BALDUCCI PEGOLOTTI, La pratica della mercatura, in Della decima e delle altre gravezze, a cura di Giovanni Francesco Pagnini, vol. 3, Lisbona-Lucca, Giuseppe Bouchard, I766.

FRANCESCO BALDUCCI PEGOLOTTI, La pratica della mercatura, a cura di Allan Evans, Cambridge, Medieval Academy of America, I936.

Pellegrini scrittori. Viaggiatori toscani del Trecento in Terrasanta, a cura di Antonio Lanza e Marcellina Troncarelli, Firenze, Ponte alle Grazie, I990.

MONIQUE PELLETIER, Le portulan d'Angelino Dulcert, I339, in "Cartographica Helvetica», 9, I994, pp. 23-3I.

ALMUDENA PÉREZ DE TUDELA - ANNEMARIE JORDAN GSCHWEND, Renaissance Menagerie. Exotic Animals and Pets at the Habsburg Courts in Iberia and Central Europe, in Early Modern Zoology. The Construction of Animals in Science, Literature and the Visual Arts, vol. 2, a cura di Karl A.E. Enenkel e Paul J. Smith, Leiden, Brill, 2007, pp. 4I9-447.

PAOLO PERI, Il costume nella festa, in Patrimonium in festa. Cortei, tornei, artifici e feste alla fine del Medioevo (secoli XV-XVI), Atti del convegno (Orte, 3-4- novembre I995), a cura di Anna Modigliani, Orte, Ente Ottava Medievale Orte e Centro Studi per il Patrimonio di S. Pietreo in Tuscia, 200o, pp. 25-47.

ANNALISA PERISSSA TORRINI, Scheda, in Da Leonardo a Canaletto. Disegni delle Galleria dell'Accademia, catalogo di mostra (Venezia, Gallerie dell'Accademia 24 aprile - 25 luglio I999), a cura di Giovanna Nepi Scirè e Annalisa Perissa Torrini, Milano, Electa, I999, pp. 22-25.

FRANÇOIS-TOMMY PERRENS, Histoire de Florence depuis la domination des Médicis jusqu'à la chute de la République (I434-I53I), vol. I, Paris, Quantin, I888.

FRANCESCO PETRARCA, De' rimedi de l'una, et l'altra fortuna. Libri II, Venezia, Domenico Farri, I584.

FRANCESCO PETRARCA, Viaggio in Terrasanta. Volgarizzamento inedito del Quattrocento, a cura di Antonio Altamura, Napoli, Società Editrice Napoletana, I979.

FRANCESCO PETRARCA, Itinerario in Terra Santa 1358 , a cura di Francesco Lo Monaco, Bergamo, Pierluigi Lubrina, I990.

FRANCESCO PETRARCA, Itinerarium breve de Ianua usque ad Ierusalem et Terram Sanctam. Volgarizzamento meridionale anonimo, a cura di Alfonso Paolella, Bologna, Commissione per i Testi di Lingua, I993. FRANCESCO PETRARCA, Les remèdes aux deux fortunes. De remediis utriusque fortune $I 354-I 366,2$ voll., a cura di Christophe Carraud, Grenoble, Jérôme Millon, 2002.

Petrarch's Guide to the Holy Land: Itinerary to the Sepulcher of our Lord Jesus Christ, a cura di Theodore J. Cachey Jr., Notre Dame, University of Notre Dame Press, 2002. 
PETRIBONI - RINALDI 200 I

PETRUCCI I983a

PETRUCCI I983b

PETRUCCI I989

PEZZAROSSA I980

PIACENTI 2017

PICCOLOMINI 2008

PINTO I982

PINZAUTI 2015

Pisanello 1996

Pisanello 200 I

PISANI I923

PISTARINO I96I

PITTALUGA 200I

PLINIO 2OII

POGGIBONSI I945

POGGIBONSI I968

POGGIBONSI I990

POLIZIANO I994
PAGOLO DI MATTEO PETRIBONI - MATTEO DI BORGO RINALDI, Priorista (I407-I459) with Two Appendices, a cura di Jacqueline A. Gutwirth e Gabriella Battista, Roma, Edizioni di Storia e Letteratura, 200 I.

ARMANDO PETRUCCI, Il libro manoscritto, in Letteratura italiana, a cura di Alberto Asor Rosa, vol. 2, Torino, Einaudi, I983, pp. 499-524. ARMANDO PETRUCCI, Le biblioteche antiche, in Letteratura italiana, a cura di Alberto Asor Rosa, vol. 2, Torino, Einaudi, I983, pp. 527-54. ARMANDO PETRUCCI, Breve storia della scrittura latina, Roma, Bagatto Libri, I989.

FULVIO PEZZAROSSA, La tradizione fiorentina della memorialistica, in GIANMARIO ANSELMI - FULVIO PEZZAROSSA - LUISA AVELLINI, La «memoria» dei mercatores. Tendenze ideologiche, ricordanze, artigianato in versi nella Firenze del Quattrocento, Bologna, Pàtron, I980, pp. 39-I 49 .

STEFANO PIACENTI, «Stella fulgore nimio rutilat». La fortuna scenica dei Magi, in La luce della stella. I Re Magi fra arte e storia, a cura di Alessandro Bedini, Giovanni Macchia, Paolo Ognibene, Antonio Panaino e Andrea Piras, Milano-Udine, Mimesis, 2017, pp. I77-2I 4. ENEA SILVIO PICCOLOMINI, I commentarii, a cura di Luigi Totaro, 2 voll., Milano, Adelphi, 2008 [I984].

GIULIANO PINTO, I costi del pellegrinaggio in Terrasanta nei secoli XIVe XV (dai resoconti dei viaggiatori italiani), in Toscana e Terrasanta nel Medioevo, a cura di Franco Cardini, Firenze, Alinea, I982, pp. 255-284.

CARLA PINZAUTI, Scheda, in Il Medioevo in viaggio, catalogo di mostra (Firenze, Museo Nazionale del Bargello 20 marzo - 2I giugno 20I5), a cura di Benedetta Chiesi, Ilaria Ciseri e Beatrice Paolozzi Strozzi, Firenze, Giunti, 2015, pp. I92-I93.

Pisanello. Le peintre aux sept vertus, catalogo di mostra (Paris, Musée du Louvre 6 maggio - 5 agosto I996), a cura di Dominique Cordellier e Paola Marini, Paris, Réunion des Musées Nationaux, I996.

Pisanello Painter to the Renaissance Court, catalogo di mostra (London, National Gallery 24 ottobre 200I - I3 gennaio 2002), a cura di Luke Syson e Dillian Gordon, London, National Gallery Company, 200 I. MARIA PISANI, Un avventuriero del Quattrocento. La vita e le opere di Benedetto Dei, Genova, Perrella, I923.

GEO PISTARINO, I Portoghesi verso l'Asia del Prete Gianni, in «Studi medievali», 2, I96I, pp. 75-I37.

STEFANO PITTALUGA, L'immaginario del viaggio e il viaggio immaginario, in Da Ulisse a Ulisse (il viaggio come mito letterario), Atti del convegno internazionale (Imperia, 5-6 ottobre 2000), a cura di Giorgetta Revelli, Pisa-Roma, Istituti Editoriali e Poligrafici Internazionali, 200I, pp. 49-55.

PLINIO IL VECCHIO, Storie naturali libri (VIII-XI), a cura di Francesco Maspero, Milano, Rizzoli, 20 I I.

NICCOLÒ DA POGGIBONSI, A Voyage Beyond the Seas (I346-I350), a cura di Theophilus Bellorini e Eugene Oade, Jerusalem, Franciscan Press, I945:

NICCOLÒ DA POGGIBONSI, Libro d'Oltramare, 2 voll., a cura di Alberto Bacchi della Lega, Bologna, Commissione per i Testi di Lingua, I968 [ed. originale Bologna, Gaetano Romagnoli, I88I].

NICCOLÒ DA POGGIBONSI, Libro d'Oltramare, a cura di Antonio Lanza, in Pellegrini scrittori. Viaggiatori toscani del Trecento in Terrasanta, a cura di Antonio Lanza e Marcellina Troncarelli, Firenze, Ponte alle Grazie, I990, pp. 3I-I58.

ANGELO POLIZIANO, Miscellaneorum centuria prima, Chiusi, Luì, I994. 
POLIZIANO 2012

POLO I928

POLO 200I-2009

POLO 200I

POLO 2002

POLO 2008

PONS 2010

PONTANO 1999

POPE-HENNESSY I95O

POPHAM I930

PORCASI 2010

PORDENONE I990

PORDENONE 2000

PORDENONE 2016

Prester John 2015

PUCCI I957

PUCCI I968

PUJADES I BATALLER 2007

PUJADES I BATALLER 2016

PULCI I886

QUAGLIO I967

QUONDAM 2013

RABY I982
ANGELO POLIZIANO, Coniurationis commentarium. Commentario della congiura dei Pazzi, a cura di Leandro Perini, Firenze, Firenze University Press, 2012.

MARCO POLO, Il Milione. Prima edizione integrale, a cura di Luigi Foscolo Benedetto, Firenze, Olschki, I928.

MARCO POLO, Le Devisement dou monde, 6 voll., a cura di Philippe Ménard, Ginevra, Droz, 200I-2009.

MARCO POLO, Milione, a cura di Valeria Bertolucci Pizzorusso, Milano, Adelphi, 200I [I975].

MARCO POLO, Il Milione, a cura di Marie-Thèrese Gousset, Paris, Bibliothèque de l'Image, 2002.

MARCO POLO, Milione. Redazione latina del manoscritto $Z$, a cura di Alvaro Barbieri, Parma, Ugo Guanda, 2008 [I998].

NICOLETTA PONS, Scheda, in Virtù d'amore. Pittura nuziale nel Quattrocento fiorentino, catalogo di mostra (Firenze, Galleria dell'Accademia - Museo Horne 8 giugno - I novembre 20Io), a cura di Claudio Paolini, Daniela Parenti e Ludovica Sebregondi, Firenze, Giunti, 20I0, pp. 2I6-2I9.

GIOVANNI PONTANO, I libri delle virtù sociali, a cura di Francesco Tateo, Roma, Bulzoni, I999.

JOHN POPE-HENNESSY, The Complete Work of Paolo Uccello, London, Phaidon, I950.

ARTHUR E. POPHAM, A Book of Drawings of the School of Benozzo Gozzoli, in «Old Masters Drawings", I6, I930, pp. 53-58.

PIETRO PORCASI, La letteratura di pellegrinaggio in Terrasanta nel Medioevo, in Studi in onore di Guglielmo de' Giovanni-Centelles, a cura di Errico Cuozzo, Salerno, SISAUS, 2010, pp. i87-2io.

ODORICO DA PORDENONE, Memoriale toscano. Viaggio in India e in Cina (13I8-I330), a cura di Lucio Monaco, Alessandria, Edizioni dell'Orso, I990.

ODORICO DA PORDENONE, Libro delle nuove e strane e meravigliose cose. Volgarizzamento italiano del secolo XIV dell'Itinerarium, a cura di Alvise Andreose, Padova, Centro Studi Antoniani, 2000.

ODORICO DA PORDENONE, Relatio de mirabilibus orientalium tatarorum, a cura di Annalia Marchisio, Firenze, SISMEL - Edizioni del Galluzzo, 20I6.

Prester John: The Legend and its Sources, a cura di Keagan Brewer, Farnham, Ashgate, 20I5.

ANTONIO PUCCI, Libro di varie storie, a cura di Alberto Varvaro, Palermo, Accademia, I957.

ANTONIO PUCCI, Historia della Reina d'Oriente, a cura di Anicio Bonucci, Bologna, Commissione per i Testi di Lingua, I968.

RAMON J. PUJADES I BATALLER, Les cartes portolanes: la representació medieval d'una mar solcada, Barcellona, Institut Cartogràfic de Catalunya, 2007.

RAMON J. PUJADES I BATALLER, Mappaemundi veneziane e catalane del basso medioevo: due rami nati da uno stesso tronco, in Venezia e la nuova oikoumene. Cartografia del Quattrocento, a cura di Ingrid Baumgärtner e Piero Falchetta, Roma, Viella, 2016, pp. 73-96.

LUIGI PULCI, Lettere di Luigi Pulci a Lorenzo il Magnifico e altri, Lucca, Giusti, I886.

ANTONIO ENZO QUAGLIO, Scienza e mito nel Boccaccio, Padova, Liviana, I967.

AMEDEO QUONDAM, Introduzione, in GIOVANNI BOCCACCIO, Decameron, a cura di Amedeo Quondam, Maurizio Fiorilla e Giancarlo Alfano, Milano, 20I3.

JULIAN RABY, Venice, Dürer and the Oriental Mode, s.1., Islamic Art Publications, I982. 
RABY 1987

\section{RACHEWILTZ I997}

RAGGHIANTI COLLOBI I974

RANDOLPH 200I

\section{RAVASCHIETTO I997}

RECANATI I998

RECANATI 2005

REEVE 2007

REINHARD 1987

RICCIARDI I992

RICHARD 1996

RICHARD 2003

Ricordi di Firenze 1907

Ricordi storici $\mathrm{I} 840$

RINGMAR 2006

RINUCCINI I993

ROGERS 1962

ROGERS 1996

ROLLO 2004

ROLLO 2005

ROMBAI 2004a
JULIAN RABY, Pride and Prejudice. Mehmed the Conqueror and the Italian Portrait Medal, in "Studies in the History of Art», 2I, I987, pp. I7I-I94.

IGOR DE RACHEWILTZ, Marco Polo Went to China, in "Zentralasiatische Studien», 27, I997, pp. 34-92.

LICIA RAGGHIANTI COLLOBI, Il Libro de' Disegni del Vasari, 2 voll., Firenze, Vallecchi, I974.

ADRIAN W.B. RANDOLPH, "Il Marzocco". Lionizing the Florentine State, in Coming about... A Festschrift for John Shearman, a cura di Lars R. Jones e Louisa C. Matthew, Cambridge, Harvad University Art Museum, 200I, pp. II-I8.

GIULIANA RAVASCHIETTO, Il viaggio dei tre monaci al paradiso terrestre, Alessandria, Edizioni dell'Orso, I997.

MARIA GRAZIA RECANATI, Taccuino di disegni della Biblioteca Civica Angelo Mai di Bergamo: Giovannino de Grassi e la sua eredità, in Taccuino di disegni di Giovannino de Grassi. Cassaf. I.2 I della Civica Biblioteca Angelo Mai di Bergamo. Commentario, Modena, Il Bulino, I998, pp. I7-43.

MARIA GRAZIA RECANATI, Un bestiario fantastico, in "FMR», 8, 2005 , pp. IO8-I32.

MICHAEL D. REEVE, The Editing of Pliny's Natural History, in «Revue d'Histoire des Textes», 2, 2007, pp. I07-I79.

WOLFANG REINHARD, Storia dell'espansione europea, Napoli, Guida, I987 [ed. originale Geschichte der Europäischen Expansion, Stuttgart, Kohlhammer, I983].

LUCIA RICCIARDI, "Col senno, col tesoro e colla lancia». Riti e giochi cavallereschi nella Firenze del Magnifico Lorenzo, Firenze, Le Lettere, I992. JEAN RICHARD, Les récits de voyage et de pèlerinages, Turnhout, Brepols, I996 [I98I].

JEAN RICHARD, La relation de pèlerinage à Jérusalem instrument de dévotion, in L'idea di Gerusalemme nella spiritualità cristiana del Medioevo, Atti del convegno internazionale in collaborazione con l'Istituto della Görres-Gesellschaft di Gerusalemme (Gerusalemme, 3I agosto - 6 settembre I999), Città del Vaticano, Libreria Editrice Vaticana, 2003, pp. 20-28.

Ricordi di Firenze dell'anno I459, a cura di Guglielmo Volpi, in Rerum Italicarum Scriptores, vol. 27. I, Città di Castello, Lapi, I907, pp. I-38.

Ricordi storici di Filippo di Cino Rinuccini dal I282 al I460 colla continuazione di Alamanno e Neri suoi figli fino al I506, a cura di Giuseppe Aiazzi, Firenze, Piatti, I840.

ERIK RINGMAR, Audience for a Giraffe. European Expansion and the Quest for the Exotic, in «Journal of World History», 4, 2006, pp. 375-397. ALESSANDRO DI FILIPPO RINUCCINI, Sanctissimo peregrinaggio del Sancto Sepolcro, I474, a cura di Andrea Calamai, Pisa, Pacini, I993. FRANCIS M. ROGERS, The Quest for Eastern Christians. Travels and Rumor in the Age of Discovery, Minneapolis, University of Minnesota Press, I962.

MARK C. ROGERS, Art and Public Festival in Renaissance Florence. Studies in Relationships, Ph.D. Dissertation, Austin, University of Texas, I996.

ANTONIO ROLLO, Sulle tracce di Antonio Corbinelli, in «Studi Medievali e Umanistici», 2004, pp. 25-95.

ANTONIO ROLLO, Dalla biblioteca di Guarino a quella di Francesco Barbaro, in «Studi Medievali e Umanistici», 2005, pp. 9-28.

LEONARDO ROMBAI, Dall'immaginario geografico alla geografia reale, in Rappresentare e misurare il mondo. Da Vespucci alla modernità, catalogo di mostra (Firenze, Istituto Geografico Militare 30 ottobre 2004 - I5 gennaio 2005), a cura di Andrea Cantile, Giovanna Lazzi e Leonardo Rombai, Firenze, Polistampa, 2004, pp. 35-50. 
ROMBAI 2004b

RONCHEY 2006

RONCHEY 2009

ROSCOE I8I6

ROSSEBASTIANO I992

ROSSI I786

ROSSI I995

ROSSI 2015

ROUX 2009

RUBÍES 2000

RUBINSTEIN I97I

RUCELLAI 2013

RUFFINI I986

RUGGERI I982

RUGGIERI TRICOLI 2004

RUSTICI 2015

SAALMAN - MATTOX I985

SABBATINI 2014

SABBATINO 2006

SACCHETTI I996
LEONARDO ROMBAI, Scheda, in Rappresentare e misurare il mondo. Da Vespucci alla modernità, catalogo di mostra (Firenze, Istituto Geografico Militare 30 ottobre 2004 - I5 gennaio 2005), a cura di Andrea Cantile, Giovanna Lazzi e Leonardo Rombai, Firenze, Polistampa, 2004, pp. 95-97. SILVIA RONCHEY, L'enigma di Piero. L'ultimo bizantino e la crociata fantasma nella rivelazione di un grande quadro, Milano, Rizzoli, 2006. SILVIA RONCHEY, Tommaso Paleologo al concilio di Firenze, in La stella e la porpora. Il corteo di Benozzo e l'enigma del Virgilio Riccardiano, Atti del convegno di studi (Firenze, I7 maggio 2007), a cura di Giovanna Lazzi e Gerhard Wolf, Firenze, Polistampa, 2009, pp. I35-I52.

WILLIAM ROSCOE, Vita di Lorenzo de' Medici detto il Magnifico, a cura di Gaetano Mecherini, 4 voll., Pisa Capurro, I8 I6 [ed. originale The Life of Lorenzo de' Medici called the Magnificent, Liverpool, M'Creedy, I795].

ALDA ROSSEBASTIANO, La tradizione manoscritta della versione italiana del Voyage d'oultremer di Jean de Mandeville, Torino, CISI, I992. TRIBALDO DE' ROSSI, Ricordanze, in Delizie degli eruditi toscani, a cura di Ildefonso di San Luigi, vol. 23, Firenze, Cambiagi, I786, pp. 236-303.

MARCO ROSSI, Giovannino de' Grassi. La corte e la cattedrale, Cinisello Balsamo, Silvana, I995.

MARCO ROSSI, Scheda, in Arte lombarda dai Visconti agli Sforza. Milano al centro dell'Europa, catalogo di mostra (Milano, Palazzo Reale I 2 marzo - 28 giugno 20I5), a cura di Mauro Natale e Serena Romano, Skira, Milano, 20I5, p. I56.

BRIGITTE ROUX, Mondes en miniatures. L'iconographie du Livre du Trésor de Brunetto Latini, Ginevra, Droz, 2009.

JOAN-PAU RUBÍES, Travel and Ethnology in the Renaissance: South India through European Eyes, I25O-I625, Cambridge, Cambridge University Press, 2000.

NICOLAI RUBINSTEIN, Il governo di Firenze sotto i Medici (I434I494), Firenze, La Nuova Italia, I97 I [ed. originale The Government of Florence under the Medici (I434 to I494), Oxford, Clarendon Press, I966]. GIOVANNI DI PAGOLO RUCELLAI, Zibaldone, a cura di Gabriella Battista, Firenze, SISMEL - Edizioni del Galluzzo, 2013.

FRANCO RUFFINI, Commedia e festa nel Rinascimento. La Calandrina alla corte di Urbino, Bologna, Il Mulino, I986.

UGO RUGGERI, Gallerie dell'Accademia di Venezia. Disegni lombardi, Milano, Electa, I982.

MARIA CLARA RUGGIERI TRICOLI, Il richiamo dell'Eden. Dal collezionismo naturalistico all'esposizione museale, Firenze, Vallecchi, 2004. MARCO DI BARTOLOMEO RUSTICI, Libro intitolato Codice Rustici. Dimostrazione dell'andata o viaggio al Santo Sepolcro e al monte Sinai, a cura di Elena Gurrieri, Kathleen Olive e Nerida Newbigin, vol. I, Firenze, Olschki, 20I5, pp. I05-298.

HOWARD SAALMAN - PHILIP MATTOX, The First Medici Palace, in "Journal of the Society of Architectural Historians", 44, 4, I985, pp. 329-345.

ILARIA SABBATINI, "Com'io cercai di molti luoghi santi». Il corpus fiorentino dei diari di pellegrinaggio a Gerusalemme, in Gli italiani in Terrasanta, a cura di Antonio Musarra, Firenze, SISMEL - Edizioni del Galluzzo, 2OI4, pp. I23-I34.

PASQUALE SABBATINO, La guida di Petrarca e il viaggio in Terrasanta lungo le coste del Mediterraneo, in Mezzogiorno \& Mediterraneo. Territori, strutture, relazioni tra antichità e Medioevo, Atti del convegno internazionale (Napoli, 9-I I giugno 2005), a cura di Giovanni Coppola, Edoardo D'Angelo e Rosario Paone, Napoli, Artemisia Comunicazione, 2006, pp. $265-277$.

FRANCO SACCHETTI, Il Trecentonovelle, a cura di Valerio Marucci, Roma, Salerno, I996. 
SAID 2019

\section{SAINTE-PALAYE I759-I78I}

SALIMBENE 1987

SALMI I930

SALUTATI i89I-I9II

SALVADORE 2017

SANTONI 1974

SAPORI 1926

SAPORI I945

SAPORI 1972

SAPORI I 982

SAVINO I994

SAYOUS I93I

SCAFI 2007

SCAFI 2012

SCARTON 2007

SCHELLER 1963

SCHELLER I995

SCHMITT 1997

SCUDIERI 2000

SCUDIERI 2009

SEGRE 2000
EDWAR SAID, Orientalismo. L'immagine europea dell'Oriente, Milano, Feltrinelli, 20I9 [ed. originale Orientalism, New York, Pantheon Books, I978].

JEAN-BAPTISTE DE LA CUNE DE SAINTE-PALAYE, Mémoires sur l'ancienne chevalerie, 3 voll., Paris, Veuve Duchesne, I759-I78I.

SALIMBENE DE ADAM DA PARMA, Cronaca, a cura di Berardo Rossi, Bologna, Rafio Tau, I987.

MARIO SALMI, Un libro di disegni fiorentino del sec. $X V$, in «Rivista d'arte", I2, I930, pp. 87-95.

COLUCCIO SALUTATI, Epistolario, a cura di Franco Novati, 4 voll., Roma, Forzani e C. tipografi del Senato, I89I-I9II.

MATTEO SALVADORE, The African Prester John and the Birth of Ethiopian-European Relations, I402-1555, London-New York, Routledge, 2017.

PIERRE SANTONI, Albert de Sarteano observant et humaniste envoyé pontifical à Jérusalem et au Caire, in «Mélanges de l'École Française de Rome. Moyen Âge - Temps modernes», I, I974, pp. I65-2 I I.

ARMANDO SAPORI, La crisi delle compagnie mercantili dei Bardi e dei Peruzzi, Firenze, Olschki, I926.

ARMANDO SAPORI, Il mercante italiano nel Medio Evo, corso di storia economica (Firenze, Università, a.a. I944-I945), Firenze, Universitaria Editrice, I945.

ARMANDO SAPORI, La mercatura medievale, Firenze, Sansoni, I972. ARMANDO SAPORI, Studi di storia economica (secoli XIII-XIV-XV), 2 voll., Firenze, Sansoni, I982 [ed. originale Studi di storia economica medievale, I940].

ENZA SAVINO, I due "Plinii Naturalis historia» della Malatestiana, in "Schede umanistiche», 2, I994, pp. 43-65.

ANDRÉ E. SAYOUS, Un manuel arabe du parfait commerçant (XI siècle environ de notre ère), in "Annales d'Histoire Économique et Sociale», I2, I93 I, pp. 577-580.

ALESSANDRO SCAFI, Il paradiso in terra. Mappe del giardino dell'Eden, Milano, Bruno Mondadori, 2007.

ALESSANDRO SCAFI, La firma di Filarete sulla porta bronzea di San Pietro: la gioia della creazione artistica, in La basilica di San Pietro. Fortuna e immagine, a cura di Giovanni Morello, Roma, Gangemi, 20I2, pp. I37-I5I.

ELISABETTA SCARTON, Giovanni Lanfredini. Uomo d'affari e diplomatico nell'Italia del Quattrocento, Firenze, Olschki, 2007.

ROBERT W. SCHELLER, A Survey of Medieval Model Books, Haarlem, De Erven F. Bohn, I963.

ROBERT W. SCHELLER, Exemplum. Model-Book Drawings and the Practice of Artistic Transmission in the Middle Ages (ca. 90o-ca. I470), Amsterdam, Amsterdam University Press, I995.

ANNEGRIT SCHMITT, Der Meister des Tiermusterbuchs von Weimar, München, Biering \& Brinkmann, I997.

MAGNOLIA SCUDIERI, La Biblioteca di San Marco dalle origini a oggi, in La Biblioteca di Michelozzo a San Marco tra recupero e scoperta, a cura di Magnolia Scudieri e Giovanna Rasario, Firenze, Giunti, 2000, pp. 9-43.

MAGNOLIA SCUDIERI, Il ciclo affrescato nel convento di San Marco a Firenze, in Beato Angelico. L'alba del Rinascimento, catalogo di mostra (Roma, Musei Capitolini 8 aprile - 5 luglio 2009), a cura di Alessandro Zuccari, Giovanni Morello e Gerardo de Simone, Milano, Skira, 2009, pp. I09-I23.

VERA SEGRE, Il Tacuinum sanitatis di Verde Visconti e la miniatura milanese di fine Trecento, in "Arte cristiana", 800, 2000, pp. 375-390. 
SEGRE RUTZ 2002a

SEGRE RUTZ 2002b

SEGRE RUTZ 2015

SETTON I976-I984

SHAPLEY I945

SIENA I935

SIENA I99I

SIGOLI I990

SIGOLI I999

SIMARI I985

SIMION - BURGIO 2015

SIVIGLIA 2004

SOLINO I557

SOMBART 1925

SOULIER I924

SPERANZI 2014

SPINALE 2005

STADERINI 2010
VERA SEGRE RUTZ, L'Historia Plantarum e la bottega di Giovannino e Salomone de' Grassi, in Historia Plantarum, a cura di Vera Segre Rutz, vol. I, Modena, Franco Cosimo Panini, 2002, pp. 69-I22.

VERA SEGRE RUTZ, L'Historia Plantarum e la tradizione dei Tacuina sanitatis, in Historia Plantarum, a cura di Vera Segre Rutz, vol. I, Modena, Franco Cosimo Panini, 2002, pp. I23-I70.

VERA SEGRE, Scheda, in Arte lombarda dai Visconti agli Sforza. Milano al centro dell'Europa, catalogo di mostra (Milano, Palazzo Reale I2 marzo - 28 giugno 20I5), a cura di Mauro Natale e Serena Romano, Skira, Milano, 20I5, p. I57.

KENNETH M. SETTON, The Papacy and the Levant (I204-I57I), 4 voll., Philadelphia, American Philosophical Society, I976-I984.

FERN RUSK SHAPLEY, Giovanni Bellini and Cornaro's Gazelle, in "Gazette des Beaux-Arts", 28, I945, pp. 27-30.

BERNARDINO DA SIENA, Le prediche volgari inedite. Firenze I424I425, Siena I425, a cura di Dionisio Pacetti, Siena, Cantagalli, I935.

MARIANO DA SIENA, Viaggio fatto al Santo Sepolcro I43I, a cura di Paolo Pirillo, Pisa, Pacini, I99I.

SIMONE SIGOLI, Viaggio al monte Sinai, a cura di Antonio Lanza, in Pellegrini scrittori. Viaggiatori toscani del Trecento in Terrasanta, a cura di Antonio Lanza e Marcellina Troncarelli, Firenze, Ponte alle Grazie, I990, pp. 2I7-255.

SIMONE SIGOLI, Mentione delle terre d'oltre mare, in ALESSANDRO BEDINI, Testimone a Gerusalemme. Il pellegrinaggio di un fiorentino del Trecento, Roma, Città Nuova, I999, pp. 67-II8.

MARIA MATILDE SIMARI, Serragli a Firenze al tempo dei Medici, in Natura viva. Dipinti di animali dai depositi di Palazzo Pitti con esemplari del Museo Zoologico La Specola, catalogo di mostra (Firenze, Palazzo Pitti I 4 dicembre I985 - I3 aprile I986), a cura di Marilena Mosco, Firenze Centro Di, I985, pp. 23-26.

SAMUELA SIMION - EUGENIO BURGIO, Il "Marcho Polo» di Meo Ceffoni. Nota su un testimone minore della tradizione poliana, in "Quaderni Veneti», 2, 20I5, pp. I89-200.

ISIDORO DA SIVIGLIA, Etimologie o Origini, a cura di Angelo Valastro Canale, 2 voll., Torino, UTET, 2004.

CAIO GIULIO SOLINO, Delle cose maravigliose del mondo, Venezia, Gabriel Giolito de' Ferrari, I557.

WEINER SOMBART, Il capitalismo moderno. Esposizione storico-sistematica della vita economica di tutta l'Europa dai suoi inizi fino all'Età Contemporanea, Firenze, Vallecchi, I925 [ed. originale Der Moderne Kapitalismus. Historisch-systematische Darstellung des gesamteuropäischen Wirtschaftslebens von seinen Anfängen bis zur Gegenwart, München-Leipzig, Duncker \& Humblot, I9I7].

GUSTAVE SOULIER, Les influences orientales dans la peinture toscane, Paris, Henri Laurens, I924.

DAVID SPERANZI, Scheda, in Animalia. Gli uomini e la cura degli animali nei manoscritti della Biblioteca Medicea Laurenziana, catalogo di mostra (Firenze, Biblioteca Medicea Laurenziana I4 aprile - I4 giugno 20I4), a cura di Donatella Lippi, Firenze, Mandragora, 20I4, pp. 90-93.

SUSAN SPINALE, Scheda, in Bellini and the East, catalogo di mostra (Boston, Isabella Stewart Gardner Museum I4 dicembre 2005 - 26 marzo 2006), a cura di Caroline Campbell e Alan Chong, London, National Gallery Company, 2005, pp. 76-77.

ANDREA STADERINI, Schede, in Virtù d'amore. Pittura nuziale nel Quattrocento fiorentino, catalogo di mostra (Firenze, Galleria dell'Accademia - Museo Horne 8 giugno - I novembre 20Io), a cura di Claudio Paolini, Daniela Parenti e Ludovica Sebregondi, Firenze, Giunti, 20IO, pp. 236-239, 246-25I. 
STADTER I984

STELLA 2012

STONEMAN 2018

STREHLKE 2005

STRICKLAND 2019

STROZZI I 877

TADDEI 2010

TAFUR 2014

TAITI 2014

TANTURLI I978

TARDIOLA I990

TARGIONI TOZZETTI I768-I779

Ta'rikh-i Bayhaqi 20 I I

TASSO 2015

TEDESCHI I993

TEDESCO 2019
PHILIP A. STADTER, Niccolo Niccoli. Winning Back the Knowledge of the Ancients, in Vestigia. Studi in onore di Giuseppe Billanovic, 2 voll., a cura di Rino Avesani, Mirella Ferrari, Tino Foffano [et al.], Roma, Edizioni di Storia e Letteratura, pp. 747-764.

FRANCESCO STELLA, "Ludibria sibi, nobis miracula». La fortuna medievale della scienza pliniana e l'antropologia della diversitas, in La Naturalis Historia di Plinio nella tradizione medievale e umanistica, a cura di Vanna Maraglino, Bari, Cacucci, 2012, pp. 39-75.

RICHARD STONEMAN, Introduction: On Using Literature for History, in The Alexander Romance: History and Literature, a cura di R. Stoneman, K. Nawotka e A. Wojciechowska, Groningen, Barkhuis \& Groningen University Library, 20I8, pp. VII-VX.

CARL B. STREHLKE, Palla di Nofri Strozzi, "Kavaliere» e mecenate, in Gentile da Fabriano agli Uffizi, a cura di Alessandro Cecchi, Cinisello Balsamo, Silvana, 2005 , pp. 4I-58.

DEBRA HIGGS STRICKLAND, The Bestiary on the Hereford World Map (c. I300), in Maps and Travel in the Middle Ages and the Early Modern Period. Knowledge, Imagination, and Visual Culture, a cura di Ingrid Baumgärtner, Nirit Ben-Aryeh Debby e Katrin Kogman-Appel, BerlinBoston, De Gruyter, 20I9, pp. 37-73.

ALESSANDRA MACINGHI STROZZI, Lettere di una gentildonna fiorentina del secolo XV ai figliuoli esuli, a cura di Cesare Guasti, Firenze, Sansoni, I877.

ILARIA TADDEI, Il sistema politico fiorentino (XIV-XV secolo), in Firenze e la Toscana. Genesi e trasformazioni di uno stato (XIV-XIX secolo), a cura di Jean Boutier, Sandro Landi e Olivier Rouchon, Firenze, Mandragora, 20Io, pp. 3I-53 [ed. originale Florence e la Toscane, XIV $V^{e}-X I X^{e}$ siècles. Les dynamiques d'un État italien, Rennes, Presses Universitaires de Rennes, 2004].

PERO TAFUR, Travels and Adventures I435-I439, a cura di Edward Denison Ross e Eileen Power, London-New York, Routledge, 2014 [1926].

ANTONELLA TAITI, Scheda, in Animalia. Gli nomini e la cura degli animali nei manoscritti della Biblioteca Medicea Laurenziana, catalogo di mostra (Firenze, Biblioteca Medicea Laurenziana I4 aprile - I4 giugno 20I4), a cura di Donatella Lippi, Firenze, Mandragora, 20I4, pp. 94-97.

GIULIANO TANTURLI, I Benci copisti. Vicende della cultura fiorentina volgare fra Antonio Pucci e il Ficino, in "Studi di Filologia Italiana», 36 , I978, pp. I97-3I3.

GIUSEPPE TARDIOLA, Atlante fantastico del Medioevo, Roma, De Rubeis, I990.

GIOVANNI TARGIONI TOZZETTI, Relazioni d'alcuni viaggi fatti in diverse parti della Toscana per osservare le produzioni naturali, e gli antichi monumenti di essa, I2 voll., Firenze, Cambiagi, I768-I779.

Ta'rikh-i Bayhaqi Excerpt, in Gifts of the Sultan. The Arts of Giving at the Islamic Courts, catalogo di mostra (Los Angeles, County Museum of Art 5 giugno - 5 settembre 20II), a cura di Linda Komaroff, New HavenLondon, Yale University Press, 20I I, p. 48.

FRANCESCA TASSO, Scheda, in Arte lombarda dai Visconti agli Sforza. Milano al centro dell'Europa, catalogo di mostra (Milano, Palazzo Reale I 2 marzo - 28 giugno 20I5), a cura di Mauro Natale e Serena Romano, Skira, Milano, 20I5, p. 223.

SALVATORE TEDESCHI, L'Etiopia di Poggio Bracciolini, in "Africa», 2, I993, pp. 333-358.

ALESSANDRO TEDESCO, Le antiche edizioni del Viaggio di Niccolò da Poggibonsi: per una prima mappatura delle serie di illustrazioni silografiche, in "Ad Stellam». Il Libro d'Oltramare di Niccolò da Poggibonsi e altri resoconti di pellegrinaggio in Terra Santa fra Medioevo ed Età moderna, Atti 
TENENTI 2004

Tessuto e ricchezza 2017

The Book of Jean $201 \mathrm{I}$

The Douce Legacy 1984

The Gates of Paradise 2007

The Public Library 1972

The Robert Lehman I987-20I2

The Trattato 1973

THUASNE I 892

TOBIENNE 2016

TOESCA I905

TOESCA I9I 2

TOESCA 1966

TOGNETTI 2002

TOGNETTI 2009

TOGNETTI 20 I I

TOGNETTI 2015

TOGNETTI 2017

TONGIORGI TOMASI I987

TONGIORGI TOMASI I992 della giornata di studi (Milano, Biblioteca Nazionale Braidense, 5 dicembre 2017), a cura di Edoardo Barbieri, Firenze, Olschki, 20I9, pp. IO7-I5O.

ALBERTO TENENTI, L'Italia del Quattrocento. Economia e società, Roma-Bari, Laterza, 2004 [ed. originale Les hommes et leurs cités, in L'Italie de la Renaissance. Un monde en mutation (I378-I494), a cura di Christian Bec, Ivan Cloulas, Bertrand Jestaz e Alberto Tenenti, Paris, Fayard, 1990].

Tessuto e ricchezza a Firenze nel Trecento. Lana, seta, pittura, catalogo di mostra (Firenze, Galleria dell'Accademia 5 dicembre 2017 - I 8 marzo 20I8), a cura di Cecilie Hollberg, Firenze, Giunti, 2017.

The Book of Jean Mandeville with Related Texts, a cura di Iain Macleod Higgins, Indianapolis-Cambridge, Hackett Publishing Company, 20 I I. The Douce Legacy. An Exhibition to Commemorate the I50 th Anniversary of the Bequest of Francis Douce (I757-I834), Oxford, Bodleian Library, I984. The Gates of Paradise. Lorenzo Ghiberti's Renaissance Masterpiece, a cura di Gary M. Radke, New Haven, Yale University Press, 2007.

The Public Library of the Renaissance Florence. Niccolò Niccoli, Cosimo de' Medici and the Library of San Marco, a cura di Berthold L. Ullman e Philip A. Stadter, Padova, Antenore, I972.

The Robert Lehman Collection. I5 voll., New York, Metropolitan Museum of Art, I987-2012.

The Trattato politico-morale (I38I- c. I45I) of Giovanni Cavalcanti, a cura di Marcella T. Grendler, Ginevra, Droz, I973.

LOUIS THUASNE, Djem-Sultan fils de Mohammed II, frère de Bayezid II (I459-I495), Paris, Leroux, I892.

FRANCIS JR. TOBIENE, Mandeville's Travails: Merging Travel, Theory, and Commentary, Newark, University of Delaware Press, 2016.

PIETRO TOESCA, Michelino da Besozzo e Giovannino de' Grassi, in "L'Arte», I905, pp. 32I-339.

PIETRO TOESCA, La pittura e la miniatura nella Lombardia, Milano, Hoepli, I9I2.

PIETRO TOESCA, La pittura e la miniatura nella Lombardia: dai più antichi monumenti alla metà del Quattrocento, Torino, Einaudi, I966.

SERGIO TOGNETTI, Un'industria del lusso al servizio del grande commercio. Il mercato dei drappi serici e della seta nella Firenze del Quattrocento, Firenze, Olschki, 2002

SERGIO TOGNETTI, Gli affari di messer Palla Strozzi (e di suo padre Nofri). Imprenditoria e mecenatismo nella Firenze del primo Rinascimento, in "Annali di Storia di Firenze», IV, 2009, pp. 7-88.

SERGIO TOGNETTI, Organizzazione dei trasporti e delle comunicazioni commerciali a Firenze tra XIV e XV secolo, in Denaro e bellezza. I banchieri, Botticelli e il rogo delle vanità, catalogo di mostra (Firenze, Palazzo Strozzi I7 settembre 20I - 22 gennaio 20I2), a cura di Ludovica Sebregondi e Tim Parks, Firenze, Giunti, 20I I, pp. 69-79.

SERGIO TOGNETTI, Le compagnie mercantili-bancarie toscane e $i$ mercati finanziari europei tra metà XIII e metà XVI secolo, in "Archivio Storico Italiano", 646, 20I5, pp. 687-7I7.

SERGIO TOGNETTI, Uomini d'affari e mobilità sociale in Italia tra metà Trecento e primo Cinquecento, in "Archivio Storico Italiano", 65I, 20I7, pp. II9-I5O.

LUCIA TONGIORGI TOMASI, Toward the Scientific Naturalism. Aspects of Botanical and Zoological Iconography in Manuscripts and Printed Books in the Second Half of XV Century, in Die Kunst und das Studium der Natur vom I4. zum I6. Jahrhundert, a cura di Wolfram Prinz e Andreas Bayer, Weinheim, Acta Humaniora, I987, pp. 9I-IOI.

LUCIA TONGIORGI TOMASI, Scheda, in Il disegno fiorentino del tempo di Lorenzo il Magnifico, catalogo di mostra (Firenze, Uffizi, Gabinetto 
TORI I990

TORTELLI 2005

TREXLER I980

TREXLER I987

TREXLER I988

TREXLER I997

TRIPODI 2010

TRIVELLATO 2019

TUCCI 1976

TUCCI I977

TUCCI 2005

TUOHY I996

TZANAKI 2003

TZANAKI 2007

UBERTI I952

ULIVI I998

ULIVI 2002
Disegni e Stampe 8 aprile - 5 luglio I992), a cura di Annamaria Petrioli Tofani, Cinisello Balsamo, Silvana, I992, p. I83 n. 9.4.

DOLCIBENE DEI TORI, Avemaria, a cura di Antonio Lanza, in Pellegrini scrittori. Viaggiatori toscani del Trecento in Terrasanta, a cura di Antonio Lanza e Marcellina Troncarelli, Firenze, Ponte alle Grazie, I990, pp. I59-I66.

ELISABETTA TORTELLI, Scheda, in Leon Battista Alberti. La biblioteca di un umanista, catalogo di mostra (Firenze, Biblioteca Medicea Laurenziana 8 ottobre 2005 - 7 gennaio 2006), a cura di Roberto Cardini, Firenze, Mandragora, 2005, pp. 470-473.

RICHARD C. TREXLER, Public Life in Renaissance Florence, New York, Academic Press, I980.

RICHARD C. TREXLER, Church and Community I200-I600. Studies in the History of Florence and New Spain, Roma, Edizioni di Storia e Letteratura, I987, pp. 75-I67 [ed. originale in «Studies in Medieval and Renaissance History», I, I978, pp. I29-2I6].

RICHARD C. TREXLER, Il rituale della celebrazione. Le forme cavalleresche e la Festa di San Giovanni, in Teatro e culture della rappresentazione. Lo spettacolo in Italia nel Quattrocento, a cura di Raimondo Guarino, Bologna, Il Mulino, I988, pp. 7I-II9.

RICHARD C. TREXLER, The Journey of the Magi. Meanings in History of a Christian Story, Princeton, Princeton University Press, I997.

CLAUDIA TRIPODI, Viaggi di ambasciatori tra Firenze e Il Cairo nel $X V$ secolo, in "Mélanges de l'Ecole Française de Rome. Moyen Âge», I 22, 2, 20IO, pp. 4II-440.

FRANCESCA TRIVELLATO, Economic and Business History as Cultural History: Pitfalls and Possibilities, in «I Tatti Studies» 22, 2, 20I9, pp. 403-4IO.

UGO TUCCI, I primi viaggiatori e l'opera di Marco Polo, in Storia della cultura veneta. Dalle origini al Trecento, vol. I, Vicenza, Neri Pozza, I976, pp. 633-670.

UGO TUCCI, Manuali di mercatura e pratica degli affari nel Medioevo, in Fatti e idee di storia economica nei secoli XII-XX. Studi dedicati a Franco Borlandi, Bologna, Il Mulino, I977, pp. 215-23I.

GIUSEPPE TUCCI, Italia e Oriente, a cura di Francesco D'Arelli, Roma, Istituto Italiano per l'Africa e l'Oriente, 2005.

THOMAS TUOHY, Herculean Ferrara. Ercole d'Este, I47I-I505, and the Invention of a Ducal Capital, Cambridge, Cambridge University Press, I996.

ROSEMARY TZANAKI, Mandeville's Medieval Audiences: A Study on the Reception of the Book of Sir John de Mandeville (I37I-I55O), Aldershot, Ashgate, 2003.

ROSEMARY TZANAKI, Aspects of Mandeville's Audiences, in Jean de Mandeville in Europa. Neue Perspektiven in der Reiseliteraturforschung, a cura di Ernst Bremer e Susanne Röhl, München, Wilhelm Fink, 2007, pp. 79-9I.

FAZIO DEGLI UBERTI, Il Dittamondo e le Rime, 2 voll., a cura di Giuseppe Corsi, Bari, Laterza, I952.

ELISABETTA ULIVI, Le scuole d'abaco a Firenze (seconda metà del sec. XIII - prima metà del sec. XVI), in Luca Pacioli e la matematica del Rinascimento, Atti del convegno internazionale di studi (Sansepolcro, I3-I6 aprile I994), a cura di Enrico Giusti, Città di Castello, Petruzzi, I998, pp. 4I-60.

ELISABETTA ULIVI, Scuole e maestri d'abaco in Italia tra Medioevo e Rinascimento, in Un ponte sul Mediterraneo. Leonardo Pisano, la scienza araba e la rinascita della matematica in Occidente, a cura di Enrico Giusti, Firenze, Polistampa, 2002, pp. I2I-I59. 
ULIVI 2009

UZZANO I766

VAGLIENTI 2006

VAGNON 2013

VARAZZE 2007

VASARI I966-I997

VATIN I997

VENTRONE I99I

VENTRONE 1992

VENTRONE 2OOI

VENTRONE 2006

VENTRONE 2016

VENTURI I927

VENTURINI I994

VERDE I973-20IO

VERDON 2015

Viaggi in Persia I929

Viaggio in Terrasanta I990

Viaggio in Oriente 2005

VIATTE 2004

Viazo da Venesia 1972
ELISABETTA ULIVI, Gli abacisti fiorentini delle famiglie «del maestro Luca", Calandri e Micceri e le loro scuole d'abaco (secc. XIV-XVI), Firenze, Olschki, 2009.

GIOVANNI DA UZZANO, Pratica della mercatura, in Della decima e delle altre gravezze, a cura di Giovan-Francesco Pagnini, vol. 4, Firenze, Giuseppe Bouchard, I766.

FRANCESCA MARIA VAGLIENTI, Benozzo Gozzoli e il cavaliere misterioso. Ipotesi per una nuova identificazione di Galeazzo Maria Sforza nel Corteo dei Magi, in Arte e storia di Lombardia. Scritti in memoria di Grazioso Sironi, Roma, Dante Alighieri, 2006, pp. 37-54.

EMMANUELLE VAGNON, La représentation cartographique de l'espace maritime, in La terre. Connaissance, représentation, mesure au Moyen Âge, a cura di Patrick Gautier Dalché, Turnhout, Brepols, 2013, pp. 443-503. IACOPO DA VARAZZE, Legenda aurea con le miniature del codice Ambrosiano C 240 inf., a cura di Giovanni Paolo Maggioni, vol. I, Firenze, SISMEL - Edizioni del Galluzzo, 2007.

GIORGIO VASARI, Le Vite de' più eccellenti pittori, scultori e architetti nelle redazioni del I550 e I568, 6 voll., a cura di Rosanna Bettarini e Paola Barocchi, Firenze, SPES, I966-I997.

NICOLAS VATIN, Sultan Djem. Un prince ottoman dans l'Europe du XV siècle d'après deux sources contemporaines: Vâki'ât-i Sultân Cem, CEuvres de Guillaume Caoursin, Ankara, Societé Turque d'Histoire, I997.

PAOLA VENTRONE, On the Use of Figurative Art as a Source for the Study of Medieval Spectacles, in "Comparative Drama", 25, I, I99I, pp. 4-I6.

PAOLA VENTRONE, Feste e spettacoli nella Firenze di Lorenzo il Magnifico, in Le tems revient 'l tempo si rinuova. Feste e spettacoli nella Firenze di Lorenzo il Magnifico, catalogo di mostra (Firenze, Palazzo Medici Riccardi 8 aprile - 30 giugno I992), a cura di Paola Ventrone, Firenze, Silvana, I992, pp. 2 I-55. PAOLA VENTRONE, "Una visione miracolosa e indicibile». Nuove considerazioni sulle feste di quartiere, in Teatro e spettacolo nella Firenze dei Medici. Modelli dei luoghi teatrali, catalogo di mostra (Firenze, Palazzo Medici Riccardi I aprile - 9 settembre 200I), a cura di Elvira Garbero Zorzi e Mario Sperenzi, Firenze, Olschki, 200I, pp. 39-5I.

PAOLA VENTRONE, L'immaginario cavalleresco nella cultura dello spettacolo fiorentino nel Quattrocento, in Paladini di carta. Il modello cavalleresco fiorentino, a cura di Marco Villoresi, Roma, Bulzoni, 2006, pp. I9I-223. PAOLA VENTRONE, Teatro civile e sacra rappresentazione a Firenze nel Rinascimento, Firenze, Le Lettere, 2016.

ADOLFO VENTURI, Studi dal vero attraverso le raccolte artistiche d'Europa, Milano, Hoepli, I927.

LISA VENTURINI, Francesco Botticini, Firenze, Edifir, I994.

ARMANDO F. VERDE, Lo Studio fiorentino 1473-1503. Ricerche e documenti, 6 voll., Pistoia, Memorie Domenicane, I973-20Io.

TIMOTHY VERDON, Beato Angelico, Milano, 24 ORE Cultura, 2015. Viaggi in Persia, India e Giava di Nicolò de' Conti, Girolamo Adorno e Girolamo di Santo Stefano, a cura di Mario Longhena, Milano, Alpes, I929.

Viaggio in Terrasanta, a cura di Antonio Lanza, in Pellegrini scrittori. Viaggiatori toscani del Trecento in Terrasanta, a cura di Antonio Lanza e Marcellina Troncarelli, Firenze, Ponte alle Grazie, I990, pp. 3I3-3 I8.

Viaggio in Oriente di un nobile del Quattrocento. Il pellegrinaggio di Milliaduse d'Este, a cura di Alda Rossebastiano e Simona Fenoglio, Torino, UTET, 2005 .

FRANÇOISE VIATTE, Scheda, in Léonard de Vinci. La collection du Musée Bonnat à Bayonne, catalogo di mostra (Bayonne, Musée Bonnat 30 luglio - 30 ottobre 2004), a cura di Françoise Viatte e Varena Forcione, Paris, Réunon des Musées Nationaux, 2004, pp. I5-I7.

Viazo da Venesia al Sancto Ierusalem, a cura di Armando e Franca Petrucci, Roma, Elefante, I972. 
VILLANI I844-I 845

VILLANI I990-I99I

VILLANI I 846

VILLORESI 2006

VISMARA I950

VITI 2012

VITI 20I3

Vocabolario degli Accademici I863-I923

VOGEL 2013

VOLPI I9O2

WALKER-MEIKLE 2012

WATANABE I986

WEBER 2010

WEDDIGEN 2006

WEDDLE I997

WEDDLE 2008

WEISS I966a

WEISS i966b

WEISS I977

WESTREM 200I

WILLIAMS LEHMANN I977

WITTKOWER I987
GIOVANNI VILLANI, Cronica a miglior lezione ridotta coll'aiuto de' testi a penna, 4 voll., a cura di Ignazio Moutier e Francesco Gherardi Dragomanni, Firenze, Sansone Coen, I844-I845.

GIOVANNI VILLANI, Nuova Cronica, 3 voll., a cura di Giuseppe Porta, Parma, Guanda, I990-I99i.

MATTEO VILLANI, Nuova Cronica a miglior lezione ridotta coll'ainto de' testi a penna, 2 voll., a cura di Francesco Gherardi Dragomanni, Firenze, Sansone Coen, I846.

MARCO VILLORESI, Tra Andrea da Barberino e Luigi Pulci. La letteratura cavalleresca a Firenze nel Quattrocento, in Paladini di carta. Il modello cavalleresco fiorentino, a cura di Marco Villoresi, Roma, Bulzoni, 2006, pp. 9-30.

GIUliO VISMARA, Bisanzio e l'Islam. Per la storia dei trattati tra la cristianità orientale e le potenze musulmane, Milano, Giuffrè, I950.

PAOLO VITI, Poliziano e Plinio. Il cap. 6I della I centuria dei Miscellanea, in La Naturalis Historia di Plinio nella tradizione medievale e umanistica, a cura di Vanna Maraglino, Bari, Cacucci, 2012, pp. I53-I69.

PAOLO VITI, Il concilio del I439, in La primavera del Rinascimento. La scultura e le arti a Firenze I4OO-I460, catalogo di mostra (Firenze, Palazzo Strozzi 23 marzo - I8 agosto 2013), a cura di Beatrice Paolozzi Strozzi e Marc Bormand, Firenze, Mandragora, 2013, pp. I97-203.

Vocabolario degli Accademici della Crusca, I2 voll., Firenze, M. Cellini, I863-I923.

HANS ULRICH VOGEL, Marco Polo Was in China: New Evidence from Currencies, Salts and Revenues, Leiden, Brill, 2013.

GUGLIELMO VOLPI, Le feste di Firenze del I459. Notizia di un poemetto del sec. XV, Pistoia, Pagnini, I9O2.

KATHLEEN WALKER-MEIKLE, Medieval Pets, Woodbridge, Boydell Press, 20I2.

HIROSHI WATANABE, Marco Polo Bibliography, I477-I983, Tokyo, Toyo Bunko, I986.

BENJAMIN WEBER, La bulle Cantate Domino (4 février I442) et les enjeux éthiopiens du concile de Florence, in «Mélanges de l'École Française de Rome. Moyen Âge», I22, 2010 , pp. 44I-449.

TRISTAN WEDDIGEN, Raffaels Papageienzimmer. Ritual, Raumfunktion und Dekoration im Vatikanpalast der Renaissance, Emsdetten, Imorde, 2006. SAUNDRA L. WEDDLE, Enclosing Le Murate. The Ideology of Enclosure and the Architecture of a Florentine Convent, I390-I597, Ph.D Dissertation, Ithaca (N.Y.), Cornell University, I997.

SAUNDRA L. WEDDLE, Saints in the City and Poets at the Gates. The Codex Rustici as a Devotional and Civic Chronicle, in Florence and Beyond. Culture, Society and Politics in Renaissance Italy. Essays in Honour of John M. Najemy, a cura di David S. Peterson e Daniel E. Bornstein, Toronto, Centre for Reformation and Renaissance Studies, 2008, pp. I79-I94.

ROBERTO WEISS, Ciriaco d'Ancona in Oriente, in Venezia e l'Oriente fra tardo Medioevo e Rinascimento, a cura di Agostino Pertusi, Firenze, Sansoni, I966, pp. 323-337.

ROBERTO WEISS, Pisanello's Medallion of the Emperor John VIII Palaeologus, Oxford, Trustees of the British Museum, I966.

ROBERTO WEISS, Medieval and Humanist Greek. Collected Essays, Padova, Antenore, I977.

SCOTT D. WESTREM, The Hereford Map. A Transcription and Translation of the Legends with Commentary, Brepols, Turnhout, $200 \mathrm{I}$.

PHYLLIS WILLIAMS LEHMANN, Cyriacus of Ancona's Egyptian Visit and its Reflections in Gentile Bellini and Hieronymus Bosch, Locust Valley (N.Y.), Augustin, I977.

RUDOLF WITTKOWER, Allegoria e migrazione dei simboli, Torino, Einaudi, I987 [ed. originale Marvels of the East, in "Journal of the Warburg and Courtauld Institutes", 5, I942, pp. I59-I97]. 
WOOD I995

WOODS-MARSDEN I992

WOODWARD 200I

YEAGER 2008

YOUSEFZADEH 2018

ZACCARIOTTO 2013

ZAGANELLI I985

ZAGANELLI I995

ZAGANELLI I997

ZAMBOTTI I934-I937

ZARNCKE I876-I879

ZDEKAUER ${ }_{1978}$

ZENTAI I973

ZERI I959

ZÖLLNER 2009

ZUCKER I994

ZUMTHOR I995
FRANCES WOOD, Did Marco Polo Go to China?, London, Secker \& Warburg, I995.

JOANNA WOODS-MARSDEN, "Draw the Irrational Animals as Often as You Can from Live». Cennino Cennini, Giovannino de' Grassi, and Antonio Pisanello, in «Studi di Storia dell'Arte», 3, I992, pp. 67-78.

DAVID WOODWARD, Il ritratto della Terra, in Nel segno di Masaccio. L'invenzione della prospettiva, catalogo di mostra (Firenze, Galleria degli Uffizi I6 ottobre 200I - 20 gennaio 2002), a cura di Filippo Camerota, Firenze, Giunti, 200I, pp. 259-26I.

SUZANNE M. YEAGER, The World Translated: Marco Polo's Le Devisement dou monde, The Book of Sir John de Madeville, and Their Medieval Audiences, in Marco Polo and the Encounter of East and West, a cura di Suzanne Conklin Akbari e Amilcare Iannucci, TorontoBuffalo-London, Toronto University Press, 2008, pp. I56-I8I.

MAHNAZ YOUSEFZADEH, Florence's Embassy to the Sultan of Egypt: An English Translation of Felice Brancacci's Diary, Cham, Palgrave Mcmillan, 2018.

GIULiA ZACCARIOTTO, Scheda, in Dal Giglio al David. Arte civica a Firenze fra Medioevo e Rinascimento, catalogo di mostra (Firenze, Galleria dell'Accademia I4 maggio - 8 dicembre 20I3), a cura di Maria Monica Donato e Daniela Parenti, Firenze, Giunti, 20I3, p. I04.

GIOIA ZAGANELLI, La Terra Santa e i miti dell'Asia, in L'Oriente. Storie di viaggiatori italiani, Milano, Electa, I985, pp. I3-27.

GIOIA ZAGANELLI, Alessandro Magno in India: storia di un'epistola e di un'immagine del mondo, in Medioevo romanzo e orientale: oralità, scrittura, modelli narrativi, 2. Colloquio Internazionale (Napoli, I7-I9 febbraio I994) a cura di Antonio Pioletti e Francesca Rizzo Nervo, Soveria Mannelli, Rubbettino, I995, pp. I39-II53.

GIOIA ZAGANELLI, L'Oriente incognito medievale: enciclopedie, romanzi di Alessandro, teratologie, Soveria Mannelli, Rubbettino, I997.

BERNARDINO ZAMBOTTI, Diario ferrarese dall'anno I476 sino al 1504, a cura di Giuseppe Pardi, in Rerum Italicarum Scriptores, vol. 24.7, Bologna, Zanichelli, I934-I937.

FRIEDRICH ZARNCKE, Der Priester Johannes, 2 voll., Leipzig, S. Hirzel, I876-I879.

LODOVICO ZDEKAUER, Tassa per vedere il leone, in Miscellanea fiorentina di erudizione e storia, a cura di Iodoco Del Badia, vol. I, Roma, Multigrafica, I978 [ed. originale Firenze, Salvadore Landi, I902].

ROLAND ZENTAI, Un livre de patrons d'animaux florentin au Musée des Beaux-Arts, in "Bulletin du Musée Hongrois des Beaux-Arts», 4O, I973, pp. 25-39.

FEDERICO ZERI, Rivedendo Piero di Cosimo, in "Paragone», II5, I959, pp. 36-50.

FRANK ZÖLLNER, Sandro Botticelli, München-Berlin-LondonNew York, Prestel, 2009.

MARK J. ZUCKER, The Illustrated Bartsch. Early Italian Masters, vol. 24. 2, New York, Abaris Book, I994.

PAUL ZUMTHOR, La misura del mondo. La rappresentazione dello spazio nel Medio Evo, Bologna, Il Mulino, I995 [ed. originale La mesure du monde. Représentation de l'espace au Moyen Âge, Paris, Seuil, I993]. 


\section{Crediti fotografici}

Fig. I - (C) su concessione della Biblioteca Apostolica Vaticana, ms. Chig.G.II.36, c. I48v, ogni diritto riservato.

Figg. 2, 3- C Comune di Milano, tutti i diritti riservati / Foto Lacitignola, 2017.

Fig. 4 - (C) Patrimonio Nacional, Biblioteca del Real Monasterio de San Lorenzo del Escorial, T-I-I.

Fig. 5 - (C) Leuphana University Lüneburg / Public Domain.

Fig. 6- (C) Hereford Cathedral.

Figg. 7, 8, 39, 94 - (C) Bibliothèque nationale de France.

Fig. 9 - (C) su concessione della Biblioteca Nazionale Centrale, Roma.

Figg. IO, I4, I5, I6, I7, I8 - C su concessione del Ministero della Cultura - Biblioteca Nazionale Centrale - Firenze. È vietata ogni ulteriore riproduzione o duplicazione con qualsiasi mezzo.

Fig. I6a - (c) su gentile concessione della Fondazione Giorgio Cini, Biblioteca Manica Lunga, Venezia.

Figg. II, I2 - (C) The British Library Board.

Fig. I3 - (C) su concessione del Ministero della Cultura - Museo Nazionale del Bargello. È vietata ogni ulteriore riproduzione o duplicazione con qualsiasi mezzo.

Figg. 19, 20 - (C) su concessione del MiC. È vietata ogni ulteriore riproduzione o duplicazione con qualsiasi mezzo.

Fig. 2 I - (C) Bodleian Libraries, University of Oxford Shared under a Creative Commons AttributionNonCommercial-ShareAlike 4.o International (CC $\mathrm{BY}-\mathrm{NC}$ 4.0) licence.

Figg. 22, 23, 24- (C) su gentile concessione della responsabile Dott.ssa Elena Gurrieri - Biblioteca del Seminario Arcivescovile Maggiore, Firenze / Foto Archivio Antonio Quattrone.

Figg. 25, 26, 27, 28, 29, 30, 3I, 32 - (C) Biblioteca Civica Angelo Mai, Bergamo.

Figg. 33, 34, 35, 36, 37, 38 - C) su concessione della Biblioteca Casanatense, Roma, MIBACT.

Fig. 40 - C http://data.onb.ac.at/dtl/3506830 / Austrian National Library.

Figg. 4I, 42 - (C) Klassik Stiftung Weimar, Museums, KK 8805 v, KK 8805 r. All rights reserved / Foto Renno.

Figg. 43, 64- (C) The Trustees of the British Museum. Shared under a Creative Commons AttributionNonCommercial-ShareAlike 4.o International (CC BY-NC-SA 4.0) licence (versione online).
(C) The Trustees of the British Museum (versione a stampa).

Fig. 44 - (C) Bayonne, Musée Bonnat-Helleu / Foto A. Vaquero.

Figg. 45, 53-(C) RMN-Grand Palais (Musée du Louvre) / Foto Michèle Bellot.

Fig. $46-$ (C) The Metropolitan Museum of Art, New York, Robert Lehman Collection, I975.

Figg. 47, 48, 49, 67 - C Roma, Istituto Centrale per la Grafica, su gentile concessione del Ministero della cultura. È vietata ogni ulteriore riproduzione o duplicazione con qualsiasi mezzo.

Figg. 50, 5I, 54 - (C) RMN-Grand Palais (Musée du Louvre) / Foto Jean-Gilles Berizzi.

Figg. 52, 55- (C) RMN-Grand Palais.

Figg. 56, 57 - (C) Collection Museum Boijmans Van Beuningen, Rotterdam. Loan: Stichting Museum Boijmans Van Beuningen I940 (former collection Koenigs) / Foto Studio Tromp.

Figg. 58, 59- (C) Musée du Louvre, Dist. RMN-Grand Palais / Foto Angèle Dequier.

Figg. 60, 61, 62, 63 - (C) Museum of Fine Arts, Budapest, $202 \mathrm{I}$.

Fig. 65 - (C) National Museum, Public Domain / Foto Cecilia Heisser.

Figg. 66, 68, 82 - C su concessione del Ministero della Cultura. È vietata ogni ulteriore riproduzione o duplicazione con qualsiasi mezzo.

Figg. 74, $92-$ (C) Fototeca Musei Civici Fiorentini.

Fig. 75 - (C) 202 I Foto Scala, Firenze/bpk, Bildagentur für Kunst, Kultur und Geschichte, Berlin / Foto Joerg P. Anders.

Figg. 76, 93 - (C) su concessione del Ministero della Cultura - Direzione regionale Musei della Toscana, Firenze. È vietata ogni ulteriore riproduzione o duplicazione con qualsiasi mezzo / Foto Archivio Antonio Quattrone.

Fig. 77 - (C) Museo di Palazzo Medici Riccardi, Città Metropolitana di Firenze / Foto Archivio Antonio Quattrone.

Fig. 78 - (C) Cincinnati Art Museum / John J. Emery Endowment / Bridgeman Images.

Fig. 80- (C) The National Gallery, London.

Fig. 83 - (C) Fondo Edifici di Culto - Amministrato dal Ministero dell'Interno / Foto Archivio Antonio Quattrone.

Fig. 84 - (C) National Gallery of Canada, Ottawa, Ontario, Canada/Bridgeman Images. 
Fig. $85-$ (C) The Metropolitan Museum of Art, New York, Gift of Robert Gordon, I875 (inv. 75.7.2).

Fig. $86-$ (C) su concessione del Ministero della Cultura / Foto Sailko licensed under CC BY 3.o.
Fig. $87-$ (C) The Art Institute of Chicago, Mr. and Mrs. Martin A. Ryerson Collection.

Fig. $89-$ (C) The Fitzwilliam Museum, Cambridge.

Fig. 90 - (C) Wawel Royal Castle / Foto 3 D Pawel Klak, Mariusz Mikołajczyk.

Fig. 9I - (C) su gentile concessione della Parker Library, Corpus Christi College, Cambridge.

L'Editore è a disposizione degli aventi diritto per eventuali fonti iconografiche non individuate. 
A Firenze, città di mercanti che intrattenevano intensi scambi commerciali con l'Oriente, il gusto per l'esotico alimentato da viaggi, pellegrinaggi, delegazioni diplomatiche, diari odeporici, novelle e mappae mundi era particolarmente vivo. Questa ricerca a carattere interdisciplinare indaga il tema vasto e complesso degli scambi culturali tra la città del giglio e l'Oriente nell'arco cronologico compreso tra la seconda metà del XIV secolo e il I492 anno della morte di Lorenzo il Magnifico ma anche della scoperta del continente americano - gettando nuova luce sul ruolo svolto dai mercanti dotati di una forma mentis analitica nell'evoluzione della conoscenza della fauna esotica, le implicazioni artistiche e culturali connesse agli «animali maravigliosi» e l'affermarsi della loro raffigurazione "naturalistica".

Patricia Lurati, storica dell'arte e della moda, si è laureata in storia delle arti decorative all'Università di Siena con una tesi sui cassoni, pubblicata con il titolo Doni nuziali del Rinascimento nelle collezioni svizzere (Armando Dadò Editore 2007), e specializzata in storia del costume e della moda all'Università di Firenze. Grazie a una borsa di ricerca del FNS ha approfondito i suoi studi a New York (Institute of Fine Arts, New York University) e a Parigi (École Pratique des Hautes Études, Sorbona). Ha scritto il libro La Chiesa di Sant'Antonio Abate a Morcote (Edizioni Casagrande 20I4), partecipato a convegni internazionali e pubblicato su riviste scientifiche. Negli ultimi anni ha curato le mostre Doni d'amore. Donne e rituali nel Rinascimento (Pinacoteca Züst di Rancate, 20I4) e Animalia Fashion (Gallerie degli Uffizi, Palazzo Pitti, Museo della moda e del costume, 20I9). Insegna storia della moda presso la New York University di Firenze. 